\title{
REVIEW OF MECHANISTIC UNDERSTANDING AND MODELING AND UNCERTAINTY ANALYSIS METHODS FOR PREDICTING CEMENTITIOUS BARRIER PERFORMANCE
}

Cementitious Barriers Partnership

November 2009

CBP-TR-2009-002, Rev. 0 



\section{REVIEW OF MECHANISTIC UNDERSTANDING AND MODELING AND UNCERTAINTY ANALYSIS METHODS FOR PREDICTING CEMENTITIOUS BARRIER PERFORMANCE}

Cementitious Barriers Partnership

November 2009 


\title{
ACKNOWLEDGEMENTS
}

This report was prepared for the United States Department of Energy in part under Contract No. DE-AC0908SR22470 and is an account of work performed in part under that contract. This report was prepared in support of the Savannah River Nuclear Solutions Cooperative Research Agreement (CRADA) CR-08-001. Reference herein to any specific commercial product, process, or service by trademark, name, manufacturer, or otherwise does not necessarily constitute or imply endorsement, recommendation, or favoring of same by Savannah River Nuclear Solutions or by the United States Government or any agency thereof. The views and opinions of the authors expressed herein do not necessarily state or reflect those of the United States Government or any agency thereof.

\section{and}

This report is based in part on work supported by the United States Department of Energy under Cooperative Agreement Number DE-FC01-06EW07053 entitled "The Consortium for Risk Evaluation with Stakeholder Participation III" awarded to Vanderbilt University. The opinions, findings, conclusions, or recommendations expressed herein are those of the author(s) and do not necessarily represent the views of the Department of Energy or Vanderbilt University.

\section{Disclaimer}

This work was prepared under an agreement with and funded by the U. S. Government. Neither the U.S. Government or its employees, nor any of its contractors, subcontractors or their employees, makes any express or implied: 1. warranty or assumes any legal liability for the accuracy, completeness, or for the use or results of such use of any information, product, or process disclosed; or 2. representation that such use or results of such use would not infringe privately owned rights; or 3. endorsement or recommendation of any specifically identified commercial product, process, or service. Any views and opinions of authors expressed in this work do not necessarily state or reflect those of the United States Government, or its contractors, or subcontractors, or subcontractors.

\section{Printed in the United States of America}

\author{
United State Department of Energy \\ Office of Environmental Management \\ Washington, DC
}

This document is available on the CBP website: http://cementbarriers.org/

and

Savannah River National Laboratory website: http://srnl.doe.gov 


\section{FOREWORD}

The Cementitious Barriers Partnership (CBP) Project is a multi-disciplinary, multi-institutional collaboration supported by the United States Department of Energy (US DOE) Office of Waste Processing. The objective of the CBP project is to develop a set of tools to improve understanding and prediction of the long-term structural, hydraulic, and chemical performance of cementitious barriers used in nuclear applications.

A multi-disciplinary partnership of federal, academic, private sector, and international expertise has been formed to accomplish the project objective. In addition to the US DOE, the CBP partners are the United States Nuclear Regulatory Commission (NRC), the National Institute of Standards and Technology (NIST), the Savannah River National Laboratory (SRNL), Vanderbilt University (VU) / Consortium for Risk Evaluation with Stakeholder Participation (CRESP), Energy Research Center of the Netherlands (ECN), and SIMCO Technologies, Inc.

The periods of cementitious performance being evaluated are $>100$ years for operating facilities and $>1000$ years for waste management. The set of simulation tools and data developed under this project will be used to evaluate and predict the behavior of cementitious barriers used in nearsurface engineered waste disposal systems, e.g., waste forms, containment structures, entombments, and environmental remediation, including decontamination and decommissioning (D\&D) activities. The simulation tools also will support analysis of structural concrete components of nuclear facilities (spent-fuel pools, dry spent-fuel storage units, and recycling facilities such as fuel fabrication, separations processes). Simulation parameters will be obtained from prior literature and will be experimentally measured under this project, as necessary, to demonstrate application of the simulation tools for three prototype applications (waste form in concrete vault, high-level waste tank grouting, and spent-fuel pool). Test methods and data needs to support use of the simulation tools for future applications will be defined.

The CBP project is a five-year effort focused on reducing the uncertainties of current methodologies for assessing cementitious barrier performance and increasing the consistency and transparency of the assessment process. The results of this project will enable improved risk-informed, performance-based decision-making and support several of the strategic initiatives in the DOE Office of Environmental Management Engineering \& Technology Roadmap. Those strategic initiatives include 1) enhanced tank closure processes; 2) enhanced stabilization technologies; 3) advanced predictive capabilities; 4) enhanced remediation methods; 5) adapted technologies for site-specific and complex-wide D\&D applications; 6) improved SNF storage, stabilization and disposal preparation; 7) enhanced storage, monitoring and stabilization systems; and 8) enhanced long-term performance evaluation and monitoring.

Christine A. Langton, PhD. Savannah River National Laboratory

David S. Kosson, PhD. Vanderbilt University/CRESP 
Review of Mechanistic Understanding and Modeling and Uncertainty Analysis Methods for Predicting Cementitious Barrier Performance

I-iv 


\section{OVERVIEW}

1.0 Introduction

\section{MINERALOGICAL AND MICROSTRUCTURAL EVOLUTION IN HYDRATING CEMENTITIOUS SYSTEMS}

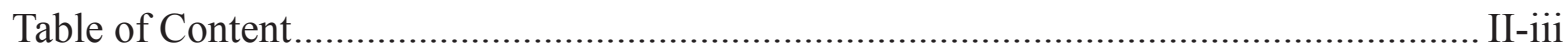

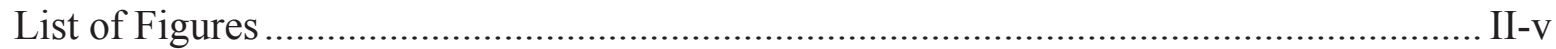

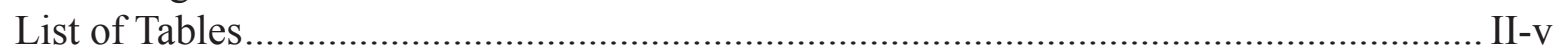

List of Abbreviations and Acronyms ............................................................................... II

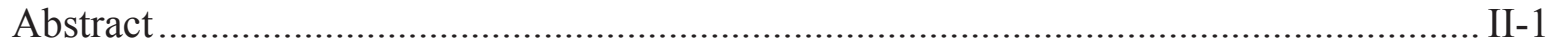

1.0 Introduction ............................................................................................... II

2.0 Mineralogy of Calcium Silicate Cement Systems and Hydration products ................ II-3

3.0 Pore Solution Compositional Evolution .............................................................. II-10

4.0 Long-term C-S-H Stability ................................................................................ II

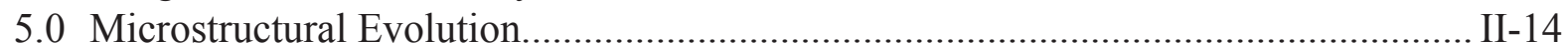

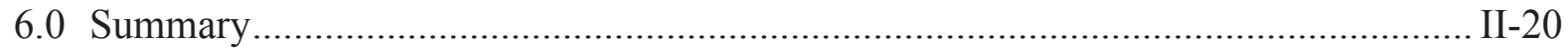

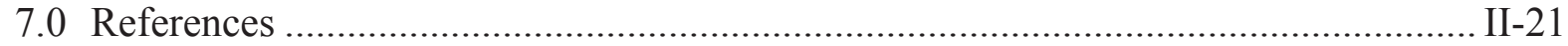

\section{EARLY-AGE CRACKING REVIEW: MECHANISMS,} MATERIAL PROPERTIES, AND MITIGATION STRATEGIES

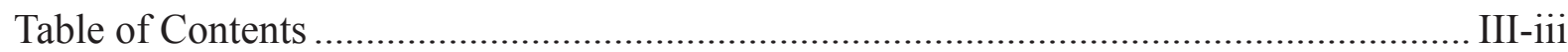

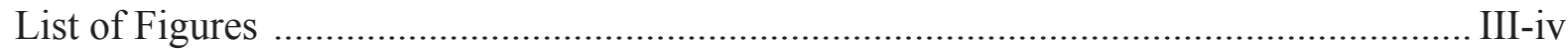

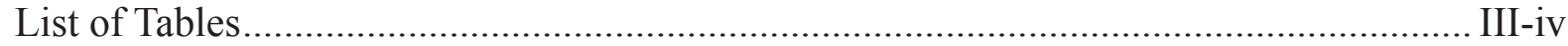

List of Abbreviations and Acronyms ............................................................................

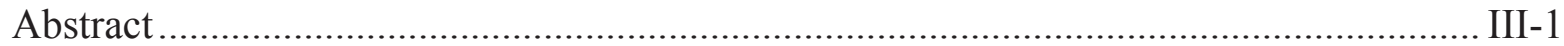

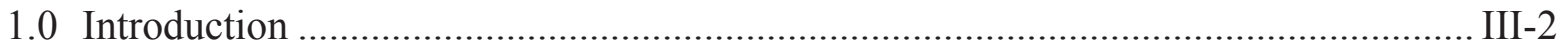

2.0 Thermal Cracking Considerations ........................................................................... III-3

3.0 Autogenous Shrinkage Considerations................................................................. III-7

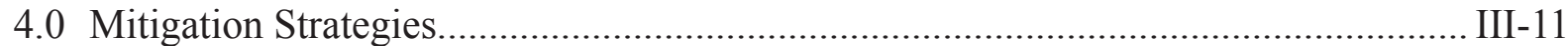

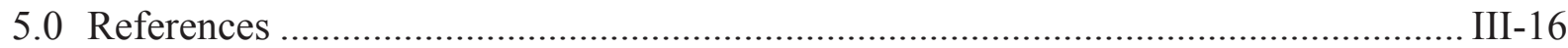

\section{CHEMICAL DEGRADATION REVIEW}

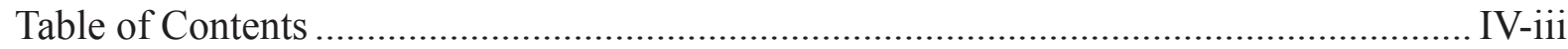

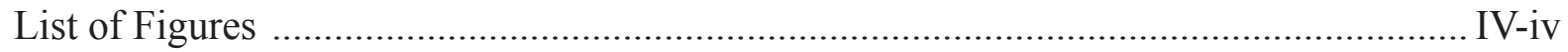

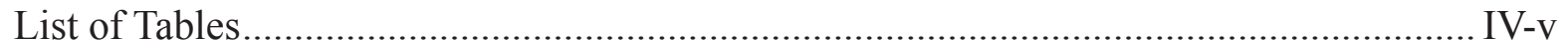

List of Abbreviations and Acronyms ......................................................................... IV-vi

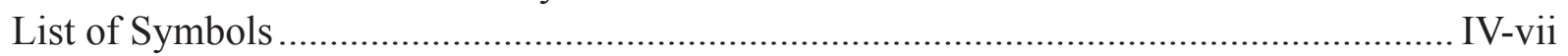

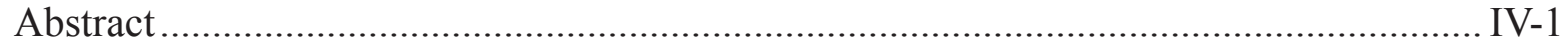




\section{CHEMICAL DEGRADATION REVIEW (contd)}

1.0 Introduction

IV-1

2.0 Transport Mechanisms

3.0 Chloride Ingress and Corrosion.....

4.0 Carbonation

IV-12

5.0 Decalcification

6.0 Sulfate Attack

7.0 Conclusions

8.0 References

\section{MECHANICAL DAMAGE REVIEW}

Table of Content............................................................................................... V-iii

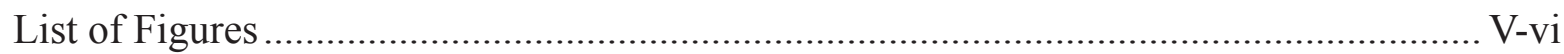

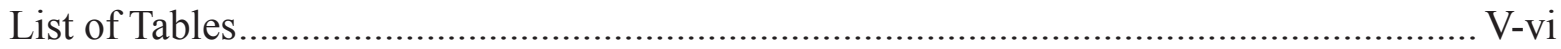

List of Abbreviations and Acronyms ...................................................................... V-vii

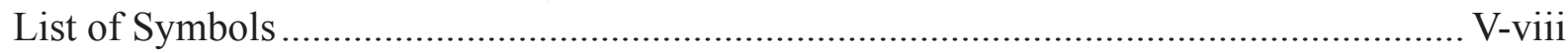

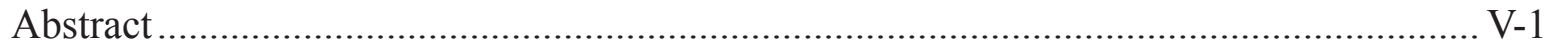

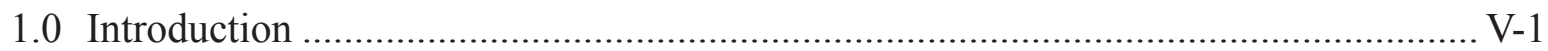

2.0 General Overview of Damage in Concrete....................................................... V-2

3.0 Modeling Mechanical Damage in Concrete ........................................................... V-5

4.0 Early-age Concrete Damage ................................................................................... V-9

5.0 Sulfate Attack ............................................................................................ V-14

6.0 Corrosion-induced Cracking............................................................................ V-21

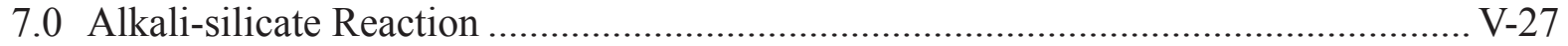

8.0 Freezing and Thawing .................................................................................. V-32

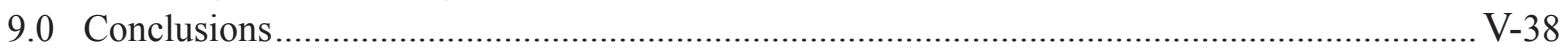

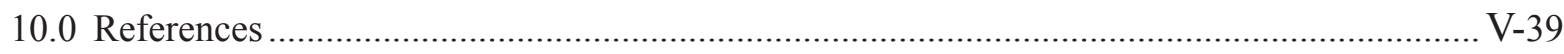

\section{MOISTURE TRANSPORT REVIEW}

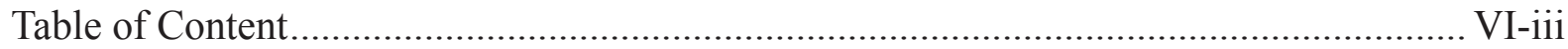

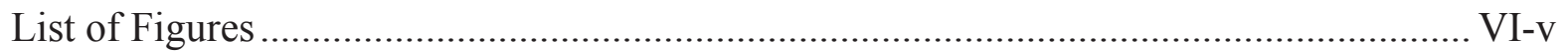

List of Tables...................................................................................................... VI-V

List of Abbreviations and Acronyms .................................................................... VI-vi

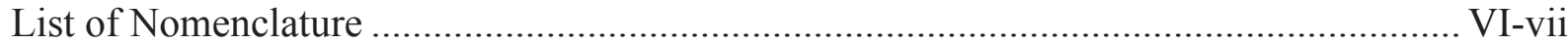

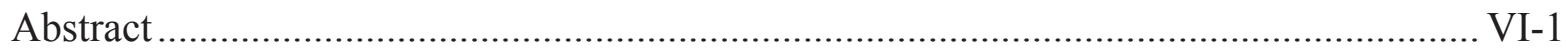

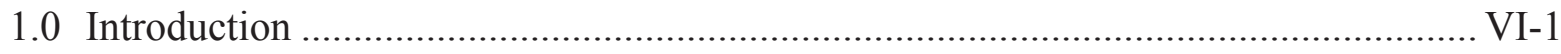

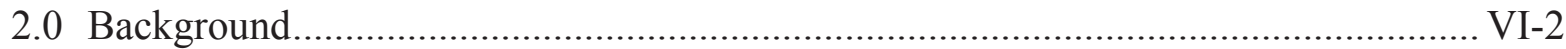

3.0 Moisture Transport in Porous Media ........................................................................ VI-5

4.0 Moisture Transport Through Fractured Media ........................................................ VI-16 
TABLE OF CONTENTS (contd)

Page No.

\section{MOISTURE TRANSPORT REVIEW (contd)}

5.0 Other Transport Models........................................................................................ VI-21

6.0 Challenges and Opportunities.............................................................................. VI-23

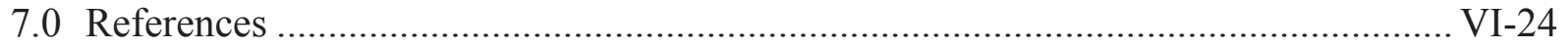

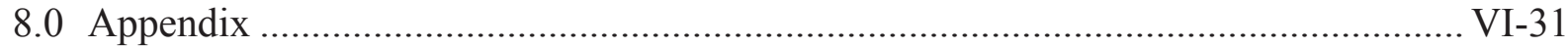

\section{REVIEW OF THE PHYSICAL AND CHEMICAL ASPECTS OF LEACHING ASSESSMENT}

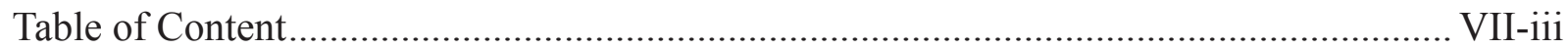

List of Figures ......................................................................................................... VII-vii

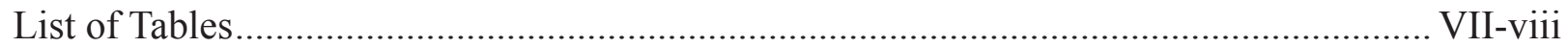

List of Acronyms and Abbreviations ....................................................................... VII-ix

List of Nomenclature ......................................................................................... VII

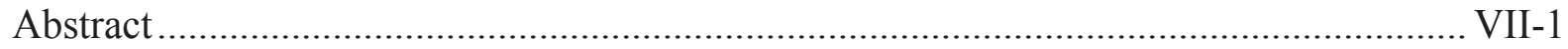

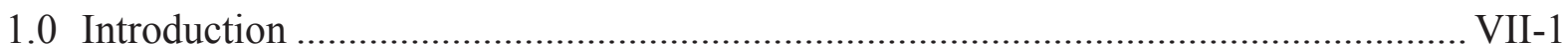

2.0 Mechanisms and Properties .............................................................................. VII-7

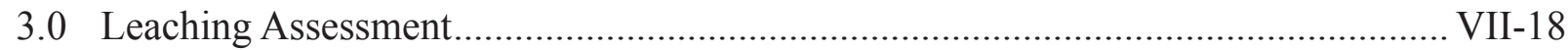

4.0 Behavior of Typical Cementitious Matrixes .......................................................... VII-37

5.0 Leaching Assessment in CBP Reference Cases...................................................... VII-45

6.0 Lysimeter Studies for Radioactive Waste .............................................................. VII-50

7.0 Knowledge Gaps And Needs .......................................................................... VII-52

8.0 References ..................................................................................................... VII 55

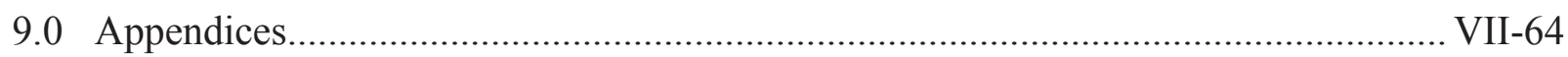

\section{REVIEW OF THERMODYNAMIC AND ADSORPTION DATABASES}

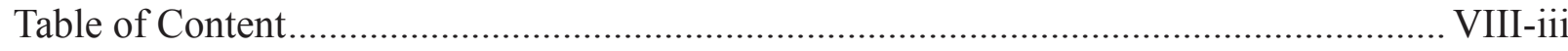

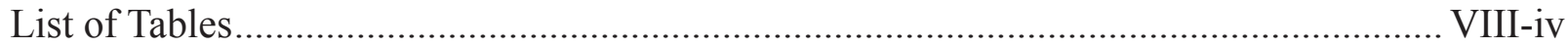

List of Abbreviations and Acronyms ...................................................................... VIII-V

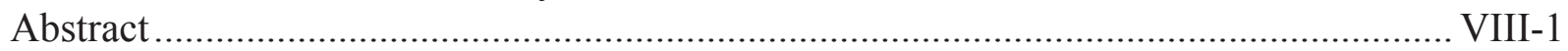

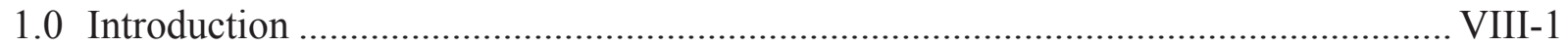

2.0 Thermodynamic Data Sources and Types............................................................ VIII-4

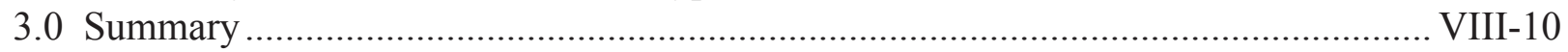

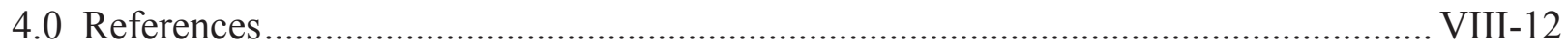

\section{REVIEW OF APPROACHES TO COUPLING PHYSICAL,} STRUCTURAL AND CHEMICAL MECHANISMS

Table of Content

IX-iii

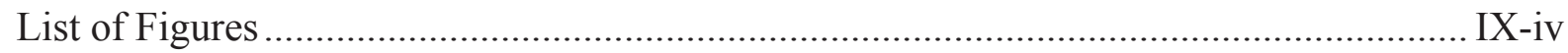

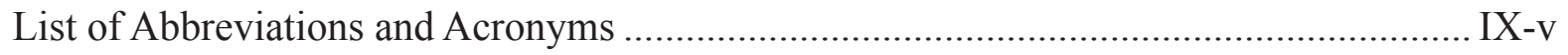


TABLE OF CONTENTS (contd)

Page No.

\section{REVIEW OF APPROACHES TO COUPLING PHYSICAL, STRUCTURAL AND CHEMICAL MECHANISMS (contd)}

List of Nomenclature

IX-vi

Abstract

IX-1

1.0 Introduction

IX-1

2.0 Coupling Transport and Chemistry

IX-2

3.0 Thermo-hydro-mechanical Models

IX-11

4.0 Coupled Ionic Transport and Mechanical Models

IX-16

5.0 Conclusions

IX-17

6.0 References

IX-19

\section{REVIEW OF INTEGRATING PROGRAMS AND CODE STRUCTURES USED FOR DOE ENVIRONMENTAL ASSESSMENTS}

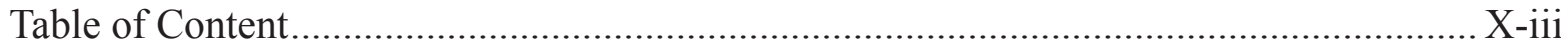

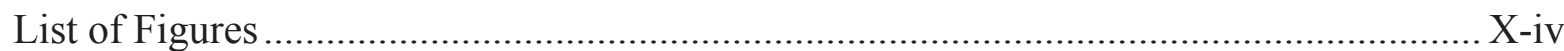

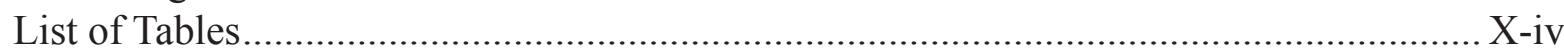

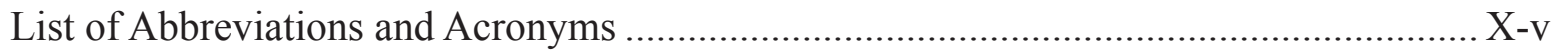

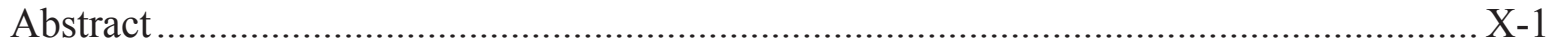

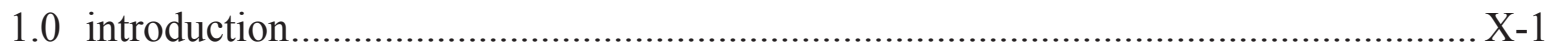

2.0 A Simplified Approach for Model Integration....................................................... X-5

3.0 Examples of Integrated Modeling Approaches and Platforms .................................. X-9

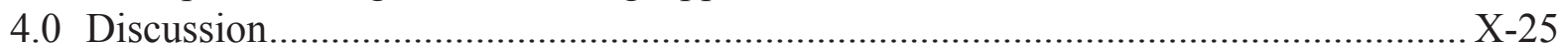

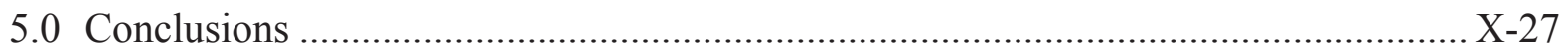

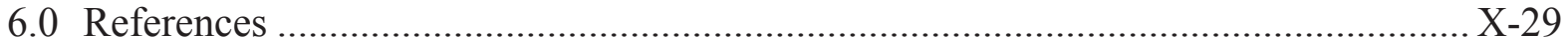

\section{UNCERTAINTY ANALYSIS METHODS}

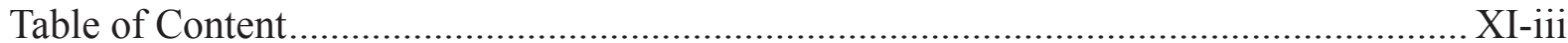

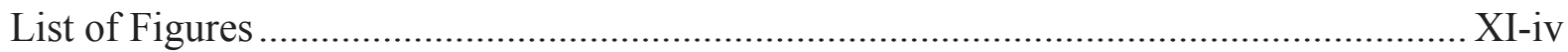

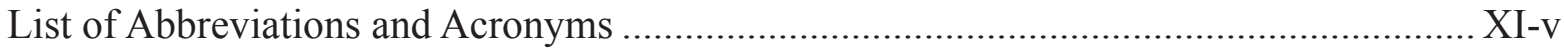

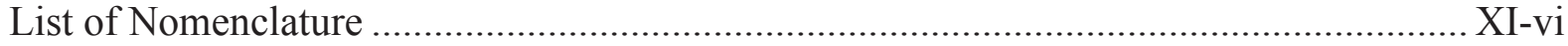

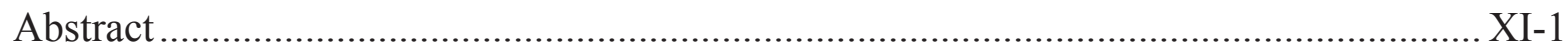

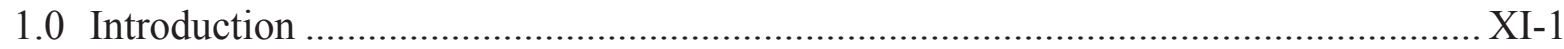

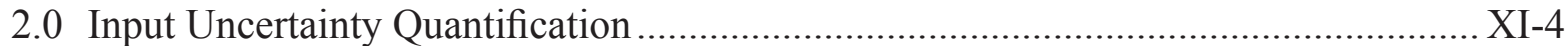

3.0 Propagation Uncertainty Methods ......................................................................... XI-9

4.0 Model Calibration, Validation and Extrapolation ..................................................... XI-15

5.0 Probabilistic Performance Assessment ....................................................................

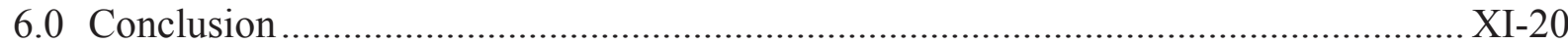

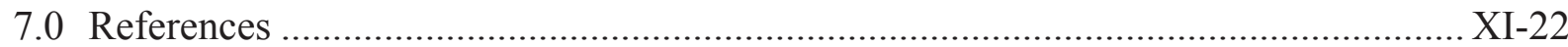




\title{
OVERVIEW
}

\author{
C. A. Langton \\ Savannah River National Laboratory \\ Savannah River Nuclear Solutions, LLC \\ Savannah River Site \\ Aiken SC 29808 \\ Email: Christine.Langton@srnl.doe.gov
}

\author{
and \\ D. S. Kosson \\ Vanderbilt University, School of Engineering \\ Consortium for Risk Evaluation with Stakeholders Participation, III \\ Nashville, TN 37235 \\ Email: David.Kosson@vanderbilt.edu
}





\title{
OVERVIEW
}

\author{
C. A. Langton \\ Savannah River National Laboratory \\ Savannah River Nuclear Solutions, LLC \\ Savannah River Site \\ Aiken SC 29808 \\ D. S. Kosson \\ Vanderbilt University, School of Engineering \\ Consortium for Risk Evaluation with Stakeholders Participation, III \\ Nashville, TN 37235
}

\subsection{INTRODUCTION}

Cementitious barriers for nuclear applications are one of the primary controls for preventing or limiting radionuclide release into the environment. At the present time, performance and risk assessments do not fully incorporate the effectiveness of engineered barriers because the processes that influence performance are coupled and complicated.

Better understanding the behavior of cementitious barriers is necessary to evaluate and improve the design of materials and structures used for radioactive waste containment, life extension of current nuclear facilities, and design of future nuclear facilities, including those needed for nuclear fuel storage and processing, nuclear power production and waste management. The focus of the Cementitious Barriers Partnership (CBP) literature review is to document the current level of knowledge with respect to 1) mechanisms and processes that directly influence the performance of cementitious materials 2) methodologies for modeling the performance of these mechanisms and processes and 3) approaches to addressing and quantifying uncertainties associated with performance predictions. This will serve as an important reference document for the professional community responsible for the design and performance assessment of cementitious materials in nuclear applications. This review also provides a multi-disciplinary foundation for identification, research, development and demonstration of improvements in conceptual understanding, measurements and performance modeling that would be lead to significant reductions in the uncertainties and improved confidence in the estimating the long-term performance of cementitious materials in nuclear applications.

This report identifies; 1) technology gaps that may be filled by the CBP project and also 2) information and computational methods that are in currently being applied in related fields but have not yet been incorporated into performance assessments of cementitious barriers.

The various chapters contain both a description of the mechanism or and a discussion of the current approaches to modeling the phenomena. The topics reviewed include:

Early Age Cracking: The definition of "early age" is somewhat arbitrary and controversial but for this review, it was considered as the time from concrete placement until an age of 7 days under ordinary field curing temperatures. For long term performance to be acceptable and predictable, early age cracking should be avoided. The inherent properties of cement based materials that contribute to early age cracking, exothermic reactions and thermal gradients and autogenous and drying shrinkage are reviewed along with strategies for mitigating early damage. 
Mineralogical and Microstructural Evolution:

Predicting the chemical, mineralogical and microstructural changes that occur in cementitious systems either due to hydration or interactions with the environment (chemical and/or physical degradation) is an important component of performance assessments. The mineralogy and microstructural properties of cementitious barriers determine the chemical stability of the solid phases and dissolved species and the overall hydraulic flow transport through the material.

Mineralogical and microstructural changes due to hydration or degradation are part of a continuous spectrum and are controlled by transport of ionic species in the aqueous pore solution and chemical reactions between ionic species in the pore solution and the insoluble mineral phases. Modeling the evolution of the cementitious fraction of a concrete or other composite material consists of treating the material as a porous composite in equilibrium with aqueous pore solution within the paste (matrix) fraction of the cement composite.

The relevant chemical reactions can be used in a thermodynamic model to calculate the compositions of solid phases in equilibrium with the pore solution. The pore solution composition can change as the result of continued hydration or through the interaction with the environment. Equilibrium calculations yield the quantity of mineral phases that must either dissolve or precipitate to maintain an equilibrium condition. Changes in the mineral assemblage or amounts of the phases result in changes in the porosity and transport properties of the material. This approach can be used to evaluate the effects of multiple degradation mechanisms occurring simultaneously provided thermodynamic data for the relevant phases and chemical reactions are available.

\section{Thermodynamic and Adsorption Databases:}

Thermodynamic databases are used to predict equilibrium phase assemblages in cementitious materials. The solid phase assemblage in the cementitious (paste) fraction of cementitious barrier materials is for the most part responsible for the mechanical, hydraulic transport, and chemical properties of these materials. Advantages of currently used thermodynamic data bases are reviewed and references for adsorption databases are provided.

Chemical Degradation: Chemical degradation is typically the result of alteration of the cement matrix mineralogy caused by leaching of, exposure to, and/or chemical reactions with ionic species in the environment. When the equilibrium between the pore solution of the cementitious materials and the solid matrix (paste) phases is disrupted, dissolution and / or precipitation of solid phases in the original material are disrupted.

The consequences of exposure of cementitious materials to several environmental chemicals including: sulfate, carbonate, and chloride, exposure and calcium and hydroxide leaching are described. Since these chemicals are transported via diffusion through the cementitious material pore water, moisture transport was also reviewed. In addition, historic and current approaches to modeling ionic and moisture transport are presented.

Moisture Transport: Water acts as both a reaction medium and as a transport pathway in porous (and also fractured) materials such as concrete and cementitious waste forms. A summary of the role moisture (liquid water and / or vapor migration through a porous or fractured medium) plays in determining how cementitious materials respond to exposure conditions and how contaminants are released into the external environment is provided.

Both gas and liquid phase moisture transport are discussed, but the emphasis is on liquid water migration. Liquid water and / or water vapor transport are driven by pressure (including capillary processes) and gravitational head gradients for 
typical fractured cementitious materials and also by diffusion gradients for micro-porous materials under environmental conditions. Saturated and unsaturated conditions are important for predicting performance since the unsaturated condition retards moisture and dissolved ionic species diffusion but enhances vapor phase diffusion. Hydraulic properties of saturated and unsaturated cementitious materials which are required as input parameters for performance modeling are also reviewed.

\section{Physical and Chemical Aspects of Leaching:}

A summary of the latest developments in understanding and predicting leaching of chemicals, with emphasis on environmental contaminants associated with radioactive waste, from cementitious barrier materials (concretes and waste forms) is provided. Retention of chemical species by the cementitious matrix material is physically controlled by hydraulic and diffusion properties and chemically controlled by precipitation/dissolution processes, sorption processes, and/or incorporation into solid solutions. Because cementitious barriers are often in contact with soil, the effect of the cementitious barrier leachates on the near field environmental media (including clays and iron and other metal hydroxides) or engineered media is also addressed. Equilibrium and kinetic based leach tests are described along with the $\mathrm{pH}$ dependence of leaching results for a whole suite of elements.

Mechanical Damage: Two approaches for predicting the formation of cracks in cementitious materials are reviewed along with the origin, detection, and prevention of cracks. The first approach is a continuum damage mechanics method based on a damage parameter that indicates the level of damage in a material. The second approach is based on fracture mechanics, i.e., the geometry and localization of cracks is predicted instead of relying on a "smeared" damage parameter.
Description of models developed for specific damage phenomena are provided for several types of degradation including: rebar corrosion, alkalisilica reaction, sulfate attack, freeze-thaw, and wet-dry cycling. The literature over the past 40 years pertaining to mechanical damage model development is provided.

\section{Coupling Physical, Structural and Chemical}

Mechanisms: Approaches used to model coupling between different degradation mechanisms affecting concrete structures are reviewed. Two main categories of models were identified: reactive transport modeling and thermo-hydro-mechanical models.

Reactive transport models are concerned with the transport of chemical species in porous materials and the multiple interactions they can have with the solid matrix. Theses models couple transport equations with complex chemical models but ignore the mechanical aspects of deleterious chemical reactions such as crack formation.

Thermo-Hydro-Mechanical (THM) models couple fluid transport with thermal and mechanical equations and can be used to simulate crack formation caused by drying shrinkage or heat release during cement hydration. The classic THM models do not incorporate the transport of species in the fluid phases and the chemical exchange with the solid minerals. Reactive transport models incorporating mechanical considerations or THM models dealing with detailed transport and chemistry are nearly non-existent. Given the time scales involved in nuclear waste storage assessment, combining these frameworks could provide a global durability assessment for structures. 
Integrating Programs and Code Structures for DOE Environmental Assessments: An overview of general approaches for code integration plus descriptions of the nature of model coupling, computing environments, and programming languages is provided. Examples of integrated modeling approaches and platforms used in the DOE complex for performance and risk assessments are described. These examples range from including all functionality in a single code to developing custom interface "middle ware" for information exchange between stand alone codes. Two examples of performance assessment models that integrate Monte Carlo simulations to address uncertainty are also described.

Uncertainty Analysis Methods: The benefit of uncertainty quantification for DOE waste disposal performance assessments is in facilitating engineering decisions, such as, comparing different design and analysis options and allocating resources for uncertainty reduction through further data collection and/or model refinement.

Uncertainty quantification involves consideration of three sources of uncertainty: physical variability, data uncertainty, and model error (arising from conceptual model and computational solution approximations), are described. Methods to quantify the uncertainty in model-based predictions due to each of these sources are addressed for four stages of an analysis: 1) quantification of input uncertainty, including conceptual model and parameter uncertainty, 2) propagation of input uncertainty through the model, 3) model error quantification via verification and validation activities, and 4) probabilistic performance assessment. Applicability of flexible distribution families to handle sparse data and interval data, autoregressive models to handle time dependence, and methods to quantify model errors resulting form both model form selection and solution approximations are discussed. Bayesian methods for model calibration, validation, and extrapolation are also reviewed.

Uncertainty quantification multiplies the computational effort of deterministic analysis typically by an order of magnitude. Therefore the use of surrogate models and first order or higher order approximations of overall output uncertainty are also described to reduce the computational expense. 


\title{
MINERALOGICAL AND MICROSTRUCTURAL EVOLUTION IN HYDRATING CEMENTITIOUS SYSTEMS
}

\author{
Kenneth A. Snyder \\ Email: kenneth.snyder@nist.gov \\ National Institute of Standards and Technology \\ Gaithersburg, MD 20899
}


Review of Mechanistic Understanding and Modeling and Uncertainty Analysis Methods for Predicting Cementitious Barrier Performance

II-ii 
LIST OF FIGURES ......................................................................................................................................... II-v

LIST OF TABLES..................................................................................................................................................... II-v

LIST OF ABBREVIATIONS AND ACRONYMS .................................................................................... II-vi

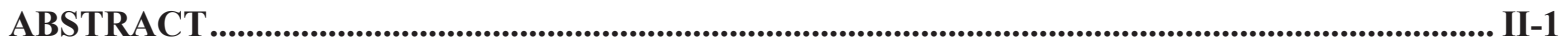

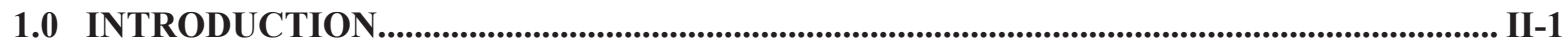

1.1 Present State of Hydration Modeling ...................................................................................... II-2

2.0 MINERALOGY OF CALCIUM SILICATE CEMENT SYSTEMS

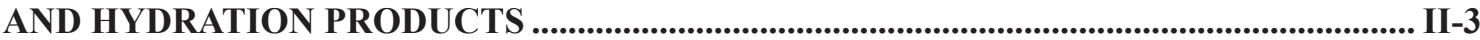

2.1 Portland Cement and Cement Hydration Products................................................................... II-4

2.1.1 Alite and Belite Hydrated Phases.......................................................................................... II-5

2.1.2 Aluminate, Ferrite, and Sulfate Hydrated Phases ........................................................... II-6

2.1.3 Siliceous Hydrogarnet Phases ................................................................................... II-6

2.1.4 Hydrated Magnesium Phases ..................................................................................... II-7

2.1.5 Proportions of Portland Cement Hydrated Phases .......................................................... II-7

2.2 Slag Cement ............................................................................................................................. III-7

2.3 Binary Blended Cement Systems ...................................................................................... II

2.3.1 Portland Cement - Fly Ash ..................................................................................... II-8

2.3.2 Portland Cement - Slag Cement …………............................................................. II-8

2.3.3 Portland Cement - Silica Fume.............................................................................. II-9

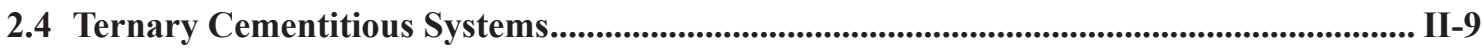

2.5 Hydration at Elevated Temperatures ............................................................................................. II-10

3.0 PORE SOLUTION COMPOSITIONAL EVOLUTION ................................................................ II-10

3.1 Portland Cement Paste Pore Solution .................................................................................................. II-11

3.2 Blended Cement Mixtures ............................................................................................................. II-11

4.0 LONG-TERM C-S-H STABILITY .............................................................................................. II-12

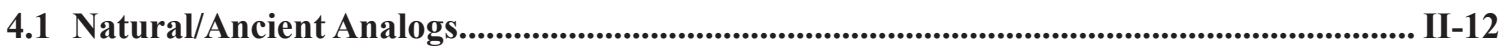

5.0 MICROSTRUCTURAL EVOLUTION............................................................................................. II-14

5.1 Microstructural Property Evolution.................................................................................................... II-14

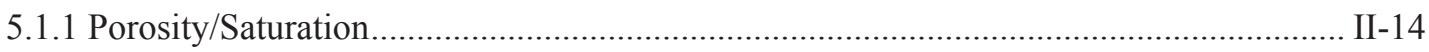

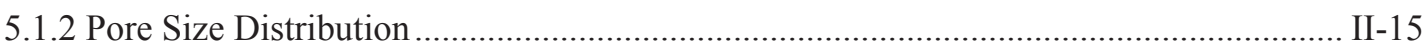

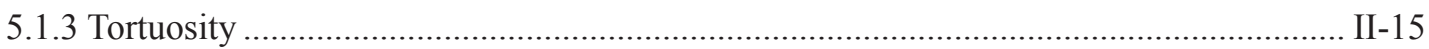


CONTENTS (contd)

Page No.

5.2 Microstructural Evolution During Degradation ........................................................................... II-16

5.3 Transport Property Evolution During Degradation ..................................................................... II-16

5.4 Modeling Microstructural Changes................................................................................ II-17

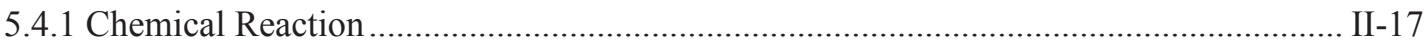

5.5 Modeling Transport Properties........................................................................................... II-18

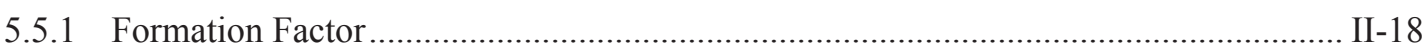

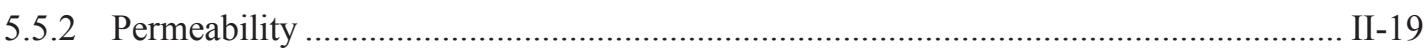

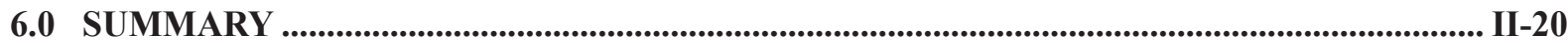

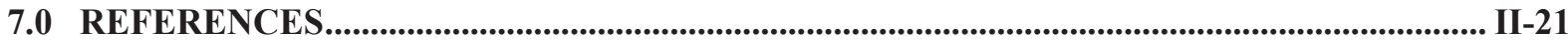

II-iv 


\section{LIST OF FIGURES}

Page No.

Figure 1. Approximate Range of Oxide Contents for Cement (C) Fly Ash (FA), Blast Furnace Slag (S), and Silica Fume (SF)

(Smolczyk 1980, Mindess \& Young 1981, Uchikawa 1986)

Figure 2. Mineralogical Assemblage of the (a) Studied Gallo-Roman Cements and

(b) Modern Pozzuolanic Cement Reported in a Al-Si-Ca Diagram (Rassineux et al. 1989)..... II-13

\section{LIST OF TABLES}

Table 1. Cement Chemistry Notation for Oxides Related to Portland Cement. II-4

Table 2. Typical Mass Fractions of Mineral Phases Found in Commercial Astm Portland Cement Types (Mindess \& Young 1981) II-5

Table 3. Typical Mass Fractions of Oxides Found in Commercial Portland Cements, Based on Data in Table 2 (Mindess \& Young 1981) II-5

Table 4. Representative Hydrated Phase Mass Fraction for a 0.50 Water: Cement (Mass) Ratio Portland Cement Paste (Lothenbach \& Winnefeld 2006) II-7

Table 5. Oxide Requirements for ASTM C 618 Class F and Class C Fly Ash (ASTM 2005b).............. II-8

Table 6. Cement Oxide Mass Fractions from (Lothenbach \& Winnefeld 2006)................................... II-11

Table 7. Pore Solution Composition ( $\mathrm{mmol} / \mathrm{kg}$ ) from (Lothenbach \& Winnefeld 2006)........................ II-11

Table 8. Calculated Ionic Speciation of Cement Paste Pore Solution Using PHREEQC (Parkhurst \& Appelo 1999 
Review of Mechanistic Understanding and Modeling and Uncertainty Analysis

Methods for Predicting Cementitious Barrier Performance

\section{LIST OF ABBREVIATIONS AND ACRONYMS}

$\begin{aligned} \text { AAS } & \text { Alkali Activated Slag } \\ \text { ASTM } & \text { ASTM International } \\ \text { CBP } & \text { Cementitious Barriers Partnership } \\ \text { CEMHYD3D } & \text { CEMent HYDration model in 3-Dimensions } \\ \text { C-S-H } & \text { Calcium Silicate Hydrate gel (amorphous) } \\ \text { DLA } & \text { Diffusion Limited Aggregation } \\ \text { DOE } & \text { U.S. Department of Energy } \\ \text { GEMS } & \text { Gibbs Energy Minimization Selektor } \\ \text { GGBFS } & \text { Ground Granulated Blast Furnace Slag } \\ \text { MIP } & \text { Mercury Intrusion Porosimetry } \\ \text { PHREEQC } & \text { pH-REdox-EQuilibrium-C (programming language) } \\ \text { QXRD } & \text { Quantitative X-Ray Diffraction } \\ \text { SRS } & \text { Savannah River Site }\end{aligned}$

II-vi 


\title{
MINERALOGICAL AND MICROSTRUCTURAL EVOLUTION IN HYDRATING CEMENTITIOUS SYSTEMS
}

\author{
Kenneth A. Snyder \\ National Institute of Standards and Technology \\ Gaithersburg, MD 20899
}

\section{ABSTRACT}

The mineralogical and microstructural changes that occur in cementitious systems during hydration are summarized. These changes depend, in large part, on the proportions of the cementitious binders (e.g., portland cement, fly ash, silica fume, and slag). Moreover, these changes are discussed in the context of hydration under sealed (no chemical exchange with the environment) and isothermal conditions. Under these conditions, the hydration reactions, and commensurate mineralogical and microstructural changes, continue over the time scale of months or years. The few very slow reactions are discussed in the context of thermodynamic modeling.

The mineralogical and microstructural stability at very long time scales (e.g., centuries, millennia) is relevant to performance assessment for nuclear applications. The very long-term stability of the hydrated phases is discussed in the context of natural and ancient analogs.

Microstructural changes due to degradation are discussed in the general context of physico-chemical service life computer modeling; the mineralogical changes due to degradation are discussed in the chapter on chemical degradation. Because there are no analytical expressions for the microstructural changes that occur during degradation (besides changes in the porosity), computer models must be used that are applied to all chemical degradation mechanisms simultaneously. As a result, the microstructural changes are discussed in the broad context of modeling, without reference to specific degradation mechanisms.

For relevance to nuclear applications, various cementitious systems are considered. These include systems having a broad range of proportions of cement, fly ash, slag, and silica fume. Moreover, the possible effects of waste stabilization, through incorporation into the mix water, are discussed.

\subsection{INTRODUCTION}

Cementitious barriers for nuclear applications must satisfy both mechanical and chemical performance criteria. A comprehensive performance assessment tool, as is being developed in the Cementitious Barriers Partnership (CBP) project, must be able to assess both types of performance. To do this, the tool must be able to quantify the chemical and physical properties of the mineralogy and the microstructure of the composite system (binder and aggregate). Moreover, the assessment tool must be able to predict changes in the mineralogy and the microstructure due to either continued hydration of the cementitious components, or due to the chemical reactions that are part of any number of degradation mechanisms. 
Anticipating the mineralogical and microstructural changes that occur in cementitious systems, either due to hydration or due to degradation, is an important component of accurate performance prediction and assessment. The mineralogical makeup and microstructural transport properties determine the chemical stability of the solid, (in some cases) the mobility of species, and the overall hydraulic flow through the system. Predicting these changes is relevant to the CBP technical challenges because a cementitious system is always hydrating, and (almost always) interacting with its environment. Moreover, in practical applications, hydration and degradation are occurring at the same time.

Predicting the mineralogical and microstructural changes during hydration alone is a difficult challenge. There is a wide range of possible blended cementitious mixtures that may be used in the nuclear infrastructure, and the specific physical/ chemical properties of supplementary materials that influence hydration are not completely understood. The different components of a nuclear facility may require a range of mechanical, chemical, and physical properties. The optimal mixture for each element may require two or three cementitious materials.

Fortunately, hydration and degradation are both controlled by transport of ionic species in the aqueous pore solution and chemical reactions between ionic species in the pore solution and the soluble mineral phases present. In effect, hydration and degradation involve the same chemical and physical mechanisms; only the specifics differ. In effect, the mineralogical and microstructural changes due to hydration or degradation are part of a continuous spectrum.

Long-time modeling of cementitious systems consists of treating the material as a porous composite in equilibrium with the aqueous pore solution within the paste fraction of the cementitious composite. Upon enumerating all the relevant chemical reactions, a thermodynamic model can be used to calculate the mineral phase composition that is in equilibrium with the pore solution. These changes in the pore solution can occur through continued hydration (dissolution of the starting cementitious starting materials) or through interaction with the material's environment. The equilibrium calculation yields the quantity of mineral phases that must either dissolve or precipitate, thereby changing the porosity and the transport properties, which can be re-calculated by a 3-D microstructure model. By treating all degradation mechanisms in the same manner, multiple degradation mechanisms can be occurring simultaneously.

A key element to this approach is sufficient and accurate thermodynamic data for all the relevant chemical reactions (hydration and degradation). Data exist for nearly all the relevant reactions for portland cement, fly ash, ground granulated blast furnace slag, and silica fume. For some mineral phases, however, more accurate data are needed for the solubility and the temperature dependence, which may be an important issue for waste immobilization.

Another key element to the thermodynamic approach to mineralogical evolution is that kinetics are independent of thermodynamics. Although most of the reactions occur over the time scales of laboratory measurements, there are some reactions that occur over very long times, and may be important to the overall performance. These reactions involve either re-crystallization of hydrated phases, or the crystallization of the amorphous calcium silicate gel that constitutes the major phase of hydrated cementitious systems. The rates of these reactions are not known, and are important for long-term performance prediction.

\subsection{Present State of Hydration Modeling}

There exist two types of hydration models: microstructural models and thermodynamic models. 
The microstructural models like CEMHYD3D ${ }^{1}$ (Bentz, 1997) and $\mu \mathrm{ic}^{2}$ (Scrivener \& Bishnoi, 2009) attempt to predict details of the hydrated microstructure with the intent of predicting transport and mechanical properties. The thermodynamic models like GEMS 3 (Lothenbach \& Winnefeld, 2006) use empirical kinetic models to predict the quantity of solid phases present, the porosity, the water content, and the pore solution composition as a function of time.

The microstructural models are not entirely physical, and the predicted transport coefficients (diffusivity and permeability) have not been validated to the extent necessary for reliable long-term performance prediction. Moreover, the chemistry incorporated into these models may not be consistent with existing thermodynamic data. On the other hand, the thermodynamic models neglect physical properties and microstructure evolution. Any attempt to couple microstructural and thermodynamic models together must overcome these issues.

In addition, a hydration model having practical relevance to the nuclear infrastructure will have to be applicable to a wide spectrum of cementitious component proportions. Existing hydration models were developed primarily for predicting the hydrated phases of pure portland cement. Some hydration models can predict, to some degree, the hydration products of systems in which a relatively small to moderate fraction of the portland cement has been replaced by any one of fly ash, silica fume, or slag. Moreover, these models are limited to mixtures in which the 'mix water' is either distilled water or from the municipal water supply. Unfortunately, hydration models have not been validated for systems where portland cement comprises less than one-half of the cementitious components, or for mixtures prepared with concentrated salt solutions. ${ }^{4}$

\subsection{MINERALOGY OF CALCIUM SILICATE CEMENT SYSTEMS AND HYDRATION PRODUCTS}

The cementitious binders of practical concern include portland cement, fly ash, ground granulated blast furnace slag (GGBFS), and silica fume. Portland cement is largely crystalline, and the other binders are mostly glass. Each contributes to the calcium and/or silica contents required to form an amorphous calcium silicate hydrate (C-S-H) gel, the primary binding phase for all these systems. Portland cement and (sometimes) slag are the only binders that contain sufficient lime and silica, and in the proper proportions, to produce a solid hydrated mass upon mixing with water. Some Class C fly ashes also have this characteristic and are referred to as hydraulic fly ashes.

Typical oxide contents of portland cement, fly ash, blast furnace slag, and silica fume are shown schematically in Figure 1. Because cementitious materials are also composed of other oxides, Figure 1 represents the typical ranges of $\mathrm{CaO}, \mathrm{SiO}_{2}$, and $\mathrm{Al}_{2} \mathrm{O}_{3}$ present in these materials.

Industry practice for characterizing a cementitious binder is most often limited to the oxide content of the binder. The oxide content alone, however, is insufficient for determining the reactivity of the binders. Additional characterization of the material is needed to determine the type and quantity of crystalline and glassy mineral phases present.

\footnotetext{
${ }^{1}$ A pixel-based microstructural development tool that recreates paste microstructures (at a fixed 1- $\mu \mathrm{m}$ pixel size) consistent with SEM micrographs.

${ }^{2}$ Pronounced "mic", the model works with discrete (spherical) elements that have a location and size. Although the model achieves the correct volume fractions and has arbitrary spatial resolution, the resulting microstructures do not resemble micrographs of cement pastes.

${ }^{3}$ http://gems.web.psi.ch/

${ }^{4}$ Relatively limited engineering experience is available for most waste forms (Bradford et al. 2005).
} 


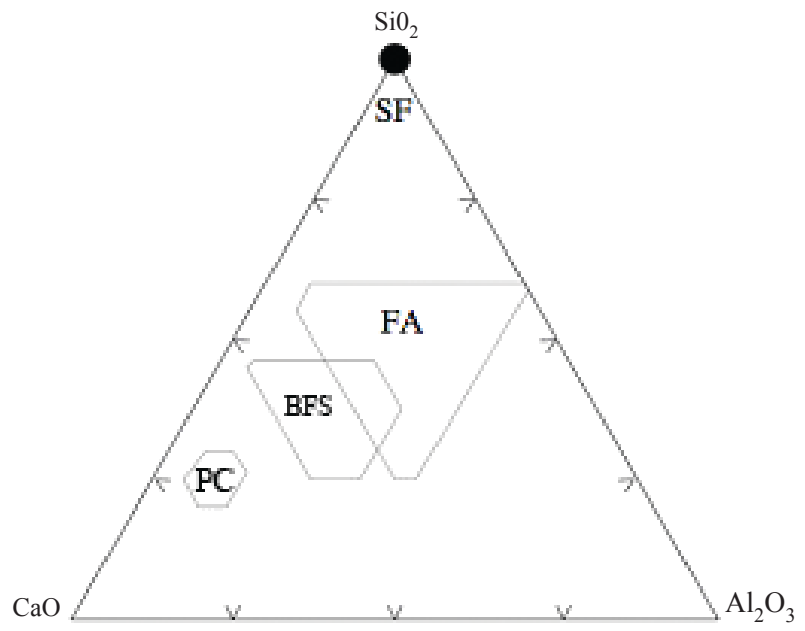

Figure 1. Approximate Range of Oxide Contents for Portland Cement (PC) Fly Ash (FA), Blast Furnace Slag (BFS), and ilica Fume (SF)

(Smolczyk 1980, Mindess \& Young 1981, Uchikawa 1986)

Unfortunately, the crystalline binder (portland cement) and glassy binders (fly ash, silica fume, and ground granulated blast furnace slag) require different techniques to determine the reactivity of the material.

\subsection{Portland Cement and Cement Hydration Products}

Historically, cement chemistry researchers have developed a shorthand notation for the oxides commonly found in portland cement, and the notation proves useful in characterizing the other cementitious materials as well. The shorthand is summarized in Table 1.

The mineral composition of portland cement is most often estimated from the cement oxide contents. This 'Bogue calculation' (Bogue 1929) is a mathematical means of de-convolving the oxide components into an estimated mineral phase composition. ASTM C 150 (ASTM 2005a) has implemented an extended version of the original Bogue calculation that assumes cement is composed of six pure phases
$\left(\mathrm{C}_{3} \mathrm{~S}, \mathrm{C}_{2} \mathrm{~S}, \mathrm{C}_{3} \mathrm{~A}, \mathrm{C}_{4} \mathrm{AF}, \mathrm{C} \overline{\mathrm{S}}, \mathrm{C} \overline{\mathrm{C}}\right)$. Another technique developed by Taylor (Taylor 1997) includes additional alkali sulfate phases and assumes that certain mineral phases contain impurities.

Quantitative X-ray diffraction (QXRD) using Rietveld analysis has been used to demonstrate that these calculations are unreliable and inaccurate, especially for minor mineral phases (Stutzman 2008). Because of the discrepancy between calculated and measured mineral phases, QXRD is the only reliable means (presently) for determining the mineral phase content of portland cement. The procedure is outlined in ASTM C 1365 (ASTM 2006b).

A summary of mineral phase mass fractions typically found in portland cement (Mindess \& Young 1981) is given in Table 2 merely as a frame of reference for the reader. The mass fractions given in Table 2 represent an average, do not necessarily represent any particular cement, and are based on the Bogue

Table 1. Cement Chemistry Notation for Oxides Related to Portland Cement

\begin{tabular}{|c|c|}
\hline $\begin{array}{c}\text { Oxide } \\
\text { Composition }\end{array}$ & $\begin{array}{c}\text { Cement Chemistry } \\
\text { Notation }\end{array}$ \\
\hline $\mathrm{CaO}$ & $\mathrm{C}$ \\
\hline $\mathrm{SiO}_{2}$ & $\mathrm{~S}$ \\
\hline $\mathrm{Al}_{2} \mathrm{O}_{3}$ & $\mathrm{~A}$ \\
\hline $\mathrm{Fe}_{2} \mathrm{O}_{3}$ & $\mathrm{~F}$ \\
\hline $\mathrm{SO}_{3}$ & $\overline{\mathrm{S}}$ \\
\hline $\mathrm{CO}_{2}$ & $\overline{\mathrm{C}}$ \\
\hline $\mathrm{K}_{2} \mathrm{O}$ & $\mathrm{K}$ \\
\hline $\mathrm{Na}_{2} \mathrm{O}$ & $\mathrm{N}$ \\
\hline $\mathrm{MgO}$ & $\mathrm{M}$ \\
\hline $\mathrm{H}_{2} \mathrm{O}$ & $\mathrm{H}$ \\
\hline
\end{tabular}


Table 2. Typical Mass Fractions of Mineral Phases Found in Commercial ASTM Portland Cement Types (Mindess \& Young 1981)

\begin{tabular}{|l|c|c|c|c|c|}
\hline \multicolumn{7}{|c|}{ Typical Mass Fractions } \\
\hline Phase & $\begin{array}{c}\text { Type } \\
\text { I }\end{array}$ & $\begin{array}{c}\text { Type } \\
\text { II }\end{array}$ & $\begin{array}{c}\text { Type } \\
\text { III }\end{array}$ & $\begin{array}{c}\text { Type } \\
\text { IV }\end{array}$ & $\begin{array}{c}\text { Type } \\
\text { V }\end{array}$ \\
\hline $\mathrm{C}_{3} \mathrm{~S}$ & 0.50 & 0.45 & 0.60 & 0.25 & 0.40 \\
\hline $\mathrm{C}_{2} \mathrm{~S}$ & 0.25 & 0.30 & 0.15 & 0.50 & 0.40 \\
\hline $\mathrm{C}_{3} \mathrm{~A}$ & 0.12 & 0.07 & 0.10 & 0.05 & 0.04 \\
\hline $\mathrm{C}_{4} \mathrm{AF}$ & 0.08 & 0.12 & 0.08 & 0.12 & 0.10 \\
\hline $\mathrm{CS}_{2}$ & 0.05 & 0.05 & 0.05 & 0.04 & 0.04 \\
\hline
\end{tabular}

calculation. These values are meant to demonstrate the type of variability expected among the different types of cement.

As can be seen in Table 1, portland cements are largely composed of alite $\left(\mathrm{C}_{3} \mathrm{~S}\right)$ and belite $\left(\mathrm{C}_{2} \mathrm{~S}\right)$, each containing impurities such as alkalis. Gypsum $\left(\mathrm{CS}_{2}\right)$ is added at the time of grinding; it is also common for portland cement producers to add small quantities ( $5 \%$ maximum) of limestone $(\mathrm{C} \overline{\mathrm{C}})$ along with the gypsum. The $\mathrm{C}_{4} \mathrm{AF}$ phase represents one particular point in the series of possible ferrites phases with composition $\left(\mathrm{Ca}_{2}\left(\mathrm{~A}_{x} \mathrm{Fe}_{1-x}\right)_{2} \mathrm{O}_{5}\right.$, where $0<x<0.7$ (Taylor 1997).

Assuming that each phase in Table 2 is pure, the corresponding oxide contents are given in Table 3. The $\mathrm{C} / \mathrm{S}$ mass ratio for most portland cements is approximately $3: 1$, and the C/A mass ratio varies from 10:1 to $15: 1$, depending upon the cement type.

\subsubsection{Alite and Belite Hydrated Phases}

Alite $\left(\mathrm{C}_{3} \mathrm{~S}\right)$ and Belite $\left(\mathrm{C}_{2} \mathrm{~S}\right)$ react with water to form approximately equal parts (molar basis) portlandite (CH) and an amorphous calcium silicate hydrate gel (C-S-H gel); the hyphens denote a non-stoichiometric mixture. The $\mathrm{Ca} / \mathrm{Si}$ molar ratio within $\mathrm{C}-\mathrm{S}-\mathrm{H}$ derived from alite and belite hydration typically varies over the range 1.6 to 2.0 (Taylor 1997).

The C-S-H gel is not a pure calcium silicate. The C-S-H may contain both metal ions and alkali ions as impurities (Taylor 1987). The amount of alkali binding depends upon the $\mathrm{Ca} / \mathrm{Si}$ molar ratio in the C-S-H and the extent of aluminum substitution for silicon (Hong and Glasser 1999, 2002, Brouwers and van Eijk 2003). The extent of alkali binding has a significant effect on the pore solution $\mathrm{pH}$.

Table 3. Typical Mass Fractions of Oxides Found in Commercial Portland Cements, Based on Data in Table 2 (Mindess \& Young 1981)

\begin{tabular}{|c|c|c|c|c|c|}
\hline \multicolumn{7}{|c|}{ Typical Mass Fractions } \\
\hline Oxide & $\begin{array}{c}\text { Type } \\
\text { I }\end{array}$ & $\begin{array}{c}\text { Type } \\
\text { II }\end{array}$ & $\begin{array}{c}\text { Type } \\
\text { III }\end{array}$ & $\begin{array}{c}\text { Type } \\
\text { IV }\end{array}$ & $\begin{array}{c}\text { Type } \\
\text { V }\end{array}$ \\
\hline C & 0.663 & 0.647 & 0.660 & 0.613 & 0.643 \\
\hline S & 0.219 & 0.223 & 0.210 & 0.240 & 0.245 \\
\hline A & 0.062 & 0.052 & 0.054 & 0.044 & 0.036 \\
\hline F & 0.026 & 0.039 & 0.026 & 0.039 & 0.033 \\
\hline $\bar{S}$ & 0.029 & 0.029 & 0.029 & 0.023 & 0.024 \\
\hline
\end{tabular}




\section{Review of Mechanistic Understanding and Modeling and Uncertainty Analysis Methods for Predicting Cementitious Barrier Performance}

In the absence of other hydrating minerals, $\mathrm{CH}$ and $\mathrm{C}-\mathrm{S}-\mathrm{H}$ are stable for very long times under sealed isothermal conditions. In the presence of pozzolanic silica-rich binders (e.g., fly ash, silica fume), however, the $\mathrm{CH}$ may be react to form additional C-S-H gel.

\subsubsection{Aluminate, Ferrite, and Sulfate Hydrated Phases}

Hydration of aluminate and ferrite phases most often leads to the formation of either $\mathrm{AFm}^{5}$ phases or $\mathrm{AFt}^{6}$ phases. The ratio of AFm to AFt formed will depend upon the amount of available alumina and sulfur.

The numerous AFm phases that can be created during portland cement hydration have the following chemical form $\mathrm{C}_{4}(\mathrm{~A}, \mathrm{~F}) \mathrm{X} \cdot \mathrm{yH}$. Under ideal conditions, AFm phases typically form platey, hexagonal crystals (Taylor 1997). Most of the AFm phases produced through portland cement hydration, however, are poorly crystalline and interspersed within the C-S-H phase (Taylor 1997). Monosulfate $\left(\mathrm{C}_{3} \mathrm{~A} \cdot \mathrm{CS} \cdot 12 \mathrm{H}\right)$ is an AFm phase often associated with sulfate attack.

The stability of monosulfate increases with increasing temperature, and forms at elevated temperatures (Matschei et al. 2007). In addition, monosulfate can react with $\mathrm{SO}_{4}{ }^{2-}$ and $\mathrm{CO}_{3}{ }^{2-}$ in presence of $\mathrm{CH}$ to form ettringite and hemicarbonate (Taylor 1997) which is relevant to modern cements that may contain limestone, respectively.

AFt phases are typically hexagonal, prismatic, or acicular crystals (Taylor 1997). In contrast to AFm phases, there are only two AFt phases significant to portland cement hydration: ettringite $\left(\mathrm{C}_{3} \mathrm{~A} \cdot 3 \mathrm{CS} \cdot 32 \mathrm{H}\right)$ and thaumasite $\left(\mathrm{C}_{3} \mathrm{~S} \cdot \overline{\mathrm{CS}} \cdot 15 \mathrm{H}\right)$. Ettringite is an expansive reaction product (with respect to monosulfate) that typically occurs through sulfate attack by the conversion of monosulfate in the presence of excess calcium and sulfate. Thaumasite is thought to form from one (or more) of three possible mechanisms (Crammond 2003): 1) a topochemical interchange of ionic species; 2) precipitation in solution; and 3) nucleation using ettringite as a template. Little is known of the reaction path, and even less is known of the reaction kinetics.

\subsubsection{Siliceous Hydrogarnet Phases}

The term 'hydrogarnet' is typically defined in the literature as a calcium aluminate hydrate: $\left(\mathrm{Ca}_{3} \mathrm{Al}_{2}(\mathrm{OH})_{12}\right.$. The presence of silica species in the pore solution of cementitious materials leads to the formation of siliceous hydrogarnets. The hydrogarnet phases are cubic and form solid solutions with end members being grossularite $\left(\mathrm{Ca}_{3} \mathrm{Al}_{2} \mathrm{Si}_{3} \mathrm{O}_{12}\right)$ and katoite $\left(\mathrm{Ca}_{3} \mathrm{Al}_{2}(\mathrm{OH})_{12}\right.$. Intermediate phases are formed by $\mathrm{F}$ replacing $\mathrm{A}$, and $\mathrm{H}$ replacing $\mathrm{S}$. These phases have the generalized chemical formula $\mathrm{C}_{3} \mathrm{~A}_{x} \mathrm{~F}_{1-x} \mathrm{~S}_{n} \mathrm{H}_{6-2 n}$ where $0 \leq x \leq 1$ and $\mathrm{n}=\{0,1,2,3\}$. In the ternary system $\mathrm{CaO}-\mathrm{Al}_{2} \mathrm{O}_{3}-\mathrm{H}_{2} \mathrm{O}$, only $\mathrm{C}_{3} \mathrm{AH}_{6}$ is stable at ordinary temperatures (Taylor 1997). The other phases are more common in autoclaved cementitious systems or as a hydration product of calcium aluminate cements.

These phases are rather complicated, and require further research. Laboratory synthesis of intermediate siliceous hydrogarnet phases typically yielded distinct phases, indicating a miscibility gap (Jappy and Glasser 1991) or contained irreducible quantities of C-S-H (Matschei et al. 2007), adding uncertainty to the estimated thermodynamic parameters. Silicious hydrogarnet phases are thought to be the stable state of AFm, but the kinetics are unknown. More research is needed for very long-term performance prediction.

\footnotetext{
${ }^{5} \mathrm{AFm}\left(\mathrm{Al}_{2} \mathrm{O}_{3}-\mathrm{Fe}_{2} \mathrm{O}_{3}\right.$-mono $\left.\mathrm{CaX}\right)$ phases are characterized by the chemical composition $\mathrm{C}_{3}(\mathrm{~A}, \mathrm{~F}) \cdot \mathrm{CX} \cdot y \mathrm{H}$ where $\mathrm{X}$ represents a divalent anion typical for cement hydration, such as, $2 \mathrm{OH}^{-}, 2 \mathrm{Cl}^{-}, \mathrm{SO}_{4}{ }^{2-}$, or $\mathrm{CO}_{3}{ }^{2-}$.

${ }^{6} \mathrm{AFt}\left(\mathrm{Al}_{2} \mathrm{O}_{3}-\mathrm{Fe}_{2} \mathrm{O}_{3}\right.$-tri $\left.\mathrm{CaX}\right)$ phases are characterized by the chemical composition $\mathrm{C}_{3}(\mathrm{~A}, \mathrm{~F}) \cdot 3 \mathrm{X} \cdot y \mathrm{H}$ where $\mathrm{X}$ again represents a divalent anion typical for cement hydration.
} 


\subsubsection{Hydrated Magnesium Phases}

Hydrated magnesium phases can occur when the cement has a relatively large magnesium content. The most common hydrated phases are brucite $(\mathrm{MH})$ and hydrotalcite $\mathrm{M}_{4} \mathrm{~A} \overline{\mathrm{C}} \mathrm{H}_{8}$. Another common form of hydrotalcite occurs when $\mathrm{OH}^{-}$replaces $\mathrm{CO}_{3}^{-2}$ to yield $\mathrm{M}_{4} \mathrm{AH}_{10}$ (meixnerite). The reactivity of periclase $(\mathrm{MgO})$ is relatively unknown, and it can remain unreacted in the paste for months.

\subsubsection{Proportions of Portland Cement Hydrated Phases}

Typical mass fractions of reaction products in a hydrated 0.50 water:cement mass ratio portland cement paste are given in Table 4 (Lothenbach \& Winnefeld 2006). C-S-H constitutes the majority of the hydration product, followed by (roughly) equal proportions of portlandite, monocarbonate, and ettringite. Because magnesium is a minor component in portland cement, hydrotalcite is a minor hydrated phase.

\subsection{Slag Cement}

Slag can react on its own if the $\mathrm{pH}$ is kept sufficiently high through the use of an activator such as calcium hydroxide, sodium hydroxide, or sodium silicate (Yuan \& Xin 1992, Taylor 1997). For these alkali activated slags (AAS), the accelerator is typically $3.5 \%$ to $5.0 \%$ (by mass) $\mathrm{Na}_{2} \mathrm{O}$ added as $\mathrm{NaOH}$ or sodium silicate. Calcium sulfate can accelerate the reaction by precipitation of ettringite to provide a sink for $\mathrm{Ca}^{2+}$ and $\mathrm{Al}(\mathrm{OH})_{4}{ }^{-}$ions released from slag, but additional alkali must be present (Regourd 1980).

The primary hydration products of AAS are C-S-H, hydrotalcite, and AFm (Jiang et al. 1997, Wang \& Scrivener 2005, Gruskovnjak et al. 2006). The $\mathrm{Ca} /$ $\mathrm{Si}$ ratio in the C-S-H formed from AAS is typically 1.1-1.2, which is low in comparison with hydrated portland cement.
Table 4. Representative Hydrated Phase Mass Fraction for a 0.50 Water: Cement (Mass) Ratio Portland Cement Paste (Lothenbach \& Winnefeld 2006)

\begin{tabular}{|l|c|}
\hline \multicolumn{1}{|c|}{ Phase } & Mass Fraction \\
\hline C-S-H & 0.45 \\
\hline CH & 0.20 \\
\hline Monocarbonate & 0.15 \\
\hline Ettringite & 0.13 \\
\hline Hydrotalcite & 0.04 \\
\hline
\end{tabular}

Supersulfated cements consist (mass percent) of $80 \%$ to $85 \%$ slag, $10 \%$ to $15 \%$ anhydrite, and approximately $5 \%$ activator that is usually portland cement clinker, and is ground more finely than ordinary portland cements. (Taylor 1997) The main reaction products are C-S-H and ettringite (Taylor 1997) with minor constituents hydrotalcite, gypsum, and merwinite $\left(\mathrm{C}_{3} \mathrm{MS}_{2}\right)$ (Gruskovnjak 2008).

\subsection{Binary Blended Cement Systems}

In many engineering applications, the most desirable properties are achieved by using binary mixtures of portland cement and a supplemental mineral admixture such as fly ash, slag, or silica fume. Each mineral admixture has unique qualities for particular applications. In virtually all cases, mixtures are designed such that the supplemental mineral admixture replaces some portion of the portland cement.

One common reason for adding supplemental pozzolans to portland cement mixtures is to consume the portlandite from portland cement hydration. The supplemental materials are typically composed of considerably more silica than calcium (silica-rich). The silica reacts with available portlandite to form additional C-S-H gel. Because the C-S-H is far more stable than portlandite, eliminating portlandite from 
the final hydration products could have a dramatic impact on the long-term leaching characteristics and on the pore solution $\mathrm{pH}$ of the system.

\subsubsection{Portland Cement - Fly Ash}

There are two commonly used classes of fly ash: Class C and Class F. The ASTM C 618 (ASTM 2005b) limits for the oxides present in Class $\mathrm{F}$ and Class $\mathrm{C}$ fly ash are given in Table 5. Class $\mathrm{C}$ fly ashes, by virtue of having less silica, alumina, and ferrite, have more calcium than Class F fly ashes.

\section{Table 5. Oxide Requirements for ASTM C 618 Class F and Class C Fly Ash (ASTM 2005b).}

\begin{tabular}{|l|c|c|}
\hline \multicolumn{1}{|c|}{ Oxides } & Class F & Class C \\
\hline $\mathrm{S}+\mathrm{A}+\mathrm{F}$ & $>70 \%$ & $>50 \%$ \\
\hline$\overline{\mathrm{S}}$ & $<5 \%$ & $<5 \%$ \\
\hline
\end{tabular}

Some Class C fly ashes are able to set and harden when mixed with only water, and are thus true hydraulic cements (Taylor 1997). The use of these stand-alone fly ash mixtures, however, is rare. When used, the initial hydration products include ettringite (Solem \& McCarthy 1992).

The vast majority of both Class F and Class C fly ash is a glassy mixture of calcium, silicon, and aluminum oxides. The glassy phases in Class F fly ashes are higher in $\mathrm{SiO}_{2}$, and the crystalline phases are typically mullite, quartz, magnetite, and hematite. The glassy phases in Class $\mathrm{C}$ fly ashes are higher in $\mathrm{CaO}$, and the crystalline phases are typically quartz, lime, and periclase (Taylor 1997). The specifics of the elemental composition of the various glassy phases and the quantity and type of crystalline phases impact the fly ash reactivity, but little is known of the significance of fly ash morphology on the final distribution of the mineral phases in hydrated cementitious systems.
As with most supplemental pozzolanic materials, the primary impact of fly ash replacement of cement is the reduction in the amount of portlandite produced and the reduced $\mathrm{Ca} / \mathrm{Si}$ molar ratio in the $\mathrm{C}-\mathrm{S}-\mathrm{H}$, typically near 1.5 initially and falling to 1.1 to 1.2 after 10 years (Taylor 1997). The hydration products of mixtures containing fly ash are very similar to the hydration products of pure portland cement pastes. The ratio of C-S-H to portlandite will increase, with the proportion of portlandite going to zero given sufficient fly ash replacement of cement.

The other types of crystalline hydrated phases are similar to those for pure portland cement paste. Within increasing fly ash content, the mass fraction of ettringite decreases due to cement sulfate dilution. The displacement of portland cement also decreases the portland cement phase reactivity, so the mass fraction of unhydrated cement increases with increasing fly ash content. Some of the fly ash crystalline phases, notably quartz, can remain in the hydrated system for months because of the relatively low reactivity.

\subsubsection{Portland Cement - Slag Cement}

Blast furnace slag is a by-product of iron manufacturing when limestone reacts with $\mathrm{SiO}_{2}$ and $\mathrm{Al}_{2} \mathrm{O}_{3}$ at very high temperatures. If forced to cool quickly below $800^{\circ} \mathrm{C}$, the result is a hydraulic cement that is over $95 \%$ glassy. The glassy material is ground, yielding a ground granulated blast furnace slag (GGBFS) (Taylor 1997).

Typical GGBFS is glassy, with the following composition range: $\mathrm{C}: 30 \%$ to $50 \%$; $\mathrm{S}: 27 \%$ to $42 \%$; A: $5 \%$ to $33 \%$; and M: $0 \%$ to $21 \%$ (Smolczyk 1980). The crystalline phases in GGBFS, if present, are melilite $(\mathrm{Ca}, \mathrm{Na})_{2}\left(\mathrm{Al}, \mathrm{Mg}, \mathrm{Fe}^{2+}\right)$ [(Al, $\left.\mathrm{Si}) \mathrm{SiO}_{7}\right]$ (sorosilicate: $\mathrm{Si}_{2} \mathrm{O}_{7}$ ) and merwinite $\mathrm{Ca}_{3} \mathrm{Mg}\left(\mathrm{SiO}_{4}\right)_{2}$ neosilicate) (Regourd 1986). The chemical requirements of slag conforming to ASTM C 989 (ASTM 2006a) are that the total 


\section{Review of Mechanistic Understanding and Modeling and Uncertainty Analysis Methods for Predicting Cementitious Barrier Performance}

sulfide $\left(\mathrm{S}^{2-}\right)$ be less than $2.5 \%$, and that sulfate reported as $\mathrm{SO}_{3}$ be less than $4.0 \%$.

Slag is desirable for use in certain radionuclide applications because the sulfide content helps to provide a reducing environment within the pore space. In certain applications, such as the chemical stabilization of Tc-99, the mobility depends strongly on the reduction-oxidation (redox) potential within the pore solution.

The principal hydration products are similar to those from portland cement hydration. The most noticeable difference is the lower amount of $\mathrm{CH}$ produced, as compared with portland cement hydration. For 50\% cement replacement, the $\mathrm{Ca} / \mathrm{Si}$ ratio was near 1.5 (Richardson \& Groves 1992). Otherwise, the effect of slag on the hydrated phase mineralogy is very similar to that of fly ash.

\subsubsection{Portland Cement - Silica Fume}

Silica fume is a by-product of the industrial processes for making either silicon or silicon alloys, and the typical dispersed particle size is $100 \mathrm{~nm}$. In industrial applications, the silica fume is often agglomerated and thus can have a much larger apparent particle size. The material is almost entirely glassy, and the most common crystalline impurities are $\mathrm{KCl}$, quartz, metallic iron, and iron silicide (Taylor 1997). The ASTM C 1240 (ASTM 2005c) specification requires that the $\mathrm{SiO}_{2}$ content of the silica fume be greater than $85 \%$.

Silica fume is most often added as a supplemental mineral admixture to accelerate hydration at early ages and to consume portlandite produced by portland cement hydration. At a cement replacement of $30 \%$ (relatively high from a practical mix design stand point), the silica fume consumes all available $\mathrm{CH}$ by $14 \mathrm{~d}$ (Huang \& Feldman 1985a, 1985b). Another effect of silica fume as a replacement for portland cement is to reduce the $\mathrm{Ca} / \mathrm{Si}$ molar ratio in $\mathrm{C}-\mathrm{S}-\mathrm{H}$ gel down to levels as low as 1.1 (Traetteberg 1978). The lower $\mathrm{Ca} / \mathrm{Si}$ molar ratio C-S-H typically bind more $\mathrm{Na}$ and $\mathrm{K}$, and also have more aluminum substitution for $\mathrm{Si}$, resulting in higher effective surface charges.

\subsection{Ternary Cementitious Systems}

Although ternary mixtures are used in practice, these mixtures are typically composed of large percentages of portland cement and considerably smaller percentages of mineral admixtures. These ternary blends are used for specialty applications such as reducing susceptibility to alkali-silica reaction (Shehata \& Thomas 2002). When used with large portions of portland cement, the typical effects of these ternary blends are to consume portlandite from the portland cement hydration reaction and to reduce the $\mathrm{Ca} / \mathrm{Si}$ molar ratio of the $\mathrm{C}-\mathrm{S}-\mathrm{H}$ gel.

Other examples of termary binder systems are found in waste forms. The proposed Savannah River Site (SRS) saltstone waste form and similar salt waste forms proposed for Hanford are approximated by a 6:47:47 (mass ratio) mixture of cement:slag: fly ash (Bradford et al. 2005). The slag is added to help provide a reducing environment; the fly ash also contributes to a reducing environment, but to a less extent.

Work is needed to transfer existing engineering knowledge into present hydration models for such material systems. The primary difficulty lies in estimating the reactivity of the individual cementitious components, particularly for systems having very low cement content. Although thermodynamic models could be used today, the reactivity of the individual components would have to be estimated from laboratory experiments performed on the systems of interest.

The types of hydrated phases found in low-cement blends made with portland cement, fly ash, slag, and water are very similar to those for pure portland cement paste and binary mixtures. As for binary 
systems, the portlandite will be consumed, but at a much greater rate. Upon consumption of the portlandite, one may find strätlingite.

\subsection{Hydration at Elevated Temperatures}

Conditions may arise where the cementitious binder will hydrate under elevated temperatures; these conditions are considered separately from autoclaved conditions. In pastes cured at elevated temperatures, X-ray microanalysis suggests that the $\mathrm{Ca} / \mathrm{Si}$ ratio increases as the temperature increases (Scrivener \& Taylor 1993). But this may be due, in part, to incorporation of poorly crystalline portlandite into the C-S-H. As for ordered C-S-H at elevated temperatures, XRD gives no evidence of C-S-H crystallization at temperatures up to at least $100^{\circ} \mathrm{C}$ (Taylor 1997).

When samples are exposed to elevated temperatures under saturated conditions for one year, ettringite begins to disappear above $70^{\circ} \mathrm{C}$, and is completely gone above $100^{\circ} \mathrm{C}$, unless there is excess aluminum, calcium and sulfate available (Buck et al. 1985). Moreover, above $100^{\circ} \mathrm{C}$, the ettringite was replaced by hydrogarnet, not monosulfate (Buck et al. 1985).

In another experiment, samples were first cured at $20^{\circ} \mathrm{C}$ for 30 days, then cured at $85^{\circ} \mathrm{C}$ for 8.4 years, and then returned to $20^{\circ} \mathrm{C}$ or periods ranging from 1.5 years to 2.0 years; companion samples were cured at $20^{\circ} \mathrm{C}$ for the entire 10 years (Paul \& Glasser 2001). The samples cured at $25^{\circ} \mathrm{C}$ were nearly completely hydrated, and the systems were composed primarily of C-S-H gel, portlandite, ettringite, and $\mathrm{AFm}$. The samples cured at $85^{\circ} \mathrm{C}$ showed no indication of additional hydration after the initial $20^{\circ} \mathrm{C}$ curing period.

\subsection{PORE SOLUTION COMPOSITIONAL EVOLUTION}

The composition of the pore solution is estimated by analyzing the aqueous solution that is in equilibrium with the soluble mineral phases present. Because the pore structure of hydrated paste is finely divided, the pore solution comes into contact with all mineral phases present. Moreover, because transport occurs at relatively long time scales, and reactions happen on relatively short time scales, the equilibrium assumption is reasonable. Similarly, changes in the pore solution composition, due to transport of ions into the cement from the external environment, may lead to dissolution/precipitation reactions that can change the microstructure and the transport properties.

Having an estimate for the pore solution composition can be important because sometimes the purpose of performance modeling is to estimate the chemical composition of the effluent from the cementitious structure. In these cases, accurate characterization of the pore solution can be vital to reliable performance assessment because the chemical composition of the effluent can have a significant impact on the overall performance.

The composition of the paste pore solution is determined experimentally by physical extraction. During the first few hours of hydration, the pore solution can be extracted by vacuum filtration or centrifuge (Gartner et al. 1985, Michaux et al 1989, Goldschmidt 1982). At later ages, a high pressure press (Longuet et al. 1973, Barneyback \& Diamond $1981)$ is needed to obtain a sufficiently large sample for analysis. 


\subsection{Portland Cement Paste Pore Solution}

The pore solutions of typical cementitious mixtures are composed of a large number of ionic species. As an example, a portland cement mixture was characterized (Lothenbach \& Winnefeld 2006) by both oxides present in the cement (see Table 6), and the elemental components of the pore solution as a function of curing time (see Table 7); undoubtedly, there were other elements present in the pore solution, such as magnesium. The data in Table 7 suggest that the pore solution of the paste analyzed became stable between $100 \mathrm{~d}$ and $300 \mathrm{~d}$.

Using the PHREEQC (Parkhurst \& Appelo 1999) speciation and thermodynamic equilibrium computer code, the component compositions in Table 7 were used to estimate the ionic species present, and the results are shown in Table 8; the boldface numbers represent the total quanitity of the component.

The important thing to notice from the speciation calculation results in Table 8 is that each element was represented by two or more ionic species in the pore solution. Therefore, each component of a multidisciplinary degradation model has to determine which of the numerous ionic species present are important, and how best to represent the total component by ionic species.
Table 6. Cement Oxide Mass Fractions from (Lothenbach \& Winnefeld 2006)

\begin{tabular}{|c|c|}
\hline Oxide & Mass Fractions \\
\hline $\mathrm{CaO}$ & 0.6320 \\
\hline $\mathrm{SiO}_{2}$ & 0.1970 \\
\hline $\mathrm{Al}_{2} \mathrm{O}_{3}$ & 0.0470 \\
\hline $\mathrm{Fe}_{2} \mathrm{O}_{3}$ & 0.0267 \\
\hline $\mathrm{SO}_{3}$ & 0.0335 \\
\hline $\mathrm{K}_{2} \mathrm{O}$ & 0.0112 \\
\hline $\mathrm{Na}_{2} \mathrm{O}$ & 0.0008 \\
\hline $\mathrm{MgO} \mathrm{O}$ & 0.0185 \\
\hline $\mathrm{CO}_{2}$ & 0.0193 \\
\hline
\end{tabular}

\subsection{Blended Cement Mixtures}

The primary difference between the pore solution of blended cement systems and pure portland cement systems is the $\mathrm{pH}$. This is due to both the alkali sorption of the lower $\mathrm{Ca} / \mathrm{Si}$ ratio $\mathrm{C}-\mathrm{S}-\mathrm{H}$ and the consumption of portlandite by the silica-rich supplemental cementitious materials. In general, fly ash, slag, and silica fume do not contribute new components to the pore solution. The only notable exception is titanium in fly ash.

Table 7. Pore Solution Composition ( $\mathrm{mmol} / \mathrm{kg}$ ) from (Lothenbach \& Winnefeld 2006)

\begin{tabular}{|c|c|c|c|c|c|c|c|}
\hline Day & $\mathbf{O H}^{-}$ & $\mathbf{K}$ & $\mathbf{N a}$ & $\mathbf{S}(\mathbf{V I})$ & $\mathbf{C a}$ & $\mathbf{S i}$ & $\mathbf{A l}$ \\
\hline 29 & 540 & 560 & 63 & 11 & 1.2 & 0.27 & 0.12 \\
\hline 105 & 570 & 650 & 57 & 17 & 1.5 & 0.21 & 0.04 \\
\hline 317 & 590 & 640 & 65 & 16 & 1.5 & 0.21 & 0.11 \\
\hline
\end{tabular}


Table 8. Calculated Ionic Speciation of Cement Paste Pore Solution Using PHREEQC (Parkhurst \& Appelo 1999)

\begin{tabular}{|c|c|c|}
\hline Component & Species & $\mathrm{mol} / \mathrm{kg}$ \\
\hline & $\mathrm{OH}^{-}$ & 0.613 \\
\hline \multirow[t]{4}{*}{$\mathbf{K}$} & & 0.640 \\
\hline & $\mathrm{K}^{+}$ & 0.584 \\
\hline & $\mathrm{KOH}^{\mathrm{O}}$ & 0.050 \\
\hline & $\mathrm{KSO}_{4}^{-}$ & 0.006 \\
\hline \multirow[t]{3}{*}{$\mathrm{Na}$} & & 0.065 \\
\hline & $\mathrm{Na}^{+}$ & 0.055 \\
\hline & $\mathrm{NaOH}^{\circ}$ & 0.010 \\
\hline \multirow[t]{3}{*}{$S(V I)$} & & 0.016 \\
\hline & $\mathrm{SO}_{4}^{-2}$ & 0.010 \\
\hline & $\mathrm{KSO}_{4}^{-}$ & 0.006 \\
\hline \multirow[t]{5}{*}{$\mathrm{Ca}$} & & 0.000480 \\
\hline & $\mathrm{CaOH}^{+}$ & 0.000308 \\
\hline & $\mathrm{Ca}^{+2}$ & 0.000127 \\
\hline & $\mathrm{CaH}_{2} \mathrm{SiO}_{4}{ }^{\circ}$ & 0.000033 \\
\hline & $\mathrm{CaSO}_{4}{ }^{\circ}$ & 0.000012 \\
\hline \multirow[t]{4}{*}{ Si } & & 0.000154 \\
\hline & $\mathrm{H}_{2} \mathrm{SiO}_{4}^{-2}$ & 0.000102 \\
\hline & $\mathrm{CaH}_{2} \mathrm{SiO}_{4}{ }^{\circ}$ & 0.000033 \\
\hline & $\mathrm{H}_{3} \mathrm{SiO}_{4}^{-}$ & 0.000019 \\
\hline \multirow[t]{2}{*}{ Al } & & 0.000110 \\
\hline & $\mathrm{Al}(\mathrm{OH})_{4}^{-}$ & 0.000110 \\
\hline
\end{tabular}

\subsection{LONG-TERM C-S-H STABILITY}

The primary hydration product of portland cement-based systems is an amorphous C-S-H gel. Amorphous materials generally have greater free energies of formation than crystalline materials with similar elemental composition. Therefore, over very long time scales, one expects amorphous materials to slowly convert to crystalline materials. This expectation and the lack of experimental data spanning millenia have limited the acceptance of cement-based materials for use in very long time (centuries to millenia) waste isolation.

If future experiments can demonstrate the conversion/re-crystallization process for $\mathrm{C}-\mathrm{S}-\mathrm{H}$, and the conditions under which the conversion occurs, one could use this evidence to predict very long-term performance. Given the limited set of elemental components present in cement-based materials, a conversion process will most likely result in the formation of familiar compounds. This information could be used to predict the chemical performance of the system over very long times; the mechanical properties may be much more difficult, or nearly impossible, to predict.

\subsection{Natural/Ancient Analogs}

Studying ancient binders and natural analogs is one approach to predicting the very long-term performance cement-based barriers. Although material formulation technology has changed since ancient times, the constituents of concretes made with ancient cements consist of hydrated calcium silicates, ettringite, etc. (Petit 1992).

There have been reports made on the properties of old cements (Steadman 1986) and archaeological binders (Jull and Lees 1990). Although direct comparisons to modern cements are problematic, the hydrated phases found in ancient, old, and modern cement-based binders are similar. This is particularly true for binders made from fired clays and volcanic rocks that contain silicon and aluminum. In these cases, the silicates, silica-aluminates, and aluminates bear a resemblance to the hydration products from modern cements (Petit 1992).

Studies of C-S-H from samples over 1800 years old suggest that the C-S-H is more stable than originally thought. Given the amorphous nature of C-S-H, the prevailing theory was that this material would, 
over long times, organize into a collection of related crystalline minerals such as tobermorite, jennite, and portlandite. The absence of this conversion in ancient cementitious systems suggests that the kinetics of any $\mathrm{C}-\mathrm{S}-\mathrm{H}$ crystallization is extremely slow. Moreover, the data suggest that systems with a lower $\mathrm{Ca} / \mathrm{Si}$ molar ratio seem to have a greater C-S-H stability (Petit 1992).

In addition competing reactions in open systems result in carbonation of C-S-H rather than formation of crystalline calcium silicate hydrate phases. The resulting mineral assemblages typically contain calcium carbonate (calcite) and amorphous silica or aluminosilicate (Roy and Langton 1983, Aloy 2005).

Some researchers indicate that the existence of C-S-H compounds in ancient binders has not been documented (Rassineux et al. 1989). Instead, authors have concluded that these ancient binders were solely composed of calcite (see references in Rassineux et al. 1989). A more careful mineralogical study of Gallo-Roman binders revealed a material resembling

(a)

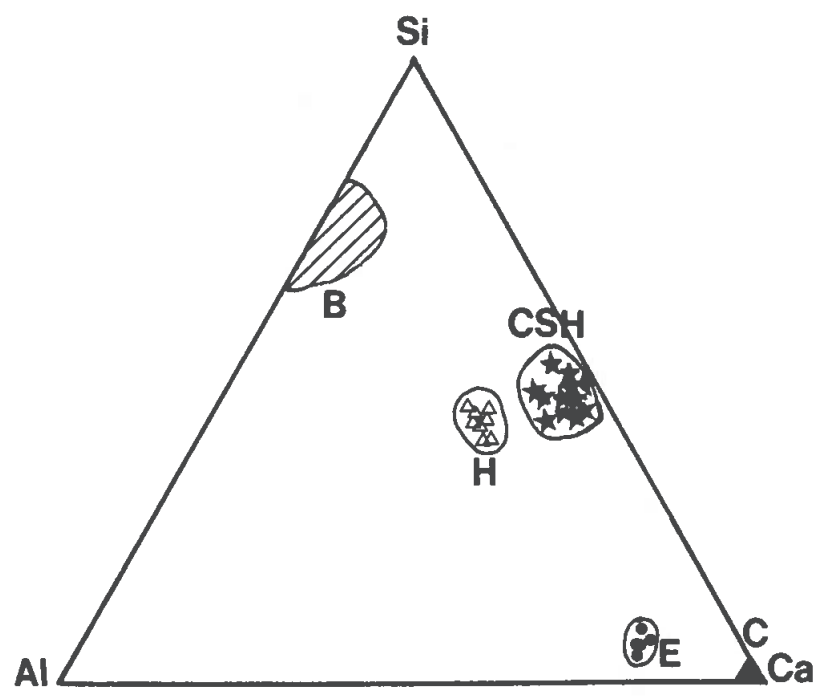

$\mathrm{C}-\mathrm{S}-\mathrm{H}$ having a $\mathrm{Ca} / \mathrm{Si}$ molar ratio varying from 1.0 to 1.2 , and containing up to $5 \%$ (by mass) $\mathrm{Al}_{2} \mathrm{O}_{3}$, up to $2 \%$ (by mass) $\mathrm{MgO}$, and up to $0.5 \%$ (by mass) $\mathrm{Fe}_{2} \mathrm{O}_{3}$ (Rassineux et al. 1989). A more detailed characterization of the phases is shown in Figure 2 for both the ancient binders and more modern binders.

There exist rock formations, primarily limestones with clay and/or manganese impurities (Bogue 1955), that contain quantities of calcium, silicon, and aluminum in roughly the same proportions as portland cement. Upon calcining, these 'natural cements' are hydraulic, and their properties have been reported upon since the eighteenth century (see Bogue 1955).

The utility of studying existing examples of these materials may be more for the general behavior than any specifics. The starting materials would have been poorly characterized by today's standards. Moreover, there would be very little similarity to modern portland cement. Furthermore, an analysis of phases found in existing examples would have to disentangle effects due to hydration and effects due to exposure.

(b)

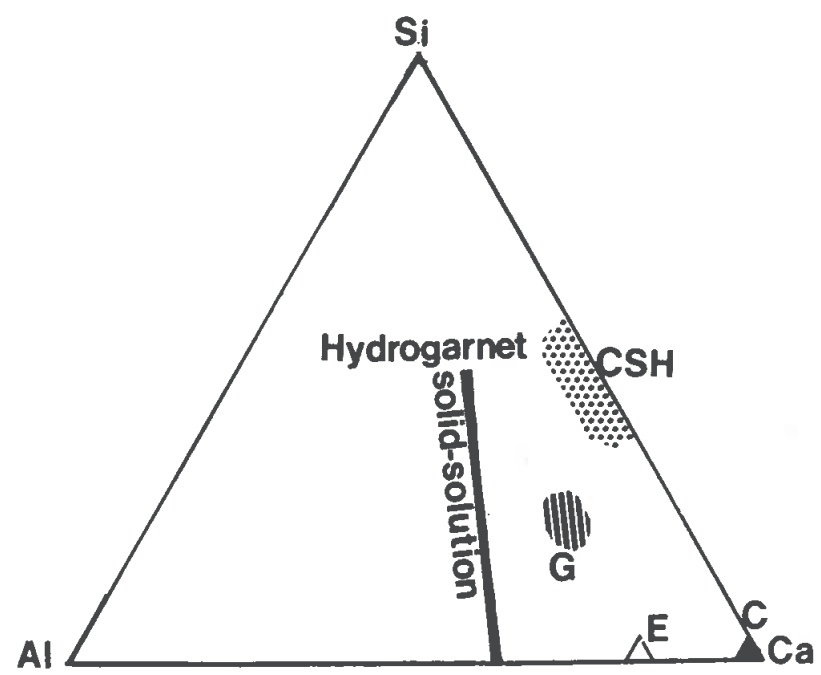

Figure 2. Mineralogical Assemblage of the (a) Studied Gallo-Roman Cements and (b) Modern Pozzuolanic Cement Reported in a Al-Si-Ca Diagram (B is composition area of brick-glass, $\mathrm{H}$ is hydrogrossular, $\mathrm{E}$ is ettringite, $\mathrm{C}$ is calcite, and $\mathrm{G}$ is hydrated gehlenite (C2ASH8)) from (Rassineux et al. 1989) 
The more general utility of existing examples of natural/ancient analogs may be in the detection of crystalline calcium silicate hydrates. The existence of crystalline calcium silicate hydrates having $\mathrm{Ca} / \mathrm{Si}$ molar ratios similar to those found today ( 0.9 to 1.8 ) may give some insight into the rate of crystallization of amorphous calcium silicate gels. This type of information may be beneficial to very long-term studies of cementititous materials performance.

\subsection{MICROSTRUCTURAL EVOLUTION}

Upon mixing with water, the cementitious constituents react to form the hydration products. The hydrating system is initially a colloidal suspension, and the hydrated reaction products consume more volume than the reactants, and begin filling the inter-particle space initially filled with water. The solid grows through a combination of topochemical reactions and through-solution precipitation reactions.

When a sufficient inter-connected network of solids exits, the paste will have mechanically "set", thereby supporting a pre-determined amount of shear stress. Continued hydration further fills in the void space with reaction products, thereby increasing the load carrying capacity, quantified in practice by the compressive strength. Not only is the total pore volume decreasing over time, the tortuosity of the pore space is simultaneously increasing; the tortuosity is a dimensionless number that represents the ratio of the characteristic path length through the pore space to the length of the specimen (a number that is greater than or equal to one).

The hydration process continues, conceptually, forever. Practically, however, most of the hydration has completed after one year. For modeling barrier performance over 100 to 1000 years of service, the hydration state at one year may be a practical initial condition, although changes in the environment or the microstructure could induce further hydration to occur. At this point, the key pieces of information for a performance assessment would be the types and quantity of mineral phases present, the total porosity remaining, and the relevant transport parameters: diffusivity, permeability, etc., which are sensitive functions of microstructure.

\subsection{Microstructural Property Evolution}

\subsubsection{Porosity/Saturation}

There are two types of porosity present in hydrated porous systems: water-filled porosity and airfilled porosity. The water filled porosity is further divided between C-S-H gel porosity, and capillary porosity. Hydration consumes water faster than the rate of hydration product formation. Thus chemical shrinkage occurs and results in cavitation and gasfilled pore space. Therefore, these systems are not completely saturated. Under sealed conditions, there is insufficient water for complete hydration for systems having a water to cement (mass) ratio less than approximately 0.38 because all capillary and gel pore water is consumed (Taylor 1997). Below a water to cement (mass) ratio of approximately 0.44 , there is insufficient water at complete hydration to fill the gel pores (capillary pores empty), and a state of self-desiccation is achieved (Taylor 1997).

The capillary porosity $\phi_{c}$ of portland cement pastes can be approximated by a function of the degree of hydration $\alpha$ and the water to cement (mass) ratio $\beta$ as shown in Equation 1 (Garboczi and Bentz 1992):

$\phi_{c}=1-\frac{1+1.16 \alpha}{1+3.2 \beta}$

As an example, using Eq. (1) and $\alpha=0, \beta=0.45$, portland cement paste has an initial capillary porosity of 0.59 . To get the value at complete hydration, insert $\alpha=1$ into Eq. (1) to calculate a capillary porosity of 


\section{Review of Mechanistic Understanding and Modeling and Uncertainty Analysis Methods for Predicting Cementitious Barrier Performance}

0.11 at complete hydration. For most cementitious systems, the capillary porosity decreases by less than an order of magnitude over the course of hydration. The critical value of the capillary porosity when it loses connectivity is denoted $\phi_{c}^{\prime}$.

In addition to the capillary porosity, the C-S-H gel is composed of approximately $28 \%$ porosity (Taylor 1997). Although this porosity is composed of much smaller pores than capillary pores which are about $5 \mathrm{~nm}$ to $50 \mathrm{~nm}$ in diameter, the C-S-H gel pores can contain water. This water can be exchanged with capillary water and it can be removed at very low relative humidity. The water-filled gel porosity can contribute to overall transport, but the gel pore relative transport coefficient ${ }^{7}$ is 2 to 3 orders of magnitude smaller than the corresponding capillary pore space transport coefficient (Garboczi 1992).

Another factor to consider when characterizing porosity is the connectedness of the pore space. If there is sufficient capillary porosity that the capillary pores are connected across a sample, these interconnected capillary pores will likely dominate the rate of transport of moisture and dissolved ions (assuming the samples is free of fractures or other macro defects). If the capillary porosity is below a critical volume fraction of the cement paste (about 0.2 ), the capillary pores will no longer be connected across the sample. Instead, transport through the sample must pass through both capillary pores and $\mathrm{C}-\mathrm{S}-\mathrm{H}$ gel pores and is therefore significantly retarded by several orders of magnitude (Garboczi 2001).

\subsubsection{Pore Size Distribution}

Very little quantitative data exist on the pore size distribution in hydrated cementitious systems. Because the hydration products are continually filling in the water-filled pore space, the pore size distribution must shift toward smaller pores as hydration continues. ${ }^{8}$

The most direct experimental technique for characterizing the pore size distribution is mercury intrusion porosimetry (MIP). This technique forces a non wetting liquid into pore space at very high pressure into a dried specimen. The resulting data for the volume of liquid intruded as a function of pressure have to be corrected for physical parameters such as the contact angle between the fluid and the microstructure. Moreover, pore constrictions mean that the intruded volume indicates the volume of pore space accessible via a minimum pore throat, not the pore size distribution. Instead, MIP can be used to characterize the largest pore diameter that percolates the microstructure (Katz \&Thompson 1987). As discussed below, this critical pore throat diameter can be used to estimate the hydraulic permeability.

\subsubsection{Tortuosity}

The tortuosity can be characterized qualitatively as the ratio of the path length through the pore space of a material, divided by the macroscopic length of the material. As more twists and turns are needed to pass through the pore space, the tortuosity increases. As additional solids precipitate, closing off pores, the tortuosity increases still further. Therefore, tortuosity is a non-trivial function of the porosity and the pore size distribution and sometimes the specific transport mechanism considered (e.g., diffusion through a liquid vs. molecular diffusion through air). Moreover, there is no theoretical approach to these relationships, so tortuosity must be approximated with empirical relationships.

\footnotetext{
${ }^{7}$ The relative transport coefficient is the rate of diffusive transport through the gel pores, relative to diffusive transport through water.

${ }^{8}$ The currently available microstructural computer models are incapable of resolving the pore network at a sufficient detail to fully characterize the pore size distribution down to the length scale of C-S-H pores.
} 
The relationship between porosity and tortuosity depends, in part, on how the material is formed.

A relationship developed for sandstone does not necessarily apply to hydrated cement pastes because sandstone is formed from a cementing process, and the hydrated cement paste is a combination of cementing (prior to set) and diffusion limited aggregation (DLA). It is the DLA process that forms the portion of the microstructure that has the greatest impact on transport.

Given that the pore space is subdivided between liquid-filled and gas-filled pores, the tortuosity should likewise be subdivided. Therefore, there is a tortuosity for the liquid-filled space and a tortuosity for the gas-filled space. These are important concepts when the environment is not saturated with water vapor.

\subsection{Microstructural Evolution During Degradation}

There are two approaches to estimating the microstructural evolution during degradation. The first is to use empirical relationships between changes in porosity (through dissolution and precipitation) and changes in transport coefficients. The second approach attempts to first estimate the microstructural changes that occur, and then use this information to predict the resulting changes in the transport coefficients.

The first approach has the advantage of expediency, but requires sufficient measurement to ensure data over the relevant parameter space. Empirical relationships are developed using data for specific mixtures under specific conditions. Therefore, the data are only applicable to similar systems under similar conditions. Given enough data over a sufficient parameter space, one can begin applying the empirical relationships over a broad set of conditions. Applying the relationships to systems (materials
+ exposure) outside the parameter space leads to uncertainties that may be difficult to quantify.

The second approach has the advantage of being better able to adapt to new materials and exposure conditions. Once the microstructural model and the estimation of transport parameters (e.g., porosity, tortuosity, formation factor) have been validated for the materials and degradation mechanisms encountered, the approach can more easily adapt to new materials and exposure conditions. If the microstructural model is based on physical principles, once these are validated, the model applies wherever the same principles apply. Moreover, one does not need to have data for simultaneous degradation mechanisms (e.g., leaching and chloride diffusion), as these are simply manifestations of the chemical and physical principles that have been validated, as long as no new principles are invoked when both mechanisms simultaneously exist. Therefore, a microstructure-based degradation model can more reliably predict the performance of new materials in complex (varying in time or multiple mechanisms) environments for which there are no experimental data.

The challenge of a microstructure-based degradation model is predicting permeability. Because the permeability depends upon the details of pore sizes on the order of the critical pore diameter, $d_{c}$, the microstructural model must somehow accurately resolve the pores at this scale. This is a particularly challenging requirement for a model, especially if the model is to perform calculations within a reasonable time limit.

\subsection{Transport Property Evolution During Degradation}

The evolution of transport properties during degradation is similar to the evolution of transport properties during hydration. Dissolution and precipitation of mineral phases change the porosity, the pore size distribution, and the pore connectivity. 
If the change in volume of mineral phases is small enough, and those mineral phases do not contribute directly to the critical pore diameter, both the diffusivity and the permeability will (roughly) vary inversely to changes in the porosity.

As the volume change increases, however, the tortuosity and critical pore diameter will change. Estimating the diffusivity and permeability will require either a microstructural model, or empirical relations based on previous experimentation. The same microstructural model used to predict the transport properties of the hydrated system would be applicable to changes in the microstructure due to degradation.

In the absence of microstructural information, changes in formation factor can be approximated by empirical power-law relationships (Grathwohl 1998). One possible expression is based Archie's law (Archie 1942) relating formation factor to porosity $\phi$ :

$$
\Gamma=\phi^{m}
$$

The exponent $m$ is the material cementation exponent. This is a purely empirical relationship, and must be validated from a database of experimental measurements.

When coupled to a microstructural model, however, the transport coefficients can be calculated directly. The formation factor (for diffusivity) can be calculated from the relative electrical conductivity of the pore space. The permeability can be calculated from the flow of fluid through the pore space due to a pressure difference across the microstructure.

\subsection{Modeling Microstructural Changes}

\subsubsection{Chemical Reaction}

Modeling the state of a cementitious material, whether in a closed system or one exposed to degradation mechanisms, requires modeling transport and reaction through the hydrated cementitious binder. The physico-chemical approach to hydration and degradation modeling uses the environment as a boundary condition, allows transport to occur through the pore space, and calculates the thermodynamic equilibrium (or appropriate kinetic approach) distribution of components between the mineral phases and the pore solution species.

The change in the mineral phases is determined by the chemical state of the system and the thermodynamic data. The change in the microstructure is due to dissolution and/or precipitation of mineral phases, which changes the porosity. The pore space tortuosity, however, is also changed and needs a 3-D microstructure model to properly compute the new transport coefficients.

The advantage of a physico-chemical approach is the ability to accommodate multiple simultaneous degradation mechanisms. All the degradation mechanisms are treated the same. The accuracy by which a degradation model accounts for a specific degradation mechanism is limited by the quality of the thermodynamic data for the anticipated reactions. Furthermore, transport through the system can be described by a number of material parameters and transport coefficients (e.g., porosity, tortuosity, permeability, hydraulic diffusivity). Therefore, to model hydration and degradation, one needs to know how changes in the microstructure affect each of the material parameters and transport coefficients.

The key to successful physico-chemical modeling is accurate thermodynamic data for the relevant mineral phases. Fortunately, there has been considerable effort expended on this topic (Berner 1992, Lothenbach \& Winnefeld 2006, Lothenbach \& Gruskovnjak 2007, Matschei, Lothenbach \& Glasser 2007). The thermodynamic data determine the type and quantity of mineral phases dissolved or precipitated. These databases are extensive but not exhaustive; in particular, gaps in the thermodynamic data for 
supplementary materials like fly ash and slag and degradation-produced materials need to be filled in.

It is important to remember that thermodynamic data differ from kinetic data. The thermodynamic data will yield mineral composition at equilibrium. Kinetic coefficients determine the time required before the system reaches equilibrium. Few, if any, kinetic data exist for mineral phases relevant to cementitious systems. Over very long time scales, performance will be controlled by the properties of the very low solubility minerals, which are the minerals that will most likely have the slowest reaction kinetics.

\subsection{Modeling Transport Properties}

From a performance assessment modeling perspective, microstructural changes via dissolution and/or precipitation lead to commensurate changes in transport coefficients. The two transport coefficients most relevant to cementitious barrier degradation are diffusivity and permeability.

\subsubsection{Formation Factor}

Diffusion is the primary transport mechanism in the absence of a hydraulic pressure gradient. Ionic diffusion occurs through the connected water-filled pore space, and vapor diffusion occurs through both the water-filled and vapor-filled pore space.

Diffusion can be described within the pore space (pore space diffusivity), or across a porous material (bulk diffusivity). The pore solution has an electrical conductivity $\sigma_{p}$, and the bulk material (saturated with the same solution) has electrical conductivity $\sigma_{b}$. The ratio of these two quantities can be used to approximate the formation factor $F$ (Collins 1961):

$$
F=\frac{\sigma_{p}}{\sigma_{b}}
$$

As defined, the formation factor is a quantity having a value greater than or equal to one because the solid comprising the bulk material is assumed to be an electrical insulator. The formation factor can also be related to the porosity $\phi$ and the tortuosity $\tau$ :

$$
F=\frac{\tau}{\phi}
$$

NOTE: The definition of tortuosity can vary among authors, with some authors defining tortuosity as the inverse of the quantity used here.

The formation factor is a property of the solid microstructure, and does not depend on the composition of the pore solution. The ratio of the pore solution and bulk conductivity has a oneto-one relationship to the diffusion coefficient of an ion in the pore solution and the bulk diffusion coefficient. Therefore, one could use the formation factor to estimate the bulk diffusion coefficient using the diffusion coefficients of the species in the pore solution. This quantity, however, can only be estimated after the pore solution composition has been established.

Alternatively, the limiting ionic self-diffusion ${ }^{9}$ coefficient $D_{i}^{\circ}$ (IUPAC 1976) is the diffusion coefficient of an ion in water given that total concentration of all ions is zero (Harned \& Owen 1958). Self-diffusion coefficients for different species can be found in reference books (Mills \& Lobo 1989). Within an inert porous microstructure saturated with a very dilute pore solution and having formation factor, $F$, the apparent bulk diffusivity, $D_{i}$ (Snyder 2001) can be estimated from the formation factor:

$D_{i}=\frac{D_{i}^{\circ}}{F}$

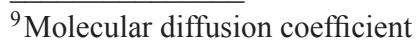




\section{Review of Mechanistic Understanding and Modeling and Uncertainty Analysis \\ Methods for Predicting Cementitious Barrier Performance}

This is not a complete description of diffusion in cementitious materials because pore solution speciation, ion exchange, and (topo-) chemical reactions can alter the apparent diffusivity of an ionic species within the pore solution (Samson et al. 2005).

\subsubsection{Permeability}

Permeability is a more complex function of changes in the microstructure than diffusivity. Not only does it depend upon changes in the porosity and tortuosity, it (most importantly) depends upon the pore size distribution. Given that the permeability of hardened portland cement paste can vary from $10^{-20} \mathrm{~m}^{2}$ to $10^{-16} \mathrm{~m}^{2}$, the relevant length scale that characterizes permeability is on the order of tens to hundreds of nanometers. Presently, there are no viable micro/ nano-structure computer models for predicting the permeability of a hydrated cement paste based on an analysis of the modeled microstructure.

In addition, the bulk permeability of a composite element containing aggregates depends upon the permeability of the hydrated cementitious binder in both the bulk pore space and near the aggregate surfaces. As the aggregate volume increases, the higher permeability regions of the paste near aggregate surfaces begin to overlap. Above a critical aggregate volume, these regions can percolate the system, thereby greatly increasing the bulk permeability of the element (Winslow et al. 1994). This phenomenon occurs over the length scale of tens of millimeters.

For structures subjected to hydraulic pressure gradient, transport of ionic species is dictated by permeation. Under these conditions, the assumption is that the ions move with the pore solution. The pore solution volume averaged velocity is calculated from the D'Arcy flux $\boldsymbol{q}$ :

$$
\boldsymbol{q}=\frac{-k}{\eta} \nabla P
$$

where: $k$ is the intrinsic permeability, $\eta$ is the dynamic fluid viscosity, and $\nabla P$ is the fluid pressure gradient. The pore solution velocity $\boldsymbol{v}$ (tracer velocity) is faster than the flux by a factor of the porosity $\phi$ :

$$
v=\frac{q}{\phi}
$$

The Katz-Thompson (Katz \& Thompson 1986, Katz \& Thompson 1987) estimation for permeability, $k$, is proportional to the ratio of the square of a critical pore size diameter, $d_{c}$, to the formation factor, $F$ (dimensionless quantity):

$k=\frac{c d_{c}^{2}}{F}$

The constant of proportionality $c$ varies, depending upon the particular microstructural formation mechanism, but is typically on the order of $10^{-1}$ to $10^{-2}$ (Garboczi 1990). The critical pore size diameter $d_{c}$ is analogous to the diameter of the largest sphere that can pass through the pores.

Using the Katz-Thompson relationship in Eq. 8, one can see how the discontinuity of the capillary pores can have a dramatic effect on permeability. If the capillary pores are connected (percolate the system), the critical pore diameter would be on the order of $10^{-6} \mathrm{~m}$. If the capillary pores no longer percolate the system (i.e., sufficient hydration at a low enough water:cement mass ratio), the critical pore diameter would have to be limited to that for the C-S-H, which would be on the order of $10^{-8} \mathrm{~m}$. Given that permeability is proportional to $d_{c}^{2}$, the ratio of permeabilities for connected vs. disconnected capillary pores would be on the order of $10^{4}$.

Similarly, if leaching occurs in a system that initially has disconnected pores, at the point where capillary pores percolate the system, the permeability would increase dramatically. 


\subsection{SUMMARY}

The mineralogical and microstructural changes that occur during hydration and reaction are numerous and complex. Treating the hydration and the degradation reactions on a similar basis, however, simplifies the problem to enumerating the relevant reactions, determining mineral phase dissolution and/or precipitation to achieve chemical equilibrium, and modifying the porosity and transport properties accordingly using a microstructure model. The accuracy of this approach depends upon a comprehensive characterization of the starting material and the environment, and upon comprehensive thermodynamic and kinetic data for the reactions.

The approach borrows from geochemical modeling, and is based on a strong foundation in thermodynamics. Moreover, the parameters have physical meaning and can be measured independently in the laboratory. As a result, the approach uses a minimum of empirical coefficients.

Although considerable information and data exist for the majority of reactions relevant to cementitious systems, additional information is needed for specific components of this approach. Applications involving waste isolation may occur at elevated temperatures. Additional work is needed to obtain missing data on the temperature dependence of the thermodynamic parameters of relevant mineral phases.

For very long-term performance predictions, a combination of kinetic experiments and studies of natural/ancient analogs may be needed. The properties of the system after a thousand or more years will depend upon the mineral phases present. These phases may arise after re-crystallization of existing crystalline phases, or the crystallization of the amorphous calcium silicate hydrate gel. Data are needed to establish the kinetics of the crystallization reactions, and the resulting phases. Estimates of the very long-term mineral phase composition will then allow researchers to study the properties of these crystalline phases, and the kinetics data will be used to estimate when these properties will occur. 


\subsection{REFERENCES}

Aloy, AS, Suvorova SN, and Holtzscheiter, EW 2005, 'Evaluation of Durability of Mortars and Concretes Used in Ancient Structures,' WSRC-RP-2005-01551, Revision 0, June 2005, Savannah River National Laboratory, Westinghouse Savannah River Company, Aiken, SC 29808.

Archie, GE 1942, 'The Electrical Resistivity Log as an Aid in Determining Some Reservoir Characteristics,' Transactions of the AIME, vol. 146, pp. 54-62.

ASTM 2005a, 'ASTM C 150: Standard Specification for Portland Cement', ASTM International, West Conshohocken, PA.

ASTM 2005b, 'ASTM C 618: Standard Specification for Coal Fly Ash and Raw or Calcined Natural Pozzolan for Use in Concrete', ASTM International, West Conshohocken, PA.

ASTM 2005c, 'ASTM C 1240: Standard Specification for Silica Fume Used in Cementitious Mixtures', ASTM International, West Conshohocken, PA.

ASTM 2006a, 'ASTM C 989: Standard Specification for Ground Granulated Blast-Furnace Slag for Use in Concrete and Mortars', ASTM International, West Conshohocken, PA.

ASTM 2006b, 'ASTM C 1365: Standard Test Method for Determination of the Proportion of Phases in Portland Cement and Portland-Cement Clinker Using X-Ray Powder Diffraction Analysis', ASTM International, West Conshohocken, PA.

Bakharev, T, Sanjayan, JG \& Cheng, Y-B 2000, 'Effect of Admixtures on Properties of Alkaliactivated Slag Concrete', Cement and Concrete Research, vol. 30, pp. 1367-1374.
Bao, Y, Grutzeck, MW \& Jantzen, CM 2005, 'Preparation and Properties of Hydroceramic Waste Forms Made with Simulated Hanford Low-activity Waste', Journal of the American Ceramic Society, vol. 88 , pp. 3287-3302.

Barneyback, RS \& Diamond, S 1981, 'Expression and Analysis of Pore Fluids of Hardened Cement Pastes and Mortars,' Cement and Concrete Research, vol. 11, pp. 383-394.

Bentz, D.P. 1997, “Three-Dimensional Computer Simulation of Portland Cement Hydration and Microstructure Development", Journal of the American Ceramic Society, vol. 80, no. 1, pp. 3-21.

Berner, UR 1992, 'Thermodynamic Modelling of Cement Degradation: Impact of Redox Conditions on Radionuclide Release', Cement and Concrete Research, vol. 22, pp. 465-475.

Bogue, RH 1929, 'Calculation of the Compounds in Portland Cement', Industrial \& Engineering Chemistry Analytical Edition, vol. 1, pp. 192-197.

Bogue, RH 1955, 'The Chemistry of Portland Cement', Reinhold Publishing Corporation, New York.

Bradford, A, Esh, D, Ridge, A, Thaggard, M, Whited, R, Treby, S, Flanders, S \& Camper LW 2005, 'U.S. Nulcear Regulatory Commission Technical Evaluation Report for the U.S. Department of Energy Savannah River Site Draft Section 3116 Waste Determination for Salt Waste Disposal', Technical Report, U.S. Nuclear Regulatory Commission, viii + $106 \mathrm{pp}$.

Brough, AR, Katz, A, Bakharev, T, Sun, G-K, Kirkpatrick, RJ, Struble, LJ \& Young, JF 1995, 'Microstructural Aspects of Zeolite Formation in Alkali Activated Cements Containing High Levels of Fly Ash,' Proceedings of the Materials Research Society, Vol. 370, pp. 199-208. 
Buck, AD, Burkes, JP \& Poole, TS 1985, 'Thermal Stability of Certain Hydrated Phases in Systems Made Using Portland Cement', ADA160443 (Defense Technical Information Center OAI-PMH Repository).

Collins, RE 1961, Flow of Fluids Through Porous Materials, Reinhold Publishing.

Cook, JR, Wilhite, EL, Hiergesell, RA \& Flach, GA 2005, 'Special Analysis: Revsion of the Saltstone Vault 4 Disposal Limits,' WSRC-TR-2005-00074, Westinghouse Savannah River Company, Aiken, South Carolina.

Cook, JR \& Fowler, JR 1992, 'Radiological Performance Assessment for the Z-Area Saltstone Disposal Facility,' WSRC-RP-92-1360, Rev. 0, Westinghouse Savannah River Company, Aiken, South Carolina.

Crammond, NJ 2003, 'The Thaumasite Form of Sulfate Attack in the UK', Cement and Concrete Composites, vol. 25, pp. 809-818.

Garboczi, EJ 1990, 'Permeability, Diffusivity, and Microstructural Parameters - A Critical Review', Cement and Concrete Research, vol. 20, pp. 591-601.

Garboczi, EJ and Bentz, DP 1992, 'Computer Simulation of the Diffusivity of Cement-Based Materials,' Journal of Materials Science, vol. 27, pp. 2083-2092 (1992).

Garboczi, EJ and Bentz, DP 2001, 'The Effect of Statistical Fluctuation, Finite Size Error, and Digital Resolution on the Phase Percolation and Transport Aspects of the NIST Cement Hydration Model,' Cement and Concrete Research, vol. 31, pp. 15011514.
Gartner, EM, Tang, FJ, \& Weis, SJ 1985, 'Saturation Factors for Calcium Hydroxide and Calcium Sulfates in Fresh Portland Cement Pastes,' Journal of the American Ceramic Society, vol. 68, pp. 667-673.

Goldschmidt, A 1982, 'About the Hydration Theory and the Composition of the Liquid Phase of Portland Cement,' Cement and Concrete Research, vol. 12, pp. $743-746$.

Grathwohl, P 1998, Diffusion in Natural Porous Media: Contaminent Transport, Sorption/Desorption and Dissolution Kinetics, Springer.

Gruskovnjak, A, Lothenbach, B, Holzer, L, Figi, R \& Winnefeld, F 2006, 'Hydration of Alkali-activated Slag: Comparison with Ordinary Portland Cement', Advances in Cement Research, vol. 18, pp. 119-128.

Gruskovnjak, A, Lothenbach, B, Winnefeld, F, Figi, R, Ko, S-C, Adler, M \& Mäder, U 2008, 'Hydration Mechanisms of Super Sulphated Slag Cement', Cement and Concrete Research, vol. 38, pp. 983-992.

Harned HS. \& Owen BB 1958, The Physical Chemistry of Electrolytic Solutions, Reinhold Publishing Corporation, New York.

Hong S.-Y. \& Glasser, FP 1999, 'Alkali Binding in Cement Pastes: Part I. The C-S-H phase,' Cement and Concrete Research, vol. 29, pp. 1893-1903.

Hong S.-Y. \& Glasser, FP 2002, 'Alkali Sorption by C-S-H and C-A-S-H: Part 2. Role of Alumina,' Cement and Concrete Research, vol. 32, pp. 11011111.

Huang, C-Y \& Feldman, RF 1985a, 'Influence of Silica Fume on the Microstructural Development in Cement Mortars', Cement and Concrete Research, vol. 15, pp. 285-294. 
Huang, C-Y \& Feldman, RF 1985b, 'Hydration

Reactions in Portland Cement-silica Fume Blends', Cement and Concrete Research, vol. 15, pp. 585-592.

IUPAC 1976, "Manual of Symbols and Terminology for Physicochemical Quantities and Units - Appendix II. Definitions, Terminology and Symbols in Colloid and Surface Chemistry. Part II: Heterogeneous Catalysis", Pure and Applied Chemistry, vol. 46, pp. 71-90.

Jappy, TG and Glasser, FP 1991, 'Synthesis and Stability of Silica-substituted Hydrogarnet Ca3Al2Si3-xO12-4x (OH)4x', Advances in Cement Research, vol. 4, pp. 1-8.

Jiang W, Silsbee, MR \& Roy, DM 1997, ‘Alkali Activation Reaction Mechanisms and it Influences on Microstructure of Slag Cement', Proceedings of the 10th International Congress on the Chemistry of Cement (Göteborg), vol. 3, p. 3 ii100 (9 pp.).

Jull, SP \& Lees, TP 1990, 'Studies of Historic Concrete,' CEC Technical Report No. 12972, CEC, Brussels.

Katz, A, Brough, AR, Kirkpatrick, RJ, Struble, LJ \& Young, JF 2000, 'Effect of Solution Concentration on the Properties of a Cementitious Grout Wasteform for Low-level Nuclear Waste,' Nuclear Technology, vol. 129, pp. 236-245.

Katz, AJ \& Thompson, AH 1986, 'Quantitative Prediction of Permeability in Porous Rocks', Physical Review B, vol. 34, pp. 8179-8181.

Katz, AJ \& Thompson, AH 1987, 'Prediction of Rock Electrical Conductivity from Mercury Injection Measurements', Journal of Geophysical Research, vol. 92, pp. 599-607.
Lichtner, PC, Steefel, CI \& Oelkers, EH (Editors) 1996, Reactive Transport in Porous Media, Reviews in Mineralogy (Volume 34), Mineralogical Society of America, Washington, D.C.

Longuet, P, Burglen, L \& Zelwer, A 1973, 'La phase liquide du cement hydraté' (in Fr.) Revue des Matériaux de Construction, vol. 676, pp. 35-41.

Lothenbach, B \& Winnefeld, F 2006, 'Thermodynamic Modelling of the Hydration of Portland Cement', Cement and Concrete Research, vol. 36, pp. 209-226.

Lothenbach, B \& Gruskovnjak, A 2007, 'Hydration of Alkali-activated Slag: Thermodynamic Modeling', Advances in Cement Research, vol. 19, pp. 81-92.

Matschei, T, Lothenbach, B \& Glasser, FP 2007, 'Thermodynamic Properties of Portland Cement Hydrates in the System CaO-Al2O3-SiO2-CaSO4CaCO3-H2O', Cement and Concrete Research, vol. 37, pp. 1379-1410.

Michaux, M, Fletcher, P, \& Vidick, B 1989, 'Evolution at Early Hydration Times of the Chemical Composition of Liquid Phase of Oil-well Cement Pastes with and without Additives. Part I. Additive Free Cement Pastes,' Cement and Concrete Research, vol. 19, pp. 443-456.

Mills R. \& Lobo V.M.M. 1989, Self-Diffusion in Electrolyte Solutions, Elsevier, New York.

Mindess S \& Young, JF 1981, Concrete, PrenticeHall, Englewood Cliffs.

Parkhurst, DL \& Appelo, CAJ 1999, 'User's Guide to PHREEQC (Version 2)--A Computer Program for Speciation, Batch-reaction, One-dimensional Transport, and Inverse Geochemical Calculations', Report 99-4259 (U.S. Geological Survey) 312 p. 
Paul, M \& Glasser, FP 2000, 'Impact of Prolonged Warm $\left(85^{\circ} \mathrm{C}\right)$ Moist Cure on Portland Cement Paste', Cement and Concrete Research, vol. 30, pp. 18691877.

Petit, JC 1992, 'Natural Analogues for the Design and Performance Assessment of Radioactive Waste Forms: A Review', Journal of Geochemical Exploration, vol. 46, pp. 1-33.

Rassineux, F, Petit, JC, \& Meunier, A 1989, 'Ancient Analogues of Modern Cement: Calcium Hydrosilicates in Mortars and Concretes from GalloRoman Thermal Baths of Western France,' Journal of the American Ceramic Society, vol. 72, pp. 10261032 .

Regourd, M 1980, 'Structure and Behavior of Slag Portland Cement Hydrates', Proceedings of the 7th International Congress on the Chemistry of Cement (Paris), vol. 1, pp. III-2 / 10-26.

Regourd, M 1986, 'Ciments spéciaux et ciments avec additions', Proceedings of the 8th International Congress on the Chemistry of Cement (Brasil), vol. 1, pp. 199-227.

Richardson, IG \& Groves, GW 1992, 'Microstructure and Microanalysis of Hardened Cement Pastes Involving Ground Granulated Blast-furnace Slag', Journal of Materials Science, vol. 27, pp. 6204-6212.

Roy, DM and Langton, CA1983, 'Characterization of Cement-Based Ancient Building Materials in Support of Repository Seal Materials Studies,' BMI/ONWI523, Technical Report, December 1983, Office of Nuclear Waste Isolation, Battelle Memorial Institute, Columbus OH, 43201.

Samson, E, Marchand J, Snyder, KA \& Beaudoin, $\mathrm{J}$ 2005, 'Modeling Ion and Fluid Transport in Unsaturated Cement Systems in Isothermal Conditions', Cement and Concrete Research, vol. 35, pp. 141-153.
Scrivener, K.L. \& Bishnoi, S. 2009, 'Microstructural

Model for Portland Cement Paste', submitted to Cement and Concrete Research.

Scrivener, K.L. \& Taylor, HFW 1993, 'Delayed Ettringite Formation: A Microstructural and Microanalytical Study,' Advances in Cement Research, vol. 5, pp. 139-146.

Shehata, MH \& Thomas, MDA 2002, 'Use of Ternary Blends Containing Silica Fume and Fly Ash to Suppress Expansion due to Alkali-silica Reaction in Concrete', Cement and Concrete Research, vol. 32, pp. 341-349.

van der Sloot, HA, Hoede, D, Rietra, RPJJ, Stenger, R, Lang, Th., Schneider, M, Spanka, G, StoltenbergHansson, E \& Lerat, A 2001, 'Environmental Criteria for Cement Based Products ECRICEM Phase I: Ordinary Portland Cements', ECN C-01-069.

Smolczyk, HG 1980, 'Slag Structure and Identification of Slags', Proceedings of the 7th International Congress on the Chemistry of Cement (Paris), vol. 1, pp. III-1 / 3-17.

Snyder, KA 2001, 'The Relationship between the Formation Factor and the Diffusion Coefficient of Porous Materials Saturated with Concentrated Electrolytes: Theoretical and Experimental Considerations', Concrete Science and Engineering, vol. 3, pp. 216-224.

Snyder, KA \& Marchand, J 2001, 'Effect of Speciation on the Apparent Diffusion Coefficient in Nonreactive Porous Systems', Cement and Concrete Research, vol. 31, pp. 1837-1845.s

Solem, JK \& McCarthy, GJ 1992, 'Hydration Reactions and Ettringite Formation in Selected Cementitious Coal Conversion By-products', Materials Research Society Symposium Proceedings, vol. 245, pp. 71-79. 
Steadman, JA 1986, 'Archaeological Concretes as Analogues', Proc. Second NAWG Meeting, Interlaken, Switzerland, CEC Technical Report No. EUR 10671 EN, CEC Brussels, pp. 165-171.

Stutzman, PE 2009, 'Effects of Analytical Precision on Bogue Calculations of Potential Cement Composition', (to be submitted) ASTM International.

Taylor, HFW 1987, 'A method for Predicting Alkali Ion Concentrations in Cement Pore Solutions,' Advances in Cement Research, vol. 1, pp. 5-17.

Taylor, HFW 1997, Cement Chemistry, (Second Edition), Thomas Telford, London.

Traetteberg, A 1978, 'Silica Fume as a Pozzolanic Material', Il Cemento, vol. 75, no. 3, pp. 369-376. Uchikawa, H 1986, 'Effect of Blending Components on Hydration and Structure Formation', Proceedings of the 8th International Congress on the Chemistry of Cement (Rio de Janeiro), vol. 1, pp. 249-280.
Wang, S-D \& Scrivener, KL 1995, 'Hydration Products of Alkali Activated Slag Cement', Cement and Concrete Research, vol. 25, pp. 561-571.

Winslow, DN, Cohen, MD, Bentz, DP, Snyder, KA \& Garboczi, EJ 1994, 'Percolation and Pore Structure in Mortars and Concrete', Cement and Concrete Research, vol. 24, pp. 25-37.

Yuan, C-Z \& Xin, L 1992, 'The selection of Stimulation Agents for Alkali-slag Cement', Proceedings of the 9th International Congress on the Chemistry of Cement (New Delhi), vol. 3, pp. 305311. 



\title{
EARLY-AGE CRACKING REVIEW: MECHANISMS, MATERIAL PROPERTIES, AND MITIGATION STRATEGIES
}

\author{
D. P. Bentz \\ E-mail: dale.bentz@nist.gov \\ National Institute of Standards and Technology
}

Gaithersburg, MD 20899 
Review of Mechanistic Understanding and Modeling and Uncertainty Analysis Methods for Predicting Cementitious Barrier Performance

III-ii 


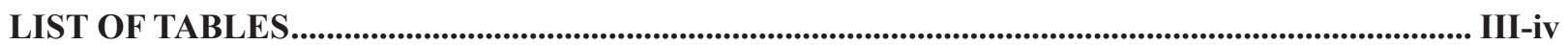

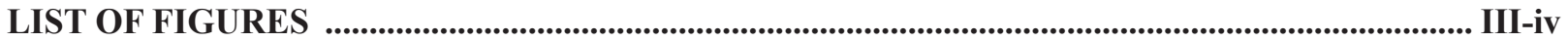

LIST OF ABBREVIATIONS AND ACRONYMS ............................................................................. III-v

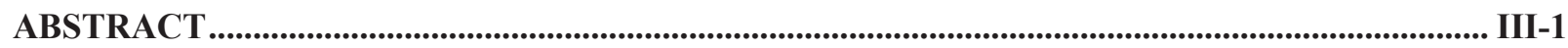

1.0 INTRODUCTION ................................................................................................................................. III-2

2.0 THERMAL CRACKING CONSIDERATIONS .....................................................................

2.1 Heat of Hydration..................................................................................................................................... III-3

2.2 Thermophysical Property Development - Heat Capacity, Thermal Conductivity, and Coefficient of Thermal Expansion .............................................................................................. III-4

2.3 Modeling Heat of Hydration and Exothermic Hydration Processes ................................. III-7

3.0 AUTOGENOUS SHRINKAGE CONSIDERATIONS........................................................... III-7

3.1 Chemical Shrinkage ......................................................................................................................... III-7

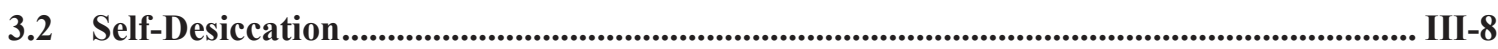

3.3 Internal Relative Humidity............................................................................................................ III-9

3.4 Autogenous Shrinkage .............................................................................................................................. III-9

3.5 Modeling Autogenous Shrinkage and Early-Age Cracking ................................................. III-10

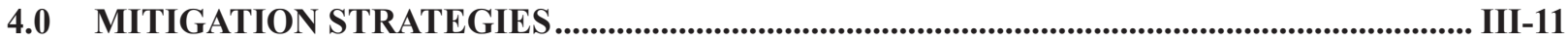

4.1 Mixture Proportioning......................................................................................................................... III-11

4.2 Reduction of Temperature Rise and Thermal Gradients ...................................................... III-12

4.3 Shrinkage-Reducing Admixtures................................................................................... III-12

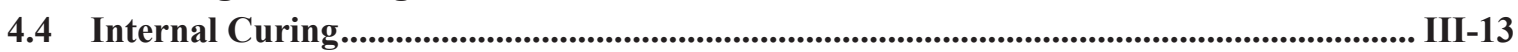

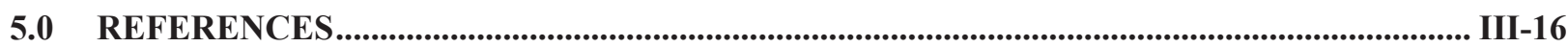


Table 1. Enthalpies of Complete Hydration for Major Phases of Portland Cement

(Taylor 1997; Fukuhara et al. 1981)

Table 2. Relative Mortar Cube Compressive Strength at 28 d, Maximum Temperature Achieved in Semi-Adiabatic Testing of Pastes, and $\left(\varepsilon_{\min }-\varepsilon_{\max }\right)$ at $7 \mathrm{~d}$ For Mortars

(Bentz \& Peltz 2008)

\section{LIST OF FIGURES}

Figure 1. Measured and Fitted Heat Capacities of Hydrating Cement Paste as A Function of Degree of Hydration, With w/c $=0.3$ and w/c $=0.4$, Cured Under Saturated or Sealed Conditions at $20^{\circ} \mathrm{C}$ (Bentz 2007a). Error Bars Indicate A Reproducibility of $\pm 2 \%$ in the Experimental Measurements.

Figure 2. Estimates Based On the H-S Bounds for the Thermal Conductivity of A Concrete as A Function of the Volume Fraction of Paste, Assuming That the Cement Paste Has $\mathrm{k}_{1}=1 . \mathrm{W} /(\mathrm{m} \cdot \mathrm{K})$ and the Limestone Aggregate Has $\mathrm{k}_{2}=3 \mathrm{~W} /(\mathrm{m} \cdot \mathrm{K})$ (Bentz 2007a)

Figure 3. Internal Relative Humidity vs. Degree of Hydration as A Function of Cement Fineness for Cement Pastes Prepared With w/c $=0.35$ and Cured Under Sealed Conditions at $30^{\circ} \mathrm{C}$ (Bentz al.2001)

Figure 4. Internal Relative Humidity vs. Degree of Hydration as A Function of Cement Fineness for Cement Pastes Prepared With w/c $=0.35$ and Cured Under Sealed Conditions at $30^{\circ} \mathrm{C}$ (Bentz al.2001)

Figure 5. Autogenous Deformation Versus Degree of Hydration as A Function of Cement Fineness for Cement Pastes With w/c $=0.35$, Cured at $30^{\circ} \mathrm{C}$ (Bentz et al. 2001). Deformation Values Were Zeroed at the Setting Time (Degree of Hydration) of Each Cement Paste

Figure 6. Differences In Autogenous Deformation (Measured Using the Experimental Setup of Jensen \& Hansen 1995b) for Cement Mortars $(\mathrm{w} / \mathrm{cm}=0.35)$ With and Without SRA, Cured Under Sealed Conditions at $30^{\circ} \mathrm{C}$ (Bentz, Geiker \& Hansen 2001).

Figure 7. Autogenous Deformation of the Blended Cement Mortars: $8 \%$ Mass Fraction Silica Fume (SF) (top), 20\% Mass Fraction Slag (middle), and 25\% Mass Fraction Type F Fly Ash (FA) (bottom) During $56 \mathrm{~d}$ of Sealed Hydration at $25^{\circ} \mathrm{C}$ (Bentz 2007b). (For the SF System, IC-8 and IC-10 Indicate Internal Curing Additions of 0.08 and 0.10 Mass Units of Water Per Mass Unit of Cement, Respectively.). III-15 


\section{LIST OF ABBREVIATIONS AND ACRONYMS}

$\mathrm{ACI}$

$\mathrm{AFm}$

$\mathrm{AFt}$

ASTM

$\mathrm{C}_{\mathrm{p}}^{\text {crseagg }}$

$\mathrm{C}_{\mathrm{p}}$ fineagg

$\mathrm{c}_{\mathrm{p}}^{\text {concrete }}$

$\mathrm{c}_{\mathrm{p}}^{\text {paste }}$

$\mathrm{C}_{\mathrm{f}}$

CBP

$\mathrm{CS}$

$\mathrm{C}_{\mathrm{n}} \mathrm{S}$

CTE

d

E

$\mathrm{E}_{\mathrm{s}}$

FA

H-S

HCSS

HPC

IC

$\mathrm{k}$

LWA

$M_{f} j$

$M_{f}$ fineagg

$M_{f}{ }^{\text {crseagg }}$

$\mathrm{M}_{\text {LWA }}$

PSD

$\mathrm{r}$

$\mathrm{R}$

RH

$\mathrm{S}$

SF

SRA

$\mathrm{T}$

$\mathrm{V}_{\mathrm{m}}$

$w / c$

$w / \mathrm{cm}$
American Concrete Institute

aluminum ferrite monosulfate hydrate phases

aluminum ferrite trisulfate hydrate phases

American Society for Testing and Materials

heat capacity of coarse aggregate

heat capacity of fine aggregate

heat capacity of concrete

heat capacity of cement paste

cement factor

Cementitious Barriers Partnership

chemical shrinkage

calcium silicate

coefficient of thermal expansion

days (curing time)

bulk modulus of porous material

bulk modulus of solid framework within a porous material

fly ash

Hashin - Shtrikman (bounds)

hard core / soft shell

high performance concrete

internal curing

thermal conductivity

lightweight aggregate

mass fraction of $\mathrm{jth}$ phase in concrete

mass fraction of fine aggregate

mass fraction of coarse aggregate

mass of (dry) LWA

particle size distribution

radius of meniscus

universal gas constant $[8.314 \mathrm{~J} /(\mathrm{mol} \cdot \mathrm{K})]$

relative humidity

degree of saturation

silica fume

shrinkage reducing admixture

temperature

molar volume of pore solution

water to cement ratio

water to cementitious material ratio (includes cement + slag cement + fly ash + silica fume 
Review of Mechanistic Understanding and Modeling and Uncertainty Analysis

Methods for Predicting Cementitious Barrier Performance

\section{LIST OF ABBREVIATIONS AND ACRONYMS (contd)}

$x$

$\alpha_{\max }$

$\varepsilon$

$\gamma$

$\phi_{\text {LWA }}$

$\sigma_{\text {cap }}$

$\theta$ volume fraction

maximum achievable degree of hydration

linear strain

surface tension

absorption (desorption) of lightweight aggregate

capillary tension (pressure)

contact angle 


\title{
EARLY-AGE CRACKING REVIEW: MECHANISMS, MATERIAL PROPERTIES, AND MITIGATION STRATEGIES
}

\author{
D. P. Bentz \\ National Institute of Standards and Technology \\ Gaithersburg, MD 20899
}

\section{ABSTRACT}

The goal of long lasting concrete for critical infrastructure applications can only be achieved when early-age cracking is avoided. This includes nuclear facilities, including waste processing, containment and storage facilities and power plant facilities. Consequently, this topic is crucial to the mission of the Cementitious Barriers Partnership (CBP). Since most concrete is cast in place, field conditions, including environmental and workmanship parameters, can significantly influence early-age cracking tendencies. Beyond this, two inherent contributions to early-age cracking are thermal and autogenous deformations. In this chapter, these latter two contributions are reviewed from the three perspectives of basic mechanisms, relevant material properties, and successful mitigation strategies for portland cement-based concrete. Cementitious waste forms have unique chemistry and will need to be considered on a case by case basis.

For thermal deformations, key considerations are hydration rates and the thermophysical properties of the cement paste or concrete. The heat of hydration of the binder sets the limit on the ultimate possible temperature rise of the concrete. Equally important to this ultimate heat of hydration is the hydration rate that governs when and how fast this heat is produced within a cement paste or concrete element. Thermophysical properties of relevance include heat capacity, thermal conductivity, and coefficient of thermal expansion. Methods for measuring these properties are discussed and representative data presented.

Autogenous deformations are driven by the volumetric chemical shrinkage that accompanies the reactions of cementitious binders. Under non-saturated conditions, this chemical shrinkage leads to self-desiccation and the creation of internal stresses and strains. Autogenous shrinkage is generally increased in lower waterto-cementitious materials ratio $(w / \mathrm{cm})$ systems and in systems that contain fine supplementary cementitious materials such as silica fume and slag. Measurement of internal relative humidity provides a convenient method for onsite monitoring of the self-desiccation process.

A wide variety of mitigation strategies have been successfully employed to mitigate thermal and autogenous contributions to early-age cracking. Modifications to the mixture proportions such as an increase in $w / \mathrm{cm}$ ratio, the utilization of a coarser cement, or a partial replacement of cement with a coarse limestone powder can effectively reduce both the maximum temperature rise and the autogenous shrinkage experienced by a concrete mixture. Two other well-developed mitigation strategies, specifically for reducing autogenous shrinkage, are the utilization of shrinkage-reducing admixtures and the application of internal curing, using 
pre-wetted lightweight aggregates for example. Both of these have progressed from laboratory evaluation to field applications in recent years and their ability to reduce plastic shrinkage cracking (as well as early-age cracking after set) has been recently documented.

\subsection{INTRODUCTION}

For the long term performance of concrete to be acceptable and predictable, in general, early-age cracking should be avoided. For example, it is known that the early-age transverse cracking of over 100,000 bridge decks in the U.S. has led to "premature corrosion of the reinforcing steel and spalling of the protective concrete cover, resulting in increased maintenance costs and reduced service life" (Cusson 2005). Improper design practices can contribute to early-age cracking, but for this review, it will be assumed that a correct design has been performed. Additionally, many field practices including concrete placement, finishing, and curing can contribute to early-age cracking, but it will be assumed that these steps are performed in a proper and controlled manner. It is further recognized that field environmental and restraint conditions may be quite different from those employed in conventional laboratory testing. Temperature, relative humidity, and wind extremes may cover a much larger range for a new concrete construction than that investigated in a typical laboratory study where environmental conditions are often held constant. Structural restraint will be a function of design and field conditions and may differ significantly from restraint conditions (if any) employed in lab testing.

The focus of this chapter will thus be on the inherent properties of hardening portland cement-based paste and concrete that contribute to the occurrence of early-age cracking, and mixture proportioning and other mitigation strategies that can be employed to reduce the probability of such cracking. Many of these issues are addressed in further detail in the recent state-of-the-art report produced by the
American Concrete Institute (ACI) Committee 231

- Properties of Concrete at Early Ages (ACI 231

2009). While the definition of "early age" is arbitrary and somewhat controversial even within ACI, for the purposes of this chapter, it shall be considered as the time from concrete placement until an age of 7 days (d) (under ordinary field curing temperatures). It should also be recognized that even when cracking does not occur during these first $7 \mathrm{~d}$, the thermal and autogenous stresses that are developed during this time can contribute to later age cracking that may be due to drying or other crack-inducing (degradation) mechanisms. Cementitious waste forms have unique chemistry and will need to be considered on a case by case basis.

Assuming proper design, placement, finishing, and curing, the two major remaining contributions to early-age cracking are the stresses that develop due to thermal and autogenous deformations. The cement hydration and pozzolanic reactions are exothermic, generating significant heat that must be dissipated from the concrete to the surroundings. Two important characteristics for a given concrete mixture in a given structure are the maximum internal temperature achieved and the maximum temperature gradient that exists across the concrete member during curing. When the former is too high $\left(>60^{\circ} \mathrm{C}\right)$, certain cement hydration phases such as ettringite may become unstable and dissolve; their subsequent and expansive reprecipitation that may occur when the concrete returns to lower temperatures can cause internal and external cracking. In terms of the temperature gradient across the concrete member, if it becomes too large, the induced thermal stresses may exceed the strength of the concrete and cause cracking. Because of this risk of thermal cracking, many specifications detail the maximum allowed values for these two 
quantities, particularly in mass concrete structures. Thermal issues are generally more pronounced in larger structures due to their lower surface to volume ratio that reduces the quantity of heat lost to the environment relative to that being generated internally by the hydration reactions. The problem is compounded by the fact that any internal temperature increases also increase the cement hydration rates producing an autoacceleratory thermal response that may be detrimental to short and long term performance.

A second inherent characteristic of the cement hydration and pozzolanic reactions is that they are accompanied by a chemical shrinkage, due to the fact that the reaction products occupy considerably less volume than the reactants. The ultimate chemical shrinkage of a typical hydrating portland cement paste can be on the order of $10 \%$ by volume (Bentz 2008). If additional curing water is not readily available, after set, this chemical shrinkage will be accompanied by the creation of empty capillary porosity within the hydrating cement paste, known as self-desiccation. The menisci in remaining partiallyfilled pores will in turn create autogenous stresses that will produce an autogenous shrinkage that may lead to early-age cracking when the concrete is restrained (externally or internally). Cracks may be produced in the vicinity of the internal restraints (steel reinforcement and aggregates) or through the depth of the concrete member when sufficient external restraint is present. Unlike thermal cracking, under isothermal conditions, autogenous deformation is inherently size independent. In real world (semiadiabatic) conditions, however, specimen size will influence autogenous and total shrinkage response (Durán-Herrera et al. 2008).

\subsection{THERMAL CRACKING CONSIDERATIONS}

\subsection{Heat of Hydration}

As cement hydrates, a significant amount of energy is released as heat. This heat of hydration must be included in any early-age model of heat transfer and/ or thermal cracking in a concrete. The heat released is dependent on the phase composition of the cement; literature values for the various cement clinker phases are compiled in Table 1 (Taylor 1997; Fukuhara et

Table 1. Enthalpies of Complete Hydration for Major Phases of Portland Cement (Taylor 1997; Fukuhara et al. 1981)

\begin{tabular}{|c|c|}
\hline Phase $^{1}$ & Enthalpy (kJ/kg phase) $^{{ }^{2}}$ \\
\hline $\mathrm{C}_{3} \mathrm{~S}$ & $-517 \pm 13$ \\
\hline $\mathrm{C}_{2} \mathrm{~S}$ & -262 \\
\hline $\mathrm{C}_{3} \mathrm{~A}$ & $-908,-1672,-1144^{+}$ \\
\hline $\mathrm{C}_{4} \mathrm{AF}$ & $-418,-725^{+}$ \\
\hline
\end{tabular}

+ For $\mathrm{C}_{3} \mathrm{~A}$ and $\mathrm{C}_{4} \mathrm{AF}$ hydration, values are for conversion to $\mathrm{C}_{3} \mathrm{AH}_{6}$, ettringite, and monosulfate $(\mathrm{AFm})$ phase (only for $\left.\mathrm{C}_{3} \mathrm{~A}\right)$, respectively. Cement chemistry notation is used throughout this chapter.

${ }^{1}$ Cement chemistry notation for oxides related to portland cement: $\mathrm{CaO}=\mathrm{C}, \mathrm{SiO}_{2}=\mathrm{S}, \mathrm{Al}_{2} \mathrm{O}_{3}=\mathrm{A}, \mathrm{Fe}_{2} \mathrm{O}_{3}=\mathrm{F}, \mathrm{SO}_{3}=\overline{\mathrm{S}}, \mathrm{CO}_{2}=\overline{\mathrm{C}}, \mathrm{K}_{2} \mathrm{O}=$ $\mathrm{K}, \mathrm{Na}_{2} \mathrm{O}=\mathrm{N}, \mathrm{MgO}=\mathrm{M}, \mathrm{H}_{2} \mathrm{O}=\mathrm{H}$. 
al.1981). In blended cements, the mass-normalized heat release can be either increased or decreased depending on the mineral admixture employed. For example, silica fume has a heat of hydration (when reacting pozzolanically with $\mathrm{Ca}(\mathrm{OH})_{2}$ ) of about $780 \mathrm{~kJ} / \mathrm{kg}$ silica fume (Waller, De Larrard \& Roussel 1996), while the reactions of fly ash and to a lesser extent slag typically produce less heat than those of portland cement. The latter effect is often compounded by the fact that slag and fly ash are typically much less reactive at early ages than is silica fume. Examples of enthalpy values for hydraulic blast furnace slag include $344 \mathrm{~kJ} / \mathrm{kg}$ slag and $440 \mathrm{~kJ} /$ $\mathrm{kg}$ slag (Bensted, 1981) and $461 \mathrm{~kJ} / \mathrm{kg}$ slag (Kishi and Maekawa, 1995). Generally, the very minor contribution to the total heat of hydration due to the incorporation of limestone filler can be neglected, although its effects on reaction kinetics and the rate of heat release may be significant and should be appropriately taken into consideration (Poppe and De Schutter, 2006).

Heat of hydration is typically measured using a standardized heat of solution technique (ASTM C186-05 2005) or semi-adiabatic methods; a new standard method based on isothermal calorimetry has been developed in the Nordic countries (Wadso 2002) and is now being balloted within the American Society for Testing and Materials (ASTM) C01 Cement Committee (Subcommittee C01.26). Both isothermal and semi-adiabatic calorimeters for cement pastes, mortars, and concretes are readily available from a variety of commercial vendors.

\subsection{Thermophysical Property Development - Heat Capacity, Thermal Conductivity, and Coefficient of Thermal Expansion}

The dissipation of the heat produced by the hydration reactions will depend strongly on the thermophysical properties of the concrete including density, heat capacity, and thermal conductivity. Because the hydration of portland cement significantly alters the volume fractions and spatial arrangement of solids, liquids, and gases (air voids and empty capillary pores) within the three-dimensional microstructure, it would be expected that these thermophysical properties could vary with hydration. As shown in Figure 1, the heat capacity of cement paste is a strong function of both water-to-cement ratio $(\mathrm{w} / \mathrm{c})$ and curing conditions (Bentz 2007a). This is mainly due to the high heat capacity of free water $(4.18 \mathrm{~J} /(\mathrm{g} \cdot \mathrm{K})$ vs. about $0.75 \mathrm{~J} /(\mathrm{g} \bullet \mathrm{K})$ for dry cement powder) that dominates the cement paste heat capacity, so that the cement paste heat capacity decreases as free water is chemically and physically bound into hydration products. More water (higher $w / c$ ) results in a higher heat capacity, as does saturated curing, with its accompanying water imbibition, relative to sealed curing.

In going from cement paste to concrete, a simple law of mixtures can be applied where the heat capacity of the concrete is the mass-weighted average of its components: cement paste, aggregates, steel, and fibers. For a basic unreinforced concrete, the law of mixtures would be (Waller, De Larrard \& Roussel 1996):

$C_{p}^{\text {concrete }}=C_{p}^{\text {paste }} M_{f}^{\text {paste }}+C_{p}^{\text {fineagg }} M_{f}^{\text {fineagg }}+C_{p}^{\text {crseagg }} M_{f}^{\text {crseagg }}$

where:

$c_{p}^{\text {paste }}$ represents the heat capacity of the hydrating cement paste at the age (degree of hydration) of interest, as provided in Figure 1, and $\mathrm{M}_{\mathrm{f}}{ }^{\mathrm{j}}$ is the mass fraction of the $\mathrm{jth}$ phase. 


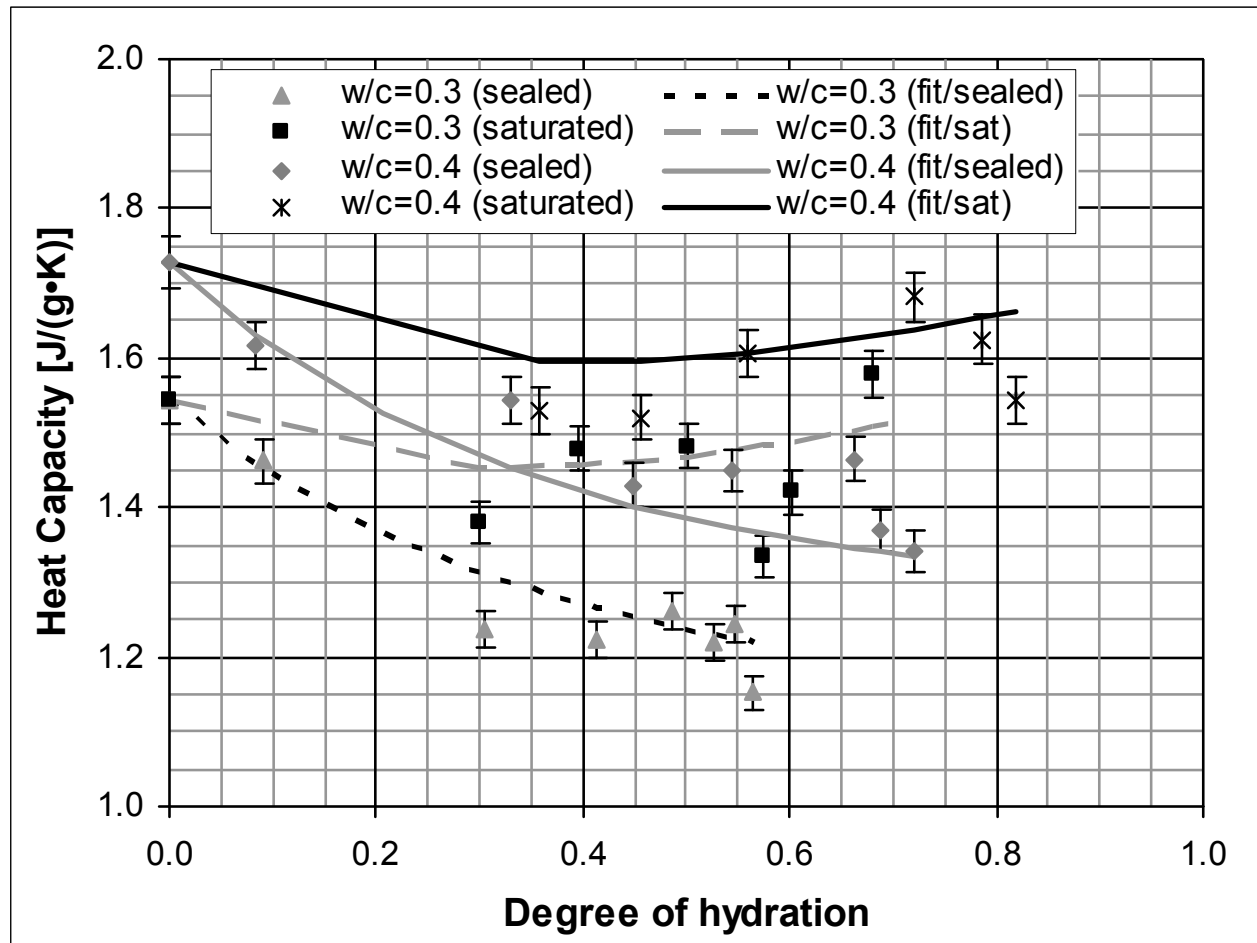

Figure 1. Measured and Fitted Heat Capacities of Hydrating Cement Paste as A Function of Degree of Hydration, With $w / c=\mathbf{0 . 3}$ and $w / c=\mathbf{0 . 4}$, Cured Under Saturated or Sealed Conditions at $20^{\circ} \mathrm{C}$ (Bentz 2007a). Error Bars Indicate A Reproducibility of $\pm 2 \%$ in the Experimental Measurements.

As shown in Figure 2, within the experimental error of the measurement, the thermal conductivity of hydrating cement pastes is basically a constant value of $1.0 \mathrm{~W} /(\mathrm{m} \cdot \mathrm{K})$, for the two values of $w / c$ and the two curing conditions used in (Bentz 2007a). The thermal conductivities of the starting materials (water: $0.604(\mathrm{~W} / \mathrm{m} \bullet \mathrm{K})$ and cement: $1.55 \mathrm{~W} /(\mathrm{m} \bullet \mathrm{K})$ at $20^{\circ} \mathrm{C}$ ) and those of the hydration products are apparently close enough to one another that as solid and liquid pathways are percolated, depercolated, and repercolated during the course of hydration and aging, the thermal conductivity remains essentially unchanged (e.g., within $\pm 10 \%$ ).

For thermal conductivity, in going from cement paste to concrete, the Hashin-Shtrikman (H-S) bounds (Hashin \& Shtrikman 1962) can be applied by considering the concrete to be a two-phase composite consisting of aggregates in hydrated cement paste and ignoring any air entrainment. The interfacial transition zones are also ignored, since Figure 2 showed that the thermal conductivity was insensitive to water to cement ratio $(w / c)$. Knowing the thermal conductivity of the specific aggregates (Horai $1971)$ and assuming a value of $1.0 \mathrm{~W} /(\mathrm{m} \cdot \mathrm{K})$ for the hydrated cement paste, equations (2) and (3) below can be applied to determine lower and upper bounds ( $\mathrm{k}_{1}$ and $\mathrm{k}_{\mathrm{h}}$, respectively) for the thermal conductivity of any concrete composite of known mixture proportions. Typically cement paste is considered as phase 1 and the aggregates as phase 2 because the thermal conductivity of most aggregates is higher than the nominal value for cement paste of $1.0 \mathrm{~W} /$ $(\mathrm{m} \bullet \mathrm{K})$ and because equations (2) and (3) require $\mathrm{k}_{2}$ $\geq \mathrm{k}_{1}$. Lightweight aggregates with their much lower thermal conductivity could be an exception to this; 


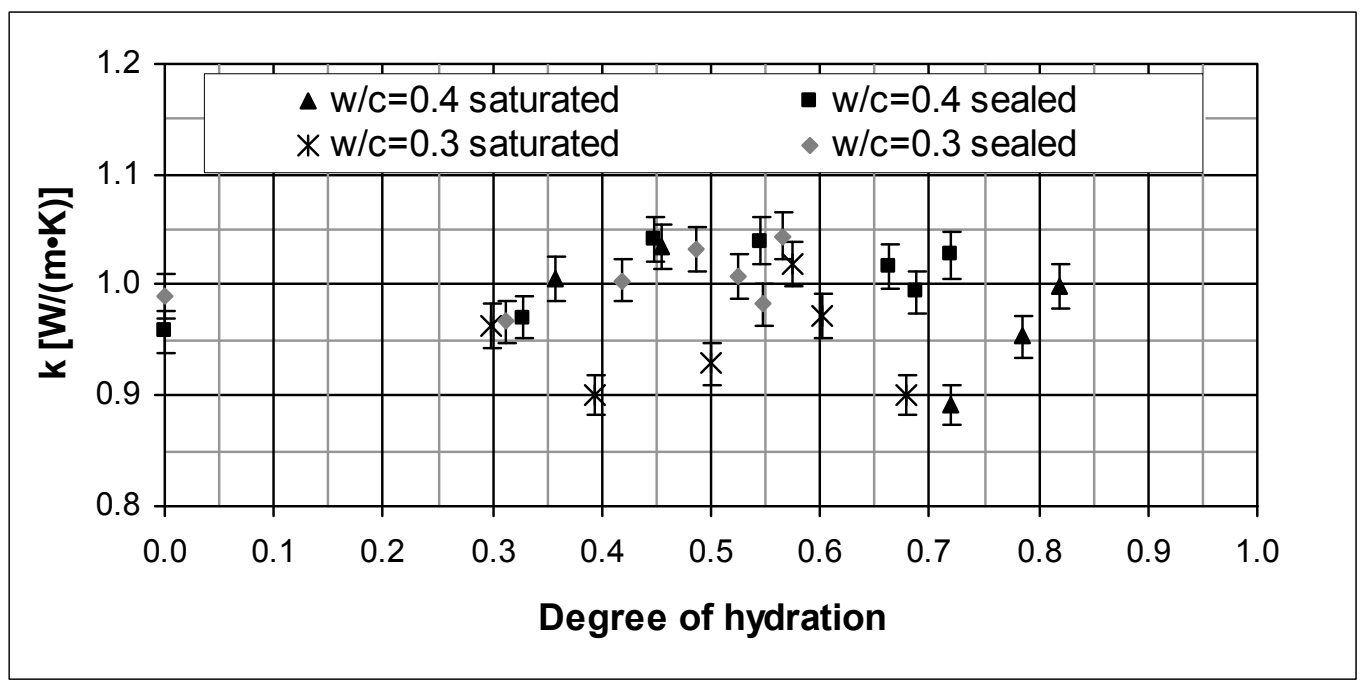

Figure 2. Measured Thermal Conductivity of Hydrating Cement Paste as A Function of Degree of Hydration, with $w / c=\mathbf{0 . 3}$ and $w / c=\mathbf{0 . 4}$, Cured Under Saturated or Sealed Conditions at $20^{\circ} \mathrm{C}$ (Bentz 2007a). Error Bars Indicate A Reproducibility of $\pm 2 \%$ in the Experimental Measurements.

in that case, the aggregates could be considered as phase 1 and the higher thermal conductivity cement paste as phase 2.) Finally, a reasonable estimate of the thermal conductivity of the concrete of interest could be taken as the mean of these upper and lower bounds.

$$
\begin{aligned}
& k_{l}=k_{1}+\frac{x_{2}}{\frac{1}{k_{2}-k_{1}}+\frac{x_{1}}{3 k_{1}}} \\
& k_{h}=k_{2}+\frac{x_{1}}{\frac{1}{k_{1}-k_{2}}+\frac{x_{2}}{3 k_{2}}}
\end{aligned}
$$

where:

$k_{1}$ and $k_{2}$ are the thermal conductivities of the cement paste and aggregate, respectively, and $x_{1}$ and $x_{2}$ are their respective volume fractions $\left(x_{1}+x_{2}=1\right)$.
As an example, Figure 3 shows the computed Hashin-Shtrikman bounds for a concrete containing limestone aggregates with $\mathrm{k}_{2} \approx 3 \mathrm{~W} /(\mathrm{m} \bullet \mathrm{K})$ (Kim et al. 2003; Vosteen \& Schellschmidt 2003). For the typical cement paste volume fraction of $30 \%$ to $35 \%$, the concrete would be expected to have a thermal conductivity of $2.1 \mathrm{~W} /(\mathrm{m} \bullet \mathrm{K})$ to $2.2 \mathrm{~W} /(\mathrm{m} \bullet \mathrm{K})$. While the H-S bounds are fairly tight in Figure 3, for siliceous aggregates, such as quartz, with their higher thermal conductivity of $\approx 5 \mathrm{~W} /(\mathrm{m} \cdot \mathrm{K})$ to $8 \mathrm{~W} /(\mathrm{m} \cdot \mathrm{K})$ (Horai 1971; Kim et al. 2003; Bougerra et al. 1997), the H-S bounds will be wider and the inaccuracy of using the mean $\mathrm{H}-\mathrm{S}$ value as an estimate for the concrete could increase.

Equally important to predicting early age thermal cracking is an accurate characterization of the concrete's coefficient of thermal expansion (CTE). This property is particularly difficult to measure at early ages due to the confounding influences of the ongoing hydration and other effects (Bjontegaard 1999). Fiber optic-based techniques may offer an 


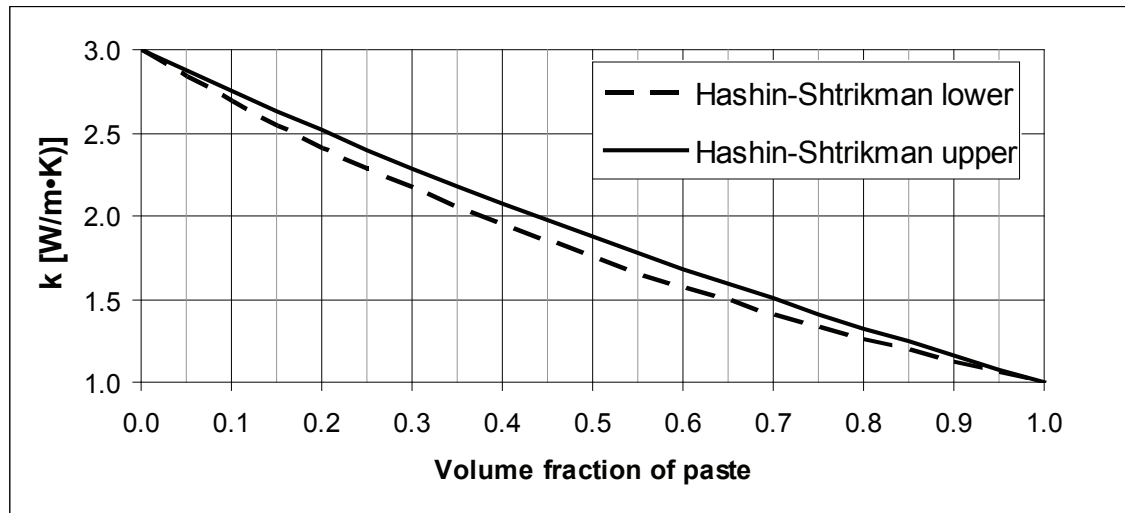

Figure 3. Estimates Based On the H-S Bounds for the Thermal Conductivity of a Concrete as A Function of the Volume Fraction of Paste, Assuming that the Cement Paste Has $k_{1}=1 . \mathrm{W} /(\mathrm{m} \cdot \mathrm{K})$ and the Limestone Aggregate Has $k_{2}=3 \mathrm{~W} /(\mathrm{m} \cdot \mathrm{K})$

(Bentz 2007a).

in-situ non-destructive solution to this dilemma (Brown et al. 2004; Viviani, Glisic \& Smith 2007). CTE values of $10 \times 10^{-6}\left[\mathrm{~K}^{-1}\right]$ to $12 \times 10^{-6}\left[\mathrm{~K}^{-1}\right]$ are typically employed for concrete at early ages. Measurement details can be found in the recent ACI state-of-the-art report (ACI 231 2009).

\subsection{Modeling Heat of Hydration and Exothermic Hydration Processes}

Computer models have been successfully applied for predicting the heat release and temperature rise of cement paste and concrete mixtures (Bentz, Waller \& De Larrard 1998; Maekawa, Chaube \& Kishi 1999; Bentz 2007c). For example, in the latter case, chemical shrinkage measurements performed to an age of 12 hours on cement pastes were employed to calibrate the kinetics (hydration rate) of a computer model for cement hydration, which was then employed to predict successfully the previously measured 7-day and 28-day heat of hydration results for a number of portland cements. Other computer models go a step further to not only predict heat release and temperature rise but to consider also the generated thermal stresses and propensity for earlyage cracking (ACI 231 2009). Examples of these that can be freely downloaded by the general public include HIPERPAV (http://www.hiperpav.com/) and Concreteworks (http://www.texasconcreteworks. $\operatorname{com} /)$.

\subsection{AUTOGENOUS SHRINKAGE CONSIDERATIONS}

\subsection{Chemical Shrinkage}

As cement hydrates, the volume of the hydration products is less than that of the starting materials (including water). Powers was the first to quantify the chemical shrinkage (water imbibition) of the various cement clinker phases (Powers 1935). An experimental technique for quantifying chemical shrinkage that was studied in detail by Geiker (Geiker 1983) has been approved by ASTM Committee C01 as Standard Test Method C1608 (ASTM C1608-06 2006). It is based on measuring the volume of water imbibed into a cement paste (or mortar) sample of known mass during hydration under isothermal saturated conditions. A similar technique has been standardized in Japan (Tazawa 1999). Due to the depercolation of the capillary porosity that may occur during hydration which limits this water 
transport (Powers, Copeland \& Mann 1959; Bentz \& Garboczi 1991), both the specimen thickness and the $\mathrm{w} / \mathrm{c}$ must be within a limited range (nominally a few millimeters to $0.4 \mathrm{~mm}$, respectively) to obtain meaningful results at later ages.

Chemical shrinkage can also be computed by assuming a set of cement hydration reactions and molar volumes for each cement component. This approach has been used by numerous authors (Bentz 1997; Justnes et al. 1999; Mounanga et al. 2005), with variable agreement between their published values. In general, though, the chemical shrinkages of the aluminate phases $\left(\mathrm{C}_{3} \mathrm{~A}\right.$ and $\left.\mathrm{C}_{4} \mathrm{AF}\right)$ are about $50 \%$ higher, on a per unit mass basis, than those of the calcium silicates, which are about $0.07 \mathrm{~mL}$ water $/ \mathrm{g} \mathrm{C}_{\mathrm{n}} \mathrm{S}\left(\mathrm{C}_{\mathrm{n}} \mathrm{S}\right.$ indicating $\mathrm{C}_{2} \mathrm{~S}$ or $\left.\mathrm{C}_{3} \mathrm{~S}\right)$. The chemical shrinkage of silica fume during its pozzolanic reaction with $\mathrm{Ca}(\mathrm{OH})_{2}$ is particularly high, being on the order of $0.22 \mathrm{~mL} / \mathrm{g}$ silica fume (Jensen 1990). Slag and fly ash also generally have chemical shrinkage coefficients that are two to three times those of portland cement (Bentz 2007b). As mentioned earlier, the ultimate chemical shrinkage of a typical hydrating portland cement paste can be on the order of $10 \%$ by volume or about $7 \%$ by mass. This means that for each $100 \mathrm{~g}$ of cement that are reacting, $7 \mathrm{~g}$ of additional curing water must be supplied if saturated conditions are to be maintained within the paste microstructure, thus avoiding self-desiccation and possible autogenous shrinkage, stresses, and cracking.

\subsection{Self-Desiccation}

When cured under sealed, partially saturated conditions, or saturated conditions but where depercolation of the capillary porosity has already occurred, chemical shrinkage can lead to the creation of empty porosity and a reduction in the internal $\mathrm{RH}$, a process known as self-desiccation. In general, the largest pores within the cement paste microstructure will empty first during self-desiccation (Bentz
1997; Hua, Acker \& Erlacher 1995). As shown in the Kelvin-Laplace equation (4) below, the menisci formed in these (partially) empty pores will create a capillary tension within the pore solution and also reduce the internal relative humidity $(\mathrm{RH})$ of the specimen.

$$
\sigma_{c a p}=\frac{2 \gamma \cos \theta}{r}=\frac{-\ln (\mathrm{RH}) R T}{V_{m}}
$$

where:

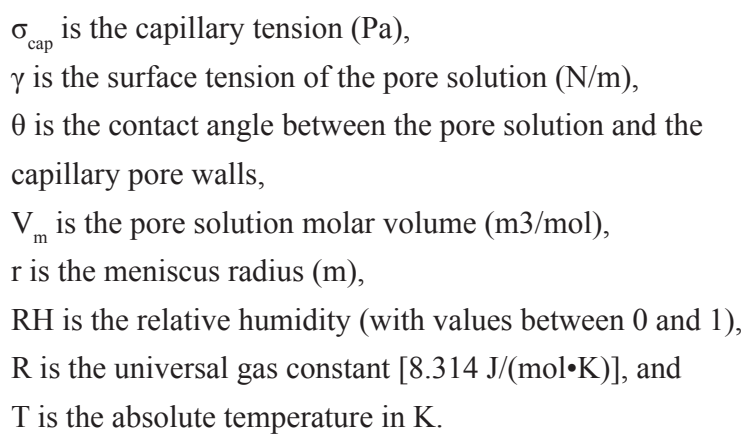

When mitigation strategies are considered later, it will be shown that equation (4) provides valuable insights into two common mitigation strategies, namely surface tension reduction via shrinkage-reducing admixtures (SRAs) and an increase in the size of the pores being emptied via internal curing (IC).

This self-desiccation process is largely responsible for the autogenous shrinkage of cement-based materials that has come to the forefront in recent years due to field problems with early-age cracking, particularly of high-performance concretes (HPC). Self-desiccation is not always detrimental, however, as it can be used to advantage in accelerating the drying of concrete floors prior to the application of carpeting and other coverings and may also increase the frost resistance of early age concrete. It has been the topic of a continuing series of international seminars, starting in 1997 (ed. Persson \& Fagerlund 1997). 


\subsection{Internal Relative Humidity}

As indicated above, measurement of the internal $\mathrm{RH}$ of cement-based materials can provide valuable insight into their internal stresses. Experimental methods have been developed both for laboratory measurements (Jensen and Hansen 1995a) and more recently for field use (Grasley, Ambrosia \& Lange 2006), but only a few data from actual field exposures (other than industrial floors) have been published to date (Andrade, Sarria \& Alonso 1999). A variety of $\mathrm{RH}$ probes that can be readily embedded in the hardening concrete are now commercially available. The reduction in internal $\mathrm{RH}$ will also reduce the hydration rates of the remaining cement clinker phases (Bentz 1997; Jensen et al. 1999). According to equation (4), this internal RH reduction will be significantly less in systems with higher $w / c$ due to the initially larger spacing between cement particles (larger pore radii) (Bentz and Aitcin 2008). At a constant $w / c$ and the same degree of hydration, the RH reduction at later ages (degree of hydration $>$ 0.4 ) will be larger the finer the cement particle size distribution (PSD) (Bentz et al. 2001), as shown in Figure 4. This is once again due to interparticle spacing considerations, since this sets the scale of the initial capillary porosity. Silica fume, because of its extremely small particle size along with the high chemical shrinkage accompanying its pozzolanic reaction, can drastically increase the measured $\mathrm{RH}$ reduction during early age hydration (Jensen \& Hansen 1995a; McGrath \& Hooton 1991).

\subsection{Autogenous Shrinkage}

Until about the time of set, the chemical shrinkage occurring during cement hydration is accompanied by an equivalent overall volumetric reduction of the "fluid" material (Hammer \& Heese 1999; Barcelo et al. 1999). During set, the cement paste develops

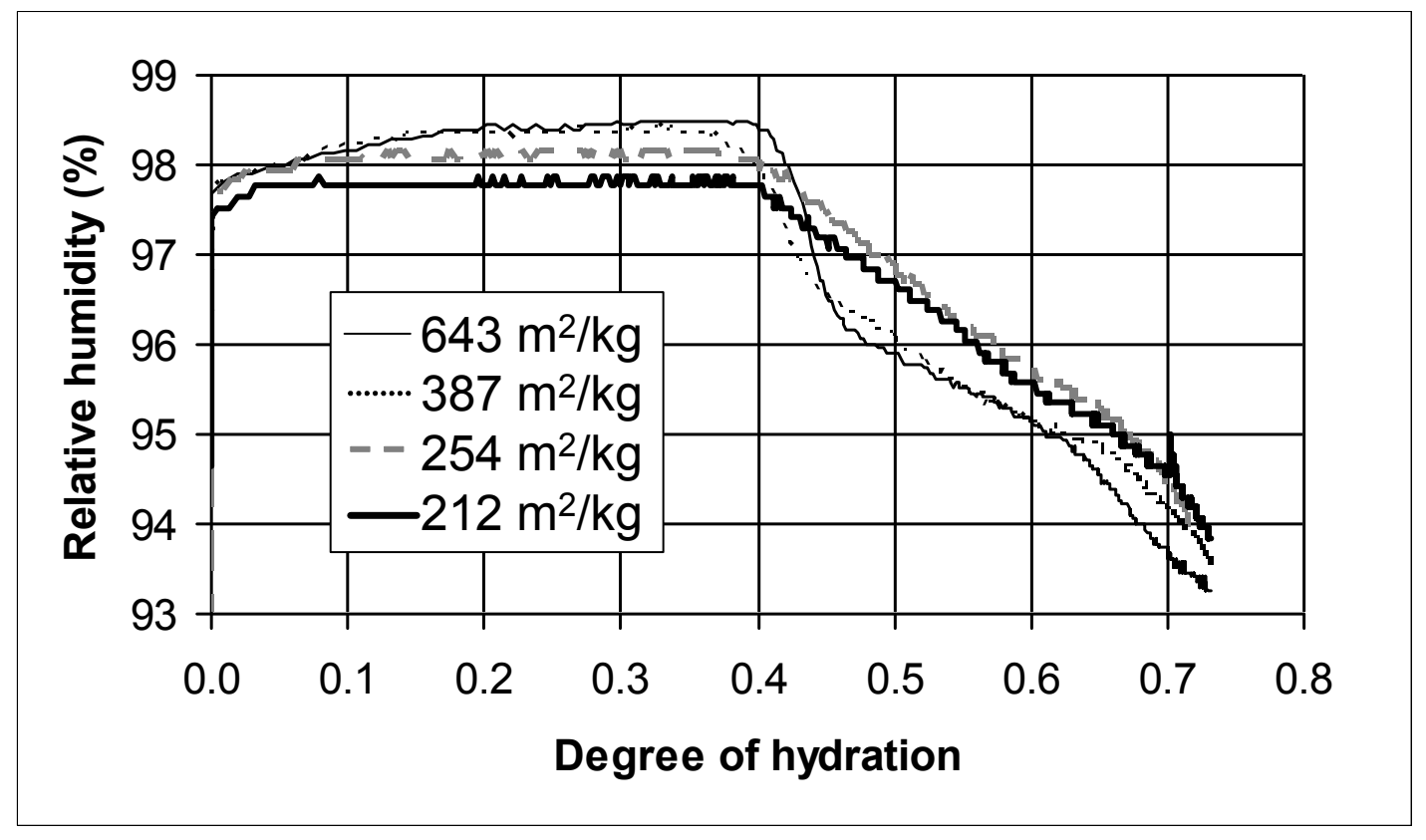

Figure 4. Internal Relative Humidity vs. Degree of Hydration as A Function of Cement Fineness for Cement Pastes Prepared With $w / c=0.35$ and Cured Under Sealed Conditions at $30^{\circ} \mathrm{C}$ (Bentz al.2001). 
a finite resistance to further volumetric reductions. After setting, the measured autogenous deformation is much smaller (up to two orders of magnitude less) than the chemical shrinkage. In the past, autogenous shrinkage has been measured using either a volumetric (immersion of a latex membrane) or a linear (sealed corrugated tube) method (Barcelo et al. 1999; Jensen \& Hansen 1995b; Jensen \& Hansen 1996), but recently, Lura and Jensen have completed a detailed investigation that suggests that the former is an inappropriate method due mainly to the confounding influence of water ingress through the membrane during the measurement time (Lura \& Jensen 2005). The linear method for cement pastes and mortars (Jensen \& Hansen 1995b) is currently being balloted for standardization by the ASTM C09 Concrete and Concrete Aggregates committee.

The capillary tension ( $\sigma$ cap in equation (4)) created in the pore solution during self-desiccation results in the autogenous deformation of the porous cementitious materials (e.g., concretes, grouts, and wasteforms). For such materials, the deformation can be estimated as (Bentz, Garboczi \& Quenard 1998; MacKenzie 1950):

$$
\varepsilon=\frac{\mathrm{S} \sigma_{\mathrm{cap}}}{3}\left(\frac{1}{\mathrm{E}}-\frac{1}{\mathrm{E}_{\mathrm{s}}}\right)
$$

where:

$\varepsilon$ is the linear strain or shrinkage,

$\mathrm{S}$ is the saturation (fraction with values between 0 and 1) or fraction of water-filled porosity,

$\mathrm{E}$ is the bulk modulus of the porous material $(\mathrm{Pa})$ with empty pores (dry), and

$\mathrm{E}_{\mathrm{s}}$ is the bulk modulus of the solid framework within the porous material $(\mathrm{Pa})$.

While equation (5) is an approximation for a purely elastic material, it has been applied with some success to cement-based materials (Lura, Jensen \& van
Breugel 2003). Extensions to include a visco-elastic component (creep) have also been made (Grasley et al. 2005). Baroghel-Bouny has pointed out the inherent similarities between autogenous shrinkage due to internal drying and drying shrinkage due to external drying (Baroghel-Bouny 1997).

Because the capillary stresses are a function of the size of the pores being emptied, autogenous deformation is an extremely strong function of $w / c$ ratio, increasing dramatically as the $\mathrm{w} / \mathrm{c}$ is lowered below 0.35 in portland cement systems. Further dramatic increases are observed in systems containing silica fume and slag additions (Bentz 2007b; Jensen \& Hansen 1996; Lee et al. 2006). Conversely, due to its generally low reactivity at early ages, fly ash additions often function similar to an inert filler and may decrease autogenous deformation due to an increase in the effective $\mathrm{w} / \mathrm{c}$ of the mixture (Bentz 2007b). At a constant $w / c$ and degree of hydration, as shown in Figure 5, autogenous shrinkage is much greater in systems prepared with a finer cement. In fact, for the two coarser cements in Figure 5, an early age autogenous expansion is observed, most likely due to swelling induced by hydration product (such as ettringite or calcium hydroxide) formation (Bentz et al. 2001).

\subsection{Modeling Autogenous Shrinkage and Early-Age Cracking}

The extension from measuring autogenous shrinkage to predicting early age cracking is not an easy task. Many of the properties that must be properly accounted for are discussed in a recent paper (Moon et al. 2005). Several of the existing models for predicting field performance with respect to early age cracking, however, already do include both thermal and autogenous effects in some form (Roelfstra, Salet \& Kuiks 1994; McCullough \& Rasmussen 1999; Ruiz et al. 2005; Maekawa, Chaube \& Kishi 1999; Tazawa 1999). Internal damage caused by self-desiccation 


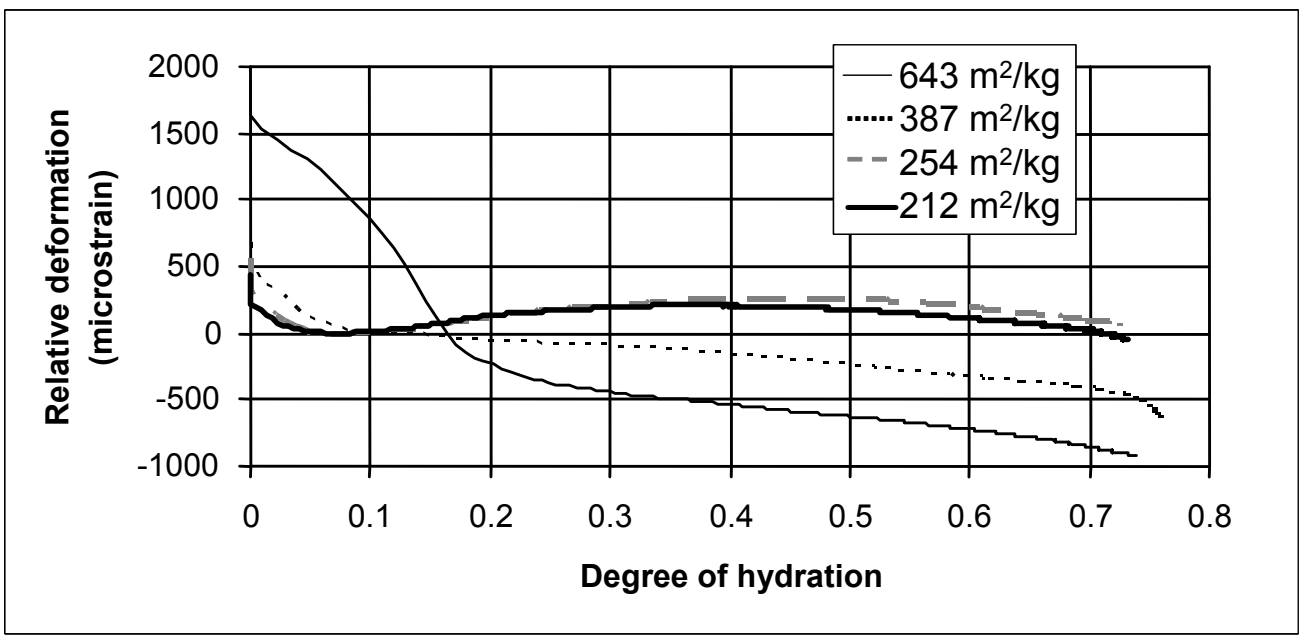

Figure 5. Autogenous Deformation Versus Degree of Hydration as A Function of Cement Fineness for Cement Pastes With $w / C=0.35$, Cured at $30^{\circ} \mathrm{C}$ (Bentz et al. 2001). Deformation Values Were Zeroed at the Setting Time (Degree of Hydration) of Each Cement Paste.

has been observed to re-percolate capillary pore networks that were originally depercolated by hydration products (Bentz 2006b).

\subsection{MITIGATION STRATEGIES}

\subsection{Mixture Proportioning}

The semi-adiabatic temperature rise and autogenous deformation experienced by a concrete mixture are strongly dependent on the interparticle spacing and the surface area of the cementitious binder that is exposed to water (Bentz, Sant \& Weiss 2008; Bentz $\&$ Peltz 2008). Since the 1950 s, the general trends in cement production have been to manufacture finer cements with higher tricalcium silicate (and possibly tricalcium aluminate) contents and a generally increased alkali content (Bentz, Sant \& Weiss 2008; Tennis \& Bhatty 2005). Each of these changes contributes to an increased reactivity at early ages, increasing the semi-adiabatic temperature rise and likely also the temperature gradient across a concrete member. The increase in fineness also decreases the interparticle spacing resulting in increased autogenous deformation, particularly in lower w/c mixtures.
Increased reactivity at early ages will also increase autogenous shrinkage, as less time is available for the beneficial effects of creep and stress relaxation to partially offset the autogenous stresses and strains. With ASTM Type IV (low heat of hydration) cements no longer available in the U.S. State departments of transportation and other concrete specifiers are basically limited to requesting the optional heat of hydration limit provided as part of the ASTM C150 specification for Type II cements if a reduced heat generation (reactivity) at early ages is desired or deemed necessary.

As indicated in Table 2, modifications to the mixture proportions can reduce both the semiadiabatic temperature rise and the net autogenous deformation. Increasing the $w / c$ from 0.35 to 0.4 , switching to a coarser cement, or replacing a portion of the cement with a coarse limestone are each effective in accomplishing this objective. However, in each case, there is a concurrent reduction in 28 $\mathrm{d}$ strength, as increased (early-age) strength and a reduced probability for early-age cracking are often conflicting performance goals that must be carefully balanced in an appropriate design of a concrete 
Table 2. Relative Mortar Cube Compressive Strength at $\mathbf{2 8} \mathrm{d}$, Maximum Temperature Achieved in Semi-Adiabatic Testing of Pastes, and $\left(\varepsilon_{\min }-\varepsilon_{\max }\right)$ at $7 \mathrm{~d}$ for Mortars (Bentz \& Peltz 2008).

\begin{tabular}{|c|c|c|c|}
\hline Cement Paste or Mortar & $\begin{array}{c}\text { Relative } \\
\text { Strength } \\
\text { at } 28 \mathrm{~d} \\
\end{array}$ & $\begin{array}{c}\text { Maximum Temperature } \\
\text { (\% Reduction } \\
\text { vs. Control) } \\
\end{array}$ & $\begin{array}{c}\text { Autogenous Shrinkage } \\
\left(\varepsilon_{\min }-\varepsilon_{\max }\right) \text { at } 7 \mathrm{~d} \text { and } \\
(\% \text { Reduction vs. Control) })\end{array}$ \\
\hline$w / c=0.35$ fine cement & $100 \%$ & $66.9{ }^{\circ} \mathrm{C}(---)$ & -127 microstrains (---) \\
\hline$w / c=0.35$ coarse cement & $74 \%$ & $47.4^{\circ} \mathrm{C}(43 \%)$ & -49 microstrains $(61 \%)$ \\
\hline$w / c=0.40$ fine cement & $93 \%$ & $59.8^{\circ} \mathrm{C}(16 \%)$ & -100 microstrains $(21 \%)$ \\
\hline $\begin{array}{l}w / \mathrm{cm}=0.357 \text { fine } \\
\text { cement } / 10 \% \text { fine limestone }\end{array}$ & $93 \%$ & $58.8^{\circ} \mathrm{C}(18 \%)$ & -163 microstrains $(-28 \%)$ \\
\hline $\begin{array}{l}w / \mathrm{cm}=0.357 \text { fine } \\
\text { cement } / 10 \% \text { coarse limestone }\end{array}$ & $93 \%$ & $57.8^{\circ} \mathrm{C}(20 \%)$ & -88 microstrains $(31 \%)$ \\
\hline
\end{tabular}

mixture. While not included in the study in the Bentz \& Peltz 2008 study, high volume fly ash mixtures that slowly hydrate and develop strength can also substantially reduce semi-adiabatic temperature rise and early-age autogenous shrinkage (Mehta 2004; Houk, Borge \& Houghton 1969).

\subsection{Reduction of Temperature Rise and Thermal Gradients}

A variety of proven technologies are available for reducing the maximum temperature rise and temperature gradients in mass concrete construction including; the use of ice as part of the mixing water, chilled aggregates, cooling pipes, night time pours, insulating blankets, fly ash additions, and the incorporation of phase change materials into the concrete mixture (Mihashi et al. 2002). These approaches generally reduce the hydration rates or increase the thermal capacity of the concrete such that the heat generated by the hydration reactions results in a smaller temperature rise within the concrete member.

\subsection{Shrinkage-Reducing Admixtures}

Traditionally employed to reduce drying shrinkage, shrinkage-reducing admixtures (SRAs) have also proven effective in reducing plastic (Lura et al. 2007) and autogenous shrinkage (Bentz, Geiker \& Hansen 2001; Bentz 2006a). These chemical admixtures reduce the surface tension of the pore solution by up to a factor of two, resulting in a proportional decrease in capillary stresses according to equation (4). Generally, they also significantly increase the viscosity of the pore solution, which can improve durability and increase service life by reducing transport by diffusion, sorption, and/or flow under pressure (Bentz et al. 2008; Bentz et al. 2009).

Figure 6 provides an example of the measured reduction in autogenous deformation produced by the incorporation of an SRA into a mortar cured under sealed conditions. In this case, the reduction in autogenous shrinkage is basically proportional to the reduction in surface tension achieved by the addition of $2 \%$ SRA by mass of cement. For certain cements, SRAs may also increase the autogenous expansion that is produced at early-ages (Weiss et al. 2008), further reducing the measured absolute shrinkage at later ages. However, it must be kept in mind that it is the net shrinkage (following any early-age expansion) that is most relevant for determining whether autogenous shrinkage cracking may occur (Cusson 2008).

Expansive cements are another viable approach for offsetting early-age shrinkage. Such cements may be 


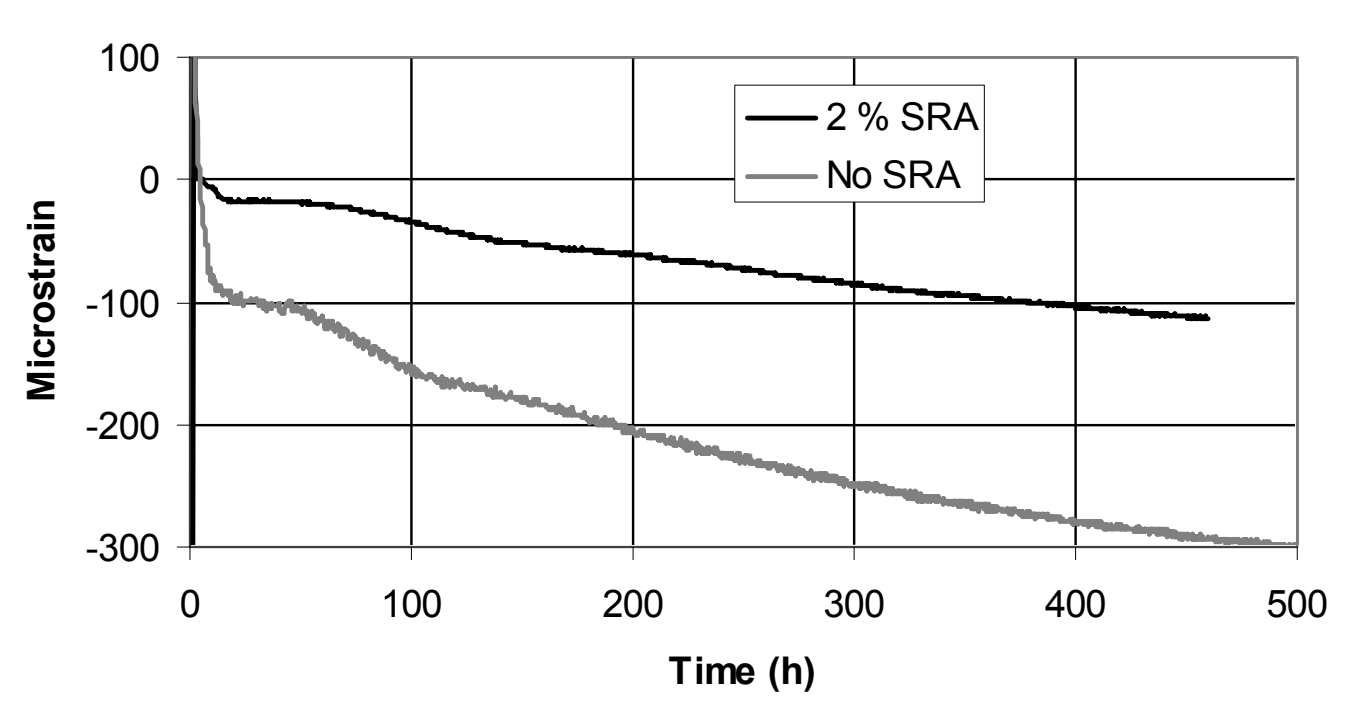

Figure 6. Differences In Autogenous Deformation (Measured Using the Experimental Setup of Jensen \& Hansen 1995b) for Cement Mortars $(W / \mathrm{cm}=0.35)$ With and Without SRA, Cured Under Sealed Conditions at $30^{\circ} \mathrm{C}$ (Bentz, Geiker \& Hansen 2001).

either shrinkage-compensating or self-stressing. In the former case, the goal is to use the expansion to balance the shrinkage in order to prevent cracking. In the latter case, larger expansions are generated to actually stress the concrete internally provided that there is restraint to the expansion. Several thousands microstrain of expansion in concrete can be produced by using expansive cements (Nagataki \& Gomi 1998). The most common method of producing an expansive cement is via the formation of ettringite. There are several additions that can be used to increase ettringite formation in a portland cement, including calcium aluminate cements or $\mathrm{C}_{4} \mathrm{~A}_{3} \overline{\mathrm{S}}$.

It is generally accepted that in these cements, expansion is due to forces generated during the growth of preferentially oriented ettringite crystals. Other possibilities for producing expansive cements are via the hydration of free lime $(\mathrm{CaO})$ or periclase $(\mathrm{MgO})$ (Taylor 1997). In practice, expansive cements are sometimes difficult to regulate and control as the expansion produced will depend on the reactivity of the expansive components and their spatial distribution within the cement powder. Thus, while self-desiccation is generally uniform throughout a concrete (due to the continuity of the water phase), expansion due to ettringite crystal formation, for example, can be a highly localized phenomena, due to the discrete nature of the growing crystals (Bentz et al. 2001).

\subsection{Internal Curing}

A careful examination of equation (4) indicates another viable approach to reducing early-age autogenous deformation: increasing the size of the pores that are emptied during self-desiccation by providing a sacrificial set of large initially-water-filled pores. These water reservoirs are typically provided by pre-wetted light weight aggregates (LWA) (Philleo 1991; Weber \& Reinhardt 1995), superabsorbent polymers (Jensen \& Hansen 2001; Jensen \& Hansen 
2002), pre-wetted wood fibers (Mohr et al. 2005), or pre-wetted crushed returned concrete aggregates (Kim \& Bentz 2008). In the U.S., internal curing via LWA has been employed in several large scale concrete projects including a railway distribution yard (Villarreal \& Crocker 2007), several bridge decks (Delatte et al. 2008), and a pavement (Friggle \& Reeves 2008).

As mentioned earlier, the amount of internal curing water needed to maintain saturation of the capillary porosity is directly related to the chemical shrinkage of the cementitious materials in a concrete. For LWA reservoirs, this amount can be calculated according to (Bentz, Lura \& Roberts 2005):

$$
M_{L W A}=\frac{C_{f}(C S) a_{\max }}{S \phi_{L W A}}
$$

where:

MLWA is the mass of (dry) LWA needed per unit volume of concrete $\left(\mathrm{kg} / \mathrm{m}^{3}\right.$ or $\left.\mathrm{lb} / \mathrm{yd}^{3}\right), \mathrm{C}_{\mathrm{f}}$ is the cement factor (content) for concrete mixture $\left(\mathrm{kg} / \mathrm{m}^{3}\right.$ or $\left.\mathrm{lb} / \mathrm{yd}^{3}\right)$, CS is the chemical shrinkage of cement (grams of water/ gram of cement or $\mathrm{lb} / \mathrm{lb}$ ) at a degree of hydration equal to $100 \%$,

$\alpha_{\max }$ is the maximum expected degree of hydration of cement,

$\mathrm{S}$ is the degree of saturation of aggregate (0-1), and $\varphi_{\mathrm{LWA}}$ is the absorption of lightweight aggregate ( $\mathrm{kg}$ water/kg dry LWA or lb/lb), or more appropriately desorption from saturated surface dry conditions down to about $93 \% \mathrm{RH}$.

In addition to supplying the needed volume of curing water, the spatial distribution of the water is also important. In this respect, using fine LWA as opposed to coarse LWA is preferable due to its more homogeneous and closer spaced distribution of the individual IC reservoirs throughout the concrete volume (Bentz \& Snyder 1999; van Breugel \& Lura 2000). A hard core/soft shell (HCSS) continuum microstructure model can be conveniently applied to quantifying this distribution and the "protected" paste volume for internal curing (Bentz \& Snyder 1999; Bentz, Garboczi \& Snyder 1999).

Figure 7 provides an indication of the reduction in autogenous deformation that is obtained when internal curing is used in a series of high performance blended cement mortars (Bentz 2007b). For systems with substantial pozzolanic reactions, such as those with silica fume and fly ash, IC may not totally eliminate autogenous shrinkage as some of this shrinkage may be due to the dissolution (and loss of micro-reinforcement) of calcium hydroxide crystals participating in the pozzolanic reactions with the mineral admixtures (Bentz \& Stutzman 1994). For pure portland cement mixtures or those with a more hydraulic slag (as indicated in Figure 7), the autogenous deformation can be effectively totally eliminated by the appropriate addition of pre-wetted LWA.

Comprehensive information on internal curing will soon be available in a guide on the topic that is being prepared by ACI Committee 308 - Curing Concrete. To date, the most comprehensive review was that provided by Hoff (Hoff 2002). In addition, a comprehensive bibliography on internal curing is available via the Internet (Internal Curing of Concrete 2009). Recent results have indicated that internal curing can also be an effective means of reducing plastic shrinkage cracking, in addition to its well established reductions in autogenous deformation (Henkensiefken et al. 2009). 

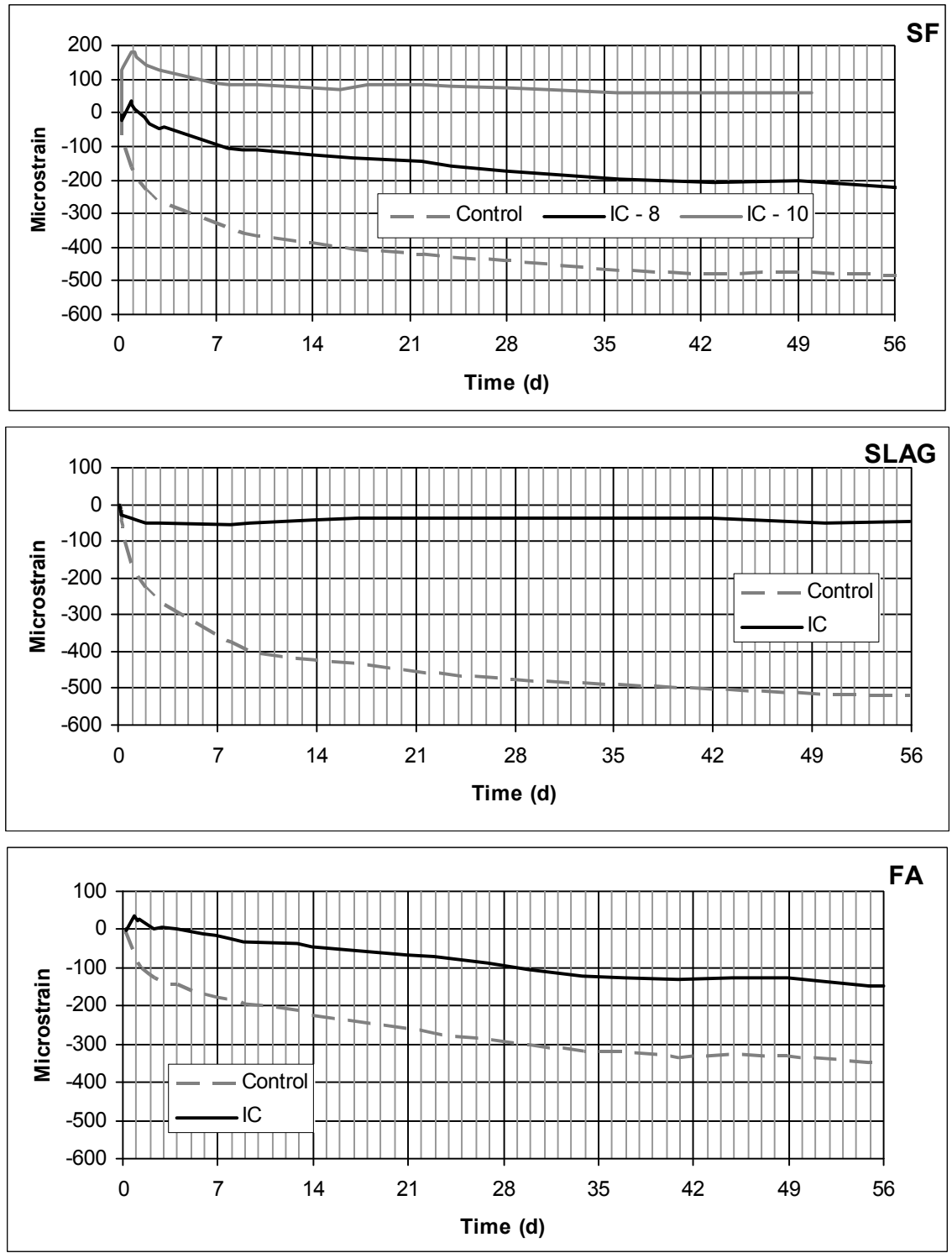

Figure 7. Autogenous Deformation of the Blended Cement Mortars: 8\% Mass Fraction Silica Fume (SF) (top), 20\% Mass Fraction Slag (middle), and 25\% Mass Fraction Type F Fly Ash (FA) (bottom) During $56 \mathrm{~d}$ of Sealed Hydration at $25^{\circ} \mathrm{C}$ (Bentz 2007b). (For the SF System, IC-8 and IC-10 Indicate Internal Curing Additions of $\mathbf{0 . 0 8}$ and $\mathbf{0 . 1 0}$ Mass Units of Water Per Mass Unit of Cement, Respectively.) 


\subsection{REFERENCES}

ACI Committee 231 State-of-the-Art Report, "Early-Age Cracking: Causes, Measurement, and Mitigation," American Concrete Institute, Farmington Hills, MI, 2009.

Andrade, C, Sarria, J, \& Alonso, C 1999, "Relative Humidity in the Interior of Concrete Exposed to Natural and Artificial Weathering, Cement and Concrete Research, vol. 29, pp. 1249-1259.

ASTM C186-05, Standard Test Method for Heat of Hydration of Hydraulic cCement, Volume 04.01, ASTM International, West Conshohocken, PA, 2005.

ASTM C1608-06, Test Method for Chemical Shrinkage of Hydraulic Cement Paste, Volume 04.01, ASTM International, West Conshohocken, PA, 2006.

Barcelo, L, Boivin, S, Rigaud, S, Acker, P, Clavaud, B, \& Boulay, C 1999, "Linear vs. Volumetric Autogenous Shrinkage Measurement: Material Behaviour or Experimental Artefact?," in Proceedings of the $2^{\text {nd }}$ International Seminar on Self-Desiccation and Its Importance in Concrete Technology, B. Persson, G. Fagerlund (Eds.), Lund University, Lund, Sweden, pp. 109-125.

Baroghel-Bouny, V 1997, "Experimental Investigation of Self-desiccation in High-performance Materials - Comparison with Drying Behaviour," in Self-Desiccation and Its Importance in Concrete Technology, Proceedings of the 1st International Seminar, Report TVBM-3075, B. Persson and G. Fagerlund, Eds., Lund University, Lund, Sweden pp. 72-87.

Bensted, J. 1981, "Hydration of Portland Cement," Advances in Cement Technology, S. N. Ghosh, ed., Pergamon Press, New York, pp. 307-347.
Bentz, DP \& Garboczi, EJ 1991, "Percolation of Phases in a Three-dimensional Cement Paste Microstructure Model," Cement and Concrete Research, vol. 21, no. 2, pp. 325-244.

Bentz, DP \& Stutzman, PE 1994, "Evolution of Porosity and Calcium Hydroxide in Laboratory Concretes Containing Silica Fume," Cement and Concrete Research, vol. 24, no. 6, pp. 1044-50.

Bentz, DP 1997, “Three-dimensional Computer Simulation of Portland Cement Hydration and Microstructure Development," Journal of the American Ceramic Society, vol. 80, no. 1, pp. 3-21.

Bentz, DP, Garboczi, EJ, \& Quenard, DA 1998, "Modeling Drying Shrinkage in Reconstructed Porous Materials: Application to Porous Vycor Glass," Modeling and Simulation in Materials Science and Engineering, vol. 6, no. 3, pp. 211-236.

Bentz, DP, Waller, V, \& De Larrard, F 1998, "Prediction of Adiabatic Temperature Rise in Conventional and High-Performance Concretes Using a 3-D Microstructural Model," Cement and Concrete Research, vol. 28, no. 2, pp. 285-297.

Bentz, DP, Garboczi, EJ, \& Snyder, KA 1999, "A Hard Core/Soft Shell Microstructural Model for Studying Percolation and Transport in ThreeDimensional Composite Media," NISTIR 6265, U.S. Department of Commerce.

Bentz, DP \& Snyder, KA 1999, "Protected Paste Volume in Concrete: Extension to Internal Curing using Saturated Lightweight Fine Aggregates," Cement and Concrete Research, vol. 29, pp. 18631867. 
Bentz, DP, Geiker, MR, \& Hansen, KK 2001, "Shrinkage-Reducing Admixtures and Early Age Desiccation in Cement Pastes and Mortars," Cement and Concrete Research, vol. 31, no. 7, pp. 1075-1085.

Bentz, DP, Jensen, OM, Hansen, KK, Oleson, JF, Stang, H, \& Haecker, CJ 2001, "Influence of Cement Particle Size Distribution on Early Age Autogenous Strains and Stresses in Cement-based Materials," Journal of the American Ceramic Society, vol. 84, no. 1, pp. 129-135.

Bentz, DP, Lura, P, \& Roberts, JW 2005, "Mixture Proportioning for Internal Curing," Concrete International, 27 (2), 35-40.

Bentz, DP 2006a, "Influence of Shrinkage-Reducing Admixtures on Drying, Autogenous Shrinkage, and Freezable Water Content of Cement Pastes at Early Ages," Journal of Advanced Concrete Technology, vol. 4, no. 3, pp. 423-429.

Bentz, DP 2006b, “Capillary Porosity Depercolation/ Repercolation in Hydrating Cement Pastes via Low Temperature Calorimetry Measurements and CEMHYD3D Modeling," Journal of the American Ceramic Society, vol. 89, no. 8, pp. 2606-2611.

Bentz, DP 2007a, “Transient Plane Source Measurements of the Thermal Properties of Hydrating Cement Pastes," Materials and Structures, vol. 40, no. 12, pp. 1073-1080.

Bentz, DP 2007b, "Internal Curing of High Performance Blended Cement Mortars," ACI Materials Journal, vol. 104, no. 4, pp. 408-414.

Bentz, DP 2007c, "Verification, Validation, and Variability of Virtual Standards," 12th International Congress on the Chemistry of Cement, Montreal.
Bentz, DP 2008, "A Review of Early-Age Properties of Cement-Based Materials," Cement and Concrete Research, vol. 38, no. 2, pp. 196-204.

Bentz, DP \& Aitcin, P-C 2008, "The Hidden Meaning of Water-to-Cement Ratio," Concrete International, vol. 30, no. 5, pp. 51-54.

Bentz, DP \& Peltz, MA 2008, "Reducing Thermal and Autogenous Shrinkage Contributions to EarlyAge Cracking," ACI Materials Journal, vol. 105, no. 4, pp. 414-420.

Bentz, DP, Sant, G, \& Weiss, WJ 2008, "Early-Age Properties of Cement-Based Materials: I. Influence of Cement Fineness," ASCE Journal of Materials in Civil Engineering, vol. 20, no. 7, pp. 502-508.

Bentz, DP, Snyder, KA, Cass, LC, \& Peltz, MA 2008, "Doubling the Service Life of Concrete. I: Reducing Ion Mobility Using Nanoscale Viscosity Modifiers," Cement and Concrete Composites, vol. 30, pp. 674678.

Bentz, DP, Peltz, MA, Snyder, KA, \& Davis, JM 2009, "VERDiCT: Viscosity Enhancers Reducing Diffusion in Concrete Technology," Concrete International, vol. 31, no. 1, pp. 31-36.

Bjontegaard, O 1999, "Thermal Dilation and Autogenous Deformation as Driving Forces to Selfinduced Stresses in High Performance Concrete," Ph.D. Thesis, Norweigan University of Science and Technology, Norway.

Bouguerra, A, Laurent, JP, Goual, MS, \& Queneudec, M 1997, "The Measurement of the Thermal Conductivity of Solid Aggregates Using the Transient Plane Source Technique," Journal of Physics D: Applied Physics, vol. 30, pp. 2900-2904. 
Brown, K, Brown, AW, Colpitts, BG, \& Bremner, TW 2004, "The Mitigation of Measurement Inaccuracies of Brillouin Scattering Based Fiber Optic Sensors Through Bonded Fiber Temperature Calibrations," in Proceedings of the $7^{\text {th }}$ Cansmart Workshop: Smart Materials and Structures, Montreal, Quebec, Canada, pp. 317-324.

Cusson, D 2005, "Early-Age Cracking of Concrete in Bridge Barrier Walls," NRC-IRC, available at http://irc.nrc-cnrc.gc.ca/ui/cs/earlyage_e.html (access verified February 2009).

Cusson, D 2008, "Effect of Blended Cements on Efficiency of Internal Curing of HPC," in ACI SP256, Internal Curing of High-Performance Concretes: Laboratory and Field Experiences, American Concrete Institute, Farmington Hills, MI, CD-ROM, pp. 105-120.

Delatte, N, Crowl, D, Mack, E, \& Cleary, J 2008, "Evaluating High Absorptive Materials to Improve Internal Curing of Concrete," in ACI SP-256, Internal Curing of High-Performance Concretes: Laboratory and Field Experiences, American Concrete Institute, Farmington Hills, MI, pp. 91-104.

Durán-Herrera, A, Petrov, N, Bonneau, D, Khayat, K, \& Aitcin, PC 2008, "Autogenous Control of Autogenous Shrinkage," in ACI SP-256, Internal Curing of High-Performance Concretes: Laboratory and Field Experiences, American Concrete Institute, Farmington Hills, MI, CD-ROM, pp. 1-12.

Friggle, T \& Reeves, D 2008, "Internal Curing of Concrete Paving: Laboratory and Field Experience," in ACI SP-256, Internal Curing of High-Performance Concretes: Laboratory and Field Experiences, American Concrete Institute, Farmington Hills, MI, pp. 71-80.
Fukuhara, M, Goto, S, Asaga, K, Daimon, M, \& Kondo, R 1981, "Mechanisms and Kinetics of C4AF Hydration with Gypsum," Cement and Concrete Research, vol. 11, pp. 407-414.

Geiker, MR 1983, "Studies of Portland Cement Hydration: Measurements of Chemical Shrinkage and a Systematic Evaluation of Hydration Curves by Means of the Dispersion Model," Ph.D. Thesis, Technical University of Denmark, Lyngby, Denmark.

Grasley, ZC, Lange, DA, Brinks, AJ, \& D’Ambrosia, MD 2005, "Modeling Autogenous Shrinkage of Concrete Accounting for Creep Caused by Aggregate Restraint," in Proceedings of the $4^{\text {th }}$ International Seminar on Self-Desiccation and Its Importance in Concrete Technology, B. Persson, D. Bentz, L.-O. Nilsson (Eds.), NIST, Gaithersburg, MD, pp. 78-94.

Grasley, ZC, D'Ambrosia, MD, \& Lange, DA 2006, "Internal Relative Humidity and Drying Stress Gradients in Concrete," Materials and Structures, vol. 39, no. 9, pp. 901-909.

Hammer, TA \& Heese, C 1999, "Early Age Chemical Shrinkage and Autogenous Deformation of Cement Pastes," in Proceedings of the $2^{\text {nd }}$ International Seminar on Self-Desiccation and Its Importance in Concrete Technology, B. Persson, G. Fagerlund (Eds.), Lund University, Lund, Sweden, pp. 7-13.

Hashin, Z \& Shtrikman, S 1962, “A Variational Approach to the Theory of the Effective Magnetic Permeability of Multiphase Materials," Journal of Applied Physics, vol. 33, pp. 3125-3131.

Henkensiefken, R, Briatka, P, Bentz, D, Nantung, T, \& Weiss, J 2009, "Plastic Shrinkage Cracking in Internally Cured Mixtures Made with Pre-wetted Lightweight Aggregate," submitted to Concrete International. 
Hoff, GC 2002, "The Use of Lightweight Fines for Internal Curing of Concrete," Northeast Solite Corporation, $44 \mathrm{pp}$, available at http://www.nesolite. com/Reports/solitepaper.pdf, access verified September 2008.

Horai, K 1971, “Thermal Conductivity of RockForming Minerals," Journal of Geophysical Research, vol. 76, no. 5, pp. 1278-1308.

Houk, IE, Borge, OE, \& Houghton, DR 1969, "Studies of Autogenous Volume Change in Concrete for Dworshak Dam," ACI Journal, vol. 66, no. 5, pp. 560-568.

Hua, C, Acker, P, \& Erlacher, A 1995, “Analyses and Models of the Autogenous Shrinkage of Hardening Cement Pastes," Cement and Concrete Research, vol. 25 , no. 7 , pp. 1457-1468.

Internal Curing of Concrete, at http://ciks.cbt.nist. gov/ bentz/phpct/database/ic.html, access verified April 2009.

Jensen, OM 1990, "The Pozzolanic Reaction of Silica Fume," M.S. Thesis, Technical Report TR229/90, Technical University of Denmark, Lyngby, Denmark, (in Danish).

Jensen, OM \& Hansen, PF 1995a, “Autogenous Relative Humidity Change in Silica Fume-modified Cement Paste," Advances in Cement Research, vol. 7, no. 25 , pp. $33-38$.

Jensen, OM \& Hansen, PF 1995b, “A Dilatometer for Measuring Autogenous Deformation in Hardening Portland Cement Paste," Materials and Structures, vol. 28, no. 181, pp. 406-409.
Jensen, OM \& Hansen, PF 1996, “Autogenous Deformation and Change of the Relative Humidity in Silica Fume-modified Cement Paste," ACI Materials Journal, vol. 93, no. 6, pp. 539-543.

Jensen, OM, Hansen, PF, Lachowski, EE, \& Glasser, FP 1999, "Clinker Mineral Hydration at Reduced Relative Humidities," Cement and Concrete Research, vol. 29, no. 9, pp. 1505-1512.

Jensen, OM \& Hansen, PF 2001, "Water-entrained Cement-based Materials I. Principles and Theoretical Background," Cement and Concrete Research, vol. 31, no. 4, pp. 647-654.

Jensen, OM \& Hansen, PF 2002, "Water-entrained Cement-based Materials: II. Experimental Observations," Cement and Concrete Research, vol. 32, no. 6, pp. 973-978.

Justnes, H, Sellevold, EJ, Reyniers, B, Van Loo, D, Van Gemert, A, Verboven, F, \& Van Gemert, D 1999, "The Influence of Cement Characteristics on Chemical Shrinkage," in Autogenous Shrinkage of Concrete, E. Tazawa (Ed.), E\&FN Spon, London, pp. 71-80.

Kim, K-H, Jeon, S-E, Kim, J-K, \& Yang, S 2003, "An Experimental Study on Thermal Conductivity of Concrete," Cement and Concrete Research, vol. 33, pp. 363-371.

Kim, H \& Bentz, DP 2008, "Internal Curing with Crushed Returned Concrete Aggregates," in NRMCA Technology Forum: Focus on Sustainable Development, CD-RoM. 
Kishi, T., and Maekawa, K. 1995, "Thermal and Mechanical Modeling of Young Concrete Based on Hydration Process of Multi-Component Cement Minerals," Proceedings of the International RILEM Symposium on Thermal Cracking in Concrete at Early Ages, R. Springenschmid, ed., E\&FN Spon, London, pp. 11-18.

Lee, KM, Lee, HK, Lee, SH, \& Kim, GY 2006, "Autogenous Shrinkage of Concrete Containing Granulated Blast-furnace Slag," Cement and Concrete Research, vol. 36, no. 7, pp. 1279-1285.

Lura, P, Jensen, OM, \& van Breugel, K 2003, "Autogenous Shrinkage in High-performance Cement Paste: An Evaluation of Basic Mechanisms," Cement and Concrete Research, vol. 33, no. 2, pp. 223-232.

Lura, P \& Jensen, OM 2005, "Volumetric Measurement in Water Bath - An Inappropriate Method to Measure Autogenous Strain of Cement Paste," PCA R\&D Serial No. 2925, Portland Cement Association, Skokie, IL.

Lura, P, Pease, B, Mazzotta, G, Rajabipour, F, \& Weiss, J 2007, "Influence of Shrinkage-Reducing Admixtures on the Development of Plastic Shrinkage Cracks," ACI Materials Journal, vol. 104, no. 2, pp. 187-194.

MacKenzie, JK 1950, "The Elastic Constants of a Solid Containing Spherical Holes," Proceedings of the Physical Society, vol. 683, pp. 2-11.

Maekawa, K, Chaube, R, \& Kishi, T (Eds.) 1999, Modelling of Concrete Performance: Hydration, Microstructure Formation, and Mass Transport, E\&FN Spon, London.
McCullough, BF \& Rasmussen, RO 1999, "Fast-track Paving: Concrete Temperature Control and Traffic Opening Criteria for Bonded Concrete Overlays, FHWA-RD-98-167.

McGrath, P \& Hooton, RD 1991, "Self-desiccation of Portland Cement and Silica Fume Modified Mortars," in Ceramic Transactions, Vol. 16, Advances in Cementitious Materials, S. Mindess (Ed.), The American Ceramic Society, Inc., Westerville, OH, pp. 489-500.

Mehta, PK 2004, "High-Performance, High-Volume Fly Ash Concrete For Sustainable Development," in Proceedings of the International Workshop on Sustainable Development and Concrete Technology, Beijing, China, pp. 3-14.

Mihashi, H, Nishiyama, N, Kobayashi, T, \& Hanada, M 2002, "Development of a Smart Material to Mitigate Thermal Stress in Early Age Concrete," in Control of Cracking in Early Age Concrete, Eds. H. Mihashi \& F. H. Wittmann, Balkema, Rotterdam, pp. 385-392.

Mohr, B, Premenko, L, Nanko, H, \& Kurtis, KE 2005, "Examination of Wood-derived Powders and Fibers for Internal Curing of Cement-based Materials," in Proceedings of the $4^{\text {th }}$ International Seminar on Self-Desiccation and Its Importance in Concrete Technology, B. Persson, D. Bentz, L.-O. Nilsson (Eds.), NIST, Gaithersburg, MD, pp. 229244.

Moon, J-H, Rajabipour, F, Pease, B, \& Weiss, WJ 2005, "Autogenous Shrinkage, Residual Stress, and Cracking in Cementitious Composites: The Influence of Internal and External Restraint," in Proceedings of the $4^{\text {th }}$ International Seminar on Self-Desiccation and Its Importance in Concrete Technology, B. Persson, D. Bentz, L.-O. Nilsson (Eds.), NIST, Gaithersburg, MD, pp. 1-20. 
Mounanga, P, Khelidj, A, Loukili, A, \& BaroghelBouny, V 2005, "Predicting $\mathrm{Ca}(\mathrm{OH}) 2$ Content and Chemical Shrinkage of Hydrating Cement Pastes using Analytical Approach," Cement and Concrete Research, vol. 34, no. 2, pp. 255-265. Erratum published in Cement and Concrete Research, vol. 35, pp. 423-424.

Nagataki, S. and Gomi, H. 1998. "Expansive Admixtures." Cement and Concrete Composites, vol. 20. pp. 163-170.

Persson, B. and Fagerlund, G. (Eds.) 1997, SelfDesiccation and Its Importance in Concrete Technology 1997, Proceedings of the $1^{\text {st }}$ International Seminar, Report TVBM-3075, Lund University, Lund, Sweden.

Philleo, RE 1991, "Concrete Science and Reality," in Materials Science of Concrete II, J. Skalny, S. Mindess (Eds.), American Ceramic Society, Westerville, $\mathrm{OH}$, pp. 1-8.

Poppe, AM, \& De Schutter, G 2006, “Analytical Hydration Model for Filler Rich Self-Compacting Concrete," Journal of Advanced Concrete Technology, vol. 4, no. 3, pp. 259-266.

Powers, TC 1935, "Adsorption of Water by Portland Cement Paste during the Hardening Process," Industrial and Engineering Chemistry, vol. 27, pp. 790-794.

Powers, TC, Copeland, LE, \& Mann, HM 1959, "Capillary Continuity or Discontinuity in Cement Paste," PCA Bulletin No. 10, pp. 2-12.
Roelfstra, PE, Salet, TAM, \& Kuiks, JE 1994, "Defining and Application of Stress-analysis-based Temperature Difference Limits to Prevent Early-age Cracking in Concrete Structures," in Proceedings of the International RILEM Symposium: Thermal Cracking in Concrete at Early Ages, Munich, pp. 273-280.

Ruiz, JM, Rasmussen, RO, Chang, GK, Dick, JC, \& Nelson, PK 2005, "Computer-based Guidelines for Concrete Pavements Volume II - Design and Construction Guidelines and HIPERPAV II User's Manual," FHWA-HRT-04-122.

Taylor, HFW 1997, Cement Chemistry $2^{\text {nd }}$ edition, Thomas Telford, London.

Tazawa, E., (Ed.) 1999, Autogenous Shrinkage of Concrete, E\&FN Spon, London, pp. 53-55.

Tennis, PD \& Bhatty, JI 2005, "Portland Cement Characteristics-2004." Concrete Technology Today, Portland Cement Association, vol. 26, no. 3, pp. 1-3.

van Breugel, K \& Lura, P 2000, "Effect of Initial Moisture Content and Particle Size Distribution of Lightweight Aggregates on Autogenous Deformation," in: Proceedings of the $2^{\text {nd }}$ International Symposium on Structural Lightweight Concrete, S. Helland, I. Holand, S. Smeplass (Eds.), Kristiansand, Norway, pp. 453-462.

Villarreal, V \& Crocker, D 2007, "Building Better Pavements through Internal Hydration," Concrete International, vol. 29, no. 2, pp. 32-36.

Viviani, M, Glisic, B, \& Smith, IFC 2007, "Separation of Thermal and Autogenous Deformation at Varying Temperature using Optical Fiber Sensors," Cement and Concrete Composites, vol. 29, pp. 435447. 
Vosteen, H-D \& Schellschmidt, R 2003, "Influence of Temperature on Thermal Conductivity, Thermal Capacity, and Thermal Diffusivity for Different Types of Rocks," Physics and Chemistry of the Earth, vol. 28, pp. 499-509.

Wadso, L 2002, “An Experimental Comparison Between Isothermal Calorimetry, Semi-adiabatic Calorimetry and Solution Calorimetry for the Study of Cement Hydration," Final Report NORDTEST project 1534-01, Lund University, Lund, Sweden.

Waller, V, De Larrard, F, \& Roussel, P 1996, "Modelling the Temperature Rise in Massive HPC Structures," in $4^{\text {th }}$ International Symposium on Utilization of High-Strength/High-Performance Concrete, RILEM S.A.R.L., Paris, pp. 415-421.
Weber, S \& Reinhardt, HW 1995, “A Blend of Aggregates to Support Curing of Concrete," in Proceedings of the International Symposium on Structural Lightweight Aggregate Concrete, I. Holand, T.A. Hammer, P. Fluge (Eds.), Sandefjord, Norway, pp. 662-671.

Weiss, J, Lura, P, Rajabipour, F, \& Sant, G 2008, "Performance of Shrinkage Reducing Admixtures at Different Humidities and at Early Ages," ACI Materials Journal, vol. 105, no. 5, pp. 478-486. 


\title{
CHEMICAL DEGRADATION REVIEW
}

\author{
Eric Samson \\ Email: esamson@simcotechnologies.com \\ SIMCO Technologies, Inc. \\ Quebec City, Canada \\ Pierre Henocq \\ Email: phenocq@simcotechnologies.com \\ SIMCO Technologies, Inc. \\ Quebec City, Canada \\ Jacques Marchand \\ Email: jmarchand@simcotechnologies.com \\ SIMCO Technologies, Inc. \\ Quebec City, Canada
}


Review of Mechanistic Understanding and Modeling and Uncertainty Analysis Methods for Predicting Cementitious Barrier Performance

IV-ii 


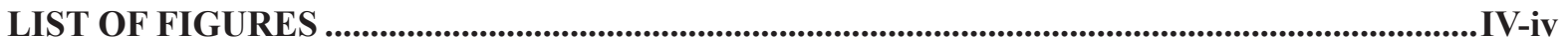

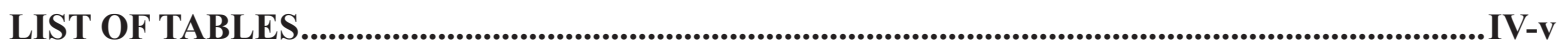

LIST OF ABBREVIATIONS AND ACRONYMS .........................................................................

LIST OF SYMBOLS............................................................................................................................. IV-vii

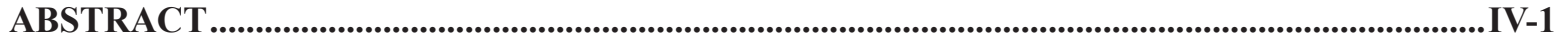

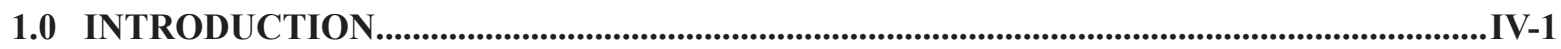

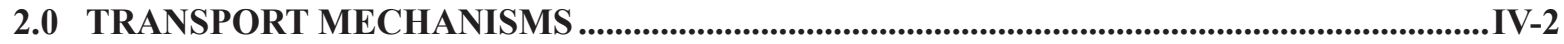

2.1 Ionic Transport ................................................................................................................................ IV-2

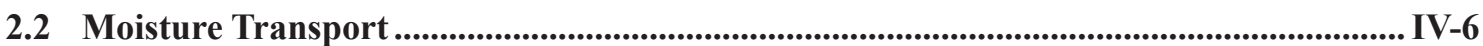

2.3 Diffusion Potential......................................................................................................................... IV-7

2.4 Temperature-Field Modeling .......................................................................................

3.0 CHLORIDE INGRESS AND CORROSION ...............................................................................IV-8

3.1 Chloride Interaction with Hydrated Cement Systems ...................................................... IV-8

3.2 Binding Mechanisms ....................................................................................................................... IV-9

3.3 Modeling Chloride Ingress ........................................................................................................ IV-11

3.4 Prediction of Corrosion Initiation ..................................................................................... IV-12

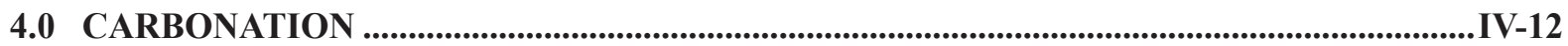

4.1 Description of the Carbonation Process....................................................................... IV-14

4.2 Carbonation Measurements .......................................................................................................... IV-16

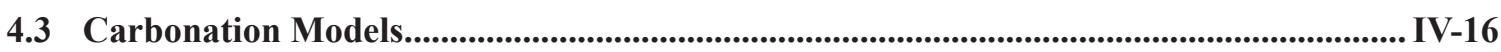

5.0 DECALCIFICATION ........................................................................................................................IV-17

5.1 Description of the Process................................................................................................................ IV-18

5.2 Experiments and Methods............................................................................................ IV-19

5.3 Modeling the Decalcification Process ................................................................................................ IV-22

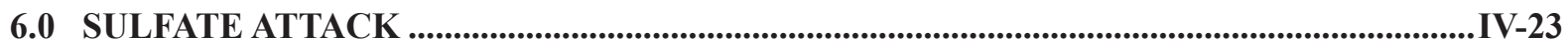

6.1 Description of the Sulfate Attack Process ..................................................................................... IV-25

6.2 Experiments and Methods.......................................................................................... IV-29

6.3 External Sulfate Attack Modeling .................................................................................................. IV-31

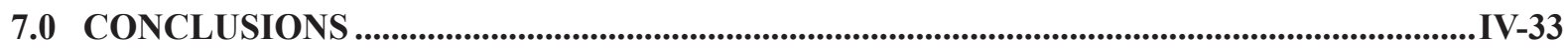

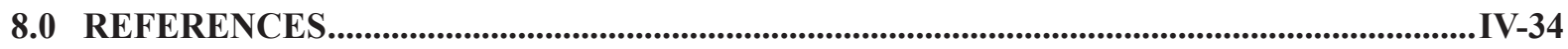




\section{LIST OF FIGURES}

Page No.

Figure 1. Contributions of the Chloride Chemical and Physical Binding In A Cement

System (from (Hosokawa 2006))

Figure 2. Predicted Total Chloride Profile in A 20-year-old Parking Structure Using the Model Presented in (Samson 2007), Compared to Measurements Performed on Two Cores. (The inserted graph illustrates the time-dependent boundary conditions over one year.)

Figure 3. Chloride Content at Different Rebar Positions(The calculations correspond to the case presented in Figure 2)

Figure 4. Relative Distribution of $\mathrm{CO}_{2}(\mathrm{aq}), \mathrm{HCO}_{3}$ - and $\mathrm{CO}_{3}{ }^{2-}$ as a Function of $\mathrm{pH}$ at $25^{\circ} \mathrm{C}$. $. \mathrm{IV}-15$

Figure 5. Carbonation Depths (a) Measured with Phenolphthalein on Mortar Samples Exposed to a 50\% RH 5\% $\mathrm{CO}_{2}$ Environment and (b) Plotted Against the Square Root of Time.

(Data provided by SIMCO Technologies Inc.) $. \mathrm{IV}-16$

Figure 6. Change of $\mathrm{Ca}^{2+}$ Concentration as A Function of the Leaching Duration (a) and Depth of the $\mathrm{Ca}(\mathrm{OH})_{2}$ Dissolved Front as A Function of the Square Root of the Leaching Period (b) (Haga 2005)

Figure 7. Pore Size Distribution on Sound and Leached Samples (Haga 2005)) IV-20

Figure 8. Cumulative Quantity of Dissolved $\mathrm{Ca}^{2+}$ for SCM Mixtures (a) Blast-furnace Slag (BF) and (b) Silica Fume (SF) (Saito 2000))

Figure 9. (a) Relationship Between Pore Volume (PV/Vp) and Compressive Strength for Sound and Degraded Materials (Saito 2000) and (b) Variation of the Strength Loss in Relation to the Degradation Ratio Ad/At ( adapted from Carde 1996)

Figure 10. Relationship Between [Ca] in the Solution and the Solid Content from Daimon et al. (Haga 2005, Daimon 1977)

Figure 11. Simulations of Calcium Leaching (a) on Cement Paste (Maltais 2004) and (b) on Mortar (Yokozeki 2004)

Figure 12. Expansions of Mortars Under Sodium Sulfate Attack as A Function of W/C:

(a) (Naik 2006) and (b) (Lee 2005). $. \mathrm{IV}-26$

Figure 13. Expansion of Mortars Under Sodium Sulfate Attack vs. C3A Content

(a) \%C3A type I > \%C3A type V (Naik 2006) and (b) (Ouyang 1988).

Figure 14. Expansions of Sandberg Prisms for Different Slag Contents (a) in $\mathrm{Na}_{2} \mathrm{SO}_{4}$ Solution $\left(1.5 \% \mathrm{SO}_{3}\right)$ and (b) in $\mathrm{MgSO}_{4}$ Solution $\left(1.5 \% \mathrm{SO}_{3}\right)$ IV-28

Figure 15. Expansions of PLC Mortar Prisms Containing Fly Ash After Immersion in $4.4 \%$ Sodium Sulfate Solution (Mulenga 2003) $. \mathrm{IV}-30$

Figure 16. Sulfur Content Mapping (a) and Sulfur Profiles (b) for 0.6 W/C Ratio CSA Type 10 Cement Pastes Exposed for 3 Months to a $50 \mathrm{mmol} / 1 \mathrm{Na}_{2} \mathrm{SO}_{4}$ Solution (Maltais 2004) $. \mathrm{IV}-32$ 


\section{LIST OF TABLES}

Page No.

Table 1. Solubility Constants of Portlandite and C-S-H (Maltais 2004, Berner 1992)............................ IV-23

Table 2. $D=M(\phi)$ Relationships Found in Literature ..................................................................... IV-23

Table 3. Solubility Constants of Solid Phases Involved During Sulfate Ingress in Hydrated Cement Systems (Maltais 2004)) ............................................................................................. IV-33 
Review of Mechanistic Understanding and Modeling and Uncertainty Analysis

Methods for Predicting Cementitious Barrier Performance

\section{LIST OF ABBREVIATIONS AND ACRONYMS}

$\begin{aligned} \text { ADE } & \text { Advective-Dispersive Equation or Advective-Diffusive Equation } \\ \text { ASR } & \text { Alcali-Silica Reaction } \\ \text { DEF } & \text { Delayed Ettringite Formation } \\ \text { FHWA } & \text { Federal Highway Administration } \\ \text { HMW } & \text { Harvies, Moller and Weare implementation of Pitzer's ionic interaction model } \\ \text { LEA } & \text { Local Equilibrium Assumption } \\ \text { opc } & \text { ordinary Portland cement } \\ \text { REV } & \text { Representative Elementary Volume } \\ \text { SIA } & \text { Sequential Iterative Approach } \\ \text { SNIA } & \text { Sequential Non Iterative Approach }\end{aligned}$




\title{
LIST OF SYMBOLS
}

\author{
a Hydration parameter (see $H(t)$ ) \\ $A \quad$ Parameter in the exponential water diffusivity expression $\mathrm{D}_{\mathrm{w}}=A \mathrm{e}^{B \mathrm{w}}$ \\ $B \quad$ Parameter in the exponential water diffusivity expression $\mathrm{D}_{\mathrm{w}}=A \mathrm{e}^{B \mathrm{w}}$ \\ $c_{i} \quad$ Concentration of species $i$ in solution at the pore scale \\ $C_{i} \quad$ Concentration of species $i$ in solution averaged over a REV \\ $C_{p} \quad$ Heat capacity \\ $D_{i}^{o} \quad$ Freewater diffusion coefficient of species $i$ (self-diffusion coefficient) \\ $D_{i} \quad$ Diffusion coefficient of species $i$ in solution at the material scale \\ $D_{\text {app }} \quad$ Chloride apparent diffusion coefficient \\ $D_{h} \quad$ Water diffusivity as a function of relative humidity \\ $D_{w} \quad$ Water diffusivity as a function of water content \\ $F \quad$ Faraday constant \\ $G(T) \quad$ Effect of temperature on diffusion coefficients \\ $H(t) \quad$ Effect of hydration on diffusion coefficients \\ I Ionic strength \\ $j_{i} \quad$ Flux of species $i$ \\ $k \quad$ Thermal conductivity \\ $K \quad$ Intrinsic permeability \\ $k_{r i} \quad$ Relative permeability of fluid $i$ \\ $M(\phi) \quad$ Function relating changes in porosity to changes in transport properties \\ $N \quad$ Number of species in solution \\ $p$ pressure \\ $r_{i} \quad$ Source/sink term for the homogeneous reaction at the pore scale \\ $R \quad$ Ideal gas constant \\ $R_{i} \quad$ Source/sink term for the homogeneous reaction averaged over a REV \\ $S_{i} \quad$ Saturation level of fluid phase $i$ \\ $S(w) \quad$ Effect of water content on diffusion coefficients \\ $S(h) \quad$ Effect of relative humidity on diffusion coefficients \\ $t$ time \\ $T$ Temperature \\ $U \quad$ Activation energy \\ $\mathbf{v}_{\mathbf{i}} \quad$ Velocity of fluid $i$ at the pore scale \\ $\mathbf{V}_{\mathbf{i}} \quad$ Velocity of fluid $i$ averaged over a REV \\ $V_{p} \quad$ Paste volume in a cementitious material mixture \\ $w \quad$ Water content \\ $x, y, z \quad$ Position \\ $\alpha \quad$ Rate parameter in the hydration function $H(t)$ \\ $\alpha \quad$ Parameter in the water diffusivity function $D(h)$ \\ $\beta \quad$ Parameter in the water diffusivity function $D(h)$ \\ $\varepsilon \quad$ Permittivity \\ $\phi \quad$ Porosity \\ $\gamma \quad$ Parameter in the water diffusivity function $D(h)$
}




\section{LIST OF SYMBOLS (contd)}

$\gamma_{i} \quad$ Chemical activity coefficient of species $i$

$\eta \quad$ Dynamic viscosity

$\mu_{i} \quad$ Electrochemical potential

$\mu_{l \rightarrow v}, \mu_{v \rightarrow l} \quad$ Water vaporization/condensation terms

$\theta^{s} \quad$ Solid phase content

$\rho_{i} \quad$ Density of phase $i$

$\tau \quad$ Tortuosity

$\psi \quad$ Diffusion potential at the pore scale

$\Psi \quad$ Diffusion potential averaged over a REV 


\title{
CHEMICAL DEGRADATION REVIEW
}

\author{
Eric Samson \\ Pierre Henocq \\ Jacques Marchand \\ SIMCO Technologies, Inc. \\ Quebec City, Canada
}

\section{ABSTRACT}

This report reviews the most common mechanisms associated with the chemical degradation of cementitious materials. The review focuses on cases where the chemical degradation of the materials is triggered by the exchange of ionic species at the material/environment interface. In some cases, ionic species are leached out of the material while in other cases, external contaminants enter the material and affect the microstructure. Many situations involve simultaneous species ingress and leaching.

Since the transport of species is prominently involved in the chemical degradation of cementitious materials, the various mechanisms affecting the movement of ions in the pore solution of cementitious materials was first reviewed. Part of the review is dedicated to moisture transport. A more detailed report on this topic can be found in Chapter $2 \mathrm{~d}$.

Following this, common chemical degradation mechanisms were reviewed, namely chloride ingress and corrosion, carbonation, decalcification due to the leaching of hydroxide and calcium and external sulfate attack.

As mentioned earlier, only cases involving the exchange of ions at the material/environment interface were considered. "Internal" degradation mechanisms such as delayed ettringite formation (DEF) and alcali-silica reaction (ASR) were left aside. Although they are commonly observed on many existing structures, they can be avoided with proper material selection and concrete practice.

Various types of cementitious materials were described in the paper reviewed. The papers dealing with chloride ingress featured mostly mortar and concrete mixtures, while the carbonation studies were primarily made on hydrated cement pastes and mortars. In the case of external sulfate attack and decalcification, the papers reviewed in this chapter were mostly based on hydrated cement pastes, which make characterization easier due to the absence of aggregates. No studies dedicated specifically to wasteforms were reviewed.

\subsection{INTRODUCTION}

While interacting with its service environment, concrete and other cementitious materials often undergo significant alterations that often have adverse consequences on their engineering properties. As a result, the durability of hydrated cement systems and their constituent phases has been studied closely by scientists and engineers. The alteration to microstructure occurs mostly following ionic exchanges between the hydrated cement paste and the environment. The exchanges affect the equilibrium between the pore solution of cementitious materials and the solid phases of the paste, resulting in dissolution and/or precipitation of minerals. 
Since the transport of species is prominently involved in the chemical degradation of cementitious materials, the various mechanisms affecting the movement of ions in the pore solution of cementitious materials were reviewed. The basic principles of gas transport are also outlined. A section of the review is also dedicated to moisture transport. However, a more detailed report on this topic can be found in the chapter dedicated to hydraulic properties.

Then, different chemical degradation phenomena were reviewed. Microstructural alterations resulting from exposure to chlorides and carbon dioxide are discussed. Sulfate attack from external sources is described including processes resulting in the formation of ettringite and thaumasite. Finally, the decalcification of hydrated cement pastes resulting from the leaching of calcium and hydroxide in the external environment is discussed. Some chemical degradation phenomena ultimately lead to physical damage on the material. The mechanical aspects were reviewed in the chapter dedicated to the mechanical damage review.

The review only focused on degradation cases involving the exchange of ions at the material/ environment interface. "Internal" degradation mechanisms such as delayed ettringite formation (DEF) and alcali-silica reaction (ASR) were left aside. DEF affects structures that exhibited internal temperature above $70^{\circ} \mathrm{C}$ during the hydration process, resulting in a deleterious dissolution/precipitation sequence for ettringite. ASR is concerned with the formation of a gel around reactive aggregates that causes tension and ultimately cracks in the concrete. Although these two mechanisms are commonly observed on many existing structures, they can be avoided with proper material selection and concrete practice.

The paper reviewed showed a large range of material types. The papers dealing with chloride ingress featured mostly mortar and concrete mixtures, while the carbonation studies were primarily made on hydrated cement pastes and mortars. In the case of external sulfate attack and decalcification, the papers reviewed in this chapter were mostly based on hydrated cement pastes, which make characterization easier due to the absence of aggregates. No studies dedicated specifically to wasteforms were reviewed.

\subsection{TRANSPORT MECHANISMS}

\subsection{Ionic Transport}

The development of ionic transport models in cementitious materials has initially been motivated by concerns over the premature degradation of concrete structures exposed to chloride-laden environments. Early models were typically limited to simplified equations describing the diffusion of a single ion (e.g., chloride) in saturated concrete. These simple models were gradually improved to account for the complexity of ionic transport in unsaturated systems. Multi-ionic models that consider not only diffusion but other transport mechanisms, such as water movement under the effect of humidity gradients, were proposed and tested.

The description of transport phenomena is usually performed by writing the mass conservation equations at the pore level. The equations are then averaged over a Representative Elementary Volume (REV) of the material. By solving the averaged mass transport equations, one can therefore perform simulations at the scale of the concrete element.

At the pore scale, it is typically assumed that ions can be transported by a combination of two phenomena: an electrochemical potential gradient and the advection caused by a flow of the aqueous solution (Bockris 1970, Helfferich 1961):

$$
\mathbf{j}_{i}=\underbrace{-\frac{D_{i}^{o}}{R T} c_{i} \operatorname{grad}\left(\mu_{i}\right)}_{\text {electrochemical }}+\underbrace{c_{i} \mathbf{v}}_{\text {advection }}
$$




\section{Review of Mechanistic Understanding and Modeling and Uncertainty Analysis Methods for Predicting Cementitious Barrier Performance}

where: $c_{i}$ is the concentration of ionic species $i, D_{i}^{o}$ is the diffusion coefficient in free water, $\mu_{i}$ is the electrochemical potential, $R$ is the ideal gas constant, $T$ is the temperature and $\mathbf{v}$ is the velocity of the liquid phase.

The electrochemical potential $\mu_{i}$ is defined as:

$\mu_{i}=\mu_{i}^{o}+R T \ln \left(\gamma_{i} c_{i}\right)+z_{i} F \psi$

where: $\mu_{i}^{o}$ is a reference level, $\gamma_{i}$ is the chemical activity coefficient, $z_{i}$ is the valence number of the ionic species, $F$ is the Faraday constant and $\psi$ is the diffusion potential.

Substituting Equation (1) in (2) yields (Samson 2007):

$$
\begin{gathered}
\mathbf{j}_{i}=-D_{i}^{o} \operatorname{grad}\left(c_{i}\right)-\frac{D_{i}^{o} z_{i} F}{R T} c_{i} \operatorname{grad}(\psi) \\
-D_{i}^{o} c_{i} \operatorname{grad}\left(\ln \gamma_{i}\right) \\
-\frac{D_{i}^{o} c_{i} \operatorname{grad}\left(\ln \gamma_{i}\right)}{T} \operatorname{grad}(T)+c_{i} \mathbf{v}
\end{gathered}
$$

Each term on the right-hand side of Eq. (3) corresponds to a different mechanism. The first term, often called the diffusion term or Fick's law, describes the movement of ionic species under the effect of a concentration gradient.

The second term involving the diffusion potential is responsible for maintaining the pore solution electroneutrality by slightly altering the velocity of individual species. The diffusion potential thus couples each individual flux equation (Sten-Knudsen 2002).

The chemical activity term is essentially a correction to the flux when the ionic strength of the pore solution is high. The chemical activity term in Equations (2) and (3) can be estimated using an equation that relates the chemical activity coefficient $\gamma_{i}$ to the concentrations in solution. Classical electrochemical models like the Debye-Hückel or extended DebyeHückel relationship are valid for weak electrolytes for which the ionic strength is on the order of 100 $\mathrm{mmol} / \mathrm{L}$, while the Davies correction can be used to describe the behavior of more concentrated solutions, i.e., with ionic strengths up to $300 \mathrm{mmol} / \mathrm{L}$ (Pankow 1994). Pore solutions extracted from hydrated cement systems are more in the $300 \mathrm{mmol} / \mathrm{L}$ (Hidalgo 2001) to $900 \mathrm{mmol} / \mathrm{L}$ range (Reardon 1992). As reported in (Zemaitis 1986), many models were developed to estimate the activity coefficients for highly concentrated solutions. One of the most commonly used approach is the implementation of Pitzer's ionic interaction model proposed by Harvie, Moller and Weare (Harvie 1984). Pitzer's model was used by Reardon (Reardon 1990) to model the hydrated paste/ solution chemical equilibrium.

The next term in Equation (3), which involves temperature, is called the Soret effect. It describes the influence of a temperature gradient on the ionic flux.

The constitutive Equation (3) can be simplified in some specific cases. For instance, the Soret effect term (i.e., the fourth term in the equation) which describes the influence of temperature gradient on ionic flux, can be neglected for isothermal cases. In saturated materials, the term associated with the fluid velocity is most of the time neglected since pressure gradients to which structures are usually exposed are too weak to induce a flow given the low permeability of concretes.

To get the complete transport equation, the constitutive Equation (3) is substituted in the mass conservation relationship (Bear 1991):

$\frac{\partial c_{i}}{\partial t}+\operatorname{div}\left(j_{i}\right)+r_{i}=0$

where: $r_{i}$ is the reaction rate term accounting for complexation in the solution. The complexation reactions are assumed to take place solely within the aqueous phase. The formation of $\mathrm{CaOH}^{+}$is an example 
of complexation reaction: $\mathrm{Ca}^{2+}+\mathrm{OH}^{-} \leftrightarrow \mathrm{CaOH}^{+}$. At the pore scale, the other types of chemical reactions, i.e., dissolution/precipitation and surface adsorption, could be modeled by exchange terms at the aqueous/solid interface.

Combining Equations (3) and (4) gives the complete ionic transport equation in the aqueous phase at the pore scale:

$$
\begin{aligned}
\frac{\partial c_{i}}{\partial t}-\operatorname{div}( & D_{i}^{o} \operatorname{grad}\left(c_{i}\right) \\
+ & \frac{D_{i}^{o} z_{i} F}{R T} c_{i} \operatorname{grad}(\psi)+D_{i}^{o} c_{i} \operatorname{grad}\left(\ln \gamma_{i}\right) \\
& \left.+\frac{D_{i}^{o} c_{i} \operatorname{grad}\left(\ln \gamma_{i}\right)}{T} \operatorname{grad}(T)-c_{i} \mathbf{v}\right)+r_{i}=0
\end{aligned}
$$

However, modeling transport of ions at the pore scale is currently a very difficult task. One has to have some 3-D representation of the entire porous network. The computational resources required to conduct these calculations are large but obtainable on modern parallel computers. To circumvent this difficulty, and to make the calculation more tractable, pore scale equations can be averaged over the scale of the material using a mathematical procedure called homogenization. The general application of the method can be found in (Bear 1991, Hassanizadeh 1979). The technique was specifically applied to cementitious materials in (Samson 2005). It should be noted that (Johannesson 2003) developed an ionic transport model on the basis of mixture theory and obtained similar results. In the homogenization (or averaging) technique, equations are integrated over the Representative Elementary Volume (REV) to lead to the equations at the scale of the material. The averaged form of Equation (5) is (Samson 2007):

$$
\begin{aligned}
\frac{\partial\left(\theta_{s} C_{i}^{s}\right)}{\partial t} & +\frac{\partial\left(w C_{i}\right)}{\partial t} \\
& -\operatorname{div}\left(D_{i} w \operatorname{grad}\left(C_{i}\right)+\frac{D_{i} z_{i} F}{R T} w C_{i} \operatorname{grad}(\Psi)\right. \\
& +D_{i} w C_{i} \operatorname{grad}\left(\ln \gamma_{i}\right) \\
& \left.+\frac{D_{i} C_{i} \operatorname{grad}\left(\ln \gamma_{i}\right)}{T} w \operatorname{grad}(T)-C_{i} \mathbf{V}\right)+w R_{i}=0
\end{aligned}
$$

where: the uppercase parameters represent the average of the corresponding quantity in Equation (5). The averaging process introduces the volumetric water content $\mathrm{w}$ in the mass transport equation. Also, a term involving the solid phase fraction $\theta_{S}$ and the content of the ionic species $i$ bound to the solid matrix, $C_{i}^{s}$, is now part of the relationship. This term is used to model chemical reactions between the pore solution and the hydrated cement paste. More details on the subject will be given in the following sections. On the contrary, the term $R_{i}$ dedicated to homogeneous chemical reactions is in most cases neglected ${ }^{1}$ in the papers reviewed for this report.

The parameter $D_{i}$ in Equation (6) is the diffusion coefficient at the macroscopic level, which can be related to $D_{i}^{o}$ by the expression:

$D_{i}=\tau D_{i}^{o}$

where: $\tau$ is the tortuosity of the aqueous phase, a purely geometrical factor accounting for the complexity of the porous network.

Many authors have relied on this definition (Bear 1991, Samson 2007, Simunek 1994). Other authors (Emmanuel 2005, Zalc 2004) elected to work instead with the following definition:

$$
D_{i}=\frac{D_{i}^{o}}{\tau}
$$

\footnotetext{
${ }^{1}$ The situation is different in groundwater transport, where the homogeneous reactions are an important part of the pollutant movement process (see for instance (MacQuarrie 2005)).
} 
Several factors can affect the diffusion coefficient such as the degree of saturation of the material, the ambient temperature, and any modification to the pore structure of the material (either induced by continuing hydration of chemical reactions). As proposed by Saetta et al. (Saetta 1993), the different factors can be expressed as separate functions such as:

$$
D_{i}=\tau D_{i}^{o} \times S(w) \times G(T) \times H(t) \times M(\phi)
$$

The function $S(w)$ models the effect of the degree of saturation on the diffusion process. Few saturation models have been developed specifically for cementbased materials. Samson and Marchand (Samson 2007) used a relationship derived by Quirk and Millington for transport in groundwater:

$$
S(w)=\frac{w^{7 / 3}}{\phi_{o}^{7 / 3}}
$$

where: $\phi_{o}$ is the initial porosity of the material.

In the approach developed by Saetta et al. (Saetta 1993), the function $S$ is based on the relative humidity inside the material:

$$
S(h)=\left(1+\frac{(1-h)^{4}}{\left(1-h_{c}\right)^{4}}\right)^{-1}
$$

where: $h_{c}$ is the critical humidity threshold at which the diffusion coefficient loses half its value.

The effect of temperature has traditionally been considered using an exponential relationship that features the activation energy (Saetta 1993):

$$
G(T)=\exp \left[\frac{U}{R}\left(\frac{1}{T_{o}}-\frac{1}{T}\right)\right]
$$

where: $U$ is the activation energy of the diffusion process and $T_{O}$ is a reference temperature, usually around $25^{\circ} \mathrm{C}$.

Recently, Samson et al. (Samson 2007) derived an expression that was found to properly describe the effect of temperature on the transport of ions in different materials:

$$
G(T)=e^{0.028\left(T-T^{o}\right)}
$$

Similarly, different relationships have been developed to model the effect of hydration on diffusion. Some are listed here:

$$
H(t)= \begin{cases}a+(1-a)\left(\frac{t^{r e f}}{t}\right)^{1 / 2} & \\ \left(\frac{t^{r e f}}{t}\right)^{m} & \text { (Thomas 1999) } \\ \frac{a}{1+(a-1) e^{-\alpha\left(t-t^{\text {ref }}\right)}} & \text { (Samson 2007) }\end{cases}
$$

All these relationships have their maximum value early in the life of the material and decrease as the hydration process proceed. In most cases, $t^{r e f}$ is taken as 28 days. The relationships presented in references (Saetta 1993, Samson 2007) converge to a as $t \rightarrow \infty$, whereas the one in reference (Thomas 1999) decreases with time. The influence of continuous hydration on the transport properties of concrete can be particularly significant for mixtures prepared with supplementary cementing materials such as fly ash for which the low hydration rate means that transport properties a poor at early ages but decrease slowly over the years to yield highperformance materials.

As previously mentioned, chemical reactions can locally modify the pore structure of concrete and its transport properties. For instance, the formation of new phases can lead to a reduction of the material's porosity and contribute to reduce its transport properties. Likewise, the dissolution of existing phases can open the pore space and increase the diffusion coefficient. A modified version of the Kozeny-Carman relationship is often used in groundwater transport to calculate the correction factor $M(\phi)$ that accounts for the effect of chemical alteration on the diffusion mechanism:

$$
M(\phi)=\left(\frac{\phi}{\phi_{o}}\right)^{3}\left(\frac{1-\phi_{o}}{1-\phi}\right)^{2}
$$


Relationships specifically devoted to cement-based materials have not been a major research topic. The following relationship was proposed recently (Samson 2006):

$$
M(\phi)=\left(\frac{e^{4.3 \phi / V_{p}}}{e^{4.3 \phi_{o} / V_{p}}}\right)
$$

where: $V_{P}$ is the paste volume of the material.

In order to solve the general ionic transport Equation (6), other relationships are needed to evaluate the temperature, water content and diffusion potential fields. These points are described in the following sections.

The basic principles of ionic transport can be applied to gas transport. However, since the gas molecules do not bear electrical charges, the term associated with electrical coupling and chemical activity in Equation (6) are dropped. Also, the water content is replaced by the gas content. The interaction term in this case can account for the adsorption of gas on the pore walls of the material and on the dissolution of gas in the pore solution. These aspects are discussed in the section dedicated to carbonation.

\subsection{Moisture Transport}

Two main approaches have been used to model moisture movement in hydrated cement systems. The first one is based on a thorough description of all the phases involved in the process: liquid (aqueous solution), water vapor and dry air. Multiple mass conservation equations are invoked to obtain a description of the global moisture fields. The second approach can be derived from the first one under simplifying assumptions. It usually leads to the single equation (called the Richards' equation), which allows the water content field to be evaluated. Both approaches are reviewed in the following paragraphs. A more detailed literature review on moisture transport mechanisms in the hydraulic properties report.
Mainguy et al. (Mainguy 2001) relied on the multiphase approach to describe moisture movement under isothermal conditions. The mass balance equations for the three phases (liquid water $(l)$, dry air (a) and water vapor (v)) that can be present in partially saturated concrete are given as:

\section{Liquid}

$\frac{\partial}{\partial t}\left(\phi \rho_{l} S_{l}\right)=-\operatorname{div}\left(\phi S_{l} \rho_{l} \mathbf{v}_{\mathbf{l}}\right)-\mu_{l \rightarrow v}$

\section{Water Vapor}

$\frac{\partial}{\partial t}\left(\phi \rho_{v}\left(1-S_{l}\right)\right)=-\operatorname{div}\left(\phi\left(1-S_{l}\right) \rho_{v} \mathbf{v}_{\mathbf{v}}\right)+\mu_{l \rightarrow v}$

\section{Dry Air \\ $\frac{\partial}{\partial t}\left(\phi \rho_{a}\left(1-S_{l}\right)\right)=-\operatorname{div}\left(\phi\left(1-S_{l}\right) \rho_{a} \mathbf{v}_{\mathbf{a}}\right)$ \\ where: $\phi$ is the porosity, $p_{i}$ is the density of phase $i, S_{l}$ is the liquid water saturation, $\mathbf{v}_{i}$ is the velocity of constituent $i$, and $\mu_{l \rightarrow v}$ is the rate of liquid water vaporization.}

The liquid phase velocity is given by the Darcy state law:

$\phi v_{i}=-\frac{K}{\eta_{i}} k_{r i}\left(S_{l}\right) \operatorname{grad}\left(p_{i}\right)$

where: $K$ is the intrinsic permeability of the porous material, $\eta_{i}$ is the dynamic viscosity of phase $i, k_{r i}(S l)$ is the relative permeability and $p_{i}$ is the pressure.

The dry air and vapor phases state law is given by Fick's relationship, expressed as:

$\phi_{g} \rho_{j} v_{j}=\phi_{g} \rho_{j} \mathbf{v}_{\mathbf{g}}-\rho_{j} \frac{D}{C_{j}} f\left(S_{l}, \phi\right) \operatorname{grad}\left(C_{j}\right)$

where: $\mathbf{v}_{\mathbf{g}}$ is the gas molar-averaged velocity satisfying Darcy's law, $D$ is the diffusion coefficient of water vapor or dry air in wet air, $f$ is the resistance factor accounting for both the tortuosity effect and the reduction of space offered to the diffusion of gaseous constituents, and $C_{j}$ is the ratio $P_{j} / P_{g}$ with $j=a$ or $v$ (Degiovanni 1987). 
Similar models were developed by Selih (Selih 1996) and Gawin (Gawin 2006). The model developed by Mainguy et al. (Mainguy 2001), has been found to properly reproduce isothermal drying test results. However, this approach has not been coupled with ionic transport models dedicated to cementitious materials.

Instead, a simplified approach is often selected to describe the variation in water content within cementbased materials. One of the main differences between two approaches is the assumption that gas pressure is uniform over the material and is equal to atmospheric pressure. Under this hypothesis, it has been shown (Samson 2005, Whitaker 1998) that the water content can be evaluated on the basis of Richards' equation:

$$
\frac{\partial w}{\partial t}-\operatorname{div}\left(D_{w} \operatorname{grad}(w)\right)=0
$$

where: $w$ is the volumetric water content and $D_{w}$ is the nonlinear water diffusivity parameter.

Using this approach, the velocity of the fluid phase appearing in Equation (6) is given by:

$$
\mathbf{V}=-D_{w} \operatorname{grad}(w)
$$

It is commonly accepted that $D_{w}$ follows an exponential relationship (Hall 1994): $D_{w}=$ $A \exp (B w)$, where $B$ is positive. Instead of using the water content as a state variable, other authors have elected to model the relative humidity field $h$, under the assumption that the driving force can be expressed as: $\mathbf{V}=-D_{h} \operatorname{grad}(h)$. In that case, Equation (24) can be written as (Bazant 1971, Xi 1994, Garrabrants and Kosson 2003):

$$
\frac{\partial w}{\partial h} \frac{\partial h}{\partial t}-\operatorname{div}\left(D_{h} \operatorname{grad}(h)\right)=0
$$

Again, the moisture diffusivity parameter is a nonlinear function that can be expressed as:
$D_{h}=\lambda+\beta\left(1-2^{-10 \gamma(\mathrm{h}-1)}\right)(\mathrm{Xi} 1994)$

$D_{h}=D_{100 \%}\left[\alpha+\frac{1-\alpha}{1+\left(\frac{1-h}{1-h_{c}}\right)^{n}}\right] \begin{aligned} & \text { Garrabrants and } \\ & \text { Kosson 2003) }\end{aligned}$

where: $\lambda, \beta$ and $\gamma$ are parameters that need to be determined experimentally, $D_{100 \%}$ is the observed moisture diffusivity at $100 \%$ relative humidity, $\alpha$ represents the ratio of $D_{0 \%}$ to $D_{100 \%}, n$ is the spread in the drop of the S-shaped curve and $h_{\mathrm{c}}$ is a critical relative humidity corresponding to the center of the drop in the S-shaped curve.

\subsection{Diffusion Potential}

Many ionic transport models neglect the diffusion potential and the electrical coupling between ions. This is the case in groundwater modeling, where the ionic concentration levels are typically relatively low, at least compared to the pore solution of hydrated cement systems. Until recently, this was accepted as being applicable to ionic diffusion in concrete. However, some recent models are now considering coupling effects, assuming that the high concentration levels in the pores may cause strong concentration gradients, in which case the diffusion potential term in the mass conservation equation is no longer negligible. Some of these models will be reviewed when specific degradation mechanisms are addressed.

Two different approaches have been used to solve the diffusion potential variable. The first one relies on the null current density hypothesis $\sum_{i} z_{i} j_{i}=0$ to eliminate the potential from the transport equation. This approach was taken by Truc et al. (Truc 2000) and Masi et al. (Masi 1997). The diffusion potential can also be taken into account with the use of Poisson's equation that directly relates the potential to the concentration in solution. It is given here in its averaged form (Samson 2005):

$$
\operatorname{div}(\mathrm{w} \tau \operatorname{grad}(\Psi))+w \frac{F}{\bar{\varepsilon}}\left(\sum_{i=1}^{N} z_{i} C_{i}\right)=0
$$


where: $\varepsilon$ is the permittivity of the solution (usually assumed to be the same as water) and $N$ is the total number of ionic species in aqueous phase. The coupling of Poisson's equation with the ionic transport relationship was used in references (Johannesson 2003, Samson 2007) to model ionic transport.

\subsection{TEMPERATURE-FIELD MODELING}

Different modeling approaches have been proposed to predict temperature distributions in porous materials. The most comprehensive approach consists of resolving the energy balance equation for each phase in the porous medium. This approach was used by Schrefler (Schrefler 2004) to model the temperature and humidity fields in concrete structures exposed to fire. The relationships are coupled through balance equations at the interfaces between each phase. However, these terms prove difficult to evaluate and are often neglected.

For most long-term durability analyses, the energy conservation equation can be simplified to the wellknown heat conduction relationship:

$$
\rho C_{p} \frac{\partial T}{\partial t}-\operatorname{div}(k \operatorname{grad} T)=0
$$

where: $\rho$ is the density of the material, $C_{p}$ is the heat capacity, and $k$ is the thermal conductivity. The thermal conductivity is a function of both the water content (saturation) and temperature (Kim 2003).

As emphasized in (Samson 2007), this relationship assumes that the heat of hydration effect are negligible after a few days, heat flow through convection caused by the fluid and gas movement in the material is negligible, and the heat capacity and conductivity parameter can be expressed as an average value of all the individual contribution of the various phases that compose the material. Equation (30) has been used by a few authors (Martin-Perez 2004, Saetta 1993) to evaluate the temperature field in concrete structures. However, temperature remains a parameter that is generally neglected in many concrete durability analyses.

\subsection{CHLORIDE INGRESS AND CORROSION}

As mentioned in the previous, the ingress of chloride and its role in corrosion initiation is what prompted the development of the first models dedicated to long-term durability analyses of concrete structures. The following sections summarize the different mechanisms involved during chloride ingress and the modeling approaches described in the literature.

\subsection{Chloride Interaction with Hydrated Cement Systems}

It is generally accepted that the penetration of chloride ions in cement-based materials does not readily lead to the formation of detrimental solid phases that may cause expansion and cracking. On the contrary, the interaction between chloride in solution and the paste is often considered to have a beneficial influence on the durability of reinforced concrete since the paste binds penetrating ions, slowing the rate of ingress toward reinforcing steel.

Analysis of cement systems exposed to chloride shows that they react with the aluminate phases in the paste to form Friedel's salt: $3 \mathrm{CaO} \cdot \mathrm{Al}_{2} \mathrm{O}_{3}$. $\mathrm{CaCl}_{2} \cdot 10 \mathrm{H}_{2} \mathrm{O}$ (Barberon 2005, Brown 2000, Brown 2004, Mohammed 2004, Nielsen 2005, Suryavanshi 1998). This chloride bearing $\mathrm{AF}_{\mathrm{m}}$ phase proved stable over a wide range of chloride concentrations (BirninYauri 1998, Brown 2004): from a few $\mathrm{mmol} / \mathrm{L}$ to greater than $3 \mathrm{~mol} / \mathrm{L}$.

Other phases have also been identified in synthetic cement systems, such as the chloro-sulfate $\mathrm{AF}_{\mathrm{m}}$ phase called Kuzel's salt $\left(3 \mathrm{CaO} \cdot \mathrm{Al}_{2} \mathrm{O}_{3} \cdot{ }^{1} / 2 \mathrm{CaCl}_{2}\right.$. $1 / 2 \mathrm{CaSO}_{4} \cdot 10 \mathrm{H}_{2} \mathrm{O}$ ) (Glasser 1999). Although no data could be found for the stability of Kuzel's salt in presence of alkalis, the solubility data given in 


\section{Review of Mechanistic Understanding and Modeling and Uncertainty Analysis Methods for Predicting Cementitious Barrier Performance}

reference (Glasser 1999) suggest that it only forms at low concentrations $(<10 \mathrm{mmol} / \mathrm{L})$.

Various forms of calcium oxychlorides have been reported (Brown 2004) with the general composition of $x \mathrm{Ca}(\mathrm{OH})_{2} \cdot y \mathrm{CaCl}_{2} \cdot \mathrm{zH}_{2} \mathrm{O}$. The compositions range from the simple 1:1:1 compound to more complex $4: 1: 10$ or $3: 1: 12$ assemblages. These chloride-bearing phases have mostly been observed in synthetic hydrated materials. But most importantly, oxychlorides observed in such laboratory conditions were only formed at very high chloride concentrations. For instance, the formation of the 3:1:12 phase requires approximately $4 \mathrm{~mol} / \mathrm{L}$ of chloride while the 1:1:1 oxychloride is formed at a $9 \mathrm{~mol} / \mathrm{L}$ chloride concentration (Brown 2004). In most practical cases, such as marine structures exposed to seawater or bridges and parking structures exposed to deicing salts, these concentration levels are not reached. It is thus doubtful that they form in structures unless chloride is concentrated by evaporation.

While many studies focused on the formation of Friedel's salt from hydrated $\mathrm{C}_{3} \mathrm{~A}$ systems, the role of Fe received very little attention. It is only recently that the formation of chloride-bearing minerals from hydrated $\mathrm{C}_{4} \mathrm{AF}$ has raised interest. Suryavanshi et al. (Suryavanshi 1995) studied the binding of chloride in synthetic $\mathrm{C}_{4} \mathrm{AF}$ hydrated with different levels of $\mathrm{NaCl}$ dissolved in the mix water. Chloride-bearing phases were identified using X-ray diffraction and differential scanning calorimetry. The results showed that a ferrite analogue to Friedel's salt was formed: $\mathrm{C}_{3} \mathrm{~F} \cdot \mathrm{CaCl}_{2} \cdot 10 \mathrm{H}_{2} \mathrm{O}$. This solid phase was also observed in (Csizmadia 2001) where pastes made of hydrated $\mathrm{C}_{4} \mathrm{AF}$ and gypsum were exposed to a $10 \%$ $\mathrm{NaCl}$ solution over one-day wetting/drying cycles for durations between 28 and 56 days.

The previous paragraphs were concerned with the chemical interaction of chloride with hydrated cement paste. Chloride also physically interacts with cement-based materials due to interaction at the pore solution/paste interface. In this case, new solid phases are not formed. Early binding experiments, such as the classical method devised by Luping and Nilsson (Luping 1993), give the overall amount of chloride that reacted with the material without making a distinction between physical and chemical interactions. But experiments with hydrated $\mathrm{C}_{3} \mathrm{~S}$ pastes (see for instance (Beaudoin 1990, Henocq 2006, Maltais 2004b) or synthetic C-S-H (Hong 1999) evidenced this phenomenon, since the absence of $\mathrm{C}_{3} \mathrm{~A}$ or $\mathrm{C}_{4} \mathrm{AF}$ in these materials prevents the formation of Friedel's salt.

\subsection{Binding Mechanisms}

Many recent studies suggest that Friedel's salt formation is the result of chlorides reacting with hydrated phases such as monosulfates $\left(\mathrm{SO}_{4}-\mathrm{AF}_{\mathrm{m}}\right)$. NMR results prompted Jones et al. (Jones 2003) to propose two different mechanisms for Friedel's salt formation: dissolution/precipitation and ionic exchange. The authors argue that both mechanisms are taking place simultaneously, and that the relative importance of each one depends on the chloride concentration in the pore solution.

Many studies suggest that the main mechanism is ionic exchange. Suryanvanshi et al. (Suryavanshi 1996) were among the first to raise this hypothesis, on the basis of pore solution analyses. They concluded that the positive principal layer of hydroxy- $\mathrm{AF}_{\mathrm{m}}$ $\mathrm{C}_{4} \mathrm{AH}_{13}\left(\left[\mathrm{Ca}_{2} \mathrm{Al}\left(\mathrm{OH}^{-}\right)_{6} \cdot \mathrm{nH}_{2} \mathrm{O}\right]^{+}\right)$releases an $\mathrm{OH}^{-}$ion in the pore solution and replaces it with a free $\mathrm{Cl}^{-}$. The relationship between hydroxy- $\mathrm{AF}_{\mathrm{m}}$ and Friedel's salt was further studied by Birnin-Yauri and Glasser (Birnin-Yauri 1998). Their results showed an almost complete solid solution between the two phases. Only a small solid miscibility gap was identified. Munshi et al. (Munshi 2005) based their chloride binding model on a complete exchange mechanism between $\mathrm{C}_{4} \mathrm{AH}_{13}$ and chloride ions in the pore solution:

$\mathrm{X}-\mathrm{OH}+\mathrm{Cl}^{-} \leftrightarrow \mathrm{X}-\mathrm{Cl}+\mathrm{OH}^{-}$ 
where: X represents ion exchange sites.

Ionic exchange was also proposed between sulfate $\mathrm{AF}_{\mathrm{m}}$ (monosulfate) and Friedel's salt (Hosokawa 2006). In this case, the proposed reaction releases sulfate in the pore solution upon chloride binding:

$\mathrm{X}-\mathrm{SO}_{4}+2 \mathrm{Cl}^{-} \leftrightarrow \mathrm{X}-\mathrm{Cl}_{2}+\mathrm{SO}_{4}{ }^{2-}+2 \mathrm{H}_{2} \mathrm{O}$

where: X represents ion exchange sites.

As mentioned in the previous section, the other mechanism responsible for chloride binding is physical interaction. In a recent paper, Henocq et al. (Henocq 2006) modeled the interaction of ions in the pore solution with the surface of C-S-H using double layer theory. The analysis showed that if a significant number of ions could be found in the diffuse layer, only a small fraction could be bound by specific adsorption. The model predictions were found to correlate well with experimental data. Overall, the authors found that physical binding could account for only a small fraction of all ions bound by the cement paste.

Hosokawa devised a model that combines the monosulfate-based ionic exchange mechanism presented previously with a physical interaction model (Hosokawa 2006). As in the model developed by Henocq et al (Henocq 2006), physical interaction is attributable to surface complexation and the electrostatic interaction of ions with the surface of C-S-H is also considered. Results also confirm that chemical reactions contribute much more than physical interaction to the total amount of chlorides bound by hydrated cement systems (Figure 1).

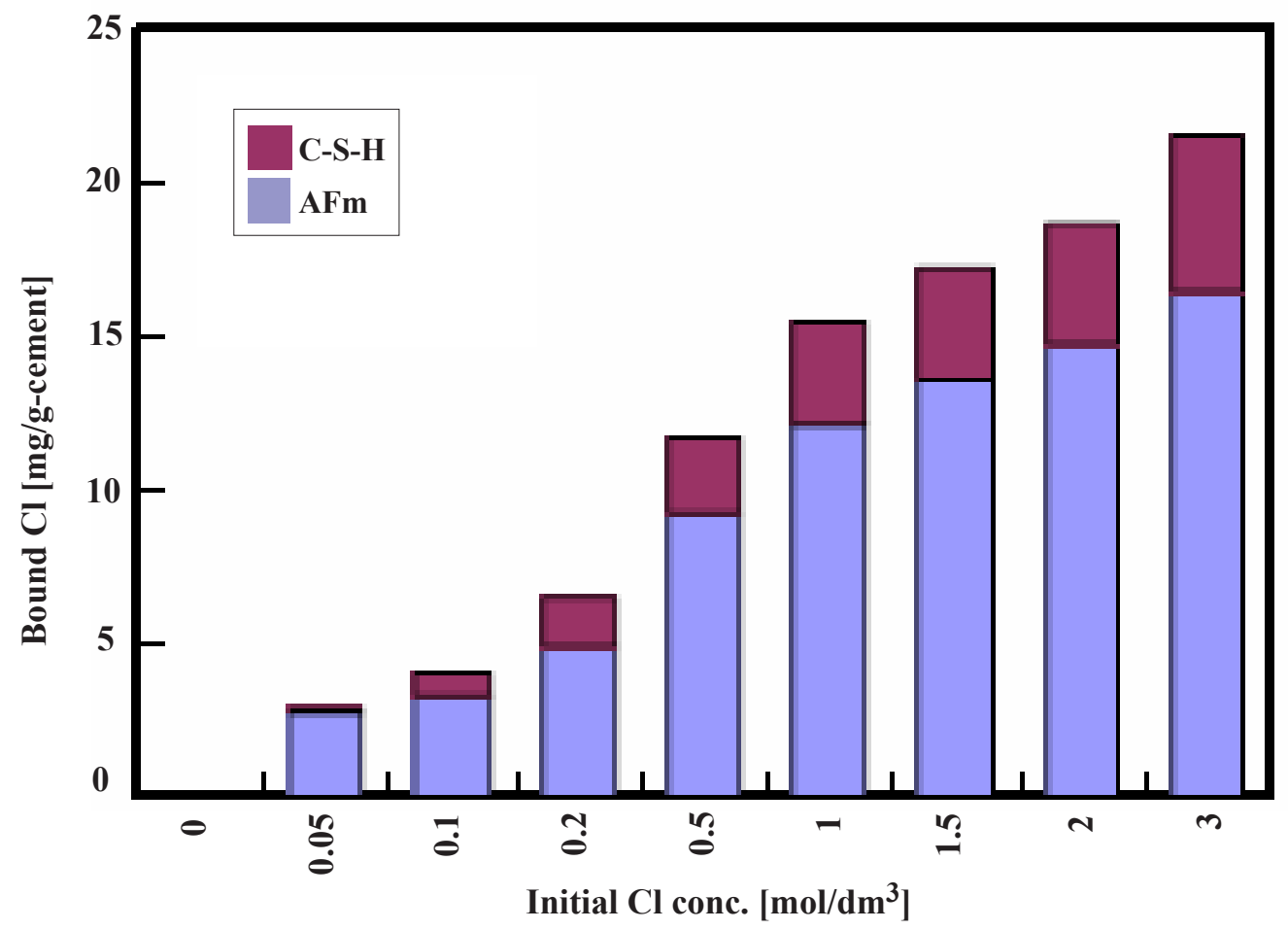

Figure 1. Contributions of the Chloride Chemical and Physical Binding In A Cement System (from (Hosokawa 2006)) 


\subsection{Modeling Chloride Ingress}

As previously emphasized, early models, developed about 30 years ago, were based on a single mass transport equation solely limited to chloride transport. Under the following assumptions: negligible electrical coupling and chemical activity effects, constant temperature, saturated material, no complexation reactions in the pore solution, and a linear relationship between bound and free chloride, Equation (6) can be simplified:

$$
\frac{\partial C}{\partial t}-D_{a p p} \frac{\partial^{2} C}{\partial x^{2}}=0
$$

where: $C$ is the chloride concentration in solution and $D_{a p p}$ is the apparent diffusion coefficient.

This coefficient integrates both the diffusion characteristics of the material and the effect of chemistry on chloride penetration. It is important to note that according to the theory leading to Equation (6), the parameter $C$ represents the chloride concentration in the pore solution. Under the assumption of constant $D_{\text {app }}$ and boundary condition at $x=0$, there exist an analytical solution to Equation (33) in a semi-infinite domain $(x \geq 0)$ :

$$
C=C_{o} \operatorname{erfc}\left(\frac{x}{\sqrt{4 D_{a p p} t}}\right)
$$

where: $\mathrm{C}_{\mathrm{o}}$ is the chloride level at $x=0$.

It should be emphasized that the validity of Equation (34) rests on a series of simplifying assumptions that are never met in reality.

Equation (34) has been used very loosely over the past decades. For instance, it has been noticed that measured chloride profiles have a shape similar to that of the profiles predicted by Equation (33). Experimental values have then been used to fit Equation (34) and determine $C_{o}$ and $D_{a p p}$ (see for instance (West 1985, Ghods 2005). In addition to the questionable validity of Equation (33), this approach is also flawed because the variable $C$ appearing in Eqs. (32) and (33) corresponds to the concentration of ions in the pore fluid, whereas Eq. (33) is often used to fit to experimental profiles of the total chloride content!

Although this method is based on very shaky scientific foundations, it is still being used to estimate the service life of partially saturated structures exposed to chloride-laden environments. In an attempt to refine the analysis, some authors have relied on the isotherm method to describe chemical reactions (Tang 1993). According to this approach, the amount of bound chlorides is linked to the chloride concentration in solution by an empirical function similar to the curve shown on Figure 1. This method does not allow a distinction between chemically and physically bound chlorides. By neglecting phenomena such as electrical coupling, chemical activity effects and Soret coupling, Equation (6) becomes:

$$
\begin{aligned}
\rho \frac{\partial C^{b}}{\partial C} \frac{\partial C}{\partial t} & +\frac{\partial(w C)}{\partial t} \\
& -\operatorname{div}(w D \operatorname{grad}(C)-\mathbf{V C})=0
\end{aligned}
$$

where: $C^{b}$ is the amount of bound chlorides and $\rho$ is the density of the material. The term $\partial C^{b} / \partial C$ corresponds to the slope of the binding isotherm curve.

This modeling approach has been used in (Hansen 1999, Martín-Pérez 2001, Nagesh 1998, Saetta 1993, Swaddiwudhipong 2000). Equation (35) can be coupled with the heat conduction Equation (30) to take into account the effect of temperature (Hansen 1999). It can also be combined with the moisture transport Equation (24) or (26) to evaluate the moisture flux $\mathbf{V}$ and the water content (Nagesh 1998, Swaddiwudhipong 2000). Some authors also proposed models where Equation (35) is coupled to both moisture and temperature diffusion equations (MartínPérez 2001, Saetta 1993). 
While the previous approaches can be considered to be improvements over Fick's second law of diffusion, they still neglect the interaction between the different ionic species present in solution. The current trend for ionic transport modeling focuses on multiionic approaches. For instance, models proposed by Masi et al. (Masi 1997) and Truc et al. (Truc 2000) consider that the transport of chlorides is coupled to that of other ionic species, using Equation (6). In these papers, the diffusion potential that couples the ionic species is solved using the null current condition: $\sum_{i} z_{i} j_{i}=0$. The chloride interaction with the paste is based on an interaction isotherm that does not consider the presence of other ionic species.

In the model presented by Samson and Marchand (Samson 2007), chloride transport is based on the mass and energy conservation Equations (6), (24), (29) and (30). The model presented by the authors is based on a Sequential Non Iterative Approach where the transport equations and chemical reactions are solved separately. The chemical interaction of chlorides with the hydrated cement paste is based on an ionic exchange mechanism between monosulfates and Friedel's salt as in Equation (32). Typical simulation results are presented in Figure 2. The predicted total chloride content accounts for chloride ions present in the pore solution and those found in Friedel's salts.

\subsection{Prediction of Corrosion Initiation}

Reinforcing steel corrosion is mainly induced by the ingress of chlorides upon exposure to marine environment or deicing salts (Hope 1985). Due to the high $\mathrm{pH}$ of the concrete pore solution, the steel surface is naturally passivated. However, this protective layer can be destroyed in the presence of chlorides. Corrosion is initiated when the chloride concentration at the vicinity of the steel surface reaches a critical value, called the chloride threshold. This chloride threshold is usually expressed as a ratio between the concentration of chlorides and that of hydroxyl ions $\left(\left[\mathrm{Cl}^{-}\right] /\left[\mathrm{OH}^{-}\right]\right)$or by the total amount of chloride in the material (wt \%) (Alonso 2000, Glass 1997, Hausmann 1967). A comprehensive review of threshold values is presented in (Alonso 2000). It shows a wide range of values depending on the characteristics of the mixture tested and on the test conditions. In most engineering analyses, the threshold value of $0.3 \%$ total chloride per cement weight (approximately $0.5 \mathrm{~g}$ of total chloride per $\mathrm{kg}$ of concrete) specified by the Federal Highway Administration (USA) (FHWA 1998) is used.

The time needed to reach the critical chloride content for corrosion corresponds to the initiation period (Tuutti 1982). It is determined by a series of parameters such as the properties of the concrete cover, its thickness and the exposure conditions. Modeling the penetration of chloride ions within cement-based materials using an advanced modeling approach (see the previous section) can thus provide a proper way of predicting corrosion initiation if a reliable threshold can be estimated. Figure 3 illustrates a corrosion analysis based on the chloride ingress simulation showed in Figure 2. It presents the time evolution of the total chloride content at various locations within the concrete element, thus allowing the determination of the initiation time.

When the corrosion process is initiated, the formation of corrosion products can lead to stresses around the rebar that can damage the concrete cover. Different models develop to analyze this mechanical problem were reviewed in the mechanical damage report.

\subsection{CARBONATION}

The penetration of gaseous carbon dioxide within partially saturated concrete usually initiates a series of reactions with both ions dissolved in the pore solutions and the hydrated cement paste. The whole process can be summarized as a series of different steps: (1) gaseous carbon dioxide first penetrates the material, (2) gaseous carbon dioxide partitions in the pore solution mainly as $\mathrm{HCO}_{3}{ }^{-}$and $\mathrm{CO}_{3}{ }^{2-}$, and (3) the $\mathrm{CO}_{3}{ }^{2-}$ species reacts with dissolved calcium 


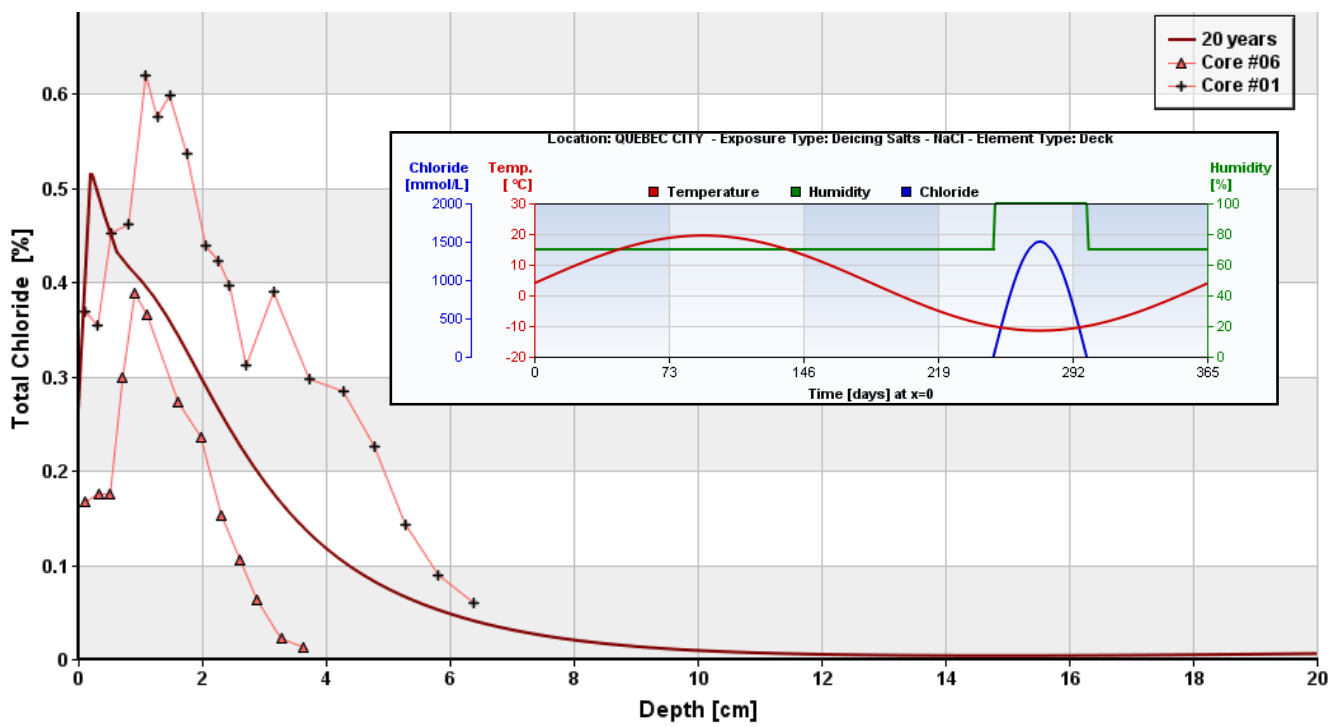

Figure 2. Predicted Total Chloride Profile in a 20-year-old Parking Structure Using the Model Presented in (Samson 2007), Compared to Measurements Performed on Two Cores. (The inserted graph illustrates the time-dependent boundary conditions over one year.)

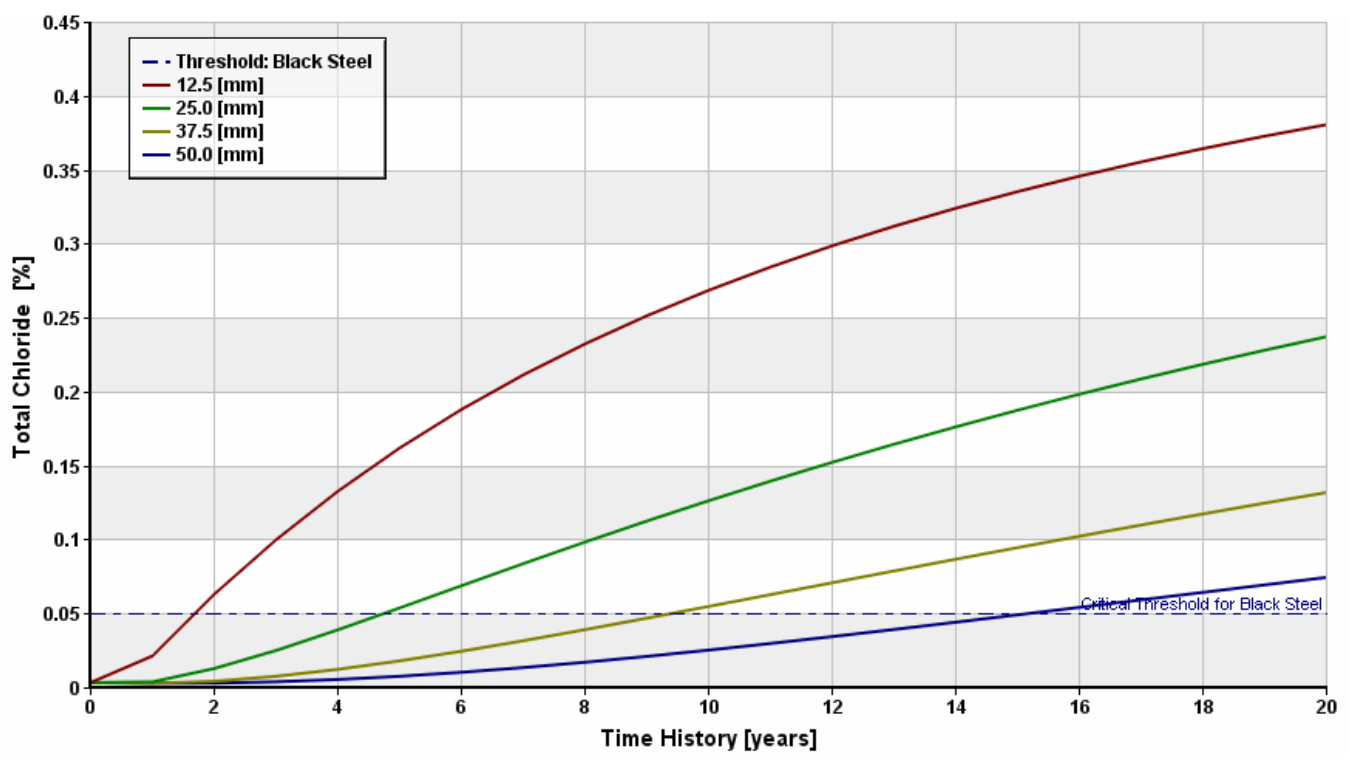

Figure 3. Chloride Content at Different Rebar Positions (The calculations correspond to the case presented in Figure 2) 
to precipitate calcite, $\mathrm{CaCO}_{3}$, as well as other $\mathrm{CO}_{2}$ based solid phases. The consumption of calcium in solution leads to the dissolution of portlandite and an associated $\mathrm{pH}$ drop when portlandite is depleted.

The carbonation process itself does not have, per se, a negative effect on the paste physical properties. In some cases, it can even result in a reduction of the material porosity and favor formation of a protective layer at the surface of concrete. These physical effects increase retention of constituents (Gervais et al, 2004). However, the results of carbonation have been shown to increase leaching of some constituents, either through changes in constituent solubility resulting from neutralization of the material or through changes in speciation of constituents (Garrabrants et al 2004, Gervais et al 2004). Furthermore, the drop in $\mathrm{pH}$ associated with the process can potentially have a detrimental effect on reinforced concrete structures by destroying the passive layer around rebars. The next sections summarize different aspects of the carbonation process.

\subsection{Description of the Carbonation Process}

Gaseous carbon dioxide partitions into the pore solution of cementitious materials as:

$$
\mathrm{CO}_{2(\mathrm{~g})} \rightarrow \mathrm{CO}_{2(\mathrm{aq})}
$$

Under equilibrium conditions, the dissolution follows Henry's law, which is expressed in low (atmospheric) pressure environments as (Plummer 1982, Xu 2004):

$\left\{\mathrm{CO}_{2(\mathrm{aq})}\right\}=\mathrm{K}_{\mathrm{h}} \mathrm{P}_{\mathrm{CO}_{2}}$

where: $\left\{\mathrm{CO}_{2(\mathrm{aq})}\right\}$ is the activity of the dissolved $\mathrm{CO}_{2(\mathrm{aq})}$, $\mathrm{Kh}$ is Henry's constant and $\mathrm{P}_{\mathrm{CO}_{2}}$ is the partial pressure of $\mathrm{CO}_{2(\mathrm{~g})}$ in the gas phase.
The temperature-dependent value of Kh can be expressed as (Plummer 1982):

$\log \mathrm{K}_{\mathrm{h}}=108.3865+0.01985076 T$

$$
-6919.53 / T-40.45154 \log T+669365.0 T^{2}
$$

where: $T$ is the temperature.

Once in solution, $\mathrm{CO}_{2(\mathrm{aq})}$ dissociates into different ionic species according to the following reactions:

$\mathrm{CO}_{2(\mathrm{aq})}+\mathrm{H}_{2} \mathrm{O} \rightarrow \mathrm{H}^{+}+\mathrm{HCO}_{3}^{-}$

$\mathrm{HCO}_{3}{ }^{-} \rightarrow \mathrm{H}^{+}+\mathrm{CO}_{3}{ }^{2-}$

These reactions respectively obey the following equilibrium relationships:

$K_{1}=\left\{\mathrm{H}^{+}\right\}\left\{\mathrm{HCO}_{3}^{-}\right\} /\left\{\mathrm{CO}_{2(\mathrm{aq})}\right\}$

$K_{2}=\left\{\mathrm{H}^{+}\right\}\left\{\mathrm{CO}_{3}{ }^{2-}\right\} /\left\{\mathrm{HCO}_{3}{ }^{-}\right\}$

where: the brackets $\{\ldots\}$ indicate chemical activity. The time-dependent values for $K_{1}$ and $K_{2}$ are given in (Plummer 1982).

Using Equations (41) and (42) with the water dissociation relationship:

$$
\left\{\mathrm{H}^{+}\right\}\left\{\mathrm{OH}^{-}\right\}=10^{-14}
$$

it is possible to estimate the fraction of each ionic species in solution as a function of the $\mathrm{pH}$. This is illustrated by Figure 4. It shows that in cementitious materials, where $\mathrm{pH}$ values are usually high, the dominant species in solution is $\mathrm{CO}_{3}{ }^{2-}$. Barret et al. (Barret 1983) suggested that the reactions in Equations (39), (40) and (43) could be summarized by:

$\mathrm{CO}_{2(\mathrm{aq})}+\mathrm{OH}^{-} \rightarrow \mathrm{CO}_{3}{ }^{2-}+\mathrm{H}_{2} \mathrm{O}$ 


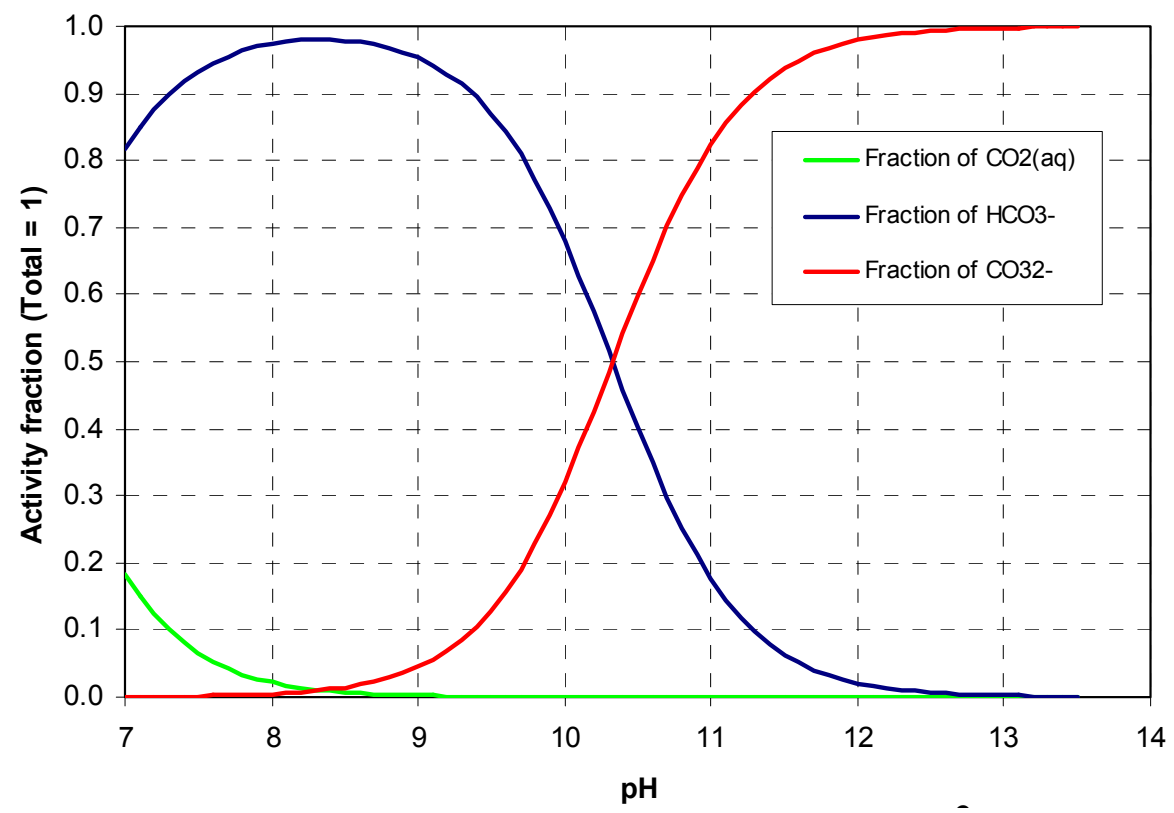

Figure 4. Relative Distribution of $\mathrm{CO}_{2(\mathrm{aq})}, \mathrm{HCO}_{3}{ }^{-}$and $\mathrm{CO}_{3}{ }^{2-}$ as a Function of $\mathrm{pH}$ at $25^{\circ} \mathrm{C}$

This reaction illustrates that carbonation lowers $\mathrm{pH}$ by consuming hydroxide ions and producing water.

Once $\mathrm{CO}_{3}{ }^{2-}$ is in the pore solution, it is free to react with other ionic species to precipitate carbonate phases. While aragonite and valerite polymorphs of $\mathrm{CaCO}_{3}$ have been reported, calcite $\left(\mathrm{CaCO}_{3}\right)$ is generally identified as the main reaction product of carbonation (Papadakis 1991, Saetta 1993b) and precipitates according to the reaction:

$\mathrm{Ca}^{2+}{ }_{(\mathrm{aq})}+\mathrm{CO}_{3}{ }^{2-}{ }_{(\mathrm{aq})} \rightarrow \mathrm{CaCO}_{3(\mathrm{~s})}$

where: the solubility constant has a value of $\log (K)=-8.48$ at $25^{\circ} \mathrm{C}$ (Plummer 1982).

The presence of carbonates in solution can also lead to the formation of other solid phases.

Barret et al. (Barret 1983) studied carbonation reactions by considering the formation of calcium hydrocarboaluminate $3 \mathrm{CaO} \cdot \mathrm{Al}_{2} \mathrm{O}_{3} \cdot \mathrm{CaCO}_{3} \cdot 11 \mathrm{H}_{2} \mathrm{O}$. The thermodynamic equilibrium of similar solid phases is described in two different papers (Damidot 1994, Damidot 1995).
According to Equations (44) and (45), the different mechanisms leading to the formation of calcite reduce the amount of calcium and hydroxide ions in the pore solution, which in turn triggers the dissolution of portlandite. The formation of calcite in replacement of portlandite reduces the porosity of the material since calcite has a higher molar volume $\left(36.9 \mathrm{~cm}^{3} / \mathrm{mol}\right.$ compared to $33.1 \mathrm{~cm}^{3} / \mathrm{mol}$ for $\mathrm{CH})$. Experimental evidence of calcium hydroxide reduction upon calcite formation was recently reported (Cultrone 2005, Rigo 2002). Neutralization of pore water alkalinity, precipitation of calcium carbonate and reduction in the calcium-silica ratio of the C-S-H are the end results of the carbonation process (Sanchez et al. 2002, Garrabrants et al. 2004, van Gerven et al. 2006, van Gerven et al. 2007). In tank leaching studies of solidified/stabilized (S/S) cementitious waste, carbonation from natural waters was shown to have the potential to alter both $\mathrm{pH}$ and concentration of species in the pore water (Sanchez et al. 2002, Garrabrants et al. 2004). 


\subsection{Carbonation Measurements}

Carbonation depth is traditionally estimated using a phenolphthalein indicator. This is an indirect measure since the pink indicator actually shows where the $\mathrm{pH}$ drops below 9 by de-colorizing. Figure 5(a) presents mortar samples made at different water to cement ratios sprayed with phenolphthalein after 14 and 28 days of exposure to a $50 \% \mathrm{RH} 5 \% \mathrm{CO}_{2}$ environment. Figure 5(b) shows that a plot of carbonation depths measured with phenolphthalein versus the square root of time yield a linear relationship. This is a common feature of the carbonation process (see for instance reference (Papadakis 1991)).

However, recent measurements showed that this technique only gives an approximate estimation of the depth of carbonation. Using a technique similar to the acid-dissolution approach for chloride profile measurements, Houst and Wittmann (Houst 2002) measured carbonate profiles in mortars exposed for 40 months to an outdoor environment. Results show that the carbonate profiles extend well beyond the depth indicated by phenolphthalein.

Similar measurements were reported by BaroghelBouny and Chaussadent (Baroghel-Bouny 2004). Calcite profiles were measured in paste samples

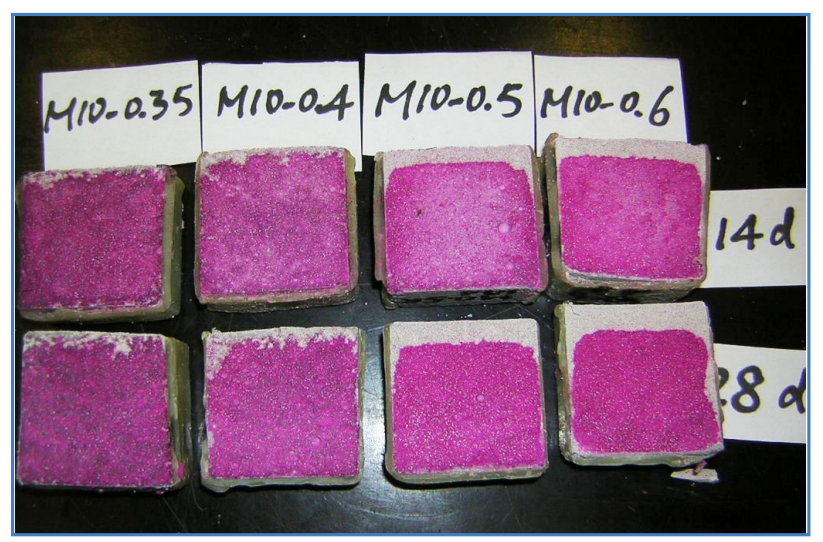

(a) maintained in an accelerated carbonation room.

Portlandite profiles were also determined.

Results show a drop of portlandite near the exposed surface, where the calcite content reaches its maximum value. According to these measurements, residual calcium hydroxide is still present near the solid/environment interface even though the material is carbonated.

\subsection{Carbonation Models}

Numerous models dedicated to the prediction of the depth of carbonation can be found in the literature (Bary 2004, Cahyadi 1993, Saetta 1993b, Saetta 2004, Song 2006]. In all cases, the ingress of $\mathrm{CO}_{2(\mathrm{~g})}$ in the material is modeled using a diffusion-based equation:

$$
\begin{aligned}
\frac{\partial(\phi-w)\left[\mathrm{CO}_{2(\mathrm{~g})}\right]}{\partial t} & -\operatorname{div}\left((\phi-w) D_{c} \operatorname{grad}\left[\mathrm{CO}_{2(\mathrm{~g})}\right]\right) \\
& -f_{c}=0
\end{aligned}
$$

where: $\phi$ is the porosity of the material, $w$ is the volumetric water content, $\left[\mathrm{CO}_{2(\mathrm{~g})}\right]$ is the gaseous carbon dioxide concentration, $D_{c}$ is the gas diffusion coefficient and $f_{c}$ is a sink term.

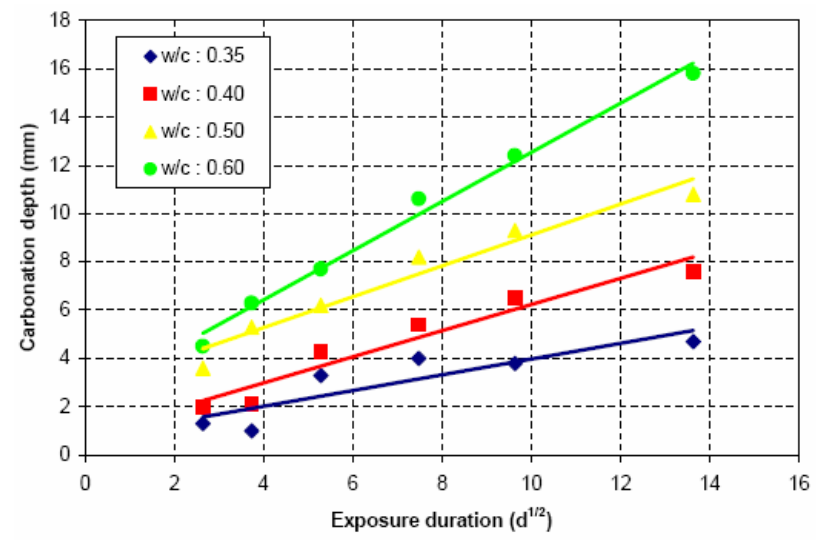

(b)

Figure 5. Carbonation Depths (a) Measured with Phenolphthalein on Mortar Samples Exposed to a 50\% RH 5\% $\mathrm{CO}_{2}$ Environment and (b) Plotted Against the Square Root of Time. (Data provided by SIMCO Technologies Inc.) 


\section{Review of Mechanistic Understanding and Modeling and Uncertainty Analysis Methods for Predicting Cementitious Barrier Performance}

In several proposed models (Bary 2004, Saetta 1993b, Saetta 2004, Song 2006), the parameter $D_{c}$ is a function of the local water content in the material. In the approaches proposed by Saetta (Saetta 1993b, Saetta 2004) and Song (2006), the effect of temperature on gas transport is also considered. In Equation (46), the sink term $f_{c}$ accounts for the transfer of carbon dioxide from the gaseous phase to the pore solution of the material (see Equation (36)).

Since gaseous carbon dioxide must enter the material to initiate the carbonation process, it is necessary to model the moisture transport process. The models cited previously are all based on Richards' Equation (24) or its relative humidity counterpart (26). In (Saetta 2004, Song 2006), a source/sink term is added to Equation (26) to model the hydration of the cement paste. This source/sink term in (Saetta 2004) also accounts for the formation of water involved in the carbonation process (see Equation (44)).

Based on Equations (46) and (24), it is possible to evaluate the amount of carbon dioxide in the pore solution $\mathrm{CO}_{2(\mathrm{aq})}$, and consequently the extent of the carbonation process. In most models, the reactions involved in the carbonation process are summarized as (Cahyadi 1993, Saetta 2004):

$$
\mathrm{Ca}(\mathrm{OH})_{2(\mathrm{~s})}+\mathrm{CO}_{2(\mathrm{aq})} \rightarrow \mathrm{CaCO}_{3(\mathrm{~s})}+\mathrm{H}_{2} \mathrm{O}
$$

Simple rate equations are then used to calculate the formation of calcite or the loss of portlandite, such as (Saetta 1993b):

$\frac{\mathrm{d}\left[\mathrm{CaCO}_{3(\mathrm{~s})}\right]}{\mathrm{dt}}=f\left(w, T,\left[\mathrm{Ca}(\mathrm{OH})_{2(\mathrm{~s})}\right],\left[\mathrm{CO}_{2(\mathrm{aq})}\right]\right)$

In (Bary 2004), the concentration of $\mathrm{Ca}^{2+}$ in solution is also taken into account, using an equation similar to (46). The source term represents the calcium that dissolves in solution when portlandite and C-S-H dissolve: it is assumed that $\mathrm{CO}_{2(\mathrm{~g})}$ dissolves in the pore solution as $\mathrm{CO}_{3}{ }^{2-}$. The amount of $\mathrm{CO}_{3}{ }^{2-}$ in solution can be calculated from the source term in Equation (46), but the transport of this ionic species in solution is neglected. Calcite is formed according to the equilibrium relationship:

$\left[\mathrm{Ca}^{2+}\right]\left[\mathrm{CO}_{3}{ }^{2-}\right]=10^{-8.35}$

where: the square brackets $[\ldots]$ indicate concentrations. Calculations do not consider the presence of alkalis, since $\mathrm{Ca}^{2+}$ varies between $22 \mathrm{mmol} / \mathrm{L}$ (when portlandite is still present) to $<1 \mathrm{mmol} / \mathrm{L}$ (upon complete decalcification of the C-S-H). In reference (Song 2006), the formation of calcite is modeled according to:

$\frac{\mathrm{d}\left[\mathrm{CaCO}_{3(\mathrm{~s})}\right]}{\mathrm{dt}}=\kappa_{r}\left[\mathrm{Ca}^{2+}\right]\left[\mathrm{CO}_{3}{ }^{2-}\right]$

where: $k_{r}$ is a reaction rate.

The concentration of $\mathrm{CO}_{3}{ }^{2-}$ follows Henry's law. The concentration of $\mathrm{Ca}^{2+}$ in the pore solution is calculated from a series of chemical equilibrium relationships. As in other references (e.g., Bary 2004), the movement of these species is not considered in the model, nor is the presence of alkalis.

This short review emphasizes the main shortcomings of most carbonation models. In most cases, the prediction of the $\mathrm{pH}$ drop is not part of the model since $\mathrm{OH}^{-}$concentration is neglected. This is particularly detrimental when the risk of corrosion needs to be evaluated. Also, one of the main characteristic of cementitious materials, which is the highly alkaline pore solution, is neglected. From the chemical point of view, the presence of high $\mathrm{Na}^{+}$and $\mathrm{K}^{+}$concentrations are likely to significantly influence the carbonation process as they affect the chemical activity of the pore solution and consequently, chemical equilibrium with the hydrated paste.

\subsection{DECALCIFICATION}

The decalcification process is usually described by the dissolution of portlandite and C-S-H in hydrated cement systems exposed to pure water, even though dissolution can be observed in other environments 
such as seawater. The leaching of ions (mainly calcium and hydroxide) from the pore solution to the external environment is primarily responsible for the dissolution of these hydrates. The decalcification phenomenon typically affects structures which have been in contact with pure or acidic waters for long time periods (e.g., dams, water pipes, radioactive waste disposal facilities). Over the past two decades, decalcification has been identified as a very relevant issue for nuclear waste storage (Berner 1992, Reardon 1992). The chemistry of attack has been described by Dow and Glasser (Dow 2003). It is shown how regimes of passivation and attack can be distinguished. The consequences of ionic leaching are an increase of the porosity and permeability, and a loss of mechanical strength. The leaching process from the stabilization and solidification of hazardous wastes standpoint has been reviewed in reference (Garrabrants 2005).

\subsection{Description of the Process}

The leaching of calcium is a coupled dissolution/ diffusion process (Hinsenveld 1992, Sanchez 1996). Leaching by deionized water induces calcium and hydroxide concentration gradients that continuously decrease from the sound zone to the exposed surface of the material. This causes the diffusion of calcium and hydroxide ions from the pore solution to the aggressive solution, and thus lowers the amount of calcium concentration in the pore solution. Loss of calcium leads to the dissolution of portlandite and secondary precipitations of AFm, ettringite and calcite (Faucon 1997-98). The precipitation of these minerals takes place in the innermost part of the degraded zone while they are dissolved in the outermost part of the altered zone (Faucon 1997-98). But overall, the process mainly leads to the dissolution of calcium hydroxide and the decalcification of C-S-H (Adenot 1992, Faucon 1997, Haga 2005].

The altered material can be seen as a layered system composed of (Adenot 1992):
- An unaltered core delineated by total dissolution of portlandite,

- Different zones separated by dissolution or precipitation fronts $\left(\mathrm{AF}_{\mathrm{m}}, \mathrm{AF}_{\mathrm{t}} \ldots\right)$,

- Progressive decalcification of C-S-H.

The degraded zone induced by water exposure is characterized by a decalcification of C-S-H inducing a silicate polymerization. The $\mathrm{Ca} / \mathrm{Si}$ ratio of the C-S-H gradually decreases between the sound and leached zones. Moreover, trivalent iron and aluminum from dissolved phases like $\mathrm{AF}_{\mathrm{m}}$ and ettringite are incorporated into the C-S-H (Faucon 1996-97-98, Hidalgo 2007).

Cement hydrates in contact with water are dissolved depending on their solubility properties. According to their respective solubilities, hydrates dissolve successively in order to restore the chemical equilibrium between pore solution and crystallized hydrates. Properties of cement hydrate dissolution were characterized by Berner (Berner 1992) and Reardon (Reardon 1992) and new data, including hydrogarnet, siliceous hydrogarnet and strätlingite $\left(\mathrm{C}_{2} \mathrm{ASH}_{8}\right)$ are presented in (Matschei 2007). The solubilities of the main hydrated phases are classified in the following order: $\mathrm{S}_{\mathrm{Ca}(\mathrm{OH}) 2}>\mathrm{S}_{\mathrm{Afm}}>\mathrm{S}_{\text {friedel's }}$ salt $>S_{\text {Aft }}$ (Taylor 1997, Rémond 2002). The kinetics is influenced by the composition of the aggressive solution $\left(\mathrm{CO}_{2}\right.$, mineralized...) (Taylor 1997, Andac 1999, Moranville 2004, Maltais 2004) or by the saturation of the specimens (Maltais 2004).

As mentioned previously, calcium hydroxide is the main phase affected by the exposure to water. Calcium hydroxide depletion increases with the exposure period (Catinaud 2000, Saito 2000, Mainguy 2000, Yokozeki 2004, Haga 2005). Figure 6 shows the influence of the water-to-cement ratio on the dissolution kinetics. The amount of leached calcium increases with water-to-cement ratio (Saito 2000, Haga 2005). A higher value corresponds to a higher porosity (higher permeability and higher 
pore volume) and a higher initial portlandite content (Moranville 2004, Haga 2005).

The increasing calcium concentration in solution is associated with a gradual penetration of the $\mathrm{Ca}(\mathrm{OH})_{2}$ dissolution front Figure 6(b). The depth of penetration increases with water-to-cement ratio, which correlates with the results given in Figure 6(a) (Haga 2005).

Decalcification changes the bulk density and the pore structure of the hydrated cement paste. Haga et al. showed that the increase of pore volume is larger for a higher initial amount of $\mathrm{Ca}(\mathrm{OH})_{2}$ (Haga 2005). This increase of pore volume is attributable to the dissolution of $\mathrm{Ca}(\mathrm{OH})_{2}$ while the porosity created by C-S-H decalcification is negligible (Figure 7) (Carde 1996, Mainguy 2000, Haga 2005).

The use of supplementary cementing materials, combined with adequate curing, decreases the permeability of concrete and changes the kinetics of calcium leaching. Figure 8 shows the influence of blast-furnace slag and silica fume on calcium leaching (Saito 2000). The beneficial influence of both supplementary cementing materials is due to the reduction in the initial portlandite content (resulting

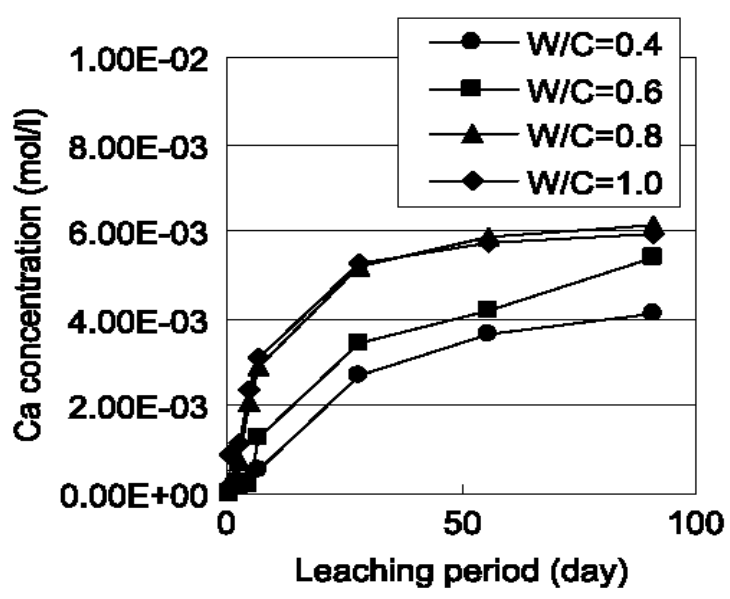

(a) from the pozzolanic reaction) and to a significant reduction of the transport properties of the mixtures (Saito 2000, Moranville 2004).

The pore volume increase resulting from calcium leaching has a detrimental influence on the mechanical properties of cement-based materials. The relationship between pore volume and strength for sound and altered mortars was clearly shown by Saito and Deguchi Figure 9(a) (Saito 2000). Uniaxial compression tests on leached materials were performed by Carde et al. (Carde 1996). The total leaching of portlandite and the progressive decalcification of C-S-H led to a linear dependence of the strength on the ratio $\mathrm{Ad} / \mathrm{At}$ between the degraded (Ad) and the sound (At) cross-sections Figure 9(b) (Carde 1996-97). The results shown on Figure 9 confirm the improvement of the leaching resistance associated with the use of supplementary cementing materials.

\subsection{Experiments and Methods}

Different test methods were developed to perform concrete decalcification experiments. Immersion tests in water (deionized or mineralized) are mainly used

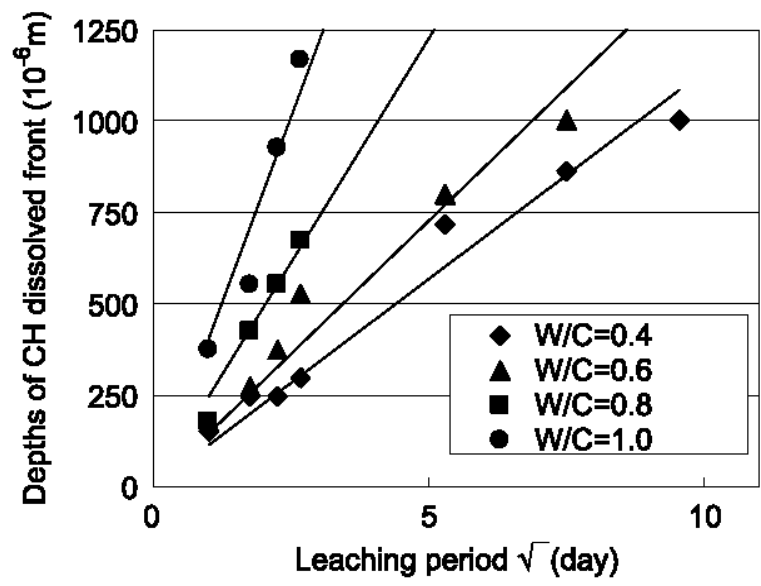

(b)

Figure 6. Change of Ca2+ Concentration as a Function of the Leaching Duration (a) and Depth of the $\mathrm{Ca}(\mathrm{OH})_{2}$ Dissolved Front as a Function of the Square Root of the Leaching Period (b) (Haga 2005) 


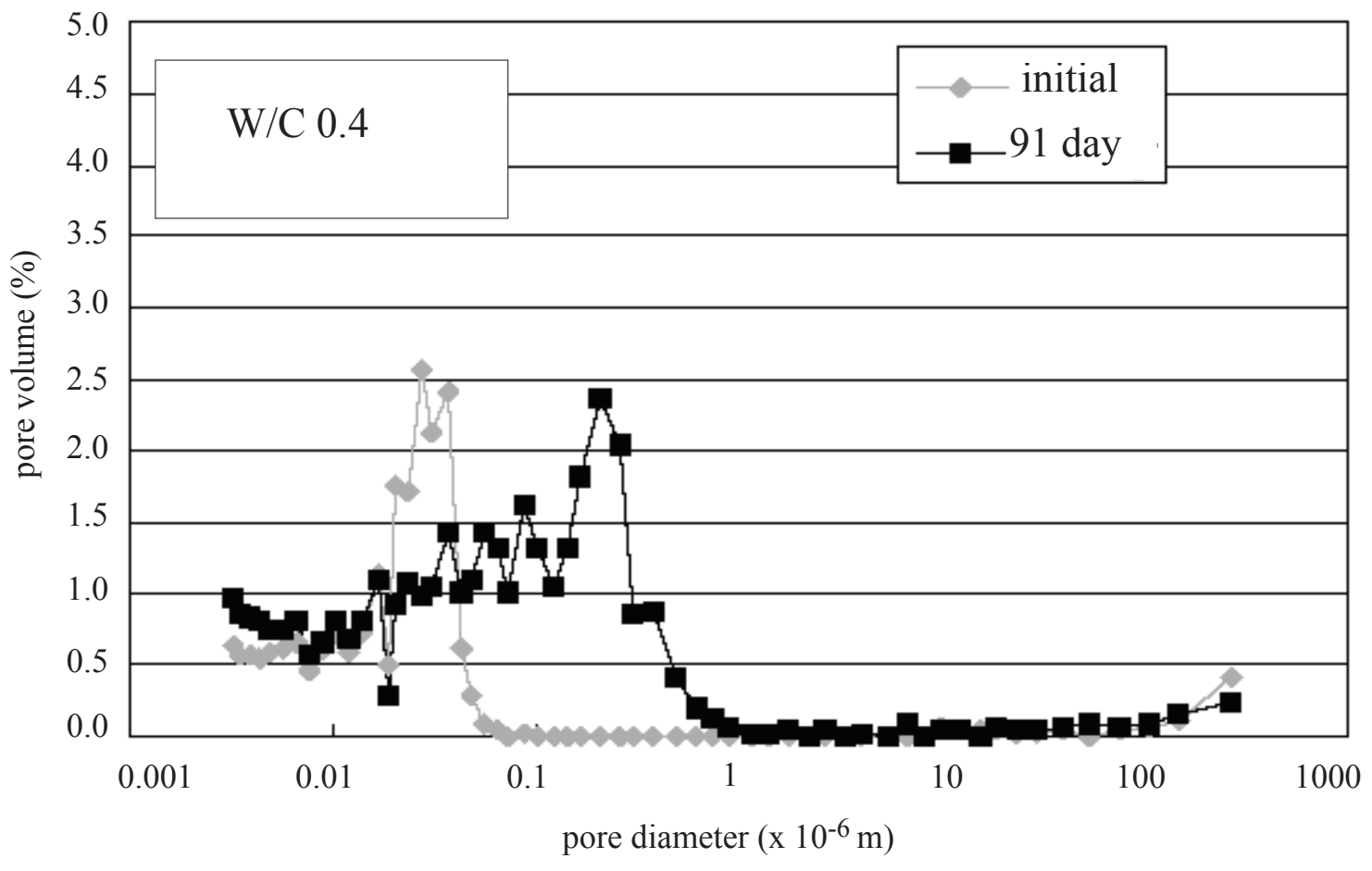

Figure 7. Pore Size Distribution on Sound and Leached Samples (Haga 2005)

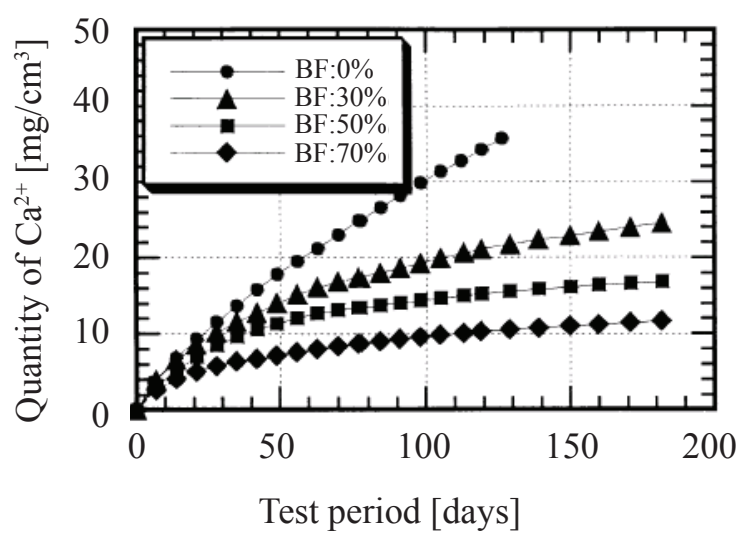

(a)

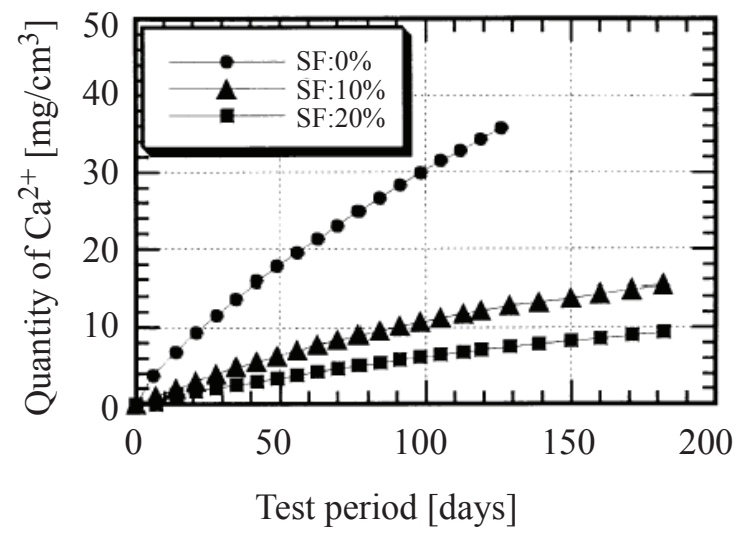

(b)

Figure 8. Cumulative Quantity of Dissolved Ca2+ for SCM Mixtures (a) Blast-furnace Slag (BF) and (b) Silica Fume (SF) (Saito 2000) 


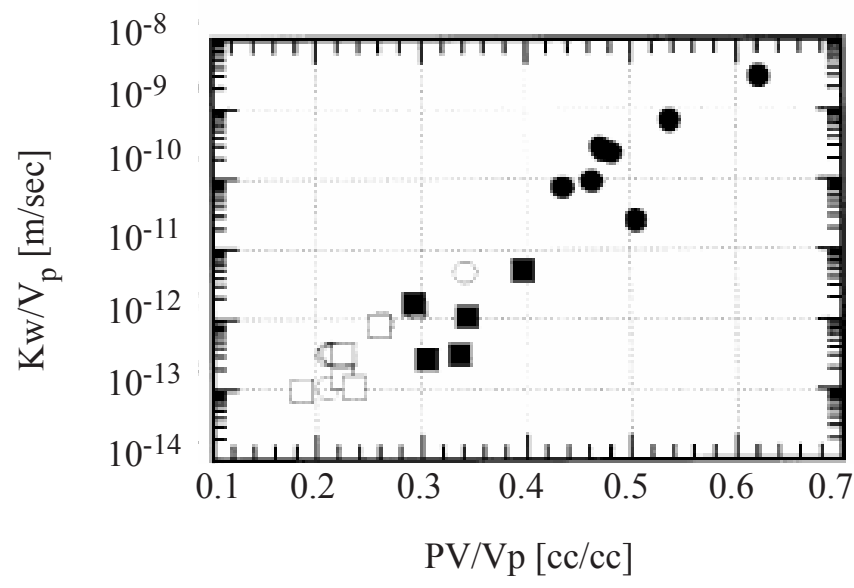

S/C, W/C (Degraded)

$\mathrm{S} / \mathrm{C}, \mathrm{W} / \mathrm{C}$ (Undegraded)

$\mathrm{BF}, \mathrm{SF}$ (Degraded)

$\mathrm{BF}, \mathrm{SF}$ (undegraded)

(a)

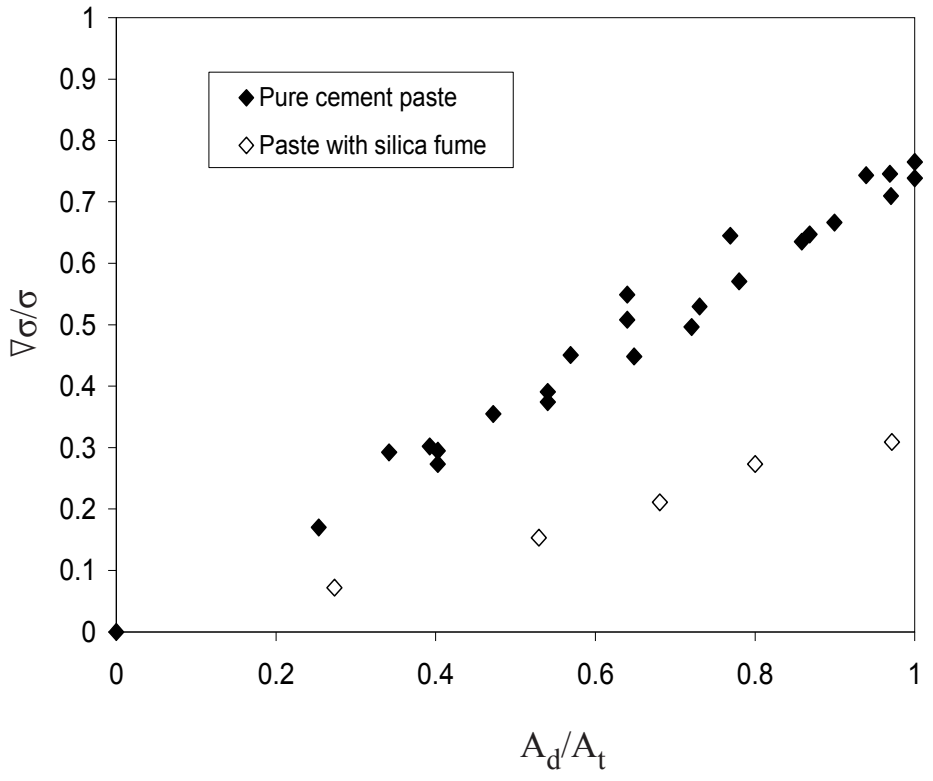

(b)

Figure 9. (a) Relationship Between Pore Volume (PV/Vp) and Compressive Strength for Sound and Degraded Materials (Saito 2000) and (b) Variation of the Strength Loss in Relation to the Degradation Ratio Ad/At ( adapted from Carde 1996) 
for characterizing the leaching process (Faucon 1996, Mainguy 2000, Maltais 2004, Haga 2005). In some studies, tests were performed on ground material to measure the amount of leached calcium (Yokozeki 2004, Hidalgo 2007).

Since calcium leaching is a relatively slow process, a wide range of accelerated tests have been developed. The majority of these procedures are carried out with strongly acidified solutions (like ammonium nitrate) instead of deionized water (Carde 1996-97, Moranville 2004). In some cases, authors have also relied on organic acids to accelerate the leaching process (Bertron 2005). Finally, in some others, calcium leaching was accelerated by applying an electrical potential gradient across a specimen (Faucon 1998, Saito 2000)

\subsection{Modeling the Decalcification Process}

Calcium leaching in cement-based materials is a coupled chemical equilibrium/diffusion phenomenon. The kinetics and the mechanisms of this ionic transport process are described by Equation (6). Most models found in the literature are based on a simplified version of this equation (Mainguy 2000, Yokozeki 2004, Kuhl 2004, Haga 2005):

$\phi(x, t) \frac{\partial C(x, t)}{\partial t}=D(x, t) \frac{\partial^{2} C(x, t)}{\partial x^{2}}-\frac{\partial C_{S}(x, t)}{\partial t}$

where: $C(x, t)$ is the $\mathrm{Ca}^{2+}$ concentration in the liquid phase, $C_{S}(x, t)$ is the content of Ca in solid phase, $\phi(x, t)$ is the porosity and $D_{(x, t)}$ is the effective diffusion coefficient of $\mathrm{Ca}^{2+}$ ions.

In Equation (51), the influence of phenomena such as chemical activity, convection and electrical coupling is neglected. The calcium content in solid $C_{S}(x, t)$ is calculated from its relationship with calcium concentration in solution (Figure 10) (Mainguy 2000, Yokozeki 2004, Haga 2005). Another approach consists in determining the calcium content in the solid by solving the chemical equilibrium between the minerals and the pore solution. The modeling of calcium leaching of hardened cement pastes in deionized water, by coupling Equation (6) and the dissolution/precipitation equilibrium of $\mathrm{Ca}(\mathrm{OH})_{2}$ and C-S-H, was presented by Maltais et al. (Maltais 2004). The dissolution of portlandite and the decalcification of C-S-H were defined by their solubility constants $\mathrm{KCa}(\mathrm{OH})_{2}$ and $\mathrm{KCSH}$ respectively (Table 1).

The different leaching models take into account the evolution of the porosity of the material as solid phases dissolve. This increase of porosity as calcium is leached is given by (Maltais 2004, Yokozeki 2004, Kuhl 2004, Haga 2005):

$\phi_{\text {leaching }}=\frac{M_{\mathrm{Ca}(\mathrm{OH})_{2}}}{d_{\mathrm{Ca}(\mathrm{OH})_{2}}}\left(\mathrm{C}_{\mathrm{S}, \mathrm{Ca}(\mathrm{OH})_{2}}{ }^{0}-\mathrm{C}_{\mathrm{S}, \mathrm{Ca}(\mathrm{OH})_{2}}\right)$

This pore volume increase modifies the diffusion coefficient of calcium. Most empirical relationships linking the diffusion coefficient to porosity are similar to Equations (17) and (18). Others relationships are presented in Table 2.

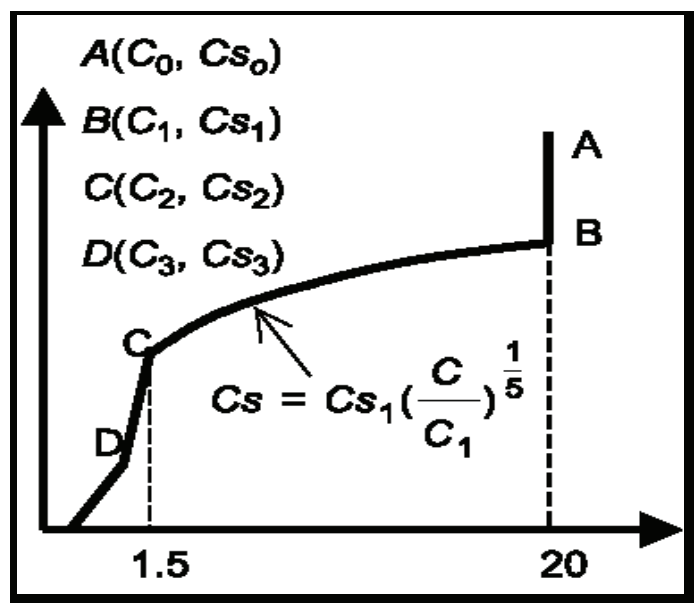

Ca concentration in aqueous phase (C) $\left(\times 10^{-3} \mathrm{~mol} / \mathrm{l}\right)$

Figure 10. Relationship Between [Ca] in the Solution and the Solid Content from Daimon et al. (Haga 2005, Daimon 1977) 
Review of Mechanistic Understanding and Modeling and Uncertainty Analysis

Methods for Predicting Cementitious Barrier Performance

Table 1. Solubility Constants of Portlandite and C-S-H (Maltais 2004, Berner 1992)

\begin{tabular}{|l|c|c|c|}
\hline \multicolumn{1}{|c|}{ Name } & Chemical Composition & Expression for Equilibrium $\left(\mathbf{K}_{\text {sp }}\right)$ & -log $\mathbf{K}_{\text {sp }}$ \\
\hline Portlandite & $\mathrm{Ca}(\mathrm{OH})_{2}$ & $\left\{\mathrm{Ca}^{2+}\right\}\left\{\mathrm{OH}^{-}\right\}^{2}$ & 5.2 \\
\hline $\begin{array}{l}\mathrm{C}-\mathrm{S}-\mathrm{H} \\
\text { (Maltais 2004) }\end{array}$ & $\begin{array}{c}0.65 \mathrm{Ca}(\mathrm{OH})_{2}+ \\
\mathrm{CaH}_{2} \mathrm{SiO}_{4}\end{array}$ & $\left\{\mathrm{Ca}^{2+}\right\}\left\{\mathrm{OH}^{-}\right\}^{2}$ & 6.2 \\
\hline $\begin{array}{l}\text { C-S-H } \\
\text { (Berner 1992, } \\
\text { Henocq 2007) }\end{array}$ & $\begin{array}{c}\mathrm{CaH}_{2} \mathrm{SiO}_{4} \text { or } \\
5 \mathrm{CaO}-5 \mathrm{SiO}_{2} \cdot 10.5 \mathrm{H}_{2} \mathrm{O}\end{array}$ & $\begin{array}{c}\left\{\mathrm{Ca}^{2+}\right\}\left\{\mathrm{H}_{2} \mathrm{SiO}_{4}^{2-}\right\} \text { or } \\
\left\{\mathrm{Ca}^{2+}\right\}^{5} \cdot\left\{\mathrm{H}_{3} \mathrm{SiO}_{4}^{-}\right\}^{6} \cdot\{\mathrm{OH}\}^{4} / \\
\left\{\mathrm{H}_{2} \mathrm{O}\right\}^{0.5}\end{array}$ & $f(\mathrm{C} / \mathrm{S})^{*}$ \\
\hline
\end{tabular}

${ }^{*}:-\log \mathrm{K}_{\mathrm{sp}}$ is a function of $\mathrm{C} / \mathrm{S}$ ratio according to the empirical function $f$.

Table 2. $D=M(\varnothing)$ Relationships Found in Literature

\begin{tabular}{|l|c|c|c|}
\hline \multicolumn{1}{|c|}{ Cement Paste or Mortar } & $\begin{array}{c}\text { Relative } \\
\text { Strength } \\
\text { at 28 d }\end{array}$ & $\begin{array}{c}\text { Maximum Temperature } \\
\text { (\% Reduction } \\
\text { vs. Control) }\end{array}$ & $\begin{array}{c}\text { Autogenous Shrinkage } \\
\left(\boldsymbol{\varepsilon}_{\min }-\boldsymbol{\varepsilon}_{\max }\right) \text { at } 7 \text { d and } \\
\text { (\% Reduction vs. Control) }\end{array}$ \\
\hline$w / c=0.35$ fine cement & $100 \%$ & $66.9^{\circ} \mathrm{C}(---)$ & -127 microstrains (---) \\
\hline$w / c=0.35$ coarse cement & $74 \%$ & $47.4{ }^{\circ} \mathrm{C}(43 \%)$ & -49 microstrains $(61 \%)$ \\
\hline$w / c=0.40$ fine cement & $93 \%$ & $59.8^{\circ} \mathrm{C}(16 \%)$ & -100 microstrains $(21 \%)$ \\
\hline $\begin{array}{l}w / \mathrm{cm}=0.357 \text { fine } \\
\text { cement } / 10 \% \text { fine limestone }\end{array}$ & $93 \%$ & $58.8{ }^{\circ} \mathrm{C}(18 \%)$ & -163 microstrains $(-28 \%)$ \\
\hline $\begin{array}{l}w / \mathrm{cm}=0.357 \text { fine } \\
\text { cement } / 10 \% \text { coarse limestone }\end{array}$ & $93 \%$ & $57.8{ }^{\circ} \mathrm{C}(20 \%)$ & -88 microstrains $(31 \%)$ \\
\hline
\end{tabular}

Marchand et al. (Marchand 2001) proposed a direct relationship between a normalized diffusion coefficient $D_{N}$ and the fraction of $\mathrm{Ca}(\mathrm{OH})_{2}(\mathrm{CH})$ leached:

$D_{N}=1+\frac{1.1 \cdot C H^{2}}{0.28+0.79 \cdot C H}$

where: $D_{N}$ is defined as:

$D_{N}=1+\frac{D(C H)-D(C H=0)}{D(C H=100)-D(C H=0)}$

Figure 11 shows simulations results compared to experimental data (Maltais 2004, Yokozeki 2004). The results in Figure 11(a) are obtained by solving Equation (6) coupled with chemical equilibrium while results in Figure 11(b) are determined by solving Equation (51) coupled with the calcium in solid phase relationship given by Figure 10 .

\subsection{SULFATE ATTACK}

Cement-based materials exposed to sulfate-bearing solutions such as some natural or polluted ground waters (external sulfate attack), or by the action of sulfates present in the original mix (internal sulfate attack) (Taylor 1997, Skalny 2002) can show signs of deterioration. Sulfate ions react with ionic species of the pore solution to precipitate gypsum $\left(\mathrm{CaSO}_{4} \cdot 2 \mathrm{H}_{2} \mathrm{O}\right)$, ettringite $\left(\left[\mathrm{Ca}_{3} \mathrm{Al}(\mathrm{OH})_{6} \cdot 12 \mathrm{H}_{2} \mathrm{O}\right]_{2}\right.$. $\left.(\mathrm{SO} 4)_{3} \cdot 2 \mathrm{H}_{2} \mathrm{O}\right)$ or thaumasite $\left(\mathrm{Ca}_{3}\left[\mathrm{Si}(\mathrm{OH})_{6} \cdot 12 \mathrm{H}_{2} \mathrm{O}\right]\right.$ $\left.\left(\mathrm{CO}_{3}\right) \cdot \mathrm{SO}_{4}\right)$ (Taylor1997) or mixtures of these phases. The precipitation of these solid phases can lead to strain within the material, inducing expansion, strength loss, spalling and severe degradation.

This section focuses on cementitious materials exposed to external sulfate sources only. The mechanical damages that can be induced upon 


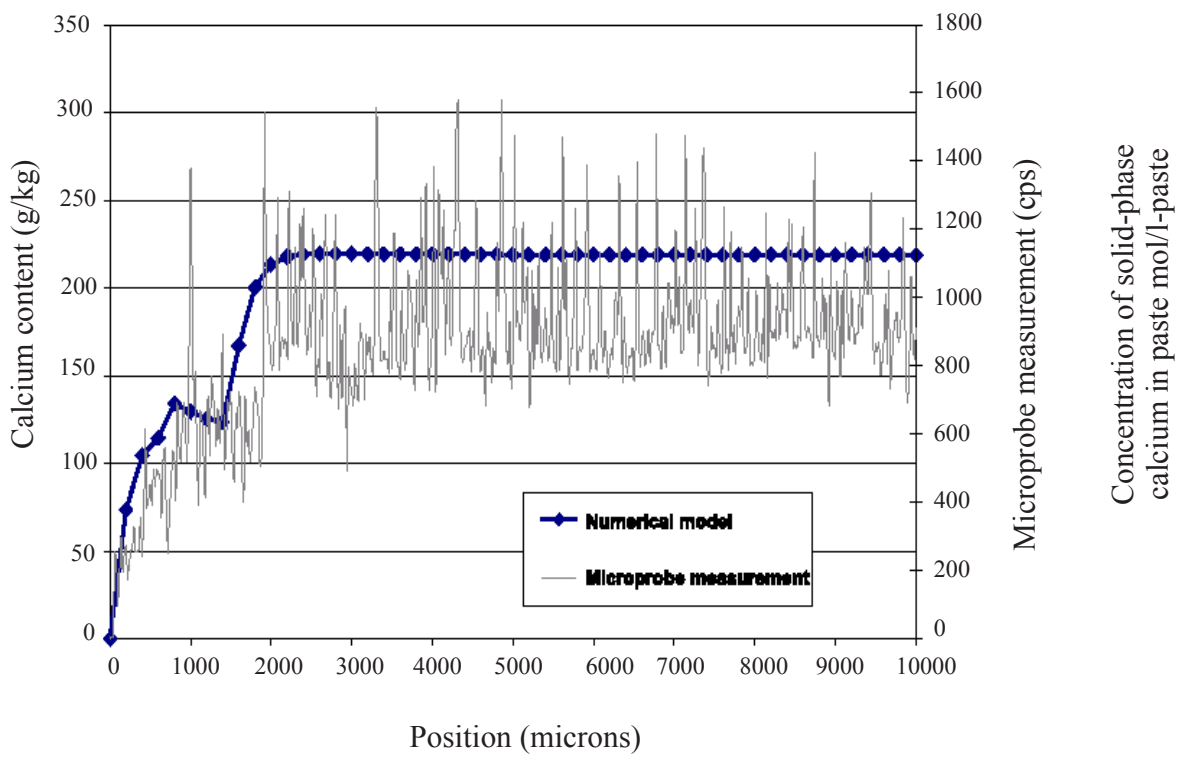

(a)

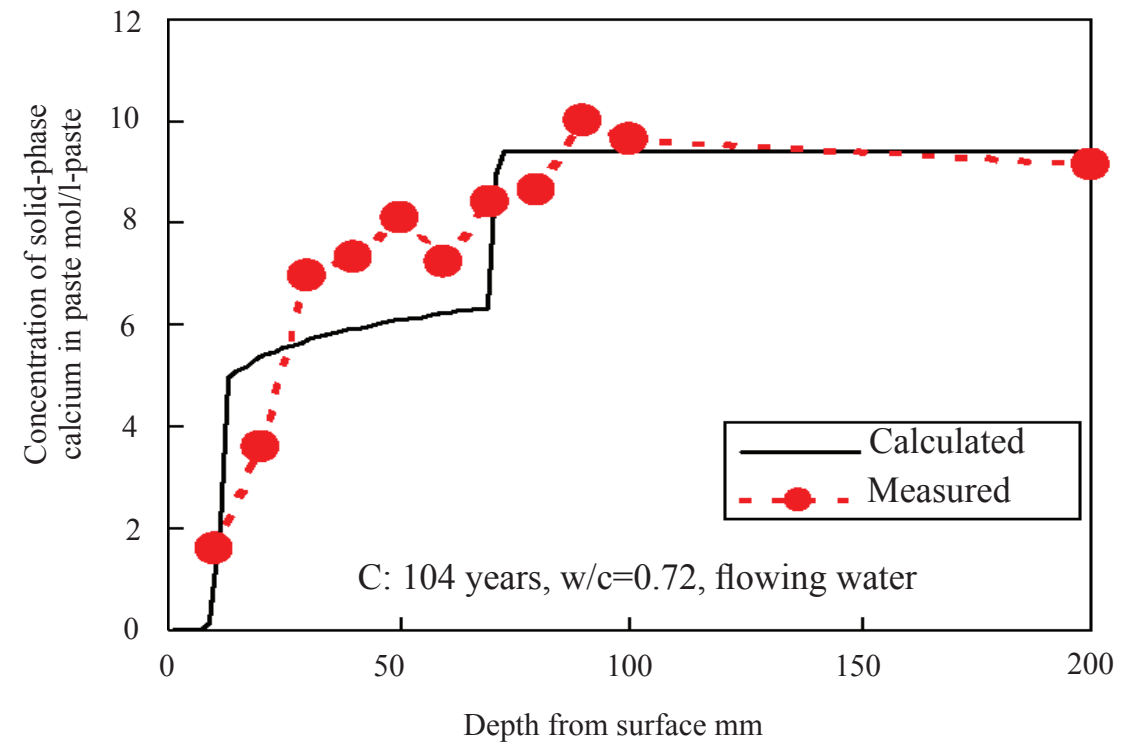

(b)

Figure 11. Simulations of Calcium Leaching (a) on Cement Paste (Maltais 2004) and (b) on Mortar (Yokozeki 2004) 
external sulfate exposure are reviewed in the mechanical damage report.

\subsection{Description of the Sulfate Attack Process}

The ingress of sulfate ions into cementitious materials from $\mathrm{Na}_{2} \mathrm{SO}_{4}$ or $\mathrm{K}_{2} \mathrm{SO}_{4}$ sulfate-bearing solutions is generally coupled with calcium leaching since groundwaters are usually near the neutral state $(\mathrm{pH} \approx 7)$. Depending on the conditions, this ingress may lead to the formation of gypsum in a layer close to the exposed surface in which calcium hydroxide is leached and/or reacted and the C-S-H phase is decalcified. Also, ettringite forms from monosulfate in a zone where calcium hydroxide is reduced (Skalny 2002, Maltais 2004, Brown 2000, Planel 2006, Dehwah 2007). In the presence of magnesium, the mechanism of sulfate ingress is different. In this case, the penetration of sulfate and magnesium ions is mainly characterized by the formation of brucite $\left(\mathrm{Mg}(\mathrm{OH})_{2}\right)$, an $\mathrm{M}-\mathrm{A}-\mathrm{H}$ phase resembling hydrotalcite, and a M-S-H gel. These replace C-S-H in addition to gypsum and ettringite formation. Particularly, the formation of M-S-H from C-S-H can result in more expansion and thus more degradation (Skalny 2002, Dehwah 2007, Higgins 2003).

The formation of gypsum and ettringite may lead to expansion and ultimately cracking. The formation of ettringite is often considered as the predominant cause of volume instability of hydrated cement systems in presence of sulfate solutions (Skalny 2002, Naik 2006). However, formation of gypsum was shown to cause expansion of C3S hydrated pastes and can probably contribute to the degradation of concrete in sulfate-laden environments (Tian 2000).

Many factors can influence the degradation of concrete by sulfate attack (Ouyang 1988). Water-tocement ratio, for instance, has been found to have a significant effect on both the penetration of sulfate ions and the resulting expansion (Figure 12) (Ouyang 1988, Naik 2006, Skalny 2002, Lee 2005). This is the reason why many standards limit the maximum water-to-cement ratio of concrete structures exposed to sulfates.

The mineralogy of cement, especially its C3A content and total aluminate content, is also known to influence the mechanisms of degradation. Expansion has been found to increase with the C3A content (Figure 13) (Ouyang 1988, Naik 2006, Skalny 2002, Odler 1999), which directly influences the amount of $\mathrm{AF}_{\mathrm{m}}$ in the hydrated cement paste that reacts with sulfate ions to form ettringite.

The presence of other ionic species also influences the product formed when concrete is exposed to sulfate. In the case of seawater for instance, the aqueous environment bears roughly $0.5 \mathrm{M} \mathrm{NaCl}$ and $0.05 \mathrm{M}$ $\mathrm{MgSO}_{4}$, with other species such as $\mathrm{K}_{+}, \mathrm{Ca}_{2+}$ and $\mathrm{HCO}_{3}{ }^{-}$present in small amount. In this environment, the formation of ettringite typically does not lead to expansion and cracking of the concrete and it is believed that the formation of this phase is nonexpanding in the presence of excessive amounts of chloride ions (Skalny 2002).

As expected, concrete mixtures prepared with supplementary cementing materials show a better resistance to sulfate attack by reducing their permeability (Ouyang 1988, Lee 2005, Higgins 2003, Bakharev 2002). Metakaolin replacement (Al-Akhras 2006), silica fume (Lee 2005), slag (Higgins 2003, Bakharev 2002) and fly ash (Ouyang 1988) reduce the expansion of specimens undergoing sulfate attack. However, the ability of supplementary cementing materials to limit damage is much less significant in the presence of $\mathrm{MgSO}_{4}$ (Figure 14) (Higgins 2003).

The presence of sulfate ions can also lead to the formation of thaumasite. Such a phenomenon occurs when the following ions are present: $\mathrm{SO}^{2}$, $\mathrm{C}-\mathrm{S}-\mathrm{H}, \mathrm{CO}_{3}{ }^{2-}$, in the presence of water (Taylor 1997, Bensted 1999, Crammond 2003). Numerous cases of field concrete degradation associated with thaumasite formation have been reported for 


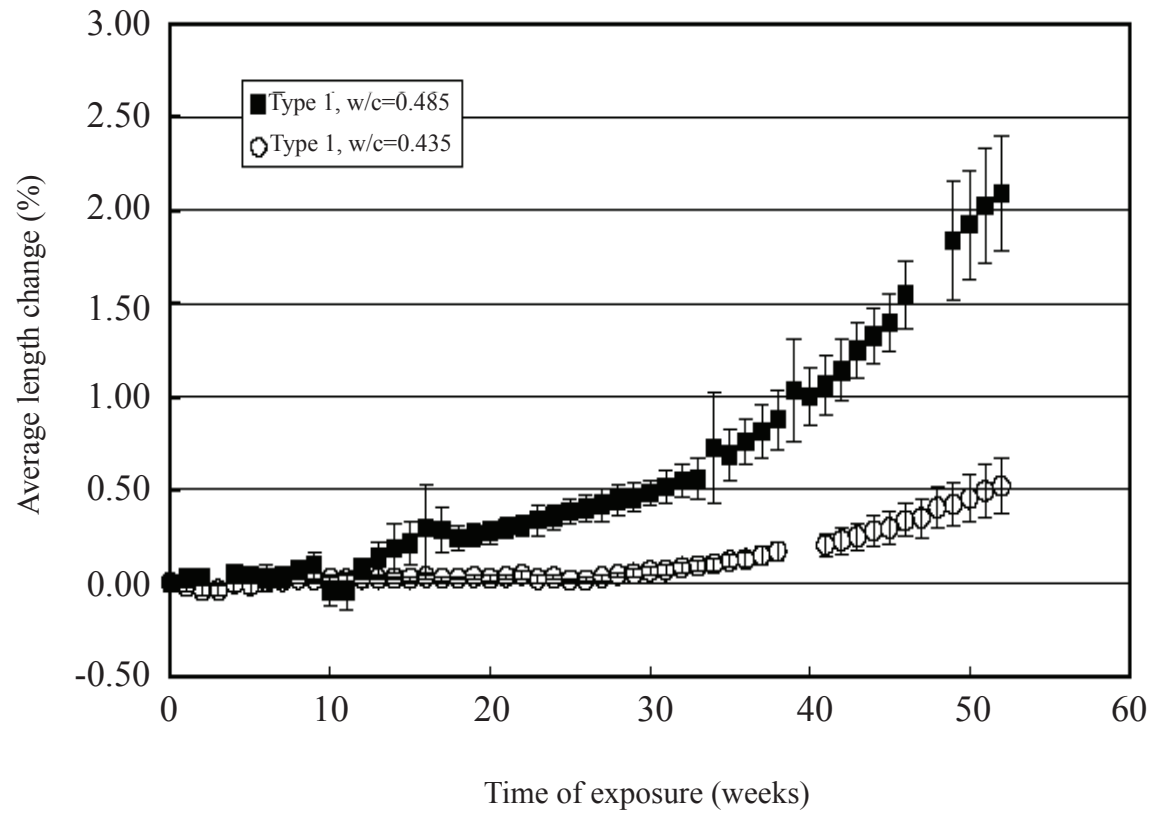

(a)

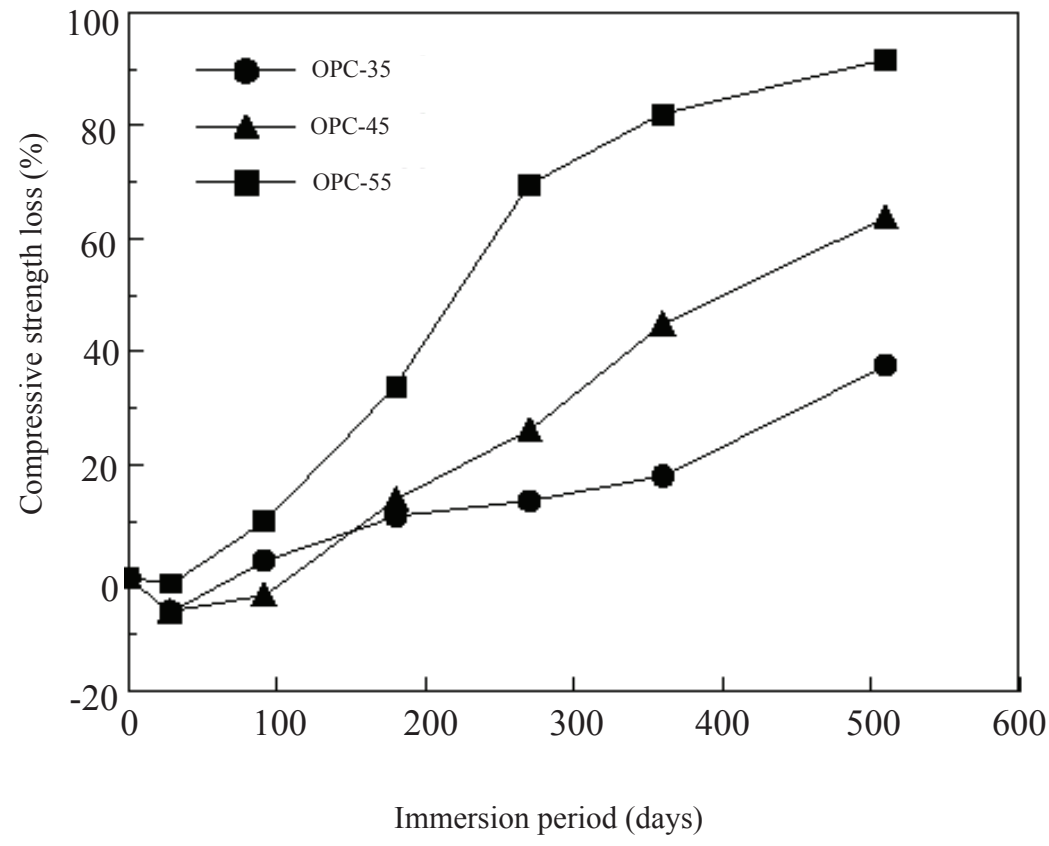

(b)

Figure 12. Expansions of Mortars Under Sodium Sulfate Attack as A Function of W/C : (a) (Naik 2006) and (b) (Lee 2005) 


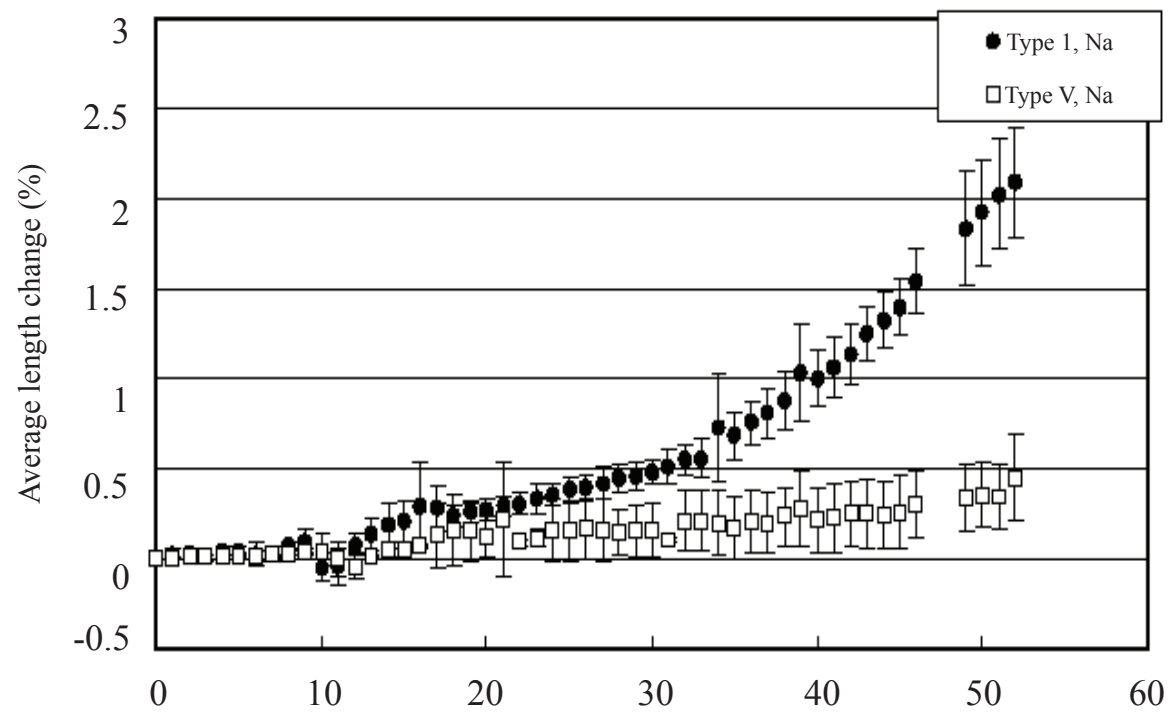

Time of exposure (weeks)

(a)

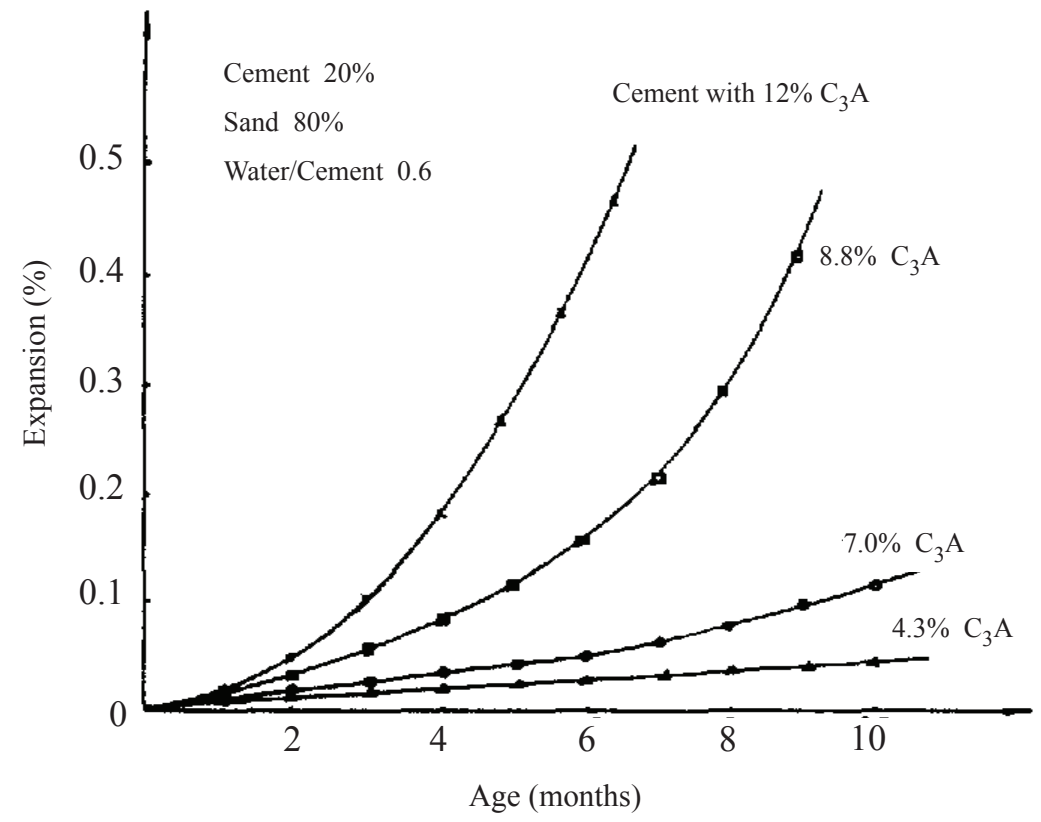

(b)

Figure 13. Expansion of Mortars Under Sodium Sulfate Attack vs. $C_{3} A$ Content (a) \% $C_{3} A$ type $I>\% C_{3} A$ type $V$ (Naik 2006) and (b) (Ouyang 1988) 


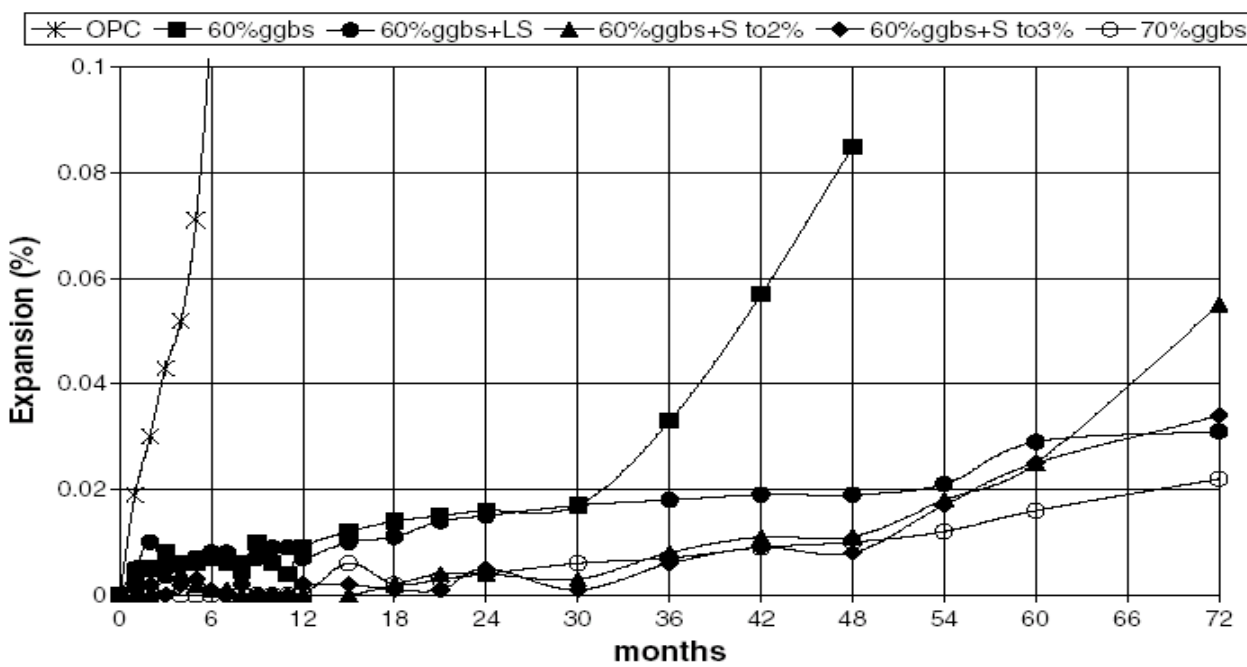

(a)

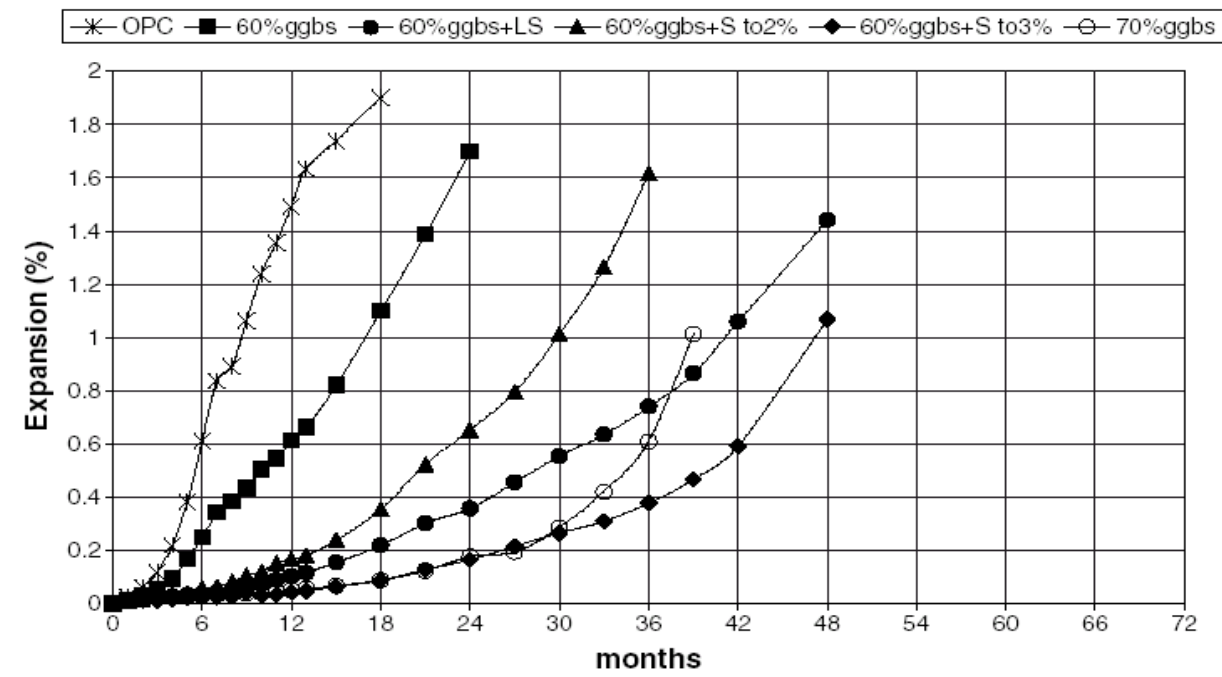

(b)

Figure 14. Expansions of Sandberg Prisms for Different Slag Contents (a) in $\mathrm{Na}_{2} \mathrm{SO}_{4}$ Solution ( $1.5 \% \mathrm{SO}_{3}$ ) and (b) in $\mathrm{MgSO}_{4}$ Solution (1.5\% $\left.\mathrm{SO}_{3}\right)$ (Higgins 2003) 


\section{Review of Mechanistic Understanding and Modeling and Uncertainty Analysis Methods for Predicting Cementitious Barrier Performance}

structures exposed to relatively low temperatures. This led some authors to believe that thaumasite was only stable at temperatures lower than $\sim 10^{\circ} \mathrm{C}$. Higher temperatures, around $20^{\circ} \mathrm{C}$, have been reported. Unexpected thaumasite was noted in warm climates such as California (Diamond 2003), Switzerland (Romer 2003) and Italy (Collepardi 1999). Clearly, thaumasite forms readily at low temperature but cold temperatures are not an essential criterion (Collet 2004).

The influence of temperature on carbon dioxide solubility is a possible reason why thaumasite forms more readily at $5^{\circ} \mathrm{C}$ (Collet 2004). Moreover, Collet et al. assume that calcium bicarbonate, instead of calcium carbonate, would be the source of carbonate ions required for thaumasite formation (Collet 2004). $\mathrm{C}-\mathrm{S}-\mathrm{H}$ provides the source of silicate ions which react to form thaumasite. Thaumasite, which apparently has no capacity to act as a binder, gradually replaces C-S-H explaining why cementitious materials can be severely degraded by its formation (Taylor 1997, Santhanam 2001, Skalny 2002, Crammond 2003).

Two mechanisms have been proposed to describe the formation of thaumasite:

- Thaumasite forms from ettringite by substitution of $\mathrm{Al}^{3+}$ by $\mathrm{Si}^{4+}$ in the presence of $\mathrm{CO}_{3}{ }^{2-}$ (Bensted 1999, Nobst 2003, Aguilera 2003, Pajares 2003),

- Thaumasite is the result of the direct interaction between C-S-H, sulfates and carbonates (Santhanam 2001, Aguilera 2003, Nobst 2003).

Thaumasite, when produced from ettringite and C-S-H mixtures, is not a pure mineral and contains other cations and anions in solid solution (Bensted 1999). More likely, thaumasite forms according to a through- solution process. As proposed by Crammond (Crammond 2003), ettringite can serve as a template for the initial nucleation of thaumasite. That would explain why some alumina is apparently beneficial
(Skalny 2002, Crammond 2003), even though thaumasite does not contain alumina. Overall, the ability of cements to allow thaumasite formation is said to be proportional to their $\mathrm{C}_{3} \mathrm{~A}$ or $\mathrm{Al}_{2} \mathrm{O}_{3}$ contents (Nobst 2003).

Thaumasite formation is delayed in the case of concrete mixtures prepared with supplementary cementing materials. Influence varies with the type and the source of materials. Metakaolin and slag have been found to improve the behavior of limestone cements, showing that supplementary cementing materials offer an effective resistance if they react sufficiently quickly (Tsivilis 2003). However, mixtures prepared with fly ash, which is known to hydrate very slowly, remain vulnerable to thaumasite sulfate attack (Figure 15) (Mulenga 2003). The use of fly ash simply seems to retard sulfate attack (Tsivilis 2003). It is also important to note that since thaumasite does not contain alumina, "sulfate resistant" portland cement does not give an improvement of resistance against the formation of this deleterious phase (Skalny 2002, Mulenga 2003).

\subsection{Experiments and Methods}

Various experimental approaches have been used to investigate the performance of hydrated cement systems exposed to sulfate solutions. Santhanam et al., have reviewed and criticized the different test methods proposed in the literature. Their analysis clearly emphasized the significant influence of experimental conditions (such as the control of $\mathrm{pH}$, sulfate concentration and type of salts $\left(\mathrm{Na}_{2} \mathrm{SO}_{4}\right.$, $\left.\mathrm{MgSO}_{4}, \mathrm{H}_{2} \mathrm{SO}_{4} ..\right)$ ) on the performance of test specimens (Santhanam 2001). Immersion tests in large volume or with renewed solutions are commonly used to maintain constant test conditions (Tian 2000, Maltais 2004, Bellmann 2006).

Microstructural alterations resulting from the exposure to sulfate-bearing solutions can be subsequently analyzed using different techniques such as microprobe analyses (Maltais 2004), SEM, 


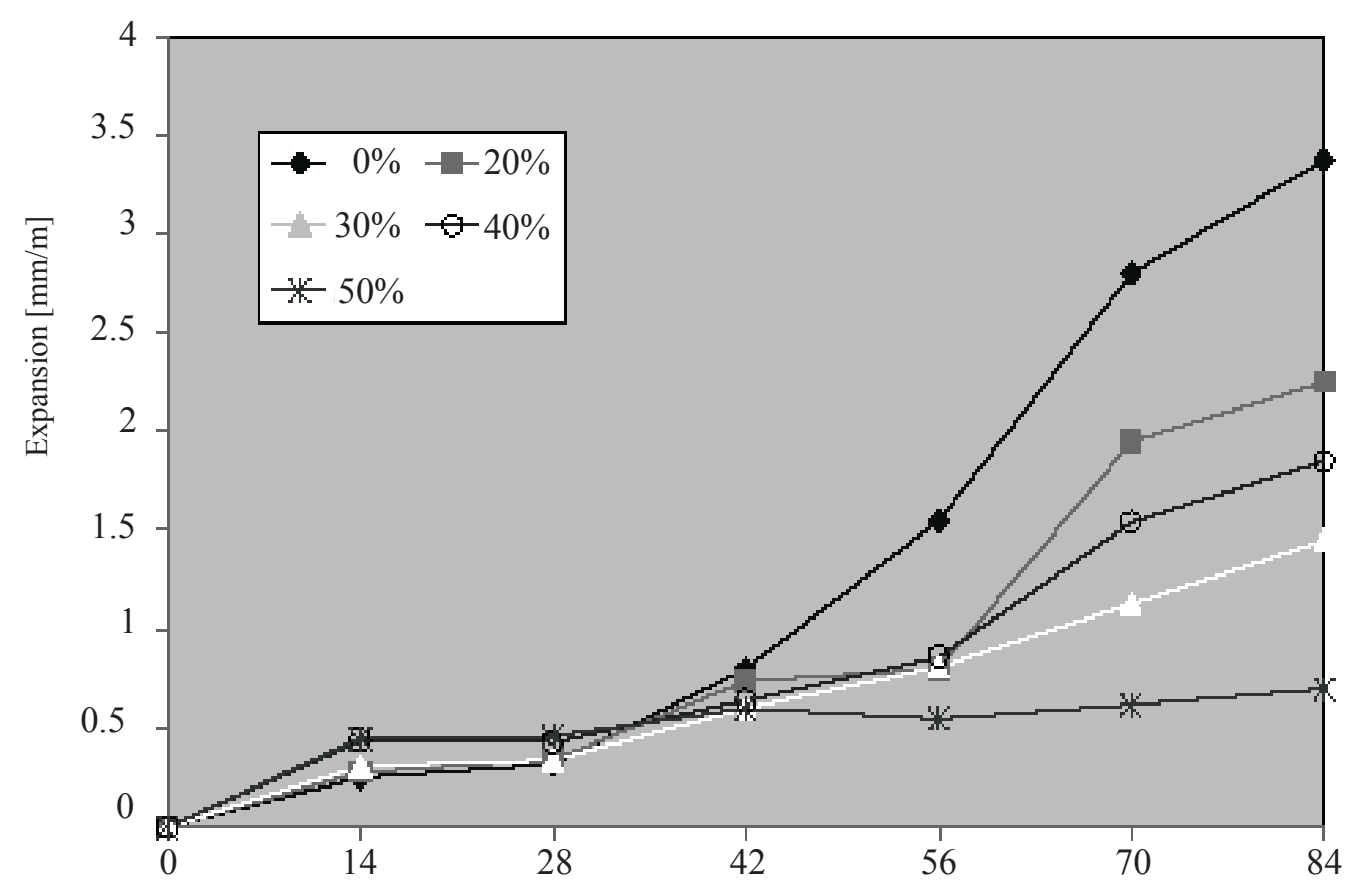

(a) Sulfate attack at $20^{\circ} \mathrm{C} \quad$ Immersion period [d]

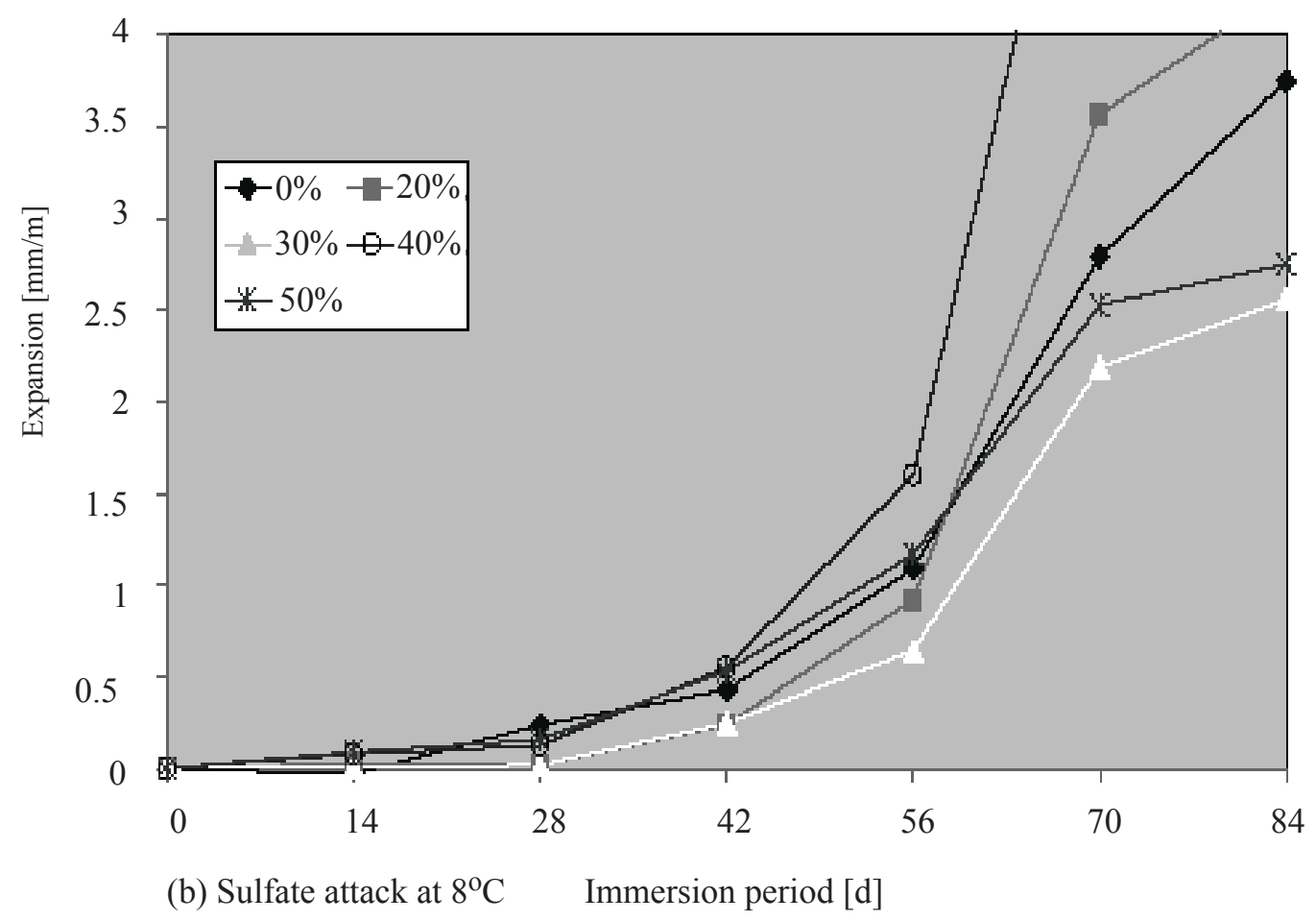

Figure 15. Expansions of PLC Mortar Prisms Containing Fly Ash After Immersion in 4.4 \% Sodium Sulfate Solution (Mulenga 2003) 


\section{Review of Mechanistic Understanding and Modeling and Uncertainty Analysis Methods for Predicting Cementitious Barrier Performance}

EDS and/or XRD for identifying crystallized phases (Brown 2000, Tian 2000). Naik et al., have also relied on X-ray microtomography and spatially resolved energy dispersive X-ray diffraction (EDXRD) to monitor the behavior of specimens exposed to sulfate solutions (Naik 2006). In some cases, damage induced by the exposure to sulfates can also be determined by compressive strength and/or volume change measurements (Ouyang 1988, Bakharev 2002, Higgins 2003, Naik 2006).

Most test methods used to investigate the resistance of cement systems to thaumasite formation are typically performed at around $5^{\circ} \mathrm{C}$ (Collet 2004, Zhou 2006, Heinz 2003, Hill 2003, Tsivilis 2003). However, some authors have also elected to investigate the influence of thaumasite by running tests at $20^{\circ} \mathrm{C}$ (Heinz 2003, Brown 2002, Tsivilis 2003, Mulenga 2003). Otherwise, thaumasite formation is mainly studied on field samples from different exposure conditions (Crammond 2003, Sibbick 2003, Diamond 2003, Romer 2003, Hobbs 2000-03, Loudon 2003). As thaumasite precipitation can occur in various environments, its solubility and its stability was respectively investigated from solid solutions by Macphee et al. (Macphee 2004) and in cement pastes by Juel et al. (Juel 2003).

\subsection{External Sulfate Attack Modeling}

Empirical, mechanistic and numerical models have been proposed in the literature for predicting the behavior of cement systems exposed to sulfate-laden environments. Empirical models estimate the sulfate resistance factor (Santhanam 2001), the expansion under sulfate attack (Kurtis 2000, Skalny 2002) or the location of the visible degradation zone (Skalny 2002). Mechanistic models typically attempt to take into account the mechanisms leading to the deterioration of the material. These models usually predict the rate of sulfate attack and the fractional or volumetric expansion (Skalny 2002). Ionic transport models simulate the chemical reactions occurring during sulfate attack and, in some cases, also estimate the damage caused by expansion (Skalny 2002, Marchand 2002, Maltais 2004).

The ability of empirical and mechanistic models to predict the behavior of concrete structures under sulfate attack remains somewhat limited. Ionic transport modeling offer a more detailed description of the process through dissolution-precipitation reactions coupled to transport of ions in cementitious matrix (see Equation 6). It is important to note that these models are inherently more complex than, for example, those used to describe chloride penetration. Since chloride ions interact only weakly with cement solids, diffusion profiles can in some cases be estimated from Fick's laws. Sulfate ions, however, react more strongly with cement substances and models need therefore to include mineralogical transformations. The complexity of the problem is increased by the fact that concrete structures in contact with a sulfate-bearing solution can not only be subjected to sulfate attack but are also usually affected by decalcification. The chemical reactions occurring under sulfate attack can be summarized by the solubility constants of ettringite, monosulfate and gypsum given in Table 3 when analyses are performed around $20^{\circ} \mathrm{C}$ (Maltais 2004).

Simulations of the chemical degradation by sodium sulfate solutions were presented by Maltais et al., Figure 16(b) (Maltais 2004) using a multiionic model that decouples transport and chemical reactions. As mentioned previously, the penetration of sulfate ions in cement-based materials can lead to the formation of a layer of gypsum at the vicinity of the exposed surface as shown in Figure 16(a). As can be seen in Figure 16(b), the multi-ionic model used in (ref. needed) could not only reproduce the sulfate distribution across the sample but was also capable of reliably predicting the distribution of all other solid phases within the material. These results provide a good example of the potential of numerical modeling to investigate the behavior of cement-based materials exposed to chemically-aggressive environments. 


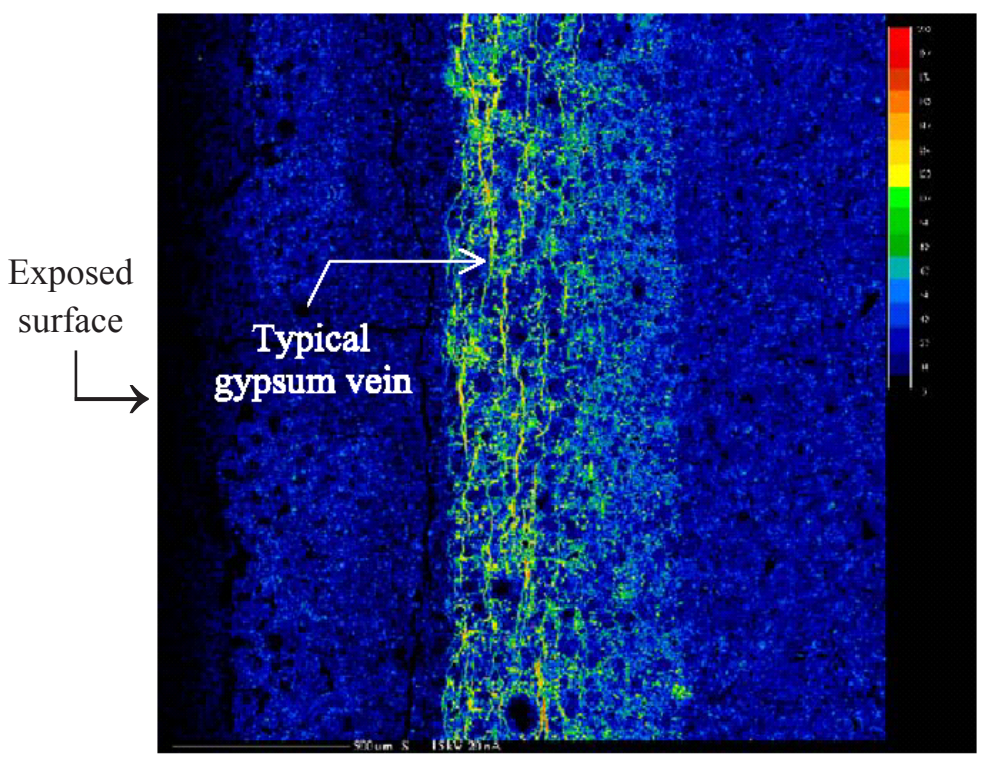

(a)

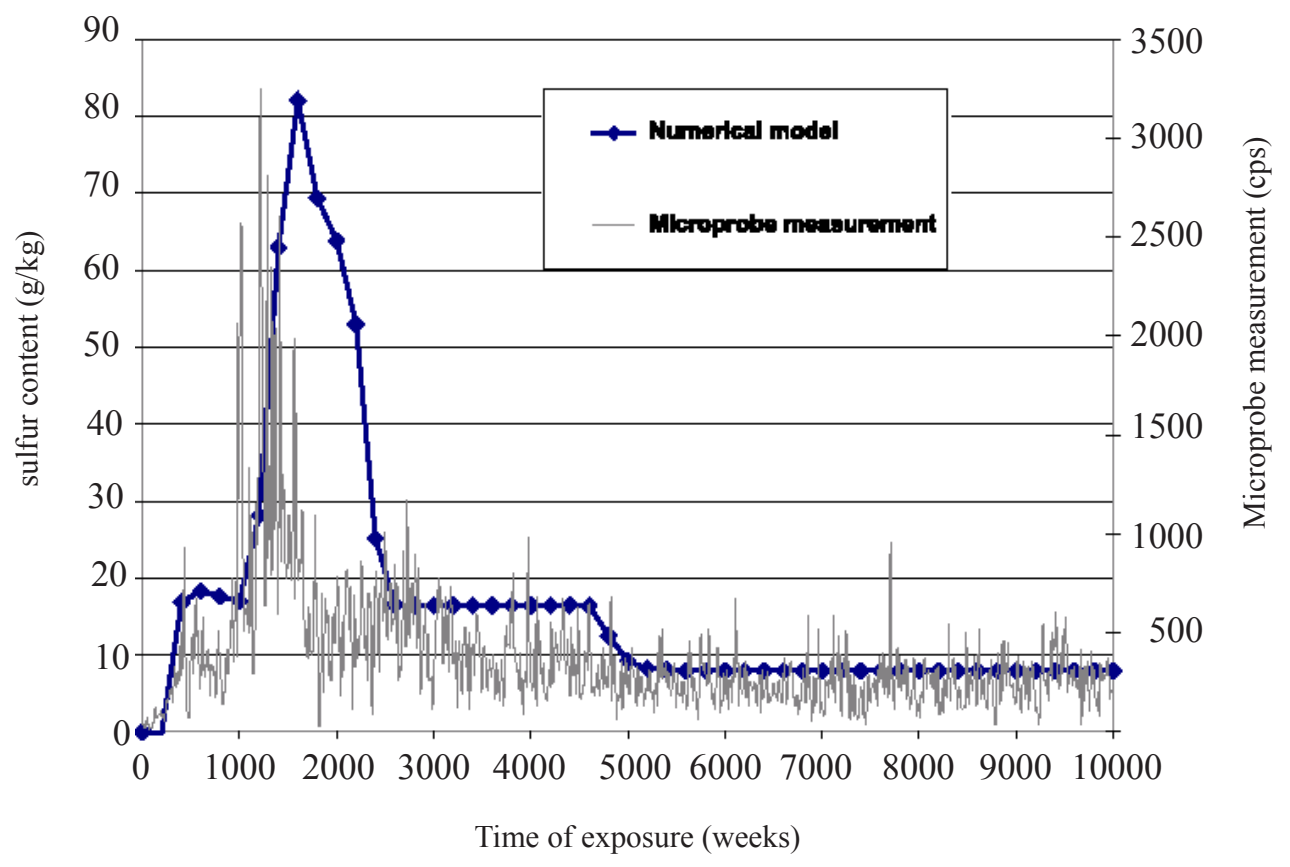

(b)

Figure 16. Sulfur Content Mapping (a) and Sulfur Profiles (b) for 0.6 W/C Ratio CSA Type 10 Cement Pastes Exposed for 3 Months to a $50 \mathrm{mmol} / \mathrm{I} \mathrm{Na}_{2} \mathrm{SO}_{4}$ Solution (Maltais 2004) 
Table 3. Solubility Constants of Solid Phases Involved During Sulfate Ingress in Hydrated Cement Systems (Maltais 2004))

\begin{tabular}{|c|c|c|c|}
\hline Name & Chemical Formula & Expression for Equilibrium $\left(\mathrm{K}_{\mathrm{sp}}\right)$ & $-\log K_{s p}$ \\
\hline Ettringite & $\begin{array}{c}3 \mathrm{CaO} \cdot \mathrm{Al}_{2} \mathrm{O}_{3} \\
3 \mathrm{CaSO}_{4} \cdot 32 \mathrm{H}_{2} \mathrm{O}\end{array}$ & $\begin{array}{l}\left\{\mathrm{Ca}^{2+}\right\}^{6}\left\{\mathrm{OH}^{-}\right\}^{4}\left\{\mathrm{~S} \mathrm{O}_{4}^{2}\right\}^{3} \\
\left.\left\{\mathrm{Al}(\mathrm{OH})_{4}\right\}^{-}\right\}^{2}\end{array}$ & 44.0 \\
\hline Monosulfate & $\begin{array}{l}3 \mathrm{CaO} \cdot \mathrm{Al}_{2} \mathrm{O}_{3} \\
\mathrm{CaSO}_{4} \cdot 12 \mathrm{H}_{2} \mathrm{O}\end{array}$ & $\begin{array}{l}\left\{\mathrm{Ca}^{2+}\right\}^{4}\left\{\mathrm{O} \mathrm{H}^{-}\right\}^{4}\left\{\mathrm{~S} \mathrm{O}_{4}^{2-}\right\} \\
\left\{\mathrm{Al}(\mathrm{OH})_{4}^{-}\right\}^{2}\end{array}$ & 29.4 \\
\hline Gypsum & $\mathrm{CaSO}_{4} \cdot 2 \mathrm{H}_{2} \mathrm{O}$ & $\left\{\mathrm{Ca}^{2+}\right\}\left\{\mathrm{SO}_{4}^{2-}\right\}$ & 4.6 \\
\hline
\end{tabular}

\subsection{CONCLUSIONS}

The present review emphasized that there are still many different approaches used to model ionic transport and chemical degradation in reactive cementitious materials. The situation is totally different from hydrogeology, where there is a general consensus around multiionic models considering multiple complexation and dissolution/ precipitation reactions. While simplified approaches are still being used, it is acknowledged that they provide a simplified view of the complex mechanisms involved.

For cementitious materials, the mechanistic models have not received the same kind of support. Consequently, they are only marginally recognized as potent tools to make long-term service-life predictions of concrete structures. Despite this lack of support, multiionic models for cementitious materials have been developed to predict the chemical degradation for sulfate or decalcification exposure cases.

The situation is worse for chloride ingress modeling. In that case, simplified models are not only widely used but based on an incorrect interpretation of the mass conservation equation. The most glaring problem with the simplified approach occurs with the use of the analytical solution to Fick's second law for chloride ingress analyses. In most cases, the total chloride content in the material is directly substituted to the chloride concentration in the pore solution, which violates the mass conservation equation at the origin of the model. Most importantly, this leads to the determination of a parameter called the apparent diffusion coefficient which does not only characterize the material but also incorporate the local exposure conditions. However, a limited number of studies based on more reliable multiionic models have been published recently.

Finally, carbonation models reviewed in this report were all based on simplified approaches. The complex interactions between gaseous carbon dioxide, the pore solution and the mineral phases such as calcite and portlandite have not so far been implemented in a mechanistic approach. A mechanistic modeling framework considering gas and ionic transport in cementitious material coupled with complex chemical reaction capabilities would be a step forward compared to existing models. 


\subsection{REFERENCES}

Adenot, F \& Buil, M 1992, 'Modelling of the corrosion of the cement paste by deionized water', Cement and Concrete Research, vol. 22, pp. 489-496.

Aguilera, J Martinez-Ramirez, S Pajarez-Colomo, I \& Blanco-Varela, MT 2003, 'Formation of thaumasite in carbonated mortars', Cement \& Concrete Composites, vol. 25, pp. 991-996.

Al-Akhras, NM 2006, 'Durability of metakaolin concrete to sulfate attack', Cement and Concrete Research, vol. 36, pp. 1727-1734.

Alonso, C Andrade, C Castellote, C \& Castro, P 2000, 'Chloride threshold values to depassivate reinforcing bars embedded in a standardized OPC mortar', Cement and Concrete Research, vol. 30, pp.10471055 .

Andac, M \& Glasser, FP 1999, 'Long-term leaching mechanisms of portland cement-stabilized municipal solid waste fly ash in carbonated water', Cement and Concrete Research, vol. 29, pp. 179-186.

Bakharev, T Sanjayan, JG \& Cheng, YB 2002, 'Sulfate attack on alkali-activated slag concrete', Cement and Concrete Research, vol. 32, pp. 211-216.

Barberon, F Baroghel-Bouny, V Zanni, H Bresson, B d'Espinose de la Caillerie, JB Malosse, L \& Zehong, G 2005, 'Interactions between chloride and cementpaste materials', Magnetic resonance Imaging, vol. 23, pp. 267-272.

Baroghel-Bouny, V \& Chaussadent, T 2004, 'Transferts dans les bétons et durabilité des ouvrages', Bull. Lab. Ponts et Chaussées, vol. 248, pp. 93-111 (in French).
Barret, P Bertrandie, D \& Beau, D 1983, 'Calcium hydrocarboaluminate, carbonate alumina gel and hydrated aluminates solubility diagram calculated in equilibrium with $\mathrm{CO}_{2 \mathrm{~g}}$ and with $\mathrm{Na}^{+}{ }_{\text {aq }}$ ions', Cement and Concrete Research, vol. 13, pp. 789-800.

Bary, B \& Sellier, A 2004, 'Coupled moisture - carbon dioxide - calcium transfer model for carbonation of concrete', Cement and Concrete Research, vol. 34, pp. 1859-1872.

Bazant, ZP Najjar, LJ 1971, 'Drying of concrete as a nonlinear diffusion problem', Cement and Concrete Research, vol. 1, pp. 461-473.

Bear, J Bachmat, Y 1991, Introduction to Modeling of Transport Phenomena in Porous Media, Kluwer Academic Publishers, The Netherlands.

Beaudoin, JJ Ramachandran, VS \& Feldman, RF 1990, 'Interaction of chloride and C S H', Cement and Concrete Research, vol. 20, pp. 875-833.

Bellmann, F Möser, B \& Stark, J 2006, 'Influence of sulfate solution concentration on the formation of gypsum in sulfate resistance test specimen', Cement and Concrete Research, vol. 36, pp. 358-363.

Bensted, J 1999, 'Thaumasite - background and nature in deterioration of cements, mortars and concretes', Cement \& Concrete Composites, vol. 21, pp. 117-121.

Berner, UR 1992, 'Evolution of pore water chemistry during degradation of cement in a radioactive waste repository environment', Waste Management, vol. 12, pp. 201-219.

Bertron, A Duchesne, J \& Escadeillas, G 2005, 'Accelerated tests of hardened cement pastes alteration by organic acids: analysis of the $\mathrm{pH}$ effect', Cement and Concrete Research, vol. 35, pp. 155-166. 
Birnin-Yauri, UA \& Glasser, FP 1998, 'Friedel's salt, $\mathrm{Ca}_{2} \mathrm{Al}(\mathrm{OH})_{6}(\mathrm{Cl}, \mathrm{OH}) \cdot \mathrm{H}_{2} \mathrm{O}$ : its solid solutions and their role in chloride binding', Cement and Concrete Research, vol. 28, pp. 1713-1723.

Bockris, JO’M \& Reddy, AKN 1970, Modern Electrochemistry - An Introduction to an Interdisciplinary Area, Plenum Press, USA.

Brown, PW \& Badger, S 2000, 'The distribution of bound sulfates and chlorides in concrete subjected to mixed $\mathrm{NaCl}, \mathrm{MgSO}_{4}, \mathrm{Na}_{2} \mathrm{SO}_{4}$ attack', Cement and Concrete Research, vol. 30, pp. 1535-1542.

Brown, P \& Hooton, RD 2002, 'Ettringite and thaumasite formation in laboratory concretes prepared using sulfate-resisting cements', Cement \& Concrete Composite, vol. 24, pp. 361-370.

Brown, $\mathrm{P} \&$ Bothe, J 2004, 'The system $\mathrm{CaO}-\mathrm{Al}_{2} \mathrm{O}_{3}$ $\mathrm{CaCl}_{2}-\mathrm{H}_{2} \mathrm{O}$ at $23 \pm 2^{\circ} \mathrm{C}$ and the mechanisms of chloride binding in concrete', Cement and Concrete Research, vol. 34, pp. 1549-1553.

Cahyadi, JH \& Uomoto, T 1993, 'Infuence of environmental relative humidity on carbonation on concrete (mathematical modeling)', Durability of Building Materials and Components, vol. 6, edited by S. Nagataki, pp. 1142-1151.

Carde, C François, R \& Torrenti, J-M 1996, 'Leaching of both calcium hydroxide and C-S-H from cement paste: modeling the mechanical behavior', Cement and Concrete Research, vol. 26, no. 8, pp. 1257-1268.

Carde, C \& François, R 1997, 'Aging damage model of concrete behavior during the leaching process', Materials and Structures, vol. 30, pp. 465-472.

Catinaud, S Beaudoin, JJ \& Marchand, J 2000, 'Influence of limestone addition on calcium leaching mechanisms in cement-based materials', Cement and Concrete Research, vol. 30, pp. 1961-1968.
Collepardi, M 1999, 'Thaumasite formation and deterioration in historic buildings', Cement \& Concrete Composites, vol. 21, pp. 147-154.

Collet, G Crammond, NJ Swamy, RN \& Sharp, JH 2004, 'The role of carbon dioxide in the formation of thaumasite', Cement and Concrete Research, vol. 34, pp. 1599-1612.

Crammond, N.J. 2003, 'The thaumasite form of sulfate attack in th UK', Cement and Concrete Composites, vol. 25, pp.809-818.

Csizmadia, J Balázs, G \& Tamás, FD 2001, 'Chloride ion binding capacity of aluminoferrites', Cement and Concrete Research, vol. 31, pp. 577-588.

Cultrone, G Sebastian, E \& Huertas, MO 2005, 'Forced and natural carbonation of lime-based mortars with and without additives: Mineralogical and textural changes', Cement and Concrete Research, vol. 35 , pp. $2278-2289$.

Daimon, M Abo-El-Enein, SA Hosaka, G Goto, S \& Kondo, R 1977, 'Pore structure of calcium silicate hydrate in hydrated tricalcium silicate', J. Am. Ceram. Soc., vol. 60, no. 3-4, pp. 110-114.

Damidot, D Stronach, S Kindness, A Atkins, M \& Glasser FP 1994, 'Thermodynamic investigation of the $\mathrm{CaO}-\mathrm{Al}_{2} \mathrm{O}_{3}-\mathrm{CaCO}_{3}-\mathrm{H}_{2} \mathrm{O}$ closed system at $25^{\circ} \mathrm{C}$ and the influence of $\mathrm{Na}_{2} \mathrm{O}^{\prime}$, Cement and Concrete Research, vol. 24, pp. 563-572.

Damidot, D \& Glasser, FP 1995, 'Thermodynamic investigation of the $\mathrm{CaO}-\mathrm{Al}_{2} \mathrm{O}_{3}-\mathrm{CaSO}_{4}-\mathrm{CaCO}_{3}-\mathrm{H}_{2} \mathrm{O}$ closed system at $25^{\circ} \mathrm{C}$ and the influence of $\mathrm{Na}_{2} \mathrm{O}$, Advance in Cement Research, vol. 7, pp. 129-134.

Degiovanni, A \& Moyne, C 1987, 'Conductivité thermique de matériaux poreux humides: évaluation théorique et possibilité de mesure', Int. J. Heat Mass Transfer, vol. 30, pp. 2225-2245 (in French). 
Dehwah, HAF 2007, 'Effect of sulfate concentration and associated cation type on concrete deterioration and morphological changes in cement hydrates', Construction and Building Materials, vol. 21, pp. 29-39.

Diamond, S 2003, 'Thaumasite in Orange County, Southern California: an inquiry into the effect of low temperature', Cement \& Concrete Composites, vol. 25, pp. 1161-1164.

Dow, C \& Glasser, FP 2003, 'Calcium carbonate efflorescence on Portland cement and building materials', Cement and Concrete Research, vol. 33, pp. 147-154.

Emmanuel, S \& Berkowitz, B 2005, 'Mixing-induced precipitation and porosity evolution in porous media', Adv. Water Res., vol. 28, pp. 337-344.

Faucon, P Le Bescop, P Adenot, F Bonville, P Jacquinot, JF Pineau, P \& Felix, B 1996, 'Leaching of cement: study of the surface layer', Cement and Concrete Research, vol. 26, no. 11, pp. 1707-1715.

Faucon, P Adenot, F Jorda, M \& Cabrillac, R 1997, 'Behaviour of crystallised phases of Portland cement upon water attack', Materials and Structures, vol. 30, pp. 480-485.

Faucon, P Adenot, F Jacquinot, JF Petit, JC Cabrillac, R \& Jorda, M 1998, 'Long-term behaviour of cement pastes used for nuclear waste disposal: review of physico-chemical mechanisms of water degradation', Cement and Concrete Research, vol. 28, no. 6, pp. 847-857.

Federal Highway Administration (FHWA) 1998, 'Corrosion Evaluation of Epoxy-coated, Metallic-clad and Solid Metallic Reinforcing Bars in Concrete', Report No. FHWA RD 98153.
Garrabrants, AC and Kosson, DS 2003, 'Modeling moisture transport from a Portland cement-based material during storage in reactive and inert atmospheres', Drying Technology, vol. 21, pp. 775-805.

Garrabrants, A.C. Sanchez, F. et al. 2004, 'Changes in constituent equilibrium leaching and pore water characteristics of a Portland cement mortar as a result of carbonation' Waste Management, vol. 24, pp. 19-36.

Garrabrants, AC and Kosson, DS 2005, 'Leaching processes and evaluation tests for inorganic constituents release from cement-based matrices' in Solidification/ Stabilization of Hazardous, Radioactive and Mixed Wastes, R Spence and C Shi (eds.), CRC Press (Boca Raton, USA), pp. 229-280.

Gawin, D Pesavento, F Schrefler B.A. 2006, 'Hygrothermo-chemo-mechanical modelling of concrete at early age and beyond. Part I: Hydration and hygrothermal phenomena', Int. J. Numer. Meth. Engng., vol. 67 , pp. 299-331.

Gervais, C. Garrabrants, A.C. Sanchez, F. and Kosson, D.S. 2004, 'The effects of carbonation and drying during intermittent leaching on the release of inorganic constituents from a cement-based matrix', Cement and Concrete Research, vol. 34, pp. 119-131.

Ghods, P Chini, M Alizadeh, R \& Hoseini, M 2005, 'The effect of different exposure conditions on the chloride diffusion into concrete in the Persian Gulf region', in Proceedings of the ConMAT Conference, N. Banthia et al. eds., Vancouver, Canada.

Glass, GK \& Buenfeld, NR 1997, 'Presentation of the chloride threshold level for corrosion of steel in concrete', Corrosion Science, vol. 39, pp. 1001-1013.

Glasser, FP Kindness, A \& Stronach, SA 1999, 'Stability and solubility relationships in $\mathrm{AF}_{\mathrm{m}}$ phases Part I. Chloride, sulfate and hydroxide', Cement and Concrete Research, vol. 29, pp. 861-866. 
Haga, K Sutou, S Hironaga, M Tanaka, S \& Nagasaki, S 2005, 'Effects of porosity on leaching of $\mathrm{Ca}$ from hardened ordinary portland cement paste', Cement and Concrete Research, vol. 35, pp. 1764-1775.

Hall, C 1994, 'Barrier performance on concrete: a review of fluid transport theory', Materials and Structures, vol. 27, pp. 291-306.

Hansen, EJ \& Saouma, VE 1999, 'Numerical simulation of reinforced concrete deterioration - part 1: chloride diffusion', ACI Materials Journal, vol. 96, pp. 173-180.

Harvie, CE Moller, N \& Weare, JH 1984, 'The prediction of mineral solubilities in natural waters: The $\mathrm{Na}-\mathrm{K}-\mathrm{Mg}-\mathrm{Ca}-\mathrm{H}-\mathrm{Cl}-\mathrm{OH}-\mathrm{HCO}_{3}-\mathrm{CO}_{3}-\mathrm{CO}_{2}-\mathrm{H}_{2} \mathrm{O}$ system to high ionic strengths at $25^{\circ} \mathrm{C}^{\prime}$, Geochimica et Cosmochimica Acta, vol. 48, pp. 723-751.

Hassanizadeh, M \& Gray, WG 1979, 'General conservation equations for multi-phase systems: 1 . Averaging procedure', Advances in Water Resources, vol. 2, pp. 131-144.

Hausmann, DA 1967, 'Steel corrosion in concrete How does it occur', Materials Protection, vol. 6, pp. 19-23.

Heinz, D \& Urbonas, L 2003, 'About thaumasite formation in Portland-limestone cement pastes and mortars - effect of heat treatment at $95^{\circ} \mathrm{C}$ and storage at $5^{\circ} \mathrm{C}^{\prime}$, Cement \& Concrete Composites, vol. 25, pp. 961-967.

Helfferich, F 1961, Ion exchange, McGraw-Hill, USA.
Henocq, P Marchand, J Samson, E \& Lavoie JA 2006, 'Modeling of ionic interactions at the C-S-H surface - Application to $\mathrm{CsCl}$ and $\mathrm{LiCl}$ solutions, in comparison with $\mathrm{NaCl}$ solutions, in 2nd Int. Symp. on Advances in Concrete through Science and Engineering (RILEM Proceedings 51), eds J. Marchand et al., RILEM Publications, France.

Henocq, P Samson, E Marchand, J 2009, 'Chemical durability of cementitious materials: modeling the decalcification of hydrated $\mathrm{C}_{3} \mathrm{~S}$ pastes', in preparation.

Hidalgo, A De Vera, G Climent, MA Andrade, C \& Alonso, C 2001, 'Measurements of chloride activity coefficients in real Portland cement paste pore solutions', J. Am. Ceram. Soc., vol. 84, pp. 3008-3012.

Hidalgo, A Petit, S Domingo, C Alonso, C \& Andrade, C 2007, 'Microstructural characterization of leaching effects in cement pastes due to neutralisation of their alkaline nature - Part I: Portland cement pastes', Cement and Concrete Research, vol. 37, pp. 63-70.

Higgins, DD 2003, 'Increased sulfate resistance of ggbs concrete in the presence of carbonate', Cement \& Concrete Composites, vol. 25, pp. 913-919.

Hill, J Byars, EA Sharp, JH Lynsdale, CJ Cripps, JC \& Zhou, Q 2003, An experimental study of combined acid and sulfate attack of concrete', Cement \& Concrete Composites, vol. 25, pp. 997-1003.

Hinsenveld, M. 1992, 'A shrinking core model as a fundamental representation of leaching mechanism is cement stabilized waste', doctoral thesis, Department of Civil and Environmental Engineering, University of Cincinnati, Cincinnati, $\mathrm{OH}$. 
Hobbs, DW \& Taylor, MG 2000, 'Nature of the Thaumasite sulafte attack mechanism in field concrete', Cement and Concrete Research, vol. 30, pp. 529-533.

Hobbs, DW 2003, 'Thaumasite sulfate attack in field and laboratory concretes: implications for specifications', Cement \& Concrete Composites, vol. 25, pp. 1195-1202.

Hong, SY \& Glasser, FP 1999, 'Alkali binding in cement pastes Part I. The C-S-H phase', Cement and Concrete Research, vol. 29, pp. 1893-1903.

Hope, BB Ip, AK \& Manning, DG 1985, 'Corrosion and electrical impedance in concrete', Cement and Concrete Research, vol. 15, pp. 525-534.

Hosokawa, Y Yamada, K Johannesson, BF \& Nilsson, LO 2006, 'Models for chloride ion bindings in hardened cement paste using thermodynamic equilibrium calculations', in 2nd Int. Symp. on Advances in Concrete through Science and Engineering (RILEM Proceedings 51), eds J. Marchand et al., RILEM Publications, France.

Houst, YF \& Wittmann, FH 2002, 'Depth profiles of carbonates formed during natural carbonation', Cement and Concrete Research, vol. 32, pp. 1923-1930.

Ishida, T Kawai, K \& Sato, R 2006, 'Experimental study on decomposition processes of Friedel's salt due to carbonation', in Proc. Int. RILEM-JCI Seminar on Concrete Durability (ConcreteLife'06), ed. K. Kovler, RILEM Publications, France, pp. 51-58.

Johannesson, BF 2003, 'A theoretical model describing diffusion of a mixture of different types of ions in pore solution of concrete coupled to moisture transport', Cement and Concrete Research, vol. 33, pp. 481-488.
Jones, MR Macphee, DE Chudek, JA Hunter, G Lannegrand, R Talero, R \& Scrimgeour, SN 2003, 'Studies using 27Al MAS NMR of Afm and Aft phases and the Freidel's salt', Cement and Concrete Research, vol. 33, pp. 177-182.

Juel, I Herfort, D Gollop, R Konnerup-Madsen, J Jakobsen, HJ \& Skibsted, J 2003, 'A thermodynamic model for predicting the stability of thaumasite', Cement \& Concrete Composites, vol. 25, pp. 867-872.

Kim, KH Jeon, SE Kim, JK \& Yang, S 2003, 'An experimental study on thermal conductivity of concrete', Cement and Concrete Research, vol. 33. pp. 363-371.

Kuhl, D Bangert, F \& Meschke, G 2004, 'Coupled chemo-mechanical deterioration of cementitious materials. Part I: Modeling', International Journal of Solids and Structures, vol. 41, pp. 15-40.

Kurtis, KE Monteiro, PJM \& Madanat, S MarchApril 2000, 'Empirical models to predict concrete expansion caused by sulfate attack', J. ACI Materials, vol. 97, pp. 156-161. Errata published NovemberDecember 2000, V97 713.

Lee, ST Moon, HY \& Swamy, RN 2005, 'Sulfate attack and role of silica fume in resisting strength loss', Cement \& Concrete Composites, vol. 27, pp. 65-76.

Loudon N 2003, 'A review of the experience of thaumasite sulfate attack by the UK Highways Agency', Cement \& Concrete Composites, vol. 25, pp. 1051-1058.

Luping, T \& Nilsson, LO 1993, 'Chloride binding capacity and binding isotherms of OPC pastes and mortars', Cement and Concrete Research, vol. 23, pp. 247-253. 
Macphee, DE \& Barnett, SJ 2004, 'Solution properties of solids in the ettringite-thaumasite solid solution series', Cement and Concrete Research, vol. 34, pp. 1591-1598.

MacQuarrie, KTB \& Mayer, KU 2005, 'Reactive transport modeling in fractured rock: a state-of-thescience review', Earth-Science Reviews, vol. 72, pp. 189-227.

Mainguy, M Tognazzi, C Torrenti, JM \& Adenot, F 2000, 'Modelling of leaching in pure cement paste and mortar', Cement and Concrete Research, vol. 30, pp. 83-90.

Mainguy, M Coussy, O \& Baroghel-Bouny, V 2001, 'Role of Air Pressure in Drying of Weakly Permeable Materials', Journal of Engineering Mechanics, vol. 127, pp. 582-592.

Maltais, Y Samson, E \& Marchand, J 2004, 'Predicting the durability of Portland cement systems in aggressive environments - laboratory validation', Cement and Concrete Research, vol. 34, pp. 1579-1589.

Maltais, Y Marchand, J Henocq, P Zhang, T \& Duchesne, J 2004b, 'Ionic interactions in cementbased materials: importance of physical and chemical interactions in presence of chloride or sulfate ions', in Materials Science of Concrete VII, ed. J.P. Skalny, American Ceramic Society, USA, pp. 181-208.

Marchand, J Bentz, D Samson, E \& Maltais, Y 2001, 'Influence of calcium hydroxide dissolution on the transport properties of hydrated cement systems', in Materials Science of Concrete - Special Volume: Calcium Hydroxide in Concrete, American Ceramic Society, USA, eds. J.P. Skalny et al., pp. 113-129.

Marchand, J Samson, E Maltais, Y \& Beaudoin, JJ 2002, 'Theoretical analysis of the effect of weak sodium sulfate solutions on the durability of concrete', Cement \& Concrete Composites, vol. 24, pp. 317-329.
Martín-Pérez, B Pantazopoulou, SJ \& Thomas, MDA 2001, 'Numerical solution of mass transport equations in concrete structures', Computers and Structures, vol. 79, pp. 1251-1264.

Masi, M Colella, D Radaelli, G \& Bertolini, L 1997, 'Simulation of chloride penetration in cement-based materials', Cement and Concrete Research, vol. 27, pp. 1591-1601.

Matschei, T Lothenbach, B Glasser, FP 2007, 'The AFm phase in Portland cement', Cement and Concrete Research, vol. 37, pp. 118-130.

Mohammed, TU Hamada, H \& Yamaji, T 2004, 'Concrete after 30 years of exposure - Part I: Mineralogy, microstructure and interfaces', $A C I$ Materials Journal, vol. 101, pp. 3-12.

Moranville, M Kamali, S \& Guillon, E 2004, 'Physicochemical equilibria of cement-based materials in aggressive environments - experiment and modeling', Cement and Concrete Research, vol. 34, pp. 1569-1578.

Mulenga, DM Stark, J \& Nobst, P 2003, 'Thaumasite formation in concrete and mortars containing fly ash', Cement \& Concrete Composites, vol. 24, pp. 907-912.

Munshi, S \& Boulfiza, M 2005, 'Chlorides ingress and carbonation: effect on partitioning between free and bound chlorides', Proceedings of the ConMAT Conference, Vancouver Canada.

Nagesh, M \& Bhattacharjee, B 1998, 'Modeling of chloride diffusion in concrete and determination of diffusion coefficients', ACI Materials Journal, vol. 95, pp. 113-120.

Naik, NN Jupe, AC Stock, SR Wilkinson, AP Lee, PL \& Kurtis, KE 2006, 'Sulfate attack monitored by microCT and EDXRD: Influence of cement type, waterto-cement ratio, and aggregate', Cement and Concrete Research, vol. 36, pp. 144-159. 
Nielsen, EP Herfort, D Geiker, MR 2005, 'Binding of chloride and alkalis in portland cement systems', Cement and Concrete Research, vol. 35, pp. 117-123.

Nobst, P \& Stark, J 2003, 'Investigations on the influence of cement type on thaumasite formation', Cement \& Concrete Composites, vol. 25, pp. 899-906.

Odler, I \& Colàn-Subauste, J 1999, 'Investigations on cement expansion associated with ettringite formation', Cement and Concrete Research, vol. 29, pp. 731-735.

Ouyang, C Nanni, A \& Chang, WF 1988, 'Internal and external sources of sulfate ions in portland cement mortar: two types of chemical attack', Cement and Concrete Research, vol. 18, pp. 699-709.

Pajares, I Martinez-Ramirez, S \& Blanco-Varela, MT 2003, 'Evolution of ettringite in presence of carbonate, and silicate ions', Cement \& Concrete Composites, vol. 25, pp. 861-865.

Pankow, JF 1994, Aquatic Chemistry Concepts, Lewis Publishers, USA.

Papadakis, VG Vayenas, CG \& Fardis, MN 1991, 'Fundamental modeling and experimental investigation of concrete carbonation', ACI Materials Journal, vol. 88 , pp. 363-373.

Planel, D Sercombe, J Le Bescop, P Adenot, F \& Torrenti, J-M 2006, 'Long-term performance of cement paste during combined calcium leaching-sulfate attack: kinetics and size effect', Cement and Concrete Research, vol. 36, pp. 137-143.

Plummer, LN Busenberg, E 1982, 'The solubilities of calcite, aragonite and vaterite in $\mathrm{CO} 2-\mathrm{H} 2 \mathrm{O}$ solutions between 0 and $90^{\circ} \mathrm{C}$, and an evaluation of the aqueous model for the system CaCO3-CO2', Geochimica et Cosmochimica Acta, vol. 46, pp. 1011-1040.
Reardon, EJ 1990, 'An ion interaction model for the determination of chemical equilibria in cement/water systems', Cement and Concrete Research, vol. 20, pp. 175-192.

Reardon, EJ 1992, 'Problems and approaches to the prediction of the prediction of the chemical composition in cement/water systems', Waste Management, vol. 12, pp. 221-239.

Rémond, S Bentz, DP \& Pimienta, P 2002, 'Effects of the incorporation of Municipal Solid Waste Incineration fly ash in cement pastes and mortars - II: Modeling', Cement and Concrete Research, vol. 32, pp. 565-576.

Rigo da Silva, CA, Reis, RJP Lameiras, FS \& Vasconcelos, WL 2002, 'Carbonation-related microstructural changes in long-term durability concrete', Materials Research, vol. 5, pp. 287-293.

Romer, M Holzer, L \& Pfiffner, M 2003, 'Swiss tunnel structures: concrete damage by formation of thaumasite', Cement \& Concrete Composites, vol. 25, pp. 1111-1117.

Saetta, A Scotta, R \& Vitaliani, R 1993, 'Analysis of chloride diffusion into partially saturated concrete', ACI Materials Journal, vol. 90, pp. 441-451.

Saetta, A Schrefler, BA \& Vitaliani, R 1993, 'The carbonation of concrete and the mechanism of moisture, heat and carbon dioxide flow through porous materials', Cement and Concrete Research, vol. 23, pp. 761-772.

Saetta, AV \& Vitaliani, RV 2004, 'Experimental investigation and numerical modeling of carbonation process in reinforced concrete structures Part I: Theoretical formulation', Cement and Concrete Research, vol. 34, pp. 571-579. 


\section{Review of Mechanistic Understanding and Modeling and Uncertainty Analysis}

Methods for Predicting Cementitious Barrier Performance

Saito, H \& Deguchi, A 2000, 'Leaching tests on different mortars using accelerated electrochemical method', Cement and Concrete Research, vol. 30, pp. 1815-1825.

Samson, E Marchand, J Snyder, KA \& Beaudoin, JJ 2005, 'Modeling ion and fluid transport in unsaturated cement systems in isothermal conditions', Cement and Concrete Research, vol. 35, pp. 141-153.

Samson, E \& Marchand, J 2006, 'Multiionic approaches to model chloride binding in cementitious materials', in 2nd Int. Symp. on Advances in Concrete through Science and Engineering (RILEM Proceedings 51), eds J. Marchand et al., RILEM Publications, France.

Samson, E \& Marchand, J 2007, 'Modeling the effect of temperature on ionic transport in cementitious materials', Cement and Concrete Research, vol. 37, pp. 455-468.

Sanchez, F 1996, 'Étude de la lixiviation de milieux poreux contenant des espèces soluble: Application au cas des déchets solidifiés par liants hydrauliques' doctoral thesis, Institut National des Science Appliquées, Lyon, France, 269 pp.

Sanchez, F Gervais, C et al. 2002, 'Leaching of inorganic contaminants from cement-based waste materials as a result of carbonation during intermittent wetting' Waste Management, vol. 22, pp. 249-260.

Santhanam, M Cohen, MD \& Olek, J 2001, 'Sulfate attack research', Cement and Concrete Research, vol. 31, pp. 845-851.

Schrefler, BA 2004, 'Multiphase flow in deforming porous material', International Journal for Numerical Methods in Engineering, vol. 60, pp. 27-50.

Selih, J Sousa, ACM \& Bremner, TW 1996, 'Moisture transport in initially fully saturated concrete during drying', Transport in porous media, vol. 24, pp. 81-106.
Sibbick, T Fenn, D \& Crammond, N 2003, 'The occurrence of thaumasite as a product of seawater attack', Cement \& Concrete Composites, vol. 25, pp. 1059-1066.

Simunek, J \& Suarez, DL 1994, 'Two-dimensional transport model for variably saturated porous media with major ion chemistry', Water Resour. Res., vol. 30, pp. 1115-1133.

Skalny, J Marchand, J \& Odler, I 2002, Sulfate Attack on Concrete, Spon Press, New-York.

Song, HW Kwon, SJ Byun, KJ \& Park, CK 2006, 'Predicting carbonation in early-aged cracked concrete', Cement and Concrete Research, vol. 36, pp. 979-989.

Sten-Knudsen, O 2002, Biological Membranes Theory of transport, potentials and electric impulses, Cambridge University Press, UK.

Suryavanshi, AK Scantlebury, JD \& Lyon, SB 1995, 'The binding of chloride ions by sulphate resistant Portland cement', Cement and Concrete Research, vol. 25, pp. 581-592.

Suryavanshi, AK Scantlebury, JD \& Lyon, SB 1996, 'Mechanism of Friedel's salt formation in cement rich in tri-calcium aluminate', Cement and Concrete Research, vol. 26, pp. 717-72.Swaddiwudhipong, S Wong, SF Wee, TH \& Lee, SL 2000, 'Chloride ingress in partially and fully saturated concrete structures', Concrete Science and Engineering, vol. 2, pp. 17-31.

Tang, L \& Nilsson, LO 1993, 'Chloride binding capacity and binding isotherms of OPC pastes and mortars', Cement and Concrete Research, vol. 23, pp. 247-253.

Taylor, HFW 1997, Cement Chemistry, Thomas Telford, London. 
Thomas, MDA 1999, 'Modeling chloride diffusion in concrete - Effect of fly ash and slag', Cement and Concrete Research, vol. 29, pp. 487-495.

Tian, B \& Cohen, MD 2000, 'Does gypsum formation during sulfate attack on concrete lead to expansion?', Cement and Concrete Research, vol. 30, pp. 117-123.

Truc, O Ollivier, JP \& Nilsson, LO 2000, 'Numerical simulation of multi-species diffusion', Materials and Structures, vol. 33, pp. 566-573.

Tsivilis, S Kakali, G Skaropoulou, A Sharp, JH \& Swamy, RN 2003, 'Use of mineral admixtures to prevent thaumasite formation in limestone cement mortar', Cement \& Concrete Composite, vol. 25, pp. 969-976.

Tuutti, K 1982, 'Corrosion of steel in concrete', Swedish Cement and Concrete Research Institute, Report Fo 4:82. CBI. Stockholm. Sweden.

van Gerven, T Cornelis, G Vandoren, E Garrabrants, AC Sanchez, F Kosson, DS and Vandecasteele, C 2006, 'Effects of progressive carbonation on heavy metal leaching from cement-bound waste', $A I C h E$ Journal vol. 52, pp. 826-837.

van Gerven, T Cornelis, G et al. 2007, 'Effects of carbonation and leaching on porosity in cement-bound waste', Waste Management, vol. 27, pp. 977-985.

West, RE \& Hime, WG 1985, 'Chloride profiles in salty concrete', Materials Performance, vol. 24, pp. 29-36.

West, RE \& Hime, WG 1985, 'Chloride profiles in salty concrete', Materials Performance, vol. 24, pp. 29-36.

Whitaker, S 1998, 'Coupled transport in multiphase systems: a theory of drying', in Advance in Heat Transfer 31, J.P. Hartnett et al. eds., pp. 1-104.
Xi, Y Bazant, ZP Molina, L \& Jennings, HM 1994, 'Moisture diffusion in cementitious materials Moisture capacity and diffusivity', Advanced Cement Based Materials, vol. 1, pp. 258-266.

Xu, T Apps, JA \& Pruess, K 2004, 'Numerical simulation of $\mathrm{CO} 2$ disposal by mineral trapping in deep aquifers', Applied Geochemistry, vol. 19, pp. 917936.

Xu, T Sonnenthal, E Spycher, N \& Pruess, K 2006, 'TOUGHREACT - a simulation program for nonisothermal multiphase reactive geochemical transport in variably saturated geologic media: applications to geothermal injectivity and $\mathrm{CO}_{2}$ geological sequestration', Computers \& Geosciences, vol. 32, pp. 145-165.

Yokozeki, K Watanabe, K Sakata, N \& Otsuki, N 2004, 'Modeling of leaching from cementitious materials used in underground environment', Applied Clay Science, vol. 26, pp. 293-308.

Zalc, JM Reyes, SC \& Iglesia, E 2004, 'The effects of diffusion mechanism and void structure on transport rates and tortuosity factors in complex porous structures', Chem. Eng. Sci., vol. 59, pp. 2947-2960.

Zemaitis, JF Clark, DM \& Rafal, M 1986, 'Scrivner N.C., Handbook of aqueous electrolyte thermodynamics', American Institute of Chemical Engineers, New-York, USA.

Zhou, Q Hill, J Byars, EA Cripps, JC Lynsdale, CJ \& Sharp, JH 2006, 'The role of $\mathrm{pH}$ in thaumasite sulfate attack', Cement and Concrete Research, vol. 36, pp. 160-170. 


\title{
MECHANICAL DAMAGE REVIEW
}

\author{
Eric Samson \\ Email: esamson@simcotechnologies.com \\ SIMCO Technologies, Inc. \\ Quebec City, Canada \\ and \\ Sohini Sarkar \\ Email: sohini.sarkara@vanderbilt.edu \\ David S. Kosson \\ Email: david.kosson@vanderbilt.edu \\ Vanderbilt University, School of Engineering \\ Consortium for Risk Evaluation with Stakeholder Participation, III \\ Nashville, Tennessee 37235
}


Review of Mechanistic Understanding and Modeling and Uncertainty Analysis Methods for Predicting Cementitious Barrier Performance 
LIST OF FIGURES ................................................................................................................................... V-vi

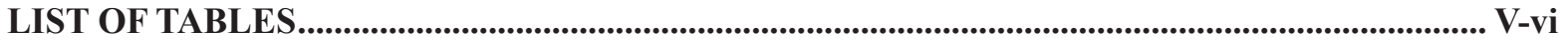

LIST OF ABBREVIATIONS AND ACRONYMS ............................................................................ V-vii

LIST OF SYMBOLS....................................................................................................................................... V-viii

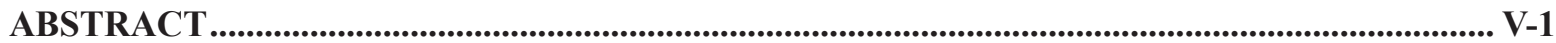

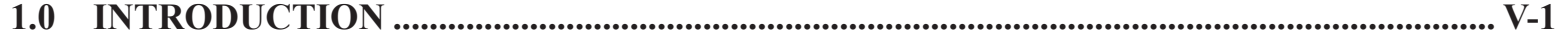

2.0 GENERAL OVERVIEW OF DAMAGE IN CONCRETE ..................................................... V-2

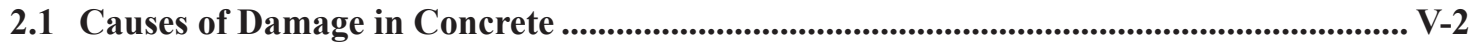

2.1.1 Cracking of Plastic Concrete ……............................................................................... V-2

2.1.1.1 Shrinkage Cracking .................................................................................. V-2

2.1.1.2 Settlement Cracking ........................................................................... V-2

2.1.2 Cracking on Hardened Concrete .............................................................................. V-3

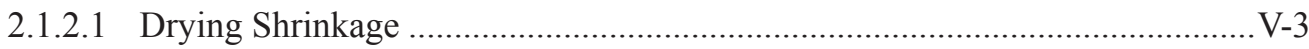

2.1.2.2 Thermal Stresses......................................................................................

2.1.2.3 Chemical Reactions ......................................................................................... V-3

2.1.2.4 Freezing and Thawing .................................................................................. V-3

2.1.2.5 Corrosion of Steel Reinforcement .................................................................. V-3

2.1.2.6 Poor Construction Practices ……................................................................... V-3

2.1.2.7 Construction Overloads .............................................................................. V-4

2.1.2.8 Errors in Design and Detailing .................................................................... V-4

2.1.2.9 Externally Applied Loads ...........................................................................

2.2 Evaluation of Damage ....................................................................................................................... V-4

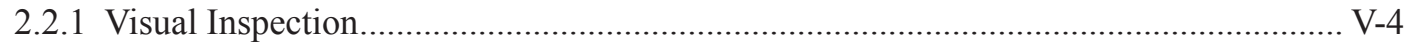

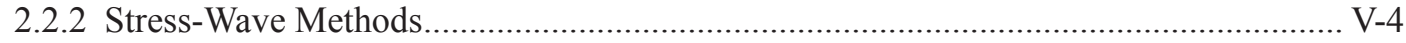

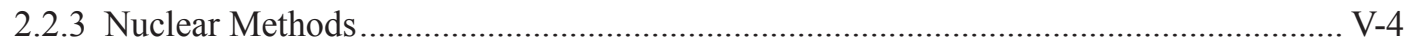

2.2.4 Magnetic and Electrical Methods …….......................................................................... V-4

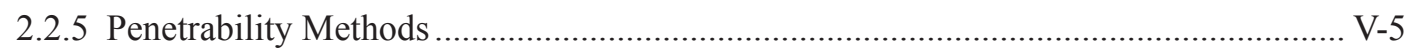

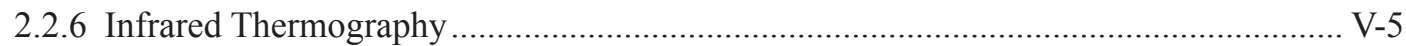

2.2.7 Radio Detection and Ranging (Radar) Method .......................................................... V-5 
3.0 MODELING MECHANICAL DAMAGE IN CONCRETE .............................................. V-5

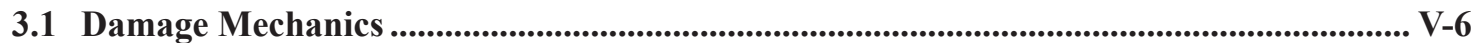

3.2 Fracture Mechanics ................................................................................................................... V-7

3.2.1 Maximum Circumferential Stress Criterion (MCSC) …................................................ V-7

3.2.2 Minimum Strain Energy Density Criterion (MCSC) …….......................................... V-8

3.2.3 Maximum Strain Energy Release Rate Criterion (MSERRC) ....................................... V-8

3.3 Coupling between Damage andTransport Properties................................................................. V-8

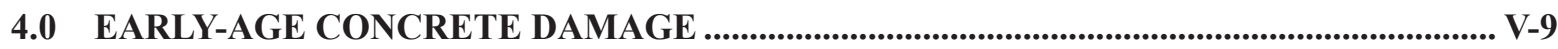

4.1 Degree of Hydration ............................................................................................................................ V-9

4.2 Evolution of Mechanical Characteristics........................................................................ V-10

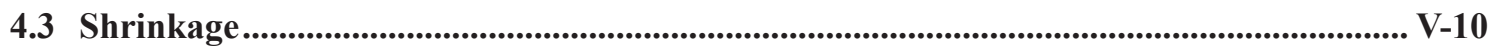

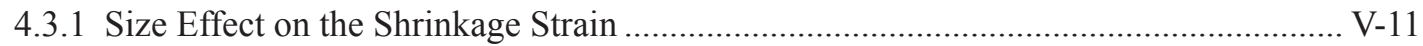

4.3.2 Relative Humidity or Water Loss Effect on the Shrinkage Strain ................................ V-11

4.3.3 Total Shrinkage Strain.............................................................................................. V-12

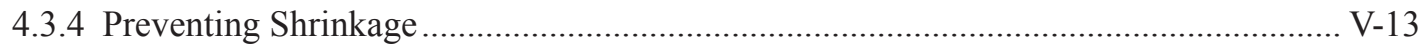

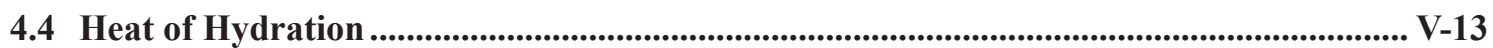

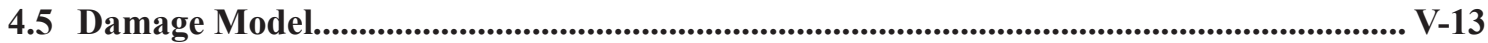

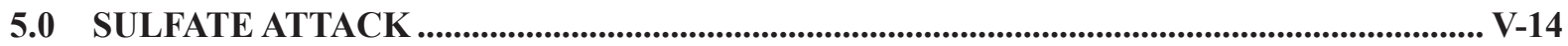

5.1 Introduction ................................................................................................................................ V-14

5.2 Numerical Modeling of Damage due to Sulfate Attack .................................................. V-15

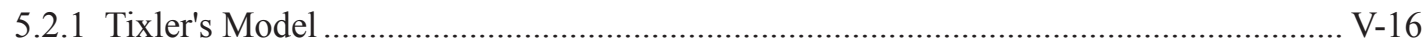

5.2.1.1 Diffusion and Chemical Reactions ...............................................................

5.2.1.2 Strain Development .....................................................................................

5.2.1.3 Stress-Strain Relations ………………...................................................... V-17

5.2.1.4 Change In Diffusivity ................................................................................

5.2.2 Krajcinovic-Basista's Model..................................................................................... V-18

5.2.2.1 Calculation of Damage Parameter................................................................... V-19

5.2.2.2 Stress-Strain Relations ............................................................................. V-19

5.2.2.3 Change in Material Properties .......................................................................... V-20

6.0 CORROSION-INDUCED CRACKING....................................................................................... V-21

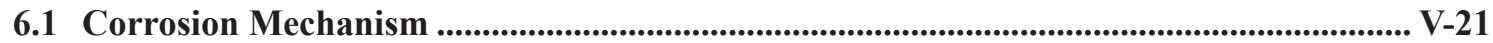

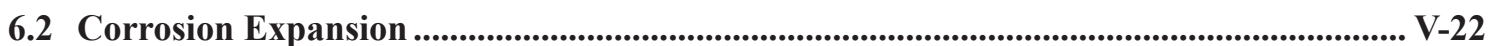


CONTENTS (contd)

Page No.

6.3 Rate of Corrosion

$\mathrm{V}-22$

6.4 Modeling the Damage Induced by Corrosion .................................................................. V-23

6.4.1 Liu and Weyers' Model (1998) ....................................................................... V-24

6.4.2 Martin-Pérez's Model (1999).......................................................................... V-25

6.5 Numerical Simulation of Corrosion Damage ................................................................... V-26

7.0 ALKALI-SILICATE REACTION ................................................................................... V-27

7.1 Mechanisms of ASR .................................................................................................... V-28

7.2 ASR Test Methods....................................................................................... V-28

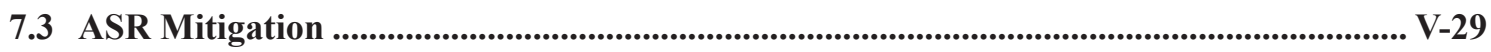

7.4 Modeling of Damage Induced by ASR .............................................................. V-29

8.0 FREEZING AND THAWING ........................................................................................... V-32

8.1 Ice Formation Mechanism ..................................................................................... V-33

8.2 F/T Cycle Damage and Saturation ....................................................................... V-33

8.3 Effect of W/C on F/T Damage...................................................................................... V-35

8.4 Cooling Rate ................................................................................................................... V-36

8.5 Pore Pressure Evolution as A Function of Ice Formation ................................................... V-36

8.5.1 Saturated Porous Media ............................................................................... V-37

8.5.2 Unsaturated Porous Media ........................................................................... V-37

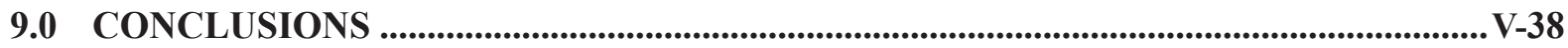

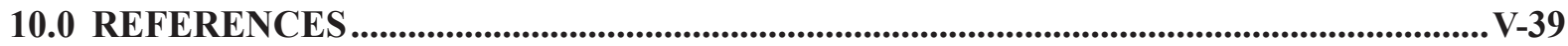




\section{LIST OF FIGURES}

Figure 1. One Dimensional Damage Effect and Concept of Effective Stress ................................... V-6

Figure 2. Crack Propagation Direction with Integration Points (Bouchard et al. 2003). ...................V-8

Figure 3. Evolution of Various Strains as A Function of Time (ACI 209.1R-05) ..............................V-11

Figure 4. Global Approach for Modeling Sulfate Attack Degradation of Cementitious Materials .....V-15

Figure 5. Stress Strain Diagram of Concrete Under Tension............................................................

Figure 6. Rust Propagation and Induced Pressure After Bhargava et al. (2006) ................................V-21

Figure 7. Pressure Distribution Around the Reinforcement............................................................ V-25

Figure 8. Maximum Pressure Resistance of Concrete Cover as A Function of Radius.......................V-26

Figure 9. Variation of the Radial Displacement Versus Time (Chen and Mahadevan 2008)..............V-27

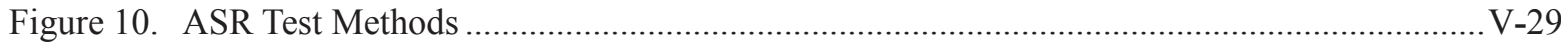

Figure 11. Stress and Pressure Induced by ASR Gel in Equilibrium .................................................. V-31

Figure 12. Rhelogical Model of One-dimensional Chemoplastic Material ........................................... V-31

Figure 13. ASR Swelling Evolution as A Function of Time. ............................................................ V-32

Figure 14. Heat Released from Ice Formation Experiments on Saturated Cement Pastes at Various Water/Cement Ratios (Bager 1986a) ................................................................. V-34

Figure 15. Expansion of Saturated Cement Pastes with Various w/c Ratios (Litvan 1978) ..................V-34

Figure 16. Relative Dynamic Young's Modulus Evolution vs. Freezing/ Thawing Cycles According to Rombèn's Results (Fagerlund 2004)............................ V-35

Figure 17. Evolution of Damage as a Function of the F/T Cycles..................................................... V-36

\section{LIST OF TABLES}

Table 1. Coefficient $\alpha_{1}$ and $\alpha_{2}$ for Different Types of Rust Production in Concrete V-23 


\title{
LIST OF ABBREVIATIONS AND ACRONYMS
}

\author{
ACI American Concrete Institute \\ ASH Alkali-Silicate-Hydrate \\ ASR Alkali Silica Reaction \\ $\mathrm{CH}$ Calcium Hydroxide \\ C-S-H Calcium Silicate Hydrate \\ DT Destructive Test \\ HPC High-Performance Concrete \\ HPFC High-Performance steel Fiber-reinforced Concrete \\ IE Impact Echo \\ MASW Multiple Impact Surface Waves \\ MCSC Maximum circumferential stress criterion \\ MD Molecular Dynamic \\ MSEDC Minimum strain energy density criterion \\ MSERRC Maximum strain energy release rate criterion \\ NDT Nondestructive Test \\ NMR Nuclear Magnetic Resonance \\ OC Ordinary Concrete \\ RVE Representative Volume Element \\ SASW Spectral Analysis of Surface Waves \\ SEM Scanning Electron Microscopy \\ SIR Slab Impulse Response \\ XRD X-Ray Diffraction
}




\section{LIST OF SYMBOLS}

$$
\begin{aligned}
& \text { a Ratio of damaged/total material surface } \\
& a_{c} \quad \text { Mean half crack length } \\
& a_{l} \quad \text { Chemical activity } \\
& A_{c} \quad \text { Material characteristic in } \mathrm{F} / \mathrm{T} \text { fatigue } \\
& A / A_{0} \quad \text { Effective/total surface } \\
& A_{H} \quad \text { Coefficient for normalized affinity of hydration } \\
& A_{\xi} \quad \text { Initial affinity of the hydration reaction } \\
& b \quad \text { Biot coefficient } \\
& b_{0} \quad \text { Available fraction of porosity } \\
& B_{c} \quad \text { Material characteristic in } \mathrm{F} / \mathrm{T} \text { fatigue } \\
& \text { c Concrete cover thickness } \\
& C \text { Weighted average of the chemical concentration } \\
& C_{d} \quad \text { Crack density } \\
& c_{p}^{s} / c_{p}^{l} \quad \text { Ice/water heat capacity } \\
& C_{t} \quad \text { Total chloride content } \\
& C_{\xi}^{t} \quad \text { Elasticity stiffness tensor of hydration } \\
& \text { d Damage parameter } \\
& \text { D Diffusion coefficient } \\
& d_{0} \quad \text { Thickness of high porous concrete zone } \\
& d_{c} \quad \text { Deformation induced by rust production } \\
& d_{c r} \quad \text { Model parameter of damaged diffusion coefficient } \\
& D_{d} / D_{0} / D_{\max } \quad \text { Damaged/initial undamaged/maximum value of the } \\
& \text { diffusion coefficient } \\
& D_{C} \quad \text { Diffusion coefficient in the cracks } \\
& D_{p} \quad \text { Conduction percolation threshold } \\
& e \quad \text { Characteristic of damageable material } \\
& \text { E Young's modulus } \\
& E_{0} \quad \text { Undamaged dynamic Young's modulus } \\
& E_{a} \quad \text { Activation energy } \\
& E_{e f} \quad \text { Effective Young's modulus } \\
& E_{n} \quad \text { Damaged dynamic Young's modulus } \\
& E_{r} \quad \text { Young's modulus of rust product }
\end{aligned}
$$




\section{LIST OF SYMBOLS (contd)}

\begin{tabular}{|c|c|}
\hline$F$ & Faraday's constant \\
\hline$F_{0} / F_{f}$ & Solution/Saturated material conductivity \\
\hline$f_{c}^{\prime}$ & Ultimate compressive strength \\
\hline$f^{d}$ & Damage criteria \\
\hline$f^{I}$ & Inclusion volume density \\
\hline$f_{t}$ & Tensile strength of concrete \\
\hline$f_{\xi}$ & Source term to model the heat of hydration \\
\hline$g_{c t}$ & $\begin{array}{l}\text { Constant for Young's modulus calculation during } \\
\text { hydration }\end{array}$ \\
\hline$h_{0}^{l s}$ & Enthalpy of ice formation \\
\hline$I$ & Unit matrix \\
\hline$I_{c o r}$ & Corrosion current density \\
\hline$i_{c o r}$ & Mean annual corrosion rate \\
\hline$J_{r}$ & Corrosion rate \\
\hline$k$ & Reaction rate constant \\
\hline$K$ & Intrinsic permeability \\
\hline$k_{0}$ & Characteristic of the ASR chemical process \\
\hline$K_{V(0)} / K_{V(d)}$ & Initial/damaged gas permeability \\
\hline$K_{g}$ & ASR gel stiffness \\
\hline$K_{I}$ & Stress intensity factor \\
\hline$K_{N}$ & Coefficient of fatigue in $\mathrm{F} / \mathrm{T}$ damage \\
\hline$K_{r}$ & Stiffness of rust product \\
\hline$L$ & Length \\
\hline$l_{r}$ & Thickness of adsorbed liquid layer \\
\hline$m$ & Weibull's law parameter \\
\hline$M$ & Molar concentration \\
\hline$m_{C}$ & $\begin{array}{l}\text { Steel bar-concrete cover coefficient in corrosion } \\
\text { model }\end{array}$ \\
\hline$M_{\text {crit }}$ & Critical corrosion mass products \\
\hline$m_{\mathrm{Fe}}$ & Equivalent iron mole \\
\hline
\end{tabular}




\section{LIST OF SYMBOLS (contd)}

\begin{tabular}{|c|c|}
\hline$M_{P}$ & $\begin{array}{l}\text { Corrosion mass products filling the porous ring around } \\
\text { steel bar }\end{array}$ \\
\hline$m_{r}$ & Corrosion produced mass \\
\hline$m_{R H}$ & Model parameter of ASR gel pressure \\
\hline$M_{S}$ & Corrosion mass products introducing the crack \\
\hline$M_{s t}$ & Steel bar mass consumed by corrosion \\
\hline$n$ & Model parameter of damaged diffusion coefficient \\
\hline$n_{0} / n_{1} / n_{2}$ & Material constant in the hydration model \\
\hline$N$ & Total molar concentration \\
\hline$n_{V}$ & Ratio of the rust volume on initial steel volume \\
\hline$p$ & Pressure \\
\hline$P_{C}$ & Pressure inside of concrete cover \\
\hline$P_{g}$ & ASR gel pressure \\
\hline$P_{l}$ & Pressure of liquid phase \\
\hline$P_{i c e}$ & Pressure due by ice formation \\
\hline$P_{r}$ & Pressure induced by corrosion product \\
\hline$P f^{A S R}$ & Cracking probability \\
\hline$P^{n}$ & Pressure exerted by the chemical expanding \\
\hline$p_{v} / p_{v s}$ & Normal / saturated vapor pressures \\
\hline$q$ & Equivalent stoichiometric coefficient \\
\hline$Q_{\xi}$ & Material parameter in the heat of hydration model \\
\hline$r_{0} / r_{1}$ & Characteristics of material in damage criteria \\
\hline$R$ & Gas constant \\
\hline$R_{0}$ & Radius of steel bar plus concrete cover \\
\hline$r_{a 0}$ & Initial radius of the calcium particle \\
\hline$R_{c}$ & Radius of damaged zone induced by rust production \\
\hline$R_{e q}$ & Equivalent pore radius \\
\hline$R H$ & Relative humidity \\
\hline$R_{i}$ & $\begin{array}{l}\text { Initial radius of the steel bar plus high porous concrete } \\
\text { zone }\end{array}$ \\
\hline$R_{s}$ & Initial radius of the steel bar \\
\hline$R_{r}$ & Ohmic resistance of the cover concrete \\
\hline
\end{tabular}




\section{LIST OF SYMBOLS (contd)}

\begin{tabular}{|c|c|}
\hline$S$ & Ratio of un-cracked on cracked surface of material \\
\hline$S_{c r}$ & Critical degree of saturation \\
\hline$S_{r}$ & Critical degree of saturation \\
\hline$S(\omega)$ & Matrix of the degradation properties of material \\
\hline$t$ & Time \\
\hline$T$ & Temperature \\
\hline$U$ & Concentration \\
\hline$V$ & Volume \\
\hline$V_{C}$ & Volume or corrosion product \\
\hline$V_{R}$ & Volume of original steel \\
\hline$V_{s}$ & Volume of solid \\
\hline$v / w_{h}$ & Effective /equivalent crack width \\
\hline$w_{c}$ & Specific weight of concrete \\
\hline$W$ & Equivalent weight of steel \\
\hline$W_{c}$ & Water content of concrete \\
\hline$W_{l}$ & Moisture loss of concrete \\
\hline$W_{t}$ & Consumed water for hydration at time $t$ \\
\hline$W_{\infty}$ & Consumed water for fully hydration \\
\hline$x_{\text {unf }}$ & Molar fraction \\
\hline$z$ & Ionic valence of iron \\
\hline$\alpha$ & Characteristic of damageable material \\
\hline$\alpha_{f}$ & Constant for compressive calculation during hydration \\
\hline$\alpha_{\varepsilon}$ & Material constant to calculate ASR part of strain \\
\hline$\alpha_{T}$ & Concrete thermal coefficient of expansion. \\
\hline$\alpha_{T}^{\xi}$ & $\begin{array}{l}\text { Thermal expansion parameter associated with the heat } \\
\text { of hydration }\end{array}$ \\
\hline${ }_{1} / \alpha_{2}$ & Corrosion mass characteristic coefficients \\
\hline$\beta$ & Characteristic of damageable material \\
\hline$\beta_{f}$ & Constant for compressive calculation during hydration \\
\hline
\end{tabular}




\section{LIST OF SYMBOLS (contd)}

\begin{tabular}{|c|c|}
\hline$\delta$ & $\mathrm{F} / \mathrm{T}$ damage \\
\hline$\varepsilon / \varepsilon^{e} / \varepsilon^{p l} / \varepsilon^{A S R} / \varepsilon^{+}$ & Total/elastic/plastic/ASR/positive part of strain \\
\hline$\varepsilon^{* *}$ & Eigenstrain \\
\hline$\varepsilon^{c h}$ & Chemical strain \\
\hline$\varepsilon^{c}$ & Creep strain \\
\hline$\varepsilon^{H}$ & Hydration strain \\
\hline$\varepsilon^{o}$ & Autogenous strain \\
\hline$\varepsilon^{s h}$ & Shrinkage strain \\
\hline$\varepsilon^{T}$ & Thermal strain \\
\hline$\varepsilon_{v}$ & Volumetric strain \\
\hline$\phi / \phi_{0}$ & Effective/initial porosity \\
\hline$\gamma$ & Characteristic of damageable material \\
\hline$\gamma_{c}$ & Rate of saturation increasing in $\mathrm{F} / \mathrm{T}$ fatigue \\
\hline$\gamma_{l s}$ & Liquid/solid surface tension \\
\hline$\varphi$ & Porosity of chemical products \\
\hline$\varphi_{\text {cap }}$ & Capillary fraction of porosity \\
\hline$\varphi(r)$ & Pore size distribution \\
\hline$\kappa_{1} / \kappa_{2}$ & $\begin{array}{l}\text { Experimental parameters describing effect of damage } \\
\text { on gas perm. }\end{array}$ \\
\hline$\kappa_{e} / \kappa_{p}$ & $\begin{array}{l}\text { Constants related to crack and porosity in ASR gel } \\
\text { pressure model }\end{array}$ \\
\hline$\kappa_{C}$ & Rust production rate \\
\hline$\lambda$ & Coefficient of Lamé \\
\hline$\lambda_{d}$ & Damage coefficient \\
\hline$\mu$ & Coefficient of Lamé \\
\hline$\mu_{\omega}$ & Exponent for a three-dimensional diffusion coefficient \\
\hline$v$ & Poisson's ratio \\
\hline
\end{tabular}




\section{LIST OF SYMBOLS (contd)}

$\begin{array}{cl}v_{s} v_{l} & \text { Ice formation/water specific volume of } \\ v_{r} & \text { Poisson's ratio of rust product } \\ \theta & \quad \text { Creep coefficient } \\ \rho_{r} & \text { Mass density of corrosion products } \\ \mu_{s} & \text { Mass density original steel } \\ \sigma / \sigma^{\prime} / \sigma_{g} & \text { Total/effective/undamaged material stress } \\ \sigma_{r} & \quad \text { Residual stress } \\ \sigma_{t} & \quad \text { Tangential stress } \\ \sigma_{u} & \quad \text { Weibull's law parameter } \\ \tau_{C} & \quad \text { Empirical parameter which describing the cracks' } \\ \omega & \quad \text { Doughness } \\ \xi & \quad \text { Degree of hydration } \\ \xi_{\infty} & \text { Maximum degree of hydration } \\ \psi_{e} & \text { Function of elastic free energy }\end{array}$




\title{
MECHANICAL DAMAGE REVIEW
}

\author{
Eric Samson \\ SIMCO Technologies, Inc. \\ Quebec City, Canada \\ Sohini Sarkar \\ David S. Kosson \\ Vanderbilt University, School of Engineering \\ Consortium for Risk Evaluation with Stakeholder Participation, III \\ Nashville, TN 37235
}

\section{ABSTRACT}

This report summarizes modeling approaches used to predict the formation of cracks in cementitious materials. General considerations related to cracks such as the origin, detection, and prevention are first outlined.

Following this, a section is dedicated to the general description of approaches to model the formation of cracks in materials. The first method reviewed is called damage mechanics. It is based on a damage parameter that indicates the level of damage in a continuous material. The second method is called the fracture mechanics. In this approach, the geometry and localization of cracks is predicted instead of relying on a smeared damage parameter.

The other sections are dedicated to the description of models developed for specific damage phenomena. Early age cracking caused by the heat generated during the hydration process and the drying shrinkage is first discussed. This is followed by reviews on damage models dealing with sulfate ingress in concrete, rebar corrosion, alkali-silica reaction and freezing/thawing cycles.

\subsection{INTRODUCTION}

Many degradation problems affecting concrete structures have their origin in ionic, energy, and moisture exchanges between the material and the surrounding environment. For example, the exchange of ions at the material/environment interface initiates chemical reactions due to the chemical imbalance between the pore solution and the hydrated cement paste, and the exchange of energy associated with temperature variations in the environment can trigger the formation of ice crystals in the pores.
Most of these internal modifications to the material are not macroscopically apparent at the time of initiation. But ultimately, the chemical and physical alterations to the microstructure translate into internal stresses and can lead to the formation of cracks.

Once the material is cracked, structural elements no longer perform according to their original design. Also, the formation of cracks marks an increase in the degradation rate of the material due to the increased ionic and moisture exchange rates through these high permeability paths. 
Good construction practices can help prevent many of these problems in conventional structures. For instance, designing a concrete mixture with the proper amount of air entraining agent and non reactive aggregates should protect the structure from freezing/thawing and alkali-silica reaction damages in all but the most severe environments. When the material is put in place, good curing practices will prevent drying shrinkage and surface cracking. Selecting low water-to-binder ratio and low permeability concretes in chloride- or sulfate-laden environments will slow the ingress of contaminants and ensure a long service-life.

The case of nuclear waste storage structures poses additional challenges to durability concerns, mainly because of the very long service-life (1000+ years) that is expected. With these structures, the objective of properly designing the concrete mixture is not to prevent cracking but to control it, because crack-free scenarios can hardly be expected over such long timeframes. Models that can predict the formation and propagation of cracks as a function of microstructure alteration and external conditions are thus valuable design tools for this specific application.

This report reviews mechanical damage models found in the literature that address the most common degradation problems. The first sections summarize the formation of cracks in concrete and general mechanical damage models. This is followed by a review of damage models for selected degradation phenomena: sulfate attack, rebar corrosion, alkalisilica reaction, and freezing and thawing damages.

\subsection{GENERAL OVERVIEW OF DAMAGE IN CONCRETE}

\subsection{Causes of Damage in Concrete}

This section summarizes the causes leading to cracks in concrete. Most of the text is taken from the ACI Concrete Repair Manual 224.1R-07 (2007).

\subsubsection{Cracking of Plastic Concrete}

Plastic concrete in this report refers to fresh concrete. (For more details, see the report chapter "Early-Age Cracking Review: Mechanisms, Material Properties, and Mitigation Strategies.")

\subsubsection{Shrinkage Cracking}

Shrinkage is caused by the evaporation of water from the surface of fresh concrete and occurs when the surface drying rate is fast and the lost water cannot be replaced by bleed water. This moisture loss shrinks the concrete during the plastic stage and generates cracks. The shrinkage cracks begin as shallow cracks, but can become full-depth cracks later in the concrete's life.

\subsubsection{Settlement Cracking}

Settlement cracks are caused by the tendency of concrete to consolidate after initial placement, vibration, and finishing. This consolidation, after fresh concrete is placed in contact with reinforcing steel or formwork, can locally restrain concrete deformation and generate cracks. 


\subsubsection{Cracking on Hardened Concrete}

\subsubsection{Drying Shrinkage}

Drying shrinkage is one of the most important causes of hardened concrete cracking. It is generated by the loss of moisture from the cement paste, which shrinks its volume. The differential shrinkage between the surface and the interior concrete (or aggregates) causes tensile stress and generates cracks.

\subsubsection{Thermal Stresses}

Temperature gradients inside concrete structures can result in differential volume changes and generate cracks. The temperature gradients can originate from heat generated during the hydration process, or from weather conditions. When the local tensile stresses due to the differential volume changes exceed the local tensile strength of the material, the concrete will crack. Crack propagation is a matter for fracture mechanics, which will be discussed later in this chapter.

\subsubsection{Chemical Reactions}

Some materials used to make concrete or some chemical materials that penetrate into the material can generate harmful chemical reactions and cause cracking. In most cases, the chemical reactions cause the formation of a solid phase that occupies more volume than the original products from which it was formed, leading to the formation of cracks. The damages associated with alkali silica reaction and external sulfate attack fall into this category. (See relevant sections in this chapter and the chapter on Chemical Degradation.)

\subsubsection{Freezing and Thawing}

Freezing and thawing cycles lead to the formation of ice in concrete. Since ice occupies $9 \%$ more space than liquid water, internal stresses are generated. The formation of ice crystals starts in the larger pores. As space is filled, liquid pressure in the smaller pores increases. If air voids are present in the material, they will fill with water and contribute to reducing the tension in the material. Unsaturated pores will act similarly. However, if the material is near saturation and the volume and spacing of voids are inadequate, the concrete will sustain damage upon freezing and thawing.

\subsubsection{Corrosion of Steel Reinforcement}

Ingress of chloride ions can initiate corrosion of the reinforcing steel in concrete. The corrosion of steel generates products (various types of iron oxides) that occupy a volume greater than the original reinforcing bar. This increase in volume creates a high radial stress around reinforcing bars and results in cracks and subsequent concrete spalling (loss of thickness) and exposure of the reinforcing steel to the environment.

\subsubsection{Poor Construction Practices}

A wide variety of poor construction practices can result in the cracking of concrete structures. Foremost among these is the common practice of adding water to concrete to increase workability. Adding water has the effect of reducing strength, increasing settlement, and increasing drying shrinkage. When accompanied by a higher cement content to help offset the decrease in strength, an increase in water content will also mean an increase in the temperature differential between the interior and the exterior portion of the structure, resulting in increasing thermal stresses and cracking. In addition, by adding cementitious materials, even if the water to binder ratio $(w / b)$ remains constant, more shrinkage will occur because the paste volume is increased.

Lack of curing will increase the degree of cracking within a concrete structure. The early termination of curing promotes shrinkage at a time when the concrete has low strength. The lack of hydration of the cement, due to drying, will result not only in 
decreased long-term strength but also in the reduced durability of structures.

\subsubsection{Construction Overloads}

Construction loads can often be more severe than those experienced in service. Unfortunately, these conditions may occur at early ages when the concrete is most susceptible to damage, and they often result in permanent cracks. Precast members, such as beams and panels, are most frequently subject to this abuse. Cast-in-place concrete can also be affected.

\subsubsection{Errors in Design and Detailing}

Errors in design and detailing that may result in unacceptable cracking include use of poorly detailed re-entrant corners in walls, precast members, and slabs; improper selection or reinforcement detailing, or both; restraint of members subjected to volume changes caused by variations in temperature and moisture; lack of adequate contraction joints; and improper foundations design, resulting in differential movement within the structure.

\subsubsection{Externally Applied Loads}

It is well known that load-induced tensile stresses result in cracks in concrete structures. This point is readily acknowledged and accepted in the design of reinforced concrete structures.

\subsection{Evaluation of Damage}

Test methods for evaluation of damage in concrete structures are divided in two main groups: destructive and non-destructive. This section focuses on nondestructive methods and attempts to present some common methods described by ACI 228.2R-98. Some destructive methods such as coring, sampling, or measuring the in-situ strength of structures are not discussed in this section.

\subsubsection{Visual Inspection}

Visual inspection is one of the most versatile and powerful Non-Destructive Test (NDT) methods. However, its effectiveness depends on the knowledge and experience of the investigator. Visual inspection has the obvious limitation that only visible surfaces can be inspected. For these reasons, a visual inspection is usually supplemented by one or more of the other NDT methods discussed in this chapter.

\subsubsection{Stress-Wave Methods}

Several test methods based on stress-wave propagation can be used for nondestructive testing of concrete structures. The ultrasonic throughtransmission method can be used for locating abnormal regions in a structure. The echo method can be used for thickness measurements and flaw detection. The spectral analysis of surface waves (SASW) method can be used to determine the thickness of pavements and elastic moduli of layered pavement systems.

\subsubsection{Nuclear Methods}

Nuclear methods can be subdivided into two groups: radiometric and radiographic. Both involve obtaining information about a test object due to interactions between high-energy electromagnetic radiation and the material.

\subsubsection{Magnetic and Electrical Methods}

These methods estimate where the corrosion of reinforcement is active. Corrosion activity can be monitored using the half-cell potential technique, and information on the rate of corrosion can be obtained from linear-polarization methods. 


\subsubsection{Penetrability Methods}

Many of the degradation mechanisms in concrete involve the penetration of aggressive materials, such as sulfates, carbon dioxide, and chloride ions. As a result, concrete that has a surface zone that is highly resistant to the ingress of water will generally be more durable than concrete without such a resistive surface zone.

To assess the potential durability of in-place concrete, it is necessary to focus on methods that assess the ability of the surface zone to restrict the passage of external agents that may lead to direct deterioration of the concrete or to depassivation and corrosion of embedded reinforcement. Many test methods are based on the resistance of concrete to surface penetration. They can be grouped in three categories: water absorption (under a relatively low pressure head), water permeability (under higher pressure head), and air permeability.

\subsubsection{Infrared Thermography}

Infrared thermography has been used for detecting subsurface anomalies in concrete. Infrared thermography senses the emission of thermal radiation and produces a visual image from this thermal signal. Infrared thermography for testing concrete is based on two principles. The first principle is that a surface emits energy in the form of electromagnetic radiation. The second principle is that subsurface anomalies in concrete affect heat flow through concrete.

\subsubsection{Radio Detection and Ranging (Radar) Method}

This method is similar to the stress-wave method, discussed in Section 2.2.2, except that electromagnetic waves (radio waves or microwaves) are used instead of stress waves.

\subsection{MODELING MECHANICAL DAMAGE IN CONCRETE}

Materials are damaged when the combination of external and internal loads exceeds their elastic properties and ultimately lead to cracks and failure. The non-linear transition between elasticity and failure is associated with damage. Two different approaches are used to model damaged materials: damage mechanics and fracture analysis. Both approaches are reviewed in the next section.

Most damage analyses are based on the evaluation of crack system in the material. Yuan and Harrison (2006) reviewed different approaches for modeling damage. They introduced continuum damage mechanics and statistical approaches, also referred to in their paper as macroscopic and microscopic damage, respectively. The microscopic approach introduces a damage parameter that is the integration of crack volume over total volume (Kachanov 1993). The macroscopic approach uses a damage parameter to modify the elastic tensor that makes the connection between stress and strain in the material.

ACI (ACI MCP 2008 - 446.3R-97) also acknowledged these two dominant techniques used in finite element modeling of fracture in concrete. Yang and Chen (2003) presented smeared fractures as a damaged zone where an infinite number of small parallel cracks are distributed. In the damaged zone, crack propagation was simulated by reducing the material stiffness and strength. The constitutive laws were defined by nonlinear stress-strain relations with strain softening. The discrete crack model is based on displacement discontinuity, which is usually represented by nonlinear interface elements. In the following sections, macroscopic and microscopic damage approaches are discussed. 


\subsection{Damage Mechanics}

The first step in damage analysis consists in defining a damage parameter for deriving a constitutive behavior law. This variable must be able to represent the state of degradation in the material in the damage phase. Carol and Bazant (1991) described damage using the concept of effective (or actual) stress. Figure 1 illustrates the concept of effective stress or real stress, which resists against loads in the undamaged zone. In this figure, $\sigma$ and $\varepsilon$ are stress and strain, respectively, $\sigma^{\prime}$ is the effective stress, which corresponds to undamaged part of material, and $E$ is Young's modulus. According to Lemaitre and Chaboche (1985), the damage parameter is related to the cracked area divided by the total surface in a given direction:

$d=\frac{A_{0}-A}{A_{0}}=(1-a)$

where: $A_{0}$ and $A$ are total and effective surface areas, respectively and $a$ is a coefficient, which presents the undamaged surface (See Figure 1).

According to Equation (1), the damage parameter $d$ can vary between 0 (undamaged) and 1 (fully damaged material).

One of the most common approaches for modeling mechanical damage in concrete was proposed by Mazars (Mazars and Pijaudier-Cabot 1989). The damage model is based on the positive part of the strain tensor. In the presence of large tensile and compressive stresses in concrete, damage is generated and propagated by tensile strain, which opens cracks. (The effect of compression strain is generally less than tensile strain because it closes cracks and does not generate damage.) In this approach, the elastic free energy of concrete $\psi^{e}$ in a damaged condition can be written as a function of the tensorial form damage parameter $\stackrel{d}{=}$ and the elastic strain $\stackrel{\varepsilon}{=}^{e}$ (Chiarelli et al. and 2003 and Shao et al. 2004):

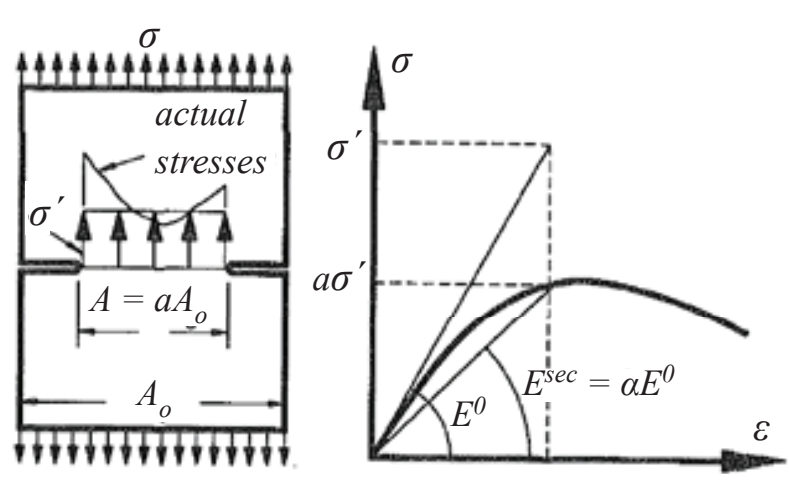

Figure 1. One Dimensional Damage Effect and Concept of Effective Stress (Carol and Bazant 1991)

$$
\begin{aligned}
& \psi_{e}\left(\underline{\varepsilon}^{e}, \underline{\underline{d}}\right)=\frac{1}{2} \lambda\left(\operatorname{tr} \underline{\underline{\varepsilon}}^{e}\right)^{2}+\mu \operatorname{tr}\left(\underline{\varepsilon}^{e}\right)^{2} \\
& +\alpha \operatorname{tr} \underset{=}{\varepsilon^{e}} \operatorname{tr}\left(\stackrel{\varepsilon^{e}}{=} \cdot \underline{=}\right)+\beta \operatorname{tr}\left[\left(\underline{\varepsilon}^{e}\right)^{2} \cdot \underline{d}\right]
\end{aligned}
$$

where: $\alpha$ and $\beta$ are the characteristic parameters, which describe the damage effects on an elastic material and can be obtained experimentally, and $\lambda$ and $\mu$ are the Lamé coefficients, corresponding to the elastic parameters $E$ (Young's modulus) and $v$ (Poisson's ratio).

A description of Lamé coefficients is given in Equation (3):

$$
\lambda=\frac{v E}{(1-2 v)(1+v)} \quad \mu=\frac{E}{2(1+v)}
$$

A linear term depending on $\underline{\underline{\varepsilon}}^{e}$ can also be added to the free energy expression (Halm and Dragon 1998). This term allows damage-induced residual phenomena to be taken into account (residual or permanent strain after unloading $\sigma=0$ ). In this case, the free energy is written as shown in Equation (4):

$$
\begin{aligned}
\psi_{e}(\underline{\underline{\varepsilon}}, \underline{\underline{e}}) & =\frac{1}{2} \lambda\left(\operatorname{tr} \underline{\underline{\varepsilon^{e}}}\right)^{2} \\
& +\mu \operatorname{tr}\left(\underline{\varepsilon^{e}}\right)^{2}+\alpha \operatorname{tr} \underline{\underline{\varepsilon}} \operatorname{tr}\left(\underline{\underline{\varepsilon^{e}}} \cdot \stackrel{d}{=}\right) \\
& +\beta \operatorname{tr}\left[\left(\underline{\underline{\varepsilon^{e}}}\right)^{2} \cdot \underline{\underline{d}}\right]+\gamma \operatorname{tr}\left(\underline{\underline{\varepsilon^{e}}} \cdot \underline{\underline{d}}\right)
\end{aligned}
$$

where: $\gamma$ is also a material parameter. 
The corresponding stress equation is provided as Equation (5):

$$
\begin{aligned}
& \underline{\underline{\sigma}}=\frac{\partial \psi_{e}}{\partial \underline{\underline{\varepsilon}}^{e}}=\lambda \operatorname{tr}\left(\underline{\underline{\varepsilon}}^{e}\right) \underline{\underline{I}}+2 \mu \underline{\underline{\varepsilon}} \underline{\underline{\varepsilon}}^{e} \\
& +\alpha\left[\operatorname{tr}\left(\underline{\varepsilon}^{e} \cdot \underline{\underline{d}}\right) \underline{I}+\operatorname{tr}\left(\underline{\varepsilon}^{e}\right) \cdot \underline{d}=\right. \\
& +\beta\left[\stackrel{\varepsilon^{e}}{=} \underline{=}=\underline{=}=\underline{\underline{\varepsilon^{e}}}\right]+\gamma \underline{\underline{d}}
\end{aligned}
$$

where: $\alpha, \beta$ and $\gamma$ can be estimated from the results of a triaxial test (Shao et al. 2004 and Halm and Dragon 1998).

Chiarelli et al. (2003) introduced the following damage criterion:

$$
f^{d}=\sqrt{\underline{\underline{\varepsilon}}}+\stackrel{\varepsilon^{+}}{=}-\left(r_{0}+r_{1} \operatorname{tr} \stackrel{d}{=}\right)=0
$$

where: $\underline{\varepsilon}^{+}$is the positive part of the strain tensor, and $r_{0}$ and $r_{1}$ are two characteristics of the material that can be estimated by a triaxial compression test. It is assumed that the evolution rate of the damage tensor has the same direction as the tensile strain tensor. (Halm and Dragon 1998).

The rate of damage evolution as a function of loading is described by Dragon et al. (2000):

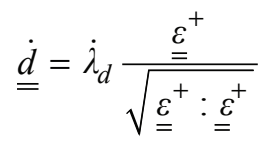

$$
\begin{aligned}
& \rightarrow\left\{\begin{array}{l}
\dot{\lambda}_{d}=0 \quad \text { if } f_{d}=0 \& \dot{f}_{d}<0 \\
\dot{\lambda}_{d}=\frac{\frac{\varepsilon}{\varepsilon}^{+}: \dot{\underline{\varepsilon}}^{+}}{r_{1} \operatorname{tr}^{\underline{\varepsilon}}} \text { if not }
\end{array}\right.
\end{aligned}
$$

In some cases, the rate of damage is related to the crack volume propagation (Shao et al. 2004), to Young's modulus reduction (Lemaitre et al. 2000), or simply to the elastic strain rate (Jun et al. 2003). In this case, damage can be obtained arbitrarily from the elastic strain evolution in each direction:

$$
\underline{\underline{d}}=e \underline{\underline{\varepsilon}}^{e}
$$

\subsection{Fracture Mechanics}

Fracture mechanics is also referred to as crack propagation or crack growth, and is similar to damage. In both approaches, the appearance of cracks is due to excess loading that results in loss of cohesion between two continuous parts of the concrete structure. Contrary to the damage mechanics approach, the fracture mechanics predicts the geometry of the crack pattern in the material. This crack analysis can fully describe the state of concrete degradation and even give a homogenous damage analysis for the fractured zones (Mazars and Pijaudier-Cabot 1996).

Buyukozturk and Hearing (1998) analyzed crack propagation in concrete through and between material constituents. The development of bond cracks at the paste-aggregate interfaces is an important factor in inelastic deformation and in the fracture behavior of concrete. Bond cracks in normal strength concrete often propagate along the interface between paste and aggregates, absorbing energy before linking and forming continuous cracks through the paste at failure. Crack propagation produces a discontinuity in the material. One of the most common finite element techniques for modeling the discontinuity is an automatic remeshing. However, several methods also exist without the discontinuity model. Bouchard et al. (2003) compared three methods for crack propagation: the maximum circumferential stress criterion, the strain energy density fracture criterion, and the maximal strain energy release rate criterion.

\subsubsection{Maximum Circumferential Stress Criterion (MCSC)}

According to this criterion, crack propagation follows the direction of the maximum stress, which also corresponds to the direction of the maximum tensile stress. The approximation here is based on the fact that a crack propagates perpendicularly to the maximum tensile stress. It is a local approach since the direction of the crack growth is directly

where: $e$ is a material characteristic. 
determined by the local stress field along a small circle centered at the crack tip. The crack propagation then proceeds toward the integration point where maximum stress occurs (see Figure 2).

\subsubsection{Minimum Strain Energy Density Criterion (MSEDC)}

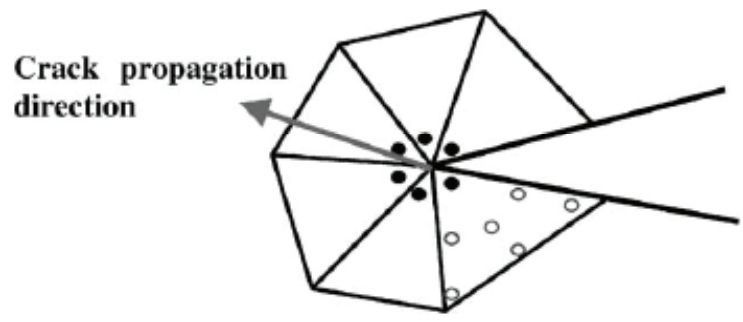

Figure 2. Crack Propagation Direction with Integration Points (Bouchard et al. 2003)

This method considers that high values of strain energy tend to prevent crack growth. Accordingly, the crack grows in the direction that minimizes this energy.

\subsubsection{Maximum Strain Energy Release Rate Criterion (MSERRC)}

The strain energy release rate represents the energy required to increase the crack length. The criterion is obtained when the strain energy release rate is maximal.

Comparisons showed that the MSEDC is less accurate than the two other criteria. The MCSC and MSERRC are equivalent in terms of accuracy and computation time. The MCSC appears to be the easiest to implement in any finite element code. However, it requires a refined mesh at the crack tip. The MSERRC is the most complex but gives good results. It requires a ring of elements around the crack tip, but its accuracy is mesh-independent (Bouchard et al. 2003).

\subsection{Coupling between Damage and Transport Properties}

Hydraulic and diffusion characteristics of concrete can be affected by damage. If concrete is damaged, the microcracks start to increase the porosity and/or connect isolated pores, which can raise the concrete's diffusivity or permeability. This report reviews relationships between damage propagation and hydraulic/diffusion characteristics of concrete.

Permeability of a single crack is often described by the simple Poiseuille flow equation (Snyder 2000, Gerard 1996). According to this theory, a crack is located between two infinite parallel plates. In this case, it is possible to show that:

$K=\frac{w^{2}}{12}$

where: $K$ is the intrinsic concrete permeability and $w$ is the crack's width.

Meschke and Grasberger (2003) present a refined expression for crack width by incorporating roughness and tortuosity effects:

$$
w_{h}=\frac{w^{2}}{\tau_{C}{ }^{2.5}}
$$

In this equation, $w_{h}$ is the equivalent crack width and $\tau_{C}$ is an empirical parameter, which describes the crack roughness. According to Meschke and Grasberger (2003), $\tau_{C}=15$ can be taken into account for cracks in an ordinary concrete (OC).

Picandet et al. (2001) studied the evolution of gas permeability with damage in OC and HPC (highperformance concrete) and HPFC (high-performance steel fiber-reinforced concrete). They considered a simple scalar damage parameter via uniaxial compressive loading that accounted for the reduction of Young's modulus of elasticity. Their results showed that the evolution of gas permeability with damage can be modeled by an arbitrary exponential function: 


$$
\frac{K_{V(d)}}{K_{V(0)}}=\exp \left(\kappa_{1} d^{\kappa_{2}}\right)
$$

in which $K_{V(0)}$ and $K_{V(d)}$ are initial and damaged gas permeabilities, respectively, $d$ is the damage parameter and $\kappa_{1}$ and $\kappa_{2}$ are two experimental parameters.

Other studies focused on the effect of damage on diffusion coefficient. The diffusion coefficient of typical undamaged $\mathrm{OC}$ is about $10^{-12} \mathrm{~m}^{2} / \mathrm{s}$ (Gerard et al. 1998). This coefficient increases until maximum damage is reached for a completely cracked material. In this case, the diffusion coefficient tends to the free water diffusion value, which is about $10^{-9} \mathrm{~m}^{2} / \mathrm{s}$. Gerard et al. (1998) presented the following relationship to take into account the changes in diffusion properties as a function of damage:

$$
D_{d}=D_{0}+D_{\max }\left[1-\frac{1}{1+\left(\frac{d}{d_{c r}}\right)^{n}}\right]
$$

where: $D_{d}, D_{0}$ and $D_{\max }$ are the damaged, initial undamaged, and maximum (for completely cracked material) diffusion coefficients, respectively, $d$ is the damage parameter, and $n$ and $d_{c r}$ are model parameters $(n=5$ and $\left.d_{c r}=0.4\right)$.

According to Gerard et al. (1998), $D_{\max }$ can be estimated as $80 \%$ of the free water diffusion coefficient.

This approach was further refined by Gerard and Marchand (2000) using the double porosity concept. From a microscopic approach based on a crack opening, they found:

$$
D_{d}=\frac{D_{\max }+S D_{0}}{1+S}
$$

where: $S$ is the ratio of the surface perpendicular to the diffusion flow of uncracked concrete, divided by the surface of cracked concrete, and can be calculated as:

$$
S=\frac{1-d}{d}
$$

where: $d$ is the damage parameter, presented by Equation (1).

\subsection{EARLY-AGE CONCRETE DAMAGE}

Early-age cracking is one of the major problems of concrete structures because it can potentially affect the durability of the structures. Fresh concrete analysis requires a thermo-hydro-chemical model coupled to mechanical equations. Rapid evolution of mechanical resistance, drying shrinkage, and heat of hydration are some of the problems related to fresh concrete. Heat of hydration, particularly in mass volume concrete structures, can be detrimental to the durability by generating cracks and consequently reducing the service life. Similarly, high moisture gradients during curing can induce drying shrinkage and cracks. The objective of this section is to explain the mechanical characteristics of early-age concrete and related damage models.

\subsection{Degree of Hydration}

One of the most important parameters for analyzing early-age concrete is estimating its degree of hydration. The degree of hydration is a time dependent variable which defines the hydration progress from the first contact of cement and water to fully hydrated cement paste. Hua et al. (1995) used this parameter to estimate the amount of shrinkage strain. They presented the degree of hydration as a ratio of bonded water at time $t$ to total consumed water for full hydration:

$$
\xi=\frac{W_{t}}{W_{\infty}}
$$


where: $\xi$ is the degree of hydration, $W_{t}$ and $W_{\infty}$ are the quantities of consumed water at time $t$ and for full hydration respectively. $W_{\infty}$ can be estimated according to the cement type and $W_{t}$ is determined by the weight difference between the specimen dried at $105^{\circ} \mathrm{C}$ and heated to $1,050^{\circ} \mathrm{C}$.

Ulm and Coussy (1998) developed this concept and presented the rate of hydration in an Arrhenius form:

$\dot{\xi}=A_{H} \exp \left(-\frac{E_{a}}{R T}\right)$

where: $\dot{\xi}$ is the rate of hydration, $E_{a}$ is the activation energy, $R$ is the gas constant, $T$ is the temperature, and $A_{H}$ can be considered as a normalized affinity.

\subsection{Evolution of Mechanical Characteristics}

Mechanical characteristics of early-age concrete change with time. ACI (ACI 209R-92) provides expressions, based on experimental results, to estimate the compressive strength and Young's modulus of concrete with time. Equations (17) and (18) provide expressions for compressive strength and Young's modulus as a function of time during concrete hydration.

$\left(f_{c}^{\prime}\right)_{t}=\frac{t}{\alpha_{f}+\beta_{f} t}\left(f_{c}^{\prime}\right)_{28}$

where: $\left(f_{c}^{\prime}\right)_{t}$ is the compressive strength at time $t$, $\left(f_{c}^{\prime}\right)_{28}$ is 28-day compressive strength and $\alpha_{f}$ and $\beta_{f}$ are two constants.

$E_{t}=g_{c t}\left[w_{c}^{3}\left(f_{c}^{\prime}\right)_{t}\right]^{1 / 2}$

where: $E_{t}$ is Young's modulus at time $t, w_{c}$ is the specific weight of concrete $\left(\mathrm{kg} / \mathrm{m}^{3}\right),\left(f_{c}^{\prime}\right) t$ is the time dependent compressive strength $(\mathrm{MPa})$, and $g_{c t}$ is a constant (0.043, according to ACI 209R-92).

\subsection{Shrinkage}

According to the definition of ACI, shrinkage is the strain measured on a load-free concrete specimen as a result of induced capillary forces occurring during drying (ACI 209.1R-05). When concrete shrinks with time due to the evaporation of moisture, stress develops if the concrete member is fixed to other structural components, thereby causing cracks. Generated cracks have adverse effects on the service life and durability of the structure. Shrinkage depends on the environment condition (especially the relative humidity), the concrete mixture and the size of the specimen and does not include length changes due to temperature variations. Shrinkage strain is usually measured by casting companion load-free specimens identical to the loaded concrete specimens used to measure the total strain. Typical shrinkage values are given by ACI (ACI 209.1R-05) as dimensionless strains. Long-term concrete shrinkage values are typically between 200 and $800 \times 10^{-6} \mathrm{~mm} / \mathrm{mm}$. Mortar shrinkage values are typically between 800 and $2,000 \times 10^{-6} \mathrm{~mm} / \mathrm{mm}$. Cement paste shrinkage values are typically between 2,000 and $6,000 \times 10^{-6} \mathrm{~mm} / \mathrm{mm}$.

ACI separates the shrinkage strain in two main groups:

- Autogenous shrinkage - The shrinkage occurring during the absence of moisture exchange (as in sealed concrete specimens), due to the hydration reactions taking place inside the cement matrix, is defined as autogenous shrinkage. Autogenous shrinkage is usually small for many normal compressive strength concretes and can usually be neglected. For concrete with water-cement ratios (w/c) less than 0.40 , however, autogenous shrinkage may be a significant component of the total measured shrinkage (ACI 209.1R-05).

- Drying shrinkage - Shrinkage occurring in a specimen that is exposed to drying condition is called drying shrinkage. For normal-strength 
concrete, it is usually assumed that the entire shrinkage strain is due to drying shrinkage, and any contribution from autogenous shrinkage is neglected. Final value of drying shrinkage can be estimated by its relation to water loss of concrete.

Figure 3 illustrates these two types of shrinkage strain and compares their intensity, time of initiation and evolution with time with other sources of strain.

Some factors that affect the drying shrinkage are: concrete quantity, characteristics, size of aggregates, water/cement ratio, size and shape of the specimens (see Equation (19) and relative humidity of environment (see Equation (20). Experimental measurements made on drying shrinkage are very sensitive to the dimensions, shape of the specimens, and boundary conditions (Benboudjema et al. 2005).

\subsubsection{Size Effect on the Shrinkage Strain}

The ACI associates the shrinkage strain to the shape of specimen with the following expression:

$$
\varepsilon^{s h} \propto \frac{1}{(V / S)^{2}}
$$

where: $V$ is the volume of specimen and $S$ is its drying surface area.

\subsubsection{Relative Humidity or Water Loss Effect on the Shrinkage Strain}

The ACI relates the shrinkage strain to the relative humidity by the following expression:

$$
\varepsilon^{s h} \propto 1-\left(\frac{R H \%}{100}\right)^{b}
$$

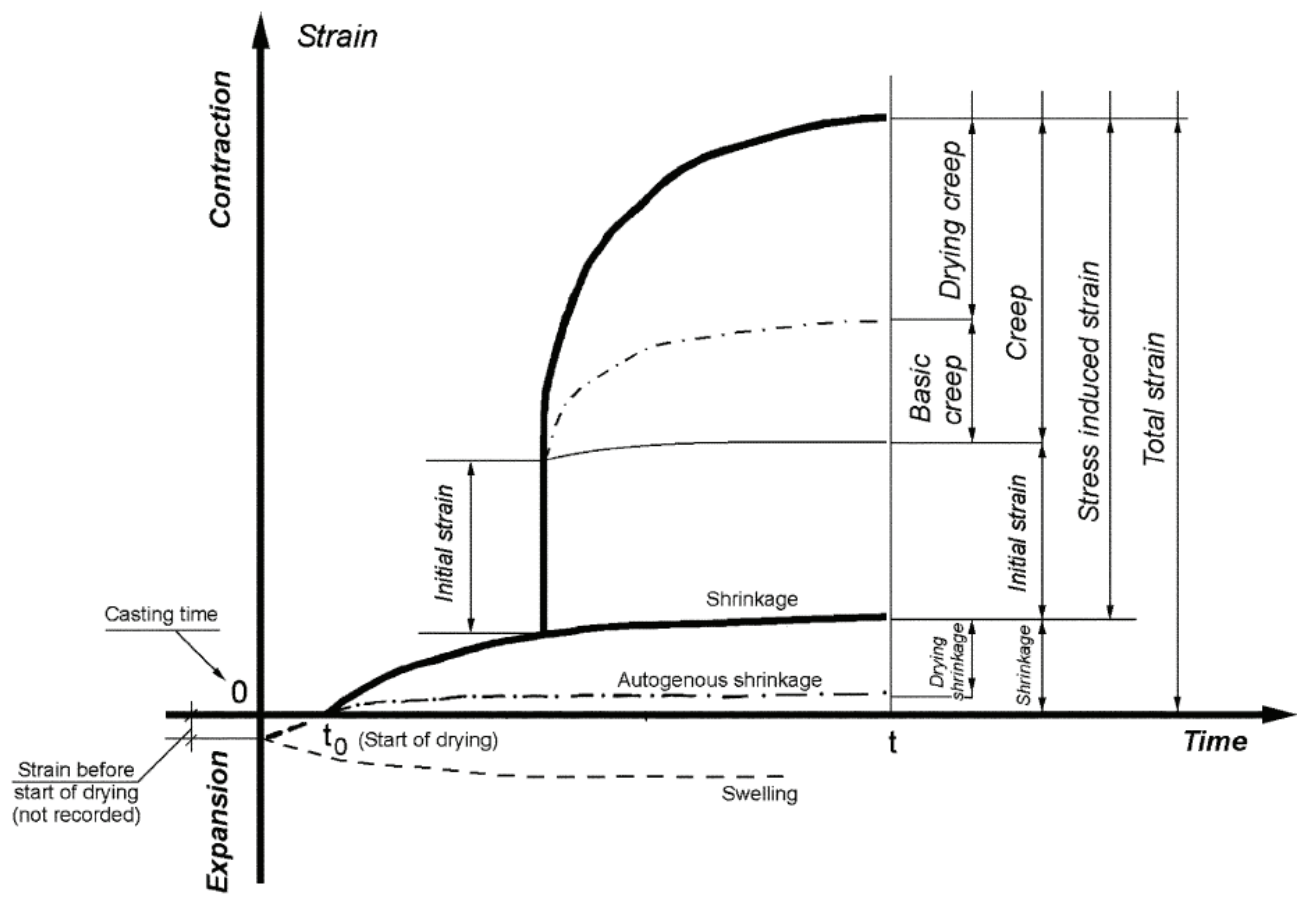

Figure 3. Evolution of Various Strains as A Function of Time (ACI 209.1R-05) 
where: $\varepsilon^{s h}$ is shrinkage strain, $R H$ is the relative humidity in percent and $b$ is a parameter that ranges from 1 to 4 .

Rahman et al. (2000), by studying repaired concrete structures, proposed a linear relationship between the moisture loss and the free shrinkage strain:

$$
\left(\Delta \varepsilon^{s h}\right)_{t}=G\left(\Delta W_{l}\right)\left(\varepsilon^{s h}\right)_{u}
$$

where: $\left(\Delta \varepsilon^{s h}\right)_{t}$ is an increment in free shrinkage strain at time $t,\left(\varepsilon^{s h}\right)_{u}$ is the ultimate free shrinkage strain and $G\left(\Delta W_{l}\right)$ is an experimentally determined function that allows the mapping from moisture loss $\Delta W_{l}$ to the free shrinkage strain.

Benboudjema et al. (2005) also reproduced experimental results, highlighting that drying shrinkage strains are proportional to moisture loss. They proposed the following relationship:

$$
\dot{\varepsilon}^{s h}=k_{d s} \dot{W}_{c} I
$$

where: $\dot{\varepsilon}^{s h}$ is the rate of drying shrinkage strain, $\dot{W}_{c}$ is the rate of water content evolution, $k_{d s}$ is the hydrous compressibility factor, and $I$ is the unit tensor.

Bazant (2001) summarized various aspects for the predicting concrete shrinkage and presented two prediction models to estimate the shrinkage strain. One model is an approximate prediction formula for pore relative humidity distributions, and is required for realistic creep and shrinkage analysis. The other deals with the extrapolation of short time measurements of creep and shrinkage to long times.

The first approach can be written as:

$$
=\frac{\left(\varepsilon^{s h}\right)_{t}}{\left(\varepsilon^{s h}\right)_{u}}=\frac{W_{c}^{0}-W_{c}^{t}}{W_{c}^{0}-W_{c}^{\infty}}
$$

where: $W_{c}^{0}$ is the initial specific evaporable water content in concrete, $W_{c}^{t}$ is the average specific water content, and $W_{c}^{\infty}$ is the final water loss.
The second approach is written as:

$\left(\varepsilon^{s h}\right)_{t+1}=P_{6}\left(\varepsilon^{s h}\right)_{t}$

where: $\left(\varepsilon^{s h}\right)_{t+1}$ is the new value of shrinkage strain obtained from the previous time step value $\left(\varepsilon^{s h}\right)_{t}$, and $P_{6}$ is defined as:

$P_{6}=\frac{\sum_{i}\left(\varepsilon^{s h}\right)_{t}\left(\bar{\varepsilon}^{s h}\right)}{\sum_{i}\left(\varepsilon^{s h}\right)_{t}{ }^{2}}$

where: $\bar{\varepsilon} s h$ and $\left(\varepsilon^{s h}\right)_{t}$ are measured and estimated values of shrinkage strain respectively for the previous time steps and subscript $i$ deals with the number of known data points.

\subsubsection{Total Shrinkage Strain}

According to ACI committee 209 (ACI 209R-92), total axial shrinkage strain varies with time and approaches its ultimate value. It can be predicted using the following formulas:

$$
\begin{array}{ll}
\left(\varepsilon^{s h}\right)_{t}=\frac{t}{35+t}\left(\varepsilon^{s h}\right)_{u} & \begin{array}{l}
\text { Shrinkage after } \\
\text { curing for } 7 \text { days } \\
\text { for moist } \\
\text { cured concrete }
\end{array} \\
\left(\varepsilon^{s h}\right)_{t}=\frac{t}{55+t}\left(\varepsilon^{s h}\right)_{u} & \begin{array}{l}
\text { Shrinkage after } \\
\text { curing for } 1-3 \text { days } \\
\text { for steam cured concrete }
\end{array}
\end{array}
$$

where: $\left(\varepsilon^{s h}\right)_{u}$ is the ultimate shrinkage strain $\left(\approx 800 \times 10^{-6}\right.$ for moist cured and $\approx 730 \times 10^{-6}$ for steam cured, according to ACI-209 for an ordinary concrete).

The calculated shrinkage strains using ACI equations can be transformed into initial strain loads or equivalent temperature gradients using Equation (27):

$$
\varepsilon^{s h} \approx \varepsilon^{T}=\alpha_{T} . \Delta T \Rightarrow \Delta T=\varepsilon^{s h} / \alpha_{T}
$$


where: $\varepsilon^{T}$ is the thermal strain, $\alpha_{T}$ is the concrete thermal expansion coefficient. Using this analogy, the thermal coefficient must be calibrated to fit the shrinkage strains.

\subsubsection{Preventing Shrinkage}

There are various methods for controlling of shrinkage cracking. Good curing practice can decrease considerably the shrinkage. Control joints, shrinkage strips, and shrinkage compensating concrete are some typical methods referred by ACI (ACI 224R-01). Rongbing and Jian (2005) also described a chemical process called ethoxylation to synthesize a shrinkage-reducing admixture.

\subsection{Heat of Hydration}

When cement is mixed with water, the exothermic chemical reactions of the hydration process generate heat. The heat generated by the cement's hydration raises the temperature of concrete. To model the heat of hydration, Cervera et al. (Cervera 1999, Cervera 1999b) added a source term $f_{\xi}$ to the energy conservation equation. This term models the heat generated by the chemical reactions when the cement is mixed with water:

$$
f_{\xi}=Q_{\xi} \dot{\xi}
$$

where: $Q_{\xi}$ is a material constant and $\xi$ is the degree of hydration.

They present a rate of hydration, $\dot{\xi}$, in Equation (29), which has a different form than that in Equations (15) and (16):

$$
\begin{aligned}
\dot{\xi} & =\frac{n_{1}}{n_{0}}\left(\frac{A_{\xi}}{n_{1} \xi_{\infty}}+\xi\right)\left(\xi_{\infty}-\xi\right) \\
& \times \exp \left(-\frac{n_{2} \xi}{\xi_{\infty}}\right) \exp \left(-\frac{E_{a}}{R T}\right)
\end{aligned}
$$

where: $A_{\xi}$ is the initial affinity of the hydration reaction, $\xi_{\infty}$ is the maximum degree of hydration, $E_{a}$ is the activation energy of the hydration process, $R$ is the ideal gas constant, and $T$ is the temperature. The other parameters, i.e., $n_{0}, n_{1}$, and $n_{2}$ are material constants to be determined experimentally.

The hydration process can be coupled with the mechanical model by adding a component to the total strain equation (30), called the hydration strain $\varepsilon^{H}$, which is the contribution from the self-generated heat of cement's hydration. This strain is proportional to the hydration degree:

$\varepsilon^{H}=\alpha_{T}^{\xi} \xi I$

where: $\alpha_{T}^{\xi}$ is the thermal expansion parameter associated to the heat of hydration and $I$ is the unit tensor.

Similar models considering the hydration process were described in (Ulm and Coussy, 1995 and 1998, and Gawin et al. 2006).

\subsection{Damage Model}

Several models have been proposed in order to study the early-age behavior of concrete structures by means of finite element calculations. Calculations are performed by considering phenomena related to fresh concrete characteristics such as thermal expansion from the hydration process, shrinkage strain, chemical strain, etc. Gawin et al. (2006) presented a rheological behavior model according to the following equation:

$\varepsilon=\varepsilon^{e}+\varepsilon^{c}+\varepsilon^{T}+\varepsilon^{o}$

where: $\varepsilon^{e}$ is elastic strain, $\varepsilon^{c}$ is creep strain (sum of viscoelastic and viscous flow strain), $\varepsilon^{T}$ is thermal strain, and $\varepsilon^{o}$ is autogenous strain. 
In this approach, drying shrinkage is assumed to be a part of the elastic strain $\varepsilon^{e}$. (Elastic strain is the sum of drying strain plus strain caused by external loading.) Moreover, the rate of shrinkage strain is modeled as a function of relative humidity evolution. Also, autogenous strain, according to this approach, is supposed to be equivalent to the chemical strain as a function of hydration degree.

Ulm and Coussy (1995) presented another model in which total strain is equal to the sum of elastic, thermal, and chemical strain.

$\varepsilon=\varepsilon^{e}+\varepsilon^{T}+\varepsilon^{s h}$

where: $\varepsilon^{\text {sh }}$ is shrinkage strain which contains autogenous and drying shrinkage. Globally, chemical strain is modeled as a function of hydration degree.

To obtain the expression of elastic strain, the mechanical behavior of fresh concrete can be modeled. Benboudjema and Torrenti (2008) presented an elastic damage model coupled to shrinkage as follow:

$$
\dot{\sigma}^{\prime}=C_{\xi}^{t} \dot{\varepsilon}^{e}
$$

where: $\dot{\sigma}^{\prime}$ is the rate of effective stress, $C_{\xi}^{t}$ is the fourth order elasticity stiffness tensor and $\dot{\varepsilon}^{e}$ is the rate of elastic strain.

The elastic strain, depending on the type of rheological model, can be obtained. Equations (31) and (32) are two examples of such models. $C_{\xi}$ can be obtained knowing Young's modulus and Poisson's ratio. In this approach, Poisson's ratio is supposed to be constant and Young's modulus can be calculated by an equation similar to Equation (18). Finally, the effective stress can be obtained from the total stress $\sigma$ and the damage parameter $d$ :

$\sigma^{\prime}=\sigma(1-d)$
The damage parameter can be calculated by a damage model such as Equation 7). It is important to mention that, in this approach, the elasticity stiffness tensor is considered independent of the damage parameters (different from Equation 5) and the elasticity stiffness tensor varies only as a function of hydration (Young's modulus evolution).

\subsection{SULFATE ATTACK}

\subsection{Introduction}

There are two main theories that attempt to explain the cause of expansion of cement-based specimens subject to sulfate ingression:

- Paste expansion hypothesis and

- Crystal growth pressure hypothesis.

Both hypotheses attempt to explain the formation of gaps around aggregates in concrete as seen in some experiments (Taylor et al. 2001). The gaps may have been caused by stress generated from the growth of ettringite crystals (crystal growth hypothesis) or from the expansion of cement paste due to the formation of fine ettringite crystals in the cement paste prior to the formation of bigger crystals in the gaps (Shimada et al. 2005).

The crystal growth pressure hypothesis suggests that the growth of large ettringite crystals around the aggregates in concrete generates pressure and leads to expansion followed by cracking. From thermodynamic considerations, it was shown that nucleation of ettringite crystals will occur preferentially at crack tips (Shimada et al. 2005 and Tixier and Mobasher 2003b) which results in stress concentration at the crack tips. If this stress is high enough, micro-cracks can form, propagate and coalesce to form macro-cracks and ultimately spalling and failure. 
The paste expansion hypothesis suggests that expansion of the paste leads to formation of gaps around the aggregates. Ettringite recrystallizes in those gaps and results in cracking (Taylor et al. 2001). Due to the heterogeneous nature of the cement paste, cracks are expected to occur in the paste region also.

The preferential location of ettringite formation has also been debated. The two schools of thought are:

- Racks are generated by the stress due to nucleation of ettringite crystals present in the crack tips (Fu et al. 1994) and

- Cracks are caused by the stress generated by the compact crystals present in the pores.

These two theories present competing explanations and accepting either one of them needs more evidence. A brief description of different issues is given by Stark and Bollman (1999). An interesting insight about the factors affecting crystallization in pores can be found in (Scherer 1999).

\subsection{Numerical Modeling of Damage Due to Sulfate Attack}

As mentioned earlier, there is no consensus among researchers regarding the mechanism of sulfate attack. Thus, numerical simulation of the phenomenon is only possible if a fairly conservative approach is taken based on simplified assumptions. Figure 4 depicts a general algorithm used to model sulfate attack, as reviewed in the next sections. When sulfate penetrates a cement-based structure, it reacts with some of the cement hydration products and forms ettringite. As the volume of ettringite is greater than the reactants, it induces strain on the surrounding cement matrix. The strain leads to stress, which results in cracking when the stress exceeds the strength of the material. The presence of cracks increases the diffusivity of sulfate in the material. This results in ingression of more sulfates and the cycle is repeated until the structure fails.
Several numerical models have been developed to numerically simulate the phenomenon of sulfate attack and are listed below:

- Atkinson and Hearne (1989) developed one of the earliest models for sulfate attack of cementitious materials. This model was based on an empirical relation between volumetric expansion of the structure and the total amount of ettringite formed. The correlation between the volume of ettringite formed and the overall expansion observed was established and based on some experimental data.

- Ping and Beaudoin (1992) developed a model based on chemical-thermodynamic principles. This model assumed that the expansion resulted from the conversion of chemical energy in the form of crystallization pressure to mechanical energy, which was sufficient to overcome the cohesion of the system.

- Krajcinovic et al. (1992) developed a simple micromechanical model based on homogenization

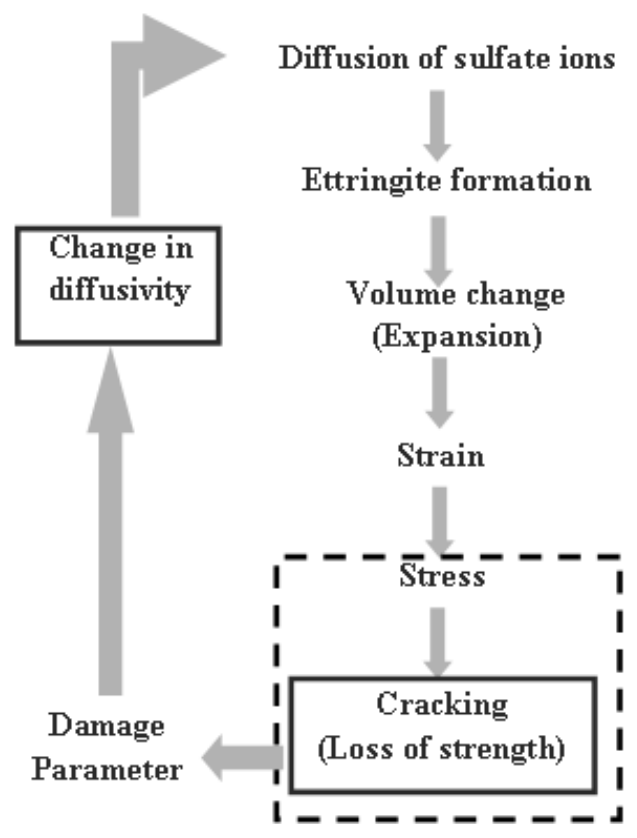

Figure 4. Global Approach for Modeling Sulfate Attack Degradation of Cementitious Materials 
of microscopic responses on a macro scale for evaluation of macro response of the structure. This model has been refined recently (Basista and Weglewski 2008).

- Clifton and Pommersheim (1994) developed a model on the assumption that volume change in the reaction expands the paste, which is linearly dependent on the amount of ettringite formed (following Atkinson and Hearne 1989).

- Gospodinov et al. (1996) developed a model, which includes diffusion of chemical species into cement and its effects (e.g., filling up voids). This model did not include the effects of cracking on the material parameters.

- Saetta et al. 1998 developed a general framework for the evaluation of mechanical behavior under physical/chemical attacks. This model evaluated the coupled effects of moisture, heat and chemical species. Evaluation of expansion and cracking due to chemical attacks was not included in the model.

- Schmidt-Dohl and Rostasy (1999) developed another general model which was based on thermodynamics and kinetics considerations for evaluating degradation of structures under chemical attacks. This model can only be used for species with known thermodynamic data. Also, comparison of the mechanical parameters obtained from this model with experimental data posed considerable difficulty.

- Samson and Marchand et al. (Marchand 2001, Marchand et al. 2002, Samson and Marchand 1999, Samson et al. 1999a, 1999b and 1999c and Samson et al. 2003) developed a numerical model for describing the mechanism of ionic transport in unsaturated cement systems. It included ionic diffusion, moisture transport, and chemical reactions in the use of the extended Nernst-Planck equation and it incorporated the effects of microstructural changes, with a considerable degree of detail, on the transport properties of chemical species in the cementitious materials. But this model did not consider the changes in mechanical properties and their effects on transport properties.

- Tixier and Mobasher (2003) developed a model similar to the one developed by Clifton and Pommersheim (1994) with a different analytical expression assumed for expansion.

- Shazali et al. (2006) developed a general model to evaluate the degradation of concrete under sulfate attack but only in relation to gypsum formation. Damage was quantified by a chemical damage parameter (similar to Saetta et al. 1998) and was incorporated to evaluate the strength of the specimen.

Tixier's (Texier and Mobasher 2003a) and Krajcinovic-Basista's model (Krajcinovic et al. 1992 and Basista and Weglewski 2008) are discussed in more detail because these two models attempted to include the effects of chemical reactions on mechanical properties and the effects of structural damage (e.g., cracking) on the hydraulic properties of structures.

\subsubsection{Tixier's Model}

The purpose of the model is to simulate the response of cement-based structures exposed to external sulfate attack. The changes in the material properties and the hydraulic properties are evaluated using a macroscale damage, represented by the damage parameter $d$ in Equation (1).

In this model, three calcium aluminate phases (e.g., calcium monosulfate, unreacted tricalcium aluminate and tetracalcium aluminate hydrate) are assumed to react with sulfate ions and produce ettringite. The equivalent reaction is given as ${ }^{1}$

$$
C_{\mathrm{av}}+q \bar{S} \rightarrow C_{6} A \bar{S} H_{32}
$$

\footnotetext{
$\overline{{ }^{1} \text { Cement Notation: }} \mathrm{C}=\mathrm{CaO} ; \mathrm{S}=\mathrm{SiO}_{2} ; \mathrm{A}=\mathrm{Al}_{2} \mathrm{O}_{3} ; \mathrm{F}=\mathrm{Fe}_{2} \mathrm{O}_{3} ; \overline{\mathrm{S}}=\mathrm{SO}_{3} ; \overline{\mathrm{C}}=\mathrm{CO}_{2} ; \mathrm{K}=\mathrm{K}_{2} \mathrm{O} ; \mathrm{N}=\mathrm{Na}_{2} \mathrm{O} ; \mathrm{M}=\mathrm{MgO} ; \mathrm{H}=\mathrm{H}_{2} \mathrm{O}$
} 
where: $C_{a v}$ is the average weight of the concentrations of tetracalcium aluminate hydrate, monosulfate and residual tricalcium aluminate and $q$ is an equivalent stoichiometric coefficient of the lumped reaction expressed as:

$$
\mathrm{q}=3 \frac{U C_{3} A}{N}+2 \frac{\text { MMono }}{N}+3 \frac{M T A H}{N}
$$

$U C_{3} A$ is the molar concentration of unreacted tricalcium aluminate, MMono is the molar concentration of calcium monosulfate, MTAH is the molar concentration of the tetracalcium aluminate hydrate, and $N$ is the total molar concentration of the three reactants.

\subsubsection{Diffusion and Chemical Reactions}

The coupled diffusion and chemical reaction processes using Fick's law of diffusion without convection and a second order reaction as expressed below:

$$
\begin{aligned}
& \frac{\partial U}{\partial t}=D \frac{\partial^{2} U}{\partial X^{2}}-k U C_{a v} \\
& \frac{\partial C_{a v}}{\partial t}=-\frac{k U C_{a v}}{q}
\end{aligned}
$$

where: $U$ is the concentration of sulfate, $C_{a v}$ is the lumped concentration of calcium aluminate, $D$ is the effective diffusivity of sulfate ions through the cementbased system, $k$ is the reaction rate constant, $q$ is defined as in Equation (36), and $t$ is the time.

\subsubsection{Strain Development}

Stress within a representative volume element is calculated based on the net change in volume of the reaction products relative to the reactants $\left(\nabla V_{s}\right)$. If $\left(\nabla V_{s}\right)>0$, volumetric strain per representative unit volume of the structure is calculated as:

$$
\bar{\varepsilon}=\frac{\Delta V_{s}}{V}
$$

where: $V$ is the initial volume. Assuming a porosity fraction $b$ is available for deposition of solid products, the net strain is computed as:

$\varepsilon^{\prime}=\bar{\varepsilon}-b \varphi$

Assuming that the material is isotropic, uniaxial strain is calculated as:

$$
\varepsilon=\frac{\varepsilon^{\prime}}{3}
$$

\subsubsection{Stress-Strain Relations}

Subsequently, experimentally determined stressstrain diagram is used to relate the calculated strain from chemical reaction due to volumetric expansion to stress, crack formation and a damage parameter, $d$. An example stress-strain diagram for cementitious materials under tensile stress is shown in Figure 5.

Cementitious materials contain pores and microcracks, which do not affect the strength of the structure in the elastic range (segment $O A$ in Figure 5). In the nonlinear phase (segment $A B$ in Figure 5), new micro-cracks will form, which will finally coalesce to $B$ to form macro-cracks leading the structure to fail as defined by the nonlinear descending curve.

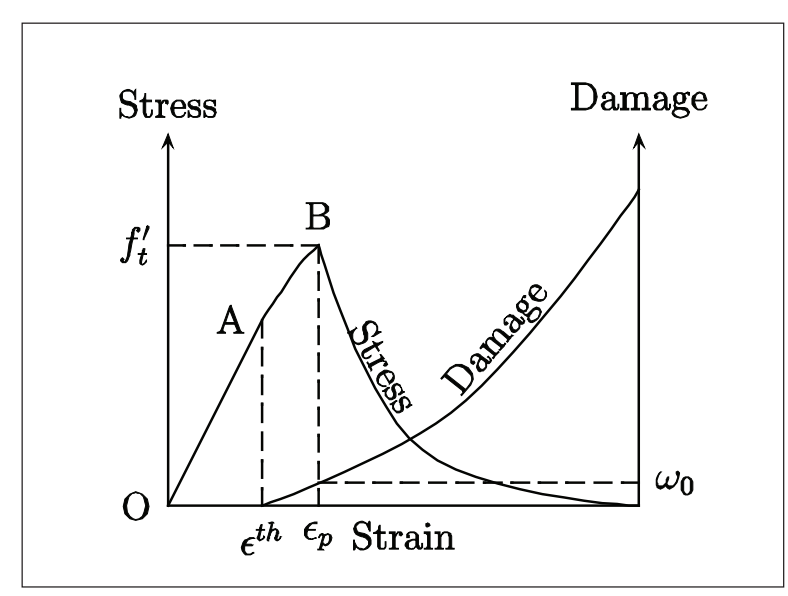

Figure 5. Stress Strain Diagram of Concrete Under Tension 
In the nonlinear ascending phase of stress strain diagram, an equivalent Young's modulus $\left(E^{*}\right)$ can be expressed as:

$E^{*}=E(1-d)$

where: $E$ is the Young's modulus obtained as the initial tangent or the slope of the linear part of the curve (segment $O A$ in Figure 5).

For the uniaxial case, stress $\sigma$, and strain $\varepsilon$ in the nonlinear phase are related as:

$\sigma=E(1-d) \varepsilon$

Assuming that the damage parameter is not affected by the Poisson's ratio of the damaged structure, $d$ can be expressed as (Karihaloo 1995 and Budiansky and O’Connell 1976):

$d \approx \frac{16}{9} k^{\prime}\left(1-\frac{\varepsilon^{t h}}{\varepsilon}\right)^{m}$

where: $\varepsilon^{\text {th }}$ is the threshold strain at which micro-cracks start forming and $k^{\prime}$ and $m$ are calibration parameters.

The parameters are calibrated by combining Eqs. (43)-

(44) and using an experimental stress-strain diagram.

The post-peak response of the structure (segment BC in Figure 5) is modeled by using a relation proposed by Nemat-Nasser and Hori in 1993 (Tixier and Mobasher 2003a) given as:

$$
\frac{\sigma}{f_{t}^{\prime}}=\sqrt{\frac{\tan \left(\pi \omega_{0} / 2\right)}{\tan (\pi \omega / 2)}}
$$

where: $\sigma$ is the stress, $f_{t}^{\prime}$ is the maximum tensile stress, and $\omega_{\mathrm{o}}$ is the damage parameter corresponding to the peak stress.
The unloading is assumed to be elastic and the elastic modulus in the post-peak region is obtained by

$$
E^{*}=\frac{\sigma}{\varepsilon-\varepsilon_{0}}
$$

where: $\varepsilon_{0}=\varepsilon_{p}-\frac{f_{t}^{\prime}}{E_{0}}, \varepsilon_{p}$ is the strain at the maximum tensile stress.

Average expansion is expressed as (Tixier and Mobasher 2003a)

$$
\Delta=\sigma_{r}\left(\frac{1}{\bar{E}}-\frac{1}{E_{0}}\right) L
$$

where: $\bar{E}$ is the average Young's modulus over the cross section, $L$ is the gauge length of the specimen and $\sigma_{r}$ is the residual strength which can be viewed as a scaling factor.

\subsubsection{Change in Diffusivity}

A linear relationship between the damage parameter and diffusivity is assumed in this work and is expressed as

$D(d)=d\left(D_{1}-D_{2}\right)+D_{2}$

where: $D_{1}$ Is the effective diffusivity of sulfate ions through cracked structure and $D_{2}$ is the effective diffusivity of sulfate ions through the uncracked structure.

\subsubsection{Krajcinovic-Basista's Model}

The Krajcinovic-Basista's model incorporates coupled physico-chemical processes of non-steady diffusion with chemical reaction, topochemical reaction ${ }^{2}$ of ettringite formation, expansion of

\footnotetext{
2 "A reversible or irreversible reaction that involves the introduction of a guest species into a host structure and that results in significant structural modifications to the host..." (IUPAC 1997).
} 
ettringite crystals, formation of micro-cracks and evolution to macro-cracks. This is a unique attempt to capture the behavior at the micro and macro-scales and the transition across these scales. For this model, the diffusion process and the second order chemical reaction are evaluated the same way as in Tixier's model (see (41) and (42)) but the diffusivity of sulfate in uncracked cement-based structure is calculated from (Garboczi and Bentz 1992):

$$
\begin{aligned}
\frac{D_{i}}{D_{i}^{\mu}} & =0.001+0.07 \varphi_{c a p}^{2} \\
& +1.8 H\left(\varphi_{c a p}-0.18\right)\left(\varphi_{c a p}-0.18\right)^{2}
\end{aligned}
$$

where: $D_{i}^{\mu}$ is the diffusivity in the free solution and $\varphi_{\text {cap }}$ is the fraction of capillary porosity.

Also, the expansive strain due to ettringite formation in this model is calculated similar to the way in Tixier's model (Tixier and Mobasher 2003).

\subsubsection{Calculation of Damage Parameter}

The damage parameter is used to bridge micro-scale and macro-scale responses. In the micro-scale, the growing ettringite crystal exerts pressure on the surrounding cement paste matrix. If the stress exceeds the fracture toughness of the cement paste matrix, micro-cracks start to propagate and finally coalesce to form macro-cracks.

Assuming that a small notch exists at the matrixinclusion interface, the stress intensity factor can be approximately calculated as

$$
K_{I}=\frac{2 p^{n}}{\sqrt{\pi a_{c}}}\left(a_{c}-\sqrt{a_{c}^{2}-r_{a 0}^{2}}\right)
$$

where: $p^{n}$ is the swelling pressure, $r_{a o}$ is the initial radius of the calcium aluminate particle and $a_{c}$ is the mean half crack length of penny shaped cracks.
The terminal half crack length at the completion of reaction by a single $C_{3} A$ particle can be approximately calculated using the fracture toughness $K_{I C}$ of the cement paste. The damage parameter, $\omega$, is then calculated using the following equation (Budiansky and O'Connell 1976):

$\omega=N_{a} a_{c}^{3}$

where: $N_{a}$ is the number of particles of $C_{3} A$ consumed (equivalent to the number of cracks if assumed to be under mean field effects) and $a_{c}$ is the half crack length.

\subsubsection{Stress-Strain Relations}

The relation between stress and strain at the macro scale is given as

$\varepsilon=S(\omega): \sigma+\varepsilon^{I}$

where: $\sigma$ is the stress at macro scale, $S(\omega)$ is the compliance matrix which reflects the degradation in material properties through $\omega$ and

$$
\varepsilon^{I}=f^{I} \varepsilon^{* *}
$$

where: $f^{I}$ is the inclusion volume density and $\varepsilon^{* *}$ is the eigenstrain.

The compatibility condition in one dimension is expressed as

$$
\frac{d^{2}}{d x^{2}}\left[\sigma(x, t)+E(x, t) f^{I}(x, t) \varepsilon^{* *}(x, t)\right]=0
$$

For the case of no external traction on the structure, the expansion is given as

$$
\begin{aligned}
\varepsilon & =\frac{1}{E(x, t)} \int \varepsilon^{* *}(x, t) E(x, t) f^{I}(x, t) d x \\
& =f^{I}(x, t) \varepsilon^{* *}(x, t)
\end{aligned}
$$


where: $\omega_{c}$ is the conduction percolation threshold at which a spanning cluster traverses and joins with another spanning cluster.

Its value is obtained as 0.182 from the results of numerical simulation by Charlaix in 1986 (Basista and Weglewski 2008).

\subsubsection{Change in Material Properties}

The effects of cracking on the mechanical as well as hydraulic properties of the structure are related to the damage parameter. Change in effective diffusivity through the structure due to crack formation in the mean field regime, when cracks are dilute in concentration allowing assumption of a homogeneous structure under the influence of average stresses, is defined as:

$$
D=D_{0}\left(1+\frac{32}{9} \omega\right)
$$

following a model developed by Salganik (1973).

where: $D_{0}$ is the diffusivity in the uncracked cementbased structure and $\omega$ is the damage parameter. Young's modulus and Poisson's ratio are obtained from the damage parameter using the following relations (Budiansky and O'Connell 1976):

$$
\begin{aligned}
& E=E_{0}\left(1-\frac{16}{9} \omega\right) \\
& v=v_{0}\left(1-\frac{16}{9} \omega\right)
\end{aligned}
$$

where: the subscript " 0 " denotes the uncracked matrix and the non-subscripted parameters denote cracked matrix.

A scaling law is used to describe diffusion in the percolation regime, where micro-cracks coalesce to form a macro-crack, following numerical simulations by Stauffer in 1985 (Krajcinovic et al. 1992):

$$
D_{p} \propto\left(\omega-\omega_{c}\right)^{\mu_{\omega}}
$$

where: $\mu_{\omega} \approx 2$ is a universal exponent for a three-dimensional case.

The modified diffusion coefficient is now given as

$D=D_{0}\left(1+\frac{32}{9} \omega\right)+D_{p}$

where: $D_{p}=D_{0} \frac{\left(\omega-\omega_{c}\right)^{2}}{\left(\omega_{e c}-\omega\right)}$ for $\omega_{c}<\omega<\omega_{e c} . \omega_{c}$ is the conduction percolation threshold as mentioned before and $\omega_{e c}$ is the elastic or rigidity percolation threshold at which a cluster of cracks transects the volume.

The stiffness of the structure beyond the elastic percolation threshold is essentially zero. In the crossover regime from conduction percolation threshold to elastic percolation threshold the variations of elastic moduli need more investigation. From a self-consistent estimation, the rigidity percolation threshold comes out to be $9 / 16$ which is 0.8 times the value of the threshold obtained through numerical simulation by Sornette (Krajcinovic et al. 1992). Krajcinovic et al. (1992) suggested, assuming the percolation threshold to be $9 / 16$, that the elastic moduli can be assumed to be linearly dependent on the damage parameter in the percolation regime. Basista and Weglewski (2008) suggested that the linear relation in the percolation regime is probably not a good approximation but rather that this regime needs to be modeled using percolation theory. However, the biggest challenges in doing so are (1) translation of the damage parameter obtained from the mean field regime to an equivalent porous structure and then (2) translating the response of the structure back to an equivalent damage parameter that will reflect the damaged state on the macro-response of the structure. 


\subsection{CORROSION-INDUCED CRACKING}

Reinforcement corrosion is one of the most important problems affecting the durability of concrete structures. When steel reinforcement corrodes, the chemical reaction produces corrosion products that occupy more volume than the original steel. This creates a pressure on the concrete cover (Dekoster et al. 2003, Bhargava et al. 2006) and hoop or tangential tension around the rebar. The radial component of this pressure increases with the corrosion product expansion. Cracking occurs when the tangential component or hoop stress exceeds the maximum tensile strength of concrete. The crack propagates from the steel-concrete interface to the surface of the concrete. Crack propagation analysis can give a criterion for an estimate of the structure's durability or service life.

This report focuses only on the mechanical aspect of the corrosion problem. The corrosion process is initiated by the ingress of chloride and carbonation. These topics are covered in the chemical degradation report.

\subsection{Corrosion Mechanism}

The mechanism of corrosion using an analytical calculation base for a single reinforcement was described by Liu and Weyers (1998). They introduced a simple model that can estimate the time needed for producing a crack in the concrete cover.

Figure 6 shows the three phases of damage propagation. On the figure, $R_{s}$ is the initial radius of the steel bar, $c$ is the thickness of the concrete cover layer, $d_{0}$ is the width of the high porosity interfacial concrete zone, $R_{i}$ is $R_{s}$ plus $d_{0}, R_{0}$ is $R_{i}$ plus $c, d_{1}$ is the radius of steel lost by corrosion, $P_{r}$. is the pressure induced by the corrosion product, $d_{c}$ is the deformation under this pressure, and $R_{c}$ is the radius of the damaged zone. In phase (I), corrosion starts. In phases (II), corrosion consumes a portion of the steel bar, fills the porous zone and starts to apply pressure on the concrete cover. Finally, in phase (III), tangential component or hoop stress of radial pressure $P_{r}$ damages the surrounding zone.

The embedded reinforcement is usually surrounded by a ring of concrete having a high porosity. When corrosion starts, the process consumes steel. The

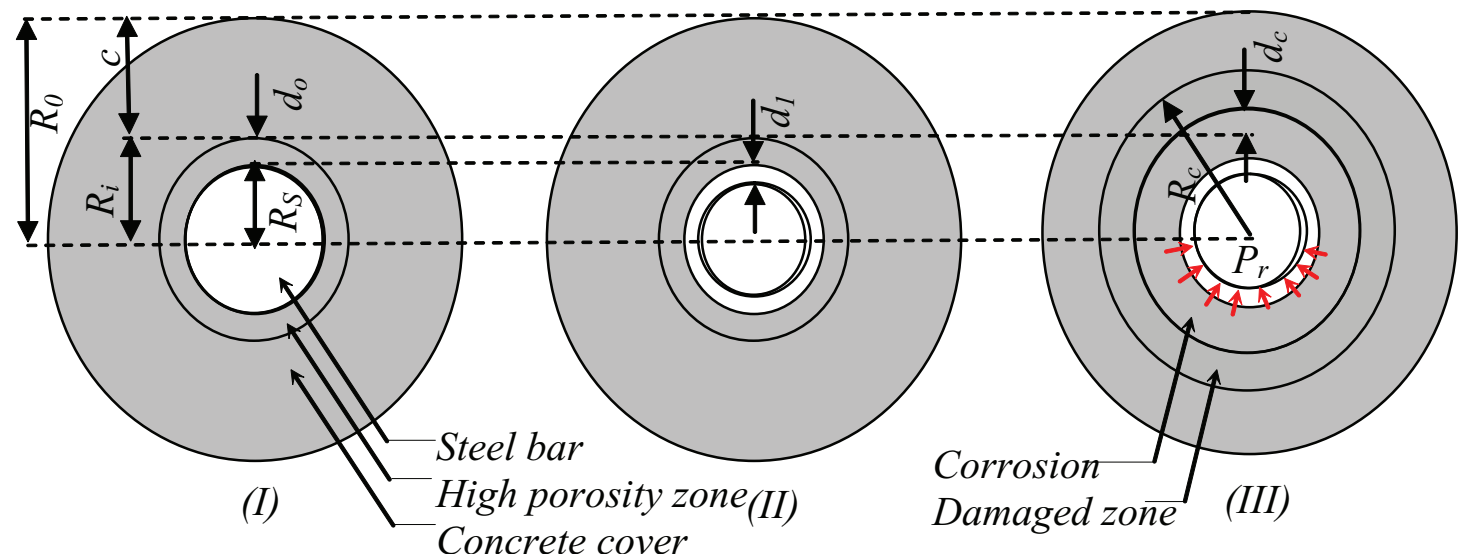

Figure 6. Rust Propagation and Induced Pressure After Bhargava et al. (2006) 
corrosion products, which occupy more volume than the original steel, fill this porous zone easily. It is assumed that filling this zone does not change the stress around the reinforcement. So, the initial radius of the reinforcement system, $R_{i}$, is considered equal to the initial radius of the steel bar, $R_{s}$, in the high porous concrete zone $d_{0}$ (Figure 6). The distance $d_{1}$ in Figure 1 shows the radius of steel lost by corrosion. When $d_{0}$ is filled completely, more corrosion product creates a pressure $P_{r}$. It is assumed that this pressure is uniform on the external face of the reinforcement, inside of the corroded zone and on the internal face of the concrete cover in contact with the corroded zone. This pressure is applied to the concrete and induces a deformation as shown by $d_{c}$ in Figure 6 . This imposed deformation creates a damaged zone with radius $R_{c}$. Bhargava et al. (2006) described an analytical method that estimates the necessary time that $R_{c}$ can reach $R_{0}$, corresponding to a completely damaged concrete cover.

A similar description was proposed by Wang and Liu (2006).

\subsection{Corrosion Expansion}

One of the most important steps in corrosion modeling is the estimation of the expansion caused by the formation of corrosion products. Empirical relationships have been proposed to model the imposed displacement by corrosion products around the reinforcement.

Dekoster et al. (2003) proposed that the expansion thickness equals two times the initial thickness. Du et al. (2006) described the crack propagation in concrete cover in four steps:

- Internal cracking due to radial expansion and tangential tension, which creates the first crack inside the concrete cover;

- Before the internal cracks penetrate the concrete cover, external cracks appear on the surface of the material;
- Penetration cracking when outside cracks reach inside cracks and;

- Ultimate cracking of concrete under tensile stress decreases the resistance and increases the softening until no further development of cracks occurs.

Du et al. (2006) proposed typical values of radial expansion of $0.005,0.0012,0.0015$, and $0.0017 \mathrm{~mm}$ for internal, external, penetration, and ultimate cracking, respectively, for a rebar with $8 \mathrm{~mm}$ diameter and $8 \mathrm{~mm}$ concrete cover.

Wang and Liu (2006) used a linear function between the volume of accumulated corrosion product $\Delta V_{C}$ and the original volume of reinforcement $V_{R}$ :

$\Delta V_{C}=n_{V} \Delta V_{R}$

where: $n_{V}$ is the ratio of the rust volume on initial steel volume and varies between 1.7 and 6.15 according to different corrosion products.

Bhargava et al. (2006) used an equation, which relates the mass density change of corrosion products to their chemical formula:

$\rho_{r}=\frac{\rho_{s}}{\alpha_{1} \alpha_{2}}$

where: $\rho_{r}$ and $\rho_{s}$ are mass densities of corrosion products and original steel respectively, and $\alpha_{1}$ and $\alpha_{2}$ are two coefficients, which depend on the type of corrosion product. They proposed the values for these two coefficients (Table 1).

\subsection{Rate of Corrosion}

Wang and Liu (2006) proposed a corrosion propagation time that is a function of the bar radius, concrete cover thickness and annual mean corrosion current density. The corrosion current density is also discussed by Ahmad (2003). It is related to the corrosion rate by: 
Table 1 . Coefficient $\alpha_{1}$ and $\alpha_{2}$ for Different Types of Rust Production in Concrete

\begin{tabular}{cllllll} 
Corrosion Products & $\mathbf{F e O}$ & $\mathrm{Fe}_{\mathbf{3}} \mathbf{O}_{\mathbf{4}}$ & $\mathrm{Fe}_{2} \mathbf{O}_{3}$ & $\mathbf{F e}(\mathbf{O H})_{2}$ & $\mathbf{F e}(\mathbf{O H})_{3}$ & $\mathbf{F e}(\mathbf{O H})_{3} \cdot \mathbf{3 H}_{2} \mathbf{O}$ \\
\hline$\alpha_{1}$ & 0.777 & 0.724 & 0.699 & 0.622 & 0.523 & 0.347 \\
\hline$\alpha_{2}$ & 1.80 & 2.00 & 2.20 & 3.75 & 4.20 & 6.40 \\
\hline
\end{tabular}

$J_{r}=\left(\frac{W}{F}\right) I_{c o r}$

where: $J_{r}$ is the instantaneous corrosion production rate, $W$ is the equivalent weight of steel, $F$ is Faraday's constant and $I_{c o r}$ is the corrosion current density that is measured on steel bar.

Martin-Pérez (1999) presents a similar procedure for computing $J_{r}$ using the ionic valence of the iron ion and equivalent molar weight of corrosion products. The proposed relationship is written as:

$J_{r}=\left(\frac{W}{z m_{F e} F}\right) I_{c o r}$.

where: $z$ is the ionic valence of ferric iron and equals 2 according to the following equation:

$\mathrm{Fe} \rightarrow \mathrm{Fe}^{2+}+2 e^{-}$

and $m_{F e}$ is the number of moles of iron needed to produce one mole of corrosion product.

It is equal to 3 for the case of magnetite formation according to the following equation:

$3 \mathrm{Fe}+2 \mathrm{O}_{2} \rightarrow \mathrm{Fe}_{3} \mathrm{O}_{4}$

where: $W$ is the molar mass of corrosion product, equals to $231.14 \mathrm{~g} / \mathrm{mol}$ for magnetite.
Assuming a homogenous distribution, the mass of the corrosion product can be calculated as:

$m_{r}=2 J_{r}(\Delta t) \pi R_{s}$

where: $m_{r}$ is the mass of the corrosion product, $R_{s}$ is the reinforcement radius and $\Delta t$ is the elapsed time.

The total expansion volume of corrosion product, $\Delta V_{c}$, can be calculated according to Martin-Pérez (1999):

$\Delta V_{C}=m_{r}\left(\frac{1}{\rho_{r}}-\frac{\alpha}{\rho_{s}}\right)$

This gives a displacement equal to (see Figure 6):

$d_{c}=\frac{\Delta V_{C}}{2 \pi R_{s}}$

This displacement, $d_{c}$, is the thickness of corrosion products on the rebar as a function of time. It can be imposed homogenously around the reinforcement for to model the mechanical effect of the corrosion process.

\subsection{Modeling the Damage Induced by Corrosion}

Most models found in the literature are based on semi-analytical approaches that estimate the time to cracking from a simple mechanical analysis. Two such models were reviewed. Another model based on a coupled multiphysic analysis was also reviewed and presented at the end of this chapter. 


\subsubsection{Liu and Weyers' Model (1998)}

According to the definition, the critical mass of corrosion products is the mass that fills the porous area surrounding the reinforcement and sets pressure on concrete cover until crack production and failure.

This critical mass calculated in Liu and Weyers' approach is the sum of two terms:

- Mass of rust for filling the porous zone that can be obtained according to Figure 6 using:

$M_{P}=2 \pi \rho_{r} R_{s} d_{0}$

where: $M_{P}$ is the mass of corrosion products needed to fill the porous ring around the reinforcement, and $\rho_{r}$ is the density of the corrosion products.

- Mass of new corrosion products that form after the porous zone is filled. These new corrosion products apply pressure on the concrete cover and generate a stress greater than the tensile strength of concrete. The mass per unit rebar length of these additional corrosion products is given by:

$M_{S}=\rho_{r}\left(2 \pi\left(R_{s}+d_{0}\right) d_{c}+\frac{M_{s t}}{\rho_{s}}\right)$

where: $M_{S}$ is the mass of the corrosion products required to produce a cracked zone with thickness equal to $d_{c}$ the thickness of corrosion. $M_{s t}$ and $\rho_{s}$ are steel bar mass consumed and steel mass density, respectively.

The critical corrosion product mass is thus given by the sum of Equations (70) and (71), after neglecting the term $d_{o} d_{c}$ as being very small:

$$
M_{c r i t}=\rho_{r}\left(2 \pi R_{s}\left(d_{0}+d_{c}\right)+\frac{M_{s t}}{\rho_{s}}\right)
$$

The stress-strain relationship, for a concrete cover with thickness $C$ around the reinforcement (see Figure 6), can be estimated analytically in a cylindrical coordinate system (Timoshenko and Goodier 1970).
Assuming that the formation of corrosion products corresponds to an imposed displacement $d_{c}$, the pressure on the concrete shell around the rebar is given by:

$$
P_{r}=\frac{E_{e f} d_{c}}{\left(R_{s}+d_{0}\right)\left(m_{C}+v\right)}
$$

where: $v$ is the Poisson's ratio and $E_{e f}$ is the effective Young's modulus, given by:

$E_{e f}=\frac{E}{1+\theta}$

where: $E$ is Young's modulus of the undamaged concrete and $\theta$ equals to the creep coefficient.

The parameter $m_{c}$ is given by:

$$
m_{C}=\frac{\left(\left(R_{s}+c\right)^{2}+R_{s}^{2}\right)}{\left(\left(R_{s}+c\right)^{2}-R_{s}^{2}\right)}
$$

By supposing a thick-wall concrete cylinder around the reinforcement with a linear stress distribution from the inside surface of concrete cover to the outside and assuming that, at the failure limit, the outside stress is equal to the tensile strength of concrete, pressure can be calculated as:

$$
P_{r}=\frac{c f_{t}}{R_{s}}
$$

in which $f_{t}$ is the tensile strength of concrete.

Combining Equation (76) with Equation (73) yields an expression for $d_{c}$, the concrete deformation due to the formation of corrosion products.

$$
d_{c}=\frac{c f_{t}}{E_{e f}}\left(m_{C}+v\right)
$$

Equations (62) and (77) can be replaced in Equation (72) to find the critical corrosion mass products. 


$$
M_{c r i t}=\frac{2 \pi \rho_{r} \rho_{s} R_{s}}{\rho_{s}-\alpha_{1} \rho_{s}}\left(\frac{c f_{t}}{E_{e f}}\left(m_{C}+v\right)+d_{0}\right)
$$

Liu and Weyers (1998) presented the corrosion product formation rate as a function of time $t$ as the following equation:

$$
\frac{d m_{r}}{d t}=\frac{\kappa_{C}}{m_{r}}
$$

The coefficient $\kappa_{C}$ is the rust production rate and is defined as (Thoft-Christensen 2000):

$$
\kappa_{C}=0.766 \times 10^{-3} R_{s} i_{c o r}
$$

where: $i_{c o r}$ is the mean annual corrosion rate, obtained from experimental measurements.

The time to initiate concrete cover cracking can be calculated by integrating Equation (79):

$$
t=M_{c r i t}^{2} / 2 \kappa_{C}
$$

\subsubsection{Martin-Pérez's Model (1999)}

Martin-Pérez (1999) assumed a concrete cover formed by a cracked and an uncracked layer (see Figure 7). The analytical solution for the tangential stress, under an imposed pressure $P_{r}$ at the boundary of the cracked zone (with radius $R_{c}$ ) can be written as:

$\sigma^{t}=\frac{R_{\mathrm{s}} R_{c} R_{r}}{\left(c+R_{\mathrm{S}}\right)^{2}-R_{\mathrm{c}}^{2}}\left(1+\frac{\left(c+R_{S}\right)^{2}}{R_{c}^{2}}\right)$

In this equation, $P_{r}$ is the pressure at the steel/ concrete interface.

The pressure distribution inside the concrete cover is given by (see Figure 7):

$$
P_{C}=P_{r} \frac{R_{s}}{R_{c}}
$$

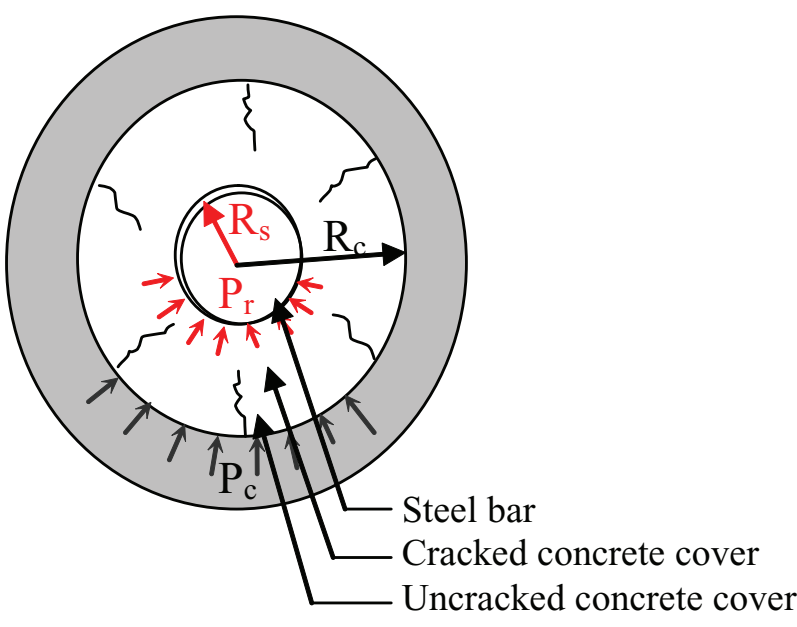

Figure 7: Pressure Distribution Around the Reinforcement

It is assumed that an internal crack occurs when the tangential stress, given by Equation (82), exceeds the concrete tensile strength.

By considering Equations (80) and (81), a value of $R_{c}$ for which the tangential stress is maximum can be found. This is illustrated by drawing the ratio of $P_{r} / \sigma_{t}$ as a function of $R_{C}$. Figure 8 shows this curve for a steel rebar of $16-\mathrm{mm}$ diameter and a $20-\mathrm{mm}$ concrete cover.

This figure shows that, for a small $R_{c}$ value (radius of damaged zone, see Figure 7), the $P_{C}$ value is high but $c$ is large; inversely for a large amount of $R_{c}, P_{C}$ is smaller but $c$ is decreased. The optimal value of $R_{c}$ can be found by calculating the derivative $P_{r} / \sigma_{t}$ with respect to $R_{c}$, which gives:

$$
R_{r}^{\operatorname{Max}}=0.486\left(c+R_{s}\right)
$$

Substituting $R_{c}^{M a x}$ in Equation (82) and replacing the tangential stress with the tensile strength of concrete $f_{t}$ gives the maximum internal pressure that can be sustained by the concrete cover before cracking:

$P_{r}^{\operatorname{Max}}=f_{t} \frac{\left(\frac{c}{2 R_{s}}\right)+0.5}{1.665}$ 


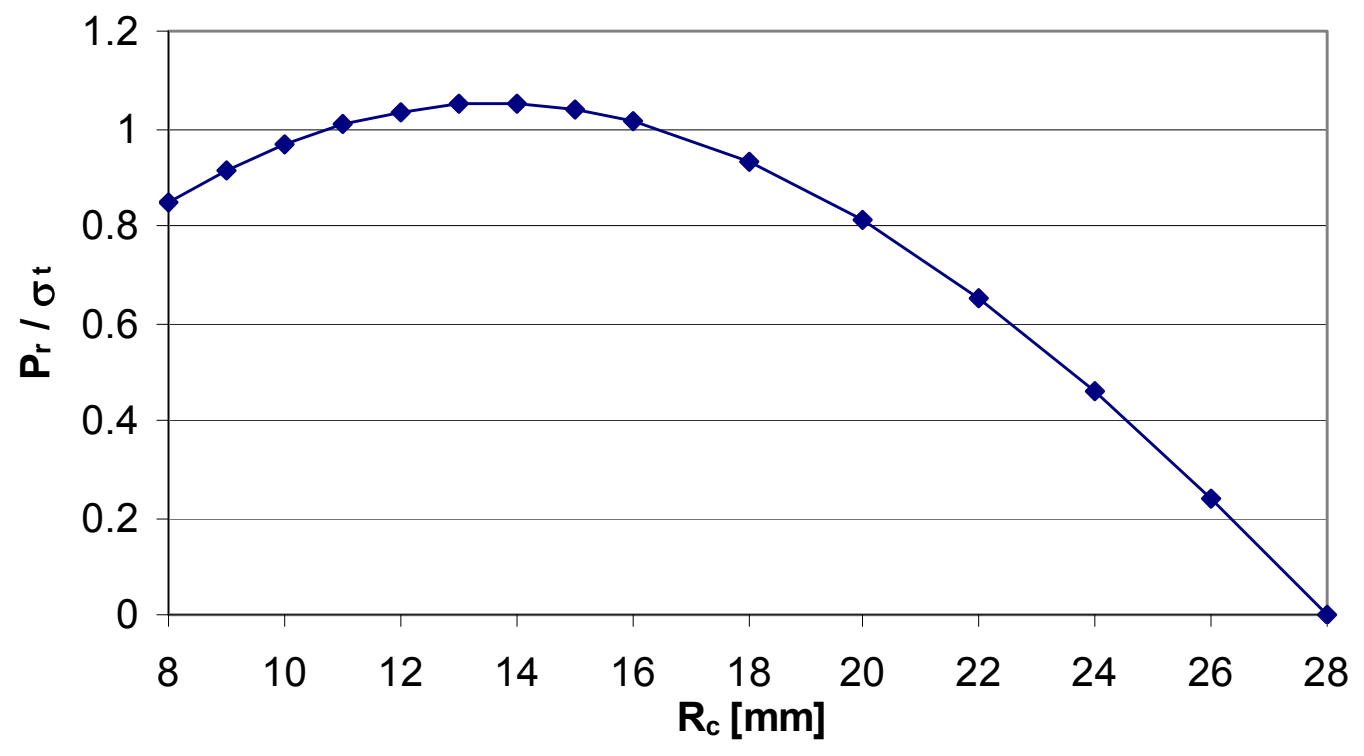

Figure 8. Maximum Pressure Resistance of Concrete Cover as A Function of Radius

This calculated $P_{c}^{M a x}$ value corresponds to the strain imposed by the corrosion expansion:

$\varepsilon_{v}=\frac{2 P_{r}^{\operatorname{Max}}}{E_{r}}\left(1+v_{r}\right)\left(1-2 v_{r}\right)$

where: $\varepsilon_{v}$ is the dilatation (volumetric strain) and $E_{r}$ and $v_{r}$ are Young's modulus and Poisson ratio of rust production, respectively.

$E_{r}$ is related to the bulk modulus of rust:

$E_{r}=3(1-2 v r) K_{r}$

The values $v_{r}=0.499$ and $K_{r}=2$ GPa were used by Martin-Pérez.

The expansion volume of concrete can be calculated from the dilatation:

$\Delta V_{C}=\varepsilon_{v} V$

where: $V$ is the initial volume of steel; it gives the mass of rust production:

$$
M_{c r i t}=\Delta V_{C} /\left(\frac{1}{\rho_{r}}-\frac{\alpha_{1}}{\rho_{s}}\right)
$$

The corresponding time for the production of the critical mass of corrosion products (mass necessary to initiate cracking), based on Equation (67), is given by:

$t=M_{c r i t} /\left(2 \pi R_{s} J_{r}\right)$

where: $J_{r}$ was defined by Equation (63).

\subsection{Numerical Simulation of Corrosion Damage}

Beside the semi-analytical models studied, concrete cracking by corrosion can also be modeled by numerical methods. Numerical models are particularly useful for complicated reinforcement geometries. The implementation of such model in a numerical code allows taking into account several multi-physics phenomena that play an important part in the estimation of the service life of materials. Chen and Mahadevan (2008) presented a numerical model of concrete cracking due to corrosion, coupled with heat transfer and chloride penetration. They compared the crack propagation patterns in concrete structures using both a constant and a dynamic corrosion rate, as a function of the chloride content. 
Equation (91) presents the corrosion current model used by Chen and Mahadevan, based on experimental data from (Liu and Weyers 1998):

$$
\begin{aligned}
I_{c o r} & =0.926 . \exp \left[7.98+0.7771 \ln \left(1.69 C_{t}\right)\right. \\
& \left.-\frac{3006}{T}-0.00011 R_{r}+2.24 t^{-0.215}\right]
\end{aligned}
$$

where: $I_{c o r}$ is the corrosion current density, $C_{t}$ is the total chloride content, $T$ is temperature, $t$ is corrosion time, and $R_{r}$ is the ohmic resistance of the concrete cover. $R_{r}$ is also related by an empirical regression relationship to the total chloride content:

$$
R_{r}=\exp \left[8.03-0.549 \ln \left(1+1.69 C_{t}\right)\right]
$$

Figure 9 shows the radial displacement on the concrete-steel interface, obtained by two methods.

To model cover cracking, Chen and Mahadevan (2008) applied a linear elastic model for the tension part of the stress and a perfectly plastic model for the compression part for which the ascending part follows the Desayi and Krishnan model with the following expression:

$$
\sigma=\frac{E \varepsilon}{1+\left(E \varepsilon / 2 f_{c}^{\prime}\right)}
$$

where: $\sigma$ and $\varepsilon$ are stress and strain, respectively, $E$ is the Young's modulus and $\left(f_{c}^{\prime}\right)$ is the ultimate compressive strength. Application of the numerical code allows using a more sophisticated mechanical model to analyze cracking and damage propagation.

\subsection{ALKALI-SILICATE REACTION}

Alkali-silica reaction (ASR) is one of the most important causes of concrete structural damage. ASR has been observed on many different types of structures including dams, pavements, and bridges. Ever since its discovery in 1940 by Stanton (Stanton 1940), many studies have been conducted to describe the mechanisms of ASR and how various parameters affect the expansion of aggregates and the production of cracking. But this phenomenon remains unclear and research is still ongoing.

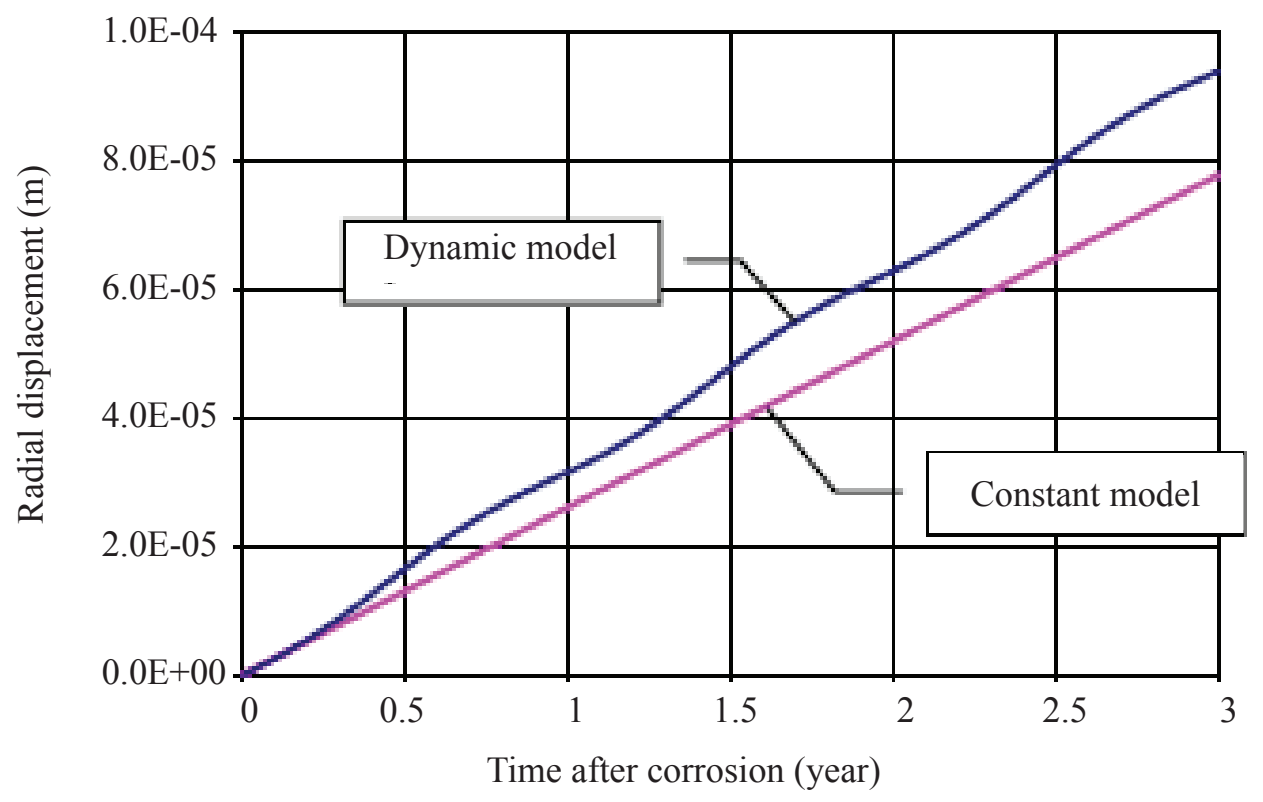

Figure 9. Variation of the Radial Displacement Versus Time (Chen and Mahadevan 2008) 


\subsection{Mechanisms of ASR}

It is generally agreed that the three essential components for the ASR in concrete structures are the presence of: (1) reactive silica (from aggregates), (2) sufficient alkalis (mainly from Portland cement, but also from other sources, internal or external, of concrete), and (3) sufficient moisture.

The term "reactive silica" refers to aggregates that tend to react with the alkali hydroxides (sodium and potassium) to form ASR gel. It is important to note that not all siliceous aggregate can be the source of ASR. The inherent reactivity of aggregates depends on several factors including; mineralogy, degree of crystallinity, and solubility of the silica in pore solution. Aggregates susceptible to ASR must also contain a certain amount of reactive minerals such as opal, tridymite, cristobalite, and volcanic glass.

The composition of the ASR gel is not well understood. It is commonly accepted that the expansion is induced by the formation of a hydrous alkali silicate gel, which forms as the result of reactions between the silicate aggregates and alkali hydroxide ions in the hydrated cement paste matrix pore solution (Glasser 1992, Diamond 2000). The composition of this gel is still a topic of discussion (Knudsen and Thaulow 1975, Diamond 2000).

Over the past decades, many researchers have considered ASR gel to be a mixture of several components containing various proportions of alkali, calcium, and silicate (Powers and Steinour 1955, Scrivener and Monteiro 1994, Helmuth and Stark 1992). Helmuth and Stark (1992), referring to the equilibrium phase results of Kalousek (1944), concluded that the gel could be entirely expressed as a combination of an alkali silicate hydrate (ASH) phase and a calcium alkali silicate hydrate phase. More recent data from X-ray diffraction (XRD) analyses, Si nuclear magnetic resonance (NMR) spectroscopy and molecular dynamic (MD) modeling, suggest that the structure of natural and synthetic
ASR gels could be rather similar to kanemite $\left(\mathrm{NaHSiO}_{2} \mathrm{O}_{5}-3 \mathrm{H}_{2} \mathrm{O}\right)$ (Weiker et al. 1996, Hou et al. 2004, Kirkpatrick et al. 2005). NMR spectroscopy data also demonstrated that the ASR gel could only be formed in chemical environments of low calcium and high silicate concentrations (in solution). In concrete, these conditions can be obtained by the formation of a reactive transport barrier around the aggregates.

\subsection{ASR Test Methods}

The ASR related test methods, according to Figure 10 , can be divided into laboratory and in-situ tests.

Laboratory tests are also divided into two main categories: tests on concrete and tests on aggregates. ASTM C 227 covers the determination of the susceptibility of cement-aggregates combination to expansive reaction with ASR by measuring the increase or decrease in length of a specimen during storage under prescribed test conditions. ASTM C 1293 allows estimating the ASR potential of aggregates with pozzolan or slag. ASTM C1260 and C 1567 can be used with more aggressive conditions, which permit detection of ASR potential within 16 days. Finally, ASTM 289 is the laboratory test that covers chemical determination of the potential reactivity of aggregates by storing crushed and sieved aggregates in sodium hydroxide solution.

In situ tests are generally divided in two main groups: destructive test (DT) and non-destructive test (NDT) methods. Destructive tests mainly consist in in-situ coring. Cored samples can then be analyzed according to the laboratory tests mentioned previously. Some common NDT methods for the assessment of condition of ASR-affected structures are Spectral Analysis of Surface Waves (SASW), related Multiple Impact Surface Waves (MASW) methods, Impact Echo (IE) using patented Impact Echo Scanner, and Slab Impulse Response (SIR). The objective of all in-situ NDT tests is to locate damaged zones affected by ASR. 


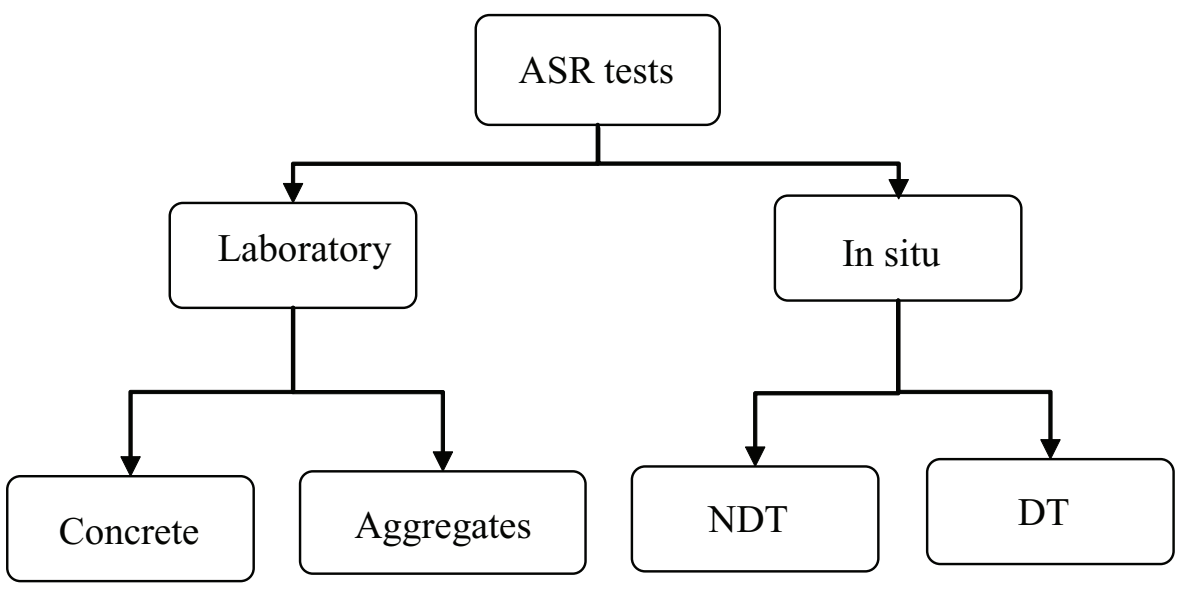

Figure 10. ASR Test Methods

\subsection{ASR Mitigation}

It is well-known that concrete expansion due to ASR can be suppressed by the addition of pozzolanic material (Chatterji 2005). The required quantity of supplementary cementitious materials is primarily a function of aggregate type and mixture characteristics (Thomas 1996, Fournier and Bérubé 2000, Duchesne and Bérubé 2000, Thomas et al. 2006). The benefits of lithium-based admixtures for ASR mitigation are also well documented (Folliard et al. 2003, Tremblay et al. 2004, Millard and Kurtis 2008). Lithium can be used to suppress the expansion arising from most reactive aggregates (Thomas et al. 2006). Finally, it is well known that restricting the alkali contribution of the portland cement component and reducing the internal relative humidity in concretes below a certain value can be effective for controlling the ASR expansion. The maximum tolerated alkali content (that associated with the expansion limit that produces damage) and critical relative humidity are both related to the reactive aggregate type (Bérubé et al. 2002a, Fournier and Bérubé 2000, Multon et al. 2008). The use of coatings and sealants to reduce the internal relative humidity of concrete can also mitigate ASR in bridge decks and pavements (Bérubé et al. 2002a).

\subsection{Modeling of Damage Induced by ASR}

Over the years, several theories have been proposed to explain the volume instability of concrete affected by ASR. Some have attempted to describe the swelling mechanisms at the pore scale. In most of these approaches, the expansion of concrete is induced by the swelling of the amorphous silica gel, which eventually cracks the material. According to one of the most prevalent views, the change in volume of concrete is due to the hydrophilic nature of the gel, which tends to absorb water by osmosis. While absorbing water, the gel swells and locally creates internal pressures (Dent-Glasser and Kataoka 1981, Diamond et al. 1981). More recently, the expansion of concrete by the alkali-silica reaction was attributed to surface phenomena. This theory assumes that the interaction of the gel with the ionic species present in the pore solution of hydrated cement pastes generates electrical double layer repulsive forces, whose intensity is determined by the composition and the ionic strength of the surrounding electrolyte (Prezzi et al. 1997, Prezzi et al. 1998). ASR production has a high sensitivity to temperature and externally applied stresses (Multon and Toutlemonde 2006). 
The progressive expansion of concrete by ASR can be described by continuum mechanic models. According to these approaches, concrete swelling is the result of the interaction between the expanding gel, the pore fluid, and the concrete skeleton (Li and Coussy 2002, Ulm et al. 2002). All these phenomena are described at the material scale.

ASR modeling at the microscopic scale is complicated because the chemical reactions are not well known and the phenomenon is not distributed homogenously. Capra and Sellier (2003) presented a probabilistic approach, which considered the ASR as a homogenous function of temperature and humidity in materials and calculated the orthotropic swelling of concrete due to gel formation. In this approach, ASR swelling is considered as one contribution of the total strain:

$\varepsilon_{i}=\varepsilon_{i}^{e}+\varepsilon_{i}^{p l}+\varepsilon_{i}^{A S R}$

in which index $i$ refers to direction, and $\varepsilon, \varepsilon^{e}, \varepsilon^{p l}$ and $\varepsilon^{A S R}$ are total, elastic, plastic and ASR-associated strain, respectively.

Inelastic strain due to ASR is modeled as a function of ASR cracking probability, $P f^{A S R}$, in the direction $i$ : $\varepsilon_{i}^{A S R}=\alpha_{\varepsilon} \frac{P f_{i}^{A S R}}{1-P f_{i}^{A S R}}$

where: $\alpha_{\varepsilon}$ is a material constant to be determined.

In this approach, the damage coefficient is presented under tensile $\left(d^{t}\right)$ or compressive $\left(d^{c}\right)$ conditions. The damage expression for tensile stress in direction $i$ is a function of cracking probabilities $P f$, and is expressed as:

$d_{i}^{t}=1-\left(1-P f_{i}^{t}\right)\left(1-P f_{i}^{c}\right)\left(1-P f_{i}^{A S R}\right)$

where: subscripts $c$ and $t$ refer to compression and tension.

The damage parameter has the same definition as in Section 3.1. Each probability of cracking, $P f$, can be calculated on the basis of a Weibull distribution (Equation 97):

$$
\begin{aligned}
& P f_{i}^{A S R}=1-\exp \left(-\frac{1}{m^{A S R}}\left(\frac{\left\langle\sigma_{i}-\sigma_{g i}\right\rangle^{+}}{\sigma_{i}^{u r}}\right)^{m^{A S R}}\right) \\
& P f_{i}^{t}=1-\exp \left(-\frac{1}{m^{t}}\left(\frac{\left\langle\sigma_{i}\right\rangle^{+}}{\sigma_{i}^{u t}}\right)^{m^{t}}\right) \\
& P f_{i}^{c}=1-\exp \left(-\frac{1}{m^{c}}\left(\frac{\left\langle\sigma_{i}+\sqrt{(C)^{2}\left(\left(\left\langle\sigma_{j}\right\rangle^{-}\right)^{2}+\left(\left\langle\sigma_{k}\right\rangle^{-}\right)^{2}\right.}\right\rangle^{+}}{\sigma_{i}^{u c}}\right)^{m^{c}}\right)
\end{aligned}
$$

where: the function $\langle x\rangle^{+}$equals zero when $x$ is negative and equals $x$ when $x$ is positive, $m$ and $\sigma^{u}$ are the Weibull's law parameters, $\sigma_{i}$ is the stress in direction $i, \sigma_{j}$ and $\sigma_{k}$ are stresses perpendicular to $i, C$ is the coefficient of variation and $\sigma_{g i}$ is the stress induced in undamaged material in direction $i$.

In the case of ASR cracking, $\sigma_{g} i$ is related to the gel pressure, $P_{g}$ :

$$
\sigma_{g i}=\frac{P_{g}}{\left(1-P f_{i}^{A S R}\right)}
$$

The relation between $\sigma_{g i}$ and $P_{g}$ is shown in Figure 11 (Capra and Sellier 2003 and Li et al. 2000).

According to this figure, the total stress $\sigma$ is equal to (Li et al. 2000):

$\sigma=\sigma_{g i}-P_{g}$

This concept is illustrated by the rhelogical model demonstrated in Figure 12 ( $\mathrm{Li}$ and Coussy 2002):

The pressure induced by the gel, as a function of time $t$, can be written as: 


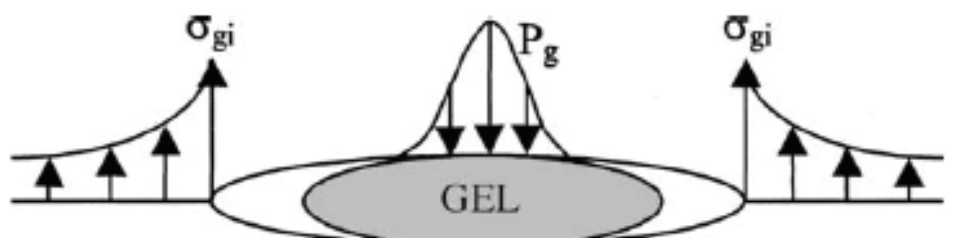

Figure 11. Stress and Pressure Induced by ASR Gel in Equilibrium

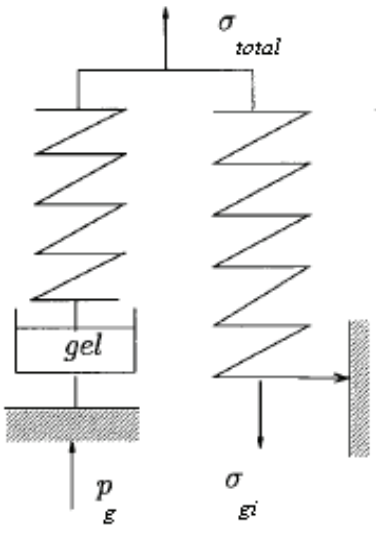

Figure 12. Rhelogical Model of One-dimensional Chemoplastic Material

$$
P_{g}(t)=K_{g}\left\langle\frac{P_{g \lim }(t)}{1+P_{g \lim }(t)\left(\kappa_{e} \operatorname{tr} \varepsilon+\kappa_{p} \phi_{0}\right)}\right\rangle^{+}
$$

where: $\operatorname{tr} \varepsilon$ is the volumetric strain, $\phi_{0}$ is the initial porosity, $K_{g}$ is the gel stiffness and $\kappa_{e}$ and $\kappa_{p}$ are two constants related to crack and porosity respectively.

The parameter $P_{g \text { lim }}(t)$ can be calculated as a function of relative humidity $R H$ and temperature $T$ by Equation (101).

$$
\begin{aligned}
P_{g \text { lim }}(t) & =P_{g \text { lim }}^{\infty} R H^{m_{R H}} \\
& \times\left(1-\exp \left(-k_{0} \exp \left(\frac{-E_{a}}{R T}\right) t\right)\right)
\end{aligned}
$$

where: $E_{a}$ is the activation energy of the ASR reaction, $R$ is the gas constant, $k_{0}$ is a characteristic of the chemical process and $m_{R H}$ is a parameter that reduces the impact of RH on pressure $\left(m_{R H}=8\right) . P_{g \text { lim }}^{\infty}$ is the maximum gel pressure in a totally saturated condition. According to the work of Larive (referred by Li et al. 2000), this value of maximum gel pressure, $P_{g \text { lim }}^{\infty}$, is independent of time. Larive's results demonstrated that the strain (ASR swelling) corresponding to the pressure induced by the ASR gel reaches a maximum value after sufficient time. Figure 13 illustrates a schematic form obtained from Larive's results on ASR swelling with a maximum strain value, $\varepsilon^{\infty}$. 


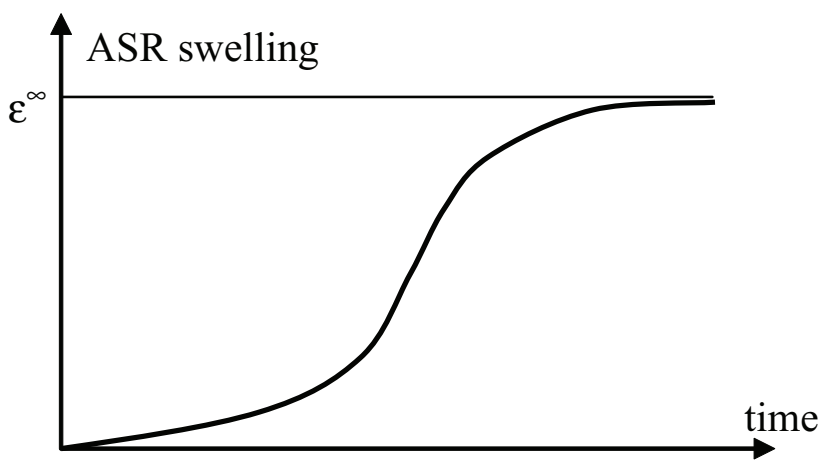

Figure 13. ASR Swelling Evolution as A Function of Time

\subsection{FREEZING AND THAWING}

Concrete structures that are exposed to harsh winter conditions can undergo several types of degradation such as micro-cracking and structural cracking (Leger et al. 1995). Micro-cracking can result from water movement within the material during the freezing process and structural cracking can result from temperature gradients throughout the structure.

Micro-cracking induced by the freeze/thaw $(\mathrm{F} / \mathrm{T})$ cycling can have a detrimental effect on the service behavior of concrete structures. It affects the physical, chemical, and mechanical properties of the concrete and often causes surface spalling.

The frost resistance of cement pastes was the topic of many model developments dedicated to the prediction of damage to concrete structures exposed to freezing/ thawing cycles. The mechanisms by which freeze/ thaw cycling affects the concrete durability are complex and modeling must take into account a wide range of more or less coupled multi-scale phenomena (Scherer 1993 and Marchand et al. 1995). Several models have been proposed to predict the behavior of cementitious materials exposed to freezing conditions (Scherer 1999, Setzer 2000 and Setzer 2001). A numerical model was also developed by Zuber (Zuber and Marchand 2000 and Zuber 2002) to predict the quantity of ice formed in a saturated material as well as the expansion caused by the ice formation.

Moreover, many experiments have also been developed to evaluate the durability of concrete subject to freezing (Pigeon and Pleau 1995). Although some of these tests provide data on the behavior of cementitious materials under freezing conditions, they cannot be used to predict the service life for structures since laboratory conditions do not accurately replicate real conditions (Litvan 1978). During these tests, the concrete samples are usually saturated and exposed to freezing conditions to accelerate degradation. In practice, however, most structures are exposed to drying and wetting cycles that maintain materials in a partially saturated state.

It is well-known that the frost resistance of concrete can be improved by adding air entraining agents in the mixture. Air bubbles inside of concrete act to absorb the pressure induced by ice formation. Many studies were carried out in recent years to describe the effect of air entrainment on the $\mathrm{F} / \mathrm{T}$ resistance of concrete (Powers 1949 and Pigeon et al. 1996). The Powers' model of the critical spacing factor of air voids has been widely used to quantify the $\mathrm{F} / \mathrm{T}$ resistance of concrete. 


\subsection{Ice Formation Mechanism}

As temperature inside concrete decreases below the freezing point, the pore solution freezes gradually. The ice formation process is accompanied by heat release that can be detected at low temperatures by calorimetry (Zuber 2002).

Figure 14 shows typical results from calorimetric testing. The testing temperatures vary over a sufficient range to ensure that heat release, throughout the testing, was not due to inherent kinetic problems. Therefore, the heat release recorded by the calorimeter was related to the progressive formation of ice in the porous material (Bager 1986a, Zuber 2002 and Kaufman 2004).

Various stages can be distinguished during a calorimetric test from the location of the main heat release. The ice formation process depends on the pore size distribution (Brun 1977, Matala 1995, Zuber 2002). The first heat peak, appearing between $0^{\circ} \mathrm{C}$ and $-15^{\circ} \mathrm{C}$, corresponds to the formation of ice within the largest capillary pores. The heat release observed in the $-15^{\circ} \mathrm{C}$ to $-35^{\circ} \mathrm{C}$ range corresponds to the formation of ice in the nanometer-sized hydrate pores. The last heat peak is related to the freezing of the liquid phase present in the C-S-H interlayer space.

During the ice formation process, water expands by approximately $9 \%$ of its volume (Kaufman 2004). This phenomenon has a direct consequence on the material's behavior since the expansion generates internal pressures. Through expansion testing, the evolution of macroscopic deformation caused by F/T cycling can be monitored. In general, a material expands when heated up and contracts when cooled down. When a saturated porous material is cooled down, contraction is observed. However, when ice is formed within the material, expansion takes place. Obviously, this type of volumetric instability cannot be connected solely to deformations of a purely thermal nature. Moreover, the expansion can induce deterioration in the material due to unrecoverable deformations.

From Figure 15, it can be seen that the expansion is greater in pastes with higher $\mathrm{w} / \mathrm{c}$ ratios. The main reason is that these materials have normally a higher porosity and contain a larger volume of freezing water (see Figure 14).

\subsection{F/T Cycle Damage and Saturation}

When porous materials are unsaturated, ice formation is decreased: the material properties are less effected and the related expansion is significantly reduced (Litvan 1978). Moreover, the unsaturated pores can potentially act like air-entrained bubbles and decrease the pressure induced by ice formation. Through calorimetric measurements, Bager (1986b and 1987) also concluded that water content contributes to ice formation in porous materials.

Repeated freezing/thawing cycles damage the material, which contributes to pore volume expansion and reduces the mechanical resistance. Fagerlund (2004) quantified the effect of saturation on the damage sustained by cementitious materials exposed to frost action. He determined that there is a critical saturation level where no damage is observed. Above this threshold, damage can be observed. The extent of damage depends on the saturation level and the number of cycles:

$$
\delta=\left\{\begin{array}{lll}
0 & \text { if } & S_{r} \leq S_{c r} \\
K_{N}\left(S_{r}-S_{c r}\right) & \text { if } & S_{r}>S_{c r}
\end{array}\right.
$$

where: $\delta$ is the damage parameter due to $\mathrm{F} / \mathrm{T}$ cycles, $S_{r}$ is the degree of saturation, $S_{c r}$ is the critical degree of saturation and $K_{N}$ is the coefficient of fatigue:

$K_{N}=\frac{A_{c} \cdot N_{c}}{B_{c}+N_{c}}$ 


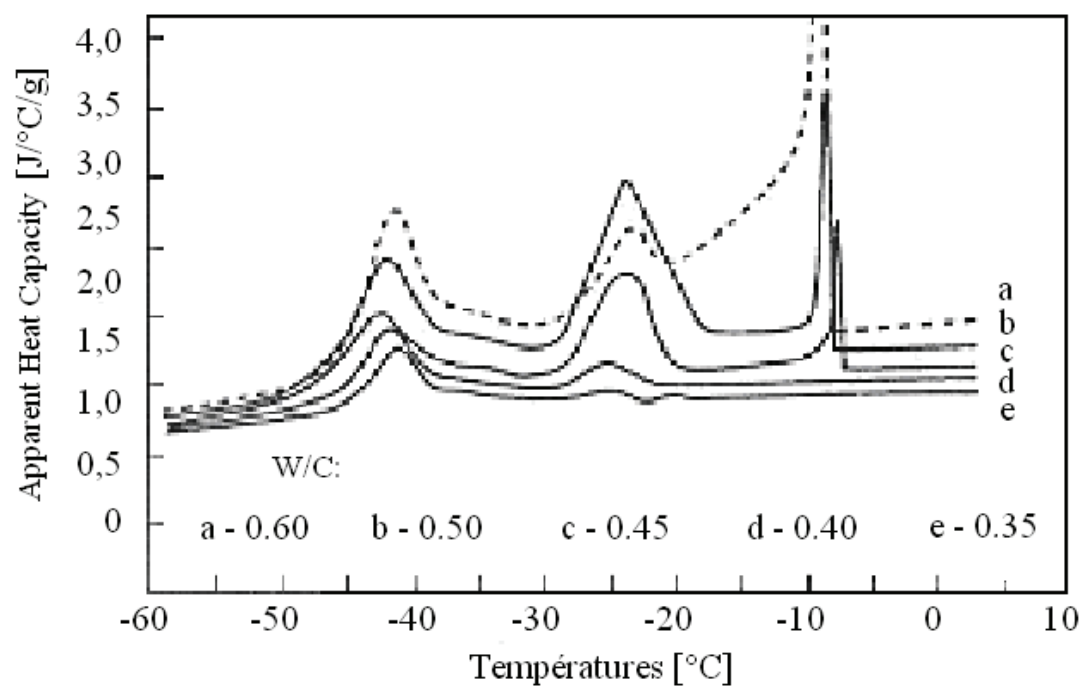

Figure 14. Heat Released from Ice Formation Experiments on Saturated Cement Pastes at Various Water/Cement Ratios (Bager 1986a)

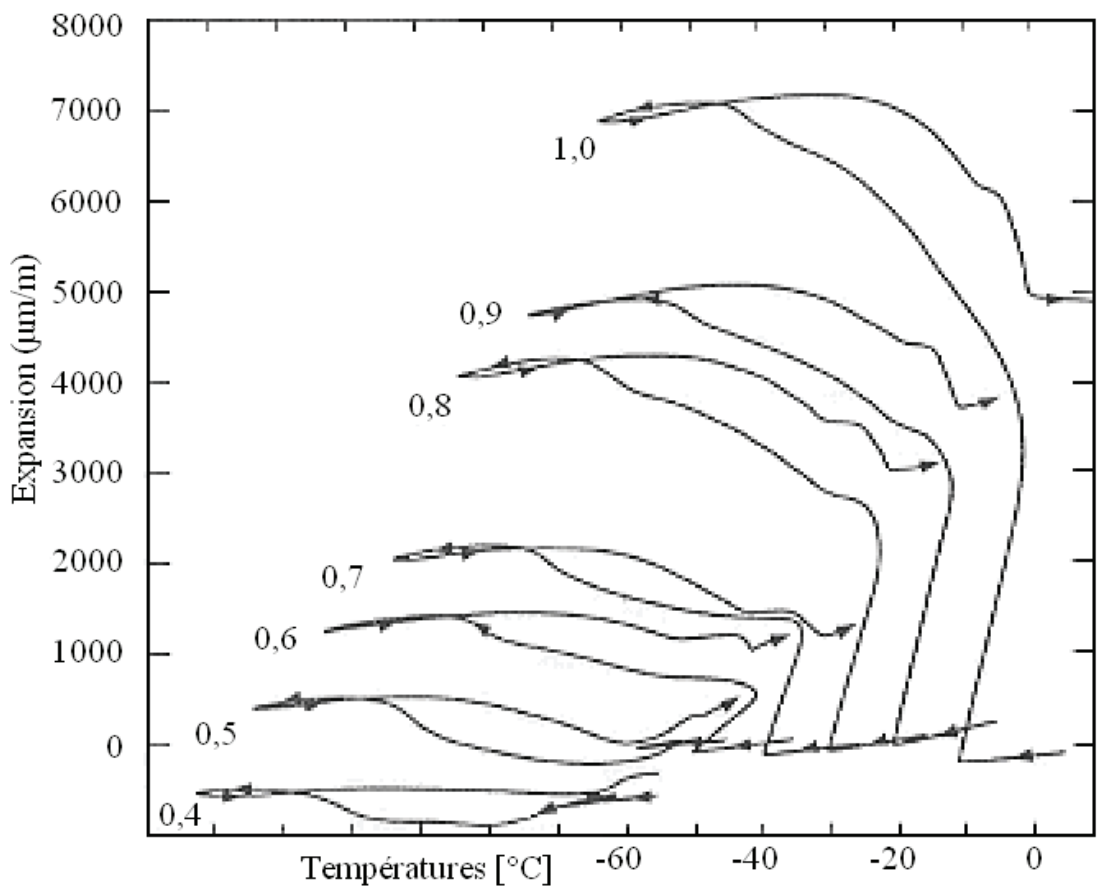

Figure 15. Expansion of Saturated Cement Pastes with Various w/c Ratios (Litvan 1978) (The start point of all curves is $0^{\circ} \mathrm{C}$ but they are moved just for comparison.) 
$N_{c}$ is the number of cycles for $S_{r}>S_{c r}$, and $A_{c}$ and $B_{c}$ are two material parameters depending on concrete type. $A_{c}$ and $B_{c}$ can be obtained by the fitting curve of $K_{N}$ versus several $N$ (see Figure 16). This equation is calibrated for a closed system and is valid for a small $N_{c}$. For large values of $N_{c}, B_{c}$ does not have any influence on $K_{N}$ and the limit of $K_{N}$ approaches $A_{c}$. In this case, Fagerlund replaced $K_{N}$ by:

$$
K_{N}=\gamma_{c} \cdot N_{c}
$$

where: $\gamma_{c}$ is the rate of saturation increase, which is different in an open or closed system.

Based on Rombén's experimental results (Fagerlund 2004), the critical degree of saturation was estimated to be between 0.75 and 0.8. As shown in Figure 16, the ratio of the damaged dynamic Young's modulus $\left(E_{n}\right)$ for $N$ cycles of freezing and thawing to the initial undamaged dynamic Young's modulus $\left(E_{0}\right)$ starts to decrease after critical saturation. Moreover, the slope of the curve after critical saturation depends on the number of $\mathrm{F} / \mathrm{T}$ cycles. For a structure without any existing or historic results that can show the amount of $\mathrm{F} / \mathrm{T}$ cycles the structure has undergone, $N$ could perhaps be estimated by relating to some experimental relationship. For example, Houvinen (1993) devised an empirical equation that is based on the change of concrete tensile strength:

$$
\log N=13.92-14.42 \frac{f_{t}}{f_{t}^{\max }}
$$

where: $f_{t}$ is the tensile strength between cement and aggregates subject to repeated loading, and $f_{t}^{\max }$ is the tensile strength between cement and aggregates subject to static loading.

\subsection{Effect of W/C on F/T Damage}

The method described in the last section is sufficient for determining the relation between freezing/ thawing cycles and damage parameters. According to Fagerlund's approach, the F/T damage is only a function of the number of cycles. But the characteristics of concrete were not considered in the relationship. One of the most important parameters that can affect the damage is the $\mathrm{w} / \mathrm{c}$ ratio. Many experimental results showed the relation between $\mathrm{w} / \mathrm{c}$ ratio and $\mathrm{F} / \mathrm{T}$ damage produced in materials. Figures 17(b) and (c) show the evolution of the dynamic Young's modulus with F/T cycles obtained by Setzer (2001) and Pinto and Hover (cited in Kosmatka

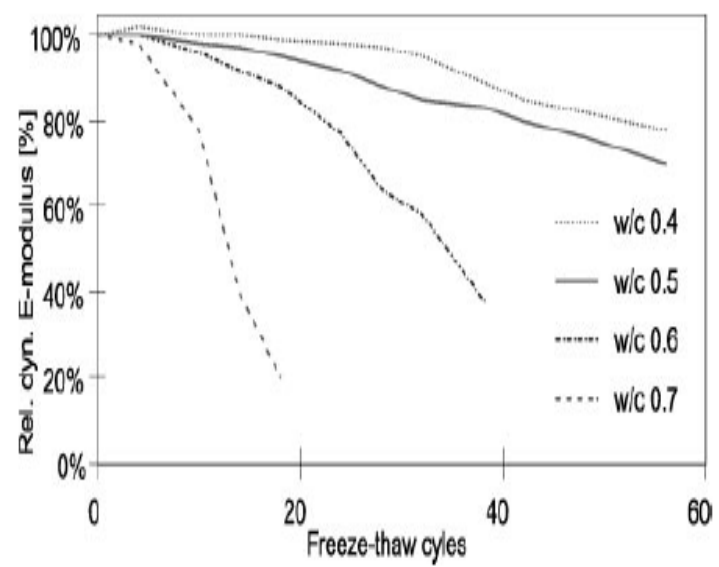

(a)

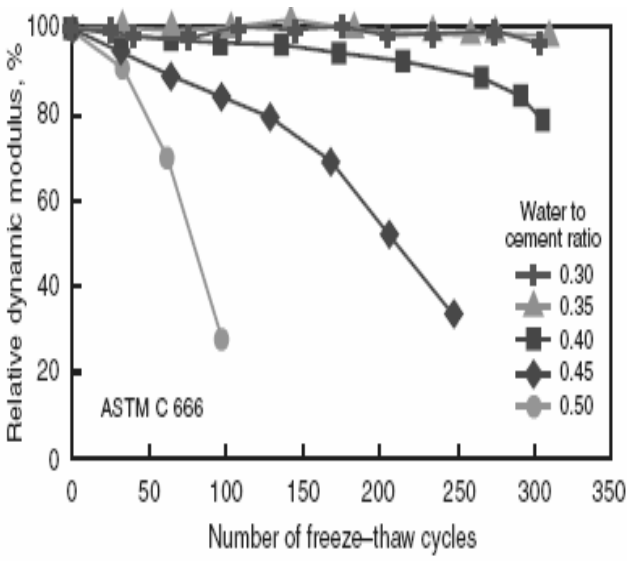

(b)

Figure 16. Relative Dynamic Young's Modulus Evolution vs. Freezing/Thawing Cycles According to Rombèn's Results (Fagerlund 2004) 
2002), respectively. Sun et al. (1999) also studied the $\mathrm{F} / \mathrm{T}$ damage under mechanical loading in different concrete types. Figure 17(c) shows their results for $\mathrm{F} / \mathrm{T}$ damage on four different concrete types, PC40, PC50, PC60, and PC80 corresponding to $\mathrm{w} / \mathrm{c}$ ratios of $0.45,0.38,0.32$, and 0.26 , respectively.

\subsection{Cooling Rate}

Freeze/thaw cycle characteristics such as the rate of cooling also influence the damage induced by ice formation. A rapid cooling rate will likely cause more damage to the material (Jacobsen et al.1997). During freezing, the pore solution can be readily transformed into ice and create strain in the material. Greater expansion occurs for faster cooling rates when the material is saturated and also when spacing factors and porosities are higher. These deformations affect the porous network at different scales. The porous network can therefore be changed during one $\mathrm{F} / \mathrm{T}$ cycle and have different properties for subsequent cycles.

\subsection{Pore Pressure Evolution as A Function of Ice Formation}

The study of the evolution of pore pressure with freezing is necessary in order to establish a coupled thermo-hydro mechanical model. The continuum

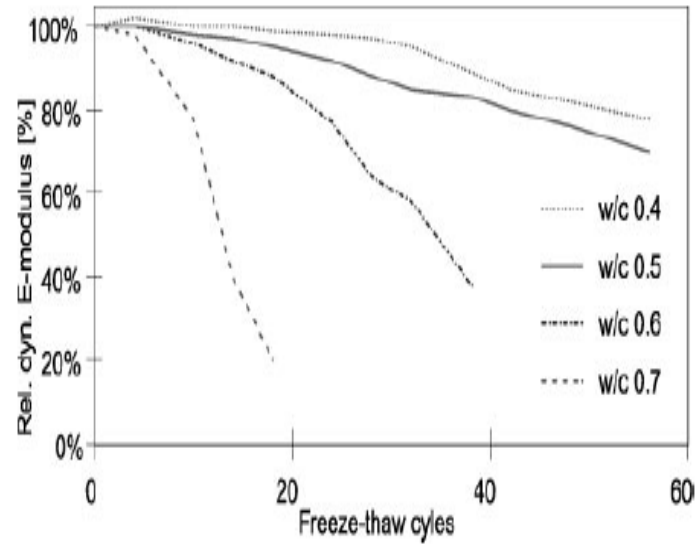

(a)

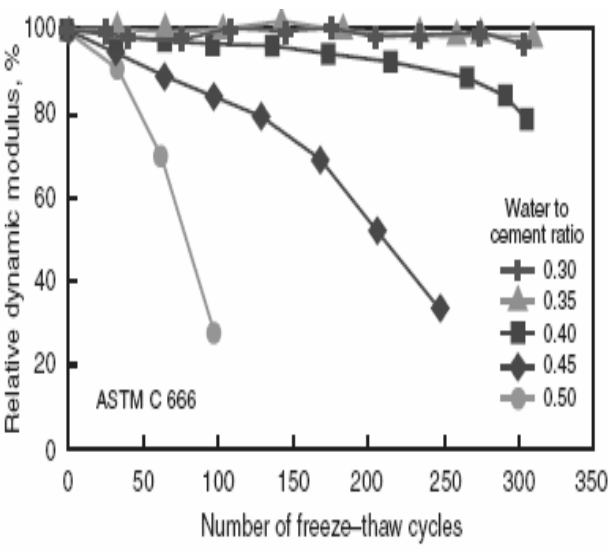

(b)

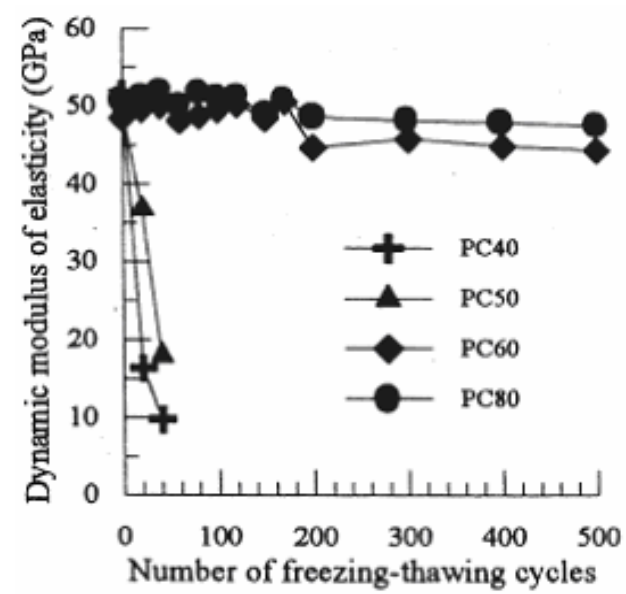

(c)

Figure 17. Evolution of Damage as A Function of the F/T Cycles 
mechanics of porous media can be used as a theoretical basis for the internal stress calculations. According to Coussy (1995), the effective stress inside thematerial can be written as:

$$
\sigma=\sigma^{\prime}-b p I
$$

In this equation, $\sigma$ and $\sigma^{\prime}$ are total and effective stress, respectively, $p$ is the internal homogenized pore pressure, $b$ is the Biot coefficient, and $I$ is the unit matrix.

Pressure evolution $p$ can be determined from microscale studies and extended to the macro-scale by a homogenization on an equivalent representative volume. This pressure is the sum of liquid pressure $p_{l}$ and the pressure induced by ice formation $p_{\text {ice }}$ and is applied as the total pore pressure in the hydrous analysis of porous media:

$$
p=p_{l}+p_{\text {ice }}
$$

Expressions for the pressure contribution $p_{\text {ice }}$ is given for saturated and unsaturated porous materials below.

\subsubsection{Saturated Porous Media}

Zuber (2002) proposed an expression for the pressure generated by ice formation for cylindrical shaped pores. According to this approach, there exists an equilibrium pore radius Req at a given freezing temperature and pore solution concentration, for which larger pores are frozen and smaller ones are not. For this equilibrium radius, the contribution of ice on the total pressure exerted on the pore walls is given by:

$$
p_{\text {ice }}=\frac{1}{\phi} \int_{\infty}^{R_{e q}} \gamma_{l s}\left(\frac{2}{R_{e q}}-\frac{1}{r-l_{r}}\right) \frac{\mathrm{d} \varphi(r)}{\mathrm{d} r} \mathrm{~d} r
$$

where: $\gamma_{l s}$ is the surface tension between liquid and solid phases, $l_{r}$ is the thickness of the adsorbed layer in the porous system, $\phi$ is the porosity, and $\varphi(r)$ is the pore size distribution.
This approach has the advantage that it considers the effects of surface tension between solid and liquid phases. However, it relies on a physically unrealistic uniform cylindrical pore shape geometry.

Penttala (2002) established an expression in which the total liquid phase pressure can be calculated in a frozen porous media. The geometry of the pores was not considered in this approach, which provides a homogenized pressure:

$$
\begin{aligned}
p & =\frac{\Delta h_{0}^{l s}}{\left(v_{s}-v_{l}\right) T} \Delta T \\
& +\frac{1}{\left(v_{s}-v_{l}\right)} \int_{T_{0}}^{T} \int_{T_{0}}^{T} \frac{c_{p}^{s}-c_{p}^{l}}{T} d T d T
\end{aligned}
$$

where: $c_{p}^{s}$ and $c_{p}^{l}$ are the heat capacity for ice and water, respectively; $v_{s}$ and $v_{l}$ are the specific volume of ice formation and water, respectively, $\Delta h_{0}^{l s}$ is the enthalpy of ice formation, and $T_{0}$ and $T$ are the initial and the current temperatures.

\subsubsection{Unsaturated Porous Media}

The water content can play an important part in the quantity of ice formed (Bager and Sellevold 1986b and 1987) and, consequently, in the service life of concrete (Fagerlund 2000). This factor must be accounted for the F/T models. In addition, the beneficial aspect of air bubbles should also be taken into account because these beneficial effects dissipate the pressures generated in porosity. However, few studies that have been conducted on pore pressure expressions during freezing of unsaturated materials.

Penttala (1998 and 2002) proposed an expression for pore pressure that also depends on the ionic species characterized by the molar fraction $x_{u n f}$ and the activity of the liquid phase $a_{l}$. 


$$
\begin{gathered}
p=\frac{R T}{v_{s}} \ln \left(\frac{R H}{a_{l} x_{u n f}}\right)+\frac{\Delta h_{0}^{l s}}{v_{s} T_{0}} \Delta T \\
+\frac{1}{v_{s}} \int_{T_{0}}^{T} \int_{T_{0}}^{T} \frac{c_{p}^{s}-c_{p}^{l}}{T} d T d T
\end{gathered}
$$

where $R H$ is the relative humidity, depending on the vapor and the saturated vapor pressures $p_{v}$ and $p_{v s}, R$ is the gas constant and $R H=\frac{p_{v}}{p_{v s}(T)}$. For an ideal solution, the molar fraction $x_{u n f}$ and the chemical activity $a_{l}$ are both equal to 1 . Adsorption/desorption isotherm tests can be used to determine the water content from relative humidity evolution (Xi et al. 1994).

\subsection{CONCLUSIONS}

This review of approaches to modeling mechanical damage in cementitious materials emphasized a clear preference toward damage mechanics, where the degradation is quantified using a damage tensor that affects the mechanical properties such as Young's modulus. No models based on fracture mechanics used in the context of concrete durability were reviewed for this report.

The review showed that it is possible to couple damage mechanics models to ionic transport equations in order to get a global durability that would be well suited for the purposes of the Cementitious Barrier Partnership project. In all cases, the mechanical and mass exchange portions of the models are solved separately, with the output of one module being used to calculate or update inputs in another. Although the papers reviewed in this report were mostly based on simplified transport equations, the splitting between transport and mechanics makes it possible to envision more complex transport models linked to damage-based modules. 


\subsection{REFERENCES}

ACI Concrete Repair Manual. 2007, 'Causes, Evaluation, and Repair of Cracks in Concrete Structures', ACI 224.1R-07.

ACI Concrete Repair Manual. 2007, 'Nondestructive Test Methods for Evaluation of Concrete in Structures', ACI 228.2R-98.

ACI Manual of Concrete Practice 2008, 'Finite element analysis of fracture in concrete structures', ACI 446.3R-97.

ACI Manual of Concrete Practice 2008, 'Prediction of creep, shrinkage, and temperature effects in concrete structures', ACI 209R-92.

ACI Manual of Concrete Practice 2008, 'Report on factors affecting shrinkage and creep of hardened concrete', ACI 209.1R-05.

ACI Manual of Concrete Practice 2008, 'Control of cracking in concrete structures’, ACI ACI 224R-01.

Achintya, M \& Prasad, MM 2003, 'Behavior of Concrete in Freeze-thaw Environment of Sea Water', Technical Journals of the Institution of Engineering (India), vol. 84.

Ahmad, S 2003, 'Reinforcement corrosion in concrete structures, its monitoring and service life prediction', Cement \& Concrete Composites, vol. 25, pp. 459471.

ASTM 2008, 'Concrete and aggregates', Annual book, vol. 04.02.

Atkinson, A \& Hearne, J A 1989, 'Mechanistic model for the durability of concrete barriers exposed to sulfate bearing ground water', Scientific Basis for Nuclear Waste Management, vol. 13, pp. 149-156.
Bager, DH \& Sellevold, E 1986a, 'Ice formation in hardened cement paste, part I: room temperature cured pastes with variable moisture contents', Cem. \& Conc. Res., vol. 16, pp. 709-720.

Bager, DH \& Sellevold, E 1986b, 'Ice formation in hardened cement paste, part II: drying and resaturation on room temperature cured pastes', Cem. \& Conc. Res., vol. 16, pp. 835-844.

Bager, DH \& Sellevold, E 1987, 'Ice formation in hardened cement paste, part III: slow resaturation of room temperature cured paste', Cem. and Conc. Research, vol. 17, pp. 1-11.

Basista, M 2001, 'Micromechanical and lattice modeling of brittle damage', Institute of Fundamental Technological Research, Warsaw, Poland.

Basista, M \& Weglewski, W 2008, 'Chemicallyassisted damage of concrete: a model of expansion under external sulfate attack', J. of Theor. and App. Mechanics, vol. 35, pp. 29-52.

Bazant, ZP 2001, 'Prediction of concrete creep and shrinkage: past, present and future', Nuclear Engineering and Design, vol. 203, pp. 27-38.

Bazant, ZP Xian, Y \& Prat, PC 1996, 'Microplane model for concrete. Part I and II', J. of Eng.

Mechanics - ASCE, pp. 245-262.

Benboudjema, F Meftah, F \& Torrenti, JM 2005, 'Interaction between drying, shrinkage, creep and cracking phenomena in concrete', Eng. Structures, vol. 27, pp. 239-250.

Benboudjema, F \& Torrenti, JM 2008, 'Early-age behaviour of concrete nuclear containments', Nuclear Engineering and Design, vol. 238, pp. 2495-2506. 
Bentz, D P Coveney, P V \& Garboczi, E J 1994, 'Cellular automaton simulations of cement hydration and microstructure development', Modelling and Simulation in Materials Science and Engineering, vol. 2, pp. 783-808.

Bérubé, MA Chouinard, D Pigeon, M Frenette, J Rivest, M \& Vézina, D 2002a, 'Effectiveness of Sealers in Counteracting Alkali-Silica Reaction in Highway Median Barriers Exposed to Wetting and Drying, Freezing and Thawing, and Deicing Salts', Canadian Journal of Civil Engineering, vol. 29, pp. 329-337.

Bhargava, K Ghoshb, AK Moric, Y \& Ramanujama, S 2006, 'Model for cover cracking due to rebar corrosion in RC structures', Engineering Structures, vol. 28, pp. 1093-1109.

Bouchard, PO Bay, F \& Chastel, Y 2003, 'Numerical modelling of crack propagation: automatic remeshing and comparison of different criteria', Comput.

Methods Appl. Mech. Eng., vol. 192, pp. 3887-3908.

Brun, M Lallemand, A Quinson, JF \& Eyraud, C 1977, 'A new method for the simultaneous determination of the size and the shape of pores: The thermoporometry', Thermochimica Acta, vol. 21, pp. 59-88,

Budiansky, B \& O’Connell, R J 1976, 'Elastic moduli of a cracked solid', International Journal of Solids and Structures, vol. 12, pp. 81-97.

Buyukozturk, O \& Hearing, B 1998, 'Crack propagation in concrete composites influenced by interface fracture parameters', Int. J Solids Struc., vol. 35, pp. 4055-4066.

Capra, B \& Sellier, A 2003, 'Orthotropic modelling of alkali-aggregate reaction in concrete structures: numerical simulations', Mechanics of Materials, vol. 35, pp. 817-830.
Carol, I \& Bazant, ZP 1991, 'Geometric damage tensor based on microplane model', Journal of Engineering Mechanics, vol. 117, pp. 2429-2448.

Cervera, M Olivier, J \& Prato, T 1999, 'Thermochemo-mechanical model for concrete. I: Hydration and aging', Journal of Engineering Mechanics, vol. 125, pp. 1018-1027.

Cervera, M Olivier, J \& Prato, T 1999b, 'Thermochemo-mechanical model for concrete. II: Damage and creep', Journal of Engineering Mechanics, vol. 125, pp. 1018-1027.

Chatterji, S 1999, 'Aspects of the freezing process in a porous material - part 1: Freezing and the properties of water and ice', J. of Cem. and Conc. Res., vol. 29, pp 627-630.

Chatterji, S 2005, 'Chemistry of alkali-silica reaction and testing of aggregates', Cement \& Concrete Composites, vol. 27, pp. 788-795.

Chen, D \& Mahadevan, S 2008, 'Chloride-induced reinforcement corrosion and concrete cracking simulation', Cement and Concrete composites, vol. 30 , pp. 227-238.

Chiarelli, AS Shao, JF \& Hoteit, N 2003, 'Modeling of elastoplastic damage behavior of claystone', International Journal of Plasticity, vol. 19, pp. 23-45.

Clifton, JR \& Pommersheim, JM 1994, 'Sulfate attack of cementitious materials: Volumetric relations and expansions Technical report, Building and Fire Research Laboratory', National Institute of Standards and Technology, Gatheirsburg, MD.

Contecvet manual 2001, 'A validated Users Manual for assessing the residual service life of concrete structures', Lund University - Division of Building Materials. 
Collepardi, M 2003, 'A state-of-the-art review on delayed ettringite attack on concrete', Cement and Concrete Composites, vol. 25, pp. 401-407.

Coussy, O 1995, 'Mechanics of porous continua', John Wiley \& Sons.

Dekoster, M Buyle-Bodin, F Maurel, O \& Delmas, Y 2003 'Modelling of the flexural behaviour of RC beams subjected to localised and uniform corrosion', Engineering Structures, vol. 25, pp. 1333-1341.

Dent Glasser, LS \& Kataoka, N 1981, 'The chemistry of alkali-aggregate reaction', Cement and Concrete Researchm, vol. 11, pp. 1-9.

Diamond, S Barneyback, RS \& Struble, LJ 1981, 'On the physics and chemistry of alkali-silica reactions', Proceedings of the 5th Int. Conf. on Alkali-Aggregate Reaction in Concrete - Cape Town (South Africa), pp. 252.

Diamond, S 2000, 'Chemistry and other characteristics of ASR gels', Proceedings of the 11th Int. Conf. on Alkali-Aggregate Reaction in Concrete, edited by Bérubé et al., Québec (CANADA), pp. 3140.

Dragon, A Halm, D \& Desoyer, Th 2000, 'Anisotropic damage in quasi-brittle solids: modeling, computational issues and applications', Comput. Meth. Appl. Mech. Eng., vol. 183, pp. 331-352.

Du, YG Chan, AHC \& Clark, LA 2006, 'Finite element analysis of the effects of radial expansion of corroded reinforcement', Computers and Structures, vol. 84, pp. 917-929.

Duchesne, J \& Bérubé, MA 2000, 'Long-term effectiveness of supplementary cementing materials against ASR', Proceedings of the 11th Int. Conf. on Alkali-Aggregate Reaction in Concrete, edited by Bérubé et al., Québec (CANADA), pp. 613-622.
Espenson, JH 1981, 'Chemical kinetics and reaction mechanisms', McGraw-Hill.

Fagerlund, G 2000, 'Mechanical damage and fatigue effects associated with freeze-thaw of materials', RILEM PRO 24, Frost Resistance of Concrete, pp. 117-132.

Fagerlund, G 2004, 'A service life model for internal frost damage in concrete', Lund University publishing, Sweden.

Folliard, KJ Thomas, MDA \& Kurtis, K 2003, 'Guidelines for the use of lithium to mitigate or prevent ASR', FHWA-RD-03-047, Federal Highway Administration, National Research Council, Washington D.C.

Fournier, B \& Bérubé, MA 2000, 'Alkali-aggregate reaction in concrete: a review of basic concepts and engineering applications', Canad. J. of Civ. Eng., vol. 27, pp. 167-191.

Fu, Y Xie, P \& Beaudoin, JJ 1994, 'Significance of pre-existing cracks on nucleation of secondary ettringite in steam cured cement paste', Cem.\& Conc. Res., vol. 24, pp. 1015-1024.

Garboczi, E J \& Bentz, DP 1992, 'Computer simulation of the diffusivity of cement-based materials', Journal of Material Sciences, vol. 27, pp. 2083-2092.

Garboczi, EJ \& Bentz, DP 2001, 'The effect of statistical fluctuation, finite size error, and digital resolution on the phase percolation and transport aspects of the NIST cement hydration model', Cem. Conc. Res. ,vol 31, pp. 1501-1514.

Gawin, D Pesavento, F \& Schrefler, BA 2006, 'Hygro-chemo-mechanical modeling of concrete at early ages and beyond. Part I: Hydration and hygrothermal phenomena', Int. J. Num. Meth. Eng., vol. 67, pp.299-331. 
Gerard, B 1996, 'Contribution des couplages mécaniques-Chimie-Transfert dans la tenue à long term des ouvrages de stockage de déchets radioactifs', Ph.D. thesis of ENS Cachan - France and Laval University of Québec - Canada.

Gerard, B Pijaudier-Cabot, G \& Laborderie, C 1998, 'Coupled Diffusion - Damage modeling and the implications on failure due to strain localization', International Journal Solids Structures, vol. 35, pp. 4107-4120.

Gerard, B \& Marchad, J 2000, 'Influence of cracking on the diffusion properties of cement-based materials Part I: Influence of continuous cracks on the steadystate regime', Cement and Concrete Research, vol. 30, pp. 37-43.

Glasser, FP 1992, 'Chemistry of the alkali-aggregate reaction, in Concrete', R.N. Swamy ed., Blackie (Glasgow, UK), pp. 30-53.

Gospodinov, P Kazandjiev, R \& Mironova, M 1996, 'The effect of sulfate ion diffusion on the structure of cement stone', Cement and Concrete Composites, vol. 18, pp. 401-407.

Halm, D \& Dragon, A 1998, 'An anisotropic model of damage and frictional sliding for brittle materials', European Journal of Mechanics and Solids, vol. 17, pp. 439-460.

Helmuth, RA \& Stark, D 1992, 'Alkali silica reactivity mechanisms', Materials Science of Concrete, J.P. Skalny ed., American Ceramic Society, Westerville (OH), pp. 131-208.

Hou, X Struble, LJ \& Kirkpatrick, RJ 2004, 'Formation of ASR gel and the roles of C-S-H and portlandite', Cement Concrete Res., vol. 34, pp. 1683-1696.
Houvinen, S 1993, 'Abrasion of concrete by ice', Journal of Cement and Concrete Research, vol. 23, pp. 68-82.

Hua, C Acker, P \& Ehrlacher A 1995, 'Analyses and models of the autogenous shrinkage of hardening cement paste', Cement and Concrete Research, vol. 25, pp. 1457-1468.

IUPAC 1997, 'Compendium of Chemical Terminology’, 2nd Edition, Editors: McNaught and Wilkinson.

Jacobsen, S Saether, D \& Sellevod, E 1997, 'Frost testing of high strength concrete: frost/salt scaling at different cooling rates', Materials and structures, vol. 30 , pp. 33-42.

Jun, W Xianghao, W \& Xialong, Z 2003, 'A model for concrete durability degradation in freezingthawing cycles', Acta Mechanica Solida Sinica, vol. 16, no. 4, pp353-358.

Kachanov, M 1993 'Elastic solid with many cracks and related problems', Advances in Applied Mechanics, vol. 30, pp. 259-445

Kalousek, G 1944, 'Studies of portions of the quaternary system soda-lime-silica-water at $25^{\circ} \mathrm{C}$, Journal of Research of the National Bureau of Standards, vol.32, pp. 285-302.

Karihaloo, B L 1995, 'Fracture mechanics and structural concrete', Longman Scientific and Technical, Harlow, Essex, England.

Kaufman, J 2004, 'Experimental identification of ice formation in small concrete pores', Cement and Concrete Research, vol. 34, pp. 1421-1427.

Kim, HS \& Cho, SH 2004, 'Shrinkage stress analysis of concrete slabs with shrinkage strips in a multistory building', Computers and Structures, vol. 82, pp. 1143-1152. 
Korhonen, C 2002, 'Effect of High Doses of Chemical Admixtures on the Freeze-Thaw Durability of Portland Cement Concrete', US Army Corps of Engineers.

Kirkpatrick, RJ Kalinichev, AG Hou, X \& Struble, L 2005, 'Experimental and molecular dynamics modeling studies of interlayer swelling: water incorporation in kanemite and ASR gel', Materials and Structures, vol. 38, pp. 449-458.

Knudsen, T \& Thaulow, N 1975, 'Quantitative microanalysis of alkali-silica gel in concrete', Cement and Concrete Research, vol. 5, pp. 443-454.

Kosmatka, S Kerkhof, B \& Panarese, W 2002, 'Design and Control of Concrete Mixtures', Portland Cement Ass., Skokie, Illinois, Item Code: EB001, 14th Edition.

Krajcinovic, D Basista, M Mallik, K \& Sumarac, D 1992, 'Chemo-micromechanics of brittle solids', Journal of Mechanics and Physics of Solids, vol. 40, pp. 965-990.

Kurtis, KE Monteiro, PJM Brown, JT \& Meyer-Ilse, W 2004, 'Mechanisms of concrete damage caused by sulfate attack examined through transmission x-ray microscopy', Adv. Light Source Compendium of User Abstracts (https://www.als.lbl.gov/als/compendium)

Léger, P Côté, M \& Tinawi, R 1995, 'Thermal protection of concrete dams subjected to freeze-thaw cycles', Canadian Journal of Civil Engineering, vol. 22 , pp. 588-602.

Lemaitre, J Demorat, R \& Sauzay, M 2000, 'Anisotropic damage law of evolution', Eur. J. Mech., vol. 19, pp. 187-208.

Lemaitre, J \& Chaboche, JL 1985, 'Mécanique des matériaux solides', Dunod Editions.
Li, K Ulm, FJ Coussy, O Larive, C \& Fan, L 2000, 'Chemoplastic modeling of alkali-silica reaction in concrete', Proceedings of the 11th Int. Conf. on Alkali-Aggregate Reaction in Concrete, edited by Bérubé et al., Québec (CANADA), pp. 989-998.

Li, K \& Coussy, O 2002, 'Concrete ASR degradation: from material modeling to structure assessment', Concrete Science and Engineering, vol. 4, pp. 35-46.

Litvan, GG 1978, 'Adsorption systems at temperatures below the freezing point of the adsorptive', Advances in Colloid and Interface Science, vol. 9, pp. 253-302.

Liu, Y \& Weyers, R 1998, 'Modeling the timeto-corrosion cracking in chloride contaminated reinforced concrete structures', ACI material journal of Nov-Dec.

Marchand, J 2001, 'Modeling the behavior of unsaturated cement systems exposed to aggressive chemical environments', Materials and Structures, vol. 34, pp. 195-200.

Marchand, J Pleau, R \& Gagné, R 1995, 'Deterioration of concrete due to freezing and thawing', Materials Science of Concrete, pp. 283-354.

Marchand, J Samson, E Maltais, Y \& Beaudoin, JJ 2002, 'Theoretical analysis of the effect of weak sodium sulfate solutions on the durability of concrete', Cement and Concrete Research, vol. 24, pp. 317-329.

Martin-Pérez, B 1999, 'Service life modeling of R.C. highway structures exposed to chlorides', Ph.D. Thesis at University of Toronto.

Matala, S 1995, 'Effects of carbonation on the pore structure of granulated blast furnace slag concrete', $\mathrm{PhD}$ thesis of University of Technology, Faculty of Civ. Eng., Espoo, Finland. 
Mazars, J \& Pijaudier-Cabot, G 1989, 'Continuum damage theory - application to concrete', Journal of Engineering Mechanics, vol. 115, no 2, pp. 345-362.

Mazars, J \& Pijaudier-Cabot, G 1996, 'Frome damage to fracture mechanics and conversely: a combined approach', Int. J. Solids Struct., vol. 33, no. 20-22, pp. 3327-3342.

Mehta, PK 1983, 'Mechanism of sulfate attack on portland cement concrete - another look', Cement and Concrete Research, vol. 13, pp. 401-406.

Meschke, G \& Grasberger, S 2003, 'Numerical modeling of coupled hygromechanical degradation of cementitious materials', J. of Eng. Mechanics, pp. 383-392.

Millard, MJ \& Kurtis, KE 2008, 'Effects of lithium nitrate admixture on early age cement hydration', Cement and Concrete Research, vol. 38, pp. 500-510.

Mindess, S, Young, J F \& Darwin, D 2002, 'Concrete', Prentice Hall, 2nd edition.

Multon, S \& Toutlemonde, F 2006, 'Effect of applied stresses on alkali-silica reaction-induced expansions', Cement and Concrete Research, vol. 36, pp. 912-920.

Multon, S Cyr, M Sellier, A Leklou, N \& Petit, L 2008, 'Coupled effects of aggregate size and alkali content on ASR expansion', Cem. and Conc. Res., vol. 38, pp. 350-359.

Mura, T 1987, 'Micromechanics of defects in solids', Martinus Nijhoff Publications, The Hague, Netherlands.

Penttala, V 1998, 'Freezing-Induced Strains and Pressures in Wet Porous Materials and Especially in Concrete Mortars', Advanced Cement Based Materials, vol. 7, pp. 8-19.
Penttala, V 2002, 'From freezing and thawing pore water pressures to concrete stresses', RILEM PRO 24, Frost Resistance of Concrete, pp. 147-160.

Picandet, V Khelidj, A \& Bastian, G 2001, 'Effect of axial compressive damage on gas permeability of ordinary and high-performance concrete', Cement and Concrete Research, vol. 31, pp. 1525-1532.

Pigeon, M \& Pleau, R 1995, 'Durability of Concrete in Cold Climates', Modern Concrete Technology series Published by Taylor and Francis, vol. 4.

Pigeon, M Marchand, J \& Pleau, R 1996, 'Frost resistant concrete', Construction and Building Materials, vol. 10, pp. 339-348.

Ping, X \& Beaudoin, JJ 1992, 'Mechanism of sulfate expansion I. thermodynamic principle of crystallization pressure', Cement and Concrete Res., vol. 22, pp. 631-640.

Powers, T 1949, 'The air requirement of frostresistant concrete', Highway Research Board, vol. 29 , pp. 184-211.

Powers, TC \& Steinour, HH 1955, 'An interpretation of some published researches on alkaliaggregate reaction 2 - An hypothesis concerning safe and unsafe reactions with reactive silica in concrete', Journal of ACI Proceedings, vol. 51, pp. 785-811.

Prezzi, M Monteiro, PJM \& Sposito, G 1997, 'The alkali-silica reaction - Part 1. Use of the double-layer theory to explain the behaviour of reaction-product gels', ACI Materials J., vol. 94, pp. 10-17.

Prezzi, M Monteiro, PJM \& Sposito, G 1998, 'The alkali-silica reaction - Part 2. the effect of chemical admixtures', ACI Materials J., vol. 95, pp. 3-10. 


\section{Review of Mechanistic Understanding and Modeling and Uncertainty Analysis}

Methods for Predicting Cementitious Barrier Performance

Rahman, MK Baluch, MH \& Al-Gadhib, AH 2000, 'Simulation of shrinkage distress and creep relief in concrete repair', Composites - Part B: Engineering, vol. 31, pp. 541-553.

Rongbing, B Jian, S 2005, 'Synthesis and evaluation of shrinkage-reducing admixture for cementitious materials', Cement and Concrete Research, vol. 35, pp. $445-448$.

Rostasy, FS \& Weidemann, G 1980, 'Stress-StrainBehaviour of concrete at extremely low temperature', Journal of cement and concrete research, vol. 10, pp. 565-572.

Saetta, A Scotta, R \& Vitaliani, R 1998, 'Mechanical behavior of concrete under physical-chemical attacks', Journal of Engineering Mechanics, vol. 1240, pp. 1100-1109.

Salganik, RL 1973, 'Mechanics of bodies with many cracks', Mechanics of Solids, vol. 8, pp. 135-143.

Samson, E \& Marchand, J 1999, 'Numerical solution of the extended nernst-plack model', Journal of Colloid and Interface Science, vol. 215, pp. 1-8.

Samson, E Lemaire, G Marchand, J \& Beaudoin, JJ 1999a, 'Modeling chemical activity effects in strong ionic solutions', Computational Materials Sci., vol. 15, pp. 285-294.

Samson, E Marchand, J \& Beaudoin, JJ 1999b, 'Describing ion diffusion mechanisms in cementbased materials using homogenization technique', Cement and Concrete Research, vol. 29, pp. 13411345 .

Samson, E Marchand, J Robert, JL \& Bournazel, JP 1999c, 'Modeling of ion diffusion mechanisms in porous media', Int. J. of Numerical Methods in Eng., vol. 46, pp. 2043-2060.
Samson, E Marchand, J \& Snyder, KA 2003, 'Calculation of ionic diffusion coefficients on the basis of migration test results', Materials and Structures, vol. 36, pp. 156-165.

Santhanam, M Cohen, MD \& Olek, J 2001, 'Review: sulfate attack research - whither now', Cement and Concrete Research, vol. 31, pp. 845-851.

Scherer, GW 1993, 'Freezing gels', Journal of NonCrystalline Solids, vol.155, pp. 1-25.

Scherer, GW 1999, 'Crystallization in pores', Cem. and Conc. Res., vol. 29, pp. 1347-1358.

Schmidt-Dohl, S \& Rostasy, FS 1999, 'A model for the calculation of combined chemical reactions and transport processes and its application to the corrosion of mineral-building materials part I. simulation model', Cement and Concrete Res., vol. 29, pp. 10391045.

Scrivener, KL \& Monteiro, PJ 1994, 'The alkali silica reaction in a monolithic opal', Journal of the American Ceramic Society, vol. 77, pp. 2849-2856.

Sellevold, E Jacobsen, S \& Bakke, J 1997, 'Highstrength concrete without air entrainment: Effect of rapid temperature cycling above and below $0^{\circ} \mathrm{C}^{\prime}$, Freeze-thaw durab. of conc. Ed. Marchand J., Pigeon M. and Setzer M., Ste-Foy, Québec, pp. 43-50.

Setzer, M 2000, 'Mechanical Stability Criterion, Triple-Phase Condition, and Pressure Differences of Matter Condensed in a Porous Matrix', Journal of Colloid and Interface Science, vol 235, pp 170-182.

Setzer, M 2001, 'Micro-Ice-Lens Formation in Porous Solid', Journal of Colloid and Interface Science, vol. 243, pp 193-201. 
Shao, JF Lu, YF \& Lydzba, D 2004, 'Damage modeling of saturated rock in drained and undrained conditions', Journal of Engineering Mechanics ASCE, pp. 733-740.

Shimada, Y Johansen, VC Miller, FM \& Mason, TO 2005, 'Chemical path of ettringite formation in heat-cured mortar and its relationship to expansion: A literature review. Technical report', Portland Cement Association, Skokie, IL.

Shazali, MA Baluch, MH \& Al-Gadhib, AH 2006, 'Predicting residual strength in unsaturated concrete exposed to sulfate attack', Journal of Materials in Civil Engineering, vol. 180 (3), pp. 343-354.

Snyder, KA 2000, 'Effect of drying shrinkage cracks and flexural cracks on concrete bulk permeability', Nat. Inst. of Stand. And Tech. May edition.

Stanton, TE 1940, 'Expansion of concrete through reaction between cement and aggregate', Proceedings of the ASCE, vol. 66, pp. 1781-1811.

Stark, J \& Bollmann, K 1999, 'Delayed ettringite formation in concrete', Nordic Concrete Research.

Sun, W Zhang, YM Yan, HD \& Mu R 1999, 'Damage and damage resistance of high strength concrete under the action of load and freeze-thaw cycles', Journal of Cement and Concrete Research, vol. 29, pp. 1519-1523.

Taylor, HFW Famy, C \& Scrivener, KL 2001, 'Review: Delayed ettringite formation', Cement and Concrete Research, vol. 31, pp. 683-693.

Thoft-Christensen, P 2000, 'Stochastic modeling of the crack initiation time for reinforced concrete structures', Structures Congress in PhiladelphiaMay 8-10, 2000.
Thomas, MDA 1996, 'Review of the effect of fly ash and slag on alkali-aggregate reaction in concrete', Building Research Establishment Report, BR314, Construction Research Communications, Ltd., Watford, U.K.

Thomas, MDA Fournier, B Folliard, K Ideker, J \& Shehata, M 2006, 'Test methods for evaluating measures for controlling expansion due to alkali-silica reaction in concrete', Cement and Concrete Research, vol. 36, pp. 1842-1856.

Timoshenko, SP \& Goodier, JN 1970, 'Theory of Elasticity', McGraw-Hill, New York.

Tixier, R 2000, 'Microstructural development and sulfate attack modeling in blended cement-based materials', PhD thesis, Arizona State University, Phoenix, Arizona.

Tixier, R \& Mobasher, B 2003a, 'Modeling of damage in cement-based materials subjected to external sulfate attack I: Formulation', J. of Materials in Civil Eng., vol. 15, pp. 305-313

Tixier, R \& Mobasher, B 2003b, 'Modeling of damage in cement-based materials subjected to external sulfate attack ii.comparison with experiments', Journal of Materials in Civil Engineering, vol. 15, pp 314-322.

Tremblay, C Bérubé, MA Fournier, B Thomas, MDA \& Stokes, DB 2004, 'Performance of lithium-based products against ASR: application to Canadian reactive aggregates, reaction mechanisms and testing', Proc. 12th Int. Conf. on Alkali-Aggregate Reaction in Concrete, Beijing (China), pp. 668-677.

Ulm, JF \& Coussy, O 1995, 'Modeling of thermochemomechanical couplings of concrete at early ages', Journal of Engineering Mechanics, vol. 121, pp. $785-794$. 
Ulm, JF \& Coussy, O 1995, 'Modeling of thermochemomechanical couplings of concrete at early ages', Journal of Engineering Mechanics, vol. 121, pp. 785-794.

Ulm, JF \& Coussy, O 1998, 'Couplings in earlyage concrete: from material modeling to structural design', Int. J. Solids and Structures, vol. 35, pp. 4295-4311.

Ulm, FJ Peterson, M \& Lemarchand, E 2002, 'Is ASR expansion caused by chemoporoplastic dilatation?', Concrete Science and Engineering, vol. 4, pp. 47-55.

Wang, X \& Liu, X 2006, 'Bond strength modeling for corroded reinforcements', Construction and Building Materials, vol. 20, pp. 177-186.

Weglewski, W \& Basista, M 2005, 'Damage of concrete in chemically aggressive environment: A micromechanical model', Technical report, Institute of Fundamental Technological Research, Warlaw, Poland.

Wieker, W Hubert, C \& Ebert, R 1996, 'Contribution to the chemical reaction mechanisms of the alkali aggregate reaction', Proc. Of the 10th Int. Conf. on Alkali-Aggregate Reaction in Concrete, Melbourne, Australia, pp. 919-926.
Xi, Y Bazant, Z \& Jennings, HM 1994, 'Moisture Diffusion in Cementitious Materials-Adsorption Isotherms', Advanced Cement Based Materials, vol. 1, pp. 248-257.

Yang, Z \& Chen, J 2004, 'Fully automatic modelling of cohesive discrete crack propagation in concrete beams using local arc-length methods', Int. J. of Solids and Structures, vol. 41, pp. 801-826.

Yuan, SC \& Harrison, JP 2006, 'A review of the state of the art in modelling progressive mechanical breakdown and associated fluid flow in intact heterogeneous rocks', Int. J Rock Mech. \& Min. Sci., vol. 43, pp. 1001-1022.

Zuber, B 2002, 'Numerical modeling of the mechanisms of frost degradation of hydrated cement systems', Ph.D. thesis of Laval University-QuébecCanada and ENS Cachan-France.

Zuber, B \& Marchand, J 2000, 'Modeling the deterioration of hydrated cement systems exposed to frost action - Part 1: Description of the mathematical model', Cement and Concrete Research, vol. 30, pp. 1929-1941. 



\title{
MOISTURE TRANSPORT REVIEW
}

\author{
J. R. Arnold \\ Email: j.arnold@vanderbilt.edu \\ and \\ A. C. Garrabrants \\ Email: a.garrabrants@vanderbilt.edu \\ Vanderbilt University, School of Engineering \\ Consortium for Risk Evaluation with Stakeholder Participation, III \\ Nashville, TN 37235 \\ E. Samson \\ Email: esamson@simcotechologies.com \\ SIMCO Technology, Inc. \\ Quebec City, Canada \\ G. P. Flach \\ Email: gregory.flach@srnl.doe.gov \\ and \\ C. A. Langton \\ Email: christine.langton@srnl.doe.gov \\ Savannah River National Laboratory \\ Aiken, SC 29808
}


Review of Mechanistic Understanding and Modeling and Uncertainty Analysis Methods for Predicting Cementitious Barrier Performance

VI-ii 


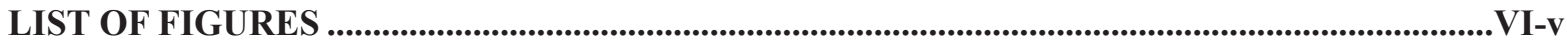

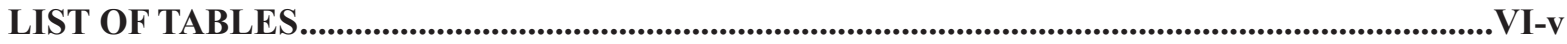

LIST OF ABBREVIATIONS AND ACRONYMS .......................................................................................VI-vi

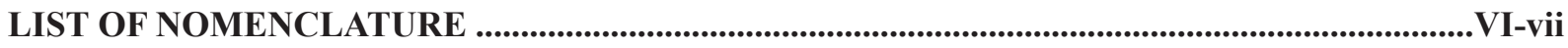

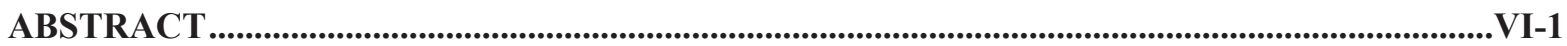

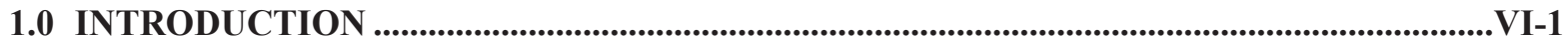

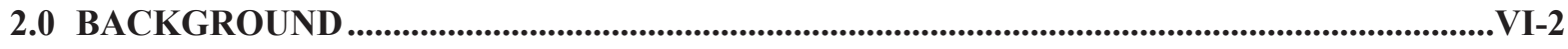

2.1 Morphology and Terminology.................................................................................................2

2.2 Mechanisms of Moisture Transport ...................................................................................

2.2.1 Flow-Inducing Potentials..........................................................................................

2.2.2 Equilibrium Pressure Conditions ..............................................................................

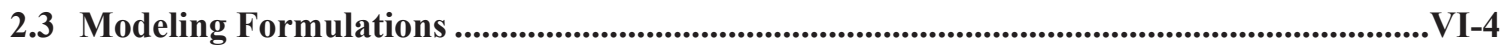

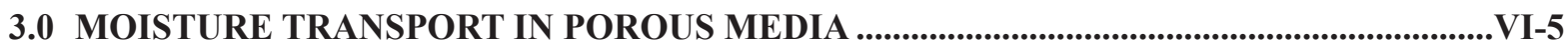

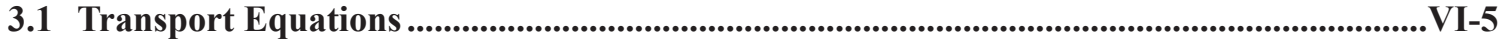

3.2 Model Parameters .............................................................................................................................

3.2.1 Relative Permeability as a Function of Saturation ........................................................ VI-6

3.2.2 Hydraulic Diffusivity as a Function of Water Content ...................................................

3.2.3 Hydraulic Diffusivity as a Function of Relative Humidity .............................................VI-8

3.3 Selected Model Parameter Measurements.........................................................................................VI-11

3.3.1 Saturated Hydraulic Conductivity (Permeability) ..........................................................

3.3.2 Porosity and Pore Size Distribution Measurements .........................................................

3.3.3 Measurement of Hydraulic Diffusivity ………...........................................................

3.4 Qualitative Tests ...................................................................................................................

4.0 MOISTURE TRANSPORT THROUGH FRACTURED MEDIA...............................................VI-16

4.1 Role of Fractures in Moisture Transport ............................................................................................VI-17

4.1.1 Modeling Approaches for Fractured Media....................................................................

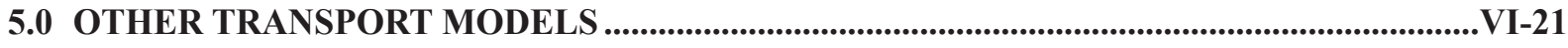

5.1 Pore-scale Models..............................................................................................................................VI-21

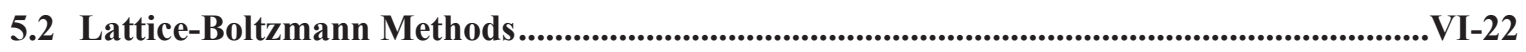


Review of Mechanistic Understanding and Modeling and Uncertainty Analysis Methods for Predicting Cementitious Barrier Performance

CONTENTS (contd)

Page No.

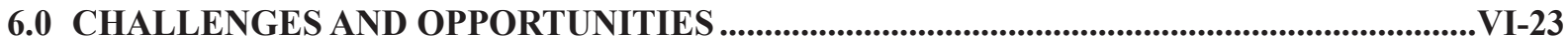

7.0 REFERENCES ...................................................................................................................................... VI-24

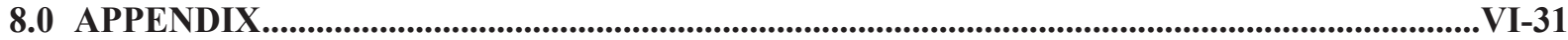

VI-iv 


\section{LIST OF FIGURES}

Page No.

Figure 1. Observed Hydraulic Diffusivity $\left(D_{R H} / D_{100 \%}\right)$ as a Function of Relative Humidity (modified from Bazant and Najjar, 1971).

Figure 2: Illustration of Moisture Transport Regimes with Respect to Liquid Saturation (modified from Garrabrants and Kosson 2003).

Figure 3: Permeability Test Apparatus (CRD 1992)

Figure 4: Triaxial Permeability Test Apparatus (CRD 1992).

Figure 5: Steps in the Dynamic Pressurization Method (Scherer 2006).

Figure 6: Critical Pore Radius (i.e., continuous pore diameter) and Threshold Radius from MIP Data (Nokken and Hooton 2006; Nokken and Hooton 2008).

Figure 7: Water Content Profiles Measured using NMR Techniques (Pel, Brocken et al. 1996)

Figure 8: Hydraulic Conductivity of a Saturated Crack as a Function of Aperture

Figure 9: Effective Unsaturated Hydraulic Conductivity Derived for a Hypothetical Cracked Concrete based on Or and Tuller (2000).

\section{LIST OF TABLES}

Table 1. Hydraulic Diffusivities of Building Materials (Hall \& Hoff 2002). VI-8

Table 2. Increase in Cracked Concrete Permeability over Uncracked Materials (Černý \& Rovnaníková 2002). VI-19

Table 3. Selected Parameters for a Hypothetical Cracked Concrete VI-20 
Review of Mechanistic Understanding and Modeling and Uncertainty Analysis

Methods for Predicting Cementitious Barrier Performance

\section{LIST OF ABBREVIATIONS AND ACRONYMS}

$\begin{aligned} \text { DFM } & \text { Discrete Fracture Modeling } \\ \text { DOE } & \text { Department of Energy } \\ \text { MIP } & \text { Mercury Intrusion Porosimetry } \\ \text { MVG } & \text { Mualem-van Genuchten (Model) } \\ \text { NMR } & \text { Nuclear Magnetic Resonance } \\ \text { NRC } & \text { Nuclear Regulatory Commission } \\ \text { REV } & \text { Representative Elemental Volume } \\ \text { RH } & \text { Relative Humidity }\end{aligned}$




\section{LIST OF NOMENCLATURE}

Roman Characters

$A$ empirical fitting parameter for hydraulic diffusivity as a function of water content [-]

$b$ fracture aperture $[\mathrm{m}]$

$B$ empirical fitting parameter for hydraulic diffusivity as a function of water content [-]

$C$ chemical potential

$C_{y}$ partial pressure [-] of species $y$ in the gas phase (e.g., water)

$d_{c}$ characteristic diameter (i.e., threshold or critical diameter) of pores as determined through MIP and the Washburn equation, i.e., the diameter at which pores form a connected network throughout the specimen and accompanied by a spike in the differential pore size distribution curve during the initial mercury intrusion

$D_{100 \%} \quad$ observed moisture diffusivity at $100 \%$ relative humidity

$D_{e j} \quad$ effective water diffusivity of phase $j$ where $j$, is $v$ for water vapor or $a$ dry air in the gas phase $\left[\mathrm{m}^{2} / \mathrm{s}\right]$

$D_{\theta} \quad$ water or hydraulic diffusivity as a function of water content $\left[\mathrm{m}^{2} / \mathrm{s}\right]$

$D_{\theta, s a t} \quad$ saturated hydraulic diffusivity $\left[\mathrm{m}^{2} / \mathrm{s}\right]$

$D_{R H} \quad$ water or hydraulic diffusivity as a function of relative humidity $\left[\mathrm{m}^{2} / \mathrm{s}\right]$

$E$ electrical potential

$F$ formation factor [-]

$g$ acceleration due to gravity $\left[9.8 \mathrm{~m} / \mathrm{s}^{2}\right]$

$\mathrm{G}$ conductance $\left[\mathrm{m}^{2} / \mathrm{s}\right]$

$\mathrm{G}_{\mathrm{c}}$ critical conductance $\left[\mathrm{m}^{2} / \mathrm{s}\right]$

$h$ total head [m]

$H \quad$ hydraulic potential $[\mathrm{m} / \mathrm{m}]$

$h_{c} \quad$ capillary or matric head $[\mathrm{m}]$

$j$ fluid flux in a single capillary tube as per the Hagen-Poisseuille equation $\left[\mathrm{m}^{3} / \mathrm{s}\right]$

$k_{r i} \quad$ relative permeability factor for phase $i$, where $i$ is $\ell$ for liquid or $g$ for gas [-]

$k^{\prime} \quad$ intrinsic permeability $\left[\mathrm{m}^{2}\right]$

$K_{\ell} \quad$ hydraulic conductivity $[\mathrm{m} / \mathrm{s}]$

$\mathbf{K}_{i}$ conductivity tensor [varies] for potential gradient $i$, where $i$ is hydraulic $H$, chemical $C$, electrical $E$, or thermal $T$ potential

$\mathbf{K}_{\ell}$ hydraulic conductivity tensor $[\mathrm{m} / \mathrm{s}]$

$l$ length of a capillary cylinder [m] as per the Hagen-Poisseuille equation

$L \quad$ fracture groove depth [m]

$m$ van Genuchten model fitting parameter [-]

$M_{w}$ molar mass of water $[\mathrm{g} / \mathrm{mol}]$

$n$ van Genuchten model fitting parameter [-] 


\section{LIST OF NOMENCLATURE (contd)}

\section{Roman Characters (contd)}

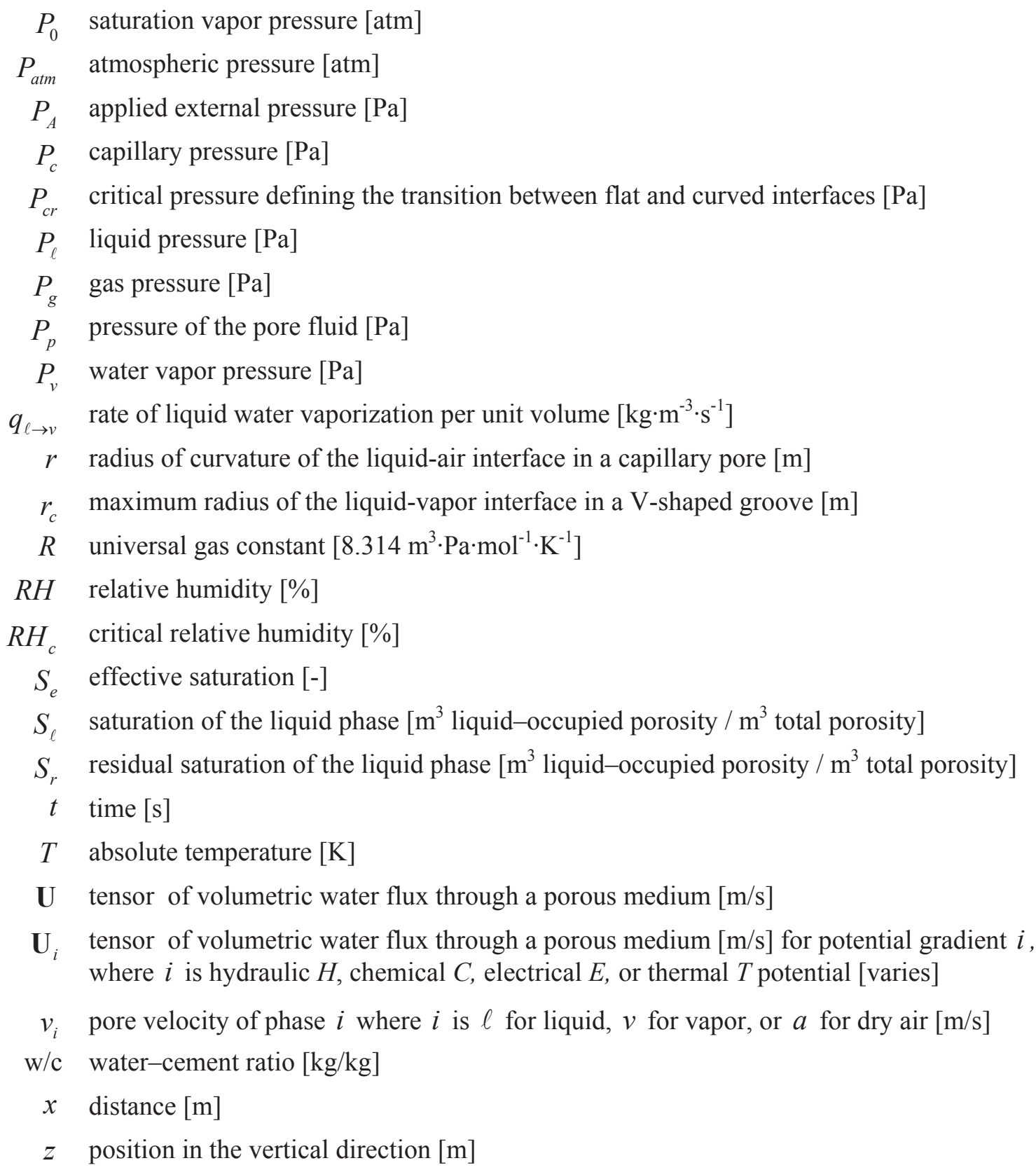




\section{LIST OF NOMENCLATURE (contd)}

\section{Greek Characters}

$\alpha$ van Genuchten model fitting parameter [-]

$\beta$ empirical fitting parameter for hydraulic diffusivity as a function of relative humidity [-]

$\gamma$ empirical fitting parameter for hydraulic diffusivity as a function of relative humidity [-]

$\varepsilon_{0} \quad$ initial strain [-]

$\varepsilon_{\infty} \quad$ residual strain [-]

$\zeta \quad$ fracture groove angle $\left[^{\circ}\right]$

$\eta_{i} \quad$ dynamic fluid viscosity of phase $i$ where $i$ is $\ell$ for liquid, $g$ for gas [Pa·s]

$\theta$ liquid water content $\left[\mathrm{m}^{3}\right.$ water $/ \mathrm{m}^{3}$ total specimen volume]

$\theta_{r} \quad$ residual liquid water content $\left[\mathrm{m}^{3}\right.$ water $/ \mathrm{m}^{3}$ total specimen volume]

$\theta_{s} \quad$ saturated liquid water content $\left[\mathrm{m}^{3}\right.$ water $/ \mathrm{m}^{3}$ total specimen volume $]$

к intrinsic permeability tensor $\left[\mathrm{m}^{2}\right]$

$\lambda$ empirical fitting parameter for hydraulic diffusivity as a function of relative humidity [-]

$\xi$ empirical fitting parameter for hydraulic diffusivity as a function of relative humidity [-]

$\pi$ osmotic suction $[\mathrm{Pa}]$

$\rho_{i} \quad$ density of phase $i$ where $i$ is $\ell$ for liquid, $v$ for water vapor, or $a$ for dry air $\left[\mathrm{kg} / \mathrm{m}^{3}\right]$

$\sigma$ interfacial surface tension $[\mathrm{N} / \mathrm{m}]$

$\tau$ tortuosity of a porous material $[\mathrm{m} / \mathrm{m}]$

$\phi$ porosity [ $\mathrm{m}^{3}$ pore volume $/ \mathrm{m}^{3}$ sample]

$\varphi \quad$ Boltzmann transform $\left[\mathrm{m} / \mathrm{s}^{1 / 2}\right]$

$\chi$ empirical fitting parameter for hydraulic diffusivity as a function of saturation [-]

$\psi \quad$ total liquid suction of a porous medium [m]

$\psi_{c} \quad$ capillary potential $[\mathrm{m}]$

$\omega$ empirical fitting parameter for hydraulic diffusivity as a function of relative humidity [-] 
VI-X 


\title{
MOISTURE TRANSPORT REVIEW
}

\author{
J. R. Arnold and A. C. Garrabrants \\ Vanderbilt University, School of Engineering \\ Consortium for Risk Evaluation with Stakeholder Participation, III \\ Nashville, TN 37235 \\ E. Samson \\ SIMCO Technology, Inc. \\ Quebec City, Canada \\ G. P. Flach and C. A. Langton \\ Savannah River National Laboratory \\ Aiken, SC 29808
}

\begin{abstract}
Moisture transport plays a key role in determining how cementitious materials respond to exposure conditions and release contaminants to the external environment. Moisture presence and movement, whether in the form of liquid water and/or water vapor, affect the concentration and transport rates of dissolved and vapor constituents. The fundamentals of moisture transport in cementitious materials are discussed. Various moisture transport formulations and associated properties are summarized with particular emphasis on moisture transport in fractured or otherwise damaged cementitious materials.
\end{abstract}

\subsection{INTRODUCTION}

Water acts as both a reaction medium and a transport pathway in a porous material. Thus, moisture transport plays a key role in determining how cementitious materials respond to exposure conditions and release contaminants to the external environment. Specifically, moisture presence and movement, whether in the form of liquid water and/or water vapor, affect the concentration and transport rates of dissolved and vapor constituents. Moisture transport is primarily driven by pressure and gravitational head gradients, but other potentials may influence migration. Local pressure conditions are controlled by capillary suction and vapor-liquid equilibrium in addition to boundary conditions.
The fundamentals of moisture transport in cementitious materials are well understood, and a variety of effective modeling approaches have been advanced for predicting moisture movement. Various moisture transport formulations and associated properties are summarized in this section. Particular emphasis is placed on moisture transport in fractured or otherwise damaged cementitious materials, which are of particular interest to the Cementitious Barriers Partnership (CBP). Physical processes, such as thermal and mechanical cracking, and chemical processes, such as continued hydration, portlandite dissolution, or ettringite and calcite formation, may alter the intrinsic properties of the material such 
that the rate of moisture migration is significantly affected. Therefore, defining material properties from initial placement through evolving degradation is essential for the predicting the long-term performance of cementitious materials.

\subsection{BACKGROUND}

The term moisture transport is used to refer to water $\left(\mathrm{H}_{2} \mathrm{O}\right)$ migration through a porous or fractured medium as both a vapor and a liquid. While both gas and liquid phase moisture transport is discussed, emphasis is placed on liquid water migration. Ingress and release of constituents into and from cementitious waste forms occurs predominately through the liquid phase, making liquid moisture transport more significant than gas-phase migration. However, gas phase transport is important relative to condensation and drying processes in unsaturated materials, whereby water uptake or reaction with other gasphase constituents such as carbon dioxide or oxygen may occur.

\subsection{Morphology and Terminology}

The volume fraction of a porous material not occupied by solids is defined as the total porosity of the material. While moisture may be present in liquid and/or gas phases throughout the total porosity, only water that is not chemically or physically bound to cement and resides in voids with connection to external boundaries is available for transport. Thus, a distinction is made between open porosity and closed porosity, the former playing a principal role in moisture transport (Hall \& Hoff 2002). Chemically bound water is associated with the cement gel, hydrated mineral phases, and crystalline phases (Černý \& Rovnaníková 2002) and is classically considered to be fixed such that it does not participate in moisture transport. The volume occupied by these bound waters is included in the closed porosity. However, bound water may indeed transport through differences in the state of bound water (Nilsson 2003). Free water is held by surface tension (capillary) forces. Such water can migrate, provided the void space is connected in some manner to an external boundary. The closed or disconnected porosity is often lumped with physical solids in defining the "solid" matrix for analysis purposes. In subsequent discussion, the abbreviated term porosity is used with the understanding that open porosity is implied.

From the perspective of long-term performance assessment, cement hydration is also assumed to be practically complete, with respect to moisture transport analysis, such that porosity and associated microstructure are fixed. Characterization of early age porosity and pore structure evolution does not assume complete cement hydration. Likewise, studies dealing with alteration of mature cementitious materials (e.g., some chemical reactions generate water) make assumptions appropriate to the phenomena. Microstructural evolution of cementitious matrices as a function of aging and chemical and structural degradation is presented in a separate chapter.

In cementitious materials, porosity generally takes the form of small-scale interstitial voids or pores between cemented solid grains/aggregates. Void space in the form of cracks or fractures may be present as an initial condition of the material (e.g., thermal and shrinkage cracking) or occur in a number of exposure and damage scenarios (e.g., early-age cracking, sulfate attack, rebar corrosion). While cracking typically has a small impact on void volume, fractures can dramatically affect moisture transport, particularly under saturated or low suction conditions in the case of liquids. Key fracture attributes influencing transport are aperture, crack density, and the degree of connectedness. The term porous medium is sometimes reserved for an un-cracked material to distinguish from a fractured medium, although both media are porous. Moisture transport in fractured materials is of particular relevance to long-term performance of cement-based materials, 
because several degradation scenarios lead to damage in the form of cracks, spalling, etc.

\subsection{Mechanisms of Moisture Transport}

Moisture transport is driven by gradients of thermodynamic potentials, principally fluid pressure. The transport rate depends on pressure and other gradients, fluid properties, fluid saturation, and the intrinsic permeability of the porous medium. Pressure conditions are influenced by external boundary conditions, and local vapor-liquid thermodynamic equilibrium in the presence of capillary and osmotic suctions.

\subsubsection{Flow-Inducing Potentials}

In principle, fluid flow can be induced by multiple potential gradients (Bear 1972). Hydraulic head or pressure gradients are the primary driver in most applications. Chemical, electrical and thermal gradients, typically considered of secondary or negligible influence, can also be important to fluid transport.

From the perspective of a porous medium continuum, the overall volumetric water flux $\mathbf{U}$ can be expressed as:

$\mathbf{U}=-\mathbf{K}_{H} \Delta H-\mathbf{K}_{C} \Delta C-\mathbf{K}_{E} \Delta E-\mathbf{K}_{T} \Delta T$

where: $H, C, E$ and $T$ are hydraulic, chemical, electrical and thermal potentials and $\mathbf{K}_{i}$ is the conductivity tensor for potential gradient $i$ (de Marsily 1986).

The velocity contribution under a hydraulic gradient, i.e., the first term in Eq. (1), is one form of Darcy's Law, and the remaining terms represent chemical, electrical and thermal osmosis respectively. Among the latter effects, chemical osmosis can be significant in cement-based materials. Examples include ice accretion (Erlin \& Mather 2005), damage from alkali-aggregate reaction (Gambhir 2004; McArthur $\&$ Spalding 2004), and evaporation in the presence of high salt concentrations (Scherer 1999).
In Darcy's Law, the flux of water transporting through a porous media is proportional to the hydraulic gradient by a factor called the hydraulic conductivity:

$$
\mathbf{U}=-\mathbf{K}_{H} \nabla H
$$

The hydraulic conductivity can be decomposed into components of permeability and fluid properties while the hydraulic gradient is separated into pressure and elevation contributions yielding:

$$
\mathrm{U}=-\frac{\mathbf{\kappa}}{\eta_{\ell}} k_{\mathrm{r} \ell}\left[\nabla P_{\ell}+\rho_{\ell} g \nabla z\right]
$$

where: $\boldsymbol{\kappa}$ is the intrinsic permeability tensor, $k_{r \ell}$ is a relative permeability function, $\eta_{\ell}$ is dynamic fluid viscosity, $P_{\ell}$ is fluid pressure, $\rho_{\ell} g$ is specific weight, and $z$ is elevation relative to a reference plane.

The intrinsic permeability is a property only of the porous medium and is not dependent on fluid properties. Relative permeability is a function of the fraction of liquid filled pore volume referred to as pore saturation.

With respect to liquid water transport in the presence of a semi-permeable membrane or strong variations in solute concentration, the chemical potential is more conveniently expressed in terms of an osmotic pressure, such that:

$$
\mathrm{U}=+\frac{\mathbf{\kappa}}{\eta_{\ell}} \mathrm{k}_{\mathrm{r} \ell} \nabla \pi
$$

where: the sign-reversal reflects the positive valued osmotic suction, $\pi$.

The overall volumetric liquid water flux due to hydraulic gradients and (chemical) osmosis is given by:

$$
\mathbf{U}=\mathbf{U}_{H}+\mathbf{U}_{\pi}=-\frac{\mathbf{\kappa}}{\eta_{\ell}} k_{r}\left[\nabla\left(P_{\ell}-\pi\right)+\rho_{\ell} g \nabla z\right]
$$

Water vapor transport in unfractured materials is driven primarily by pressure and vapor concentration gradients, with elevation gradient considered 
insignificant. The volumetric water vapor flux is typically expressed as an advective flux, from pressuredriven bulk gas flow, plus a diffusive flux relative to the mean flow due to a concentration gradient.

\subsubsection{Equilibrium Pressure Conditions}

Locally, liquid pressure is coupled to equilibrium vapor pressure through pore structure, water content relative to porosity, and solute concentration(s). Total liquid suction (negative pressure; positive-valued), also known as the free energy state of pore water, is the sum of matric and osmotic suctions (Fredlund \& Rahardjo 1993; Dao, Morris \& Dux 2008):

$$
\psi=\left(P_{g}-P_{\ell}\right)+\pi=\psi_{\mathrm{c}}+\pi
$$

where: $P_{g}$ is gas pressure, $P_{\ell}$ is liquid pressure, an $\mathrm{d} \psi_{c}$ is matric or capillary suction.

Pore structure, water content, and porosity influence liquid pressure through the matric suction, while the osmotic suction is controlled by solute concentrations. Total suction is closely related to chemical potential.

Total suction is related to vapor pressure through the equilibrium thermodynamic relationship (Richards 1965; Fredlund \& Rahardjo 1993):

$$
\psi=-\frac{R T}{g M_{w}} \ln \frac{P_{v}}{P_{0}}
$$

where: $\psi$ is total liquid suction, $R$ is the universal (molar) gas constant $\left[\mathrm{m}^{3} \cdot \mathrm{Pa} \cdot \mathrm{mol}^{-1} \cdot \mathrm{K}^{-1}\right], g$ is acceleration due to gravity $\left[\mathrm{m} / \mathrm{s}^{2}\right], M_{w}$ is molar mass of water $[\mathrm{kg} / \mathrm{mol}], T$ is absolute temperature $[\mathrm{K}], P_{0}$ is vapor pressure at saturation $\left[P_{v}\right]$, and $P_{v}$ is water vapor pressure $[\mathrm{Pa}]$.
In light of this expression, water vapor pressure can be viewed as a master variable defining the pressure state of both the gas and liquid phases (Hall \& Hoff 2002).

\subsection{Modeling Formulations}

A number of approaches have been devised for describing water transport through porous media. The vast majority involve using macroscopic formulations derived from volume averaging over a Representative Elementary Volume (REV; Bear 1972) or ensemble averaging concepts (Bear \& Buchlin 1991). These approaches enable a continuum treatment of porous medium properties and introduce the concept of fluid saturation. Fluid saturation is the average presence of the fluid phase within the REV; or the probability of occurrence across an ensemble of realizations.

Fractures within a porous medium can be addressed using continuum or discrete fracture models. Continuum fractured media formulations include: 1) the single-continuum effective property approach, whereby the original porous medium properties are modified to capture the combined effects of matrix and fracture transport, and 2) dual-porosity/permeability models, which utilize a dual-continuum concept whereby water transport occurs in overlapping matrix and fracture volumes. Discrete fracture models explicitly simulate flow through individual fractures while preserving the key attributes of the fracture geometry such as aperture, spacing, asperity, and connectivity.

Pore scale models, although less commonly used, are valuable for investigating pore scale phenomena, such as chemical reactions and crack initiation and propagation within the cement-based material microstructure. Other models of potential interest include lattice-Boltzmann models. 


\subsection{MOISTURE TRANSPORT IN POROUS MEDIA}

\subsection{Transport Equations}

Mainguy (2001) expressed the mass balance equations for the two-phase, three-component (liquid water, dry air and water vapor) water transport system as:

$$
\begin{aligned}
& \text { Liquid } \\
& \frac{\partial}{\partial t}\left(\phi S_{\ell} \rho_{\ell}\right)=-\nabla\left(\phi S_{\ell} \rho_{\ell} v_{\ell}\right)-q_{\ell \rightarrow v}
\end{aligned}
$$

\section{Water Vapor}

$$
\begin{aligned}
& \frac{\partial}{\partial t}\left(\phi\left(1-S_{\ell}\right) \rho_{v}\right)= \\
& \quad-\nabla\left(\phi\left(1-S_{\ell}\right) \rho_{v} v_{v}\right)+q_{\ell \rightarrow v}
\end{aligned}
$$

\section{Dry Air}

$$
\frac{\partial}{\partial t}\left(\phi\left(1-S_{\ell}\right) \rho_{a}\right)=-\nabla\left(\phi\left(1-S_{\ell}\right) \rho_{a} v_{a}\right)
$$

where: $\phi$ is porosity, $\rho_{i}$ is density of phase (e.g., where $i$ is $\ell$ for liquid, $v$ for vapor, or $a$ for dry air), $S_{\ell}$ is liquid saturation, $v_{\mathrm{i}}$ is velocity of phase $i$, and $q_{l \rightarrow v}$ is the rate of liquid water vaporization per unit volume.

Considering hydraulic and osmotic potentials for liquid flow, the liquid phase Darcy velocity is defined by (5):

$$
\phi v_{\ell}=-\frac{\mathbf{\kappa}}{\eta_{\ell}} k_{r \ell}\left\langle S_{\ell}\right\rangle\left[\nabla\left(P_{\ell}-\pi\right)+\rho_{\ell} g \nabla z\right]
$$

where: the saturation dependence of relative permeability is explicitly denoted as $\mathrm{k}_{r \ell}\left\langle S_{\ell}\right\rangle$.

Under these conditions, the gas phase velocity is defined by:

$$
\phi v_{g}=-\frac{\mathbf{\kappa}}{\eta_{g}} k_{r g}\left\langle S_{\ell}\right\rangle \nabla P_{g}
$$

The water vapor and dry air mass fluxes can then be expressed as the sum of advective and diffusive components as:

$$
\begin{aligned}
\phi \rho_{j} v_{j} & =\phi \rho_{j} v_{g} . \\
& -D_{e j}\left\langle S_{\ell}\right\rangle \phi\left(1-S_{\ell}\right) \nabla \rho_{j}
\end{aligned}
$$

where: the subscript $j$ indicates air or water vapor components, and $D_{e j}<S_{\ell}>$ is a saturation-dependent effective diffusion coefficient accounting for tortuosity effects.

Several moisture transport models have been developed for various applications using this approach (Šelih, Sousa \& Bremner 1996; Gawin, Pesavento \& Schrefler 2006; Mainguy, Coussy \& Baroghel-Bouny 2001) to describe isothermal drying test results in cementitious materials using the expression:

$\phi_{g} \rho_{j} v_{j}=\phi_{g} \rho_{j} v_{g}$

$$
-\rho_{j} \frac{D_{j}}{C_{y}} f\left\langle S_{\ell}, \phi\right\rangle \nabla C_{y}
$$

where: $\mathrm{D}_{j}$ is the diffusion coefficient of component $j$ (e.g., $v$ or $a$ for water vapor or dry air in the gas phase), $f\left\langle S_{\ell}, \phi\right\rangle$ is the resistance factor accounting for both tortuosity effects $\left(D_{e j}=D_{j} f\right)$ and the effective area for diffusion and $C_{y}$ is the partial pressure of species $y$ (e.g., water).

The general multiphase moisture transport equation set is commonly simplified by: 1) neglecting osmotic effects, bulk gas phase transport, and evaporation, 2) assuming constant liquid properties, and 3) taking the gas pressure as uniformly equal to atmospheric pressure. Then the liquid mass balance Eq. (8) and Darcy's Law Eq. (11) can be combined to yield a form of the Richards Equation (1931):

$$
\begin{aligned}
\frac{\partial \theta}{\partial t} & =\nabla\left[\mathbf{K}_{\ell} k_{r \ell}\langle\theta\rangle \nabla\left(\frac{-\psi_{\mathrm{c}}\langle\theta\rangle}{\rho_{\ell g}}+z\right)\right] \\
& =\nabla\left[\mathbf{K}_{\ell} k_{r \ell}\langle\theta\rangle \nabla h\right]
\end{aligned}
$$


where: $\theta=\phi S_{\ell}$ is water content, $\mathbf{K}_{\ell}=\mathbf{\kappa} \rho_{\ell} g / \eta_{\ell}$ is hydraulic conductivity tensor, $\kappa_{\mathrm{r} \ell}\langle\theta\rangle$ is relative permeability now expressed as a function of water content, $\psi_{c}\langle\theta\rangle / \rho_{\ell} g$ is matric (capillary) suction head, and $h$ is total head.

The nonlinear relative permeability $\left(K_{r \ell}\langle\theta\rangle\right.$ and water retention $\left(\psi_{c}\langle\theta\rangle / \rho_{\ell} g\right)$ functions must be empirically defined to complete the formulation. Richards equation may not be accurate for cases where the external relative humidity is less than $100 \%$, such that evaporation is important.

Further simplification can be achieved by neglecting gravity effects if present and assuming a homogeneous material, conditions often valid in cementitious material applications. By viewing matric suction as a function of water content and using the chain rule on the right hand side of Eq. (15), the (positive-valued) water or hydraulic diffusivity parameter can be defined as:

$$
\begin{aligned}
\mathbf{D}_{\theta}\langle\theta\rangle & =\mathbf{K}_{\ell} k_{r \ell}\langle\theta\rangle \frac{d\left(-\psi_{c} / \rho_{\ell g}\right)}{d \theta} \\
& =-\mathbf{K}_{\ell} k_{r \ell}\langle\theta\rangle \frac{d h_{\mathrm{c}}}{d \theta}
\end{aligned}
$$

where: $h_{c}$ is matric (capillary) suction head.

With this definition, Eq. (15) can then be simplified as:

$$
\frac{\partial \theta}{\partial t}=\nabla\left[\mathbf{D}_{\theta}\langle\theta\rangle \nabla \theta\right]
$$

The nonlinear water diffusivity is normally observed directly from measurements, rather than computed using the above relation, in a similar manner to water retention and relative permeability functions. The water diffusivity formulation is convenient because three material properties (saturated hydraulic conductivity, relative permeability, and water retention) are replaced by a single empirical function. Similar equations using relative humidity as the dependent variable have also been derived (Xi et al. 1994).

\subsection{Model Parameters}

The material property needs associated with the two simplified moisture transport formulations differ. Richards Equation (15) requires hydraulic conductivity $\left(\mathbf{K}_{\ell}=\boldsymbol{\kappa} \rho_{\ell} g / \eta_{\ell}\right)$, relative permeability $\left(\mathrm{k}_{r \ell}\langle\theta\rangle\right)$, and water retention functions $\left(\psi_{c}\langle\theta\rangle / \rho_{\ell} g\right)$, while Eq. (17) requires only a water diffusivity function $\left(\mathbf{D}_{\theta}\langle\theta\rangle\right)$. The relative permeability, water retention, and water diffusivity functions are referred to as characteristic curves of the porous medium (Webb 2006). Although shown as a function of water content $(\theta)$, the moisture characteristic curves may also be expressed as functions of saturation through the relationship:

$\theta=\phi S_{\ell}$

These parameters are empirically determined through experimentation and generally exhibit hysteresis, leading to separate wetting/adsorption and drying/ desorption curves.

The appendix lists the properties needed to define the physical state of a porous medium. These include the fluid and porous-medium properties related to moisture transport encountered in this chapter and, for completeness, other physical and material properties related to solute transport and leaching processes.

\subsubsection{Relative Permeability as a Function of Saturation}

Many closed form expressions have been proposed for representing water retention and relative permeability (e.g., Brooks and Corey 1964); however, the Mualemvan Genuchten (MVG) model (Mualem 1976; van Genuchten 1980) is the most widely used. The MVG model defines an effective saturation (Se) as:

$S_{e}=\frac{S-S_{r}}{1-S_{r}}=\frac{\theta-\theta_{r}}{\theta_{\mathrm{s}}-\theta_{r}}$

where: $S_{e}$ is the effective saturation and the subscripts $r$ and $s$ refer to the residual and saturated water conditions, respectively. 
The effective saturation and relative permeability are then expressed as:

$S_{e}=\left[\frac{1}{1+\left(\alpha h_{c}\right)^{n}}\right]^{m}$

$k_{r}\left\langle S_{e}\right\rangle=S_{e}^{1 / 2}\left[1-\left(1-S_{e}^{1 / m}\right)^{m}\right]^{2}$

where: it is often assumed that $m=1-1 / n$.

Thus, the MVG model contains two empirical parameters, $n$ and $\alpha$. In these expressions, $h_{c}=\psi_{c} / \rho_{\ell} g$ is matric (capillary) suction head.

Although developed in the context of unsaturated soils, the MVG model has been validated for cement concretes (Savage \& Janssen 1997; Wardeh \& Perrin 2006). The MVG model equations and the input parameters of porosity and moisture desorption curves have been utilized to make indirect measurements of the intrinsic permeability of cementitious specimens (Baroghel-Bouny 2007a). Application of the MVG model in this manner avoids the difficulty in obtaining direct measurements of unsaturated conductivity. However, even saturated permeability can be difficult to determine experimentally due to the relatively low porosity of cementitious materials. Typically, in order to induce flow, large external pressures must be applied to a surface which could potentially result in microstructural damage (Olson, Neubauer \& Jennings 1997; Feldman 1984).

If total potential $\psi$ is assumed to be a function of water content $\theta_{\ell}$ then the change in water content with time may be expressed as a function of only the water content gradient by embedding the value of $K\langle\theta\rangle$ in the hydraulic diffusivity coefficient $D_{\theta}\langle\theta\rangle\left[\mathrm{m}^{2} / \mathrm{s}\right]$ as shown in Eq. (16).

The term "diffusivity" was ascribed to water migration because one-dimensional moisture migration is defined by a second order differential equation, analogous to Fick's second law of diffusion describing Brownian motion. This nomenclature should be used with caution as the migration of moisture in this instance is due to the chemical, electrical and thermal potentials described above. For clarity, $D_{\theta}\langle\theta\rangle$ is referred to as water diffusivity or hydraulic diffusivity.

\subsubsection{Hydraulic Diffusivity as a Function of Water Content}

Although the Mualem-van Genuchten model can be recast in terms of the hydraulic diffusivity parameter (van Genuchten 1980), simpler expressions to parameterize Eq. (17) are typically used for cementitious materials (Hall \& Hoff 2002). A common empirical relationship relating 1-D hydraulic diffusivity to water content is:

$D_{\theta}=A \exp (B \theta)$

where: $A$ and $B$ are constants (Hall \& Hoff 2002;

Mensi, Acker \& Attolou 1988).

Table 1 lists hydraulic diffusivity parameter values $D_{\theta}$ for various building materials which may be considered analogs to some cementitious barrier materials.

A non-destructive means of experimentally determining $D_{\theta}\langle\theta\rangle$ was first reported in 1979 (Gummerson et al. 1979). The method involves measuring time-dependent moisture profiles of one-dimensional water uptake into an initially dry mortar bar via nuclear magnetic resonance (NMR) spectroscopy, a technique which detects the interaction of magnetic moments of nuclei with quantum spin state of $+1 / 2$ (including hydrogen) and an applied external magnetic field (Blümich 2000). Neutron radiography has also been successfully employed to determine the hydraulic diffusivity in a similar manner (Pel et al. 1993; Cnudde et al. 2008). However, air blockages which are common in one-dimensional uptake experiments on initially dry samples, may lead to complications with data interpretation. 
Table 1. Hydraulic Diffusivities of Building Materials (Hall \& Hoff 2002)

\begin{tabular}{|l|c|c|}
\hline \multicolumn{1}{|c|}{ Material } & \multicolumn{2}{|c|}{ Diffusivity } \\
\hline Lepine limestone & $\mathbf{D}_{\mathbf{\theta}} \mathbf{D}_{\text {wsat }}\left[\mathbf{m}^{\mathbf{2}} / \mathbf{s}\right]$ & $\left(\theta_{3}-\theta_{r}\right) B$ \\
\hline Cleris limestone & $6.3 \times 10^{-9}$ & 4.9 \\
\hline St. Maximin fine limestone & $3.2 \times 10^{-9}$ & 6.4 \\
\hline Gres de Vosges sandstone & $1.3 \times 10^{-8}$ & 5.6 \\
\hline Clay brick ceramic, moulded & $2.4 \times 10^{-9}$ & 5.0 \\
\hline Clay brick ceramic, extruded & $3.4 \times 10^{-9}$ & 8.3 \\
\hline Sand-lime brick & $2.2 \times 10^{-9}$ & 6.3 \\
\hline $1: 5$ cement:sand mortar & $7.9 \times 10^{-11}$ & 8.4 \\
\hline $1: 3: 12$ cement:lime:sand mortar & $9.5 \times 10^{-10}$ & 8.0 \\
\hline
\end{tabular}

Values of the hydraulic diffusivity $D_{o}\langle\theta\rangle$ may be well fit with exponential equations (Hazrati et al. 2002; Leech, Lockington \& Dux 2003; Pel et al. 1998). Some researchers have found sufficient agreement using power law approximations of the form:

$D_{\theta}\langle\theta\rangle=D_{\theta, s a t} \theta^{\chi}$

where: $D_{\theta, \text { sat }}$ is the hydraulic diffusivity at full saturation and $\chi$ is a constant.

However, at least one study suggests that an exponential fit might be a better approximation than power law expressions (Hall \& Hoff 2002; Lockington, Parlange \& Dux 1999). Neither Eq. (20) nor Eq. (21) has a strong theoretical basis, but both expressions have been found useful for describing moisture transport in cementitious materials (Hall \& Hoff 2002).

\section{Boltzman Transform Approach}

A closed form solution for the hydraulic conductivity parameter shown in the partial differential equation Eq. (16) may be found through the Boltzman transformation:

$\varphi=x t^{-1 / 2}$
The resulting partial differential equation takes the form:

$-\frac{\varphi}{2} \frac{d \theta}{d \varphi}=\frac{d}{d \varphi}\left(D_{\theta} \frac{d \theta}{d \varphi}\right)$

Setting the conditions that $\theta=\theta_{S}$ at $\varphi=0$ and $\theta=\theta_{r}$ as $\varphi \rightarrow \infty$, the closed form solution is given by (Hall \& Hoff 2002):

$$
x\langle\theta, t\rangle=\phi\langle\theta\rangle t^{1 / 2}
$$

Eq. (26) demonstrates that plotting water content as a function of $\varphi$ will result in a single master curve, and by dividing the master curve into small increments from the residual water content $\theta_{r}$ to any water content $\theta_{x}$, hydraulic diffusivity may be determined via the Matano method as (Hall \& Hoff 2002; Matano 1932-33):

$$
D_{\theta}\left\langle\theta_{x}\right\rangle=\frac{1}{(d \theta / d \phi)_{\theta_{x}}}-\frac{1}{2} \int_{\theta_{r}}^{\theta_{x}} \varphi d \theta
$$

\subsubsection{Hydraulic Diffusivity as a Function of Relative Humidity}

A similar expression of moisture transport shown in Eq. (17) has also been derived using relative humidity $R H$ as the dependent variable (Xi et al. 
1994). This approach assumes that the driving force can be expressed as: $\mathbf{U}=-D_{R H} \nabla R H$ where $D_{\mathrm{RH}}$ is hydraulic diffusivity as a function of $R H$. In that case, Eq (17) can be written as (Bazant \& Najjar 1971; Xi et al. 1994; Garrabrants \& Kosson 2003):

$\frac{\partial \theta}{\partial R H} \frac{\partial R H}{\partial t}=\nabla\left(D_{R H} \nabla R H\right)$

where: $\partial \theta / \partial R H$ represents the water content as a function of relative humidity.

In practice, this relationship exhibits hysteresis, that is, the function is distinct depending on whether the specimen adsorption or desorption is measured. However, due to the shape of the adsorption and desorption curves being nearly the same (Hagymassy et al. 1972), use of the term $\partial \theta / \partial R H$ is consistent whether measured from wetting or drying experiments.

Inference of hydraulic diffusivity from these relatively simple water sorption/desorption experiments has proven successful although somewhat sensitive to experimental conditions (Ketelaars et al.

1995; Garbalinska 2006; Anderberg \& Wadsö 2008). Experiments of this type typically involve measurement of mass change over short time intervals and can be fit to analytical solutions of diffusivity (Crank 1975) or to empirical forms. An empirical expression was presented by $\mathrm{Xi}$ et al 1994) as:

$D_{R H}=\lambda+\beta\left(1-2^{-10 \gamma(R H-1)}\right)$

where: $\lambda, \beta$ and $\gamma$ are parameters that need to be determined experimentally.

\section{Two Regime Model}

The hydraulic diffusivity expression used by Garrabrants and Kosson (2003) was derived from the work of Bazant and Najjar (1971) in which the function is described as "an S-shaped curve" with the general expression:

$D_{R H}=D_{100 \%}\left[\xi+\frac{1-\xi}{1+\left(\frac{1-R H}{1-R H_{c}}\right)^{\omega}}\right]$

where: $D_{100 \%}$ is the observed moisture diffusivity at $100 \%$ relative humidity and $\xi, \omega$, and $R H_{c}$ are fitting parameters.

Bazant and Najjar described the ratio of of $D / D_{100 \%}$ as an "S-shaped" curve where $\xi$ is the ratio of $D_{0 \%} / D_{100 \%}$, $\omega$ represents the spread in the drop of the S-shaped curve, and $R H_{c}$ is a critical relative humidity corresponding to the center of the drop in curve (Figure 1).

Garrabrants and Kosson interpretated the dependence of the hydraulic diffusivity on water saturation (or relative humidity) with respect to the evolution of continuous liquid and gas phases during the drying process Figure 2). The critical phases of the drying process include:

- Funicular Drying (Fully Saturated to Capillary Saturation): $\mathrm{RH}$ at the bulk material surface is $100 \%$ and evaporation away from surface is driven by the relative humdity gradient between the surface and ambient conditions. During this funicular drying regime, bulk phase movement occurs in response to pressure gradients within the porous network and the liquid phase is considered to be continuous while the gas phase is discontinuous at $\mathrm{RH}=100 \%$.

- Transistion Zone Drying (Capillary Saturation to Insular Saturation): At capillary saturation, both liquid and gas phases are continuous and the observed hydraulic diffusivity is a combination of bulk liquid movement and vapor transport. During the transistion zone drying regime, the ratio of $D_{R H} / D_{100 \%}$ drops toward the value of $\xi$. 


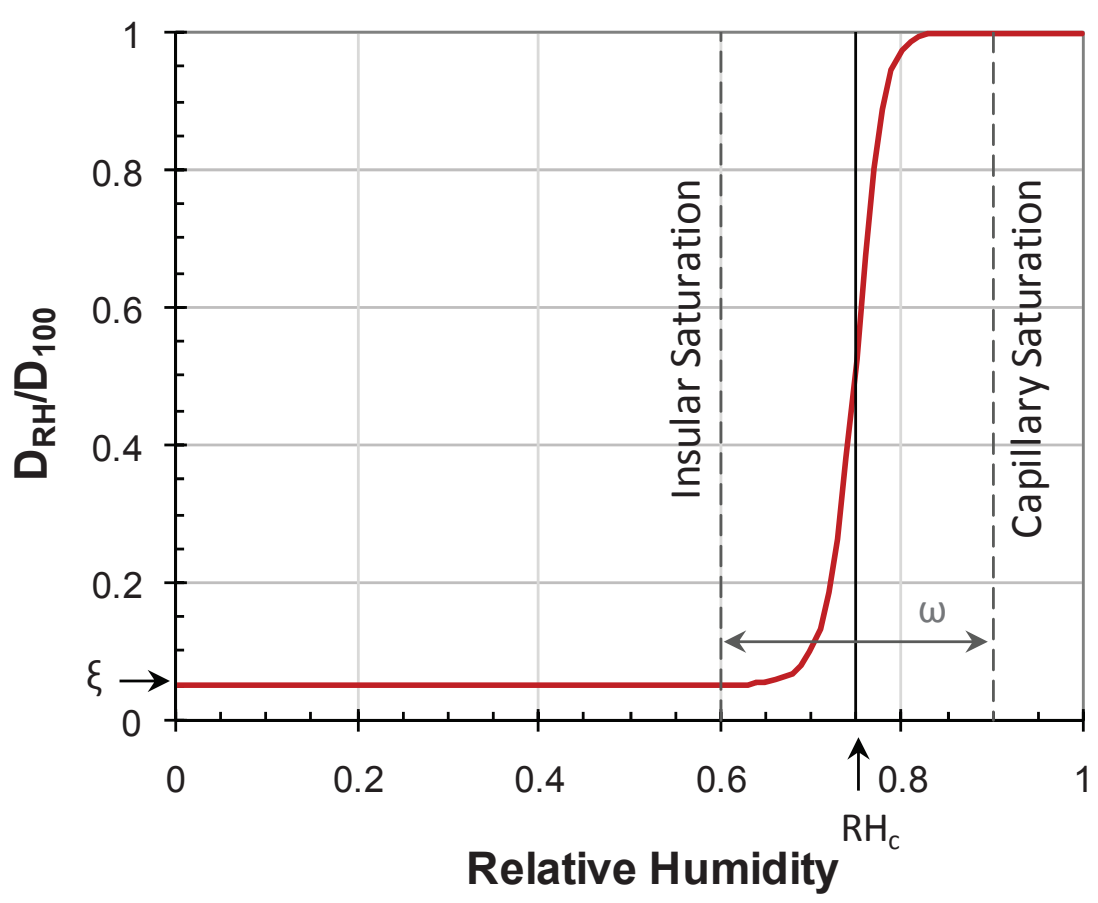

Figure 1. Observed Hydraulic Diffusivity $\left(\mathbf{D}_{R H} / \mathbf{D}_{100 \%}\right)$ as a Function of Relative Humidity (modified from Bazant and Najjar, 1971)

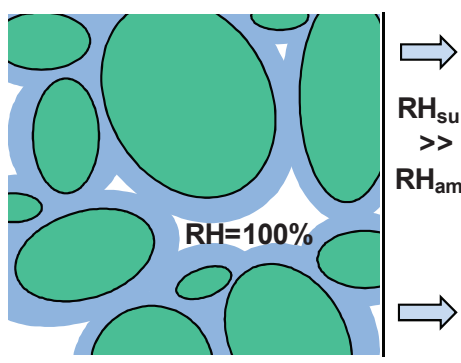

Funicular Drying

\begin{tabular}{|l|}
\hline Full Saturation \\
Funicular Drying \\
Continuous Liquid Phase \\
- Discontinuous Gas Phase \\
Capillary Saturation \\
\hline
\end{tabular}

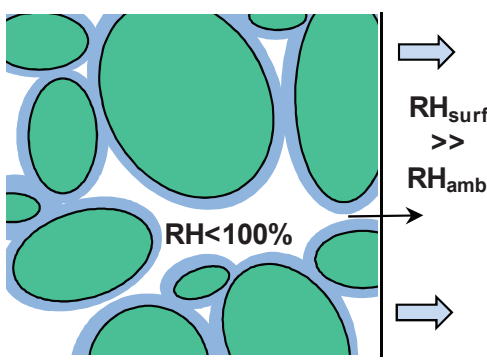

Transition Zone Drying

\section{Capillary Saturation \\ Transition Zone Drying \\ - Continuous Liquid Phase \\ - Continuous Gas Phase}

Insular Saturation

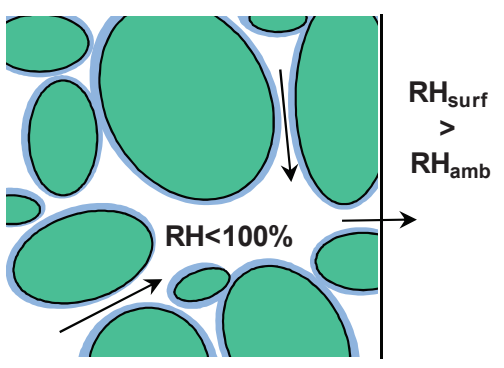

Isothermal Drying

\section{Insular Saturation}

Isothermal Drying

- Discontinuous Liquid Phase

- Continuous Gas Phase

Completely Dry

Figure 2: Illustration of Moisture Transport Regimes with Respect to Liquid Saturation (modified from Garrabrants and Kosson 2003) 


\section{- Isothermal Drying (Insular Saturation to}

Completely Dry): At the point of insular saturation, liquid phase becomes discontinuous and moisture transport is dominated by the diffusion of water vapor in the continuous gas phase. The water content is given as a function of internal $\mathrm{RH}$ through the vapor-liquid isotherm and this phase of the drying process is referred to as the isothermal drying regime. However, the theoretical construct of a "completely dry" cementitious matrix is not realistic, even at very low ambient relative humidity, due to existence of bound water in the matrix.

\subsection{Selected Model Parameter Measurements}

Accurate simulation of moisture transport using either the Richards equation (15) or the hydraulic diffusion equation requires measurement of key moisture parameters. For the Richards equation, these parameters include the hydraulic conductivity, relative permeability, and water retention functions while a water diffusivity function and vapor-liquid isotherm may be required for the hydraulic diffusion equation. Several direct and indirect measurement methods are available.

\subsubsection{Saturated Hydraulic Conductivity (Permeability)}

Direct Permeability Methods: The direct estimation of cementitious material permeability is based on Darcy's law shown in Eq. (2) and consists of exposing a saturated material sample to a constant 1-D pressure gradient with measurement of the water flow across the sample. The 1-D water transport is enforced by coating the side surface of the sample with epoxy or a similar sealant. Upon reaching steady-state, the permeability is calculated from the ratio of the flow over the applied pressure gradient. This methodology is used in the CRD-C 48-92 Standard Test Method for Water Permeability of Concrete (CRD 1992a) and the experimental setup is illustrated in Figure 3.

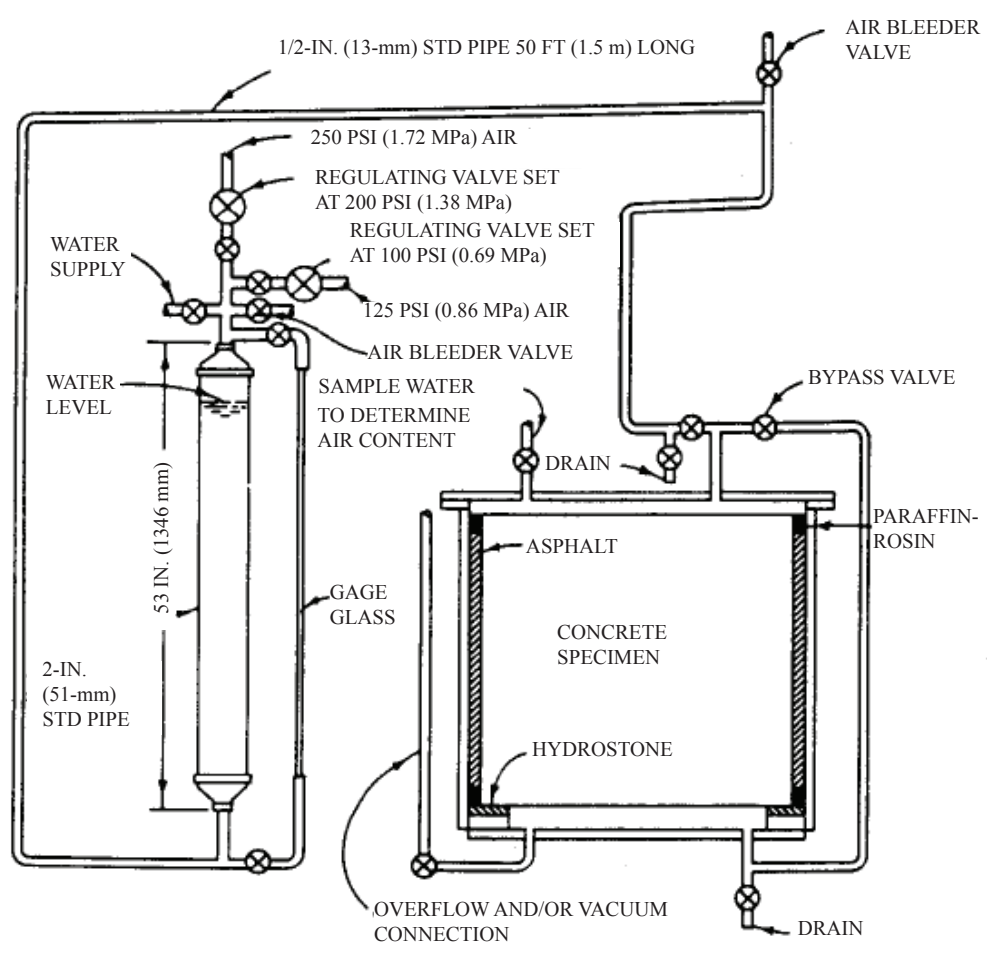

Figure 3: Permeability Test Apparatus (CRD 1992) 
Although the principle is very simple, this method has been hampered by the material itself. The highly tortuous and narrow pore network of cementitious materials translates into very low permeability values and, consequently, high pressures are needed to generate a measurable and stable flow. High pressures can lead to leakages around the sample (Hope \& Malhotra 1984). In addition, the surface of the sample must be dried in order to apply most sealants or coatings, which may affect the permeability estimation (Scherer, Valenza \& Simmons 2007). Because of these experimental problems, high variability in permeability values have been reported (El-Dieb \& Hooton 1995). Improvements to the basic setup have been proposed in the literature (Hope \& Malhotra 1984; Hearn \& Mills 1991), but, overall, the method is not well adapted to high quality materials due to the high pressure needed to maintain constant water flows (Nokken \& Hooton 2008).

An alternate method for measuring permeability was proposed based on the use of a triaxial test (CRD 1992b). The basic principle is the same as the previous method except that lateral pressure is applied on a rubber sleeve surrounding the entire sample to prevent leakages (see Figure 4).

Variations on this setup have been proposed in the literature (e.g., (El-Dieb \& Hooton 1994b). Test results with the triaxial procedure showed less variability than with the previous method, even for high quality materials (El-Dieb \& Hooton 1995). Despite these improvements, the triaxial method is rarely used (Nokken \& Hooton 2008).

Indirect Permeability Methods: The technical difficulties associated with the direct methods have led to the development of indirect methods, where the experimental conditions are easier to control. On the other hand, these methods often are accompanied by theory that is more complex than the simple theory of Darcy's law.

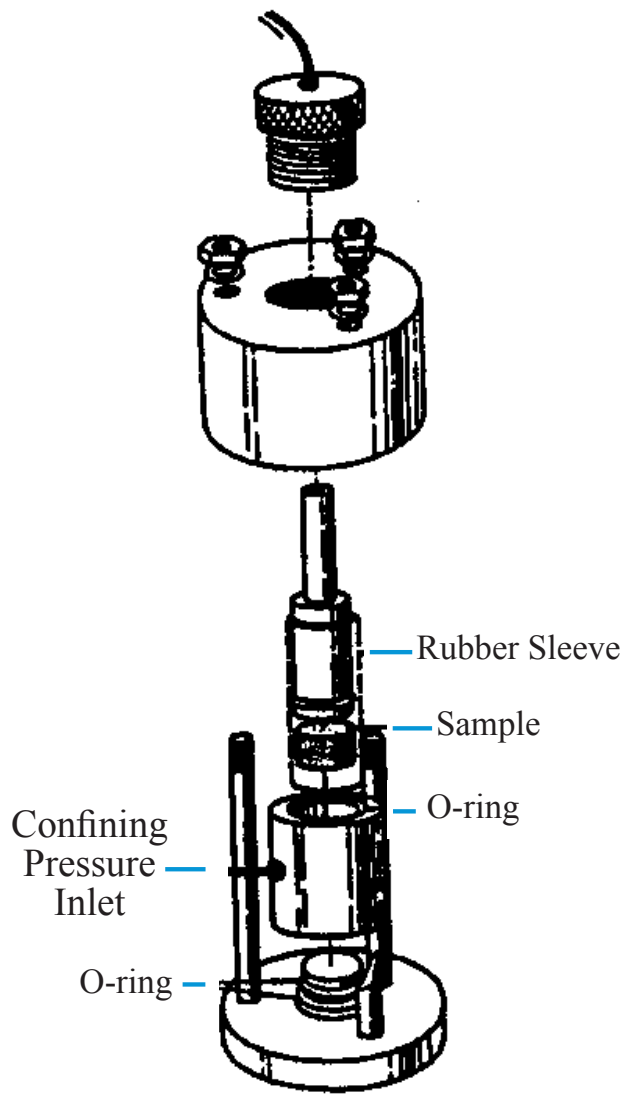
Figure 4: Triaxial Permeability Test Apparatus (CRD 1992)

The Dynamic Pressurization Technique (Scherer 2006) is illustrated in Figure 5. A saturated material is immersed in a vessel filled with water with the initial pressure of the water in the vessel $\left(P_{v}\right)$ and in the pore fluid $\left(P_{p}\right)$ is equal to the atmospheric pressure $\left(P_{\text {atm }}\right)$. At the start of the experiment $\left(\mathrm{t}=0^{+}\right)$, a pressure jump $\left(P_{A}\right)$ is applied to the liquid in the vessel and maintained for the remainder of the test. The applied pressure contracts the sample $\left(\varepsilon_{0}\right)$, in part, because the initial pore pressure is less than the applied pressure. Over time, the pore fluid reaches the same pressure as the vessel pressure and the material contraction relaxes somewhat. When equilibrium is reached, the sample still exhibits a 

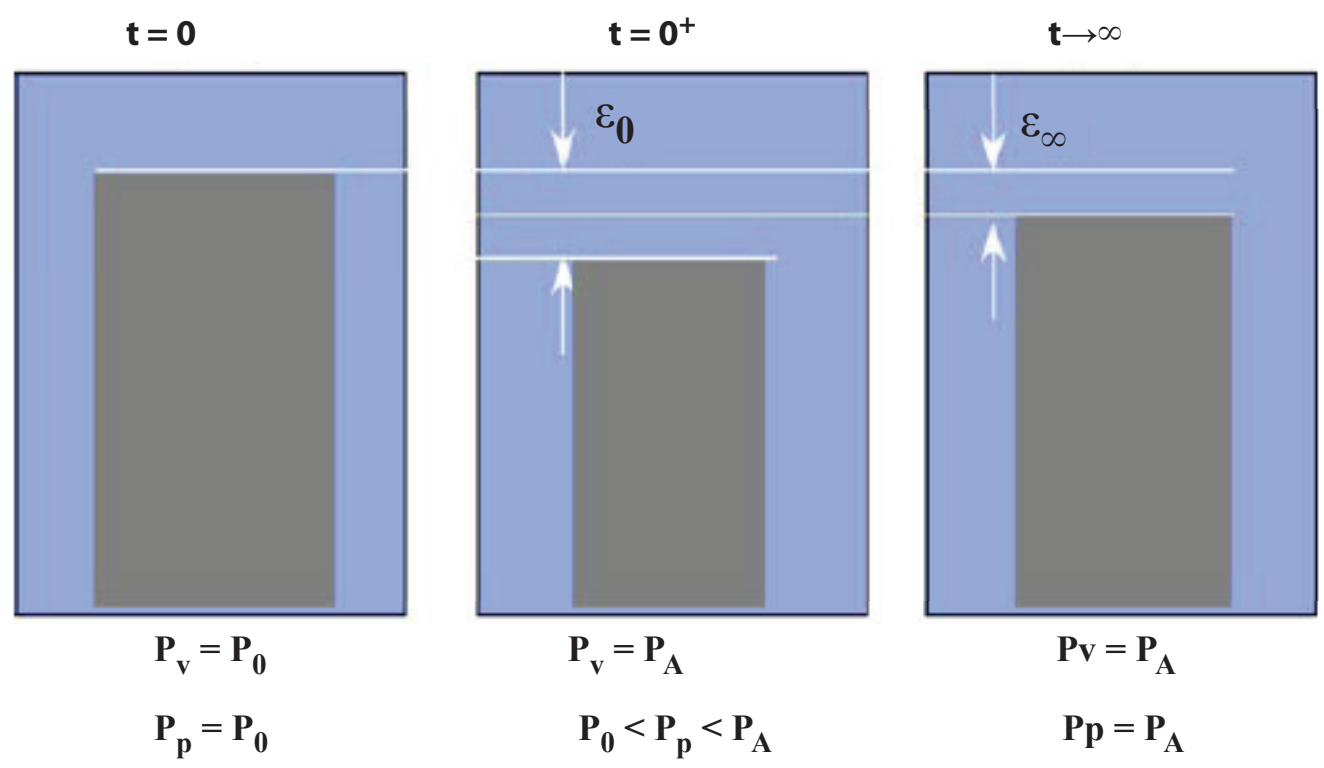

Figure 5: Steps in the Dynamic Pressurization Method (Scherer 2006)

contraction $\left(\varepsilon_{\infty}\right)$ that is less than the initial contraction $\left(\varepsilon_{0}\right)$. The relaxation time is a function of the permeability of the material which can be calculated from the dynamic pressurization technique theory (Scherer 2006).

Grasley et al. (2007) have described the application of the dynamic pressurization technique to hydrated cement pastes $(\mathrm{w} / \mathrm{c}$ of $0.4,0.5,0.6)$ and concrete samples (w/c of 0.5$)$. The method showed good repeatability, but the results were not compared to permeability values obtained with direct methods. This technique is best suited to material with low permeability because the rapid relaxation times of highly permeable materials renders this technique difficult (Jones \& Grasley 2009).

A related method called Beam-Bending Method has been developed (Scherer, Valenza \& Simmons 2007; Vichit-Vadakan \& Scherer 2002). The method consists of applying a three-point bending load to a beam-shaped sample immersed in water in order to maintain a fixed deflection. The deformation induced by the load creates pressure gradients in the material that are not in equilibrium with the pressure in the surrounding fluid. As the pore pressure equilibrates, the force required to sustain a fixed deflection decreases, and the kinetics of relaxation of the force can be analyzed to obtain the permeability (Scherer, Valenza \& Simmons 2007).

Comparisons between permeability values of hydrated cement pastes obtained with the beambending and dynamic pressurization techniques showed good agreement between the methods (Grasley et al. 2007).

Another indirect method to estimate the permeability of cementitious materials is based on the pore size distribution and the Katz-Thompson permeability theory (Katz \& Thompson 1986; Garboczi 1990; Scherer, Valenza \& Simmons 2007). The KatzThompson theory assumes fluid transport through pores will not be possible unless pores intersect, forming a connected network which spans the specimen length. The theory states:

$$
k^{\prime}=\frac{1}{226} d_{c}^{2} \frac{\phi}{\tau}
$$


where: $k^{\prime}$ is the intrinsic permeability, $d_{c}^{2}$ is the critical pore diameter, $\phi$ is the porosity and $\tau$ is the tortuosity.

The ratio $1 / 226$ is not empirical, but is a calculated value resulting from the cylindrical pore assumption and the theory of mercury intrusion porosimetry (MIP). The ratio $\tau / \phi$ is called the formation factor $F$ which can be estimated from bulk and pore solution conductivity analysis (Snyder \& Marchand 2001). The tortuosity can be estimated on the basis of migration test results (Samson et al. 2008). The critical pore diameter $d_{c}$ can be estimated from MIP results, where successive volumes of mercury $d V$ are forced into the material under pressure increments $d P$.

\subsubsection{Porosity and Pore Size Distribution Measurements}

Mercury intrusion porosimetry (MIP) has frequently been employed to measure the distribution of pore sizes from cementitious samples. To be precise, the result obtained through MIP is not a pore size distribution but rather a pore-throat size distribution (Diamond 2000).

The inflection point of the cumulative-intruded-volume pore size distribution curve (corresponding to the maximum of the differential-intruded-volume curve) denotes an equivalent pore diameter which accounts for the largest volume contribution to the pore space (Figure 6).

The parameter $d_{c}$ corresponds to the inflection point in the curve relating the intruded mercury volume to the pore radius, as shown in Figure 6. Thus, a characteristic diameter $d_{c}[\mathrm{~m}]$ may be defined which is proportional to the intrusion pressure and which accounts for the greatest overall volume contribution to the porosity. The importance of $d_{c}$ follows from the idea that, in a system of randomly distributed conductances, the cumulative conductance is influenced much more strongly by conductances $G \geq$ $G_{c}$. The characteristic conductance $G_{c}$ represents the largest conductance at which all conductances form an infinite, connected path and thus, corresponds to the diameter $d_{c}$ in the case of MIP (Katz \& Thompson 1986).

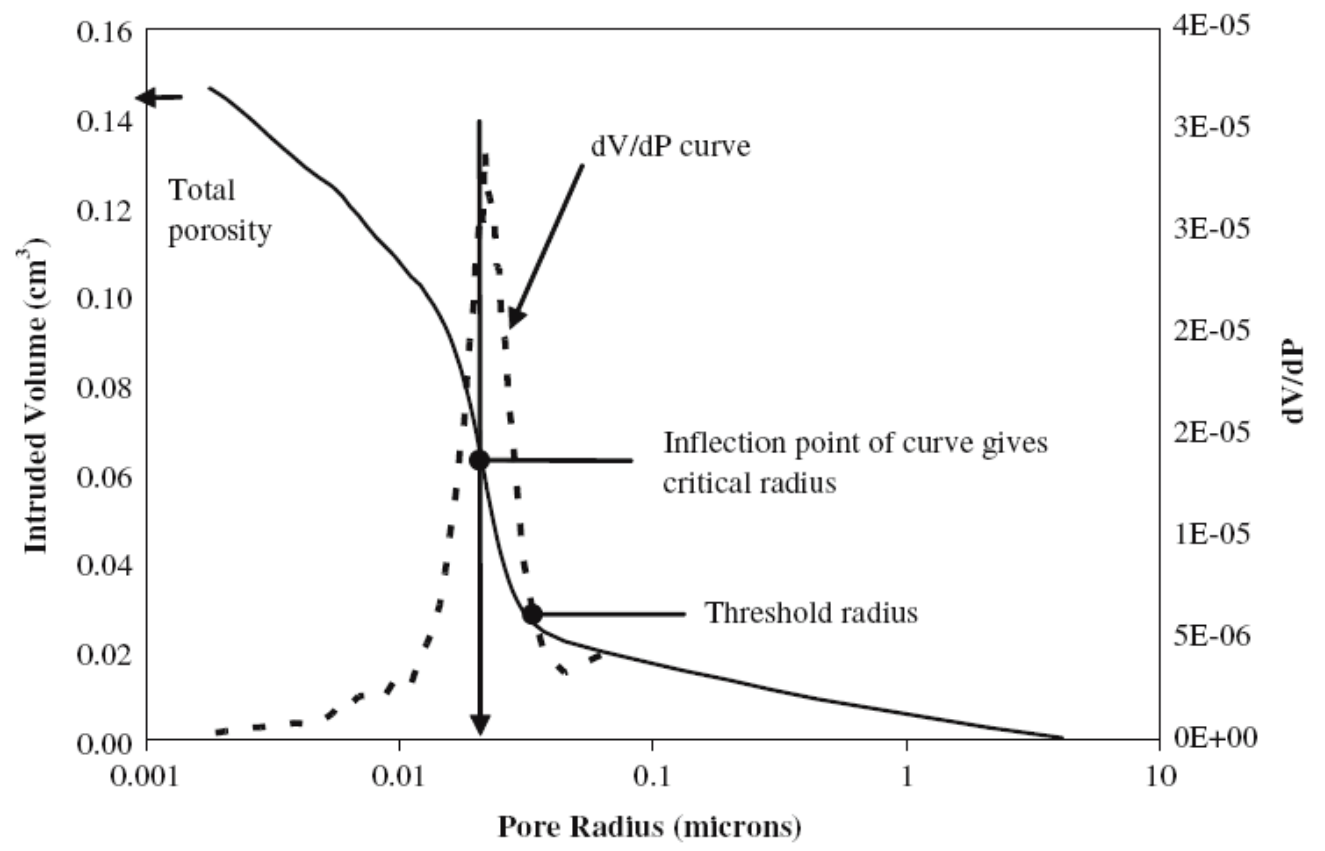

Figure 6: Critical Pore Radius (i.e., continuous pore diameter) and Threshold Radius from MIP Data (Nokken and Hooton 2006; Nokken and Hooton 2008) 


\section{Review of Mechanistic Understanding and Modeling and Uncertainty Analysis Methods for Predicting Cementitious Barrier Performance}

The applicability of Eq. (31) to cementitious materials has been discussed in many references. Test results obtained on hydrated cement pastes have validated the relationship (Nokken \& Hooton 2008; Christensen, Mason \& Jennings 1996). However, the Katz-Thompson theory has proven insufficient for predicting permeability of cement paste and concrete (El-Dieb \& Hooton 1994a). Similarly, the Katz-Thompson model was demonstrated to consistently under-predict permeability values of concretes by two orders of magnitude (Tumidajski \& Lin 1998). Halamickova (Halamickova et al. 1995) obtained good results with the Katz-Thompson model for hydrated cement pastes made at $\mathrm{w} / \mathrm{c} 0.5$, but proposed to modify the constant to $1 / 180$ for w/c 0.4 pastes. Cui and Cahyadi (2001) argue that the Katz-Thompson model as shown cannot be applied to cementitious materials because the pore structure is a combination of two distinctive pore classes (i.e., fine gel pores and coarser capillary pores) and significantly improved the accuracy by modifying the equation to account for transport through gel pores using general effective medium theory (Cui \& Cahyadi 2001).

Another parameter obtained from the MIP curve and used to predict permeability is the threshold diameter, that is the diameter corresponding to the lowest pressure at which mercury is able to begin invading the interior of the specimen through a connected, or percolating path, filling larger but previously disconnected pores termed "ink-bottle" pores (Hall \& Hoff 2002; Moro \& Bohni 2002). Thus the threshold diameter is typically defined somewhat arbitrarily as the diameter corresponding to the intrusion pressure where mercury first begins to invade the specimen in significant quantity (Nokken \& Hooton 2006).

\subsubsection{Measurement of Hydraulic Diffusivity}

Test method ASTM E96-90 (ASTM E96 2005) is a so-called "cup test" method that is used to determine hydraulic diffusivity by placing a cementitious slab in a sealed apparatus such that two opposing sides of the slab are exposed to different relative humidity conditions controlled by salt solutions. As relative humidity equilibrates via moisture movement through the sample, the mass of the salt-solution in one chamber is monitored until a steady flow of vapor is reached. Hydraulic diffusivity can then be calculated from these steady flow mass change measurements (Mosquera et al. 2006; Baroghel-Bouny 2007b).

An alternate methodology, based on drying an intitially saturated sample at $50 \%$ relative humidity, has been used to estimate the $A$ and $B$ parameters of the exponential expression shown in Eq. (22) for the hydraulic diffusivity (Samson et al. 2008). Two series of samples with different thicknesses (i.e., $1-\mathrm{cm}$ and 5 -cm thick) are dried at 50\% RH until the masses of the thinner samples have stabilized. The drying step can take up to three months for high performance concretes. The stabilized mass of the thinner samples provides the equilibrium water content at $50 \% \mathrm{RH}$ if the porosity of the material is known. The thicker drying series is terminated when the mass of the thinner samples is stable. Using the equilibrium value obtained for the thin samples series, a numerical algorithm solves Richards equation and adjusts $A$ and $B$ in Eq. (22) to fit the mass loss curves of the $5-\mathrm{cm}$ series. Results show that a value of $B=80$ can be used for most concrete mixtures.

The ingress of absorbed water into oven-dried samples of construction materials has been investigated using NMR techniques (Pel 1996) and X-ray tomography (Carmeliet 2004). Figure 7 shows the moisture content profiles for a material using NMR (Pel 1996). With both techniques, the profiles at different time intervals were analyzed using the Boltzmann transformation of Richards equation to yield the liquid water diffusivity.

Such approaches are influenced by problems in sample preparation, analytical techniques and 
interpretation of the acquired data. The method also relies on drying the samples before water absorption takes place. Marsh et al. (1983) argued that the process of oven-drying concrete samples induces microcracks that can affect the water transport characteristics. Coarse aggregates, air voids, and even sand grains weaken the signal and prevent reliable analysis. Marsh et al. noted that the Boltzman transform, and in general scaling uptake to $t^{1 / 2}$, is strictly limited for one-dimensional cases and anomalies from $t^{1 / 2}$ scaling may result from trapped air during uptake. In general, these techniques are limited to mostly homogeneous hydrated cement paste.

\subsection{Qualitative Tests}

Other test methods exist to assess the moisture transport characteristics of cementitious materials, such as ISO12572 and ASTM C1585. These test methods allow qualitative comparisons between

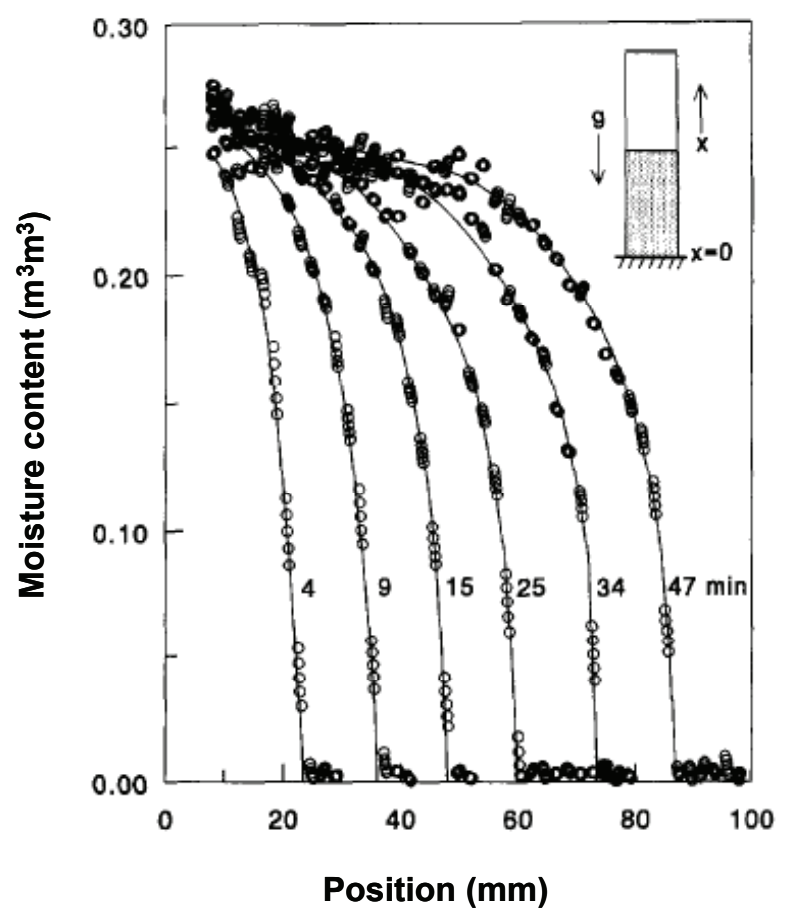

Figure 7: Water Content Profiles Measured using NMR Techniques

(Pel, Brocken et al. 1996) materials, but do not provide a direct estimation of transport properties.

In the ISO12572 procedure, entitled Hygrothermal Performance of Building Materials and Products, cylindrical samples are exposed to humidity gradients. One face is maintained close to water, thus creating a high humidity boundary condition. The other face is exposed to a lower humidity environment. The humidity gradient drives water through the sample. The mass of the set-up is measured until it is stable. The test provides the steady-state moisture flux across the sample. The method is similar to the ASTM E96 Standard Test Methods for Water Vapor Transmission of Materials which can be applied to any porous materials, including concrete.

The procedure ASTM C1585 Standard Test Method for Measurement of Rate of Absorption of Water by Hydraulic-Cement Concretes consists of exposing a pre-dried cylindrical sample to water vapor at $50-70 \%$ RH causing the cementitious material to absorb water. During absorption, mass is recorded on a regular basis and the experimental data is expressed in terms of the volume of water absorbed per unit surface area (e.g., $\mathrm{mm}^{3} / \mathrm{mm}^{2}$ ). Data are plotted against the square root of time and the curve usually shows two linear segments, respectively called initial and secondary absorption. The slope of the initial absorption is called the sorptivity and can be used to compare the absorption of different cementitious materials.

\subsection{MOISTURE TRANSPORT THROUGH FRACTURED MEDIA}

Although undesirable, cementitious materials may become fractured due to various design, placement, and exposure/degradation conditions. Fractures generally enhance water (and solute) transport under saturated and film flow conditions. The extent depends on saturation conditions and fracture aperture, spacing, asperity, and connectivity. Thus, 
moisture transport in fractured media is of particular relevance to the performance of damaged engineered cementitious barriers.

\subsection{Role of Fractures in Moisture Transport}

Under saturated conditions, cracks typically dominate liquid moisture flow and solute transport. Under unsaturated conditions and sufficient matric suction, fractures become relatively inactive in transporting water and dissolved species, because they are effectively dewatered and may also form a discontinuity in capillary suction. At intermediate suction levels cracks may have a significant influence on moisture transport. Similarly, moisture transport via gas phase transport can be greatly enhanced in unsaturated fracture networks. The behavior of liquid fracture flow is strongly influenced by capillary suction in the adjoining intact porosity, and the focus of subsequent discussion.

Engineered cement-based waste forms and barriers for DOE and NRC applications typically reside (or will reside) in the vadose zone after facility closure, although these barriers will reside above grade during operations. Vadose conditions in humid climates (e.g., Savannah River Site) exhibit relatively low soil suctions, and suggest that cracks in cementitious materials would be important to facility performance. In more arid climates (e.g., Hanford site), cracks may be relatively less important to liquid transport.

A fracture with aperture $b$ can be liquid-filled under the condition:

$$
P_{\ell}>-\frac{2 \sigma}{b}
$$

where: $\sigma$ is surface tension and $P_{\ell}$ is the liquid pressure imposed by the surrounding matrix and boundary conditions, and suction is indicated by a negative pressure value (Wang \& Narasimhan 1985).
The equivalent intrinsic permeability of the fracture is:

$$
k^{\prime}=\frac{b^{2}}{12}
$$

and the saturated liquid hydraulic conductivity is:

$$
K_{\ell}=\frac{\rho_{\ell} g b^{2}}{12 \eta_{\ell}}
$$

Figure 8 shows hydraulic conductivity as a function of aperture for water at $20^{\circ} \mathrm{C}$. Note that even narrow cracks have a high saturated conductivity compared to typical saturated conductivity of cementitious materials $\left(<10^{-8} \mathrm{~cm} / \mathrm{s}\right)$.

Although water cannot bridge an aperture when $P_{\ell}<-2 \sigma / b$ and the fracture becomes largely dewatered, non-stationary liquid films may still coat the crack faces. Water flow through a rough walled crack in a porous medium has been documented to occur in at least three distinct regimes (Tokunaga \& Wan 1997; Pruess \& Tsang 1990; Or \& Tuller 2000):

- Saturated flow, that is, liquid completely filling the aperture.

- "Thick" film flow on each crack wall, where water is present as a film completely filling surface pits and grooves and the air-water interface is relatively flat.

- "Thin" film flow, where water recedes into surface pits/grooves by capillary forces and adheres to flat surfaces by adsorption.

The saturated flow regime occurs at positive or very slightly negative pressures. The "thick" and then "thin" film flow regimes occur with increasing suction in the surrounding porous medium.

The full spectrum of flow regimes for idealized fractures has been analyzed theoretically by Or and Tuller (2000) considering uniform crack width and simplified geometry. The authors conceptualize a 


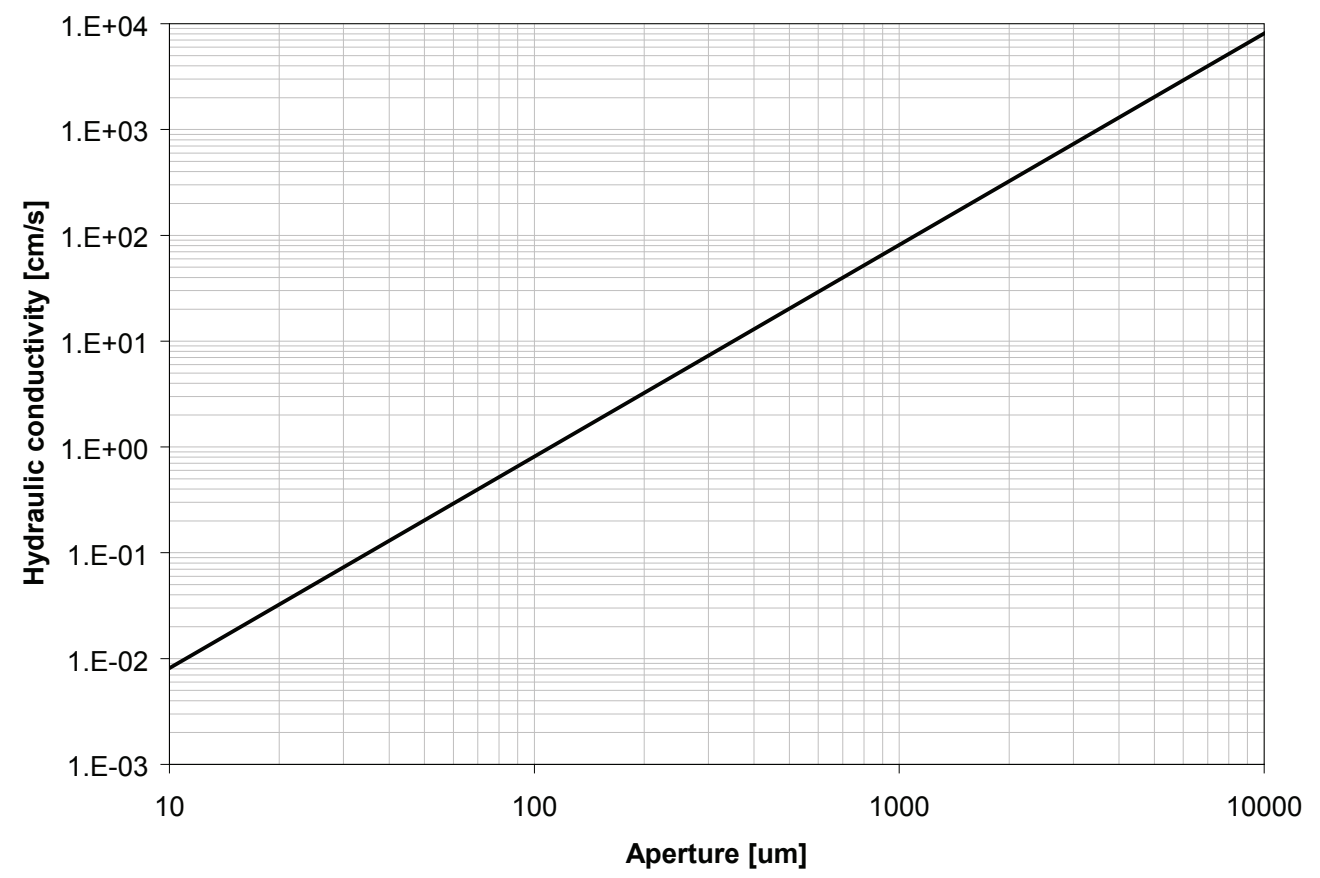

Figure 8: Hydraulic Conductivity of a Saturated Crack as a Function of Aperture

rough fracture face as a repeating series of vertical flat surfaces and $\mathrm{V}$-shaped grooves to facilitate further analysis. At pressures slightly below $-2 \sigma / b$, liquid will completely fill a groove and form a flat liquidvapor interface. At a sufficiently low pressure, liquid will recede into the corner of the groove and be retained by capillary forces. Under this condition, the matric potential determines the radius of the liquid vapor interface in a groove. For a groove of depth $L$ and angle $\zeta$, the maximum radius accommodated by the groove geometry is:

$r_{c}=\frac{L \tan (\zeta / 2)}{\cos (\zeta / 2)}$

and the critical pressure defining the transition between flat and curved interfaces is:

$P_{c r}=-\frac{\sigma}{r_{c}}$

Thus, the three flow regimes identified earlier occur over the following specific pressure ranges for the assumed geometry of the fracture face:
Saturated flow:

$P_{\ell}>-\frac{2 \sigma}{b}$

"Thick" film flow:

$-\frac{\sigma}{r_{c}}<P_{\ell}<-\frac{2 \sigma}{b}$

"Thin" film flow:

$P_{\ell}<-\frac{\sigma}{r_{c}}$

Liquid not being held by capillary suction in groove corners adheres to the remaining surfaces of the fracture face as a thin film by van der Waal forces. Or and Tuller (2000) show that residual liquid on fracture faces flows downward under the force of gravity. Thus moisture transport is non-zero despite the aperture being mostly de-saturated, an important issue for evaluating the performance of cementitious barriers. 
Microcracks with sufficiently small aperture do not enhance transport of water and solutes. Wang et al. (1997) found that crack openings less than $50 \mu \mathrm{m}$ had "little effect on concrete permeability", implying a similarly small effect on effective diffusion coefficient. In agreement with the latter, apertures less than about $50 \mu \mathrm{m}$ did not produce accelerated chloride penetration in cracked concrete (Ismail et al. 2004). In another chloride propagation study, Sahmaran and Yaman (2008) report that "for crack widths less than about 135 $\mu \mathrm{m}$, the effect of crack width on the effective diffusion coefficient ... was found to be marginal when compared to virgin specimens."

Larger cracks increase permeability to a widely variable degree (one to several orders of magnitude), depending on the cementitious material, exposure/degradation conditions and resulting crack geometry, and matric suction. Some examples compiled by Černý \& Rovnaníková (2002) are reproduced in Table 2.

\subsubsection{Modeling Approaches for Fractured Media}

The most widely-used approach for simulating moisture transport through a fractured medium at a systems level utilizes a single continuum with effective properties. The effective properties approximate the collective or homogenized behavior of cracks embedded in a porous matrix. Continuum approaches tend to be valid under steady nonlocalized flow conditions, produce reasonable predictions of average seepage rates (flow integrated across time and/or space), and avoid sophisticated characterization of the fracture network (e.g., (Finsterle 2000; Liu et al. 2003). However, this approach can over-estimate constituent release when coupled with mass transfer of dissolved constitiuents and local dissolution kinetics or diffusion controls pore water composition (see dual medium approaches below). Effective properties can be derived from

\section{Table 2. Increase in Cracked Concrete Permeability over Uncracked Materials (Černý \& Rovananiková 2002)}

\begin{tabular}{lll}
\hline \multicolumn{1}{c}{ Material } & \multicolumn{1}{c}{ MF $^{\mathbf{a}}$} & \multicolumn{1}{c}{ Source } \\
\hline $30 \mathrm{MPa}$ concrete, comp. stress $70 \%$ ult. load & $10^{2}-10^{4}$ & (Kermani 1991) \\
Ordinary concrete, $100^{\circ} \mathrm{C}$ & 102 & (Bazant \& Thonguthai 1978) \\
Ordinary concrete, bending stress, $0.1 \mathrm{~mm}$ & 2.25 & (Bazant, Sener \& Kim 1987) \\
Cement paste, tensile stress, $110 \mu \mathrm{m}$ & 14 & (C. Aldea, S. Shah \& A. Karr 1999) \\
Cement mortar, $130 \mu \mathrm{m}$, tensile stress & 10 & (C. Aldea, S. Shah \& A. Karr 1999) \\
Ordinary concrete, $130 \mu \mathrm{m}$, tensile stress & $2 \times 10^{3}$ & (C. Aldea, S. Shah \& A. Karr 1999) \\
HPC, $110 \mu \mathrm{m}$, tensile stress & 102 & (C. Aldea, S. Shah \& A. Karr 1999) \\
$45 \mathrm{MPa}$ concrete, $350 \mu \mathrm{m}$, tensile stress & 107 & (Wang et al. 1997) \\
$45 \mathrm{MPa}$ concrete, $550 \mu \mathrm{m}$, tensile stress under load & 107 & (Wang et al. 1997) \\
Ordinary concrete, $350 \mu \mathrm{m}$, tensile stress under load & $2.5 \times 10^{3}$ & (C.M. Aldea, S.P. Shah \& A. Karr 1999) \\
HPC, $300 \mu \mathrm{m}$, tensile stress under load & 35 & (C.M. Aldea, S.P. Shah \& A. Karr 1999) \\
Cement mortar, comp. stress, 90\% ult. load & 16 & (Černý et al. 2000) \\
\hline
\end{tabular}

${ }^{\mathrm{a}} \mathrm{MF}=$ multiplication factor (i.e., increase in permeability compared to uncracked material). 


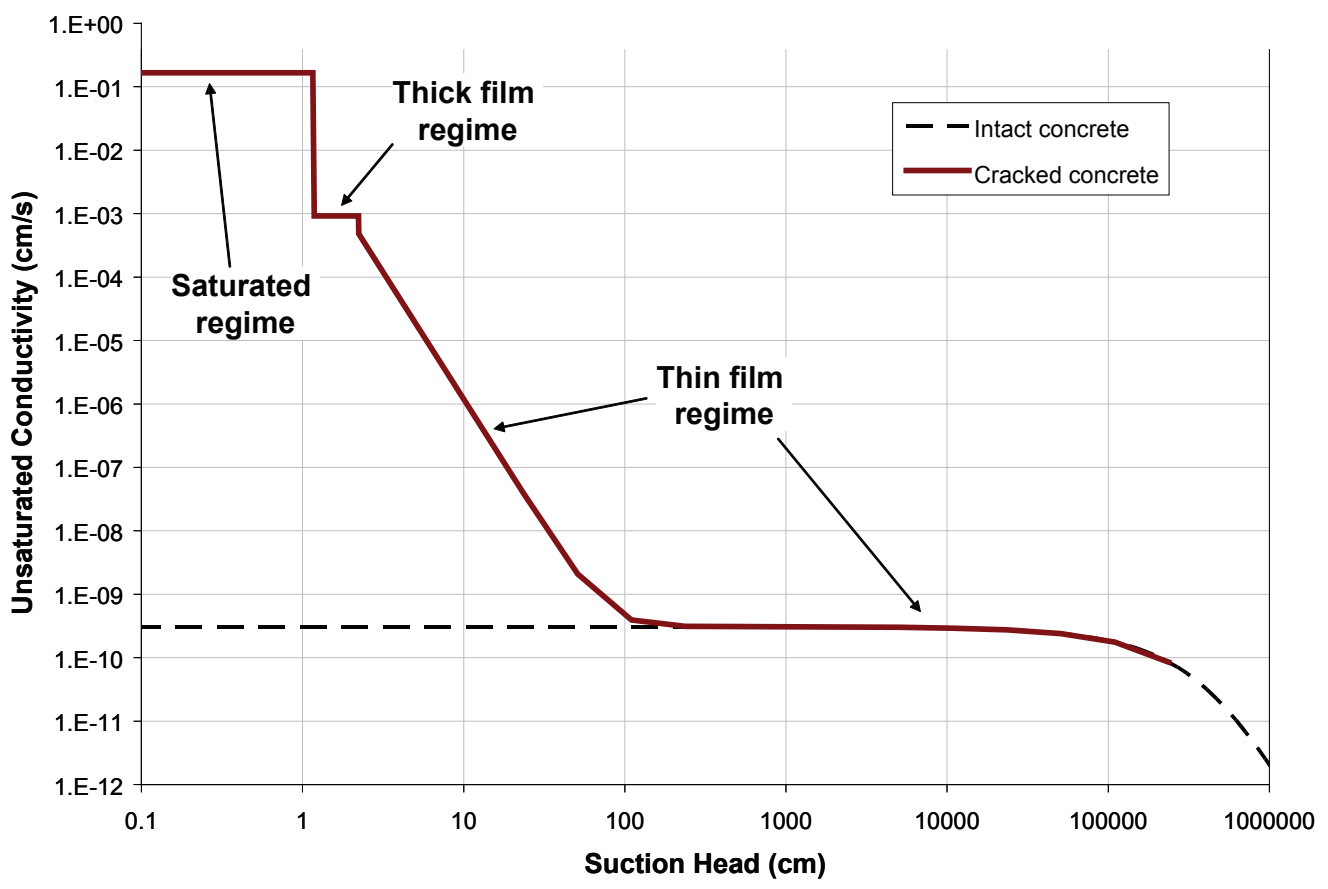

Figure 9: Effective Unsaturated Hydraulic Conductivity Derived for a Hypothetical Cracked Concrete based on Or and Tuller (2000)

Table 3: Selected Parameters for a Hypothetical Cracked Concrete

\begin{tabular}{|l|c|c|c|}
\hline \multicolumn{1}{|c|}{ Parameter } & $\begin{array}{c}\text { Symbol } \\
\text { (Or and Tuller 2000) }\end{array}$ & Value & Units \\
\hline ratio of pit spacing to pit depth & $b$ & 1 & unitless \\
\hline pit connectivity factor & $\delta$ & 1 & unitless \\
\hline pit angle & $\gamma$ & 60 & deg \\
\hline pit depth & $\boldsymbol{L}$ & $5.0 \mathrm{E}-04$ & $\mathrm{~m}$ \\
& & 0.500 & $\mathrm{~mm}$ \\
\hline width of unit element & $W$ & 0.020 & in \\
\hline aperture & $\mathrm{b}$ & $1.08 \mathrm{E}-03$ & $\mathrm{~m}$ \\
\hline & & 0.05 & in \\
\hline & & 50 & $\mathrm{mil}$ \\
\hline & & 1.27 & $\mathrm{~mm}$ \\
\hline spacing between fractures & $B$ & 1270 & $\mathrm{micron}$ \\
\hline saturated matrix conductivity & & 1 & $\mathrm{~m}$ \\
\hline & & 100 & $\mathrm{~cm}$ \\
\hline porosity & & $3.1 \mathrm{E}-12$ & $\mathrm{~m} / \mathrm{s}$ \\
\hline
\end{tabular}




\section{Review of Mechanistic Understanding and Modeling and Uncertainty Analysis}

Methods for Predicting Cementitious Barrier Performance

experimentation (Persoff \& Pruess 1995) or from theoretical or numerical analysis of fracture flow (Pruess \& Tsang 1990; Kwicklis \& Healy 1993; Liu \& Bodvarsson 2001).

As an illustration of the latter, the analysis of Or and Tuller (2000) can be applied to a hypothetical fracture geometry to derive an effective hydraulic conductivity for cracked concrete. An example variation is shown in Figure 9, where for comparison the hydraulic conductivity of uncracked concrete is included. An aperture of $127 \mu \mathrm{m}$ (5 mil) and crack spacing of $1 \mathrm{~cm}$ were chosen, along with the other settings indicated in Table 3. The aperture $(>50 \mu \mathrm{m})$ is large enough to have a significant influence on moisture transport, and the ratio of crack spacing to aperture is 78. Gèrard \& Marchand (2000) define the latter ratio as the mean crack spacing factor and note that the parameter "rarely goes below 100, even for concrete samples severely degraded." Thus the selected crack geometry is representative of severe microcracking. Under saturated flow conditions, the hydraulic conductivity contrast is observed to be nearly 9 orders of magnitude. On the other hand, the cracked and uncracked materials are hydraulically the same for suctions exceeding about $100 \mathrm{~cm}$. At intermediate suction levels, between 1 and $100 \mathrm{~cm}$, the influence of cracks is strongly dependent on suction.

Motivated primarily by solute rather than water transport considerations, a fractured porous medium is often separated conceptually into separate, but spatially overlapping, matrix and fracture continuum domains (or porosities). The dual-porosity concept has been applied to several physical settings, including laboratory soil columns, heterogeneous granular aquifers, aggregated media, and in the situation most relevant to the present, fractured geologic media (Passioura 1971; Skopp \& Warrick 1974; van Genuchten \& Wierenga 1976; van Genuchten \& Wierenga 1977; van Genuchten,
Wierenga \& O’Connor 1977; Rao et al. 1980; Hayot \& Lafolie 1993; Lafolie \& Hayot 1993; Brusseau et al. 1994; Griffioen, Barry \& Parlange 1998). Specific formulations range from mobile-immobile regions with first-order mass transfer (Coats and Smith, 1964) to dual-permeability, in which advection occurs in both regions (Gerke \& van Genuchten 1993). Generalizations of the concept have also been developed (Haggerty and Gorelick 1995, Wang et al. 2005). Dual-porosity formulations generally assume that all water transport occurs in fractures and none in the matrix, while dual-permeability implies moisture movement in both domains. Effective porous medium properties are required for the active domain(s), analogous to single-domain modeling.

In Discrete Fracture Modeling (DFM) flow is explicitly simulated through individual fractures, as well as the surrounding matrix (Yu, Ruiz \& Chaves 2008; Kim \& Deo 2000). DFM preserves the physical geometry of fractures, or at least approximately in terms of key attributes such as aperture, spacing and connectivity. The approach offers a more accurate representation of the physical system, at the expense of additional effort to characterize the fracture network and significantly higher computational demands. In practice, singleor dual-continuum models are typically chosen for system level or field scale modeling, while discrete fracture modeling is better suited to laboratory or small scale simulations.

\subsection{OTHER TRANSPORT MODELS}

\subsection{Pore-Scale Models}

Pore-scale models explicitly model flow processes occurring on the scale of pores. While this level of detail is computationally impractical for simulating integrated effects over much larger scales, pore-scale models are of interest for studying key phenomena at the microscale. 
Since water migration through cementitious materials primarily depends upon capillary potential, many researchers have utilized the Hagen-Poisseuille relation to model liquid transport on a fundamental mechanistic level (Capek et al. 2007; Martys \& Ferraris 1997; Song \& Kwon 2007; Leventis et al. 2000). The HagenPoisseuille relation expresses the fluid flux $j\left[\mathrm{~m}^{3} / \mathrm{s}\right]$ in a capillary tube as a function of pressure $\operatorname{drop} \Delta P \Delta P_{\ell}$ [Pa], given as (Leventis et al. 2000).

$j=\frac{\pi\left(\frac{d^{4}}{2}\right)}{8 \eta} \frac{\Delta P_{\ell}}{1}$

where: $d$ is the diameter of the pore [m], $l$ is the length of the pore $[\mathrm{m}], \eta$ is the dynamic viscosity of the fluid $[\mathrm{Pa} \cdot \mathrm{s}]$. These models greatly simplify pore geometry by conceptualizing pores as orthogonally interconnected cylinders or cubes, for which the Poiseuille equation has an exact analytical solution.

The orthogonal nature of such models lends their use to three-dimensional determination of fluid flow but inherently necessitates empirical correction factors for tortuosity or connectivity of pores. Generation of these network models is accomplished either by randomly selecting pore size and connectivity based upon real pore-size distribution data (Garboczi 1991; Kainourgiakis et al. 2005; Oren \& Bakke 2003; Pradhan, Nagesh \& Bhattacharjee 2005) or by tracing the void spaces in tomographed images of real materials (Carmeliet et al. 2004). The main advantage of using such a network lies in computing transport through macro-pores $(\gtrsim 20 \mu \mathrm{m})$ which exhibit open-channel flow behavior (Roels, Vandersteen \& Carmeliet 2003). A major limitation of these models is the difficulty in quantifying water migration through gel pores ( $\lesssim 2 \mathrm{~nm}$ diameter) in a mechanistic manner.
Researchers have combated this problem by superimposing a 3-D cubic macropore network, a capillary pore continuum, and a nano-scale pore network (Philippi \& Souza 1995). It is important to note that cylindrical pore networks are useful only for the calculation of the phenomenon upon which they are calibrated and are not representative of true pore geometry (Garboczi 1991). Therefore, determination of transport rates that depend on other physical and chemical characteristics, such as phase surface area, must be accounted for explicitly in the model.

\subsection{Lattice-Boltzmann Methods}

The lattice-Boltzmann modeling approach presents an elegant yet computationally intensive method for determining multi-phase fluid transport parameters in porous media. The lattice-Boltzmann method is a numerical simulation technique that allows for the movement, and subsequent collisions, of particles along a regular lattice. Collisions are deterministic and governed by rules so as to conserve number of particles and momentum (McNamara \& Zanetti 1988). The method entails discretizing an entire pore space into static nodes of solid phase and dynamic nodes of fluid phases (typically one wetting phase and one non-wetting phase). Martys and Hagedorn implemented the lattice-Boltzmann approach on tomographic reconstructions of sandstone and cracked mortars (Martys \& Hagedorn 2002). LatticeBoltzmann routines have the advantage of being adaptable to any spatial scale, but rely on accurate model representations of physical pore structure. The heterogeneity of porous microstructures across length scales presents a challenge for delineating single lattice spacing. One method of dealing with this problem is discretizing the larger pores and treating the smaller pores as a permeable continuum which obeys Darcy's law. The boundary conditions at 
interfaces between the larger pores and the permeable medium are determined by the Brinkman equation which satisfies both the continuity equation and the shear stress condition (Martys \& Hagedorn 2002).

\subsection{CHALLENGES AND OPPORTUNITIES}

The fundamentals of moisture transport in cementitious materials are well understood, and a variety of effective modeling approaches have been advanced for predicting moisture movement. The Cementitious Barriers Partnership will likely choose a single- or dual-domain continuum formulation for macroscale moisture transport simulation. At smaller scales, discrete fracture and/or pore-scale models are likely to be useful for estimating effective parameters and understanding specific coupled phenomena.

Accurate simulations do depend on adequate characterization of key physical properties, typically defined by empirical relationships requiring experimental testing. The key properties for moisture transport simulation include:

- hydraulic conductivity (permeability) in saturated and unsaturated materials,

- hydraulic diffusivity as a function of water content, and

- water retention curves (water content or saturation as a function of relative humidity

While established techniques are available for measuring the porous medium properties of intact undamaged laboratory specimens, characterization of damaged (e.g., fractured) cementitious materials will be a challenge. When damage is in the form of cracking, complete characterization may encompass definition of aperture distribution, spacing, orientation, connectivity, asperity, etc., which may be useful for system conceptualization and model validation but are impractical for long- term prediction. Large samples may be required to define representative properties. Furthermore, in many Cementitious Barriers Partnership applications of interest, damage will evolve over many thousands of years, such that representative contemporary specimens are not available for direct testing.

Thus, the primary challenge to accurate moisture simulation will be adequate definition of hydraulic properties and how these properties evolve in response to physical and chemical changes and stresses imposed on the system.

These challenges create opportunities for devising accelerated degradation tests and innovative experiments at the laboratory and field scales to define the hydraulic properties of damaged cementitious materials. 


\subsection{REFERENCES}

Aldea, C, Shah, S \& Karr, A 1999, 'Permeability of cracked concrete', Materials and Structures, vol. 32, no. 5 , pp. 370-376.

Aldea, CM, Shah, SP \& Karr, A 1999, 'Effect of cracking on water and chloride permeability of concrete', Journal of Materials in Civil Engineering, vol. 11, pp. 181-187.

Anderberg, A \& Wadsö, L 2008, 'Method for simultaneous determination of sorption isotherms and diffusivity of cement-based materials', Cement and Concrete Research, vol. 38, no. 1, pp. 89-94.

ASTM E96 2005, Standard Test Method for Water Vapor Transmission of Materials, ASTM International, West Conshohocken, PA.

Baroghel-Bouny, V 2007a, 'Water vapour sorption experiments on hardened cementitious materials. Part II: Essential tool for assessment of transport properties and for durability prediction', Cement and Concrete Research, vol. 37, no. 3, pp. 438-454.

Baroghel-Bouny, V 2007b, 'Water vapour sorption experiments on hardened cementitious materials: Part I: Essential tool for analysis of hygral behaviour and its relation to pore structure', Cement and Concrete Research, vol. 37, no. 3, pp. 414-437.

Bazant, ZP \& Najjar, LJ 1971, 'Drying of concrete as a nonlinear diffusion problem', Cement and Concrete Research, vol. 1, no. 5, pp. 461-473.

Bazant, ZP, Sener, S \& Kim, JK 1987, 'Effect of cracking on drying permeability and diffusivity of concrete', ACI Materials Journal, vol. 84, pp. 351357.
Bazant, ZP \& Thonguthai, W 1978, 'Pore pressure and drying of concerete at high temperatures', Journal of Engineering Mechanics Division ASCE, vol. 104, pp. 1059-1079.

Bear, J 1972, Dynamics of Fluids in Porous Media, American Elsevier, New York.

Bear, J \& Buchlin, J-M (eds) 1991, Modelling and Applications of Transport Phenomena in Porous Media., Springer.

Blümich, B 2000, NMR Imaging of Materials, Oxford University Press, New York.

Brusseau, ML, Gerstl, Z, Augustijn, D \& Rao, PSC 1994, 'Simulating solute transport in an aggregated soil with the dual-porosity model: measured and optimized parameter values', Journal of Hydrology, vol. 163, no. 1-2, pp. 187-193.

Capek, P, Hejtmanek, V, Brabec, L, Zikanova, A \& Kocirik, M 2007, 'Network modelling of capillary pressure curves, permeability, and diffusivity', Chemical Engineering Science, vol. 62, no. 18-20, pp. 5117-5122.

Carmeliet, J, Delerue, JF, Vandersteen, K \& Roels, S 2004, 'Three-dimensional liquid transport in concrete cracks', International Journal for Numerical and Analytical Methods in Geomechanics, vol. 28, no. 7-8, pp. 671-687.

Černý, R, Madera, J, Podebradská, J, Toman, J, Drchalová, J, Klecka, T, Jurek, K \& Rovnaníková, P 2000, 'The effect of compressive stress on thermal and hygric properties of Portland cement mortar in wide temperature and moisture ranges', Cement and Concrete Research, vol. 30, no. 8, pp. 1267-1276. 
Černý, R \& Rovnaníková, P 2002, Transport

Processes in Concrete, Spon Press, New York.

Christensen, BJ, Mason, TO \& Jennings, HM 1996, 'Comparison of measured and calculated permeabilities for hardened cement pastes', Cement and Concrete Research, vol. 26, no. 9, pp. 1325-1334.

Cnudde, V, Dierick, M, Vlassenbroeck, J, Masschaele, B, Lehmann, E, Jacobs, P \& Van Hoorebeke, L 2008, 'High-speed neutron radiography for monitoring the water absorption by capillarity in porous materials', Nuclear Instruments and Methods in Physics Research Section B: Beam Interactions with Materials and Atoms, vol. 266, no. 1, pp. 155-163.

Crank, J 1975, The Mathematics of Diffusion, Oxford University Press, London, UK.

\section{CRD 1992a, Standard Test Method for Water}

Permeability of Concrete in Handbook of Cement and Concrete, US Army Corp of Engineers.

CRD 1992b, Standard Test Method for Water Permeability of Concrete using Triaxial Cell, US Federal Standards.

Cui, L \& Cahyadi, JH 2001, 'Permeability and pore structure of OPC paste', Cement and Concrete Research, vol. 31, no. 2, pp. 277-282.

Dao, VNT, Morris, PH \& Dux, PF 2008, 'On equations for the total suction and its matric and osmotic components', Cement and Concrete Research, vol. 38, no. 11, pp. 1302-1305.

de Marsily, G 1986, Quantitative Hydrogeology: Groundwater Hydrology for Engineers, Academic Press, New York.
Diamond, S 2000, 'Mercury porosimetry: An inappropriate method for the measurement of pore size distributions in cement-based materials', Cement and Concrete Research, vol. 30, no. 10, pp. 1517-1525.

El-Dieb, AS \& Hooton, RD 1994a, 'Evaluation of the Katz-Thompson model for estimating the water permeability of cement-based materials from mercury intrusion porosimetry data', Cement and Concrete Research, vol. 24, no. 3, pp. 443-455.

El-Dieb, AS \& Hooton, RD 1994b, 'A high pressure triaxial cell with improved measurement sensitivity for saturated water permeability of high performance concrete', Cement and Concrete Research, vol. 24, no. 5 , pp. 854-862.

El-Dieb, AS \& Hooton, RD 1995, 'Waterpermeability measurement of high performance concrete using a high-pressure triaxial cell', Cement and Concrete Research, vol. 25, no. 6, pp. 1199-1208.

Erlin, B \& Mather, B 2005, 'A new process by which cyclic freezing can damage concrete--the Erlin/ Mather effect a concept', Cement and Concrete Research, vol. 35, no. 7, pp. 1407-1411.

Feldman, RF 1984, 'Pore structure damage in blended cements caused by mercury intrusion', Journal of the American Ceramic Society, vol. 67, no. 1, pp. 30-33.

Finsterle, S 2000, 'Using the continuum approach to model unsaturated flow in fractured rock', Water Resources Research, vol. 36, no. 8, pp. 2055-2066.

Fredlund, DG \& Rahardjo, H 1993, Soils Mechanics for Unsaturated Soils, John Wiley, New York.

Gambhir, ML 2004, Concrete Technology, Tata McGraw-Hill, New Delhi. 
Garbalinska, H 2006, ‘Application of $\sqrt{t}$-type, logarithmic and half-time methods in desorptive measurements of diffusivity in narrow humidity ranges', Cement and Concrete Research, vol. 36, no. 7, pp. 1294-1303.

Garboczi, EJ 1990, 'Permeability, diffusivity, and microstructural parameters: A critical review', Cement and Concrete Research, vol. 20, no. 4, pp. 591-601.

Garboczi, EJ 1991, 'Mercury porosimetry and effective networks for permeability calculations in porous materials', Powder Technology, vol. 67, no. 2, pp. 121-125.

Garrabrants, AC \& Kosson, DS 2003, 'Modeling moisture transport from a portland cement-based material during storage in reactive and inert atmospheres', Drying Technology, vol. 21, no. 5, pp. 775 - 805[October 01, 2008].

Gawin, D, Pesavento, F \& Schrefler, BA 2006, 'Towards prediction of the thermal spalling risk through a multi-phase porous media model of concrete', Computer Methods in Applied Mechanics and Engineering, vol. 195, no. 41-43, pp. 5707-5729.

Gerard, B \& Marchand, J 2000, 'Influence of cracking on the diffusion properties of cement-based materials: Part I: Influence of continuous cracks on the steady-state regime', Cement and Concrete Research, vol. 30 , no. 1 , pp. 37-43.

Gerke, H \& van Genuchten, MT 1993, 'A dual-porosity model for simulating the preferential movement of water and solutes in structured porous media', Water Resources Research, vol. 29, no. 2, pp. 305-319.

Grasley, ZC, Scherer, GW, Lange, DA \& Valenza, JJ 2007, 'Dynamic pressurization method for measuring permeability and modulus: II. Cementitious materials', Materials and Structures, vol. 40, no. 7, pp. 711721.
Griffioen, J, Barry, D \& Parlange, J-Y 1998, 'Interpretation of two region model parameters', Water Resources Research, vol. 34, no. 3, pp. 373384.

Gummerson, RJ, Hall, C, Hoff, WD, Hawkes, R, Holland, GN \& Moore, WS 1979, 'Unsaturated water flow within porous materials observed by NMR imaging', Nature, vol. 281, no. 5726, pp. 56-57.

Hagymassy, J, Odler, I, Yudenfreund, M, Skalny, J \& Brunauer, S 1972, 'Pore structure analysis by water vapor adsorption. III. Analysis of hydrated calcium silicates and portland cements', Journal of Colloid and Interface Science, vol. 38, no. 1, pp. 20-34.

Halamickova, P, Detwiler, RJ, Bentz, DP \& Garboczi, EJ 1995, 'Water permeability and chloride ion diffusion in portland cement mortars: Relationship to sand content and critical pore diameter', Cement and Concrete Research, vol. 25, no. 4, pp. 790-802.

Hall, C \& Hoff, W 2002, Water Transport in Brick, Stone and Concrete, Spon Press, New York.

Hayot, C \& Lafolie, F 1993, 'One-dimensional solute transport modelling in aggregated porous media Part 2. Effects of aggregate size distribution', Journal of Hydrology, vol. 143, no. 1-2, pp. 85-107.

Hazrati, K, Pel, L, Marchand, J, Kopinga, K \& Pigeon, M 2002, 'Determination of isothermal unsaturated capillary flow in high performance cement mortars by NMR imaging', Materials and Structures, vol. 35 , no. 10 , pp. 614-622.

Hearn, N \& Mills, RH 1991, 'A simple permeameter for water or gas flow', Cement and Concrete Research, vol. 21, no. 2-3, pp. 257-261.

Hope, BB \& Malhotra, VM 1984, 'The measurement of concrete permeability', Canadian Journal of Civil Engineering, vol. 11, no. 2, pp. 287-292. 
Ismail, M, Toumi, A, François, R \& Gagné, R 2004, 'Effect of crack opening on the local diffusion of chloride in inert materials', Cement and Concrete Research, vol. 34, no. 4, pp. 711-716.

Jones, CA \& Grasley, ZC 2009, 'Correlation of hollow and solid cylinder dynamic pressurization tests for measuring permeability', Cement and Concrete Research, vol. 39, no. 4, pp. 345-352.

Kainourgiakis, ME, Kikkinides, ES, Galani, A, Charalambopoulou, GC \& Stubos, AK 2005,

'Digitally reconstructed porous media: Transport and sorption properties', Transport in Porous Media, vol. 58, no. 1, pp. 43-62.

Katz, AJ \& Thompson, AH 1986, 'Quantitative prediction of permeability in porous rock', Physical Review B, vol. 34, no. 11, p. 8179.

Kermani, A 1991, 'Permeability of stressed concrete', Building Research and Information, vol. 19, pp. 360366.

Ketelaars, AAJ, Pel, L, Coumans, WJ \& Kerkhof, PJAM 1995, 'Drying kinetics: A comparison of diffusion coefficients from moisture concentration profiles and drying curves', Chemical Engineering Science, vol. 50, no. 7, pp. 1187-1191.

Kim, J-G \& Deo, MD 2000, 'Finite element, discretefracture model for multiphase flow in porous media', AIChE Journal, vol. 46, no. 6, pp. 1120-1130.

Kwicklis, E \& Healy, R 1993, 'Numerical investigation of steady liquid water flow in a variably saturated fracture', Water Resources Research, vol. 29, no. 12, pp. 4091-4102.

Lafolie, F \& Hayot, C 1993, 'One-dimensional solute transport modelling in aggregated porous media Part 1. Model description and numerical solution', Journal of Hydrology, vol. 143, no. 1-2, pp. 63-83.
Leech, C, Lockington, D \& Dux, P 2003, 'Unsaturated diffusivity functions for concrete derived from NMR images', Materials and Structures, vol. 36 , no. 6, pp. 413-418.

Leventis, A, Verganelakis, DA, Halse, MR, Webber, JB \& Strange, JH 2000, 'Capillary imbibition and pore characterisation in cement pastes', Transport in Porous Media, vol. 39, no. 2, pp. 143-157.

Liu, H-H \& Bodvarsson, GS 2001, 'Constitutive relations for unsaturated flow in a fracture network', Journal of Hydrology, vol. 252, no. 1-4, pp. 116-125.

Liu, H-H, Haukwa, CB, Ahlers, CF, Bodvarsson, GS, Flint, AL \& Guertal, WB 2003, 'Modeling flow and transport in unsaturated fractured rock: an evaluation of the continuum approach', Journal of Contaminant Hydrology, vol. 62-63, pp. 173-188.

Lockington, D, Parlange, J \& Dux, P 1999, 'Sorptivity and the estimation of water penetration into unsaturated concrete', Materials and Structures, vol. 32 , no. 5 , pp. 342-347.

Mainguy, M, Coussy, O \& Baroghel-Bouny, V 2001, 'Role of air pressure in drying of weakly permeable materials', Journal of Engineering Mechanics, vol. 127 , no. 6 , pp. 582-592.

Martys, NS \& Ferraris, CF 1997, 'Capillary transport in mortars and concrete', Cement and Concrete Research, vol. 27, no. 5, pp. 747-760.

Martys, NS \& Hagedorn, JG 2002, 'Multiscale modeling of fluid transport in heterogeneous materials using discrete Boltzmann methods', Materials and Structures, vol. 35, pp. 650-649.

Matano, C 1932-33, 'On the relation between the diffusion-coefficients and concentrations of solid metals (the nickel-copper system)', Japanese Journal of Physics, vol. 8, pp. 109-113. 
McArthur, H \& Spalding, D 2004, Engineering Materials Science: Properties, Uses, Degradation and Remediation, 577 vols, Horwood.

McNamara, GR \& Zanetti, G 1988, 'Use of the Boltzmann equation to simulate lattice-gas automata', Physical Review Letters, vol. 61, no. 20, p. 2332.

Mensi, R, Acker, P \& Attolou, A 1988, 'Séchage du béton: analyse et modélisation', Materials and Structures, vol. 21, no. 1, pp. 3-12.

Moro, F \& Bohni, H 2002, 'Ink-bottle effect in mercury intrusion porosimetry of cement-based materials', Journal of Colloid and Interface Science, vol. 246, no. 1, pp. 135-149.

Mosquera, MJ, Silva, B, Prieto, B \& Ruiz-Herrera, E 2006, 'Addition of cement to lime-based mortars: Effect on pore structure and vapor transport', Cement and Concrete Research, vol. 36, no. 9, pp. 1635-1642.

Mualem, Y 1976, 'A new model for predicting the hydraulic conductivity of unsaturated porous media', Water Resources Research, vol. 12, no. 3, pp. 513522.

Nilsson, L-O 2003, 'Durability concept: Pore structure and transport processes', in Advanced Concrete Technology: Concrete Properties, eds JB Newman \& BS Choo, Butterworth-Heinemann.

Nokken, M \& Hooton, R 2006, 'Using pore parameters to estimate permeability or conductivity of concrete', Materials and Structures.

Nokken, M \& Hooton, R 2008, 'Using pore parameters to estimate permeability or conductivity of concrete', Materials and Structures, vol. 41, no. 1, pp. 1-16.
Olson, RA, Neubauer, CM \& Jennings, HM 1997, 'Damage to the pore structure of hardened portland cement paste by mercury intrusion', Journal of the American Ceramic Society, vol. 80, no. 9, pp. 24542458.

Or, D \& Tuller, M 2000, 'Flow in unsaturated fractured porous media: Hydraulic conductivity of rough surfaces', Water Resources Research, vol. 36, no. 5, pp. $1165-1177$.

Oren, P-E \& Bakke, S 2003, 'Reconstruction of Berea sandstone and pore-scale modelling of wettability effects', Journal of Petroleum Science and Engineering, vol. 39, no. 3-4, pp. 177-199.

Passioura, J 1971, 'Hydrodynamic dispersion in aggregated media: 1. Theory', Soil Science, vol. 3, no. 6, pp. 339-344.

Pel, L, Hazrati, K, Kopinga, K \& Marchand, J 1998, 'Water absorption in mortar determined by NMR', Magnetic Resonance Imaging, vol. 16, no. 5-6, pp. 525-528.

Pel, L, Ketelaars, AAJ, Adan, OCG \& Van Well, AA 1993, 'Determination of moisture diffusivity in porous media using scanning neutron radiography', International Journal of Heat and Mass Transfer, vol. 36, no. 5, pp. 1261-1267.

Persoff, P \& Pruess, K 1995, 'Two-phase flow visualization and relative permeability measurement in natural rough-walled rock fractures', Water Resources Research, vol. 31, no. 5, pp. 1175-1186.

Philippi, PC \& Souza, HA 1995, 'Modelling moisture distribution and isothermal transfer in a heterogeneous porous material', International Journal of Multiphase Flow, vol. 21, no. 4, pp. 667-691. 
Pradhan, B, Nagesh, M \& Bhattacharjee, B 2005, 'Prediction of the hydraulic diffusivity from pore size distribution of concrete', Cement and Concrete Research, vol. 35, no. 9, pp. 1724-1733.

Pruess, K \& Tsang, YW 1990, 'On two-phase relative permeability and capillary pressure of rough-walled rock fractures', Water Resources Research, vol. 26, no. 9, pp. 1915-1926.

Rao, PSC, Rolston, DE, Jessup, RE \& Davidson, JM 1980, 'Solute transport in aggregated porous media: Theorectical and experimental evaluation', Soil Science Society of America Journal, vol. 44, pp. 1139-1146.

Richards, BG 1965, 'Measurement of free energy of soil moisture by the psychrometric technique using thermistors', Mositure Equilibria and Moisture Changes in Soils Beneath Covered Areas: A Symposium.

Roels, S, Vandersteen, K \& Carmeliet, J 2003, 'Measuring and simulating moisture uptake in a fractured porous medium', Advances in Water Resources, vol. 26, no. 3, pp. 237-246.

Samson, E, Maleki, K, Marchand, J \& Zhang, T 2008, 'Determination of the water diffusivity of concrete using drying/adsorption test results', Journal of the ASTM International, vol. 5.

Savage, BM \& Janssen, DJ 1997, 'Soil physics principles validated for use in predicting unsaturated moisture movement in portland cement concrete', ACI Materials Journal, vol. 94, no. 1, pp. 63-70.

Scherer, GW 1999, 'Crystallization in pores', Cement and Concrete Research, vol. 29, no. 8, pp. 1347-1358.

Scherer, GW 2006, 'Dynamic pressurization method for measuring permeability and modulus: I. Theory', Materials and Structures, vol. 39, no. 10, pp. 10411057.
Scherer, GW, Valenza, JJ, II \& Simmons, G 2007, 'New methods to measure liquid permeability in porous materials', Cement and Concrete Research, vol. 37, no. 3, pp. 386-397.

Šelih, J, Sousa, ACM \& Bremner, TW 1996, 'Moisture transport in initially fully saturated concrete during drying', Transport in Porous Media, vol. 24, no. 1 , pp. 81-106.

Skopp, J \& Warrick, AW 1974, 'A two-phase model for the miscible displacement of reactive solutes in soils', Soil Science Society of America Journal, vol. 38, pp. 545-550.

Snyder, KA \& Marchand, J 2001, 'Effect of speciation on the apparent diffusion coefficient in nonreactive porous systems', Cement and Concrete Research, vol. 31 , no. 12, pp. 1837-1845.

Song, H-W \& Kwon, S-J 2007, 'Permeability characteristics of carbonated concrete considering capillary pore structure', Cement and Concrete Research, vol. 37, no. 6, pp. 909-915.

Tokunaga, TK \& Wan, J 1997, 'Water film flow along fracture surfaces in porous rock', Water Resources Research, vol. 33, no. 6, pp. 1287-1295.

Tumidajski, PJ \& Lin, B 1998, 'On the validity of the Katz-Thompson equation for permeabilities in concrete', Cement and Concrete Research, vol. 28, no. 5, pp. 643-647.

van Genuchten, MT 1980, 'A closed-form equation for predicting the hydraulic conductivity of unsaturated soils', Soil Sciene Society America Journal, vol. 44, no. 5, pp. 892-898.

van Genuchten, MT \& Wierenga, PJ 1976, 'Mass transfer studies in sorbing porous media I. Analytical solutions', Soil Science Society of America Journal, vol. 40, pp. 473-480. 
van Genuchten, MT \& Wierenga, PJ 1977, 'Mass transfer studies in sorbing porous media II. Experimental evaluation with tritium (3H2O)', Soil Science Society of America Journal, vol. 41, pp. 272278.

van Genuchten, MT, Wierenga, PJ \& O'Connor, GA 1977, 'Mass transfer studies in sorbing porous media III. Experimental evaluation with 2,3,4-T', Soil Science Society of America Journal, vol. 41, pp. 278285.

Vichit-Vadakan, W \& Scherer, GW 2002, 'Measuring permeability of rigid materials by beam-bending method: III. Cement paste', Journal of the American Ceramic Society, vol. 85, pp. 1537-1544.

Wang, J \& Narasimhan, T 1985, 'Hydrologic mechanisms governing fluid flow in a partially saturated fractured, porous medium', Water Resources Research, vol. 21, no. 12, pp. 1861-1874.
Wang, K, Jansen, DC, Shah, SP \& Karr, AF 1997, 'Permeability study of cracked concrete', Cement and Concrete Research, vol. 27, no. 3, pp. 381-393.

Wardeh, G \& Perrin, B 2006, 'Relative permeabilities of cement-based materials: Influence of the tortuosity function', Journal of Building Physics, vol. 30, no. 1, pp. 39-57.

Webb, SW 2006, 'Two-phase gas transport', in Gas Transport in Porous Media, eds CK Ho \& SW Webb, Springer, New York, pp. 55-70.

Xi, Y, Bazant, ZP, Molina, L \& Jennings, HM 1994, 'Moisture diffusion in cementitious materials Moisture capacity and diffusivity', Advanced Cement Based Materials, vol. 1, no. 6, pp. 258-266.

Yu, RC, Ruiz, G \& Chaves, EWV 2008, 'A comparative study between discrete and continuum models to simulate concrete fracture', Engineering Fracture Mechanics, vol. 75, no. 1, pp. 117-127. 


\subsection{APPENDIX: MATERIAL PROPERTIES DEFINING THE PHYSICAL STATE OF A POROUS-MEDIUM}

\begin{tabular}{|c|c|c|}
\hline Property & Symbol & Definition \\
\hline \multicolumn{3}{|r|}{ Porosity } \\
\hline total & $\phi$ & void volume divided by total volume \\
\hline open/connected & $\phi_{o}$ & $\begin{array}{l}\text { porosity with connection to external boundaries that is occupied by air } \\
\text { and/or water that is not chemically or physically bound to cement }\end{array}$ \\
\hline closed/unconnected & $\phi_{c}$ & $\begin{array}{l}\text { porosity without connection to external boundaries or occupied by water } \\
\text { that is chemically or physically bound to cement }\end{array}$ \\
\hline effective & $\phi_{e}$ & $\begin{array}{l}\text { porosity through which primary (e.g., advective) solute transport occurs } \\
\text { for particular time and spatial scales }\end{array}$ \\
\hline \multicolumn{3}{|r|}{ Permeability } \\
\hline intrinsic & $\kappa$ & $\begin{array}{l}\text { flow proportionality coefficient that is independent of fluid properties } \\
\text { and defined through a form of Darcy's law: } U=-\left(\kappa \rho g k_{r} / \eta_{\ell}\right) \nabla h\end{array}$ \\
\hline relative & $k_{r}\langle S \mid \theta\rangle$ & $\begin{array}{l}\text { water or air permeability under unsaturated conditions relative to the } \\
\text { saturated condition; may be defined as a function of saturation or water } \\
\text { content }\end{array}$ \\
\hline \multicolumn{3}{|r|}{ Hydraulic Conductivity } \\
\hline $\begin{array}{l}\text { (water or air) satu- } \\
\text { rated }\end{array}$ & $K$ & $\begin{array}{l}\text { flow proportionality coefficient dependent on fluid properties and de- } \\
\text { fined for through a form of Darcy's law: } U=-K k_{r} \nabla h\end{array}$ \\
\hline unsaturated & $K k_{r}$ & hydraulic conductivity under unsaturated conditions \\
\hline $\begin{array}{l}\text { hydraulic } \\
\text { diffusivity }\end{array}$ & $D_{\theta}\langle\theta\rangle$ & flow proportionality coefficient defined by: $D_{\theta}=-K_{\ell} k_{r \ell} \frac{d h_{c}}{d \theta}$ \\
\hline water retention & $S \mid \theta\left\langle h_{c}\right\rangle$ & saturation or water content as a function of capillary suction head \\
\hline \multicolumn{3}{|r|}{ Diffusion Coefficient } \\
\hline molecular & $D_{m}$ & proportionality coefficient for diffusive transport in open/free fluid \\
\hline effective & $D_{e}$ & $\begin{array}{l}\text { diffusion coefficient accounting for slower transport due to flow path } \\
\text { tortuosity in a porous medium: } D_{e}=D / \tau\end{array}$ \\
\hline intrinsic & $D_{i}$ & $\begin{array}{l}\text { diffusion coefficient accounting for tortuosity and flow area reduction } \\
\text { due the presence of solids (porosity): } D_{i}=\phi D_{e}=\phi D / \tau\end{array}$ \\
\hline apparent & $D_{a}$ & $\begin{array}{l}\text { diffusion coefficient accounting for tortuosity, porosity, and solute sorp- } \\
\text { tion/binding }\end{array}$ \\
\hline \multicolumn{3}{|r|}{ Tortuosity } \\
\hline tortuosity & $\tau$ & $\begin{array}{l}\text { diffusion rate through open water relative to saturated pore space (com- } \\
\text { prising tortuous flow paths) }\end{array}$ \\
\hline \multicolumn{3}{|r|}{ Solid Density } \\
\hline particle & $\rho_{S}$ & mass of solid per unit volume of solid \\
\hline bulk & $\rho_{b}$ & mass of solid per unit volume of sample \\
\hline \multicolumn{3}{|r|}{$\begin{array}{l}\text { Fluid Properties } \\
\end{array}$} \\
\hline fluid density & $\rho_{f}$ & fluid (water or air) mass per unit volume of fluid \\
\hline fluid viscosity & $\eta_{f}$ & nse to shear $\mathrm{s}$ \\
\hline
\end{tabular}





\title{
REVIEW OF THE PHYSICAL AND CHEMICAL ASPECTS OF LEACHING ASSESSMENT
}

\author{
H. A. van der Sloot \\ Email: vandersloot@ecn.nl \\ Energy Research Centre of the Netherlands \\ Petten, The Netherlands \\ and \\ J. C. L Meeussen \\ Email:meeussen@ecn.nl \\ Energy Research Centre of the Netherlands \\ Petten, The Netherlands \\ A. C. Garrabrants \\ Email: a.garrabrants@vanderbilt.edu \\ Vanderbilt University, School of Engineering \\ Consortium for Risk Evaluation with Stakeholder Participation, III \\ Nashville, TN 37235 \\ and \\ D. S. Kosson \\ Email: david.kosson@vanderbilt.edu \\ Vanderbilt University, School of Engineering \\ Consortium for Risk Evaluation with Stakeholder Participation, III \\ Nashville, TN 37235 \\ M. Fuhrmann \\ Email: mark.fuhrmann@nic.gov \\ Nuclear Regulatory Commission, Washington, D.C.
}

November 2009

CBP-TR-2009-002, Rev. 0 
Review of Mechanistic Understanding and Modeling and Uncertainty Analysis Methods for Predicting Cementitious Barrier Performance 
1.1 Conceptual Model of Cementitous Barrier in the Environment

1.1.1 Barrier Material - Scenario Description.

1.1.2 Water Contact Mode and Moisture Transport..... VII-3

1.1.3 Ionic Transport. VII-5

1.1.4 Internal Factors VII-6

1.1.5 External Stresses. VII-6

1.2 Overview of Leaching Assessment Approaches VII-6

2.0 MECHANISMS AND PROPERTIES VII-7

2.1 Mass Transport Mechanisms

VII-7

2.1.1 Convection VII-7

2.1.1.1 Osmotic Pressure. VII-8

2.1.2 Diffusion VII-8

2.1.2.1 Diffusion Coefficients VII-8

2.1.2.2 Porosity VII-9

2.1.2.3 Tortuosity .VII-10

2.1.3 Sink/Source Terms. VII-11

2.2 Chemical Retention Mechanisms

2.2.1 Precipitation. VII-11

2.2.1.1 Solid Solutions VII-12

2.2.2 Adsorption and Surface Precipitation VII-12

2.2.2.1 Adsorption to Metal (Hydr) Oxides VII-13

2.2.2.2 Surface Precipitation VII-13

2.2.2.3 Modeling Oxide Adsorption. VII-14

2.2.3 Ion Exchange VII-14

2.2.4 Organic Matter Interactions. VII-15 
2.2.5 Inorganic Complexation VII-16

2.2.6 Redox Processes VII-16

2.3 Mass Transport Equations. VII-16

3.0 LEACHING ASSESSMENT VII-18

3.1 Regulatory Approaches VII-18

3.2 Leaching Tests

3.2.1 Common Equilibrium-based Tests VII-19

3.2.1.1 EPA Method 1311: The Toxicity Characteristic Leaching Procedure (TCLP) VII-19

3.2.2 Common Kinetic-based Tests VII-19

3.2.2.1 ANS 16.1: Measurement of the Leachability of Solidified Low-Level Radioactive Wastes by A Short-term Test Procedure VII-19

3.2.2.2 ASTM C1308: Accelerated Leach Test VII-19

3.2.3 USEPA Draft Methods VII-20

3.2.3.1 Draft Method 1313: Leaching Test (Liquid-Solid Partitioning as a Function of Extract $\mathrm{pH}$ ) for Constituents in Solid Materials Using A Parallel Batch Extraction Test VII-20

3.2.3.2 Draft Method 1314: Leaching Test (Liquid-Solid Partitioning as A Function of Liquid-Solid Ratio) of Constituents in Solid Materials Using an Up-Flow Percolation Column.

3.2.3.3 Draft Method 1315: Mass Transfer Rates of Constituents in Monolithic or Compacted Granular Materials Using A Semi-Dynamic Tank Leaching Test

\subsection{Integrated Assessment Approach}

3.3.1 Defining the Source Term

3.3.1.1 Constituent Selection. VII-22

3.3.2 Material Characterization VII-22

3.3.2.1 Redox Titration VII-23

3.3.2.2 Reactive Oxide Phases VII-24

3.3.2.3 Organic Matter Characterization. VII-24

3.3.2.4 Solid Analysis. VII-24

3.3.3 Interpretation of Leaching Data ... VII-25

3.3.4 Modeling \& Simulation VII-28

3.4 Chemical Reaction Transport Modeling for Monolithic Wastes VII-29 


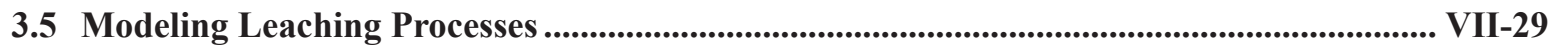

3.5.1 Solubility-controlled Release …..................................................................................

3.5.2 Diffusion-controlled Release .................................................................................. VII-30

3.5.3 Multi-component Diffusion-Controlled Release ............................................................... VII-30

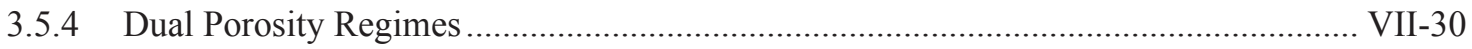

3.5.5 Orthogonal Diffusion with Convection .................................................................... VII-31

3.5.6 Unsaturated Flow (Richards equation) Coupling ....................................................... VII-31

3.5.7 Release from Structures Intermittently Wetted by Rain or Spray Water ..................................................................................................... VII-31

3.5.8 Multi-phase Equilibrium vs. Kinetic Controls ............................................................. VII-31

3.5.9 Mechanistic Chemical Retention vs Linear Sorption ................................................. VII-32

3.6 Transport and Thermodynamic Codes.............................................................................. VII-34

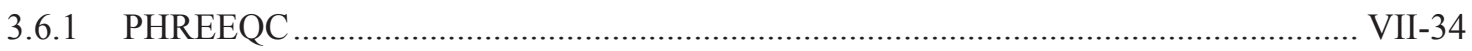

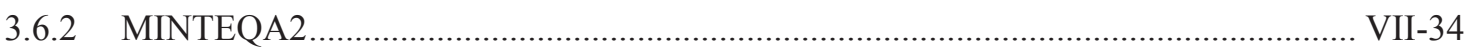

3.6.3 Geochemists Workbench ....................................................................................... VII-35

3.6.4 HYDRUS ….......................................................................................... VII-36

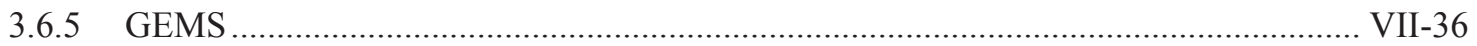

3.6.6 HYTEC-CHESS .................................................................................... VII-36

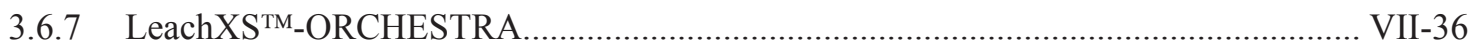

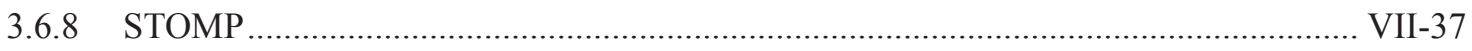

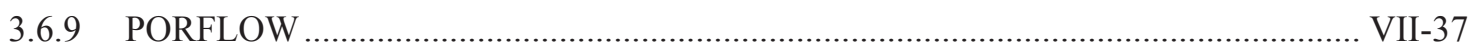

4.0 BEHAVIOR OF TYPICAL CEMENTITIOUS MATRIXES ...................................................... VIII-37

4.1 Cement Mortars and Concretes ......................................................................................................... VIII-37

4.1.1 Roman Cement Analog ........................................................................................... VII-40

4.2 Cement-stabilized Wastes ....................................................................................................... VII-40

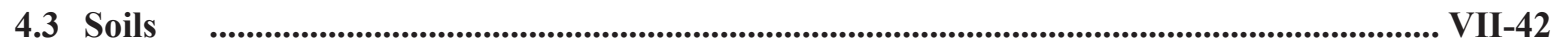

5.0 LEACHING ASSESSMENT IN CBP REFERENCE CASES............................................ VII-45

5.1 Interface Identification in CBP Reference Cases ........................................................................ VIII-45

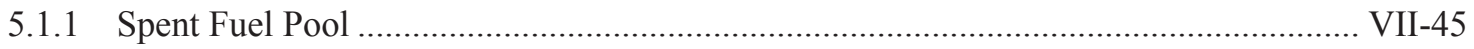

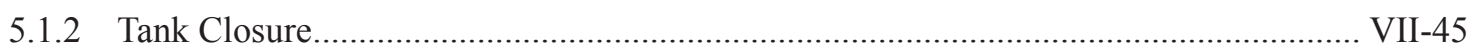

5.1.3 Low-level Radioactive Waste Vault ........................................................................... VII-47

5.1.4 Cementitious Wasteforms and Grouts-Concrete ......................................................... VII-47

5.1.5 Concrete-Soil Interface ...................................................................................... VII-47

5.1.6 Additional Barriers ………….................................................................................. VII-48 


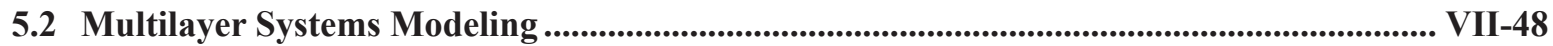

6.0 LYSIMETER STUDIES FOR RADIOACTIVE WASTE ........................................................... VII-50

6.1 Special Waste Forms Lysimeter Project ................................................................................ VII-51

6.2 Other Lysimeter Studies.................................................................................................................. VII-51

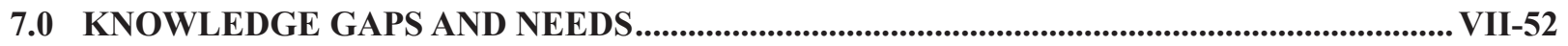

7.1 Aging of Cementitious Materials .................................................................................................................. VII-52

7.2 Chemical Retention of Radionuclides ........................................................................................... VIII-52

7.3 Uniform Testing and Interpretation ................................................................................................ VIII-53

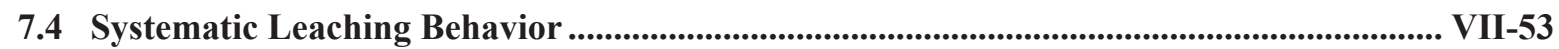

7.5 Predominance Diagrams...................................................................................................................... VIII-53

7.6 Kinetically-Controlled Processes ...................................................................................... VII-53

7.7 Transport in Unsaturated Materials................................................................................... VII-53

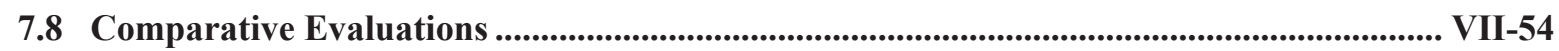

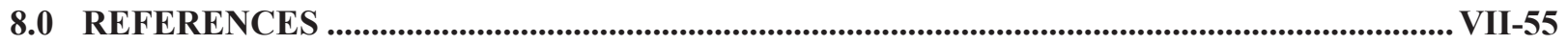

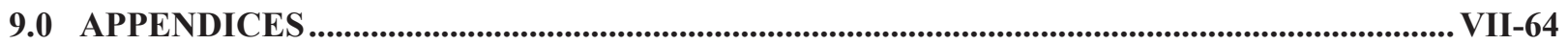

A. Comparison of Leaching Results from Cement Mortars ........................................................ VII-64

B. Comparison of Leaching Test Results from Portland Cement Mortar, Blended Cement Mortar, Stabilized Waste and Roman Cement Mortar........................... VII-65

C. Acid Neutralization Capacity ................................................................................................................... VIII-76

D. Chemical Speciation Modeling....................................................................................................... VII-77

E. Comparison of Stabilized Hazardous Waste and Simulation Grout .................................... VII-86 


\section{LIST OF FIGURES}

Page No.

Figure 1. Internal Factors and External Phenomena That Influence the Leaching

Process in Cementitious Materials

Figure 2. Conceptual Physical Degradation States of Cementitious Material.

Figure 3. Flowchart Indicating Test Method Selection Based on Material Type Used in Integrated Assessment Approach.

Figure 4. Distribution of Trace Species in Secondary Calcite Growth Found in Column Leaching Experiments of Tank Backfill Grouts

Figure 5. Results of Equilibrium-based Leaching Tests for Lead in A Cement-Stabilized Waste VII-26

Figure 6. Results of Kinetics-based Leaching Tests for Lead in a Cement-Stabilized Waste VII-26

Figure 7. $\mathrm{pH}$ Development in A Tank Leach Test with Leachant Renewal VII-33

Figure 8. Na Development in A Tank Leach Test with Leachant Renewal VII-33

Figure 9. Simulation of Calcium Leaching Data from A Tank Leach Test of Cement-stabilized Waste

Figure 10. pH Dependence and Tank Leaching Test Behavior of Al, Ca, Si and SO4 (Shown as Total S) from Cement Mortars of Worldwide Origin

Figure 11. pH Dependence and Tank Leaching Test Behavior of $\mathrm{Co}, \mathrm{Cr}, \mathrm{Sr}$ and V from Cement Mortars of Worldwide Origin

Figure 12. Comparison of Leaching Behavior of $\mathrm{Cr}, \mathrm{Sr}$, and $\mathrm{V}$ from Portland Cement and Selected Blended Cements, Roman Cement, and Cement Stabilized Waste Using $\mathrm{pH}$ Dependence and Tank Leaching Tests

Figure 13. Geochemical Speciation Modeling Of pH-Dependence Data Using LeachXS ${ }^{\text {TM }}$ _ORCHESTRA for Several Cement-stabilized Wastes Including Freshly-stabilized Waste, Cored Samples from A Stabilized Waste Cell, and Field Leachate Data. VII-43 


\section{LIST OF FIGURES (contd)}

Page No.

Figure 14. Comparison of Release of Cement-stabilized Waste Grout and Cement-stabilized Radioactive Waste Solution with Illite Addition Containing ${ }^{137} \mathrm{Cs},{ }^{90} \mathrm{Sr}$ and ${ }^{125} \mathrm{Sb}$ Using A Tank Leach Test. VII-44

Figure 15. Spent Fuel Pool Scenario with Breakout of Multilayer System Abstraction VII-46

Figure 16. Tank Closure Scenario with Breakout of Multilayer System Abstraction. VII-46

Figure 17. Low-level Waste Vault Scenario with Breakout of Multilayer System Abstraction VII-48

Figure 18. LeachXS ${ }^{\mathrm{TM}}$-ORCHESTRA Simulation of $\mathrm{SO}_{4}$ and $\mathrm{Sr}$ Transport by Diffusion in A 3-layer System of Stabilized Waste/cement Mortar/soil with 3-cm Layers

Figure 19. LeachXS ${ }^{\mathrm{TM}}$-ORCHESTRA Simulation of $\mathrm{Pb}$ and Ca Transport by Diffusion in A 3-layer System of Stabilized Waste/cement Mortar/soil with 3-cm Layers.. VII-50

\section{LIST OF TABLES}

Table 1. Selected Characteristics of Amorphous Metal Hydr(oxides) from

Fan et al. 2005 VII-14

Table 2. Comparison of Chemical and Physical Processes of Different Thermodynamic Programs VII-35 


\section{LIST OF ACRONYMS AND ABBREVIATIONS}

\begin{tabular}{|c|c|}
\hline ACRi & Analytic \& Computational Research, Inc. \\
\hline ANS & American Nuclear Society \\
\hline ASTM & ASTM International (formerly American Society for Testing and Materials) \\
\hline BDAT & Best Demonstrated Available Treatment \\
\hline CEN & European Committee on Standardization \\
\hline CBP & Cementitious Barriers Partnership \\
\hline $\mathrm{CSF}$ & Chemical Speciation Fingerprint \\
\hline DOC & Dissolved Organic Carbon \\
\hline EXAFS & Extended X-ray Absorption Fine Structure \\
\hline FA & Fulvic Acid \\
\hline GTLM & Generalized Two Layer Model \\
\hline HA & Humic Acid \\
\hline HAO & Hydrous Aluminum Oxides \\
\hline HFO & Hydrous Ferric Oxides \\
\hline HMO & Hydrous Manganese Oxides \\
\hline HY & Hydrophilic content of organic matter \\
\hline IHSS & International Humic Substances Society \\
\hline ISO & International Organization for Standardization \\
\hline LS & Liquid to Solid ratio [L/kg] \\
\hline NICA & Non-Ideal Competitive Adsorption \\
\hline ORCHESTRA & Objects Representing CHEmical Speciation and TRAnsport model \\
\hline PA & Performance Assessment \\
\hline POM & Particulate Organic Matter \\
\hline $\mathrm{PZC}$ & Point of Zero Charge \\
\hline RCRA & Resource Conservation and Recovery Act \\
\hline SEM & Scanning Electron Microscopy \\
\hline SRS & Savannah River Site \\
\hline TCLP & Toxicity Characteristic Leaching Procedure (EPA Method 1311) \\
\hline XANES & X-ray Absorption Near-Edge Structure \\
\hline $\mathrm{XRD}$ & X-Ray Diffraction \\
\hline USDOE & US Department of Energy \\
\hline USEPA & United States Environmental Protection Agency \\
\hline USNRC & US Nuclear Regulatory Commission \\
\hline
\end{tabular}




\section{LIST OF NOMENCLATURE}

\section{Roman Variables}

$a_{a w} \quad$ specific surface area of immiscible fluid (air-water) from interface tracer experiments $\left[\mathrm{m}^{2} / \mathrm{cm}^{3}\right]$

$a_{a w, o} \quad$ specific surface area of immiscible fluid (air-water) in an idealized capillary bundle $\left[\mathrm{m}^{2} / \mathrm{cm}^{3}\right]$

$C_{i} \quad$ concentration of species $i$ in a material $\left[\mathrm{mg} / \mathrm{m}^{3}\right]$

$c_{i} \quad$ concentration of species $i$ in the liquid phase $[\mathrm{mg} / \mathrm{L}]$ or $[\mathrm{Bq} / \mathrm{L}]$

$D \quad$ generalized representation of the diffusion (dispersion) coefficient $\left[\mathrm{m}^{2} / \mathrm{s}\right]$

$D^{a p p} \quad$ apparent, or observed, diffusion coefficient (diffusivity) $\left[\mathrm{m}^{2} / \mathrm{s}\right]$

$D^{e f f} \quad$ effective diffusion coefficient (diffusivity) in a porous media $\left[\mathrm{m}^{2} / \mathrm{s}\right]$

$D^{\text {mol }}$ molecular diffusion coefficient (diffusivity) $\left[\mathrm{m}^{2} / \mathrm{s}\right]$

$D^{\text {int }} \quad$ intrinsic diffusion coefficient (diffusivity) in a porous media $\left[\mathrm{m}^{2} / \mathrm{s}\right]$

$D_{w} \quad$ water diffusivity $\left[\mathrm{m}^{2} / \mathrm{s}\right]$

F $\quad$ Faraday constant $(96,485 \mathrm{C} / \mathrm{mol})$

$J_{i} \quad$ mass flux of a diffusing species $i\left[\mathrm{mg} / \mathrm{m}^{3} \mathrm{~s}\right]$

$J_{i}^{d i f f} \quad$ diffusional mass flux of a diffusing species $i\left[\mathrm{~mol} / \mathrm{m}^{3} \mathrm{~s}\right]$

$J_{i}^{e l e c} \quad$ electrical mass flux of a diffusing species $i\left[\mathrm{~mol} / \mathrm{m}^{3} \mathrm{~s}\right]$

$\widetilde{K}_{i} \quad$ NICA-Donnan median value of the affinity distribution for species $i[\mathrm{~L} / \mathrm{kg}]$

$K_{d} \quad$ linear partition coefficient $[\mathrm{L} / \mathrm{kg}]$

$\dot{m}_{i} \quad$ source rate term of species $i\left[\mathrm{~mol} / \mathrm{m}^{3} \mathrm{~s}\right]$

$N \quad$ total number of ionic species [-]

$n_{i} \quad$ NICA-Donnan exponent reflecting overall non-ideality of the proton adsorption reaction [-]

$n_{H} \quad$ NICC-Donnan parameter of representing the overall non-ideality of the adsorption process [-]

$p \quad$ NICA-Donnan width of the affinity distribution [-]

$R \quad$ ideal gas constant $(9.841 \mathrm{~J} / \mathrm{mol} \mathrm{K})$

$R\left\langle C_{i}\right\rangle$ production rate (sink or source) of species $i\left[\mathrm{mg} / \mathrm{m}^{3} \mathrm{~s}\right]$

$Q_{i} \quad$ NICA-Donnan amount of species $i$ bound to organic matter [mol $\left./ \mathrm{kg}\right]$ 


\section{LIST OF NOMENCLATURE (contd)}

Roman Variables (contd)

$Q_{\max } \quad$ NICA-Donnan maximum amount of the species that can be bound to organic matter $[\mathrm{mol} / \mathrm{kg}]$

$S \quad$ specific surface area of the material from gas adsorption experiments $\left[\mathrm{m}^{2} / \mathrm{cm}^{3}\right]$

$S_{o} \quad$ calculated surface area of an idealized capillary bundle $\left[\mathrm{m}^{2} / \mathrm{cm}^{3}\right]$

$s_{i} \quad$ concentration of species $i$ in the solid phase $[\mathrm{mg} / \mathrm{kg}]$ or $[\mathrm{Bq} / \mathrm{kg}]$

$T$ temperature $[\mathrm{K}]$

$t \quad$ time $[\mathrm{s}]$

$v \quad$ bulk velocity of the liquid or gas phase $[\mathrm{m} / \mathrm{s}]$

$w \quad$ fixed charge density $\left[\mathrm{mol} / \mathrm{m}^{3}\right]$

$x \quad$ 1-dimensional spatial variable $[\mathrm{m}]$

$z_{i} \quad$ valance state of species $i[-]$

\section{Greek Variables}

$\gamma_{i} \quad$ activity coefficient of species $i[-]$

$\delta \quad$ constrictivity of the pore network [-]

$\varepsilon \quad$ dielectric constant of the media $[\mathrm{C} / \mathrm{V} \mathrm{m}]$

$\theta \quad$ water content in the matrix $\left[\mathrm{m}^{3}{ }_{\text {water }} / \mathrm{m}^{3}\right.$ material $]$

$\phi \quad$ total porosity $\left[\mathrm{m}^{3}\right.$ pore $\left./ \mathrm{m}^{3}\right]$

$\phi_{d} \quad$ "diffusion through" porosity $\left[\mathrm{m}^{3}{ }_{\text {pore }} / \mathrm{m}^{3}\right]$

$\rho_{s} \quad$ density of the bulk solid phase $\left[\mathrm{kg} / \mathrm{m}^{3}\right.$ solid $]$

$\tau, \tau^{\prime} \quad$ tortuosity based on ratio of diffusional path to straight line path $\left[\mathrm{m}_{\text {pore }} / \mathrm{m}\right]$

$\tau_{s a t}^{a} \quad$ tortuosity of a saturated matrix based on ratio of interfacial surface area to idealized capillary bundle [-]

$\tau_{\text {unsat }}^{a} \quad$ tortuosity of an unsaturated matrix based on ratio of interfacial surface area to idealized capillary bundle [-]

$\psi \quad$ electrodiffusion potential [V] 
Review of Mechanistic Understanding and Modeling and Uncertainty Analysis Methods for Predicting Cementitious Barrier Performance

VII-xii 


\title{
REVIEW OF THE PHYSICAL AND CHEMICAL ASPECTS OF LEACHING ASSESSMENT
}

\author{
H. A. van der Sloot \\ J. C. L Meeussen \\ Energy Research Centre of the Netherlands \\ Petten, The Netherlands \\ A. C. Garrabrants \\ D. S. Kosson \\ Consortium for Risk Evaluation with Stakeholder Participation, III \\ Vanderbilt University, Nashville, TN \\ M. Fuhrmann \\ Nuclear Regulatory Commission, Washington, D.C.
}

\begin{abstract}
The objective of this chapter is to provide a summary of the latest developments in leaching from cementitious barrier materials consisting of different concrete formulations and cement stabilized waste forms. The chemical retention of substances in the matrix, which is controlled physically by material hydraulic and diffusion properties and chemically by precipitation/dissolution processes, sorption processes onto iron oxides and organic matter, incorporation in solid solutions and interactions with clay, is addressed. The influence of external factors such as oxidation and carbonation on constituent release can be very important because large $\mathrm{pH}$ and redox gradients may exist initially, but the chemistry within and surrounding the matrix will change with time and consequently different release behaviors may occur at over different time intervals. In addition, physical stresses may occur that change the physical and hydraulic properties of the material (this aspect is addressed in other report chapters). From a leaching perspective, the release controlling phases are not necessarily the primary matrix minerals, but also may be phases only present in very minor quantities. An integrated set of tools for testing and evaluation of release is presented, which lend themselves for chemical speciation modeling and subsequent chemical reaction transport modeling. The important role of field verification in lysimeters and test bed studies is stressed and experiences in nuclear waste management are identified.
\end{abstract}

\subsection{INTRODUCTION}

One focus of the Cementitious Barriers Partnership (CBP) is to advance the general understanding and prediction of the long-term physical, hydraulic and chemical performance of cementitious materials used for nuclear applications. Since these barriers are designed and implemented to retard the release of waste materials into the environment, knowledge of the processes and phenomena that control the release of constituents from cementitious barriers and the evolution of the influential properties of cementitious materials and related systems over time and space is central to CBP mission. Thus, this chapter focuses on the mass exchanges that occur across interfaces between the cementitious barrier and surrounding media 
and the effect of such exchanges on the ability of the cementitious barrier to retain species of interest.

The Encyclopedia of Science and Technology ${ }^{1}$ describes "leaching" as the removal of a soluble fraction, in the form of a solution, from an insoluble permeable solid with which it is associated. In this sense, leaching is a macroscopic process bounding by the mass of a substance passing boundaries of the permeable solid in question. In performance assessments (PAs) developed for the US Department of Energy (USDOE) and US Nuclear Regulatory Commission (USNRC), leaching of radionuclides from a source material through the environment is the primary mechanism that defines doses to a potential receptor. Often descriptions of leaching are based on simple diffusion models with constant diffusivity and source terms. However, within the pore structure of cementitious materials, leaching is a complex coupling of mass transport mechanisms through a tortuous pore system and a wide range of chemical reactions which help to retain constituents within the matrix.

The constituents in cementitious materials, in general, can be categorized by the relative concentration of the element or species present in the bulk solid and the element's characteristic chemical behavior. For this conceptual model, the constituents of interest are grouped as follows:

\section{- Primary matrix constituents}

» cations (e.g., calcium, aluminum, silicon, iron)

» anions (e.g., sulfate, carbonate, hydroxide)

- Minor constituents at concentrations where mineral precipitation is possible

» cations with $\mathrm{pH}$-dependent solution behavior (e.g., manganese, chromium III, barium)

» cations with minimal dependence on solution pH (e.g., sodium, potassium),
» anions with $\mathrm{pH}$-dependent solution behavior (e.g., arsenate, chromate)

» anions with minimal dependence on solution pH (e.g., chloride)

- Trace constituents at concentrations below the point where mineral precipitation is likely

» most radionuclides

» trace ionic constituents (e.g., cadmium, mercury)

Leaching from a porous material is an integrated process of mass transport due to gradients in concentration, chemical potential or pressures, combined with all chemical interactions between the solid phase and the pore solution. The release from the solid into the pore water, at every point in time and space, is controlled by a complex set of interactions which include:

- dissolution-precipitation,

- adsorption-desorption,

- cation exchange,

- incorporation into solid solutions, and

- complexation within the aqueous phase.

The mutual interaction between material constituents deposited into precipitates, engaged in competitive sorption to surfaces, or incorporated in solid solutions, implies that individual elements or radionuclides cannot be considered without taking the chemical context dictated by major and minor elements into account. Thus, chemical form of the species (i.e., speciation) determines the ability of the cementitious barrier to retain trace constituents and dictates the compositions of the pore water and gas phases, which are the two phases through which mass transfer results in release.

\footnotetext{
${ }^{1} \mathrm{http} / /$ www.accessscience.com/topic.aspx?searchStr=leaching\&term=Leaching
} 


\subsection{Conceptual Model of Cementitous Barrier in the Environment}

The following conceptual model of a cementitious barrier material in a generic placement scenario is used for illustrative purposes in subsequent discussions.

\subsubsection{Barrier Material - Scenario Description}

Fundamentally, cementitious barriers are porous solids consisting of a complex mixture of crystalline and gel-like phases with an interstitial pore solution that is in chemical equilibrium with the solid phase. The relative amounts of the different solid phases that form as a result of hydration reactions are dependent on the components of the "dry blend" or binder, the water/binder ratio, and admixtures included to facilitate placement or handling of the product. If the intent of the cementitious material is to immobilize or retard the release of constituents of concern contained in a waste stream, the composition of the waste also may influence the solid phases of the final wasteform. The physical properties of the matrix (e.g., porosity, permeability, conductivity, etc) will be dependent on both the solid phase composition and on the amount of coarse and/or fine aggregate typically added to the process to increase strength and durability.

Over a given period of performance, a cementitious monolith may be contacted by one or more forms of surrounding media where water, dissolved constituents, and/or gases including water vapor and air (i.e., nitrogen, oxygen, carbon dioxide) are transported between materials. The physical-chemical nature of the materials surrounding the cementitious barrier will depend on the design of the engineered system, but may include an open atmosphere (e.g., air contacting above-ground vaults), soil or granular fill (e.g., unsaturated or water-saturated compacted fill around buried structures), steel (e.g., tank liners), or contained liquids (e.g., for unlined spent fuel pools).
In these scenarios, the cementitious monolith may be structural concrete, grout or a waste form, any of which may have some degree of initial cracking. Figure 1 is a conceptual illustration of release processes, influential physical and chemical factors, and interfacial phenomena that may exist upon placement of a cementitious barrier into the environment.

\subsubsection{Water Contact Mode and Moisture Transport}

By definition, leaching occurs when the cementitious matrix is in contact with a continuous liquid phase and aqueous constituents are transported across the material interface. Although significant cracking may exist as a result of curing phenomena (e.g., autogenous shrinkage), the initial cementitious barrier is assumed to have lower permeability than the surrounding material, such that the majority of infiltrating or groundwater will flow around the matrix. Over time, physical loads, water-borne chemical reactions (e.g., sulfate ingress and subsequent ettringite precipitation) and thermal gradients imposed on the cementitious monolith may induce physical stresses and the monolith may deteriorate through a series of states from (a) an intact monolith, to (b) a stressed matrix to (c) a spalled matrix (Figure 2). The rate and extent of the physical degradation is material- and scenario-specific, primarily controlled by the stresses induced in the system and the strength of the material. The changes in the physical state of the cementitious monolith will significantly affect the surface area exposed to the environment, mode of water contact (e.g., flow-around or percolation through), and the rate and extent of water and/or gas exchange between the monolith and its surroundings.

The permeability or hydraulic conductivity of the cementitious barrier increases with the degree of degradation, resulting in a larger fraction of water flowing or percolating through the material. If the hydraulic conductivity of the material is low or approximately $1 / 100$ that of the surrounding material, 


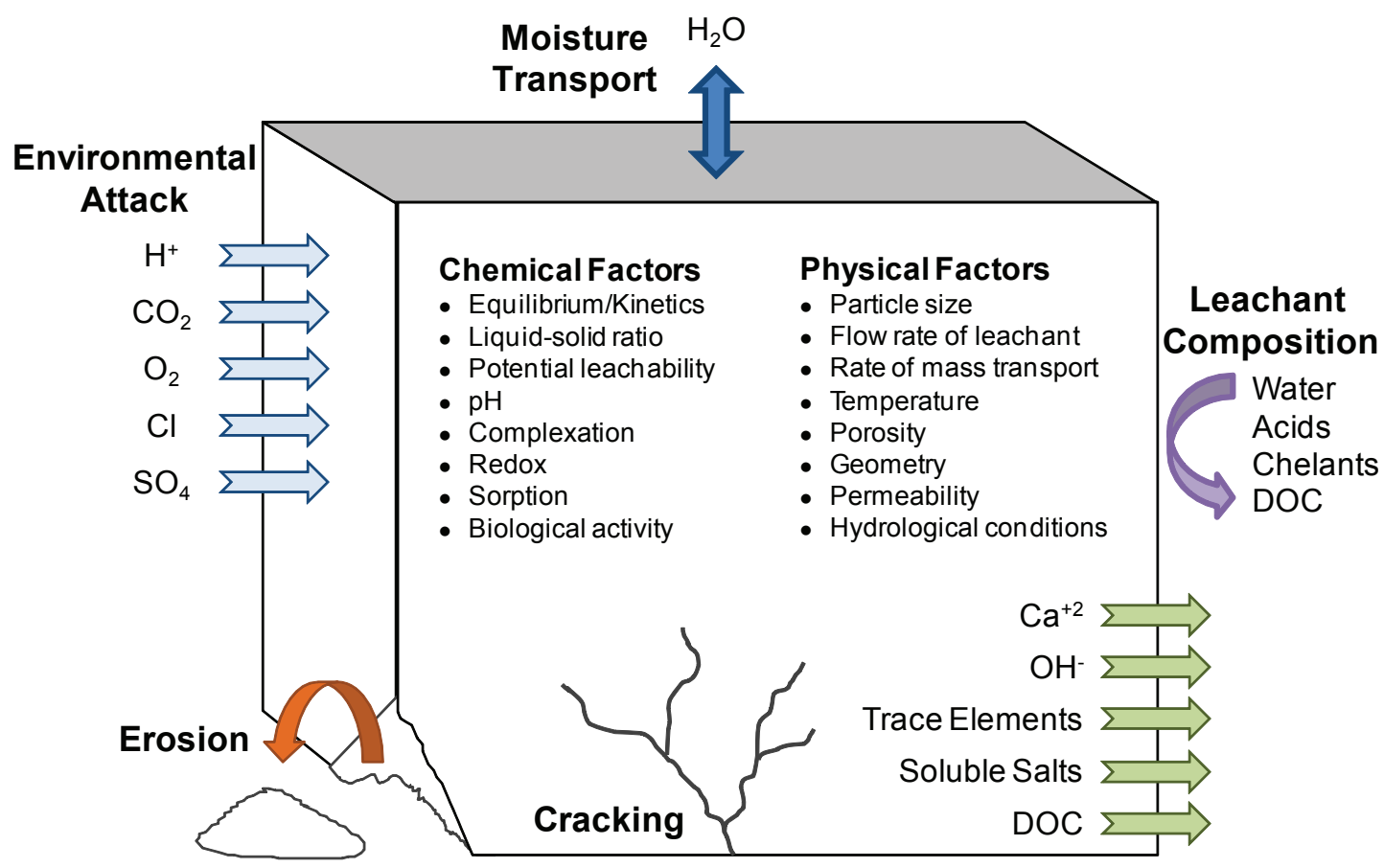

Figure 1. Internal Factors and External Phenomena That Influence the Leaching Process in Cementitious Materials
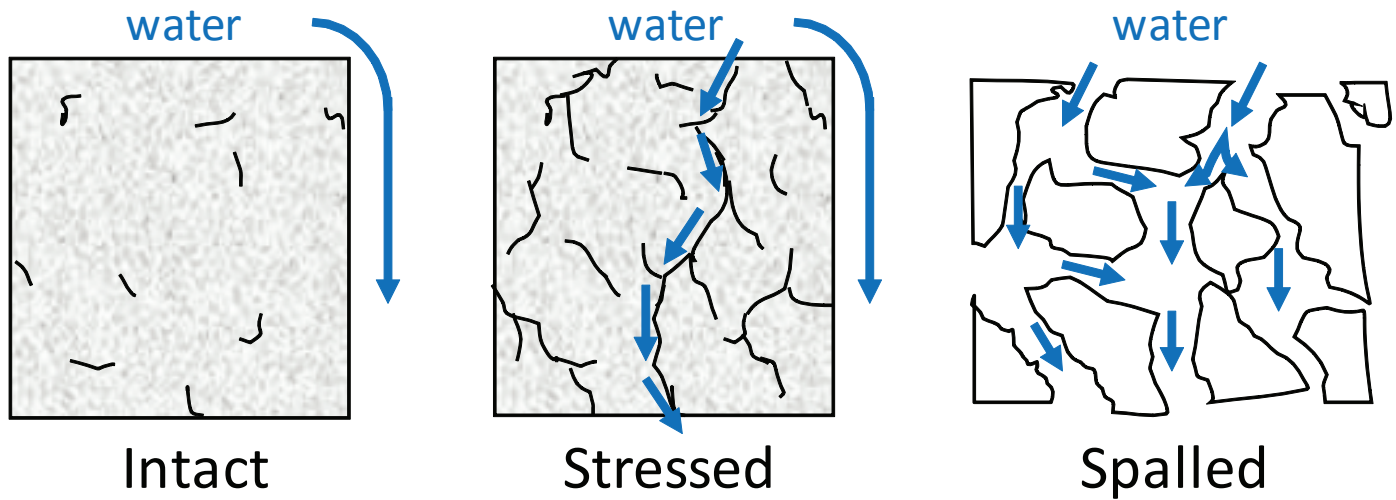

Figure 2. Conceptual Physical Degradation States of Cementitious Material

infiltration due to percolation events or groundwater will preferentially flow around the cementitious mass. However, when the hydraulic conductivity is sufficiently high (e.g., $>10^{-8} \mathrm{~m} / \mathrm{s}$ ) and on the same order of magnitude or greater than that of the adjacent material, water will percolate through the cementitious mass. The same guidelines hold for localized percolation through regions of the cementitious material 


\section{Review of Mechanistic Understanding and Modeling and Uncertainty Analysis \\ Methods for Predicting Cementitious Barrier Performance}

(e.g., through continuous cracks or degraded zones). At low permeability, water will be stagnant or move driven by capillary effects in response to gradients in matrix potential (i.e., capillary suction) created by changes in external saturation or evaporation and condensation processes. In low- or no-flow regimes, diffusion will dominate mass transfer and release; while in localized high flow regions around a crack, diffusion may be the release rate limiting step in the diffusion-convection process.

In the absence of large air-voids, the pore of structure cementitious materials may be considered initially saturated if sufficient water is present during curing. Saturation of the cementitious material with water (i.e., extent of pore-filling with water) can vary spatially and temporally. Relative saturation, defined as the fraction of the total pore volume filled with water, is a continuous function taking values between 0 and 1 for completely dry and fully saturated materials, respectively. The following saturation states are important relative to overall diffusive moisture transport through the liquid and vapor phases.

- Full Saturation - no gas phase present; evaporation from the surface induces liquid movement within the material

- Capillary Saturation - gas phase becomes continuous; diffusion of water vapor starts to influence overall rate of water transport

- Insular Saturation - liquid phase becomes discontinuous; vapor phase diffusion dominates transport process

- Completely Dry - theoretical construct, typically not obtained in natural systems, where all moisture transport stops.

Drying or moisture transport may occur if:

- the surrounding media is unsaturated with a capillary suction greater than that expressed by the cementitious material,

- the surrounding media is unsaturated and the adjacent air or pore gas is at less than $100 \%$ relative humidity,

- hydration reactions of the cementitious material and/or phases such as hydrated salts causes selfdesiccation.

Ingress of water can occur by:

- capillary suction,

- percolation through interconnected pores and cracks,

- condensation in response to temperature and external relative humidity changes, or

- chemical reactions which generate water.

Although frequently neglected in environmental assessments, significant water exchange by a combination of capillary uptake, vapor migration and condensation has been documented at low-level nuclear waste vaults in Spain (Zuloaga, Andrade \& Castellote 2009). As the level and extent of damage to the matrix increases, then water exchange by percolation will increase because of increased hydraulic conductivity if sufficient water is present in the immediate surroundings.

Bulk gas exchange with the monolith will occur in response to:

- changes in barometric pressure (i.e., barometric pumping), or

- displacement during capillary imbibition of water, or

- temperature changes.

\subsubsection{Ionic Transport}

Leaching, or constituent release as ionic species dissolved in the aqueous phase, occurs in response to gradients in chemical activity between the pore water solution and the external boundary. The release of constituents from a porous matrix results from dissolution of the solid phase into the pore solution, 
coupled with mass transport with the pore system (1) by gradients between the interior of the cementitious material and the surroundings (diffusion-controlled release), and/or (2) by convection of the pore water through the solid material by capillary suction or percolation.

In actuality, the impact of leaching on environmental assessment is the net result of a complex combination of water movement within and around a porous solid material and the chemical conditions that occur locally within the material pores and at the external boundary. These chemical conditions are spatially variable and dynamic, changing in response to ingress and release of chemical species and their redistribution between solid and liquid phases in response to precipitation-dissolution, adsorption-desorption, ionexchange and solution complexation reactions.

\subsubsection{Internal Factors}

There are several chemical and physical factors that affect the measured rate of leaching from porous materials. Chemical factors primarily influence the concentrations of species in the pore solution, whereas physical factors control the mode of water contact and the rate of mass transport through a pore to the environment.

For inorganic constituents, the master chemical variable is local $\mathrm{pH}$ in that many of the solid-liquid partitioning reactions are controlled or influenced by changes in $\mathrm{pH}$. The high $\mathrm{pH}$ of cementitious materials is primarily responsible for stabilization of species through formation of solid phases (e.g., precipitates or solid solutions) and for cation binding to negative surface charge on metal oxide surfaces. High $\mathrm{pH}$ is indirectly a factor in increasing both inorganic and organic species leaching through mobilization of dissolved organic carbon which may complex with porewater components and increase leachable concentrations.
Permeability of the solid material may be the master physical factor that dictates the mode of water contact and the rate controlling mechanisms of mass transport. Infiltrating water is likely to percolate through highly permeable materials and flow around low permeability fills. In the former case, solid-liquid partitioning will dominate the rate of release while mass transport processes (e.g., diffusion, convection) will control the rate of release in the latter case.

\subsubsection{External Stresses}

Since the leaching matrix is in direct contact with surrounding materials in the placement scenario, a cementitious material is susceptible to exchange of liquid and gases across the matrix boundary. For example, an initially water saturated material (e.g., as the result of complete hydration during curing) will tend to lose water. If the water loss is significant, gases from subsurface soils or materials can diffuse into the matrix and react with the pore solutions (e.g., carbonation, oxidation). The cementitious material may be contacted with pore solution that is "acidic" or demineralized relative to the pore solution; both of which aggressively influence the durability of the cementitious barrier and the leaching of major and trace constituents. Therefore, examination of interfaces between the environment and the cementitious barrier material and the alteration of leaching mechanisms due to potential boundary reactions become as important as the study of leaching rates from the material under controlled conditions.

\subsection{Overview of Leaching Assessment Approaches}

A critical aspect of the assessment methodology for environmental performance of cementitious materials is the approach for characterizing leaching rates and interactions at material interfaces. Under current US environmental policy, management and disposal of hazardous and radioactive wastes/waste forms is regulated by local, state and federal agencies. 
Assessment methodologies and acceptance criteria for leachability from these materials historically has been based, in part, on screening procedures promulgated by the United States Environmental Protection Agency (USEPA) for hazardous waste classification or stipulated through the USNRC for nuclear waste disposal. Research in Europe and the US provides an integrated leaching assessment framework (Kosson et al. 2002) into the current regulatory context.

This chapter presents conceptual models describing the interdependency between processes, material characteristics and constituent release, constitutive relationships for relevant leaching and chemical retention processes, experimental approaches to determining material-specific leaching characteristics, and integration of experimental data with modeling and simulation. These phenomena will be placed in context of the leaching behavior of typical cementitious matrices as well as identification of knowledge gaps and opportunities for advancement of the current understanding.

\subsection{MECHANISMS AND PROPERTIES}

Migration of constituents through porous solid media can take place via a combination of several mechanisms; molecular diffusion in the water phase, diffusion in the gas phase, and/or convection of dissolved ions in flowing fluid phases. The generalized mass transport of a species in a porous media can be described using the convection-diffusion-reaction equation:

$\frac{\partial C_{i}}{\partial t}=\nabla\left(D \nabla C_{i}\right)-v \nabla C_{i}+R\left\langle C_{i}\right\rangle$

where: $C_{i}$ is the concentration of the species $i$ in a unit volume of liquid [mg $/ \mathrm{m}^{3}$ liquid], $t$ is time [s], $D$ is the diffusion (dispersion) coefficient $\left[\mathrm{m}^{2} / \mathrm{s}\right], v$ is the bulk velocity of the liquid or gas phase $[\mathrm{m} / \mathrm{s}]$, and $R\left\langle C_{i}\right\rangle$ is the production rate for the species $\left[\mathrm{mg} / \mathrm{m}^{3} \mathrm{~s}\right]$, typically considered a function of the concentration of the transporting species.

The overall rate of mass transfer and the relative importance of the terms in Eq. (1) are determined by a combination of chemical and physical processes and properties. The following is a brief review of physical properties and processes relevant to leaching form cementitious materials.

\subsection{Mass Transport Mechanisms}

Leaching from cementitious materials is often considered to be a diffusion-based process where the flux of a species is directly proportional to a gradient in concentration. However, the leaching process in natural systems is influenced not only by concentration gradients but by convection and chemical reaction processes. Chemical processes play an especially important role in the degradation of cement matrices which, in turn, affects the rate of leaching. A wellbalanced review of the theoretical and numerical representation of cementitious material based on mass transport and degradation reactions is presented by Glasser, Marchand, \& Samson (Glasser, Marchand \& Samson 2008).

\subsubsection{Convection}

When the hydraulic conductivity of the cementitious material is high enough to allow a significant pressure-driven flow of water through the material, dissolved species in the pore solution are carried along with flowing water by a process called convection. Convective transport is not likely to be a significant mechanism for mass transport in intact cementitious material; however, convection will play a role in mass transport when considerable physical damage (e.g., cracking) and disintegration convection are evident. Mechanisms and modeling of convective transport are discussed in the chapter on mass transport processes. 


\subsubsection{Osmotic Pressure}

One important issue poorly defined in the literature is the effect of osmotic pressures which may build up in the pore fluid of cement-stabilized matrices with high salt loadings, possibly leading to expansion of the system (Bénard et al. 2008). Osmotic pressure will only be important in systems where there is no free movement of ions possible, as in cases of a semi-permeable membrane with solutions of different salt concentrations on both sides. Rowe et al. (2004) related the movement of water as a result of the osmotic countercurrent due to double layer repulsion in microporous, reactive materials (e.g., clays). To what extent small pores in concrete act as a "membrane" is not clear; however, if osmotic effects are possible, the maximum pressures may be derived from the estimated salt concentrations in the pore solutions.

\subsubsection{Diffusion}

Molecular diffusion is the autonomous process by which dissolved ions migrate from high to lower concentrations in order to relax existing concentration gradients. Over short distances (e.g., $\mathrm{mm}$ to $\mathrm{cm}$ scales), the diffusion process dominates mass transport, but becomes increasingly less significant over larger distances. In cracked matrices, liquid phase diffusion can play a role in migration of substances from intact regions towards the crack surface where bulk flow dominates the rate of mass transport. In this way, diffusion can be the rate limiting factor for species that can be transported over longer distances by convection.

Molecular diffusion occurs because of gradients in chemical potential developed within the material relative due to internal heterogeneity or between the material and surrounding media due to external conditions. In turn, chemical potential is related to porewater concentrations through the ionic strength of the pore solution (e.g., through the Debye-Hückel or Davies equation). Thus, high concentrations within the material relative to those at the boundary or interface cause diffusion out (leaching or release), while higher external concentrations than within the material cause diffusion into the material (ingress).

\subsubsection{Diffusion Coefficients}

In aqueous, non-porous system without bulk phase movement, the one-dimensional (1-D) mass flux of a dissolved species often is described by Fick's first law:

$$
J=-D^{m o l} \frac{\partial C}{\partial x}
$$

where: $J$ is the flux of the diffusing species $\left[\mathrm{mg} / \mathrm{m}^{3} \mathrm{~s}\right]$, $\partial C / \partial x$ is the 1-D gradient of the species $\left[\mathrm{mg} / \mathrm{m}^{3} \mathrm{~m}\right]$, and $D^{m o l}$ is the proportionality constant known as the molecular diffusivity or molecular diffusion coefficient $\left[\mathrm{m}^{2} / \mathrm{s}\right]$.

Molecular diffusivity is a property of the diffusing species and temperature with no consideration for the physical or chemical effects. Values of the molecular diffusion coefficient for a wide variety of species fall typically within a relatively narrow range of (1-4) $\times$ $10^{-9} \mathrm{~m}^{2} / \mathrm{s}$ at $25^{\circ} \mathrm{C}$ (Robinson \& Stokes 1959). These diffusion coefficients are determined at infinite dilution and tabulated in the literature (ACG).

Three variants to the molecular diffusion coefficient may be seen in the porous media literature depending on incorporation of various physical and chemical influences. Since the nomenclature associated with diffusion coefficients is widely inconsistent within the literature, the following definitions are used (Walton et al. 1990 and Seitz and Walton, 1993):

The effective diffusivity describes the rate of diffusion of a species in a tortuous, porous medium relative to the pore area through which diffusion occurs. Thus, effective diffusivity accounts for tortuosity, but not 


\section{Review of Mechanistic Understanding and Modeling and Uncertainty Analysis Methods for Predicting Cementitious Barrier Performance}

for porosity or chemical effects. This form of diffusivity is the diffusion coefficient required in the PORFLOW model (Phifer, Millings and Flach, 2006).

$D^{e f f}=\frac{1}{\tau} D^{m o l}$

where: $D^{e f f}$ is the effective diffusion coefficient and $\tau$ is the matrix tortuosity $\left[\mathrm{m}_{\text {pore }} / \mathrm{m}\right]$. One variant of the effective diffusivity expression shown in Eq. (3) includes the constrictivity of the pore network (Grathwohl 1998; Saripalli et al. 2002):

$D^{e f f}=\frac{\delta}{\tau^{\prime}} D^{m o l}$

However, neither tortuosity $\left(\tau^{\prime}\right)$ nor constrictivity $(\delta)$ are measurable parameters and it is likely that these may be lumped into a single tortuosity term $(\tau)$ such that the discrepancy between Eq. (3) and Eq. (4) is likely to be minor.

Intrinsic diffusivity represents the rate of diffusional transport that is hindered by the effective surface area (e.g., porosity) and the tortuous pathway of the fluid phase (e.g., tortuosity). Intrinsic diffusivity does not account for chemical effects on mass transport. The majority of the literature shows the intrinsic diffusion coefficient as (Bear 1979):

$D^{\text {int }}=\frac{\phi_{d}}{\tau} D^{m o l}$

where: $D^{\text {int }}$ is the intrinsic diffusivity $\left[\mathrm{m}^{2} / \mathrm{s}\right], \phi_{d}$ is the "diffusion-through" or connected porosity of the media $\left[\mathrm{m}^{3}\right.$ pore $\left./ \mathrm{m}^{3}\right]$ and $\tau$ is the geometric tortuosity factor $\left[\mathrm{m} / \mathrm{m}_{\text {pore }}\right]$. The porosity term represents the reduced effective surface area for diffusion while the tortuosity term accounts for the elongated and twisted pathway that a diffusing species must navigate in a porous matrix.

The apparent diffusivity describes all physical and chemical effects that hinder the diffusion of constituents in a porous material. Classically, the associated form of the diffusion coefficient is derived from the closed form solution of the semi-infinite diffusion into to an infinite bath (Crank, 1975) under the assumption that all chemical interactions may be described by a linear portioning coefficient.

$D^{a p p}=\frac{1}{\tau\left[1+\frac{\rho_{s} \cdot K_{d}}{\phi}\right]} D^{m o l}$

where: $D^{a p p}$ is the apparent diffusion coefficient $\left[\mathrm{m}^{2} / \mathrm{s}\right]$, $\rho_{s}$ is the density of the solid phase $\left[\mathrm{kg} / \mathrm{m}^{3}{ }_{\text {solid }}\right], \phi$ is the total porosity $\left[\mathrm{m}^{3}{ }_{\text {pore }} / \mathrm{m}^{3}\right]$, and $K_{d}$ is the linear partitioning coefficient $\left[\mathrm{L} / \mathrm{kg}_{\text {solid }}\right]$. The apparent diffusivity is the rate of diffusion observed from experimental mass transfer tests.

\subsubsection{Porosity}

Since chemical interactions typically are dependent on the solid-liquid surface area, the total porosity is used to describe chemical interactions. However, the porosity used to describe the decrease in crosssectional area available for diffusion is only a fraction of the total matrix porosity. This "diffusion-through" porosity does not include ink-bottle or dead end pores which do not participate in the mass transport processes. The volume of these non-percolating pores typically is not appreciable in soil systems, but can be as much as significant of the pore structure in cementitious systems. Schaefer et al., suggested a method for determining the fraction of dead end pores in porous media using cyclic mercury intrusion porosimetry (Schaefer, Arands \& Kosson 1999).

In cementitious materials, pore size distribution is a continuous spectrum of pore diameters. Gel pores, representing the smallest pore diameters $\left(5 \times 10^{-4}<\right.$ $\mathrm{d}<0.01 \mu \mathrm{m}$ ), are formed as calcium silica hydrate gels fill in the spaces between crystalline phases. Capillary pores $(0.01<\mathrm{d}<10 \mu \mathrm{m})$ are the void space remaining when the amount of hydration product is insufficient to fill in the original water volume fraction; thus, greater water-binder ratios will result in increased capillary porosity. Gel pores and capillary 


\section{Review of Mechanistic Understanding and Modeling and Uncertainty Analysis Methods for Predicting Cementitious Barrier Performance}

pore make up the majority of the pore volume available for mass transport. The combined porosity of gel and capillary pores are considered to represent the "diffusion-through" porosity used to modify the intrinsic diffusion coefficient in mass transport equations.

Larger pore fractions, such as entrained air $(25<\mathrm{d}$ $<50 \mu \mathrm{m})$ and air voids $(100<\mathrm{d}<2,000 \mu \mathrm{m})$ occur due to poor consolidation or gaps between course aggregates. In some cases, entrainment of air is purposefully intended to reduce the effects of volumeincrease stresses due to precipitation reactions or freezing of water.

\subsubsection{Tortuosity}

In a porous matrix, the actual distance that a species travels through the pore structure is longer than the linear distance in the material, because the travel path through the pores is indirect. In this text, tortuosity is defined as the ratio of the effective travel path to the straight line distance traveled by a diffusing species and, thus, value of tortuosity are always $\geq 1$. When defined as such, the molecular diffusivity is divided by the tortuosity term to yield a reduced effective, intrinsic or apparent diffusivity. Some researchers (Glasser, Marchand \& Samson 2008; Marchand \& Samson 2009 in press; Truc, Ollivier \& Nilsson 2000; Šimurek \& Suarez 1994) prefer to define a tortuosity factor in terms of the inverse ratio such that the value is $\leq 1$ and the parameter acts as a multiplier of the molecular diffusion. The former definition will be used for all discussions here.

In saturated materials, with high porosity (e.g., $>$ $20 \%$ ), tortuosity usually is in the range of $1.5<\tau<10$ while for materials with low porosity (e.g., $<10 \%$ ), tortuosity can be significantly higher, $200<\tau<500$ in cement mortars (van der Sloot et al. 2001).

The relationship between porosity and tortuosity is material dependent and changes in physical integrity and pore structure result in changes in tortuosity. Upon aging of mortars, an increase in tortuosity has been observed indicating a continued chemical reaction within the concrete matrix (van der Sloot et al. 2001; van der Sloot 2000). Salt dissolution, precipitation reactions and cracking all affect tortuosity. Partial saturation of the pore space also has a significant effect on the effective tortuosity, with tortuosity increasing in response to decreasing water saturation (Schaefer et al. 1995).

One potential problem with the common definition of matrix tortuosity, is that it is not directly measurable and, therefore, typically estimated empirically by fitting a diffusion equation to observed mass transport measurements of either a nominally inert species (e.g., sodium or potassium) or of chloride under the influence of an applied electrical potential (Samson, Marchand \& Snyder 2003).

Saripalli et al. suggested an alternative description of tortuosity in porous media could be directly measured as the ratio between interfacial surface areas (Saripalli et al. 2002). For sample, the tortuosity of a saturated porous matrix would be ratio between solid-liquid surface area (i.e., the "specific surface area") and the surface area of an idealized capillary bundle:

$\tau_{s a t}^{a}=\frac{S}{S_{o}}$

where: $\tau_{\text {sat }}^{a}$ is the area-based tortuosity of a saturated medium [-], $S$ is the specific surface area $\left[\mathrm{m}^{2} / \mathrm{cm}^{3}\right]$, and $S_{\mathrm{o}}$ is the surface area of an idealized porous medium (e.g., a capillary bundle) $\left[\mathrm{m}^{2} / \mathrm{cm}^{3}\right]$.

In unsaturated media, Saripalli et al. proposed that the

$\tau_{u n s a t}^{a}=\frac{a_{a w}}{a_{a w, o}}$

where: $\tau_{\text {unsat }}^{a}$ is the area-based tortuosity of an unsaturated porous media [-], $a_{a w}$ is the specific immiscible fluid 


\section{Review of Mechanistic Understanding and Modeling and Uncertainty Analysis}

Methods for Predicting Cementitious Barrier Performance

(air-water) interfacial area determined using interfacial tracers (Saripalli et al. 1997) $\left[\mathrm{m}^{2} / \mathrm{cm}^{3}\right]$, and $a_{a w, o}$ is the same quantity for the unsaturated idealized capillary bundle calculated by the geometry of an annulus $\left[\mathrm{m}^{2} / \mathrm{cm}^{3}\right]$. Thus, tortuosity may be determined from measurable or calculable parameters rather that empirical estimation.

\subsubsection{Sink/Source Terms}

For non-reactive substances that are only present in the dissolved phase, the total concentrations are equal to the dissolved concentrations and the reaction term is zero. For reactive species, however, the concentration in solution of reactive substances is a function of many parallel phenomena, which cannot be readily expressed in a single formula. In many models, the observed diffusivity of all ions is assumed to be constant and independent of the specific ionic species. However, for some problems the difference in diffusivity between ionic species needs to be considered (Li \& Gregory 1974). Furthermore, for many species the observed diffusivity is highly dependent on pore water $\mathrm{pH}$ and multiple partitioning processes between the pore-water and solid phases.

\subsection{Chemical Retention Mechanisms}

Although transport can be considered primarily physical in nature, chemical processes are of equal importance in determining migration rates, as chemical processes determine the distribution of reactive substances over different chemical forms (e.g., dissolved, precipitated and gaseous forms). As this distribution can vary considerably in time and space, a good understanding of the chemical retention mechanisms involved in the local distribution of species between solid, liquid and gas phases is necessary to fully describe the leaching process.

In the case of chemical reactions between ions, the driving force for these reactions is not the individual concentrations of ions, but their thermodynamic activities (i.e., chemical potential). For solutions with a significant amount of dissolved solutes, or with a high ionic strength, which is generally the case for pore solutions in cementitious materials, the ion activity can be quite different from the ion concentration. Ion activity correction models that provide activity coefficients allow calculation of activities from concentrations as necessary to calculate chemical equilibrium conditions. For environmental conditions (surface water, soil solutions) the Davies equation is the most widely used model. The extended Davies equation (Appelo \& Postma 2005) also allows a more simple approach to correct for ionic strength. At high salt concentrations $(>0.5 \mathrm{M})$, the Davies equation becomes inaccurate. For those conditions, the Pitzer equations (Pitzer 1973) have been developed, which are based on empirical ion-ion interaction terms. However, detailed information on correction parameters is only available for a limited set of substances and elements, and therefore it is in practice not possible to take these corrections into account in most current multi-element speciation models. A simplified Pitzer model for limited species interaction was described by Samson et al. (Samson et al. 1999).

\subsubsection{Precipitation}

Dissolution of minerals and other precipitated solid phases with fixed stoichiometry occurs in response to under-saturation in the aqueous phase. Precipitation, the reverse reaction, occurs in response to oversaturation in the aqueous phase. In these cases, the maximum dissolved concentration achieved for a dissolved species is controlled by the solubility of the least soluble precipitate or mineral and results in a saturated solution with respect to that species at local equilibrium. As a result, when saturation with respect to a specific species occurs, the total amount of the substance in the solid phase is not proportional to the dissolved concentration. Thus, increasing the amount of the species in the system will not lead to an increase in dissolved concentration, but only to an increase in the amount of the precipitated solid 
phase. Conversely, removing some of the species from the system will not result in a lower dissolved concentration until all of the precipitate is completely dissolved. The primary phases of cementitious materials (major matrix constituents, including calcium, silica, alumina, sulfur, iron) will behave according to dissolution-precipitation phenomena. Modeling of dissolution-precipitations processes as linear partitioning processes is not appropriate because of the absence of proportional behavior of the system.

Numerical modeling of dissolution-precipitation reactions is relatively simple in the form of chemical reactions at equilibrium, if thermodynamic data are available. However, for some cases these reactions are kinetically controlled and then reaction rate data is necessary for more accurate modeling.

\subsubsection{Solid Solutions}

Solid solutions are a special form of precipitate in which the composition and element stoichiometry of the precipitate varies with the composition of the solution with which it is in contact. Solid solutions are considered a mixture of different minerals or precipitates. For most radionuclides in cementitious materials, the total mass of the species present is so small that precipitation is unlikely; however, solid solution or inclusion during precipitation of other solid phases may be relevant. The thermodynamic activity of each component in the solid solution is not the same as that for a pure mineral phase, but is a function of the relative fraction of that component in the overall solid solution. For ideal solid solutions, the constituent activity within the solid solution is equal to its mole fraction in the solid solution phase.

In cement-based systems, incorporation of elements into ettringite has been shown to have significant influence on pore solution behavior (Klemm 1998; Gougar, Scheetz \& Roy 1996). This is particularly relevant for oxyanions such as $\mathrm{CrO}_{4}^{-2}, \mathrm{AsO}_{3}^{-3}, \mathrm{MoO}_{4}^{-}$,
$\mathrm{VO}_{4}^{-3}, \mathrm{PO}_{4}^{-3}, \mathrm{SeO}_{3}^{-2}, \mathrm{BO}_{3}^{-3}, \mathrm{IO}_{3}^{-}$, and $\mathrm{TcO}_{4}^{-}$, many of which can substitute for sulfate (Klemm 1998;

Kumarathansan et al. 1990; Poellmann et al. 1993; Myneni et al. 1997; Perkins \& Palmer 2000; Kindness et al. 1994; Zhang \& Reardon 2003). Solid solutions are also relevant for $\mathrm{Fe}, \mathrm{Ba}$ and $\mathrm{Sr}$ which can substitute for $\mathrm{Al}$ or $\mathrm{Ca}$. In addition, anionic complexes of $\mathrm{U}$ are readily incorporated into carbonate solids (Koroleva \& Mangini 2005).

Solid solutions can decrease the aqueous solubility of the minor fractions in the solid solution. Although the aqueous solubility of the major constituents in a solid solution will not change significantly, trace elements that form a small fraction of the solid solution may have a much lower solubility than if they precipitated as a separate mineral phase. The extent to which solid solutions reduce the solubility, and therefore the release, of anionic and cationic radionuclides is not clear.

Solid solution modeling parameters for ettringite substitution are provided in another chapter that focuses on thermodynamic databases. These modeling parameters allow description of leaching of these elements and estimation of the order of magnitude of the potential impact of solid solutions on radionuclide leaching. A variety of cement mortars and cement-stabilized wastes with varying concentrations of oxyanions modeled with these parameters have indicated generally good agreement between measurement and predicted concentrations (van der Sloot et al. 2007b). Further experimental investigation of incorporation into and release from solid solutions is warranted to meet CBP objectives.

\subsubsection{Adsorption and Surface Precipitation}

Adsorption processes are an important form of solid phase association that influence distribution of solutes between dissolved and solid phases, especially for ion concentrations less than the solubility concentration 


\section{Review of Mechanistic Understanding and Modeling and Uncertainty Analysis Methods for Predicting Cementitious Barrier Performance}

where precipitation would occur. Adsorption to inorganic surfaces, such as metal (hydr)oxide surfaces, appears to be a multi-component process, with competition for available adsorption sites by ionic species with different charges and chemical binding properties. As a result, adsorption behavior of ions is mutually interdependent with coupled physical and chemical behavior of the system, such that it is difficult to study the transport behavior of trace species without considering the behavior of the major constituents (macro elements) of the system (Goldberg et al. 2007).

\subsubsection{Adsorption to Metal (Hydr) Oxides}

Reactive metal (hydr)oxide minerals exhibit $\mathrm{pH}$ dependent surface charges which result in multicomponent adsorption. The surface of reactive oxide minerals is covered with hydroxyl groups that dissociate in water as a function of $\mathrm{pH}$. At higher $\mathrm{pH}$ levels, more protons leave the surface, making the surface negatively charged and, thus, more attractive to cations. As $\mathrm{pH}$ levels decrease, iron surfaces pass through a point of zero charge (PZC), such that at low $\mathrm{pH}$ surfaces become positive, allowing anions to sorb more strongly.

Examples of reactive metal (hydr)oxides relevant to chemical retention and leaching include iron oxides, aluminum oxides, and manganese oxides in both crystalline and amorphous forms. Although these different mineral phases, in many ways, behave similarly, their relative importance in retention of species depends upon matrix properties, the relative solubility of each mineral, and specific sorption reaction constants. For example, Al-oxides are more soluble than iron oxides and dissolve in acidic solutions (i.e., $\mathrm{pH}<4$ ). The effect of manganese oxides is generally considered to be less than Fe- and Al-oxides, but is known to be of relevance for some specific systems with elevated Mn levels.
Amorphous forms of ferric, aluminum and manganese oxides are porous, poorly crystalline solids with high specific surface areas. These solid phases have been shown to retain metal species through a combination of surface adsorption and diffusion through microporous particles (Fan et al. 2005). Table 1 presents a comparison of properties of amorphous Fe (HFO), $\mathrm{Al}$ (HAO), and Mn (HMO) oxides.

Extensive research in the field of surface chemistry and colloidal interfaces has been completed on characterization and retention mechanisms for metal (hydr)oxides relative to heavy metals and radionuclides (Crawford, Harding \& Mainwaring 1996; Charlet \& Manceau 1992; Manceau et al. 1992; Axe \& Anderson 1995; Axe \& Trivedi 2002; Axe et al. 2000; Fan et al. 2005; Thomas et al. 2004; Trivedi \& Axe 1999; Trivedi \& Axe 2001; Trivedi, Axe \& Tyson 2001; Karthikeyan \& Elliott 1999; Karthikeyan, Elliott \& Chorover 1999; Peak 2006; Tiffreau, Lützenkirchen \& Behra 1995).

\subsubsection{Surface Precipitation}

When the sorbate concentration exceeds $1 / 10$ of the solubility concentration and more than half of the total amount of surface sites, accounting for surface precipitation is recommended (Dzombak \& Morel 1990). Although the combination of these conditions is not common for in most materials, surface precipitation has been shown to provide an adequate description of local equilibrium and release behavior for specific cases when these conditions are present (Meima \& Comans 1998; Dijkstra, van der Sloot \& Comans 2002). For most radionuclides, however, it is unlikely that the conditions specified for surface precipitation will be fulfilled as radionuclides concentrations are generally too low. One notable exception is uranium which can be present in high enough concentrations such that it forms discrete surface precipitated phases. Other actinides, having extremely low solubility values, may also form surface precipitates. 
Review of Mechanistic Understanding and Modeling and Uncertainty Analysis

Methods for Predicting Cementitious Barrier Performance

Table 1. Selected Characteristics of Amorphous Metal Hydr(oxides) from Fan et al. 2005

\begin{tabular}{|l|c|c|c|}
\hline & HFO & HAO & HMO \\
\hline Specific Surface Area $\left[\mathrm{m}^{2} / \mathrm{g}\right]$ & $600^{\mathrm{a}}$ & $411^{\mathrm{b}}$ & $359^{\mathrm{a}}$ \\
\hline Porosity $\left[\mathrm{m}^{3}{ }_{\text {pore }} / \mathrm{m}^{3}\right]$ & 0.5 & 0.45 & 0.35 \\
\hline Mode Pore Diameter $[\mathrm{nm}]$ & 3.8 & 1.9 & $2.1,6.1$ \\
\hline Mean Particle Diameter $[\mu \mathrm{m}]$ & 13.0 & 7.5 & 19.6 \\
\hline
\end{tabular}

a Dzomback and Morel (1990)

b Trivedi and Axe (1999)

\subsubsection{Modeling Oxide Adsorption}

In addition to electrostatic interactions, the empty surface "sites" can react chemically with dissolved ions. Therefore, the overall adsorption of ions on oxide surfaces is a combination of chemical and electrostatic interactions. As a result, adsorption of ions on oxide surfaces is not only $\mathrm{pH}$ dependent, but also dependent on the presence of competing ions. Describing the adsorption behavior of oxide surfaces requires accounting for these chemical and electrostatic interactions in thermodynamic simulations, referred to as adsorption or surface complexation models.

The Generalized Two-Layer Model (GTLM) presented by Dzombak and Morel (1990) is probably the most widely used multi-component adsorption model for oxide surfaces. The model was initially developed for hydrous ferric oxides (HFO), but is general in nature such that it can be applied to other oxide surfaces. The GTLM, described in detail by Appelo and Postma (Appelo \& Postma 2005), is based on the diffuse layer surface complexation model (Stumm \& Morgan 1996) with modifications to allow for multiple adsorption site types and surface precipitation. For this model, an extensive set of binding reactions and constants is available for both cation and anion adsorption onto HFO; however, data on specific adsorption parameters for aluminum and manganese oxides are currently lacking. Sorption onto Al-oxide is often modeled with the available sorption reactions for a HFO surface, using different values for the PZC and site densities (Meima \& Comans 1998). A key element in the GTML is the competition for available sorption sites, which is influenced significantly by the concentration the various competing elements. Using the GTLM, adsorption of radionuclides, such as $\mathrm{Np}(\mathrm{V}), \mathrm{U}(\mathrm{VI}), \mathrm{Se}(\mathrm{IV} / \mathrm{VI}), \mathrm{Co}$ and several others, onto HFO has been shown important (Brendler et al. 2004; Saunders \& Toran 1995; Musić \& Ristić 1988).

\subsubsection{Ion Exchange}

Surfaces with constant charges are important in environmental systems and are referred to as ion exchange surfaces (Appelo \& Postma 2005). Most important representatives are different forms of clays that have a fixed, negative charge as a result of their chemical structure. In solution, the negative surface charge is compensated for by surrounding aqueous cations forming a diffuse double layer. These counter ions are bound by electrostatic forces and not by specific chemical reactions. Competition between different cations takes place, but is less specific and related to their charge and size. Of all the solid surface interaction processes, ion exchange through the diffuse double layer generally provides the smallest contribution. Due to the non-specific nature of ion exchange, this process is more important for the ions that make up the bulk of the solutes, and is less important for the trace ions. Consequently, it is also of limited 


\section{Review of Mechanistic Understanding and Modeling and Uncertainty Analysis Methods for Predicting Cementitious Barrier Performance}

relevance for radionuclides. However, in materials that contain large amounts of clay or zeolites, ion exchange may become a dominant adsorption process when ionic size becomes selective in accessing exchange sites.

\subsubsection{Organic Matter Interactions}

Another important adsorption surface is formed by organic matter (e.g., solid phase humic and fulvic substances). The surfaces of organic matter also exhibit $\mathrm{pH}$ dependent charging behavior but their charge is net negative over the complete $\mathrm{pH}$ range. Thus, only cations adsorb significantly to organic particles. Heavy metal cations (e.g., copper) adsorb especially strongly to organic matter, such that solution concentrations of dissolved metals can be decreased by orders of magnitude even at organic matter concentrations as low as $1 \%$ by mass (van der Sloot \& Dijkstra 2004).

The state-of-the-art model for describing these interactions is the Non-Ideal Competitive Adsorption (NICA)-Donnan model (Kinniburgh et al. 1999) using model parameters described by Milne et al. (Milne, Kinniburgh \& Tipping 2001; Milne et al. 2003). The NICA-Donnan model, which describes metal ion binding to natural organic matter, is an example of a relatively simple model that is not straightforward to implement in standard algorithms. The principle equation for the amount of a species bound to organic matter is given by:

$$
\begin{aligned}
Q_{i, t}=Q_{\max } \times\left[\frac{n_{i}}{n_{H}}\right] \times\left[\frac{\left(\widetilde{K}_{i} C_{i}\right)^{n_{i}}}{\sum_{i}\left(\widetilde{K}_{i} C_{i}\right)^{n_{i}}}\right] \\
\times\left[\frac{\left\{\sum_{i}\left(\widetilde{K}_{i} C_{i}\right)^{n_{i}}\right\}^{p}}{\left.1+\left\{\sum_{i}\left(\widetilde{K}_{i} C_{i}\right)^{n_{i}}\right\}^{p}\right]}\right]
\end{aligned}
$$

where: $Q_{i}$ is the amount of species $i$ bound $[\mathrm{mol} / \mathrm{kg}$ ], $Q_{\max }$ is the maximum amount of the species that can be bound $[\mathrm{mol} / \mathrm{kg}], C_{i}$ is the concentration of species $i$ in solution $[\mathrm{mg} / \mathrm{L}], n_{i}$ is an exponent that reflects overall non-ideality of the adsorption reaction, $n_{H}$ is a parameter representing the non-ideality for the proton adsorption reaction, $\widetilde{K}_{i}$ is the median value of the affinity distribution for species $i[\mathrm{~L} / \mathrm{kg}]$, and $\rho$ is an exponent representing the width of the affinity distribution [-]. As with the Freundlich model of adsorption, the adsorbed concentrations can be calculated, in principle, directly from the aqueous phase ion concentrations.

Organic matter can be part of the immobile, solid matrix or dispersed as dissolved organic carbon (DOC). Often, the total solid-phase particulate organic matter $(\mathrm{POM})$ is fractionated into a hydrophilic fraction (HY) and more reactive fulvic acid (FA) and humic acid (HA) fractions (van Zomeren \& Comans 2007). Each of these functional groups plays some role in the binding process. Ions that are bound by particular organic matter fractions are considered to become immobile and not available for transport by diffusion or convection. Dissolved organic matter is described as small aqueous phase colloidal particles that can significantly bind metal ions. The interaction of soluble cations with DOC increases the concentrations of cations in the aqueous phase and may greatly enhance the transport of cations by convection. However, since these organic matter molecules are much larger than simple ions, diffusion rates of DOC-associated ions are slow relative diffusion rates of free dissolved ions. As with particulate organic matter, fractionation of DOC into HY, FA and HA can be used to describe the mobilization of trace constituents as DOC complexes (van Zomeren \& Comans 2007).

In systems considered to be predominantly inorganic, the role of organic matter interaction has been found to be of great importance due to the order of magnitude change in mobility that can occur. In particular, 
the fraction of organic matter mobilization as DOC has been shown to play a significant role in relevance to radionuclide mobility and transport (Reiller 2005; Reiller, Evans \& Szabó 2008; Reiller et al. 2002; Saunders \& Toran 1995).

\subsubsection{Inorganic Complexation}

Inorganic complexes can be important for the behavior of contaminants. For example, high concentrations of chloride can make cadmium more soluble, and hence mobile, under conditions where it would otherwise be precipitated. Interactions of this type are rather specific and many well known reactions are implemented in thermodynamic databases. When species known to be susceptible to complexation are observed in higher than expected concentrations, mobilization by inorganic complexation is likely to be the cause.

\subsubsection{Redox Processes}

Reduction oxidation processes are a specific form of chemical reactions in which electron transfer is involved. For many redox processes reaction rates are slow, so reaction kinetics are important. Redox processes are important for reduced materials that are exposed to air, as these will be (slowly) oxidized by oxygen, gradually changing from reduced to oxidized form which may have a large impact on chemical and transport behavior. In thermodynamic databases stability constants for many reduced species are available. The gas-solid interaction (here oxygen-reduced solid) is extremely slow in dry conditions, whereas under moist conditions a much faster oxidation can occur. In modeling such redox changes these aspects should be considered.

\subsection{Mass Transport Equations}

Within pores, transport can be described as a diffusion process with the flux of species $i$ following Fick's first law of diffusion:
$J_{i}=-D_{i}^{m o l} \nabla c_{i}$

where: $J_{i}$ is the flux of species $i\left[\mathrm{mg} / \mathrm{m}^{2} \mathrm{~s}\right], D_{i}^{m o l}$ is the molecular diffusion coefficient of species I $\left[\mathrm{m}^{2} / \mathrm{s}\right]$ and $C_{i}$ is the concentration of species $i$ in the liquid phase $[\mathrm{mg} / \mathrm{L}]$. This expression is combined with the conservation of mass equation law for species $i$ :

$\frac{\partial c_{i}}{\partial t}+\nabla J_{i}+r_{i}=0$

where: $\partial C_{i} \partial \tau$ is the accumulation rate of species $i$ with time and $r_{i}$ is the source/sink reaction term. When the reaction term is neglected and the porous material in taken into account, the result is one form of Fick's second law of diffusion describing diffusional transport of a molecular species in the liquid phase:

$\frac{\partial C_{i}}{\partial t}=\nabla\left(D_{i}^{e f f} \nabla C_{i}\right)$

where: $C_{i}$ is the concentration of the species in the porous material and $D_{i}^{e f f}$ is the effective diffusion coefficient $\left[\mathrm{m}^{2} / \mathrm{s}\right] \mathrm{m}$. At the microscale (e.g., within a pore), chemical reactions are expressed as boundary conditions and are not included in the transport equation (Samson \& Marchand 1999). Thus, Eq. (12) assumes that only concentration gradients drive the transport of the species.

The microscale transport equation is often extended to the macroscale (e.g., the material scale), by manipulation of the diffusion coefficient term to account for physical and chemical effects of a reactive, porous matrix according the diffusivity definitions described in Section 2.1. In many cases, linear solid-liquid partitioning is assumed and a simplified transport equation is applied to the complex diffusion-reaction process:

$$
\frac{\partial C_{i}}{\partial t}=\nabla\left(D_{i}^{a p p} \nabla C_{i}\right)
$$


where:

$$
D^{a p p}=\frac{1}{\tau\left[1+\frac{\rho_{s} \cdot K_{d}}{\phi}\right]} D^{m o l}
$$

The combination of Eq. (13) and Eq. (6) represent a simplified modeling approach for mass transport based on Fick's law. The assumptions of this simplified approach (Marchand \& Samson 2009 in press) include:

- Negligible effect of the electrical coupling between the ions

- Minimal influence of chemical activity gradients

- A linear relationship describes all binding interactions

- Insignificant temperature gradients

- Fully saturated porous material without liquid movement

Marchand and Samson (2009 in press) note that these assumptions are rarely valid for mass transport of ionic species through cementitious materials in natural environments, in part, due to the electrical field created by diffusion of ionic species moving at different rates. Several researchers suggest that such effects be taken into account using the Nernst-Planck equation for the flux of ionic species in ideal electrolytic solutions (Marchand \& Samson 2009 in press; Samson \& Marchand 1999; Samson, Marchand \& Beaudoin 1999; Samson, Marchand \& Beaudoin 2000; Černý \& Rovnaníková 2002).

$J_{i}=J_{i}^{\text {diff }}+J_{i}^{\text {elec }}=-D_{i}^{m o l} \nabla c_{i}-\frac{z_{i} F}{R T} D_{i}^{m o l} c_{i} \nabla \psi$

where: $J_{i}^{\text {diff }}$ is the diffusional flux represented by Fick's first law of diffusion $\left[\mathrm{mol} / \mathrm{m}^{2} \mathrm{~s}\right], J_{i}^{\text {elec }}$ is the electrical flux resulting from the interaction and relative movement of ionic species in the pore solution $\left[\mathrm{mol} / \mathrm{m}^{2} \mathrm{~s}\right], C_{i}$ is the molar concentration of species $i$ in solution $[\mathrm{mol} / \mathrm{L}], Z_{i}$ is the valance of species $i[-], F$ is the Faraday constant $(96,485 \mathrm{C} / \mathrm{mol}), R$ is the ideal gas constant $(9.841 \mathrm{~J} / \mathrm{mol} \mathrm{K}), T$ is the temperature $[\mathrm{K}], \psi$ is the electrodiffusion potential [V]. The Nernst-Plank equation holds true for all mobile species in dilute electrolytes (Marchand \& Samson 2009 in press).

The electrodiffusion potential can be expressed using the electroneutrality condition (Nguyen et al. 2008), a null current condition, or Poisson's equation (Samson \& Marchand 1999):

$\nabla^{2} \psi+\frac{F}{\varepsilon}\left(\sum_{i=1}^{N} z_{i} c_{i}+w\right)=0$

where: $\varepsilon$ is the dielectric constant of the media $[\mathrm{C} / \mathrm{V} \mathrm{m}]$, $w$ is a fixed charge density in the domain $\left[\mathrm{mol} / \mathrm{m}^{3}\right]$, and $N$ is the total number of ionic species in solution.

Extension of the Nernst-Planck-Poisson model has been proposed to account for changes in activity coefficients (Samson \& Marchand 1999), temperature gradients (Samson \& Marchand 2007) and chemical reaction (Černý \& Rovnaníková 2002). Marchand and Samson (2009 in press) express a general form of the mass conservation of ionic species in unsaturated porous media as shown in Equation 16 below.

$$
\begin{aligned}
\frac{\partial\left(\theta c_{i}\right)}{\partial t}=\nabla\left[\theta D_{i}^{\text {eff }} \nabla c_{i}\right. & \\
& +\frac{z_{i} F}{R T} \theta D_{i}^{\text {eff }} c_{i} \nabla \psi \\
& +\theta D_{i}^{\text {eff }} c_{i} \nabla\left(\ln \gamma_{i}\right) \\
& +\frac{\theta D_{i}^{e f f} c_{i} \ln \left(\gamma_{i} c_{i}\right)}{T} \nabla T \\
& \left.+D_{w} c_{i} \nabla \theta\right]+\dot{m}_{i}
\end{aligned}
$$

where: $\theta$ is the water content in the matrix $\left[\mathrm{m}^{3} \mathrm{water} /\right.$ $\mathrm{m}^{3}$ material], $\gamma_{i}$ is the activity coefficient of species $i$ $[-], T$ is the temperature $[\mathrm{K}], D_{w}$ is the water diffusivity $\left[\mathrm{m}^{2} / \mathrm{s}\right]$, and $\dot{m}_{i}$ is the source rate term of species $i[\mathrm{~mol} /$ $\left.\mathrm{m}^{3} \mathrm{~s}\right]$. 


\subsection{LEACHING ASSESSMENT}

\subsection{Regulatory Approaches}

Historically, leaching assessment has been carried out to satisfy the needs of (1) environmental regulatory compliance, for example under the Resource Conservation and Recovery Act (RCRA), and (2) the PA process under the self-regulating authority of USDOE for radionuclides. However, fulfilling each of these assessment needs has required different testing, interpretation, and documentation approaches.

- Under RCRA, wasteforms considered "hazardous" are classified for treatment and disposal following leaching limits established by the USEPA as applicable to a wide range of waste types. Leaching limits pertaining to a select list of 8 metals and some 30 organic species for materials are based on the assumed worst case "plausible mismanagement scenario" of co-disposal with municipal solid waste. The legislation resulted in promulgation of leaching tests, e.g., the Toxicity Characteristic Leaching Procedure (TCLP), and associated pass/ fail thresholds based on an assumed dilution/attenuation factor of 100 between the source term and the point of compliance. Initially, leaching tests and release thresholds were intended only as hazardous waste classification approaches. Subsequently, technology-based treatment standards were developed for specific constituents in wastes and waste types based on evaluation of best demonstrated available treatment (BDAT) using TCLP as the reference test. Thus, RCRA compliance has evolved towards technology-based standards in relation to a presumed worst case testing scenario. However, the TCLP approach has been fraught with criticism because of specific test method conditions, inappropriateness of the presumed mismanagement scenario for many waste management decisions, and the inability of TCLP to provide an estimate of leaching under a range of actual waste management scenarios (USEPA 1991; USEPA 1999).
- The release of radionuclides from USDOE wastes is self-regulated through USDOE while the USNRC has the authority for safety regulation of civilian uses of nuclear materials in the United States. Performance assessments document the process of determining release rates and dose to receptors through estimation of anticipated constituent release in relationship to the scenario under which the wasteform or barrier is expected to function. In many cases, performance assessment estimates have taken "conservative" assumptions (i.e., biasing the release estimate towards poorer than expected performance in the absence of more detailed information) to ensure that the design basis of the overall engineered system was protective of human health and the environment. Thus, testing has focused on estimation of release under a range of controlling conditions, with subsequent assessment assumptions to extrapolate results to the anticipated scenario. However, the resulting conservative assumptions also have the potential to be dramatically over-conservative (e.g., overestimating release by orders of magnitude) resulting in overly restrictive treatment requirements and waste acceptance criteria.

\subsection{Leaching Tests}

Garrabrants and Kosson (Garrabrants \& Kosson 2005) discussed different leaching test methodologies and reviewed test methods for leaching assessment of cement-stabilized wastes. In general, leaching test approaches are designed to either simulate release under a specific set of experimental conditions (i.e., attempt to mimic field conditions) or challenge the waste material to a broad range of experimental conditions with the intent to derived characteristic leaching data. Additionally, leaching test methods may be categorized as "equilibrium-based" and "kinetic-based" by whether the intent of the method is to establish equilibrium between a solid and a liquid or measure kinetic parameters such as diffusion coefficients. 


\subsubsection{Common Equilibrium-based Tests}

\subsubsection{EPA Method 1311: The Toxicity Characteristic Leaching Procedure (TCLP)}

In context to the above leaching test categories, the current regulatory test for waste classification, the TCLP is an equilibrium-based simulation tests designed to mimic the result of co-disposal of the tested waste with municipal solid waste. The procedure is a single batch extraction of particle-size reduced material $(<9.5 \mathrm{~mm})$ with dilute acetic acid in either deionized water or a $\mathrm{NaOH}$ buffer depending on the acid neutralization capacity of the material. The liquid-solid (LS) ratio is $20 \mathrm{~L} / \mathrm{kg}$ of material and the contact time is 18 hours. The extract is considered to be representative of leachate in the simulated release scenario. The USEPA Science Advisory Board (USEPA 1991; USEPA 1999) has recognized several limitations of TCLP including (1) overuse to purposes and materials for which the method was not designed, (2) the fact that end-point $\mathrm{pH}$ is not recorded, (3) the method does not account kinetic-effects, and (4) chemical and physical reactions common in many release scenarios are not considered.

\subsubsection{Common Kinetic-based Tests}

\subsubsection{ANS 16.1: Measurement of the Leachability of Solidified Low-Level Radioactive Wastes by a Short-term Test Procedure}

The tank leaching test, ANS 16.1 (ANS 16.12003 ) is the most commonly used US leaching test for solidified low-level (radioactive) waste (LLW) and is one of several tests required by the USNRC to characterize LLW as stipulated in the Waste Form Technical Position. This test method, an adaptation of an earlier test proposed by the International Atomic Energy Agency (Hespe 1971), is a semi-dynamic tank leach test whereby a monolithic material is contacted with demineralized water with the leachant changed periodically for fresh water following a specified schedule. The test stipulates 7 leaching intervals over a 5 day period but the schedule can be extended to a total of 90 days with intervals at 2, 7, 24, 48, 72, 96, 120, $456,1,128$, and 2,160 hours. Leaching data is interpreted using tables or graphs and effective diffusion coefficient is calculated assuming diffusion-controlled release. However, the experimental parameters of ANS 16.1 have fallen under criticism in that release rates were found to be suppressed, especially during the longer intervals due to elevated concentrations of elements in the leachate (Fuhrmann et al. 1989). Failure to maintain an assumed infinite bath at the monolith boundary may lead to back reactions causing precipitation of secondary products and yield erroneous effective diffusion coefficients. Several variations on this leaching tests address these concerns by adjusting the schedule of exchanges, e.g., USEPA Draft Method 1315, or use of ion-exchange resin to remove ions from solution, e.g., the Simulated Infinite Dilution Leach Test (Schwantes \& Batchelor 2006).

\subsubsection{ASTM C1308: Accelerated Leach Test}

ASTM C-1308 (2002) was developed to obtain the net forward rate of release, a material property, as opposed to an environmentally specific release rate. This test is designed to determine if leaching is diffusion-controlled by using a computer code that was developed for the test method (Fuhrmann et al. 1990). It allows computation of a diffusion coefficient from the data and a check of the data against a shrinking core diffusion model. It also can be used to project releases for different size waste forms and for long times based on the observed diffusion coefficient. Elevated temperatures can be used to accelerate leaching, and if modeling shows no alteration in the process relative to room temperature tests, these data can be used to define leaching out to long times. This test is a semi-dynamic procedure that stipulates a cylindrical sample. Large volumes of leachate and frequent leachate changes maintain low concentrations in solution. 
Several leaching tests, such as ASTM C1220 (2002), ASTM C1285 (2002), MCC-5s, and MCC-4, were developed for evaluation of radionuclide release from glass or other wasteforms. These leaching tests have limited applicability to cementitious barriers in that glass wasteforms have inherently different leaching mechanisms and characteristics than cementitious materials. Only a few tests have been designed for specifically for wide-based use on cementitious materials.

\subsubsection{USEPA Draft Methods}

In response to criticisms and misapplication of TCLP for purposes other than hazardous/non-hazardous waste determination, the USEPA recently has been focused on development of alternative test methods to better understand the processes involved in release of contaminants from waste and provide more robust estimates of constituent release under specific disposal and beneficial use scenarios. These methods will not replace TCLP for subtitle D (industrial) versus Subtitle C (hazardous) waste determination under RCRA but rather allow greater flexibility in leaching test applications that do not statutorily specify TCLP (e.g., determinations of equivalent treatment, delisting petitions, treatment effectiveness comparisons, beneficial use determinations). The USEPA draft test methods include:

- equilibrium-based, $\mathrm{pH}$ dependence leaching test (Draft Method 1313),

- equilibrium-based, upflow percolation column test (Draft Method 1314), and

- kinetics-based, mass transfer rate test for monolith or compacted granular materials (Draft Method 1315).

Assessment based on test results is scenario-based and follows a leaching assessment framework recommended by Kosson et al. (2002). Some of the methods presented here are similar to methods adopted in Europe under the European Committee on
Standardization (CEN) for waste, mining waste, soil, sludge and construction products (CEN TS14405, 2005; CEN TS 15863, 2009; ISO TS 21268-3, 2007; ISO TS 21268-4, 2008; CEN TC 351 drafts, 2009; see section 3.3.3)

\subsubsection{Draft Method 1313: Leaching Test (Liquid-Solid Partitioning as a Function of Extract $\mathrm{pH}$ ) for Constituents in Solid Materials using a Parallel Batch Extraction Test}

Draft Method 1313 (USEPA 2009a) is designed to provide the liquid-solid partitioning (LSP) curve of constituents as a function of eluate $\mathrm{pH}$ and is similar to CEN/TS 14429 (CEN PrEN-14429 2005) used in Europe and ISO/TS 21268-4 (ISO TS 21268-4 2007) developed for soil and soil-like materials. The protocol consists of nine parallel extractions of a particlesize reduced solid material in dilute acid or base. Particle-size reduction facilitates the approach to solid-liquid equilibrium during the test duration. A mass of solid material, equivalent to a specified dry mass (value depends on sample heterogeneity and particle size), is added to nine extraction bottles. Deionized water is added to supplement the calculated acid or base addition such that the final liquid-solid (LS) ratio is $10 \mathrm{~mL} / \mathrm{g}$-dry. Addition of acid or base is based on a pre-test titration procedure to determine the required equivalents/gram yielding a series of eluates in the $\mathrm{pH}$ range between 2 and 13. The extraction vessels are sealed and tumbled in an end-over-end fashion for a specified contact time that depends on the particle size of the sample. Liquid and solid phases are separated via settling or centrifugation and an aliquot is removed for measurement of eluate $\mathrm{pH}$ and conductivity. The remainder of the eluate is filtered $(0.45 \mu \mathrm{m}$ filter) by pressure or vacuum and saved for chemical analysis. The eluate concentrations of constituents of interest are reported and plotted as a function of eluate $\mathrm{pH}$. These concentrations may be compared to quality control and assessment limits for interpretation of method results. 


\subsubsection{Draft Method 1314: Leaching Test (Liquid- Solid Partitioning as a \\ Function of Liquid-Solid Ratio) of Constituents in Solid Materials using an Up-Flow Percolation Column}

Draft Method 1313 (USEPA 2009b) is designed to provide the LSP of constituents in a granular solid material as a function of LS ratio under percolation conditions and is similar to CEN TS 14405 (CEN PrEN-14405 2005) and ISO 21268-3 (ISO TS 21268-3 2007). A 5-cm diameter $x 30 \mathrm{~cm}$ column is packed with solid material. Eluant is introduced to the column in up-flow pumping mode to minimize air entrainment and flow channeling. For most materials, the default eluant is deionized water; however, a solution of $1.0 \mathrm{mM}$ calcium chloride in deionized water is used when testing materials with either high clay content (i.e., to prevent deflocculation of clay layers) or high organic matter (i.e., to minimize mobilization of dissolved organic carbon). The eluant flow rate is be maintained between 0.5-1.0 LS/day to increase the likelihood of local equilibrium within the column. Liquid fractions are collected as a function of the cumulative LS ratio and saved for chemical analysis. The cumulative mass release is plotted as a function of cumulative LS ratio.

\subsubsection{Draft Method 1315: Mass Transfer Rates of Constituents in Monolithic or Compacted Granular Materials using a Semi-Dynamic Tank Leaching Test}

Draft Method 1315 (USEPA 2009c) provides mass transfer rates (release rates) of constituents contained low permeability material under diffusioncontrolled release conditions, similar to ANS 16.1 (2003), NEN 7345 (NEN 7345 1995) and PrEN15863 (CEN PrEN-15863 2009). The procedure consists of continuous leaching of a monolithic or compacted granular material in an eluant-filled tank with periodic renewal of the leaching solution. The vessel and sample dimensions are chosen such that the sample is fully immersed in the leaching solution at a liquid-surface area ratio of $9 \mathrm{~mL} / \mathrm{cm}^{2}$. Monolithic samples may be cylinders or parallelepipeds while granular materials are compacted into cylindrical molds at optimum moisture content using modified Proctor compaction methods. At nine pre-determined intervals, the leaching solution exchanged with fresh reagent water and the previous leachate is collected. For each eluate, the $\mathrm{pH}$ and conductivity are measured and analytical samples are saved for chemical analysis. Eluate concentrations are plotted as a function of time, as a mean interval flux and as cumulative release as a function of time. Observed diffusivity and tortuosity may be estimated through analysis of the resulting leaching test data.

\subsection{Integrated Assessment Approach}

Although more than 50 leaching tests have been identified for various purposes and materials, a limited number of carefully selected tests can cover a wide range of possible exposure conditions (van der Sloot, Heasman \& Quevauviller 1997). However, test methods alone are not sufficient to evaluate leaching as test results need to be linked to an assessment basis. This linkage requires a conceptual and computational framework to extrapolate laboratory test results to field scenarios.

An integrated assessment approach proposed by Kosson et al. (2002) uses the results obtained from leaching tests, in conjunction with other material and scenario characteristics, to provide the necessary information to describe a source term for assessment modeling. Simplified, semi-empirical and semi-analytical models, which though knowingly over-predict release (i.e., are conservative), can be used for initial screening purposes with the caveat that results be verified against field observations. Coupled chemical reaction-transport modeling is the preferred and most robust option available to provide insight in the long term behavior of materials under changing exposure conditions in the field (Dijkstra et al. 2008; Dijkstra, van der Sloot \& Comans 2006; Dijkstra et al. 2005; van der Sloot \& Dijkstra 2004; Kosson et al. 2002). 
The sequence of steps from problem definition, through test method selection and leaching simulation, to lab-to-field validation (Kosson et al. 2002; CEN EN-12920 2003).

Under the integrated assessment approach, an important distinction is made between the equilibriumbased release mechanisms in the case of granular materials (percolation scenario) versus kinetic-based release mechanisms that dominate release from monolithic materials (flow-around scenario). A generic testing approach has been developed for granular and monolithic materials as shown in the flowchart in Figure 3.

In both cases, constituent analysis in leaching tests should address all major and minor species as well as $\mathrm{pH}$, electrical conductivity, redox potential, and dissolved carbon (organic and inorganic) in order to facilitate speciation modeling. The basis for testing in both percolation and flow-around scenarios is the $\mathrm{pH}$ dependence leaching test which provides insight into the chemical speciation of the constituents in the solid phase of the materials by evaluation of constituent release in response to different end-point $\mathrm{pH}$ conditions. For granular materials, where the mode of water contact is anticipated to be percolation through the material, release under the natural $\mathrm{pH}$ of the material is determined using a percolation test. For low permeability materials (monoliths or compacted granular fills), a tank leach test with leachant renewal is formulated. This testing approach was the underlying methodology behind the development of the USEPA Draft Methods 1313 through 1315 described above; however, analogous leaching tests are available through the CEN and the International Organization for Standardization (ISO).

\subsubsection{Defining the Source Term}

Environmental model/assessment approaches commonly assume, either explicitly or implicitly, a constant source term ${ }^{2}$ which is not a proper representation of the long-term leaching behavior from cementitious materials in many cases.

\subsubsection{Constituent Selection}

Previous source term descriptions have applied independent release functions to individual constituents. Thus, these models neglect the effect of interactions between elements and changes in mobility due to significant changes in solubility controlling factors.

Inclusion of all constituent interactions within the cementitious material, as well as those external stresses that alter the properties of the material or constituent retention, is a daunting challenge. However, accounting for all the additional complexity provides a more realistic and mechanistically-based representation of the source term. Current computational advances, both in hardware and software, are beginning to make this approach practical for many applications.

\subsubsection{Material Characterization}

In addition to the leaching tests, methods for additional modeling parameters are currently being implemented in standardized protocols (ISO/TC190 Soil, 2008). This effort includes standardization of test methods to quantify reactive surfaces such as hydrated iron oxide surfaces, aluminum oxide surfaces, fractionation of dissolved and particulate organic matter, which are important for speciation modeling and reactive transport.

\footnotetext{
${ }^{2}$ In terms of the CBP, "source term" is the representation of the contaminant flux from within the confines of the engineered barrier system to the environment (e.g., vadose zone and groundwater).
} 


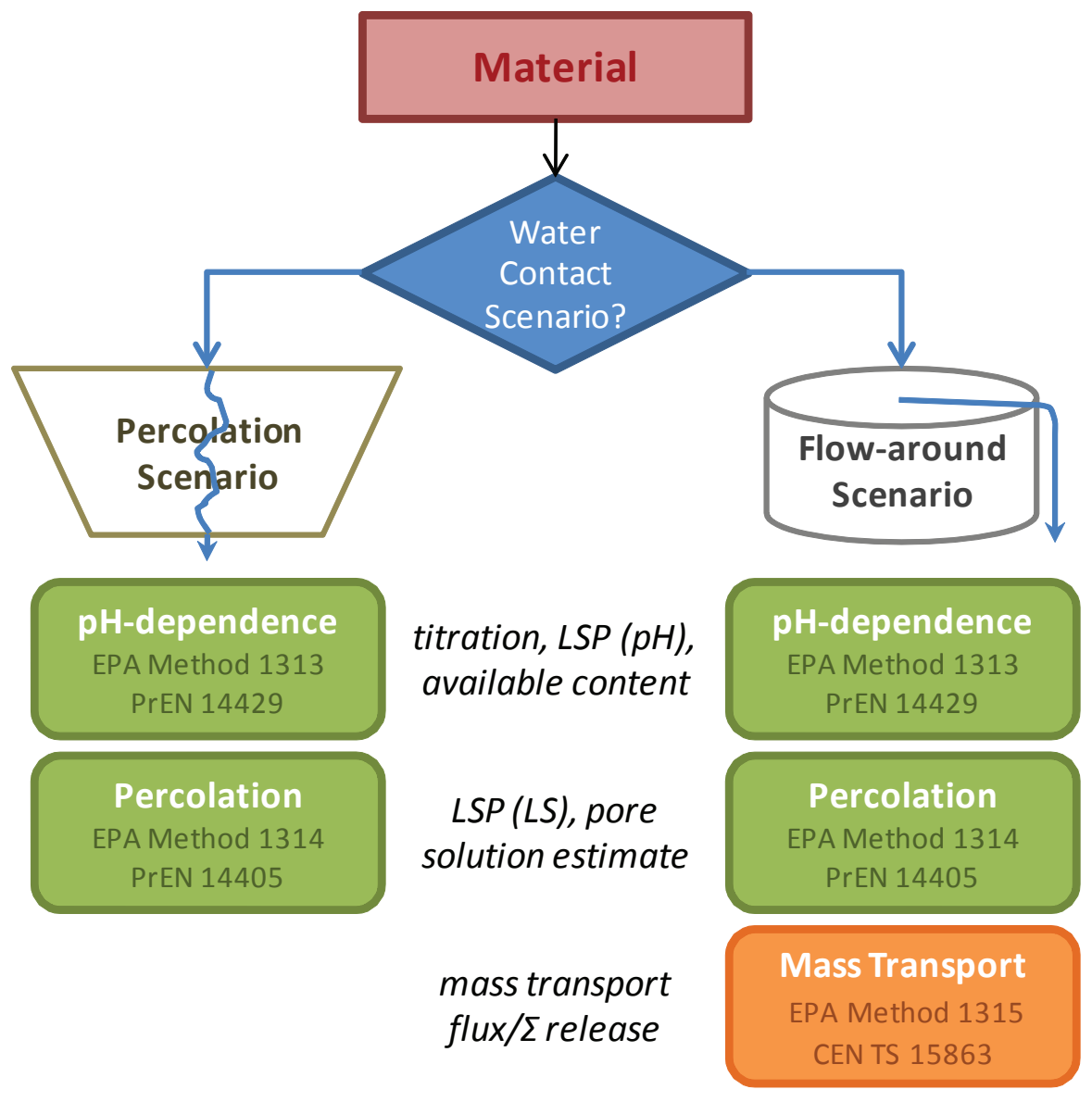

Figure 3. Flowchart Indicating Test Method Selection Based on
Material Type Used in Integrated Assessment Approach

\subsubsection{Redox Titration}

The redox capacity of a material is an important property of the material that allows the quantification of the overall rate at which oxidation may occur when balanced against the rate of oxygen ingress for a given scenario. For reducing materials like reducing grouts it is important to be able to assess the reducing capacity of the material (expressed in $\mathrm{mol} / \mathrm{kg}$ ) as it determines the resistance of the matrix to oxidation. In the Netherlands, a procedure (NEN 7348 2006) is described based on exposing a material to an excess of Ce (IV) in 2M sulfuric acid and back titration with $\mathrm{Fe}(\mathrm{II})$ as originally proposed by Angus and Glasser (Angus \& Glasser 1985).
A similar procedure for measuring reductive capacity for cementitious materials using $\mathrm{Cr}(\mathrm{VI})$ in $\mathrm{NaHCO}_{3}$ followed by slurrying with $\mathrm{NaSO}_{4}$ to desorb chromate (Lee \& Batchelor 2003) showed a $20 \times$ decrease in reductive capacity on blast furnace slag compared to the Angus and Glasser procedure (Serne 2006). However, the values determined according to the Angus and Glasser method match better with the reducing capacity independently calculated from the sulphide content, which is the main contributor to the reducing capacity relevant for impact on the environment. In blast furnace slag reducing capacity values in the order of 300-400 $\mathrm{mmol} \mathrm{O}_{2} / \mathrm{kg}$ have been measured (van der Sloot et al. 2007a). 


\subsubsection{Reactive Oxide Phases}

The quantification of reactive sorptive surfaces proceeds by selective extractions. The amount of amorphous and crystalline iron (hydr)oxides in the materials to be studied can be estimated by a dithionite extraction (Kostka \& Luther 1994). The amount of amorphous aluminum (hydr)oxides can be estimated by an oxalate extraction (Blakemore, Searle \& Daly 1987). The extracted amounts of $\mathrm{Fe}$ and $\mathrm{Al}$ can then be summed and used as a surrogate for hydrous ferric oxides (HFO) in the geochemical speciation modeling (Meima \& Comans 1998).

\subsubsection{Organic Matter Characterization}

The quantities of "reactive" organic carbon in the solid phase (i.e., HA and FA) can be estimated by a batch procedure (van Zomeren \& Comans 2007), which is derived from the procedure currently recommended by the International Humic Substances Society (IHSS) for solid samples (Swift 1996). In brief, the procedure is based on the solubility behavior of $\mathrm{HA}$ (flocculation at $\mathrm{pH}<1$ ) and the adsorption of FA to a polymer resin. This fractionation allows identification of the most relevant sub-fraction of DOC, because not all parts constituting DOC are equally reactive towards the substances of interest.

\subsubsection{Solid Analysis}

Discerning the structure and chemistry of the solid phases of cementitious materials (including containment structures and waste forms) and how those materials change with time is important to understanding their long-term behavior. Many of the techniques to study solids are x-ray methods and their sensitivity is limited by the intensity of the source of $\mathrm{x}$-rays. Synchrotron based methods take advantage of very high fluxes of $\mathrm{x}$-rays and the ability to supply $\mathrm{x}$-rays of specific energies to provide techniques that have revolutionized the analysis of the solid phase. Detailed descriptions of these techniques can be found in several reviews (Sparks 2004; Fenter et al. 2002; Brown \& Sturchio 2002). A few applications relevant to study of cementitious waste forms are briefly given below.

Elemental analysis of materials on the microscopic scale is an important tool in assessing behavior of cementitious materials. Scanning Electron Microscopes (SEM) and microprobes provide excellent images but detection limits for elemental concentrations are typically $1,000 \mathrm{mg} / \mathrm{kg}$ or greater. Synchrotron microprobes can provide elemental analyses with spot sizes as small as about a micrometer and detection limits of less than $1 \mathrm{mg} / \mathrm{kg}$. With this sensitivity, geochemical processes can be explored. Locations and associations of elements in a complex system can be resolved. For example, adsorption of contaminants on individual minerals in a soil can be determined as can their incorporation into new phases such as secondary weathering products. An example is shown in Figure 4 which illustrates the incorporation of $U$ and As into calcite during column leaching experiments with a tank backfill grout (Fuhrmann \& Gillow 2009). Arsenic was readily incorporated into the calcite as was U. Apparently U was available for incorporation earlier in the experiment but not later. Calcite continued to grow around older calcite containing $\mathrm{U}$.

Determining the oxidation state of elements, e.g., U, Tc and I, whose redox sensitive behavior controls their mobility, is an important tool in designing materials and systems for waste disposal. X-ray absorption near-edge structure (XANES) spectroscopy allows determination of oxidation states and co-ordination chemistry of individual elements in complex solid and liquid samples. For example, XANES can determine the speciation of contaminants under different conditions or over time as a reagent is added to a system. XANES analysis can be coupled with elemental mapping on microprobe systems so that images can be produced showing the distribution of elements in different oxidation states or in association with different ligands (see examples in Sparks, 2004). 

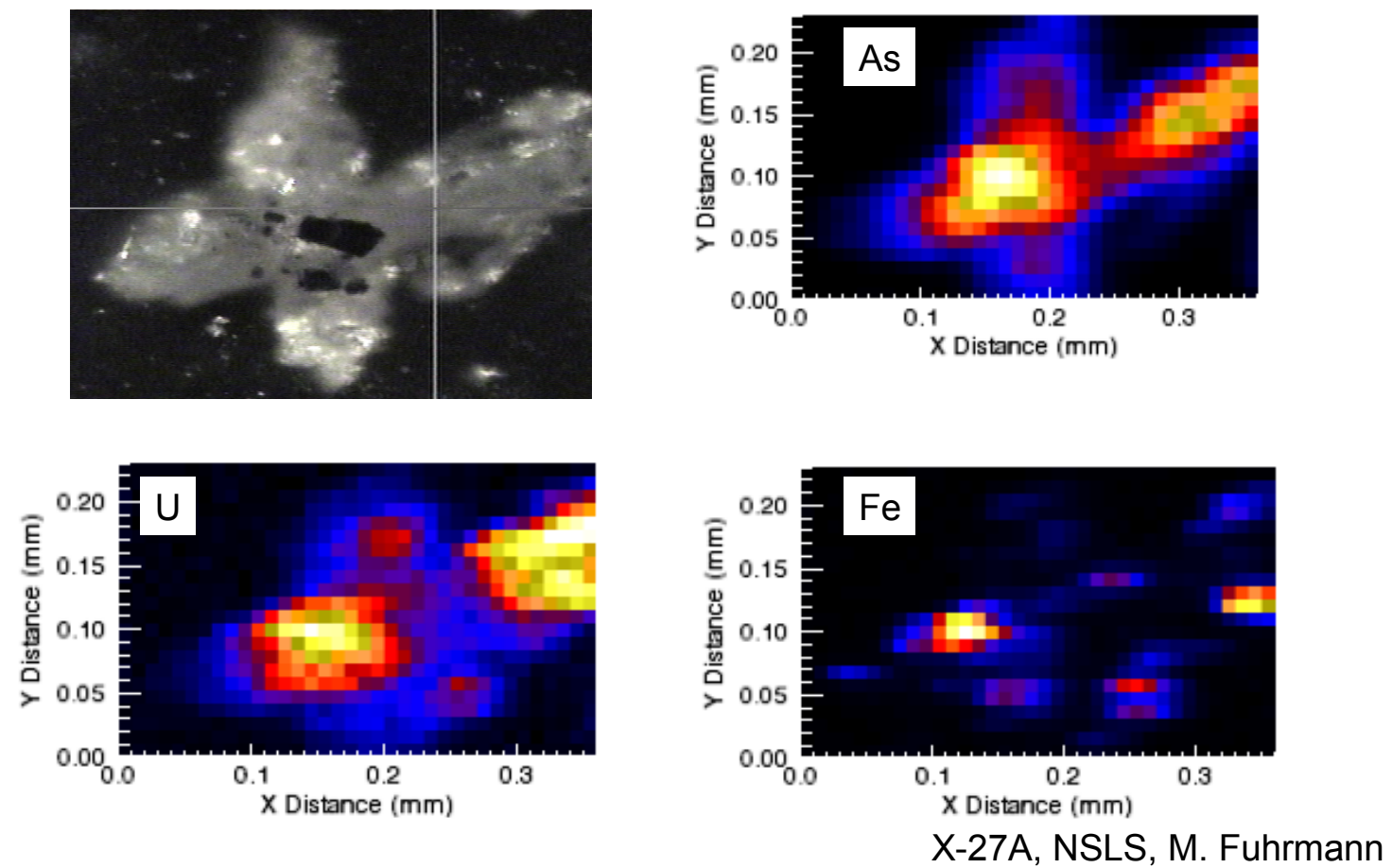

Figure 4. Distribution of Trace Species in Secondary Calcite Growth Found in Column Leaching Experiments of Tank Backfill Grouts. (1000 pore volumes of leachate through grout G-21 designed for filling high-level waste tanks at West Valley, New York)

These techniques can be used to determine distribution of waste species in grouts and other cementitious materials. For example, the distribution and elemental associations of reduced forms of $\mathrm{Tc}$ and I can be determined in newly produced reducing grouts. As these materials are exposed to accelerated aging conditions, the oxidation state and possibly the speciation of Tc and I can be determined as oxygen and carbon dioxide enter the system, secondary weathering products form and reducing species (e.g., Fe (II)) are depleted. For example, Luckens (Lukens et al. 2005), used extended X-ray absorption fine structure (EXAFS) to show that Tc(IV) in the form of $\mathrm{Tc}_{3} \mathrm{~S}_{10}$ in reducing grouts will slowly oxidize to the readily mobile $\mathrm{TcO}_{4}{ }^{-}$when oxygen can diffuse through the container. Oxidation does not take place when oxygen is not available, demonstrating that the high nitrate content of the waste does not oxidize Tc (Lukens et al. 2005; Allen et al. 1997).

\subsubsection{Interpretation of Leaching Data}

Following the testing approach shown in Figure 3, characterization of the leaching behavior of monolithic materials like cement-stabilized waste is carried out by a combination of two equilibrium-based leaching tests (i.e., a pH dependence leaching test and a percolation test) and kinetics-based monolithic leach test. This combination of leaching tests allows for many conclusions to be drawn about leaching behavior, including long-term leaching of a monolith and after full disintegration of the monolith to granular rubble. The approach to interpretation and integration of leaching tests is described in reference to the leaching test data for lead leaching in a cementitious material, presented in Figure 5 and in Figure 6.

The first two graphs in Figure 5 show the relationship between $\mathrm{pH}$-dependent leaching and release from 

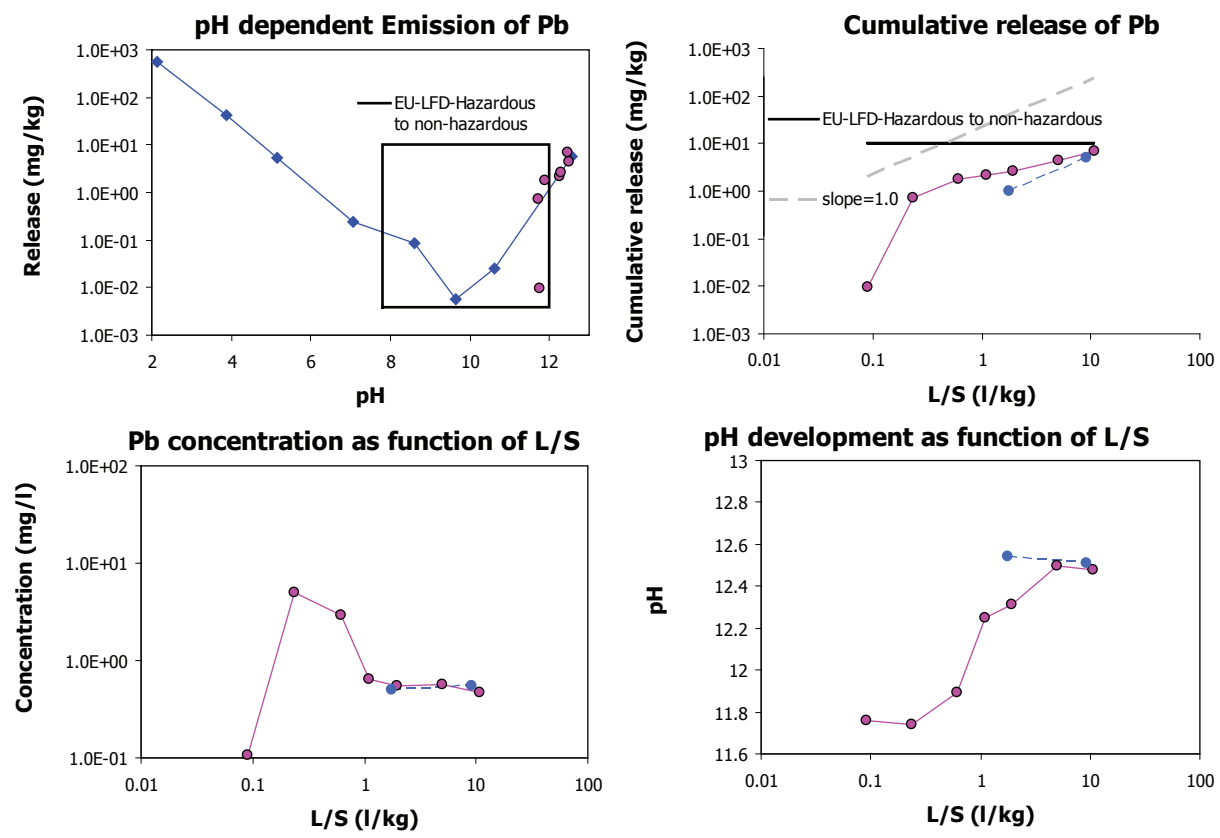

Figure 5. Results of Equilibrium-based Leaching Tests for Lead in A Cement-Stabilized Waste:

a) comparison of $\mathrm{pH}$-dependence and percolation test data as a function of $\mathrm{pH}$,

b) cumulative release from percolation tests as a function of LS ratio, c) concentration data from percolation test, and d) $\mathrm{pH}$ evolution in percolation test.
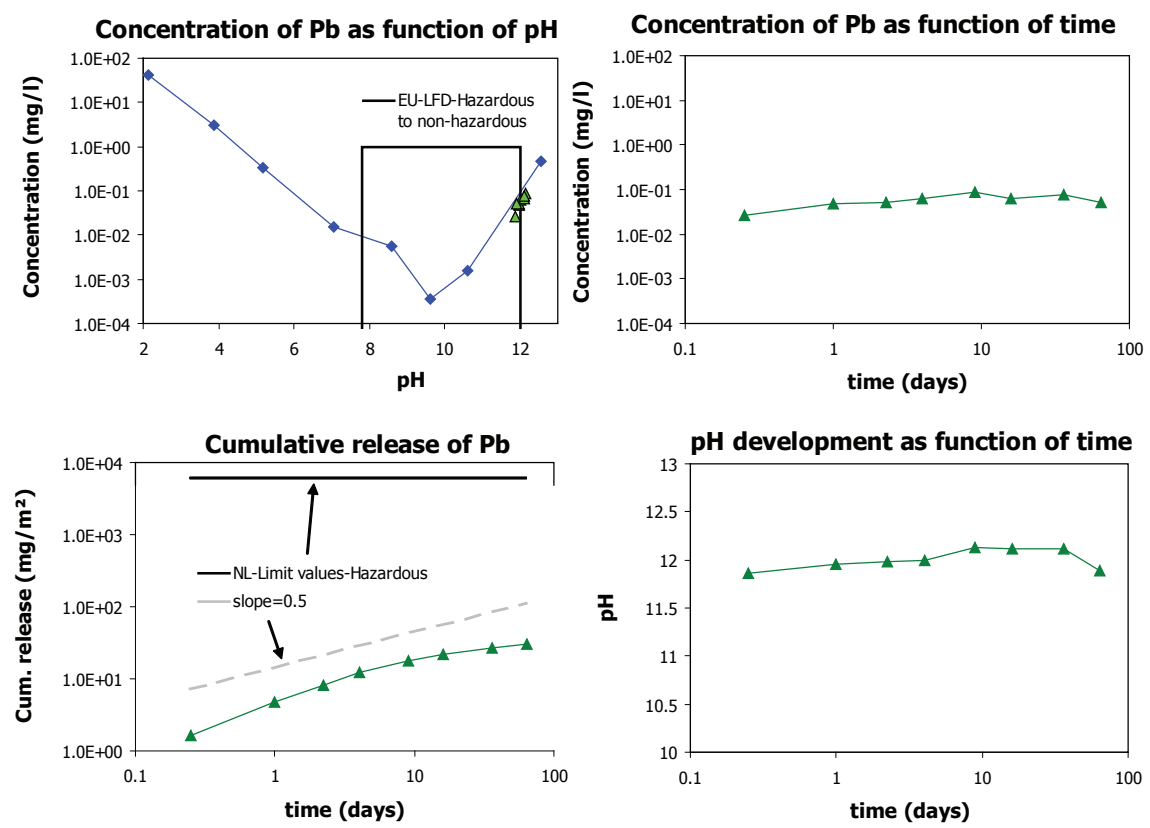

Figure 6. Results of Kinetics-based Leaching Tests for Lead in a Cement-Stabilized Waste:

a) comparison of tank leaching test and $\mathrm{pH}$-dependence as a function of $\mathrm{pH}$,

b) concentration in tank leach test, c) cumulative release from tank leach test, and

d) $\mathrm{pH}$ evolution in tank leach test. 


\section{Review of Mechanistic Understanding and Modeling and Uncertainty Analysis Methods for Predicting Cementitious Barrier Performance}

column percolation experiments. In general, the data from the percolation test (pink) correspond well with $\mathrm{pH}-$ dependence test at the same $\mathrm{pH}$ (blue data). This correspondence implies that, under the assumption of local equilibrium, the release can be predicted based on the average $\mathrm{pH}$ in the percolation test provided that the $\mathrm{pH}$ changes during the percolation experiment are not too large. However, when $\mathrm{pH}$ varies greatly (e.g., through carbonation), Figure 5a shows that a relatively large range of lead concentrations can be observed for the size-reduced stabilized waste. The graph of cumulative release as a function of LS ratio can be used to formulate conclusions on the main release mechanism in the percolation test:

- If the cumulative release data is linear with a slope of 1 , release is likely controlled by solubility limitations.

- Depletion of highly soluble species (e.g., $\mathrm{Cl}, \mathrm{Na}$ ) is likely when the release curve is shown to become horizontal with increasing LS (i.e., no further release with increasing LS).

- The constituent concentration observed for low LS ratio provides an indication of the concentrations in the porewater of the monolithic material.

The box in the $\mathrm{pH}$ dependence graph can be used to reflect the relevant $\mathrm{pH}$ domain for a given application and upper and lower threshold concentrations. In the plot of cumulative release as a function of LS, the same reference criterion has been inserted. For the case of cement-stabilized waste, the relevant $\mathrm{pH}$ range for size-reduced material is from the $\mathrm{pH}$ of the fresh material $(\mathrm{pH} \sim 12.8)$ to the $\mathrm{pH}$ associated with fully carbonated material ( $\mathrm{pH} 7.8)$. The lower horizontal line denotes the lowest analytical detection limit. The upper horizontal line is used to reflect a comparative threshold (i.e., a regulatory criterion; here conversion from hazardous to non-hazardous waste in the European Union Landfill Directive). Selection of appropriate upper threshold comparisons should be made in accordance with the anticipated release scenario (e.g., comparison to drinking water or groundwater quality criteria typically is not appropriate for waste disposal scenarios because dilution and attenuation between the source term and the point of compliance is not considered).

Many factors cause changes in the percolate concentrations during their transport through the soil, especially when large transport distances are considered. One important factor to be considered is preferential flow (only a portion of the material is in direct contact with percolating water). Lysimeter and field data point suggest that $\sim 20 \%$ of the total volume of material being directly in contact with infiltrating water (van Zomeren \& Comans 2007). A second important factor is the change in $\mathrm{pH}$ when leachate enters soil, which can result in precipitation/dissolution reactions leading to substantial alterations in the percolate in the soil. Overestimation of release will occur when precipitation of constituents of interest occurs at the interface but not considered in the assessment model. The effect of alkaline leachate on near-field soils is difficult to address without appropriate geochemical representation of the interface between materials (e.g., cementitious barrier and soil). The primary constituents of concern will be those constituents that are mobile in the cement-stabilized waste and remain mobile in the subsoil and groundwater system in spite of $\mathrm{pH}$ change and other changes.

In Figure 6, the leaching data for lead from a monolithic stabilized waste are provided in a four-panel format that provides useful insights about leaching information about kinetic-based leaching from monolithic materials. The first two graphs show the relationship between $\mathrm{pH}$-dependent concentrations (from equilibrium-based testing) and eluate concentrations from monolith diffusion tests. The concentrations in the tank test correspond generally well with the appropriate $\mathrm{pH}$ conditions in the $\mathrm{pH}$ dependence test, implying that solubility controls the release from monolithic waste. Solubility control indicates that the dilute solution boundary condition for estimating diffusion-controlled release from a semi-infinite material 
into an infinite bath is not satisfied (i.e., the conditions for estimating a valid observed diffusivity have not been met). The $\mathrm{pH}$-concentration box shown in Figure 6a is the same as that discussed earlier for granular material. For this case of lead release from a cementitious material, the $\mathrm{pH}$ change with time and, hence, solubility concentration is more important than transport by diffusion. Neutralization of the matrix associated with aging would be expected to decrease the release rate of lead in accordance with the $\mathrm{pH}$ dependence data. The conclusion can be reached that release in the long term will not exceed a limiting value (e.g., the horizontal line shown in Figure 6c), if that limit is not exceeded in the short term.

\subsubsection{Modeling \& Simulation}

A geochemical speciation/transport modeling framework forms an integrated approach that allows linking together various aspects of materials. Proper thermodynamic stability data and other solubility controlling parameters (Fe-oxide, Al-oxide, dissolved organic carbon and particulate organic matter) are used for modeling of the complex systems indicated above. The modeling code used to illustrate this simulation approach, the Objects Representing CHEmical Speciation and TRAnsport model or ORCHESTRA (Meeussen 2003), is one of several geochemical speciation and reactive transport simulation codes that can be applied. Several other geochemical speciation and reactive transport simulation codes are discussed in later in this chapter.

Using a geochemical speciation and reactive transport approach involves the following steps:

- Characterization of the Material: Measurement of leaching properties using equilibrium-based and kinetics-based leaching tests following the flowchart shown in Figure 3. Note that for monolithic materials, the first fractions of a percolation test on size reduced material provide a suitable estimate for the porewater composition of the monolithic material. In addition, direct observation of solid phases (i.e., by x-ray diffraction) should be conducted when available in order to define solid phase chemical speciation.

\section{- Chemical Speciation Fingerprint of the}

Material: Prediction of the $\mathrm{pH}$-dependent release from size-reduced sample based on a selected mineral set, sorption onto $\mathrm{Fe}$ - and $\mathrm{Al}$-oxides, interaction with dissolved and particulate organic matter and incorporation in solid solutions, thus establishing a "chemical speciation fingerprint" (CSF).

- Simulation/Verification of Percolation Release: The CSF is used in combination with a percolation transport scenario using a dual porosity model to describe the outcome of laboratory percolation tests. Comparison of predicted release to laboratory data is used to verify CSF mineral selection.

\section{- Simulation/Verification of Mass Transport}

Release: The CSF is used in combination with transport in a dissolution-diffusion scenario to simulate release from a monolithic material, taking into account refresh or leachant renewal cycles, continuous renewal, and estimated product tortuosity (measured for porosity and pore structure). Comparison of predicted release and laboratory data verify that all transport phenomena and chemical interactions are accounted for in the simulation scenario.

- Scenario- or Site-specific Simulation: When a satisfactory prediction is obtained for the CSF over time- or LS-dependent release, the material can be assumed to be well characterized over a wide range of $\mathrm{pH}$ and time or $\mathrm{L} / \mathrm{S}$ conditions relevant for long term behavior. The chemical speciation fingerprint of the material in conjunction with obtained mass transfer parameters can then be used as the basis for reactive transport modeling to predict release under well-defined field scenarios with external influencing factors (e.g., carbonation, redox change, degree and variation in water contact, and varying degrees of preferential flow). 


\subsection{Chemical Reaction Transport Modeling for Monolithic Wastes}

The release from monolithic waste materials is governed by chemical reactions and by transport processes inside the material. As has been observed in recent years (Tiruta-Barna, Barna \& Moszkowicz 2001; van der Sloot et al. 2007b), release from monolithic products is not only controlled by diffusion from the interior of the product, but to a large extent also governed by solubility limitations. Major efforts have been made in recent years to find means to establish under what circumstances solubility control governs and when diffusion is the main release controlling mechanism (Piantone et al. 2006; van der Sloot et al. 2007b; van Zomeren et al. 2007).

Under landfill conditions, most trace constituents are found to be solubility-controlled, while soluble salts are dominated by diffusion-controlled release (Aarnink, Bleijerveld \& van der Sloot 2007; van der Sloot et al. 2007b). The tank leaching test can be used to determine the apparent tortuosity of the material in its original physical state. This information is important input for chemical reaction transport models that allow transport by diffusion to be taken into account. Diffusion is driven by a concentration gradient with limited external solution rather than by an assumption of an infinite bath. The leachant renewal cycles as applied in the DMLT (CEN PrEN-15863 2009) have been modeled for some major, minor and trace elements. In modeling, the first step is to ensure that the proper tortuosity is used by matching release of soluble salts like $\mathrm{Na}, \mathrm{K}$ and $\mathrm{Cl}$ with observed release in a laboratory experiment. The CSF is applied and the initial $\mathrm{pH}$ is adjusted to obtain a proper $\mathrm{pH}$ and electrical conductivity model description. It is important to obtain a good match for the major elements, since these to a large extent control the release behavior of trace constituents. Also, use of sufficiently small spatial cells is important in order to allow a good description of the $\mathrm{pH}$ gradient

\subsection{Modeling Leaching Processes}

Leaching rates of substances from monolithic porous material can conceptually be assumed to be governed by different processes. The release can be expressed in a leaching rate $[\mathrm{mg} / \mathrm{kg}$ of material/day], cumulative release $\left[\mathrm{mg} / \mathrm{m}^{2}\right]$ at a given time, or concentration $[\mathrm{mg} / \mathrm{L}]$ in time and space. Radionuclide release often is expressed as fractional release per unit time; however, fractional release assumes that the total concentration of the radionuclide is available for release which is not realistic in most cases. Many publications address release modeling from cement-based materials (Aarnink, Bleijerveld \& van der Sloot 2007; Černý \& Rovnaníková 2002; Garrabrants \& Kosson 2005; Garrabrants, Sanchez \& Kosson 2003; Jones \& Serne 1995; Marchand \& Samson 2009 in press; Samson, Marchand \& Beaudoin 2000; Nguyen et al. 2008; Tiruta-Barna, Barna \& Moszkowicz 2001; van der Sloot et al. 2007b; Garrabrants, Kosson \& DeLapp 2007; Sanchez et al. 2003), with governing equations ranging from empirical (e.g., simple, 1-dimensional diffusion) to almost fully mechanistic (e.g., transport by diffusion coupled with full chemistry). Common assumptions and simplifications are used to describe constituent release mechanisms and release rates.

\subsubsection{Solubility-controlled Release}

Under this assumption, the dissolved concentration of a substance is in equilibrium with a solid phase which buffers the dissolved concentration to a constant value as long as a solid phase exists. This assumption implies that leaching rates are independent of external conditions and remain constant over time until the solid component is depleted. Leaching rates would not be affected by surface area (i.e., larger surface area would not increase leached concentrations).

However, cumulative leaching rates in a leaching test would be affected by the amount of water in contact with the sample. 


\subsubsection{Diffusion-controlled Release}

Under this assumption, leaching rates are controlled by individual component diffusion rates and concentration profiles in the solid matrix. For 1-dimensional (1-D) systems the leaching rates as a function of time can be described with closed form, mathematical analytical solution. In that case there would be a linear relationship with a slope of $1 / 2$ between cumulative leached concentrations and log time, implying that leaching rates decrease logarithmically over time. Fitting of linear partitioning ( $K_{d}$ approach) and/ or tortuosity can be used to calibrate the model. This model can only describe mono-component, linearly adsorbing species in a 1-D infinite media system.

\subsubsection{Multi-component Diffusion-controlled Release}

Under this assumption, diffusion rates of substances are determined by local concentrations in pore solutions and resulting local concentration gradients. In turn, these local concentrations are assumed to be governed by multi-component interaction processes between solutes and solid phase via precipitation and adsorption reactions. The multi-component nature of these interactions implies that the behavior of a substance is dependent on the behavior of other substances and, therefore, cannot be isolated from the rest of the system. For example, the $\mathrm{pH}$ dependent dissolution of calcium, aluminum, iron, lead and zinc in concrete are all interdependent. Porewater concentrations of the species are dependent on localized $\mathrm{pH}$ and can increase or decrease as a function of $\mathrm{pH}$ changes according to the LSP curves. Generally, cationic species become more soluble at low $\mathrm{pH}$, but the solubility of amphoteric species (e.g., lead and aluminum) also increases at the very alkaline conditions that exist in cementitious materials. For such constituents, long-term leaching rates may actually become higher over time.
Depending on chemical conditions, leaching rates even can become negative (i.e., the material takes up constituents from the surrounding environment). This behavior can be observed under tank test conditions for substances such as magnesium, which after a refresh of solution initially leaches from the solid material, but re-precipitates if $\mathrm{pH}$ increases during the test. It shows that leaching behavior is not an intrinsic material property that can be measured in a simple test, but is determined by understanding the interaction processes between the material and the contacting environment.

In light of the complexity described above, release behavior often cannot be expressed by simple solubility, linear partitioning $\left(K_{d}\right)$, or purely diffusion-controlled processes and a more mechanistic approach is required to achieve more accurate release estimates. In order to use results of short term leaching tests for estimation of long term leaching rates under field conditions, mechanistic models are necessary that predict changes over time in effective diffusion rates. However, even though mechanistic models can take into account the effect of changing chemical conditions on effective leaching/diffusion rates, these models only provide a "best estimate" based on the current level of understanding of the processes involved. Validating the predictive capabilities of these models over longer time scales is very difficult.

\subsubsection{Dual Porosity Regimes}

In a number of cases, zones with different flow rates, connected with concentration gradient driven mass exchange (diffusion analog), are important to properly describe release. This conceptual model is for systems that consist of a combination of distinct zones where convective transport dominates, and zones where diffusive transport dominates. Examples are cracked concrete, heterogeneous soils, and systems exposed to natural infiltration and, thus, subject to preferential flow 
paths. For concrete materials, this situation occurs between the cement paste and the aggregates. If the aggregates are relatively porous, the total mass transport simulation may require separate descriptions of the transport through the paste and mass release from relatively porous aggregates (Sanchez et al. 2003). In the case of essentially non-porous aggregates, only the space occupied by aggregate affects the tortuosity of the material; however, transport through the interfacial transition zone in the cement paste around aggregates can play an important role.

\subsubsection{Orthogonal Diffusion with Convection}

This conceptual model can be considered as an extension of the dual porosity model, in which the stagnant zone is subdivided in a series of cells so as to calculate diffusion and concentration gradients within the stagnant zone. Mass exchange is in that case controlled by the concentration gradient over diffusion convection boundary (Schaefer et al. 1995).

\subsubsection{Unsaturated Flow (Richards equation) Coupling}

For transport of solutes in unsaturated systems (pores partially filled with water), it is necessary to calculate the unsaturated water flow, and to use this information in combination with dissolved ion concentrations for calculating the resulting mass transport by convection. Unsaturated conditions also greatly affect diffusion rates, as ions need to travel longer distances and the cross-section for diffusion processes is reduced. This is reflected in the increase in tortuosity with decreasing saturation.

\subsubsection{Release from Structures Intermittently Wetted by Rain or Spray Water}

Utilization of concrete in surface structures (all forms of building on land) is characterized by intermittent wetting and drying. Drying of the porous network greatly facilitates formation of calcite as uptake of $\mathrm{CO}_{2}$ from the air, via gas diffusion, is five orders of magnitude faster than through liquid phase diffusion under saturated conditions. In carbonation cases, the release can be estimated based on the progression of the neutralization front. Modern concretes have a rather low connected porosity, which delays ingress of substances as well as release of substances. In Roman cements, which at the time of placement were considerably more porous, full carbonation is observed after 2,000 years (van der Sloot et al. 2008b). This process may even have been enhanced by the higher porosity and the uptake of moisture in the structure, which would thus effectively act as a $\mathrm{CO}_{2}$ pump.

\subsubsection{Multi-phase Equilibrium vs. Kinetic Controls}

In considering transport processes over long time scales, interactions amongst elements potentially are important. For reactive elements and substances, single substance calculations that do not account for multi-species interactions (e.g., as a function of $\mathrm{pH}$ and porewater composition) often will not provide good estimation of actual system behavior. Thus, multi-element modeling that can account for the competitive effects and multiple factors affecting solid-liquid partitioning over different chemical forms is recommended. While local thermodynamic equilibrium is an appropriate assumption for most reactions over long time scales, some chemical reactions proceed at very slow rates, especially some precipitation/ dissolution reactions. For these cases, the progress of reactions is kinetically controlled, and should be taken into account accordingly in modeling the system. In laboratory studies, such kinetic effects have been identified for $\mathrm{Ca}, \mathrm{Mg}, \mathrm{Al}, \mathrm{SO}_{4}, \mathrm{Mo}, \mathrm{Pb}, \mathrm{Ni}, \mathrm{Cd}$, $\mathrm{Cu}$ and $\mathrm{Zn}$ in MSWI bottom ash leaching (Dijkstra, van der Sloot \& Comans 2002). 


\subsubsection{Mechanistic Chemical Retention vs. Linear Sorption}

Prediction of leaching rates of elements from porous solid samples is often done with an empirical, linear sorption model ( $K_{d}$ approach). In this model, it is assumed that the mobility of the element of interest in the porous matrix is a constant fraction of the mobility of this element in free water:

$$
K_{d}=\frac{s_{i}}{c_{i}}
$$

where: $K_{d}$ is the linear partitioning coefficient of species $i[\mathrm{~L} / \mathrm{kg}], S_{i}$ is the concentration of species $i$ bound to the solid phase $[\mathrm{mg} / \mathrm{kg}]$, and $c_{i}$ is the concentration of species $i$ in the liquid phase $[\mathrm{mg} / \mathrm{L}]$. In several transport models, the partition coefficient, $K_{d}$, is used as a mass ratio between adsorbed and free masses $\left[\mathrm{mg}_{\text {solid }} /\right.$ $\mathrm{mg}_{\text {liquid }}$; however, the mass ratio form is both sensitive to variations in LS ratio as well as changes in chemical conditions (e.g., $\mathrm{pH}$, redox, etc).

Often, this fraction applied as a constant over time and being independent of changing chemical conditions or interactions with other substances. Under the $K_{d}$ approach, it is possible to measure the leach rate in a short term experiment, and the resulting calculated $K_{d}$ is then used to predict leaching rates over long times. When large changes in chemical conditions are anticipated, the $K_{d}$ value for a particular species may be varied in response to chemical conditions when supporting data is available. Under the assumption that linear sorption describes all chemical reactions $R\left\langle C_{i}\right\rangle$, the 1-D diffusion-reaction equation becomes:

$$
\frac{\partial C_{i}}{\partial t}=\frac{\phi_{d} D_{e f f}}{\left[1+\frac{\rho_{b} \cdot K_{d}}{\phi}\right]} \frac{\partial^{2} C_{i}}{\partial x^{2}}=\frac{\phi_{d} D_{e f f}}{R_{d}} \frac{\partial^{2} C_{i}}{\partial x^{2}}
$$

where: $\phi_{d}$ is the "diffusion through" porosity $\left[\mathrm{m}^{3}{ }_{\text {pore }} / \mathrm{m}^{3}\right]$, $\phi$. is the total porosity of the porous material $\left[\mathrm{m}^{3}\right.$ pore $\left./ \mathrm{m}^{3}\right]$, $\rho_{b}$ is the bulk solid phase density $\left[\mathrm{kg}_{\text {solid }} / \mathrm{m}^{3}\right.$ solid $]$ and $R_{d}$ is the chemical retention term [-].
The $K_{d}$ approach is easy to implement and adequately approximates liquid-solid partitioning dilute species in groundwater. Many USDOE performance assessments, as well as PAs by USNRC licensees, represent very complex systems incorporating data and conceptual model uncertainties such that errors in release models may represent a small fraction of the uncertainty of the total assessment. If the chemical conditions of the disposal unit can be expected to remain constant over some long period, and if the $K_{d}$ values were determined under similar and representative conditions, then this approach may be appropriate within the uncertainty of the leaching assessment. This is particularly so when the $K_{d}$ value is high and releases are a small fraction of the inventory.

However, the simple partitioning approaches (e.g., linear, Langmuir and Freundlich isotherms) are well known to by insufficient for describing complex geochemical reaction that control partitioning in subsurface environments (Zhu 2003). For these systems, a more sophisticated model can improve the accuracy of predictions for understanding the evolution of chemical conditions within a system where (1) the behavior of primary matrix constituents is controlled by dissolution-precipitation phenomena, (2) mobility of trace constituents is known to change under the chemical conditions that are likely to evolve over time. In cementitious materials, major parameters that can lead to enhanced mobility of radionuclides include decreases in $\mathrm{pH}$, oxidation of initially reduced wasteforms, and complexation with components of water entering the system (e.g., $\mathrm{CO}_{2}$ ). Since the "effective $K_{d}$ " depends strongly on local chemical conditions which can vary over time and location, leaching estimates based on initial release rates can lead to inaccurate predictions of long term leaching behavior.

As an illustration of the differences between $K_{d}$ and mechanistic approaches, the simulation of leaching test data for sodium representing a non-reactive constituent and calcium as a reactive constituent are shown in Figure 7, 8, and 9, respectively (Meeussen, 


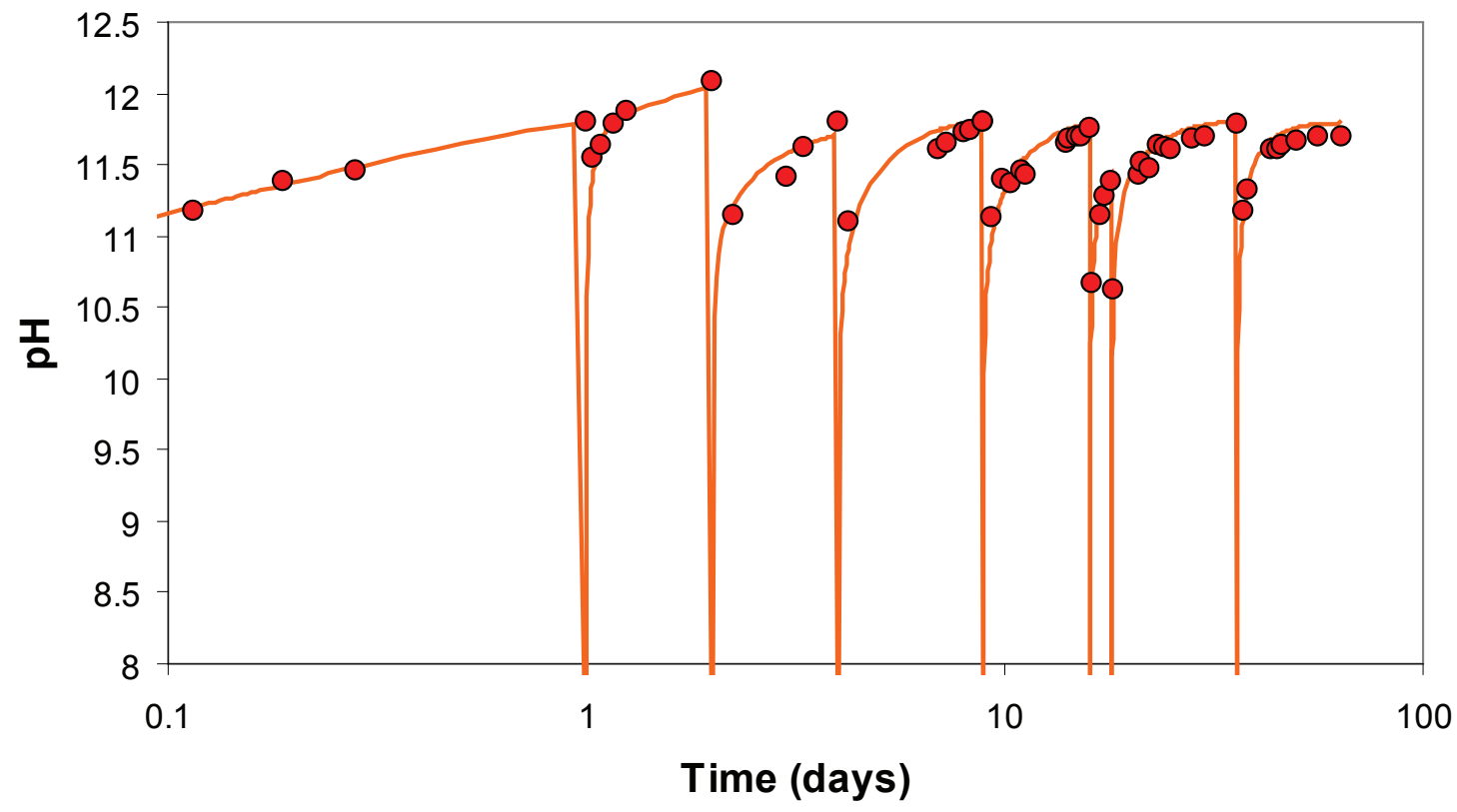

Figure 7. pH Development in A Tank Leach Test with Leachant Renewal

(Red Data Points) for a Cement-stabilized Waste in Comparison with Results from Mechanistic Modeling Taking A Mineral Assemblage into Account.

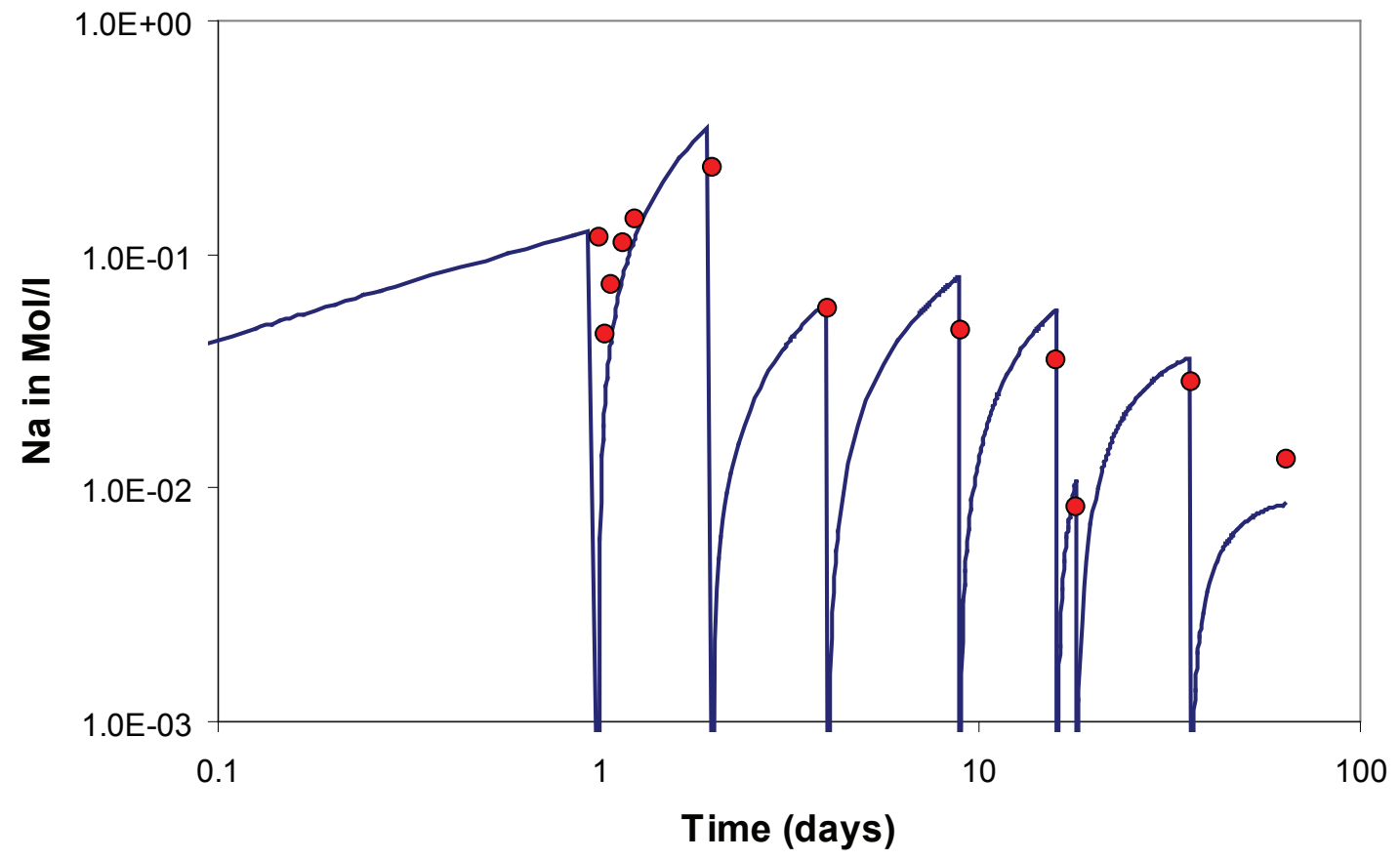

Figure 8. Na Development in A Tank Leach Test with Leachant Renewal

Red Points Represent Lab Data, Predicted Concentration Using Linear Sorption $\left(\mathrm{K}_{d}\right)$ and Predicted Concentration Using Multiphase Thermodynamic Approach) Overlap. 


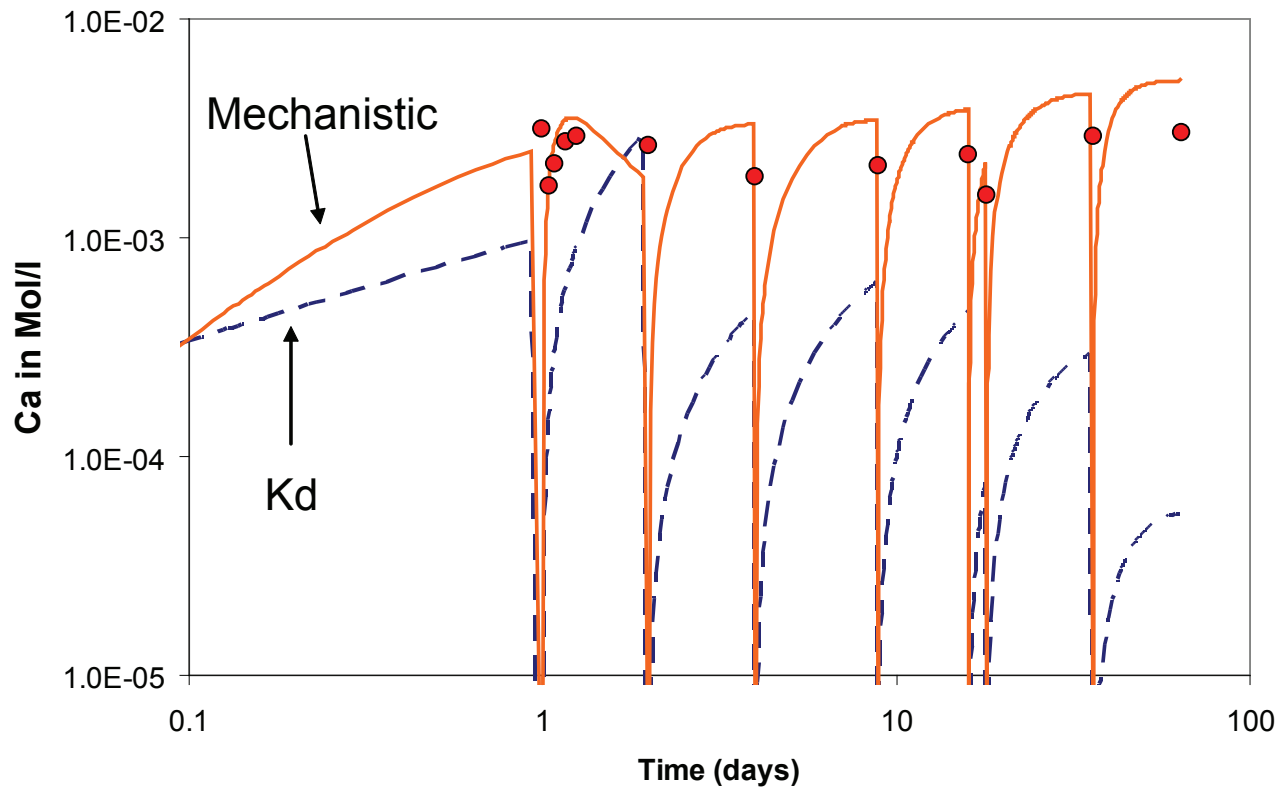

Figure 9. Simulation of Calcium Leaching Data from A Tank Leach Test of Cement-stabilized Waste Red Points Represent Lab Data, Blue Line Indicates Predicted Concentration Using Linear Sorption $\left(\mathrm{K}_{\mathrm{d}}\right)$ and Orange Line Indicates Predicted Concentration Using Multiphase Thermodynamic Approach).

2009). The $K_{d}$ values used were estimated from initial leaching rates during the first two days of leaching. For non-reactive substances such as $\mathrm{Na}$ or $\mathrm{Cl}$, the $K_{d}$ model is sufficient and the diffusion model adequately simulates leaching data. However, applying the $K_{d}$ approach to substances that have a pH-dependent solubility (e.g., $\mathrm{Ca}, \mathrm{Mg}, \mathrm{Al}$ ) can lead to significant over- or under-prediction of long term leaching rates.

\subsection{Transport and Thermodynamic Codes}

Several well-known computer codes exist that can calculate chemical speciation and reactive transport ${ }^{3}$. The capabilities of these models in terms of chemical and physical processes are compared in Table 2 .

\subsubsection{PHREEQC}

PHREEQC (http://www.brr.cr.usgs.gov/projects/ GWC_coupled/phreeqc) is probably the most widelyused, general-purpose chemical speciation software (Parkhurst \& Appelo 1999) to the point that it has become the de-facto standard for chemical speciation calculations in aqueous or soil systems. In addition to standard aqueous complexation, ion activity, and precipitation models, PHREEQC contains a number of surface complexation models. The greatest drawbacks of this model are (1) a dated approach to ionic interaction with organic matter and (2) limited transport capabilities which cannot be extended.

\subsubsection{MINTEQA2}

MINTEQA2 (http://www.epa.gov/ceampubl/mmedia/ minteq/index.html) is an older generation speciation

\footnotetext{
${ }^{3}$ STADIUM (http://www.sem.qc.ca/en/slm/softwares.html) is another chemo-physical transport code primarily focused on durability assessments in structural cement-based materials. Therefore, description and application of this code is discussed in another chapter.
} 
program that comes with an extended database of chemical equilibrium constants. Although it can handle precipitation reactions, MINTEQA2 includes only limited surface complexation models and does not contain a transport module. In addition, all MINTEQA2 (sub)models are available within PHREEQC, which offers more functionality.

\subsubsection{Geochemists Workbench}

The focus of Geochemist Workbench (http://www. rockware.com) is inorganic systems. The model contains extended graphical options (e.g., predominance diagrams), but only limited surface complexation options. Neither organic matter adsorption models

Table 2. Comparison of Chemical and Physical Processes of Several Thermodynamic Programs

\begin{tabular}{|c|c|c|c|c|c|c|c|c|c|}
\hline & 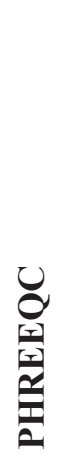 & 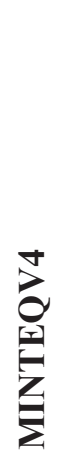 & 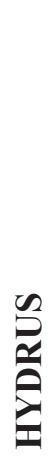 & 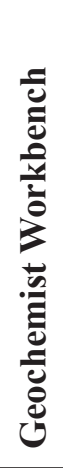 & 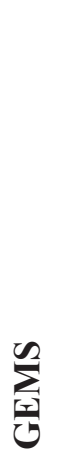 & $\begin{array}{l}0 \\
0 \\
0 \\
0 \\
0 \\
0 \\
0 \\
0 \\
0 \\
0 \\
0\end{array}$ & 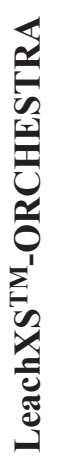 & 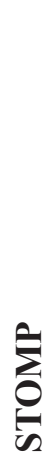 & 発 \\
\hline Aqueous Complexation & $r$ & $\checkmark$ & & $v$ & $\checkmark$ & $v$ & $\checkmark$ & & \\
\hline Ion Activity Correction & $\checkmark$ & $\checkmark$ & & $\checkmark$ & $\checkmark$ & $\checkmark$ & $\checkmark$ & $\checkmark$ & \\
\hline Precipitation & $\checkmark$ & $\checkmark$ & & $\checkmark$ & $\checkmark$ & $\checkmark$ & $\checkmark$ & $\checkmark$ & $\checkmark$ \\
\hline Solid Solutions & $\checkmark$ & & & & $\checkmark$ & & $\checkmark$ & & \\
\hline Ion Exchange & $\checkmark$ & $\checkmark$ & $\checkmark$ & $\checkmark$ & & $\checkmark$ & $\checkmark$ & & \\
\hline Surface Complexation (Fe/Al oxides) & $\checkmark$ & $\checkmark$ & $\checkmark$ & $\checkmark$ & & $\checkmark$ & $\checkmark$ & & \\
\hline Organic Matter Complexation & & & & & & & $\checkmark$ & & \\
\hline Colloids & & & & & & & $\checkmark$ & & \\
\hline Diffusion & $\checkmark$ & & $\checkmark$ & & & $\checkmark$ & $\checkmark$ & $\checkmark$ & $\checkmark$ \\
\hline Electro-neutral Diffusion & $\checkmark$ & & & & & & $\checkmark$ & $\checkmark$ & $\checkmark$ \\
\hline Ion-specific Diffusion & $\checkmark$ & & & & & & $\checkmark$ & $\checkmark$ & \\
\hline Gas Diffusion & $\checkmark$ & & & & & & $\checkmark$ & $\checkmark$ & $\checkmark$ \\
\hline Convection & $\checkmark$ & & $\checkmark$ & & & $\checkmark$ & $\checkmark$ & $\checkmark$ & $\checkmark$ \\
\hline Colloid Transport & & & & & & $\checkmark$ & $\checkmark$ & & \\
\hline Unsaturated Water Flow & & & $\checkmark$ & & & & $\checkmark$ & $\checkmark$ & $\checkmark$ \\
\hline Porosity/Permeability Feedback & & & & & & & & $\checkmark$ & \\
\hline Cracked Material Feedback & & & & & & & & & \\
\hline
\end{tabular}


nor unsaturated transport modeling capabilities are embedded into Geochemist Workbench.

\subsubsection{HYDRUS}

HYDRUS (http://www.pc-progress.com) is primarily a model for describing water flow in the vadose soil zone and it describes unsaturated water flow in combination with transport of a small number of predefined ions. The model does not contain full speciation, or multi-component interactions with solid soil phase. Therefore, this model is of limited use for describing the mass transport of ions in highly reactive porous media such as cementitious barriers. Hybrid models combining HYDRUS and PHREEQC chemical speciation are in use in Europe (Jacques et al. 2003).

\subsubsection{GEMS}

The GEMS (http://gems.web.psi.ch) chemical speciation code was developed by Dimetri Kulik at the Paul Scherrer Institute (PSI) in Switzerland. The model uses Gibbs free energy minimization as the numerical approach rather than the standard way of solving the set of non-linear equations formatted by the massaction, mass balance relationships. Thermodynamic data is supplied by the PSI thermodynamic database and de Cement 2007 database of Lothenbach et al. (Lothenbach et al. 2008; Lothenbach \& Wieland 2006; Lothenbach \& Winnefeld 2006; Matschei, Lothenbach \& Glasser 2007). The GEMS code addresses temperature/pressure dependency and high ionic strength effects on multi-component, non-ideal solid solutions. However, the model does not contain adsorption models for organic matter.

\subsubsection{HYTEC-CHESS}

CHESS is a geochemical speciation module developed by Jacques van der Lee at the Ecole des Mines in Paris (www.cig.ensmp.fr/chess). The CHESS geochemical module can calculate chemical speciation taking into account standard chemical reaction types (e.g., aqueous complexation, precipitation, ion exchange, surface complexation according to the GTLM), but does not contain adsorption models for organic matter.

HYTEC is a transport algorithm that combines the CHESS geochemical module with a model for convection/diffusion. There is only limited feedback possible between chemical and physical processes (i.e., changes in speciation, such as leaching of calcium mineral or precipitation, which would be expected to change the porosity and, hence, physical transport, are not linked).

\subsubsection{LeachXSTM-ORCHESTRA}

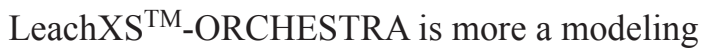
framework than a specific model itself. LeachXS ${ }^{\mathrm{TM}}$ has several databases, among which a database with leaching data in unified format to facilitate comparison of test results from various sources (van der Sloot et al. 2008a). ORCHESTRA is used as a calculation engine with a number of predefined model systems, within the expert system LeachXS ${ }^{\mathrm{TM}}$. The combination is a uniquely open system, where chemical and physical model components can be extended by users. Extended model databases include parameters for surface complexation and solid solution models and all chemical models can be used in combination with mass transport to calculate diffusion and convection in systems of arbitrary lay out (e.g., 1-D diffusion, dual porosity, diffusion-convection, radial diffusion, and multi-flow domains like cracked matrices). The program can take into account system phases with different diffusion-convection properties (dissolved, solid, gas, colloidal phase). The LeachXS ${ }^{\mathrm{TM}}$ shell creates the necessary input information from stored experimental data, and conveniently presents the calculated output in graphical form which greatly facilitates the use of advanced geochemical and transport models by non-specialists. 


\subsubsection{STOMP}

The Subsurface Transport Over MultiPhases (STOMP) code developed by the Pacific Northwest National Laboratory (PNNL) calculates the timedependent thermal and hydrogeologic flow and contaminant transport, including volatile and nonvolatile organic compounds, in variably saturated subsurface aqueous and vapor phase environments (White \& Oostrom 1996; White, Oostrom \& Lenhard 1995). The code can be run in one, two, or three dimensional modes and has been used by the Hanford Groundwater Remediation Project and by the team preparing the Hanford Tank Closure and Waste Management Environmental Impact Statement.

\subsubsection{PORFLOW}

PORFLOW is developed and marketed by Analytic \& Computational Research, Inc. (ACRi) to solve problems involving transient and steady-state fluid flow, heat and mass transport processes in multiphase, variably saturated, porous or fractured media with dynamic phase change. The porous/fractured media may be anisotropic and heterogeneous, arbitrary sources may be present and, chemical reactions or radioactive decay may occur. PORFLOW accommodates alternate fluid and media property relations and complex and arbitrary boundary conditions. The geometry may be 2-D or 3-D and the mesh may be structured or unstructured, giving flexibility to the user. PORFLOW has been widely used at the Savannah River Site (SRS) and in the USDOE complex to address major issues related to the groundwater and nuclear waste management.

\subsection{BEHAVIOR OF TYPICAL CEMENTITIOUS MATRIXES}

The CBP reference cases include a range of concretes, grouts, and stabilized wastes with binders based on tertiary and quaternary blends of portland cement, blast furnace slag, coal fly ash, and silica fume (Langton 2009). The release from cement mortars, concrete, and cement-stabilized waste with different waste loading have some common aspects due to the common factor of cement. Comparisons will be made in the following to illustrate relationships and discrepancies between the different cement-based materials.

\subsection{Cement Mortars and Concretes}

The leaching behavior of a wide range of some 60 cement mortars and concretes from worldwide origin have been tested using the combination of $\mathrm{pH}$-dependence leaching test (TS14429) and tank leaching test (NEN 7345) similar to the integrated leaching assessment approach. The leaching test results, shown in its entirety in Appendix A and for a selected range of major and minor elements in Figure 10 and Figure 11 show systematic leaching behavior for a wide range of constituents as a function of $\mathrm{pH}$ and leaching time. In the $\mathrm{pH}$ dependence leaching test, concentrations are dictated by the chemical speciation in the cement matrix where as systematic release from monolithic materials is largely controlled by the tortuosity of the matrix and by the release levels governed by $\mathrm{pH}$. The bandwidth of leaching of major elements for all mortars irrespective of its type or origin falls within relatively narrow ranges (van der Sloot et al. 2008b). This implies that the same mineral phases are controlling release. One important to note is that the matrix mineralogy as obtained from X-Ray Diffraction (XRD) and other techniques does not necessarily reflect the phases controlling release.

In fact, the exposure of products to the atmosphere results in significant changes in surface mineralogy as $\mathrm{pH}$ and redox conditions change in a thin surface layer. If the $\mathrm{pH}$ in the surface of a cement mortar changes from $\mathrm{pH}>12$ to a $\mathrm{pH}$ around 10 or even lower, then several elements show a significantly altered leachability (e.g., $\mathrm{SO}_{4}, \mathrm{~V}, \mathrm{Cr}, \mathrm{Ca}$ ) over sometimes orders of magnitude. This is reflected in the release 

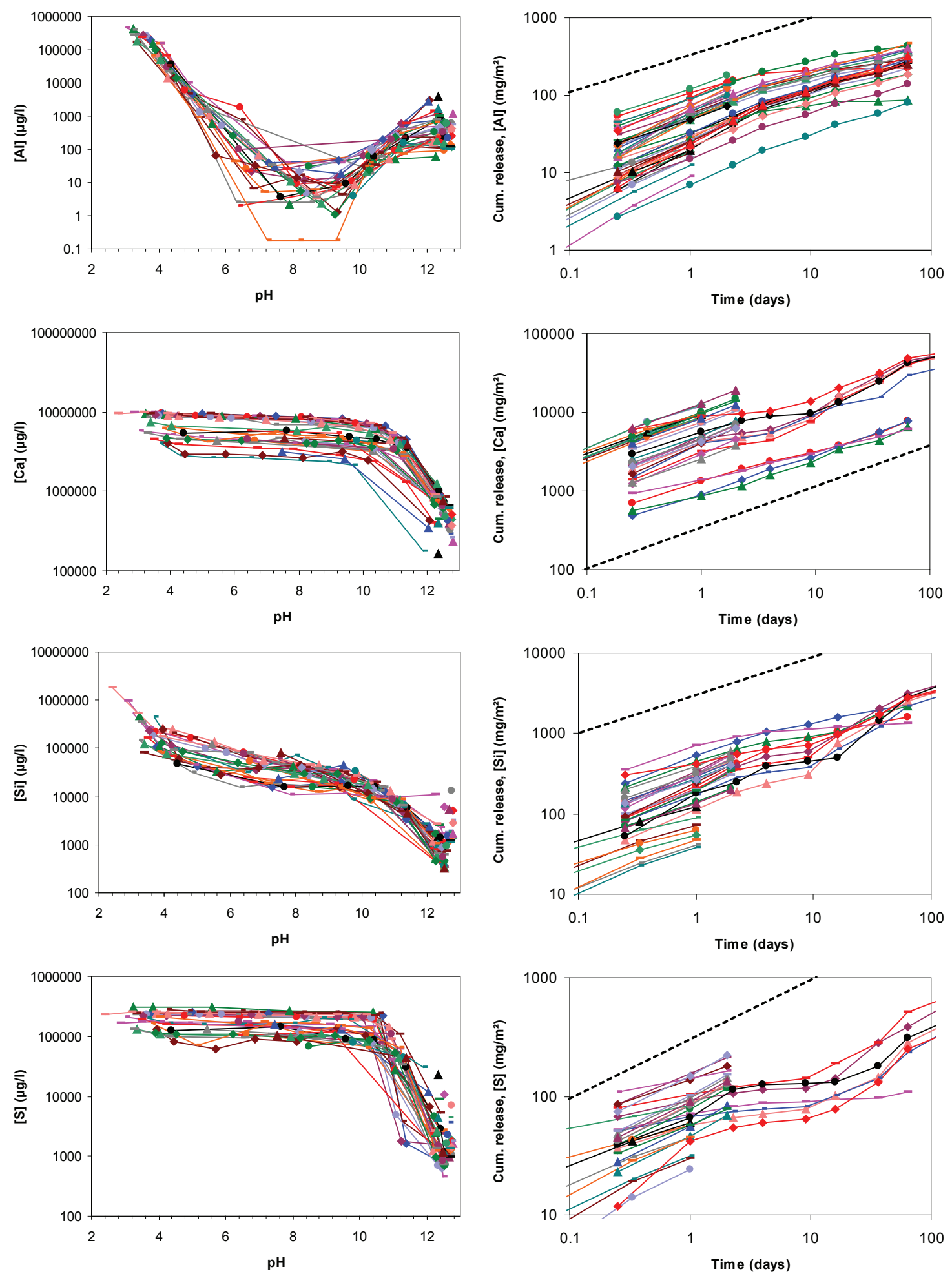

Figure 10. pH Dependence and Tank Leaching Test Behavior of $\mathrm{Al}, \mathrm{Ca}, \mathrm{Si}$ and $\mathrm{SO}_{4}$ (Shown as Total S) from Cement Mortars of Worldwide Origin 
Review of Mechanistic Understanding and Modeling and Uncertainty Analysis Methods for Predicting Cementitious Barrier Performance
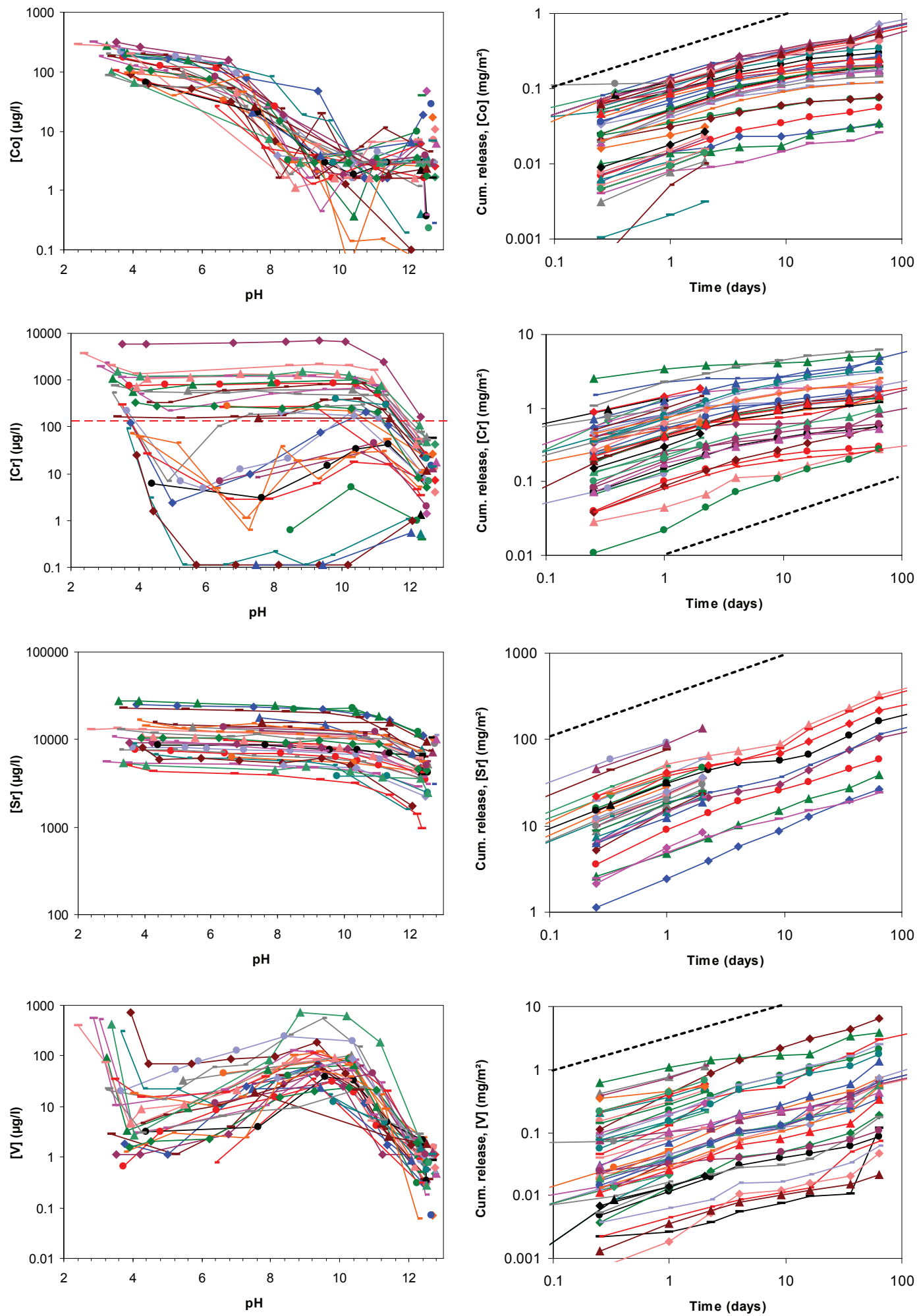

Figure 11. pH Dependence and Tank Leaching Test Behavior of $\mathrm{Co}, \mathrm{Cr}$, Sr and V from Cement Mortars of Worldwide Origin 
from a monolith leach test. The larger bandwidth in the monolith leach test is associated with the elements that show the largest sensitivity to $\mathrm{pH}$ change in the domain $\mathrm{pH}$ 12-9.

A consequence of the release behavior of oxyanions as a function of $\mathrm{pH}$ is that upon carbonation oxyanions are readily released. As a simplified assumption, one can model the progression of the carbonation front and use the neutralized layer to quantify the oxyanion release by assuming complete release of the mobile fraction of the oxyanion from this layer (van der Sloot et al. 2008b).

\subsubsection{Roman Cement Analog}

In Figure 12, a comparison of major, minor and trace elements is given for Portland cement (CEM I), blended cements (different blends of Portland cement with blast furnace slag cement and fly ash), Roman cement (2000 years old from an aqueduct in Germany) and cement-stabilized hazardous waste (MSWI fly ash). The leaching behavior as a function of $\mathrm{pH}$ in the cement-based materials is mostly very similar, which indicates that the same mineral and sorptive phases control release. The structure of the Roman cement is fully carbonated throughout which has consequences for the leaching behavior of $\mathrm{Ca}, \mathrm{Ba}, \mathrm{Mg}$ and $\mathrm{Sr}$ as these species are directly or indirectly affected by carbonation. The leaching of sulfate, $\mathrm{Se}$ and $\mathrm{Cr}$ is lower than in the other cement mortars, but since the original composition of the Roman cement is not known, it is hard to link the decreased release to leaching and a more likely explanation would seem that these trace constituents are incorporated in less soluble phases. The oxyanion leaching from Roman cement at high $\mathrm{pH}$ (e.g., Cr and V) does not show the decrease that is characteristic of substitution into ettringite, indicating the absence of ettringite in the fully carbonated matrix. In the cement-stabilized waste, the leaching behavior of metals show an increase towards low $\mathrm{pH}$ that is related to the higher contamination level in the waste as compared to the commercial cements. Salts $(\mathrm{Na}, \mathrm{K})$ and some anions (Mo, B, Sb) are also increased relative to the commercial cements. The distinction between the blended cements containing blast furnace slag and regular Portland cements is the reducing nature of these blends, which is reflected in the leaching behavior of Fe (leachability edge shifted to higher $\mathrm{pH}$ ), and $\mathrm{Cr}$ (low leachability due to conversion of $\mathrm{Cr}$ VI to $\mathrm{Cr}$ III).

In Appendix B, results of chemical speciation modeling of cement mortars is given. Information on major elements, minor element and a range of trace elements is available. Information of this type is currently lacking for radionuclides. From the stable element chemistry, insight in the chemical behavior of specific radionuclides can be inferred (e.g., $\mathrm{Pb}, \mathrm{Mo}$, $\mathrm{Sr}, \mathrm{Cs}, \mathrm{Rb})$.

\subsection{Cement-Stabilized Wastes}

In Appendix $\mathrm{C}$ results of different types of cementstabilized waste are compared. This relates to cement-stabilized MSWI fly ash (a material with a high concentration level of trace elements and a high salt load) and stabilization recipes as simulant for grouts to be used in conjunction with waste liquids. It follows that for some elements the release behavior is rather similar between the different mixes. For some constituents, however, the release behavior is significantly different.

In spite of such differences, elements with comparable release behavior can be identified, e.g., metals behave a certain way with low leachability at mild alkaline conditions. On the other hand oxyanions may consistently show a maximum release at $\mathrm{pH}$ between 8 and 11. Depending on the sulfate loading, oxyanion substitution in ettringite type phases may be limited by competition between the trace constituents and the abundantly present sulfate. 


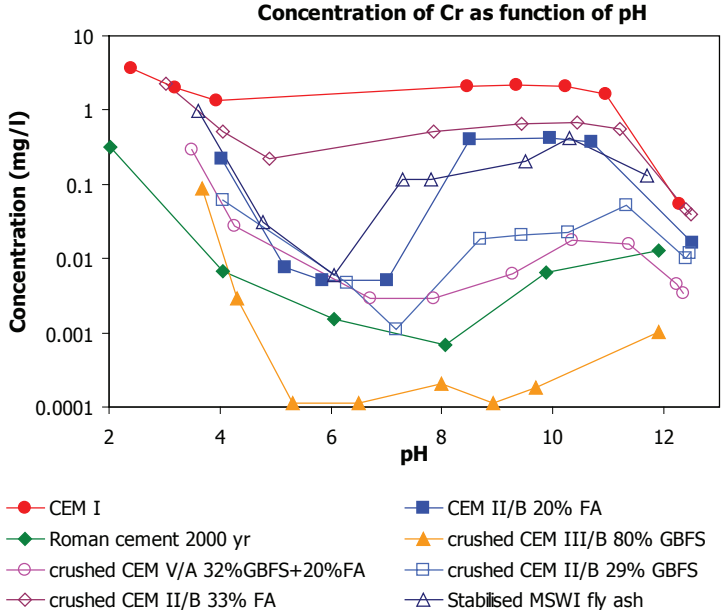

Concentration of $\mathrm{Sr}$ as function of $\mathrm{pH}$

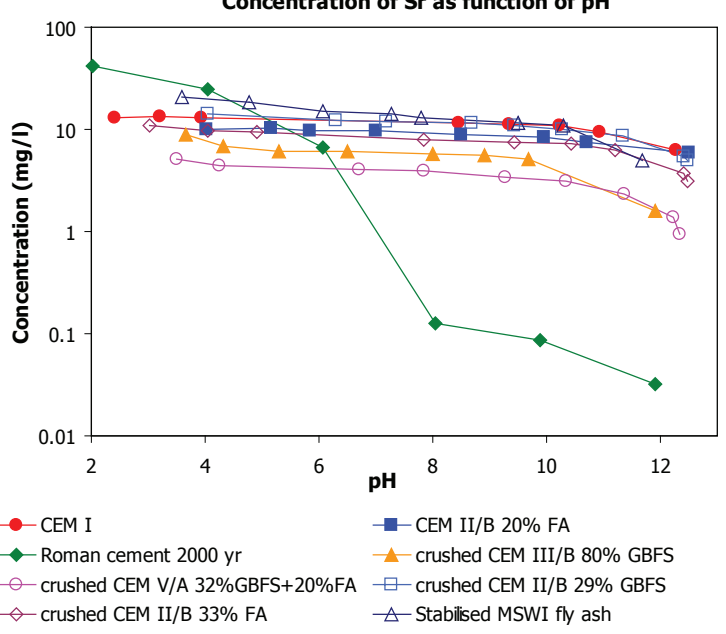

Concentration of $\mathrm{V}$ as function of $\mathrm{pH}$

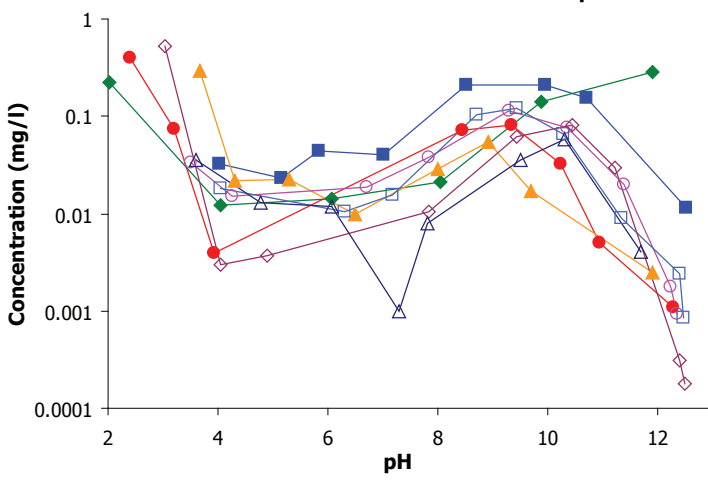

- CEM I

- CEM II/B 20\% FA

- Roman cement 2000 yr

- crushed CEM III/B 80\% GBFS

- crushed CEM V/A 32\%GBFS+20\%FA $\square$ crushed CEM II/B 29\% GBFS

$\diamond$ crushed CEM II/B 33\% FA $\triangle$ Stabilised MSWI fly ash
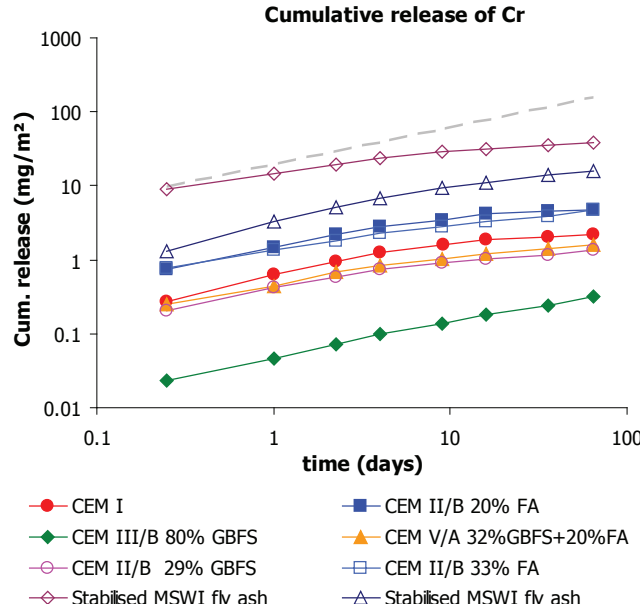

$\diamond$ Stabilised MSWI fly ash $\quad \triangle$ Stabilised MSWI fly ash

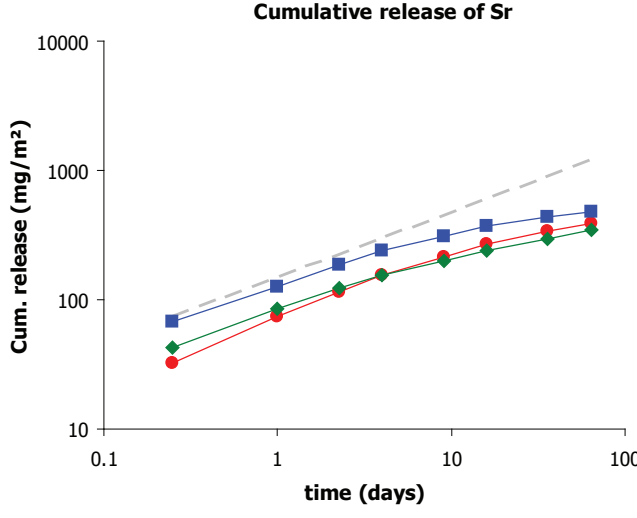

$\longrightarrow$ CEM II/B 20\% FA $\longrightarrow$ - Stabilised MSWI fly ash

$\longrightarrow$ Stabilised MSWI fly ash — slope $=0.5$

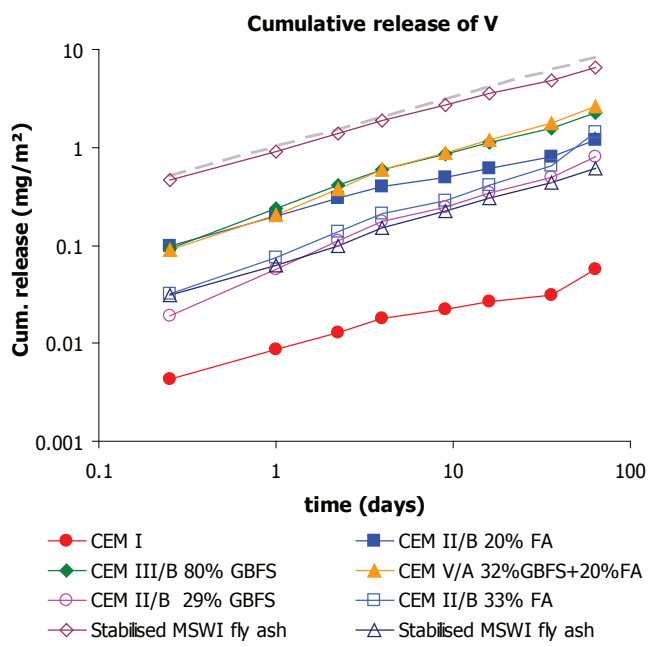

Figure 12. Comparison of Leaching Behavior of $\mathrm{Cr}$, $\mathrm{Sr}$, and $\mathbf{V}$ from Portland Cement and Selected Blended Cements, Roman Cement, and Cement Stabilized Waste Using pH Dependence and Tank Leaching Tests 
In works by Aarnink et al. (2007) and van der Sloot et al. (2007b), the low LS ratio fraction of column tests could be used to optimize the chemical speciation fingerprint for the sample as a function of LS ratio. If at low LS ratio (0.2-0.3), the same concentration is observed (deviation less than $50 \%$ ), diffusion is not likely to be the main controlling release mechanism but rather solubility control is the controlling mechanism.

In terms of leaching behavior, the release of a wide range of major, minor and trace elements from stabilized waste is very similar. Differences in release level, which are related to the loading of a particular constituent, may be evident as shown for the sample series (MBD, SWD and AMD) with increasing of relevant constituents (Garrabrants, Kosson \& DeLapp 2007). This series represents a solidified matrix similar in recipe to saltstone or caststone with no salt loading (MBD), salt solution at 2.5 M sodium with trace I and Re (SWD), and salt loading with enhance levels of I and Re along with several heavy metals (AMD). The absence of ettringite in the highlyloaded stabilized hazardous waste (NL) is indicated in Appendix $\mathrm{C}$ figures as the release at high $\mathrm{pH}$ not showing the characteristic decrease between $\mathrm{pH} 11.5$ and 12.5. In contrast, this reduction in release is obvious for several oxyanions in the hazardous stabilized waste (UK).

For the cement-stabilized MSWI fly ash, laboratory leaching data have been compared with data obtained from leaching studies on core samples taken from a test bed for studying hazardous waste disposal and from the full scale operation (field). In Figure 13, the comparison at the different levels of testing is given.

For all matrices, information is available on a wide range of major, minor and trace elements. As indicated before, for several the stable elements release behavior may be indicative for radionuclides of interest. This applies in particular for $\mathrm{Sr}, \mathrm{Cs}$ and $\mathrm{Sb}$. In Figure 14 , a comparison is given between stable element leaching and radionuclide leaching from cementstabilized radioactive waste solution. In the case of the stabilized radioactive waste solution (containing in a first solution Cs-137, Ce-144 and U-234 and in a second solution Ru-103 and Ru-106) illite was added to increase the retention capabilities of the mix.

Experimental data on a stabilized radioactive waste solution using cement and tested according to a tank test protocol is given in Figure 14. The composition of the mixes was: BFS cement, silica fume waste solution and a retarder in the ratio 8:2:7:0.08 and BFS cement, silica fume, illite, waste solution and a retarder in the ratio 8:1.6:0.4:7:0.1)

In the mix, illite was used under the assumption that Cs would interact with the illite to stabilize it and reduce its leaching behavior. In this figure a comparison is made of stable elements and the radioactive species for similar grout formulations.

\subsection{Soils}

Both clay barriers (e.g., bentonite type clays, Boom clay) and natural soil behavior is of relevance in judging release behavior in the scenarios to be evaluated. Release behavior is available on a range of natural soils and contaminated soils. Although the behavior is rather variable, release behavior from soil is largely dictated by sorption for which interaction with hydrated iron-oxides and both particulate and dissolved organic matter play a major role. When the proper interaction parameters are known, there is good agreement between model and observed release behavior (Dijkstra et al. 2008; Dijkstra, van der Sloot \& Comans 2006).

The neutralization of alkalinity released from cementitious matrices by a clay backfill, clay liner or natural soil is important for the release of substances from cementitious barriers, as the changes in soil due to alkalinity changes have significant influence on mobility of various substances. The neutralization is 
significantly influenced by the degree of saturation, as carbon dioxide may contribute to the neutralization. Modeling of oxidation/carbonation of a steel slag as sub-base of a parking lot (H.A. van der Sloot et al. 2007) has shown the magnitude of such influences. Both clay barriers (e.g., bentonite type clays,
Boom clay) and natural soil behavior is of relevance in judging release behavior in the scenarios to be evaluated. Release behavior is available on a range of natural soils and contaminated soils. Although the behavior is rather variable, release behavior from soil is largely dictated by sorption for which interaction
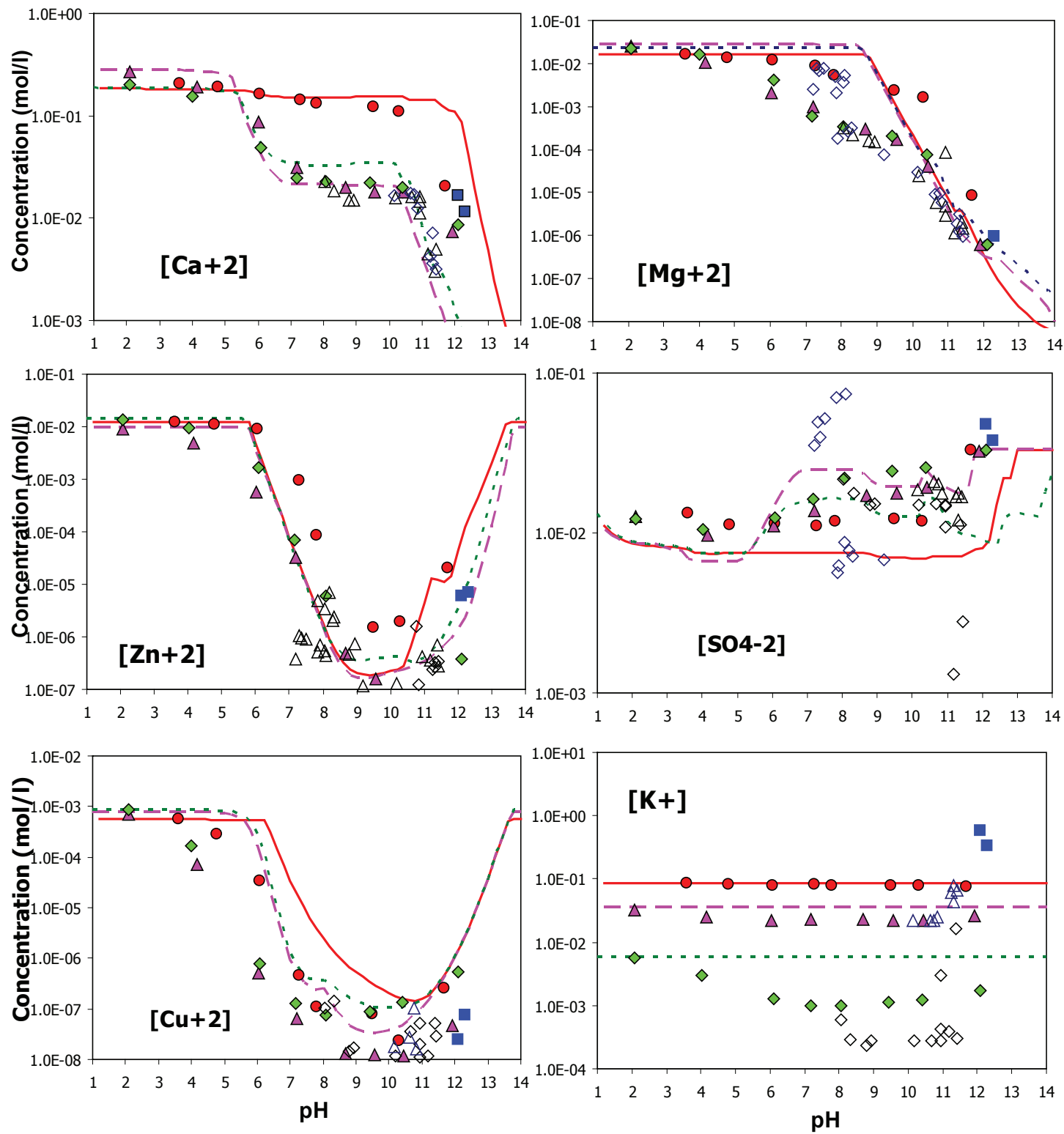

Figure 13. Geochemical Speciation Modeling Of pH-Dependence Data Using LeachXS ${ }^{\mathrm{TM}}$-ORCHESTRA for Several Cement-stabilized Wastes Including Freshly-stabilized Waste (Red Points), Cored Samples from A Stabilized Waste Cell (Green Diamonds and Pink Triangles), and Field Leachate Data (Open Diamonds). 


\section{Cumulative release of $\mathrm{Sr}$}

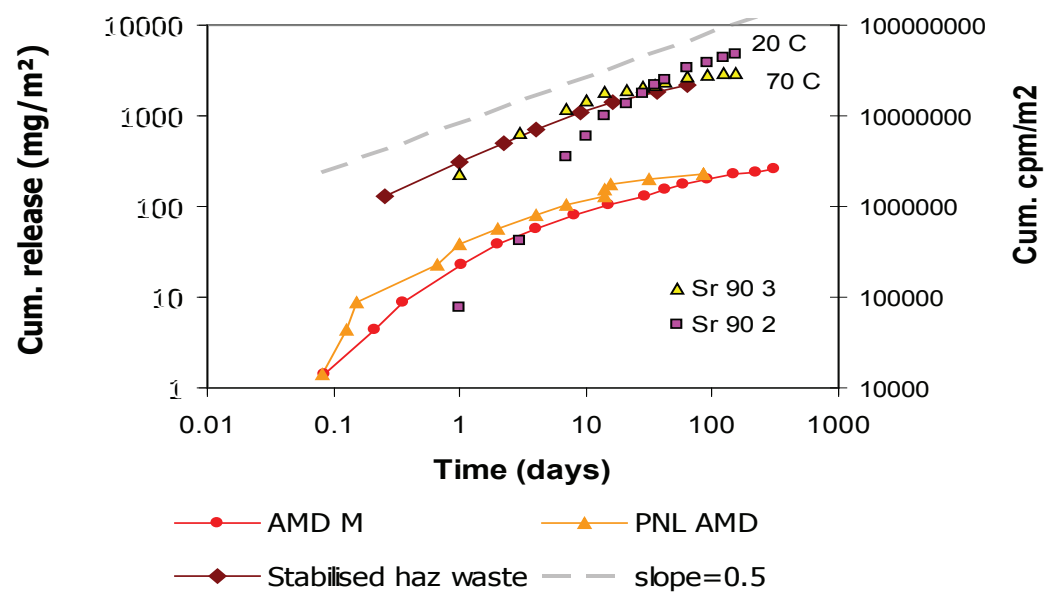

Cumulative release of $\mathbf{S b}$
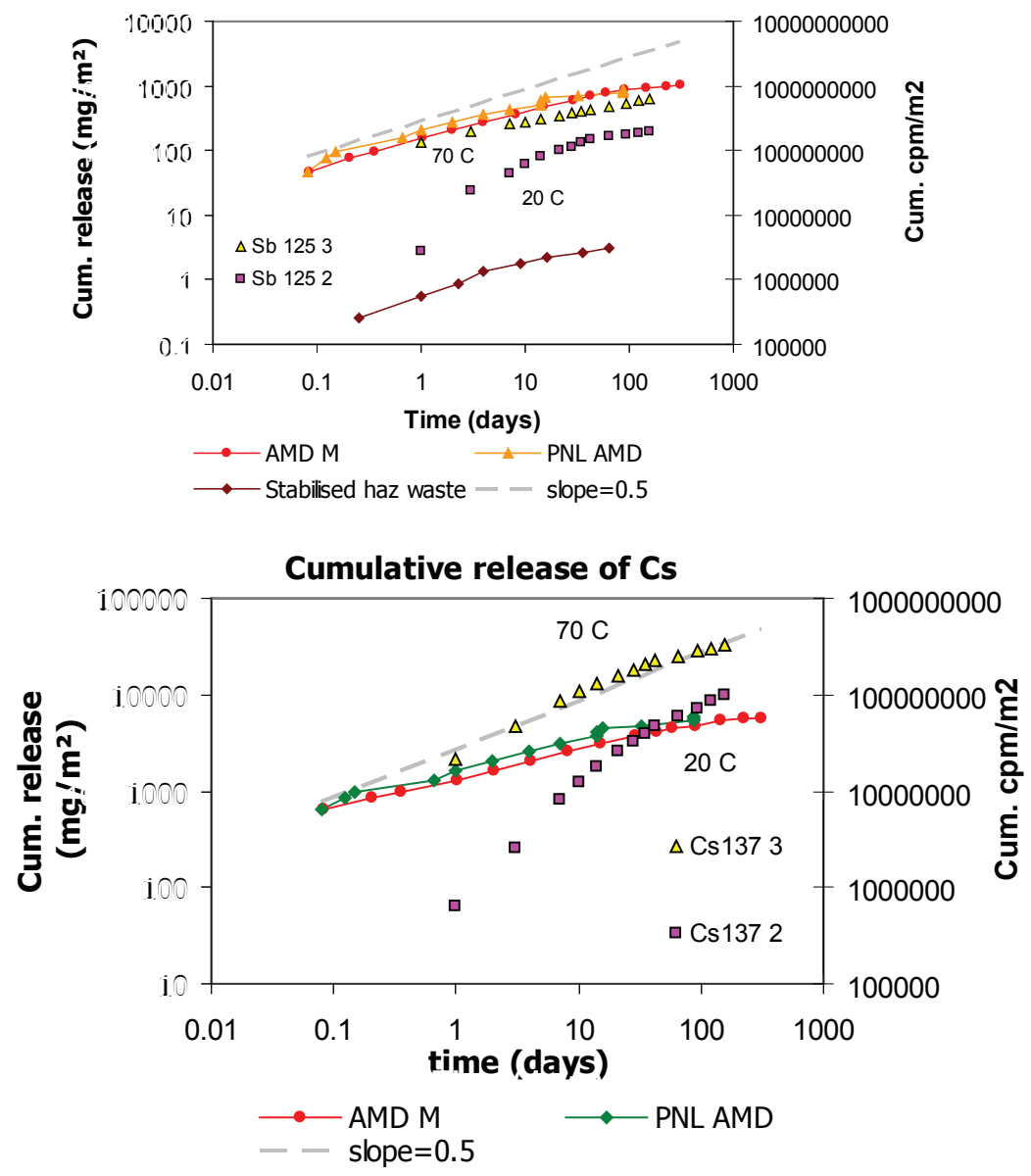

Figure 14. Comparison of Release of Cement-stabilized Waste Grout and Cement-stabilized Radioactive Waste Solution with Illite Addition Containing ${ }^{137} \mathrm{Cs},{ }^{90} \mathrm{Sr}$ and ${ }^{125} \mathrm{Sb}$ Using A Tank Leach Test 
with hydrated iron-oxides and both particulate and dissolved organic matter play a major role. When the proper interaction parameters are known, there is good agreement between model and observed release behavior (Dijkstra et al. 2008; Dijkstra, van der Sloot \& Comans 2006).

The neutralization of alkalinity released from cementitious matrices by a clay backfill, clay liner or natural soil is important for the release of substances from cementitious barriers, as the changes in soil due to alkalinity changes have significant influence on mobility of various substances. The neutralization is significantly influenced by the degree of saturation, as carbon dioxide may contribute to the neutralization. Modeling of oxidation/ carbonation of a steel slag as sub-base of a parking lot (Van der Sloot, 2008) has shown the magnitude of such influences.

\subsection{LEACHING ASSESSMENT IN CBP REFERENCE CASES}

The transport of constituents across interfaces plays a large role in the assessment of leaching, both in the short-term (e.g., precipitation leading to boundary layer formation) and long-term (e.g., $\mathrm{CO}_{2}$ or $\mathrm{O}_{2}$ ingress and associated effects). Therefore, it is important to relevant interfaces of CBP reference cases into context with leaching processes and aging effects.

\subsection{Interface Identification in CBP Reference cases}

The CBP has identified reference cases in which cementitious media are relied upon to retard the release of constituents: (1) a spent fuel pool scenario, (2) waste tank closure scenario, and (3) low-level radioactive waste vault scenario (Langton 2009). The interfaces associated with each of these cases can be expressed as a one-dimensional abstraction of a conceptualized multi-layer system.

\subsubsection{Spent Fuel Pool}

In Figure 15, a prototypical spent fuel pool is depicted with a break out to show the main release scenario related to this reference case. Interaction of pool water with a concrete pool wall will show a very slow carbonation progression. As pool water is maintained with low concentrations in critical salts (e.g., $\mathrm{Cl}^{-}, \mathrm{SO}_{4}{ }^{2-}$ and $\mathrm{Mg}^{2+}$ ) the effects on rebar will be less severe than attack from the outside in case of aggressive groundwater containing higher levels of these potentially critical components. In the long-term pool scenario, the development of a crack or fissure is more serious threat to long term containment. Once a through thickness crack or fissure develops, the interior hydraulic head (up to ca. $6 \mathrm{~m}$ ) will force water to start flowing facilitating transport. The flowing water may further erode the crack serving as the flow conduit. It is unlikely that species dissolving from the matrix will have a chance to precipitate and clog the pores in spite of the fact that under stagnant conditions such sealing might occur or might even be stimulated. The water containing dissolved radionuclides will enter into the second barrier, if any, and enter the surrounding soil system, where depending on the outflow rate soil erosion may occur. The interaction of released substances with soil will proceed and can be described provided the interaction parameters are known.

\subsubsection{Tank Closure}

In Figure 16, tank closure is depicted with a break out to show the main long-term release issues indicated. For tank closure, a grout formulation is used to fill the tank and the annulus between the tank liner and tank wall in order to reduce direct emission by restricting water flow and to provide the chemical conditions ( $\mathrm{pH}$, redox) which enhance constituent retention. In this case, a range of conditions are relevant: (1) the degree to which the waste is adequately mixed with grout or remains as sludge in the bottom of the tank; 


\section{SPENT FUEL POOL}

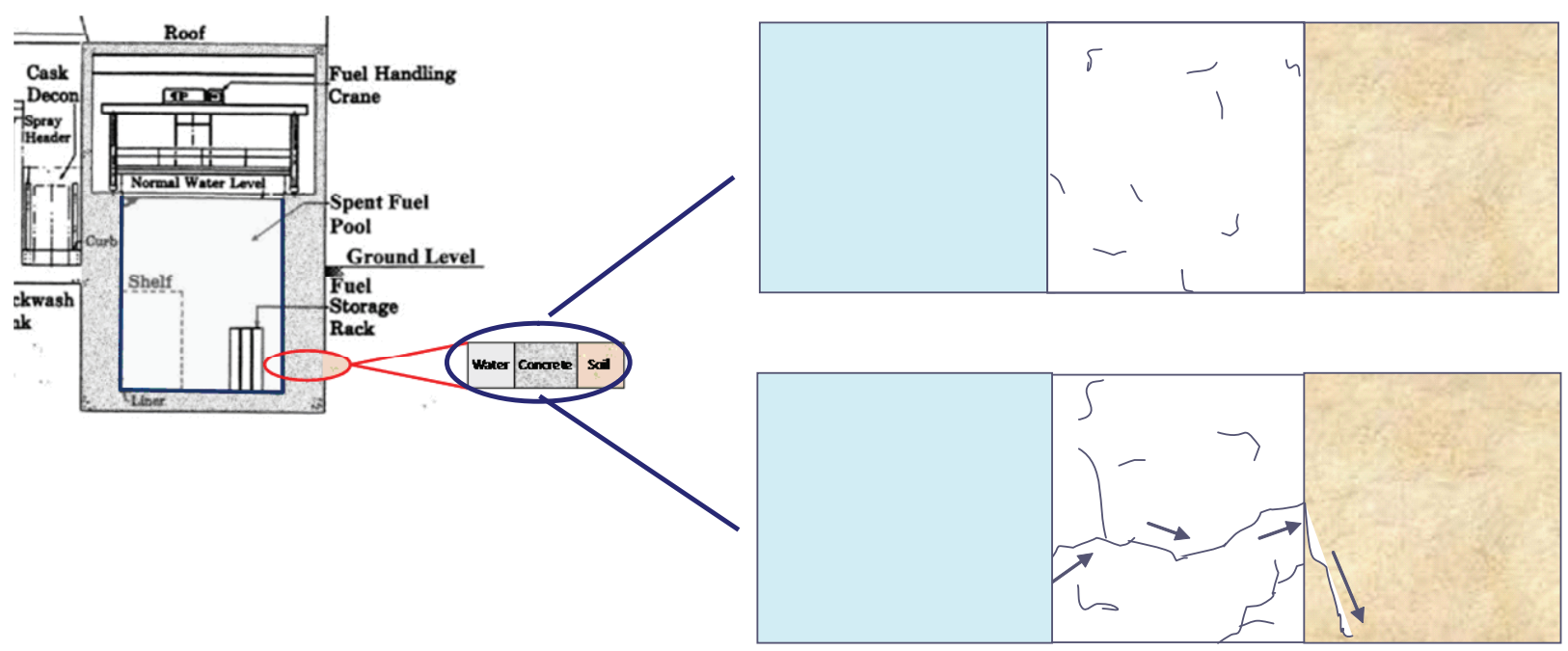

Figure 15. Spent Fuel Pool Scenario With Breakout of Multilayer System Abstraction

\section{TANK CLOSURE}
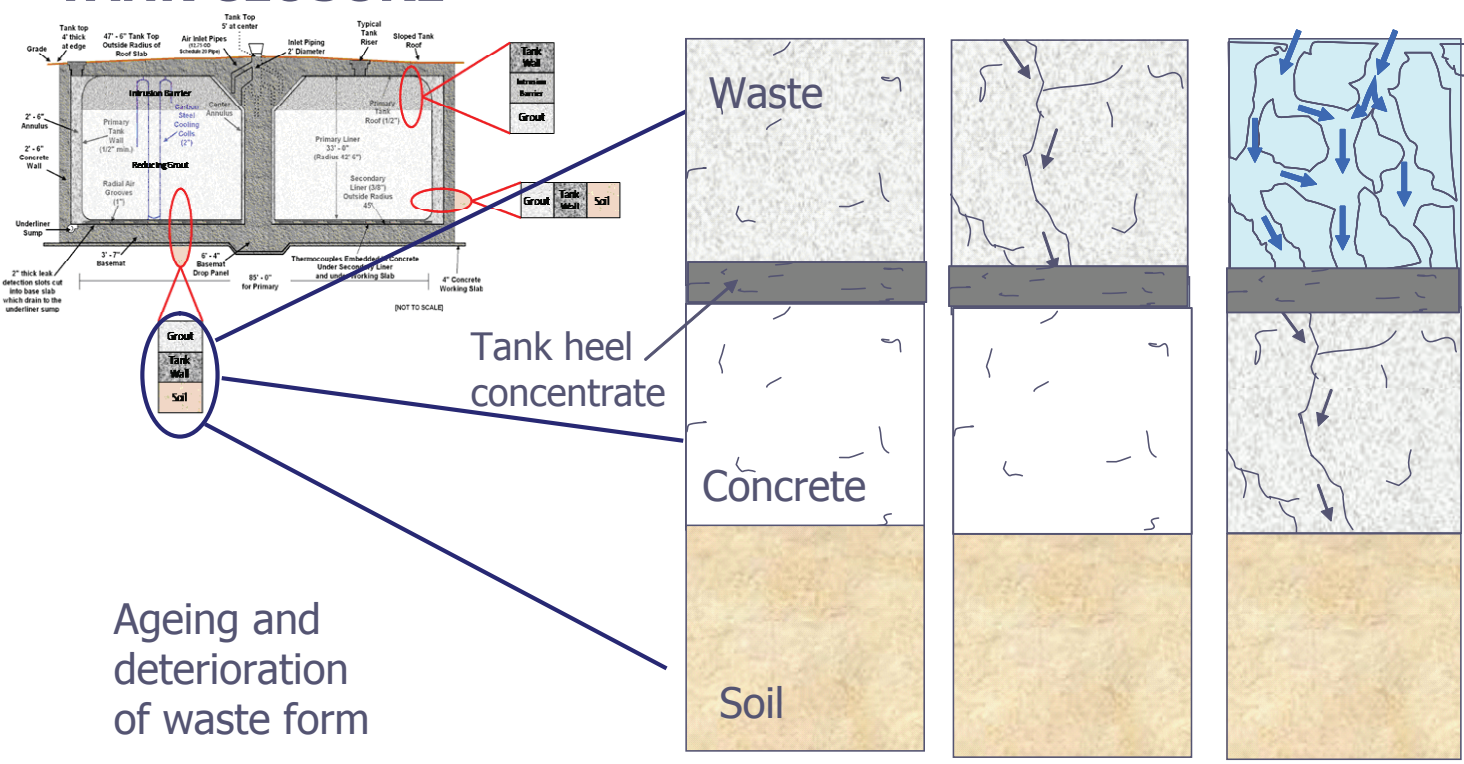

Figure 16. Tank Closure Scenario with Breakout of Multilayer System Abstraction 
(2) the degree to which the grout interacts with the steel lining, and (3) the extent of contact with $\mathrm{CO}_{2}$ from the atmosphere and the ingress of water. The interactions at the different material interfaces forms a first step in evaluating long term processes. In a second step, the quantification of carbonation and oxidation fronts is important because they determine to a large extent the potential mobilization of radionuclides of concern. The formation of cracks in the grout enhances these processes.

\subsubsection{Low-level Radioactive Waste Vault}

In Figure 17, a low level radioactive waste vault is depicted with a break out to show the main long-term release interfaces. This case has many similarities with the tank closure in that the development of carbonation and oxidation fronts are important to determine the release behavior of many radionuclides. Evaluation of the interaction at interfaces with or without air space between them is an important first step to quantify the potential release, which may be further augmented by further deterioration of the matrix. Sulfate attack from the waste form into concrete is important in case where sulfate concentrations are elevated in the residual waste or soil.

The most important chemical gradients within and at the boundaries of a cementitious material are with respect to $\mathrm{pH}$, redox, salt (total dissolved ionic content) and, obviously, radionuclide concentrations within cement-stabilized grout and waste forms. The reactions at interfaces are quite complex with the possibility of very substantial changes in pore solution composition and solubility controlling conditions occurring over a relatively small distance. Understanding the processes and conditions at interfaces between dissimilar materials is helpful in deciding whether such reactive zones play an active role in the transport of substances across an interface. Several material interfaces relevant to cementitious materials in nuclear applications are discussed below.

\subsubsection{Cementitious Wasteforms and Grouts- Concrete}

The interface between cement-stabilized waste and concrete is characterized by a gradient in soluble salts and depending on the nature of the cement used (i.e., reducing waste forms, grouts and concretes), a redox gradient. Different pore structures amongst the two materials can also result in capillary suction between materials across the interface. Cement-stabilized waste forms and grouts may contain substances that can have a detrimental effect on concrete (like sulfates) or chlorides. If there is a void between the concrete and the waste form or grout, then carbonation and oxidation will likely proceed faster in the waste form or grout than in the concrete because porosity is usually lower in concrete. The rate of front movement (especially in $\mathrm{pH}$, carbonation and sulfate) will likely significantly influence the mobility of different elements.

\subsubsection{Concrete-Soil Interface}

The interface between concrete and a clay barrier, soil or backfill typically is characterized by a large $\mathrm{pH}$ gradient. The consequences are re-mineralization reactions which, depending on the nature of the soil, can have surface effects on the concrete (Viani, Torretto \& Matzen 1997). Organic matter from soil interacts with the concrete and can potentially mobilize constituents. As long as the monolithic product remains intact, the affected layer is generally limited. Concrete exposed to a moist soil atmosphere will carbonate faster than when exposed to the atmosphere, as the $\mathrm{CO}_{2}$ concentration in the soil gas phase is generally higher than the $\mathrm{CO}_{2}$ level in the atmosphere as a consequence of biodegradation of organic matter in soil systems. Modern concretes exposed to soil and other environmental conditions are only slowly carbonated, unlike the much more porous Roman cements used to construct aqueducts. The ancient pozzolans, e.g., volcanic tuff or trass, have rather high porosity, which allows drying to occur more 


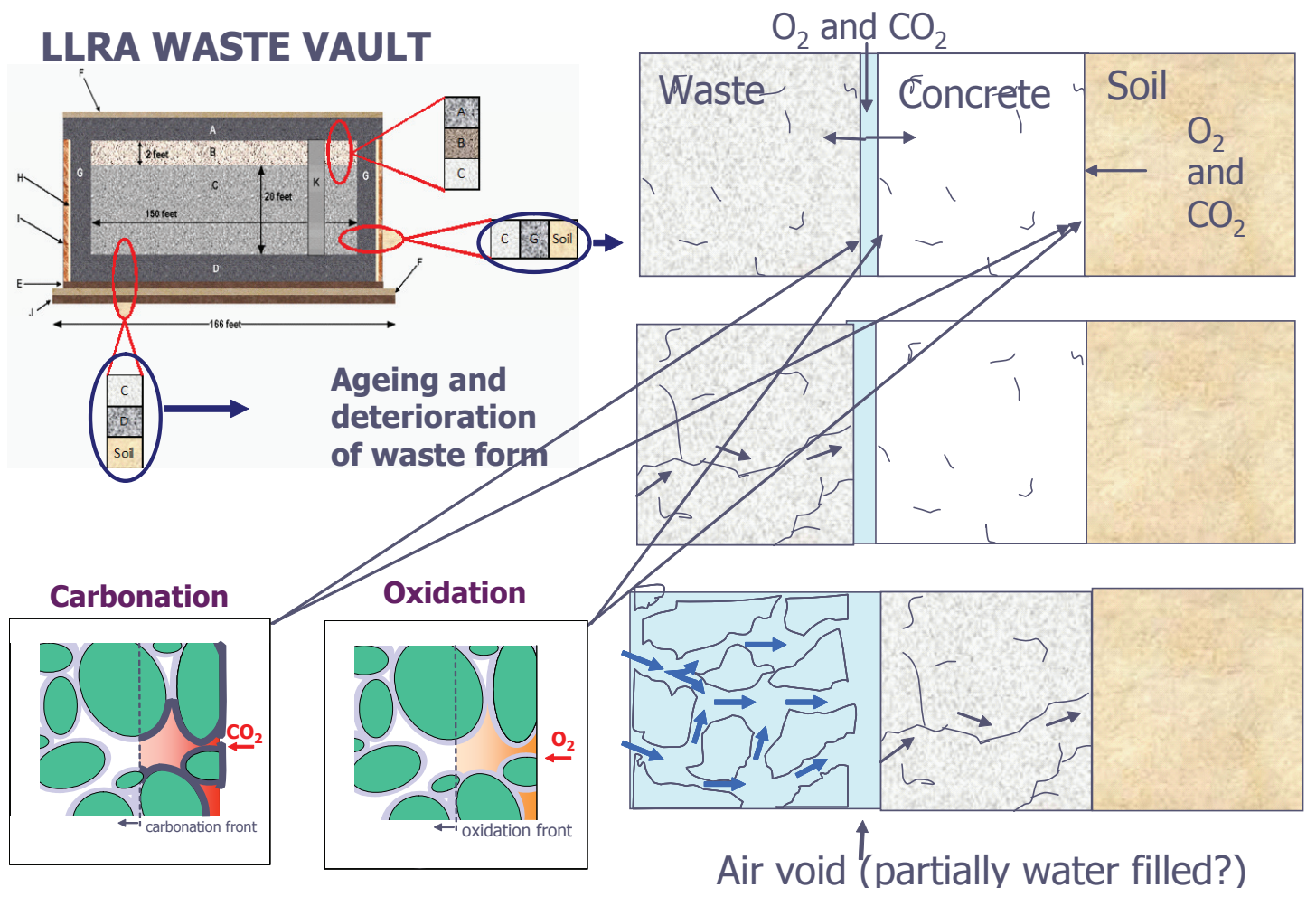

Figure 17. Low-level Waste Vault Scenario with Breakout of Multilayer System Abstraction

rapidly and carbonation to penetrate deeper. Lumps of Roman cement, sampled from ancient German aqueducts, were tested for trace element behavior and found to be fully carbonated to the depth of the core $(\sim 10 \mathrm{~cm})$ after approximately 2,000 years (van der Sloot et al. 2008b).

\subsubsection{Additional Barriers}

Additional barriers between grout and surroundings may be steel linings or other additional barriers like high density polyethylene. These will form an effective barrier, until the lining fails, which is likely at a time scale of 1,000 s of years. Corrosion of the barrier will be dependent on the interfacial chemistry. The modeling must assume failure at some point in time.

\subsection{Multilayer Systems Modeling}

The above sections highlight the importance of material interfaces within the CBP reference cases. The chemical interactions between the materials layers in a multilayer system can be studied by applying a saturated system of granular materials of all of these matrices using diffusion as the only transport process (tortuosity of mortar about 10 times higher than stabilized waste and soil). This type of system can elucidate the chemical interactions occurring at interfaces (mobilization and precipitation). The full CSF as derived from modeling the $\mathrm{pH}$-dependence test results for the individual materials of this multilayer system are used as starting point. 
In Figure 18 and Figure 19, an example of the modeling is given. Each figure represents the concentrations of speciated solid and liquid phases as a function of depth through a 3-layered system comprising a stabilized waste, a cement mortar and a soil. In order to be able to simulate a response with relative short computational duration, the layers are kept relatively thin $(3-\mathrm{cm})$. The concentrations are shown on both linear (left) and logarithmic (right) scales.

The composition of the stabilized waste (increased sulfate and imposed reducing conditions) and the soil have been modified to force a response to sulfate and $\mathrm{Mg}$ from the soil on the cement mortar. In the model run with LeachXS ${ }^{\mathrm{TM}}$-ORCHESTRA the distribution over dissolved and solid phases is calculated. Interactions at the interface between the cement matrix and the soil are of particular interest due to the large gradient in $\mathrm{pH}$ between the two matrices. To some degree, the soil buffering capacity will neutralize the alkalinity released from the cement-based matrix; however, the buffer capacity of most mortars will exceeds that of the soil, implying movement of an alkaline $\mathrm{pH}$ front. Since soil organic matter is mobilized at high $\mathrm{pH}$, progression of an alkaline front into the soil may affect transport of species. When an ettringite front develops at the soil-cement interface, species may be incorporated into precipitated ettringite by substitution.
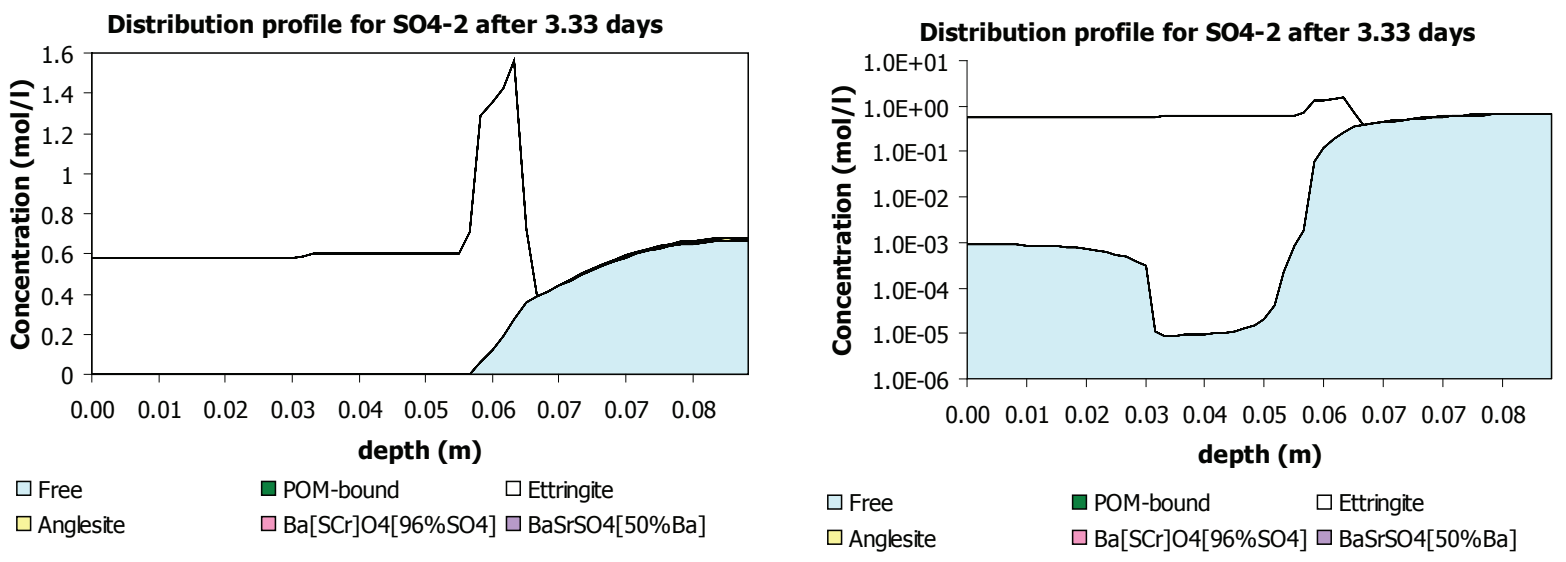

Distribution profile for $\mathrm{Sr}+2$ after 3.33 days

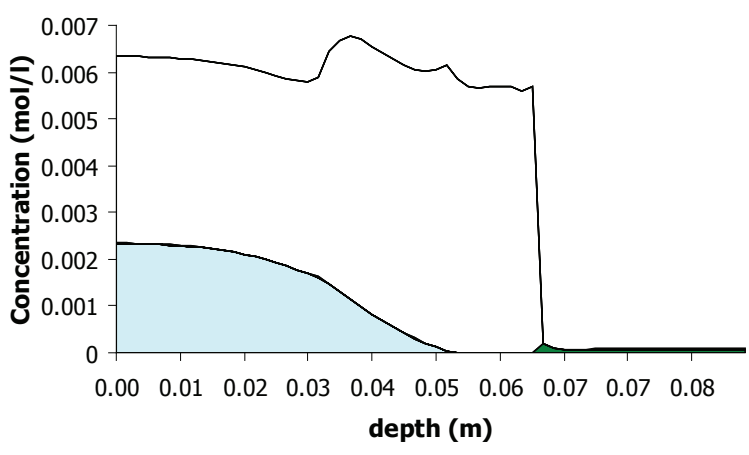

$\square$ Free $\square$ DOC-bound $\square$ POM-bound $\square$ Ettringite $\square$ BaSrSO4[50\%Ba]

Distribution profile for $\mathrm{Sr}+2$ after 3.33 days

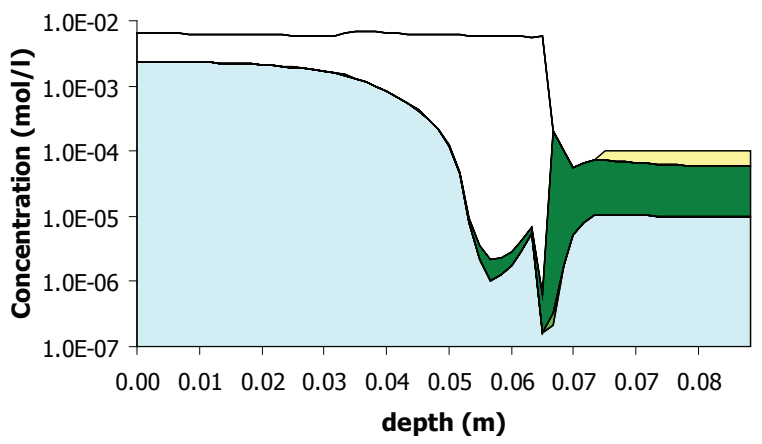

$\square$ Free $\square$ DOC-bound $\square$ POM-bound $\square$ Ettringite $\square$ BaSrSO4[50\%Ba]

Figure 18. LeachXS ${ }^{\mathrm{TM}}$-ORCHESTRA Simulation of $\mathrm{SO}_{4}$ and $\mathrm{Sr}$ Transport by Diffusion in A 3-layer System of Stabilized Waste/cement Mortar/soil with 3-cm Layers. 

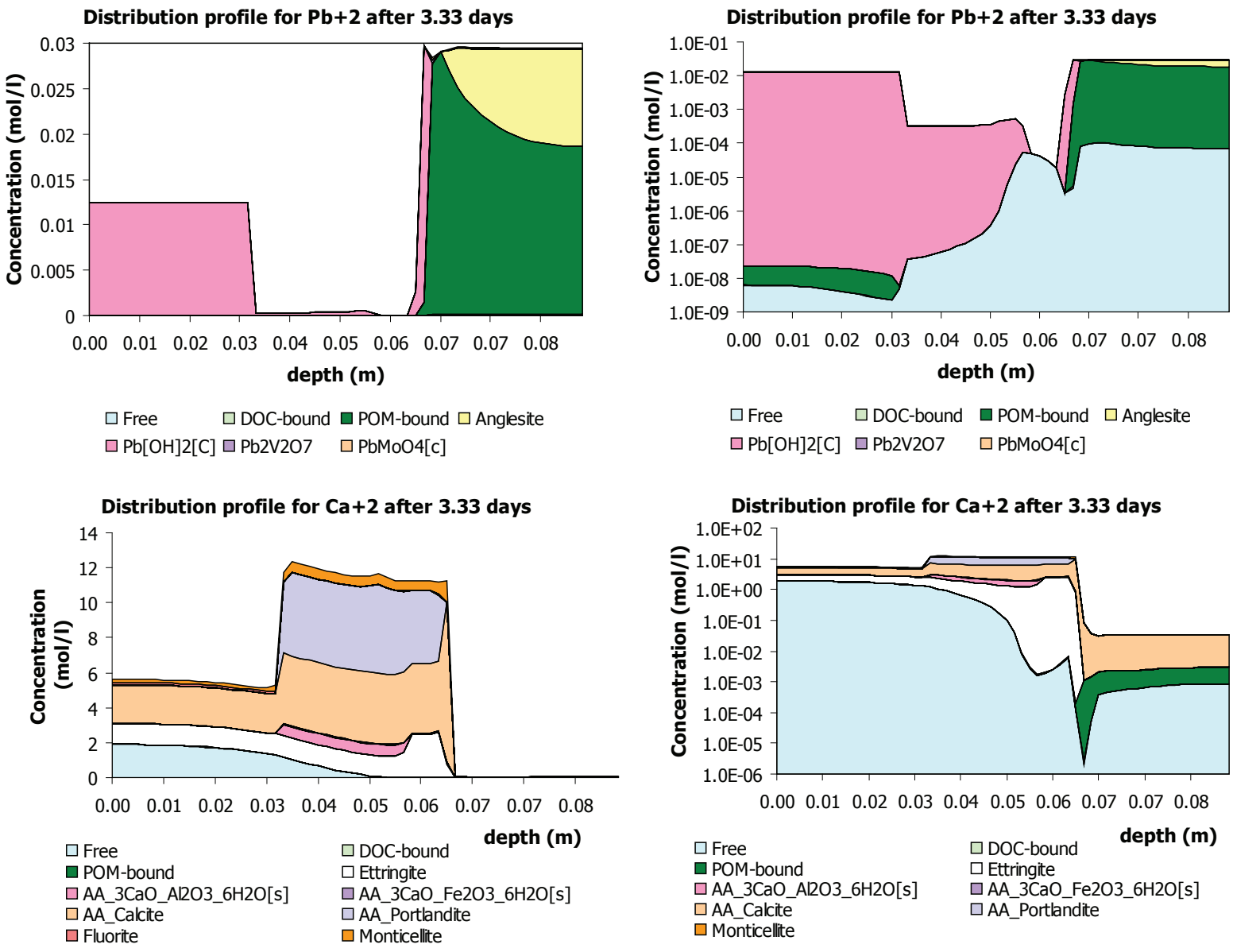

\section{Figure 19. LeachXS ${ }^{\mathrm{TM}}$-ORCHESTRA Simulation of $\mathrm{Pb}$ and $\mathrm{Ca}$ Transport by Diffusion in $\mathrm{A}$ 3-layer System of Stabilized Waste/cement Mortar/soil with 3-cm Layers}

In future work, unsaturated conditions with gas interaction will be taken into account. When air can penetrate at the stabilized waste-cement interface then due to carbonation, a substantial gradient may develop at this interface as well.

\subsection{LYSIMETER STUDIES FOR RADIOACTIVE WASTE}

The use of field lysimeter systems provides the realistic experimental conditions to assess the leachability and durability of radioactive waste. Field lysimeters are devices that are designed to contain waste, soil, and a means of sampling water in a sump at the bottom of the lysimeter. Often pore water samplers are installed, as well as other instrumentation to monitor percolate properties.

Typically, lysimeters are installed in the field with the intention of collecting long-term data on leachability of waste under natural precipitation conditions. Thus, the systems are open to precipitation (and generally plant growth), but are isolated from the subsurface to prevent loss of leachates. Although lysimeters may provide credible field conditions, the leachate results may be difficult to interpret because of limited experimental control of the system. In addition, the 
process of setting up, monitoring, and decommissioning lysimeters can be costly, especially when radioactive species are present. Several projects that used lysimeters to examine the behavior of radionuclides in waste are discussed below.

\subsection{Special Waste Forms Lysimeter Project}

Starting in 1982, the USDOE sponsored the Special Waste Forms Lysimeter Project, with two sets of lysimeters; one set at an arid site (at Hanford) and another at a humid site (at SRS). Each set of lysimeters consisted of a series of 1.8-m diameter by 3-m deep cylinders, arrayed around an instrument caisson. The wastes were full-size (210 liters) commercial nuclear power plant wastes, solidified in Portland cement, bitumen, or a polymer. Replicate waste forms, of both small and full scale, were leached in laboratory experiments (Arnold et al. 1983) allowing for comparison of field data to lab data at various scales.

Interim results (Skaggs \& Walter 1989) of arid site lysimeters at Hanford showed water balance data as well as leaching information after three years of exposure (1984-1987). All the lysimeters contained boiling water reactor wastes, in most cases, solidified with cement. Five of the lysimeters showed breakthrough of ${ }^{60} \mathrm{Co}$, but no release of other radionuclides. Between 1 and $6 \mu \mathrm{Ci}$ of ${ }^{60} \mathrm{Co}$ were detected in percolation waters over about 720 days. Although only a small fraction of the total ${ }^{60} \mathrm{Co}$ inventory was leached, it was not sorbed onto the lysimeter soil, presumably because the ${ }^{60} \mathrm{Co}$ was complexed with a chelating agent. By 1992 (eight years of exposure), results indicated that about $27 \%$ of the precipitation had percolated through the lysimeters, removing $71-76 \%$ of the wastes tritium inventory. Much lower fractional releases $(<0.1 \%)$ of ${ }^{60} \mathrm{Co}$ and ${ }^{137} \mathrm{Cs}$ were also observed (Jones \& Serne 1995). Laboratory leach tests conducted on replicate waste forms using a modified ANS 16.1 test showed that large quantities of ${ }^{137} \mathrm{Cs}$ $(80 \%)$ leached from the waste in 35 days, while only $0.5 \%$ of the ${ }^{60} \mathrm{Co}$ was released.
Substantially more activity was observed in the leachate from the humid site than the arid site (McIntyre 1987). An anionic form of ${ }^{60} \mathrm{Co}$ was found in concentrations as high as $1,120 \mathrm{pCi} / \mathrm{L}$ in leachates of cement waste forms and $11.1 \mathrm{pCi} / \mathrm{L}$ in polymer solidified waste leachates. The polymer waste form released more ${ }^{90} \mathrm{Sr}$ (up to $6.6 \mathrm{pCi} / \mathrm{L}$ ) than the cement waste forms. ${ }^{137} \mathrm{Cs}$ was also observed in leachate from one of the cement waste form lysimeters.

Radial soil cores were taken below the waste forms that showed the distribution of radionuclides in the soil of the lysimeter. In both the arid and humid sites, ${ }^{60} \mathrm{Co}$ was found to be the most mobile radionuclide, especially from cement waste forms, because a fraction of it was complexed and in an anionic form which was not retained by lysimeter soils. The implication of this study for cement-like waste forms was that anionic radionuclides (e.g., Tc, I, and complexed transition metals) will be difficult to sequester.

\subsection{Other Lysimeter Studies}

At SRS, 115 lysimeters of various designs were installed, many to investigate leaching of defense wastes. Of these, 12 were small 52 liter lysimeters (upside down plastic carboys with the bottoms cut off) used to study leaching and geochemistry of $\mathrm{Pu}$ in SRS soil (Kaplan et al. 2003). The key finding from these studies was that regardless of its original oxidation state, the $\mathrm{Pu}$ converted within 33 days to less mobile $\mathrm{Pu}(\mathrm{IV})$ form. $\mathrm{Pu}$ (VI), a mobile form that was placed in a lysimeter, moved $5 \mathrm{~cm}$ over 2 years, implying that it converted to a less soluble form.

Three lysimeters at Savannah River were put in place in 1983-4 containing 9,500 liter saltstone wasteform. One lysimeter had a gravel cap, one a clay cap, and the third was uncapped. Leaching of ${ }^{99} \mathrm{Tc}$ and nitrate from the uncapped lysimeter was greatest with the highest activity in leachate being $11.9 \mathrm{nCi} / \mathrm{L}$. Leachates of the other lysimeters were consistent with background concentrations (McIntyre, Oblath \& Whilhite 1989). 
Thirteen years of experimental results from field tests in Russia provide information on leaching and wasteform integrity under simulated repository conditions and more open, subsurface conditions (Ojovan et al. 2002). The materials were sodium nitrate reactor wastes that were incorporated into glass, bitumen and cement waste forms. The cement waste form lost $2.02 \%$ of its activity in 13 years while bitumen lost $0.65 \%$ and glass $0.007 \%$. Under repository-like conditions, releases were much lower, 0.04, 0.002, and $0.001 \%$ for cement, bitumen and glass, respectively. Under these conditions, leach rates appear to reach steady state after about ten years. There was little change in glass waste forms, with the exception of a thin weathering layer detected by $\mathrm{x}$-ray analysis. The cement waste forms were fragile with compressive strengths around $1 \mathrm{MPa}$ and appeared to have undergone deterioration and recrystalization. Bitumen waste forms had become harder and more thermostable over time with the leach rate also decreasing over time.

The USNRC funded a series of lysimeter studies to develop information on low-level waste form behavior (McConnell et al. 1998; Rogers et al. 1989). Epicor-II resin used to decontaminate water from the Three-Mile Island accident was solidified in portland cement and vinyl ester styrene polymer. These experiments ran for ten years and consisted of field tests at Oak Ridge and Argonne National Laboratories. Comparisons were made to two computer models. Cement waste forms retained ${ }^{90} \mathrm{Sr}$ better than VES but on average $65 \%$ of ${ }^{90} \mathrm{Sr}$ was leached. An average of $37 \%$ of ${ }^{137} \mathrm{Cs}$ was leached. ${ }^{134 / 137} \mathrm{Cs}$ and ${ }^{90} \mathrm{Sr}$ were detected at the surface of one lysimeter in which unidentified plants had grown and drawn activity up through the roots. Comparison of lysimeter leaching with leach test results indicate that lysimeter releases of ${ }^{90} \mathrm{Sr}$ were at least 100 times lower than leach tests, while for ${ }^{137} \mathrm{Cs}$ releases were 5 orders of magnitude less. These differences include limited contact with percolating water as well as retention of radionuclides on the soil of the lysimeters. Most of the activity remained bound to soil within the first $10-20 \mathrm{~cm}$ under the waste forms.

\subsection{KNOWLEDGE GAPS AND NEEDS}

The most important "gaps" in our knowledge which, when understood in more detail, would lead to greater understanding of long term release from cementitious barriers used in radioactive waste management are summarized below.

\subsection{Aging of Cementitious Materials}

The chemical and physical aging phenomena for cementitious materials, not uniformly taken into account in most leaching evaluations, may be deleterious or beneficial to long-term performance of cementitious barriers. Enhanced understanding of aging phenomena for cementitious material under credible release scenario conditions will improve prediction of constituent release over extended performance periods.

Aging and leaching evaluation of cementitious materials should take advantage of natural analogues and studies conducted on historical materials. Further investigations are needed to assess the rate of carbonation and oxidation processes and the effect of these aging mechanisms on constituent release. Descriptions of historical situations like the 2000-year-old Roman aqueducts cement and analogues from the waste management field (e.g., radionuclides in waste) or from long-term technical performance studies on concrete in Germany and Sweden also can provide valuable information.

\subsection{Chemical Retention of Radionuclides}

The thermodynamic data required to properly predict radionuclide behavior under defined chemical conditions in cementitious materials is either lacking or not compiled in a concise, readily available form. This data includes thermodynamic constants for 
precipitation, aqueous complexation, sorption to solid phases of cementitious materials and soils, interactions with mobile colloidal organic material and reduction/ oxidation. Testing should provide data on $\mathrm{pH}$-dependence, redox capacity, metal (hydr)oxide sorption and organic carbon (total organic carbon and DOC). The use of stable isotope data where radionuclides data is lacking might be feasible. Radioactive decay constants and decay series need to be including in the presented leaching assessment approaches.

\subsection{Uniform Testing and Interpretation}

The process of leaching assessment would benefit from a uniform approach in terms of guidance documents, a battery of integrated leaching tests, interpretation methodologies, and integrated database of leaching data for relevant materials. Cementitious materials and other radionuclide containing wastes may be assessed by the same set of leaching tests (e.g., pH dependence test, percolation leaching test, and mass transfer test, with redox capacity test where appropriate). Formation of an integrated database of release and chemical retention data for soils and cementitious materials would benefit leaching assessment by providing the ability to directly compare different leaching tests, test conditions and field scale results. Information should include as many constituents as possible (e.g., radionuclides, metals, and primary constituents).

\subsection{Systematic Leaching Behavior}

Evaluating of the potential sensitivities of systematic leaching behavior to perceived heterogeneities between cementitious material formulations and contaminants can simplify the assessment process considerably. Mixed municipal solid wastes have been found to behave in a remarkably constituent, systematic matter in spite of obvious macroscopic heterogeneities. Similar characteristic behavior is likely for cementitious barrier materials, especially cement-treated wastes, in that the conditions created by the stabilization process tend to make these materials behave more systematically, thereby making the release process more predictable.

\subsection{Predominance Diagrams}

The use of predominance diagrams developed using thermodynamic data of the major, minor and trace constituents that control conditions in cementitious systems can be integrated with the thermodynamic data of radionuclides to the extent available. Predominance diagrams not only allow assessment of pH-pe fields, but also put focus on changes in other chemical retention factors like carbonate, organic matter, and iron oxide. Such insights would be beneficial for defining anticipated initial, intermediate and end point conditions of disposal scenarios without knowing precisely at what time scale such changes may occur.

\subsection{Kinetically-Controlled Processes}

Investigation of the role of kinetically-controlled reactions would enhance current descriptions of chemical retention for species and conditions where the local equilibrium assuming is not valid. For example, conducting $\mathrm{pH}$-dependence tests at extended contact times, within the practical limitations of maintaining experimental conditions, would improve the understanding of slow chemical reactions.

\subsection{Transport in Unsaturated Materials}

Using a multi-element mechanistic model to describe transport by solely diffusion processes can be monitored and combined with verification experiments in the laboratory by applying the diffusion tube principle (Schaefer et al. 1995). In the case of reducing materials, experience has already been gained on how to avoid oxidation during the diffusion experiment from work on sediments. The model to describe the multielement transport behavior of this type is operational in LeachXS ${ }^{\mathrm{TM}}$. 
The modeling and experimental work needs to be expanded for different material combinations (groutcement, cement mortar-bentonite clay, cement mortar-natural soil). Basic information on $\mathrm{pH}$ dependent behavior of bentonite and clay used as barrier is currently lacking and needs to be developed. In this modeling, the electrochemical potential is likely to be consideration. This appears to be important, not only in case an electrical potentials is applied, but also for high concentration electrolytic solutions. It would be valuable to compare the effects of Nernst equation methodologies to the traditional diffusionbased approach.

\subsection{Comparative Evaluations}

Comparative studies, conducted by interpreting model methodologies (e.g., linear sorption vs. mechanistic chemical retention), conceptual models (e.g., cracked vs. uncracked materials), and parameters appear to be a useful tool in development of mechanistic leaching simulation approaches. Good understanding of the limitations and possibilities of various modeling approaches (e.g., $K_{d}$ approach versus a mechanistic approach) is mandatory. Model runs on the same test data with different model approaches can provide insight in this aspect. In addition, to what extent derived parameters (from analogy in behavior with stable elements) can be used to describe release under a range of experimental test conditions needs to be determined. To date, these derived parameters have not been individually verified by adequate chemical and physical characterization (e.g., ettringite substitution, iron-oxide sorption, organic matter interaction).understanding of slow chemical reactions. 


\subsection{REFERENCES}

Aarnink, W, Bleijerveld, R \& van der Sloot, HA 2007, 'Experiences with leaching tests for waste characterization in support of European legislation for monolithic waste disposal', Sardinia 2007 - 11th International Waste Management and Landfill Symposium.

Allen, PG, Siemering, GS, Shuh, DK, Bucher, JJ, Edelstein, NM, Langton, CA, Clark, SB, Reich, T \& Denecke, MA 1997, 'Technetium speciation in cement waste forms determined by X-ray absorption fine structure spectroscopy', Radiochimica Acta, vol. 76, no. $1 / 2$, pp. $77-86$.

Angus, MJ \& Glasser, FP 1985, 'The chemical environment in cement matrices', in Scientific Basis for Nuclear Waste Management IX, ed. LO Werme, Materials Research Society, pp. 547-556.

ANS 16.1 2003, Measurement of Leachability of Solidified Low-Level Radioactive Wastes by a Shortterm Test Procedure, American Nuclear Society, Illinois, USA.

Appelo, CAJ \& Postma, D 2005, Geochemistry, Groundwater and Pollution, 2nd edn, Taylor \& Francis, London.

Arnold, G, Colombo, P, Doty, RM, Franz, E-M, Kalb, P, Kemeny, P \& Nielson, RM, Jr 1983, Lysimeter Study of Commercial Waste Forms: Waste Form Aquisition, Characterization and Full-scale Leaching, BNL-51613, Brookhaven National Laboratory, Upton, NY.

Axe, L \& Anderson, PR 1995, 'Sr diffusion and reaction within Fe-oxides: Evaluation of the ratelimiting mechanism for sorption', Journal of Colloid and Interface Science, vol. 175, no. 1, pp. 157-165.
Axe, L \& Trivedi, P 2002, 'Intraparticle surface diffusion of metal contaminants and their attenuation in microporous amorphous $\mathrm{Al}, \mathrm{Fe}$, and Mn oxides', Journal of Colloid and Interface Science, vol. 247, no. 2, pp. 259-265.

Axe, L, Tyson, T, Trivedi, P \& Morrison, T 2000, 'Local structure analysis of strontium sorption to hydrous manganese oxide', Journal of Colloid and Interface Science, vol. 224, no. 2, pp. 408-416.

Bear, J 1979, Hydraulics of Groundwater, McGrawHill, New York.

Bénard, P, Cau-dit-Coumes, C, Garrault, S \& Nonat, A 2008, 'Influence of high nitrate salt concentrations on dimensional variation of mortars under wetcuring', 2nd International Workshop: Mechanisms and Modelling of Waste/Cement Interactions.

Blakemore, LC, Searle, PL \& Daly, BK 1987, Methods for Chemical Analysis of Soils, Science Report 80, NZ Soil Bureau, Lower Hutt, New Zealand.

Brendler, V, Arnold, T, Richter, A \& Bernhard, G 2004, 'Capability of surface complexation models and databases for predicting radionuclide sorption', Waste Management 2004.

Brown, GE \& Sturchio, NC 2002, 'An overview of synchrotron radiation applications to low-temperature geochemistry and environmental science', in Reviews in Mineralogy and Geochemistry, vol. 49, eds PA Fenter, ML Rivers, NC Sturchio \& SR Sutton, Mineralogical Society of America, pp. 1-115.

CEN EN-12920 2003, Methodology Guideline for the Determination of the Leaching Behaviour of Waste under Specified Conditions, CEN/TC 292 WG6, European Committee for Standardization (CEN), Brussels, Belgium. 
CEN PrEN-14405 2005, Characterisation of Waste: Leaching Behaviour Tests - Up-flow Percolation Test, CEN/TC 292 WG6, European Commitee for Standarization (CEN), Brussels, Belgium.

CEN PrEN-14429 2005, Characterisation of Waste: Leaching Behaviour Tests - $p H$ Dependence Test with Initial Acid/Base Addition, CEN/TC 292 WG6, European Committee for Standardization (CEN), Brussels, Belgium.

CEN PrEN-15863 2009, Characterisation of Wastes: Leaching Behaviour Test for Basic Characterisation - Dynamic Monolithic Leaching Test with Periodic Leachant Renewal under Fixed Test Conditions, CEN/TC 292 WG6, European Committee for Standardization (CEN), Brussels, Belgium.

Černý, R \& Rovnaníková, P 2002, Transport Processes in Concrete, Spon Press, New York.

Charlet, L \& Manceau, AA 1992, 'X-ray absorption spectroscopic study of the sorption of $\mathrm{Cr}$ (III) at the oxide-water interface : II. Adsorption, coprecipitation, and surface precipitation on hydrous ferric oxide', Journal of Colloid and Interface Science, vol. 148, no. 2, pp. 443-458.

Crawford, RJ, Harding, IH \& Mainwaring, DE 1996, 'The zeta potential of iron and chromium hydrous oxides during adsorption and coprecipitation of aqueous heavy metals', Journal of Colloid and Interface Science, vol. 181, no. 2, pp. 561-570.

Dijkstra, JJ, Meeussen, JCL, Van der Sloot, HA \& Comans, RNJ 2008, 'A consistent geochemical modelling approach for the leaching and reactive transport of major and trace elements in MSWI bottom ash', Applied Geochemistry, vol. 23, no. 6, pp. 1544-1562.
Dijkstra, JJ, van der Sloot, HA \& Comans, RNJ 2002, 'Process identification and model development of contaminant transport in MSWI bottom ash', Waste Management, vol. 22, no. 5, pp. 531-541.

Dijkstra, JJ, van der Sloot, HA \& Comans, RNJ 2006, 'The leaching of major and trace elements from MSWI bottom ash as a function of $\mathrm{pH}$ and time', Applied Geochemistry, vol. 21, no. 2, pp. 335-351.

Dijkstra, JJ, van der Sloot, HA, Spanka, G \& Thielen, G 2005, How to Judge Release of Dangerous Substances from Construction Products to Soil and Groundwater - CPD Topic 1 - Soil and Groundwater Impact - CPD Topic 2 - Hierarchy in Testing: Characterisation, Initial Type Testing, Further Testing and Selection of Tests in Specific Stages of Material Judgement - CPD Topic 3-Proposal for Reference to ER 3 Aspects in Product Standards and in CE Marking, ECNC-05-045, Energy Research Centre of the Netherlands, Petten, the Netherlands.

Dzombak, DA \& Morel, FMM 1990, Surface Complexation Modeling: Hydrous Ferric Oxide, Wiley-Intersciences, New York.

Fan, M, Boonfueng, T, Xu, Y, Axe, L \& Tyson, TA 2005, 'Modeling Pb sorption to microporous amorphous oxides as discrete particles and coatings', Journal of Colloid and Interface Science, vol. 281, no. 1, pp. 39-48.

Fenter, PA, Rivers, ML, Sturchio, NC \& Sutton, SR (eds) 2002, Applications of Synchrotron Radiation in Low-Temperature Geochemistry and Environmental Science, Mineralogical Society of America.

Fuhrmann, M \& Gillow, J 2009, Fate of uranium in contact with West Valley grouts, draft manuscript.

Fuhrmann, M, Heiser, JH, Pietrzak, R, Franz, E \& Colombo, P 1990, User's Guide for the Accelerated Leach Test Computer Program, BNL-52267, Brookhaven National Laboratory. 
Fuhrmann, M, Pietrzak, R, Franz, E, Heiser, JH \& Colombo, P 1989, Optimization of the Factors that Accelerate Leaching BNL-52204, Brookhaven National Laboratory.

Garrabrants, AC \& Kosson, DS 2005, 'Leaching processes and evalution tests for inorganic constiuent release from cement-based matrices', in Stabilization/ Solidification of Hazardous, Radioactive and Mixed Wastes, eds RD Spence \& C Shi, CRC Press, pp. 229279.

Garrabrants, AC, Kosson, DS \& DeLapp, RC 2007, Leaching Results and Interpretation of Constituent Release from a Representative Low-activity Waste Treated with Reducing Grout, Consortium for Risk Evaluation with Stakeholder Participation (CRESP).

Garrabrants, AC, Sanchez, F \& Kosson, DS 2003, 'Leaching model for a cement mortar exposed to intermittent wetting and drying', AIChE Journal, vol. 49, no. 5, pp. 1317-1333.

Glasser, FP, Marchand, J \& Samson, E 2008, 'Durability of concrete -- Degradation phenomena involving detrimental chemical reactions', Cement and Concrete Research, vol. 38, no. 2, pp. 226-246.

Goldberg, S, Criscenti, LJ, Turner, DR, Davis, JA \& Cantrell, KJ 2007, 'Adsorption-desorption processes in subsurface reactive transport modeling', Vadose Zone Journal, vol. 6, no. 3, pp. 407-435.

Gougar, MLD, Scheetz, BE \& Roy, DM 1996, 'Ettringite and C-S-H Portland cement phases for waste ion immobilization: A review', Waste Management, vol. 16, no. 4, pp. 295-303.

Grathwohl, P 1998, Diffusion in Natural Porouis Media: Contaminant Transport, Sorption/Desorption and Dissolution Kinetics, Springer, New York.
Hespe, ED 1971, 'Leach testing of immobilized radioactive waste solids', Atomic Energy Review, vol. 9, no. 1, pp. 195-207.

ISO TS 21268-3 2007, Soil Quality - Leaching Procedures for Subsequent Chemical and Ecotoxicological Testing of Soil and Soil Materials - Part 3: Up-flow Percolation Test, International Organization for Standardization (ISO), Geneva, Switzerland.

ISO TS 21268-4 2007, Soil Quality - Leaching Procedures for Subsequent Chemical and Ecotoxicological Testing of Soil and Soil Materials - Part 4: Influence of pH on Leaching with Initial Acid/Base Addition, International Organization for Standardization (ISO), Geneva, Switzerland.

Jones, TL \& Serne, RJ 1995, 'Contaminant release from solidified radioactive wastes buried in unsaturated sediments: Lysimeter study', Journal of Environmental Quality, vol. 24, no. 6, pp. 1063-1073.

Kaplan, DI, Demirkanli, D, Fjeld, R, Molz, F, Powell, B, Reid, D \& Serkiz, S 2003, Plutonium Transport Through Lysimeters Exposed to Natural Weather Conditions for Two to Twelve Years, WSRCTR-2003-00300, Savannah River Site, Aiken, SC.

Karthikeyan, KG \& Elliott, HA 1999, 'Surface complexation modeling of copper sorption by hydrous oxides of iron and aluminum', Journal of Colloid and Interface Science, vol. 220, no. 1, pp. 8895.

Karthikeyan, KG, Elliott, HA \& Chorover, J 1999, 'Role of surface precipitation in copper sorption by the hydrous oxides of iron and aluminum', Journal of Colloid and Interface Science, vol. 209, no. 1, pp. 72-78. 
Kindness, A, Lachowski, EE, Minocha, AK \& Glasser, FP 1994, 'Immobilisation and fixation of molybdenum (VI) by Portland cement', Waste Management, vol. 14, no. 2, pp. 97-102.

Kinniburgh, DG, van Riemsdijk, WH, Koopal, LK, Borkovec, M, Benedetti, MF \& Avena, MJ 1999, 'Ion binding to natural organic matter: competition, heterogeneity, stoichiometry and thermodynamic consistency', Colloids and Surfaces A: Physicochemical and Engineering Aspects, vol. 151, no. 1-2, pp. 147-166.

Klemm, WA 1998, Ettringite and Oxyaion-Substituted Ettringites - Their Characterization and Applications in the Fixation of Heavy Metals: A Synthesis of the Literature, Research and Development Bulletin RD116, Portland Cement Association, Skokie, Illinios, USA.

Koroleva, M \& Mangini, A 2005, Laboratory investigation of U(VI) incorporation into calcium carbonate minerals, EGU05-A-03404, Geophysical Research Abstracts, vol 7.

Kosson, DS, van der Sloot, HA, Sanchez, F \& Garrabrants, AC 2002, 'An integrated framework for evaluating leaching in waste management and utilization of secondary materials', Environmental Engineering Science, vol. 19, no. 3, pp. 159-204.

Kostka, JE \& Luther, GW, III 1994, 'Partitioning and speciation of solid phase iron in saltmarsh sediments', Geochimica et Cosmochimica Acta, vol. 58, no. 7, pp. 1701-1710.

Kumarathansan, P, McCarthy, GJ, Hassett, DJ \& Pflughoeft-Hassett, DF 1990, 'Oxyanion-substituted ettringites - synethesis and characterization, and their potential roll in immoblization of As, B, Cr, Se, and V', Materials Research Society Proceedings, vol. 178, pp. 83-104.
Langton, C 2009, Reference Cases for Use in the Cementitious Barriers Partnership, SRNLSTI-02009-00005, United States.

Lee, W \& Batchelor, B 2003, 'Reductive capacity of natural reductants', Environmental Science and Technology, vol. 37, no. 3, pp. 535-541.

Li, Y-H \& Gregory, S 1974, 'Diffusion of ions in sea water and in deep-sea sediments', Geochimica et Cosmochimica Acta, vol. 38, no. 5, pp. 703-714.

Lothenbach, B, Matschei, T, Möschner, G \& Glasser, FP 2008, 'Thermodynamic modelling of the effect of temperature on the hydration and porosity of Portland cement', Cement and Concrete Research, vol. 38, no. 1, pp. 1-18.

Lothenbach, B \& Wieland, E 2006, 'A thermodynamic approach to the hydration of sulphate-resisting Portland cement', Waste Management, vol. 26, no. 7, pp. 706-719.

Lothenbach, B \& Winnefeld, F 2006, 'Thermodynamic modelling of the hydration of Portland cement', Cement and Concrete Research, vol. 36 , no. 2 , pp. 209-226.

Lukens, WW, Bucher, JJ, Shuh, DK \& Edelstein, NM 2005, 'Evolution of technetium speciation in reducing grout', Environmental Science and Technology, vol. 39, no. 20, pp. 8064-8070.

Manceau, A, Charlet, L, Boisset, MC, Didier, B \& Spadini, L 1992, 'Sorption and speciation of heavy metals on hydrous Fe and Mn oxides. From microscopic to macroscopic', Applied Clay Science, vol. 7, no. 1-3, pp. 201-223.

Marchand, J \& Samson, E 2009 in press, 'Predicting the service-life of concrete structures - Limitations of simplified models', Cement and Concrete Research. 
Matschei, T, Lothenbach, B \& Glasser, FP 2007, 'Thermodynamic properties of Portland cement hydrates in the system $\mathrm{CaO}-\mathrm{Al} 2 \mathrm{O} 3-\mathrm{SiO} 2-\mathrm{CaSO} 4-$ CaCO3-H2O', Cement and Concrete Research, vol. 37, no. 10, pp. 1379-1410.

McConnell, JW, Jr., Rogers, RD, Jastrow, JD, Cline, SR \& Findlay, MW 1998, Low-level Waste Database Development Program, NUREG/CR-6569, US Nuclear Regulatory Commission, Rockville, MD.

McIntyre, PF 1987, Performance of special waste form lysimeters and waste migration at a humid site, CONF-860990-Pt.5, US Department of Energy, Washington, D.C.

McIntyre, PF, Oblath, S \& Whilhite, E 1989, 'Large-scale Demonstration of Low-level Waste Solidification in Saltstone', in Environmental Aspects of Stabilization and Solidification of Hazardous and Radioactive Wastes (STP-1033), eds P Côté \& M Gilliam, American Society for Testing and Materials, Baltimore, MD, pp. 392-403.

Meeussen, JCL 2003, 'ORCHESTRA: An objectoriented framework for implementing chemical equilibrium models', Environmental Science and Technology, vol. 37, no. 6, pp. 1175-1182.

Meeussen, JCL 2009, unpublished work, Energy Research Centre of the Netherlands, Petten, the Netherlands.

Meima, JA \& Comans, RNJ 1998, 'Application of surface complexation/precipitation modeling to contaminant leaching from weathered municipal solid waste incinerator bottom ash', Environmental Science and Technology, vol. 32, no. 5, pp. 688-693.

Milne, CJ, Kinniburgh, DG \& Tipping, E 2001, 'Generic NICA-Donnan model parameters for proton binding by humic substances', Environmental Science and Technology, vol. 35, no. 10, pp. 2049-2059.
Milne, CJ, Kinniburgh, DG, van Riemsdijk, WH \& Tipping, E 2003, 'Generic NICA-Donnan model parameters for metal-ion binding by humic substances', Environmental Science and Technology, vol. 37, no. 5, pp. 958-971.

Musić, S \& Ristić, M 1988, 'Adsorption of trace elements or radionuclides on hydrous iron oxides', Journal of Radioanalytical and Nuclear Chemistry, vol. 120, no. 2, pp. 289-304.

Myneni, SCB, Traina, SJ, Logan, TJ \& Waychunas, GA 1997, 'Oxyanion behavior in alkaline environments: Sorption and desorption of arsenate in ettingite', Environmental Science and Technology, vol. 31 , no. 6 , pp. 1761-1768.

NEN 7345 1995, Leaching Characteristics of Solid Earthy and Stony Building and Waste Materials Leaching Tests - Determination of the Leaching of Inorganic Components from Buildings and Monolithic Waste Materials with the Diffusion Test, NEN, Delft, The Netherlands.

NEN 7348 2006, Method to Determine Redox Status and Redox Capacity of Waste and Construction Materials, NEN, Delft, The Netherlands.

Nguyen, TQ, Petkovic, J, Dangla, P \& BaroghelBouny, V 2008, 'Modelling of coupled ion and moisture transport in porous building materials', Construction and Building Materials, vol. 22, no. 11, pp. 2185-2195.

Ojovan, MI, Ojovan, NV, Startceva, IV \& Barinov, AS 2002, 'Some trends in radioactive waste form behavior revealed in long-term field tests', Waste Management 2002. 
Parkhurst, DL \& Appelo, CAJ 1999, User's Guide to PHREEQC (version 2) - A Computer Program for Speciation, Reaction-path, 1D Transport, and Inverse Geochemical Calculations, Water Resources Investigations Report 99-4259, US Geological Survey.

Peak, D 2006, 'Adsorption mechanisms of selenium oxyanions at the aluminum oxide/water interface', Journal of Colloid and Interface Science, vol. 303, no. 2, pp. 337-345.

Perkins, RB \& Palmer, CD 2000, 'Solubility of $\mathrm{Ca}_{6}\left[\mathrm{Al}(\mathrm{OH})_{6}\right]_{2}\left(\mathrm{CrO}_{4}\right)_{3} \cdot 26 \mathrm{H}_{2} \mathrm{O}$, the chromate analog of ettringite; $5-75^{\circ} \mathrm{C}^{\prime}$, Applied Geochemistry, vol. 15, no. 8 , pp. $1203-1218$.

Pitzer, KS 1973, 'Thermodynamics of electrolytes, I: Theorectical basis and general equations', Journal of Physical Chemistry, vol. 77, no. 2, p. 286.

Poellmann, H, Auer, S, Kuzel, HJ \& Wenda, R 1993, 'Solid solution of ettringites: Part II: Incorporation of $\mathrm{B}(\mathrm{OH})_{4}{ }^{-}$and $\mathrm{CrO}_{4}{ }^{2-}$ in $3 \mathrm{CaO} \cdot \mathrm{Al}_{2} \mathrm{O}_{3} \cdot 3 \mathrm{CaSO}_{4} \cdot 32 \mathrm{H}_{2} \mathrm{O}^{\prime}$, Cement and Concrete Research, vol. 23, no. 2, pp. 422-430.

Reiller, P 2005, 'Pronosticating the humic complexation for redox sensitive actinides through analogy, using the charge neutralisation model', Radiochimica Acta, vol. 93, no. 1, pp. 43-56.

Reiller, P, Evans, NDM \& Szabó, G 2008, 'Complexation parameters for the actinides(IV)-humic acid system: A search for consistency and application to laboratory and field observations', Radiochimica Acta, vol. 96, no. 6, pp. 345-358.

Reiller, P, Moulin, V, Casanova, F \& Dautel, C 2002, 'Retention behaviour of humic substances onto mineral surfaces and consequences upon thorium (IV) mobility: case of iron oxides', Applied Geochemistry, vol. 17, no. 12, pp. 1551-1562.
Robinson, RA \& Stokes, RH 1959, Electrolytic Solutions, Butterworths-Heinemann, London.

Rogers, RD, McConnell, JW, Davis, E \& Findlay, MW 1989, 'Field testing of waste forms using lysimeters', in Environmental Aspects of Stabilization and Solidification of Hazardous and Radioactive Wastes (STP-1033), eds P Côté \& M Gilliam, American Society for Testing and Materials, Baltimore, MD, pp. 404-417.

Samson, E, Lemaire, G, Marchand, J \& Beaudoin, JJ 1999, 'Modeling chemical activity effects in strong ionic solutions', Computational Materials Science, vol. 15 , no. 3, pp. 285-294.

Samson, E \& Marchand, J 1999, 'Numerical Solution of the Extended Nernst-Planck Model', Journal of Colloid and Interface Science, vol. 215, no. 1, pp. 1-8.

Samson, E \& Marchand, J 2007, 'Modeling the effect of temperature on ionic transport in cementitious materials', Cement and Concrete Research, vol. 37, no. 3, pp. 455-468.

Samson, E, Marchand, J \& Beaudoin, JJ 1999, 'Describing ion diffusion mechanisms in cementbased materials using the homogenization technique', Cement and Concrete Research, vol. 29, no. 8, pp. 1341-1345.

Samson, E, Marchand, J \& Beaudoin, JJ 2000, 'Modeling the influence of chemical reactions on the mechanisms of ionic transport in porous materials: An overview', Cement and Concrete Research, vol. 30, no. 12 , pp. 1895-1902.

Samson, E, Marchand, J \& Snyder, KA 2003, 'Calculation of ionic diffusion coefficients on the basis of migration test results', Materials and Structures, vol. 36, no. 3, pp. 156-165. 
Sanchez, F, Massry, IW, Eighmy, T \& Kosson, DS 2003, 'Multi-regime transport model for leaching behavior of heterogeneous porous materials', Waste Management, vol. 23, no. 3, pp. 219-224.

Saripalli, KP, Kim, H, Rao, PSC \& Annable, MD 1997, 'Measurement of specific fluid-fluid interfacial areas of immiscible fluids in porous media', Environmental Science and Technology, vol. 31, no. 3, pp. 932-936.

Saripalli, KP, Serne, RJ, Meyer, PD \& McGrail, BP 2002, 'Prediction of diffusion coefficients in porous media using tortuosity factors based on interfacial areas', Ground Water, vol. 40, no. 4, pp. 346-352.

Saunders, JA \& Toran, LE 1995, 'Modeling of radionuclide and heavy metal sorption around lowand high-pH waste disposal sites at Oak Ridge, Tennessee', Applied Geochemistry, vol. 10, no. 6, pp. 673-684.

Schaefer, CE, Arands, RR \& Kosson, DS 1999, 'Measurement of pore connectivity to describe diffusion through a nonaqueous phase in unsaturated soils', Journal of Contaminant Hydrology, vol. 40, no. 3, pp. 221-238.

Schaefer, CE, Arands, RR, van der Sloot, HA \& Kosson, DS 1995, 'Prediction and experimental validation of liquid-phase diffusion resistance in unsaturated soils', Journal of Contaminant Hydrology, vol. 20, no. 1-2, pp. 145-166.

Schwantes, JM \& Batchelor, B 2006, 'Simulated infinite-dilution leach test', Environmental Engineering Science, vol. 23, no. 1, pp. 4-13.

Serne, RJ 2006, 'Technical issues on laboratory methodology to assess long-term release of contaminants form grout/cement in the vadose zone', Cementitious Materials for Waste Treatment, Disposal, Remediation and Decommissioning.
Šimurek, J \& Suarez, DL 1994, 'Two-dimensional transport model for variably staturated porous media with major ion chemistry', Water Resources Research, vol. 30, no. 4, pp. 1115-1133.

Skaggs, R \& Walter, MB 1989, 'Special waste from lysimeters - Arid program, 1987', in Environmental Aspects of Stabilization and Solidification of Hazardous and Radioactive Wastes (STP-1033), eds P Côté \& M Gilliam, American Society for Testing and Materials, Baltimore, MD, pp. 96-106.

Sparks, DL 2004, 'The role of synchrotron radiatoin in advancing the frontiers of water-rock interactions', in Water-Rock Interaction: Proceedings of the Eleventh International Symposium on Water-Rock Interaction, WRI-11, 27 June - 2July 2004, Saratoga Springs, New York, USA, eds RB Wanty \& RR Seal, II, Balkema, Leiden, the Netherlands, pp. 609-614.

Stumm, W \& Morgan, J 1996, Aquatic Chemistry: Chemical Equilibria and Rates in Natural Waters, Third Ed., Third edn, John Wiley \& Sons, Inc, New York.

Swift, RS 1996, 'Organic matter characterization', in Methods of Soil Analysis. Part 3: Chemical Methods, eds DL Sparks, AL Page, ME Sumner, MA Tabatabai $\&$ PA Helmke, Soil Science Society of America, Madison, WI, pp. 1011-1069.

Thomas, JJ, Chen, JJ, Allen, AJ \& Jennings, HM 2004, 'Effects of decalcification on the microstructure and surface area of cement and tricalcium silicate pastes', Cement and Concrete Research, vol. 34, no. 12, pp. 2297-2307.

Tiffreau, C, Lützenkirchen, J \& Behra, P 1995, 'Modeling the adsorption of mercury(II) on (hydr) oxides: I. Amorphous iron oxide and $\alpha$-quartz', Journal of Colloid and Interface Science, vol. 172, no. 1, pp. 82-93. 
Tiruta-Barna, LR, Barna, R \& Moszkowicz, P 2001, 'Modeling of solid/liquid/gas mass transfer for environmental evaluation of cement-based solidified waste', Environmental Science and Technology, vol. 35 , no. 1 , pp. 149-156.

Trivedi, P \& Axe, L 1999, 'A Comparison of Strontium Sorption to Hydrous Aluminum, Iron, and Manganese Oxides', Journal of Colloid and Interface Science, vol. 218, no. 2, pp. 554-563.

Trivedi, P \& Axe, L 2001, 'Ni and Zn Sorption to Amorphous versus Crystalline Iron Oxides: Macroscopic Studies', Journal of Colloid and Interface Science, vol. 244, no. 2, pp. 221-229.

Trivedi, P, Axe, L \& Tyson, TA 2001, 'An Analysis of Zinc Sorption to Amorphous versus Crystalline Iron Oxides Using XAS', Journal of Colloid and Interface Science, vol. 244, no. 2, pp. 230-238.

Truc, O, Ollivier, J-P \& Nilsson, L-O 2000, 'Numerical simulation of multi-species transport through saturated concrete during a migration test -- MsDiff code', Cement and Concrete Research, vol. 30, no. 10, pp. 1581-1592.

USEPA 1991, Leachability Phenomena: Recommendations and Rationale for Analysis of Contaminant Release by the Environmental Engineering Committee, EPA-SAB-EEC-92-003, USEPA Science Advisory Board, Washington, DC.

USEPA 1999, Waste Leachability: The Need for Review of Current Agency Procedures, EPA-SABEEC-COM-99-002, USEPA Science Advisory Board, Washington, DC.

USEPA 2009a, Draft Method 1313: Leaching Test (Liquid-Solid Partitioning as a Function of Extract pH) for Constituents in Solid Materials using a Parallel Batch Extraction Test United States Environmental Protection Agency, Washington, DC.
USEPA 2009b, Draft Method 1314: Leaching Test (Liquid-Solid Partitioning as a Function of Liquid-toSolid Ratio) for Constituents in Solid Materials using an Up-flow Percolation Column Test United States Environmental Protection Agency, Washington, DC.

USEPA 2009c, Draft Method 1315: Leaching Test (Mass Transfer Rates) for Constituents in Monolithic or Compacted Granular Materials using a Semi-Dynamic Tank Leaching Test United States Environmental Protection Agency, Washington, DC.

van der Sloot, HA 2000, 'Comparison of the characteristic leaching behavior of cements using standard (EN 196-1) cement mortar and an assessment of their long-term environmental behavior in construction products during service life and recycling', Cement and Concrete Research, vol. 30, no. 7, pp. 1079-1096.

van der Sloot, HA \& Dijkstra, JJ 2004, Development of Horizontally Standardized Leaching Tests for Construction Materials: A Material-based or Release-based Approach?, ECNC-04-060, Energy Research Centre of the Netherlands (ECN), Petten, the Netherlands.

van der Sloot, HA, Heasman, L \& Quevauviller, P 1997, Harmonization of Leaching/Extraction Test, Elsevier Science, Amsterdam.

van der Sloot, HA, Hoede, D, Rietra, RPJJ, Stenger, R, Lang, T, Schneider, M, Spanka, G, StoltenbergHansson, E \& Lerat, A 2001, Environmental Criteria for Cement-based Products, ECN C-01-069, Energy Research Centre of The Netherlands, Petten, The Netherlands.

van der Sloot, HA, Seignette, PFAB, Meeussen, JCL, Hjelmar, O \& Kosson, DS 2008a, 'A database, speciation modeling and decision support tool for soil, sludge, sediments, wastes and construction products: LeachXS ${ }^{\mathrm{TM}}$-ORCHESTRA', Venice 2008. 
van der Sloot, HA, van Zomeren, A, de Nie, DS \& Meeussen, JCL 2007a, $p H$ and Redox Effect of Construction Materials (in Dutch), ECN-E-07-093, Energy Research Centre of the Netherlands, Petten, the Netherlands.

van der Sloot, HA, van Zomeren, A, Meeussen, JCL, Seignette, P \& Bleijerveld, R 2007b, 'Test method selection, validation against field data, and predictive modelling for impact evaluation of stabilised waste disposal', Journal of Hazardous Materials, vol. 141, no. 2, pp. 354-369.

van der Sloot, HA, van Zomeren, A, Stenger, R, Schneider, M, Spanka, G, Stoltenberg-Hansson, E \& Dath, P 2008b, Environmental CRIteria for CEMentbased Products (ECRICEM) Phase I: Ordinary

Portland Cements and Phase II: Blended Cements, ECN-E-08-011, Energy Research Center of The Netherlands, Petten, The Netherlands.

van Zomeren, A \& Comans, RNJ 2007, 'Measurement of humic and fulvic acid concentrations and dissolution properties by a rapid batch procedure', Environmental Science and Technology, vol. 41, no. 19, pp. 6755-6761.

Viani, BE, Torretto, PC \& Matzen, SL 1997, Radionuclide Transport through Engineered Barrier System Alteration Products, UCRL-ID-129281, Lawrence Livermore National Laboratory.
White, MD \& Oostrom, M 1996, STOMP, Subsurface Transport Over Multiple Phases, Theory Guide, PNNL-11217, Pacific Northwest National Laboratory, Richland, WA.

White, MD, Oostrom, M \& Lenhard, RJ 1995, 'Modeling fluid flow and transport in variably saturated porous media with the STOMP simulator. 1. Nonvolatile three-phase model description', Advances in Water Resources, vol. 18, no. 6, pp. pp. 353-364.

Zhang, M \& Reardon, EJ 2003, 'Removal of B, Cr, $\mathrm{Mo}$, and Se from wastewater by incorporation into hydrocalumite and ettringite', Environmental Science and Technology, vol. 37, no. 13, pp. 2947-2952.

Zhu, C 2003, 'A case against $\mathrm{K}_{\mathrm{d}}$-based transport models: natural attenuation at a mill tailings site', Computers \& Geosciences, vol. 29, no. 3, pp. 351359.

Zuloaga, P, Andrade, C \& Castellote, M 2009, 'Leaching of reinforced concrete vaults subjected to variable water content due to capillary suction created by seasonal temperature changes', NUCPRERF 2009: Long-term Performance of Cementitious Barriers and Reinforced Concrete in Nuclear Power Plants and Waste Management. 


\section{APPENDIX A. Comparison of Leaching Results from Cement Mortars}

Cement mortars studied in ECRICEM I and II (2001 and 2008) are presented in Table A.1.

Table A.1. Cementitious materials studied.

\begin{tabular}{|c|c|}
\hline Material Type & Material Components \\
\hline \multicolumn{2}{|c|}{ Commercial Portland Cement } \\
\hline CEM I & Clinker, gypsum, filler \\
\hline CEM I & Clinker, gypsum \\
\hline CEM I & Clinker, gypsum, filler \\
\hline CEM II-L & Clinker, gypsum, limestone (14 \%) \\
\hline CEM I & Clinker, gypsum \\
\hline CEM I & Clinker, gypsum, filler \\
\hline CEM I & Clinker, gypsum, filler \\
\hline CEM I & Clinker, gypsum, filler \\
\hline CEM I & Clinker, gypsum, filler \\
\hline CEM I-HS & Clinker, gypsum \\
\hline \multicolumn{2}{|l|}{ Slag Cement } \\
\hline CEM III/B & $80 \%$ GBFS \\
\hline CEM III/B $32.5 \mathrm{~N}$ & $66 \%$ GBFS \\
\hline CEM II/B-S 32.5 R & $29 \%$ GBFS \\
\hline CEM II/B-S 32.5 R & $29 \%$ GBFS \\
\hline CEM II/A-S 32.5 R & $20 \%$ GBFS \\
\hline CEM III/A 32.5 & $69 \%$ GBFS $+5 \%$ LS \\
\hline \multicolumn{2}{|l|}{ CEM II/A-S 32.5 R } \\
\hline \multicolumn{2}{|l|}{ CEM II/B-S 32.5 R } \\
\hline \multicolumn{2}{|c|}{ Composite Cement (with one component) } \\
\hline CEM II/B-V $32.5 \mathrm{~N}$ & $33 \% \mathrm{FA}$ \\
\hline CEM II/A-V $42.5 \mathrm{~N}$ & $10 \% \mathrm{FA}$ \\
\hline CEM II/A-V & with chromate reduction and $17 \%$ FA \\
\hline CEM II/B-Q & $32 \% \mathrm{P}$ \\
\hline CEM II/B-P 32.5 R & $26 \%$ Trass $(\mathrm{P})$ \\
\hline CEM II/B-L & $28 \% \mathrm{LS}$ \\
\hline CEM II/A-L 32.5 R & $13 \% \mathrm{LS}$ \\
\hline CEM II/A-LL $32.5 \mathrm{R}$ & $13 \% \mathrm{LS}$ \\
\hline \multicolumn{2}{|c|}{ Composite Cements (with more than one component) } \\
\hline CEM V/A $32.5 \mathrm{~N}$ & $32 \% \mathrm{GBFS}+20 \% \mathrm{FA}$ \\
\hline $\mathrm{CEM} \mathrm{V} / \mathrm{A} 32.5 \mathrm{~N}$ & $23 \% \mathrm{GBFS}+22 \% \mathrm{FA}$ \\
\hline CEM II/B-M 32.5 R & $33 \%$ GBFS $+9 \%$ LS \\
\hline CEM IV/A $32.5 \mathrm{R}$ & $15 \% \mathrm{FA}+17 \% \mathrm{P}$ \\
\hline CEM II/B-M 32.5 R & $14 \% \mathrm{GBFS}+12 \% \mathrm{LS}+5 \% \mathrm{FA}$ \\
\hline CEM II/B-T 42.5 R & Burnt Oil Shale \\
\hline \multicolumn{2}{|l|}{ Portland Cements } \\
\hline CEM I & without LD slag in raw mix \\
\hline CEM I & with LD slag in raw mix \\
\hline CEM I $42.5 \mathrm{R}$ & with chromate reduction \\
\hline $\begin{array}{l}\text { Notes: } \\
\text { GBFS = granulated blas } \\
\text { FA = fly ash } \\
\text { LD = Linz-Donawitz } \\
\text { LS = limestone } \\
\text { P = pozzolan }\end{array}$ & \\
\hline
\end{tabular}




\section{APPENDIX B. Comparison of Leaching Test Results from Portland Cement Mortar, Blended Cement Mortar, Stabilized Waste and Roman Cement Mortar.}

In the graphs shown below the leaching behavior as a function of $\mathrm{pH}(\mathrm{pH}$ dependence test) and as a function of time (monolith leach test) for the following materials are given:

- CEM I cement mortar

- $\mathrm{CEM} \mathrm{II/B} 20 \%$ FA

- Roman cement 2000 year (fully carbonated)

- $\mathrm{CEM}$ III/B $80 \%$ GBFS

- $\mathrm{CEM}$ V/A 32\%GBFS+20\%FA

- CEM II/B 29\% GBFS

- $\mathrm{CEM}$ II/B 33\% FA

- Cement stabilized MSWI fly ash

Graphs for the following elements are given in the figures indicated:

Fig. B.1.

Fig. B.2.

$\mathrm{Al}, \mathrm{As}, \mathrm{B}$

Fig. B.3.

$\mathrm{Ba}, \mathrm{Ca}, \mathrm{Cd}$

Fig. B.4.

$\mathrm{Cl}, \mathrm{Co}, \mathrm{Cr}$

Fig. B.5.

$\mathrm{Cu}, \mathrm{Fe}, \mathrm{K}$

Fig. B.6.

$\mathrm{Li}, \mathrm{Mg}, \mathrm{Mn}$

Fig. B.7.

$\mathrm{Mo}, \mathrm{Na}, \mathrm{Pb}$

Fig. B. 8 .

$\mathrm{SO}_{4}$ as $\mathrm{S}, \mathrm{Sb}, \mathrm{Se}$

Fig. B.9.

$\mathrm{Si}, \mathrm{Sn}, \mathrm{SO}_{4}$

Fig. B.10.

$\mathrm{Sr}, \mathrm{V}, \mathrm{Zn}$

DOC

The first graph gives the release as a function of $\mathrm{pH}$, the second graph shows the concentration in eluates from the monolith leach test as a function of time. The third graph shows the cumulative release expressed in $\mathrm{mg} / \mathrm{m}^{2}$ as a function of time and the fourth graph shows the $\mathrm{pH}$ as a function of time (days).

The Roman is fully carbonated, which is reflected in the behavior of many elements, but in particular in $\mathrm{Ca}$, $\mathrm{Mg}$, and $\mathrm{Sr}$. 

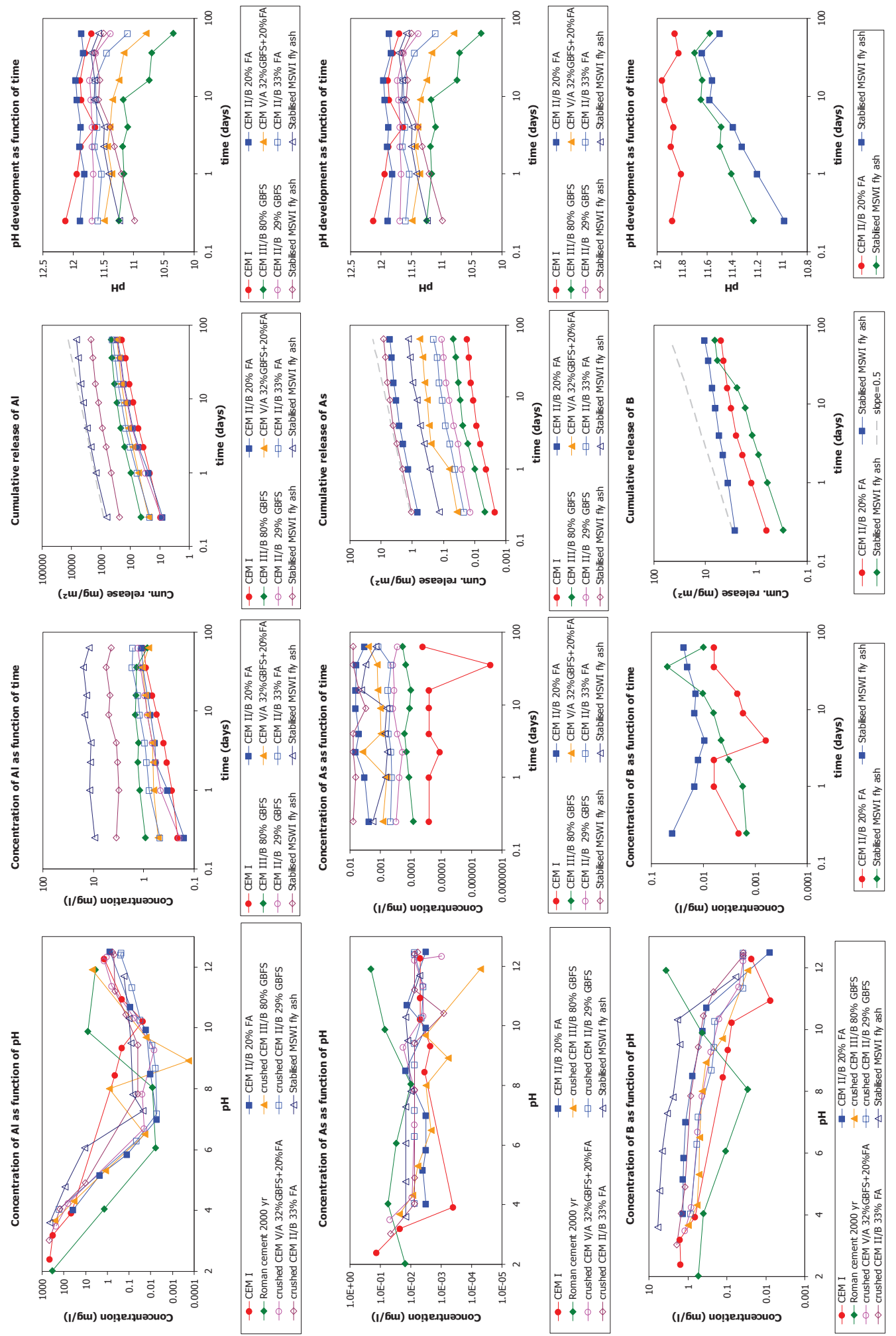

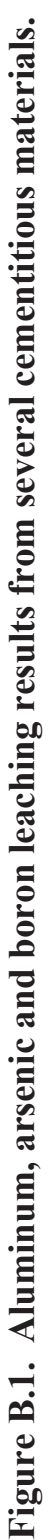



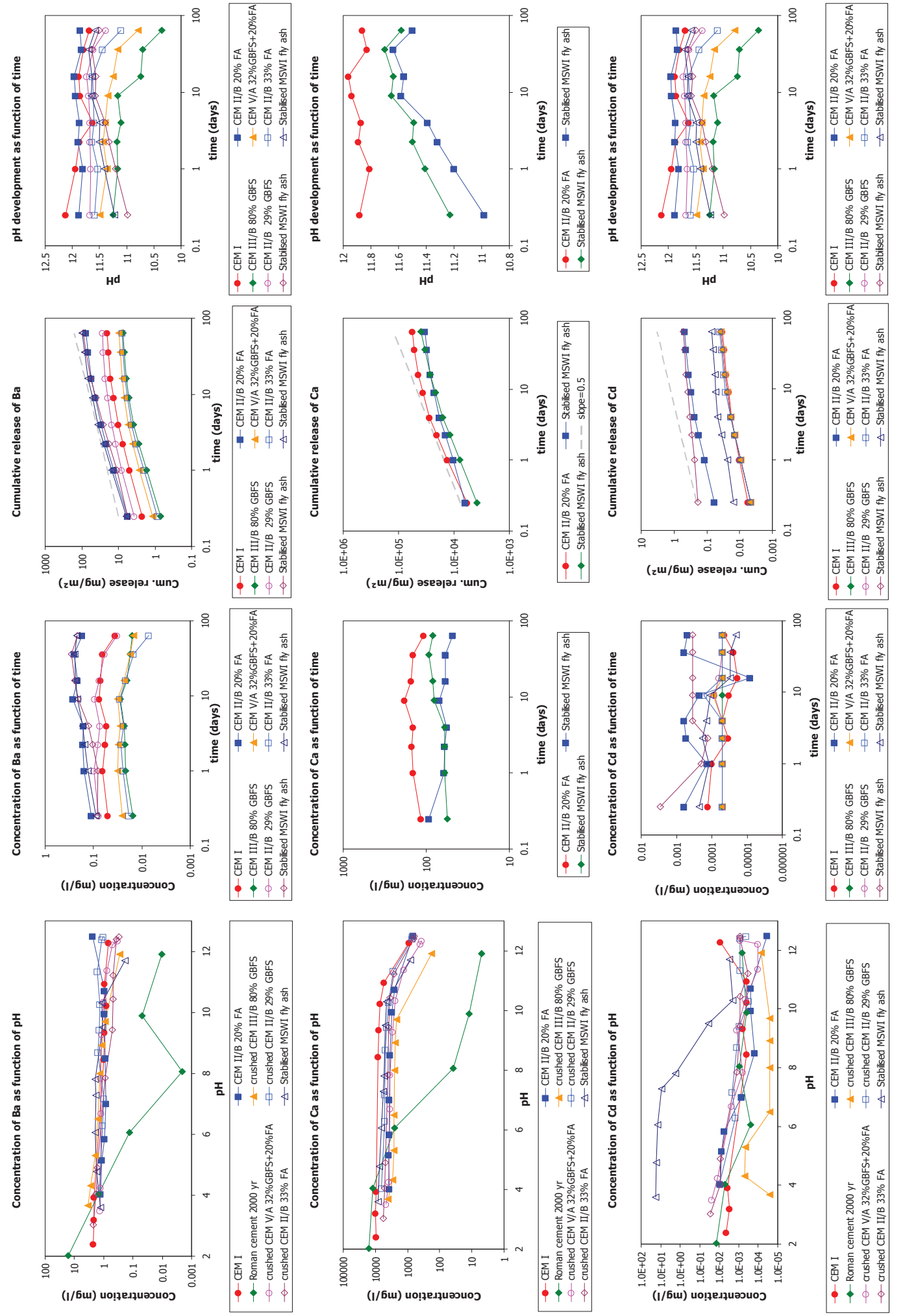

อี 

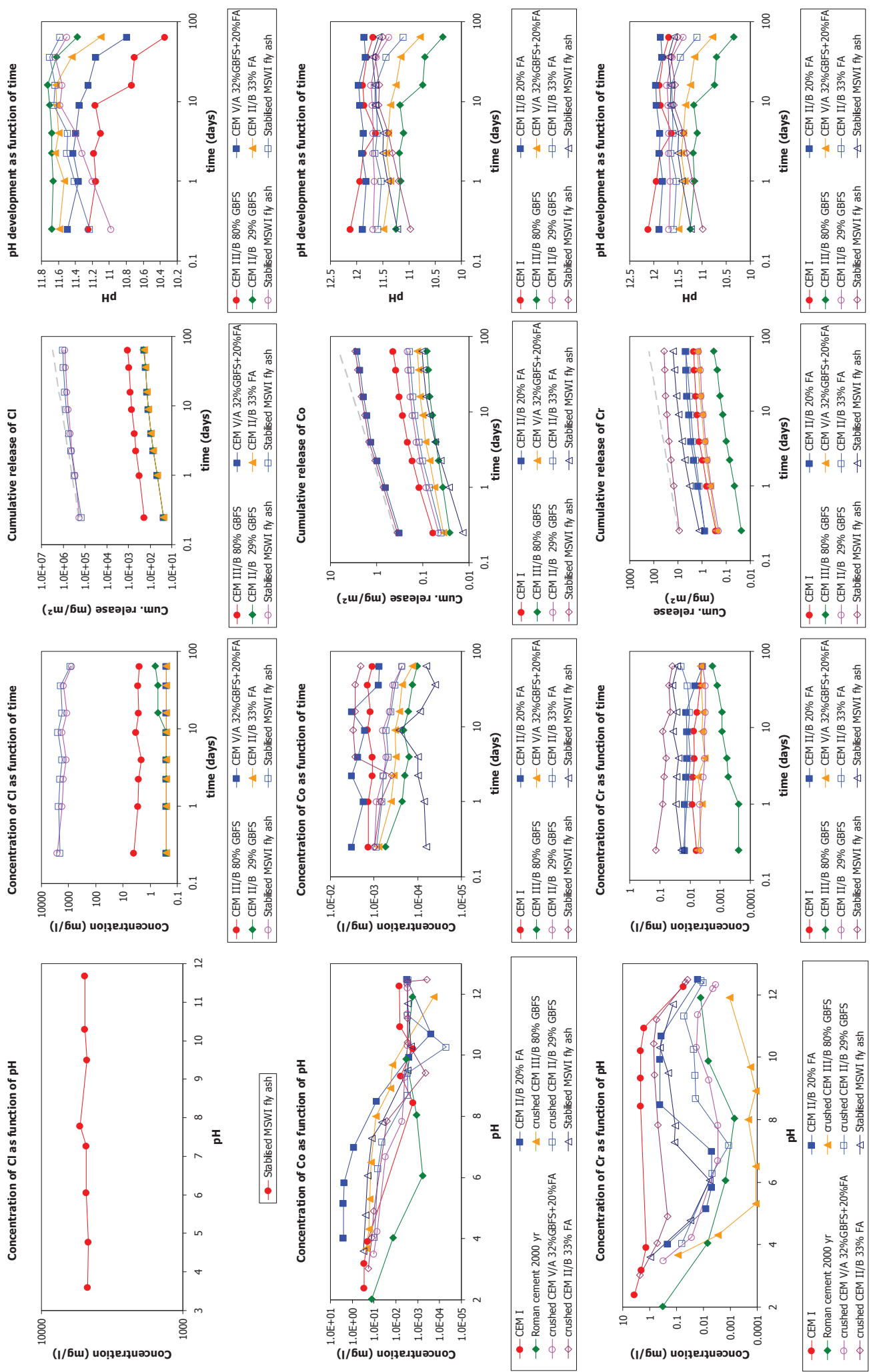

فํ. 

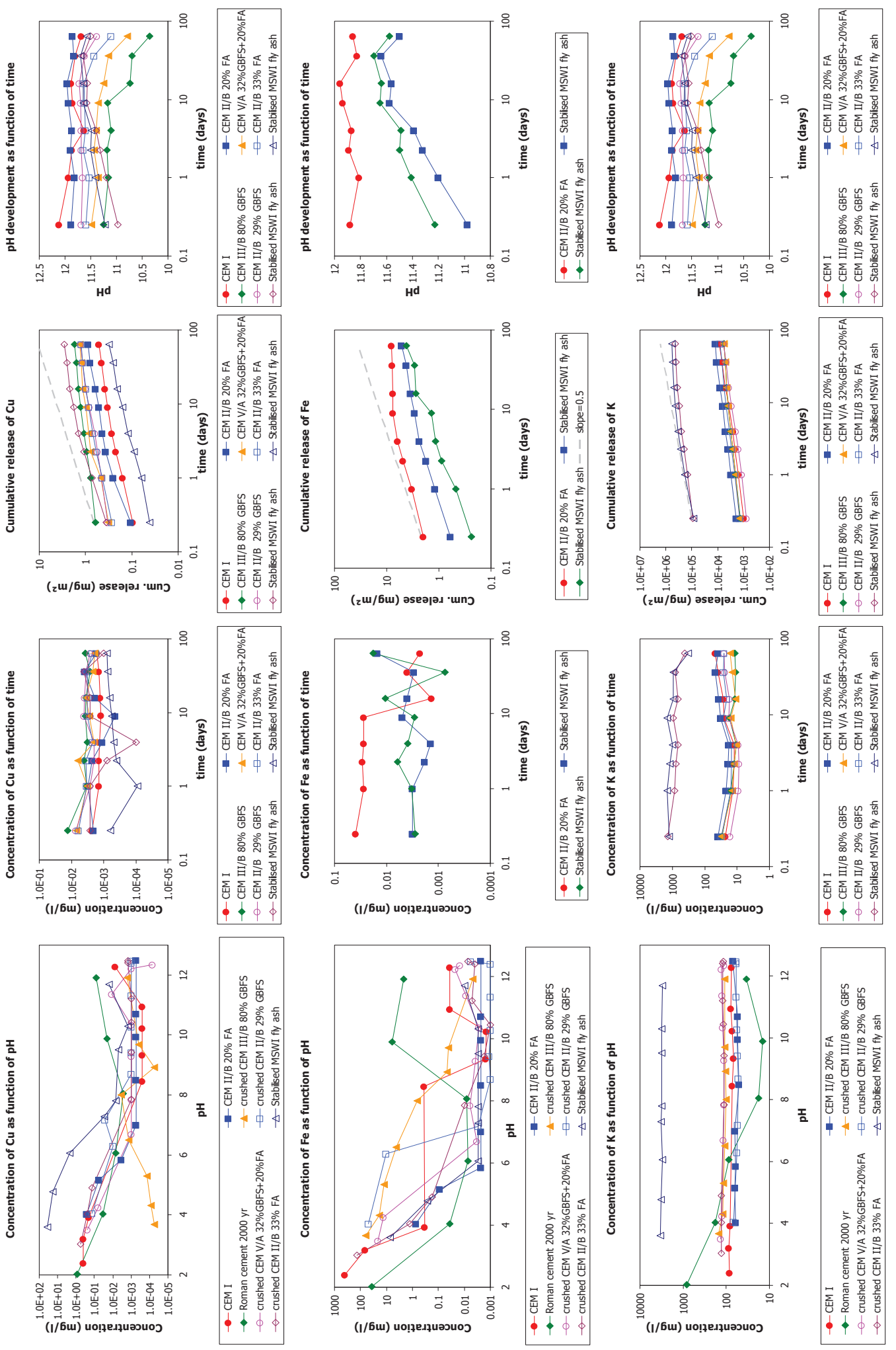

فํ. 

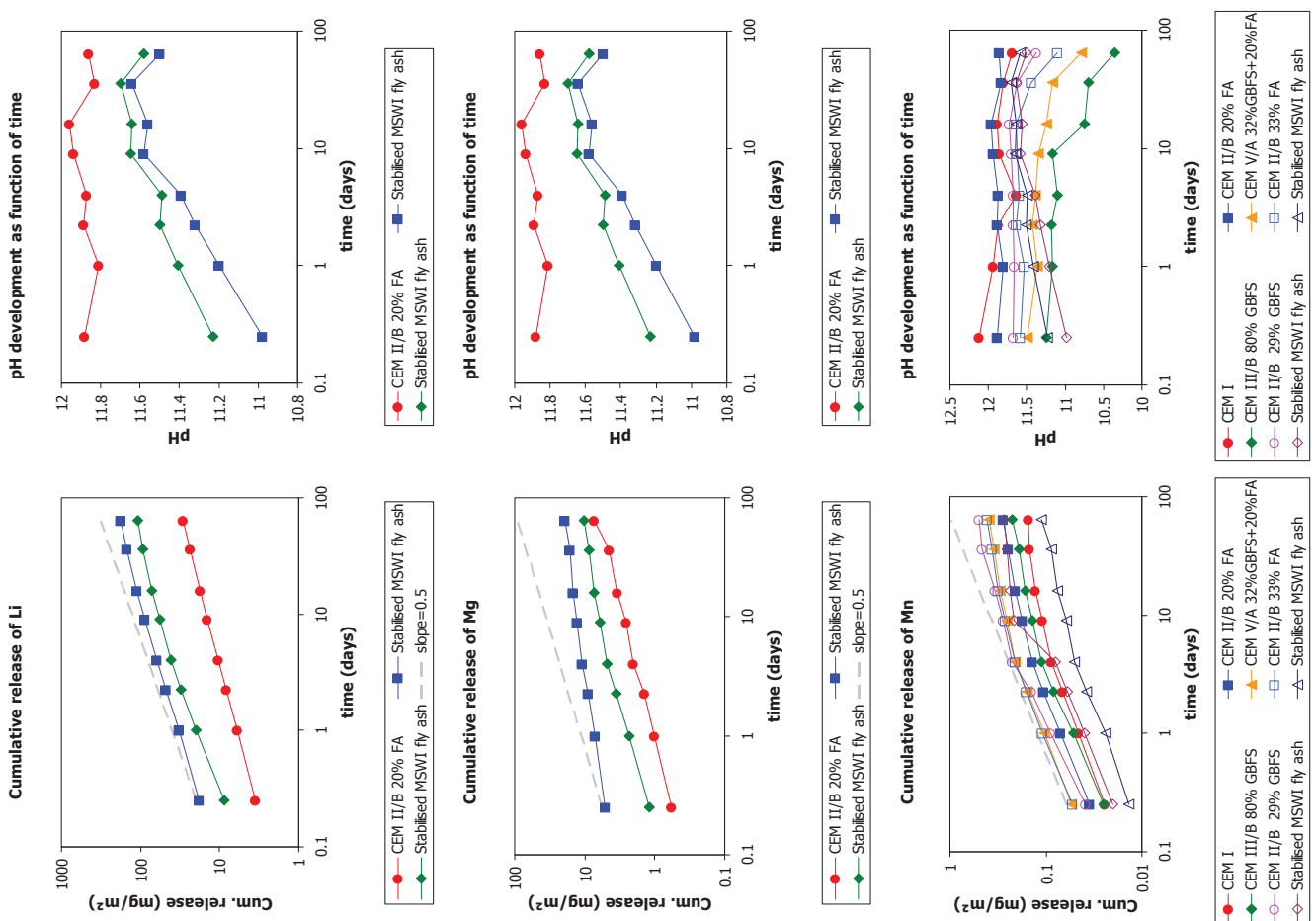

.
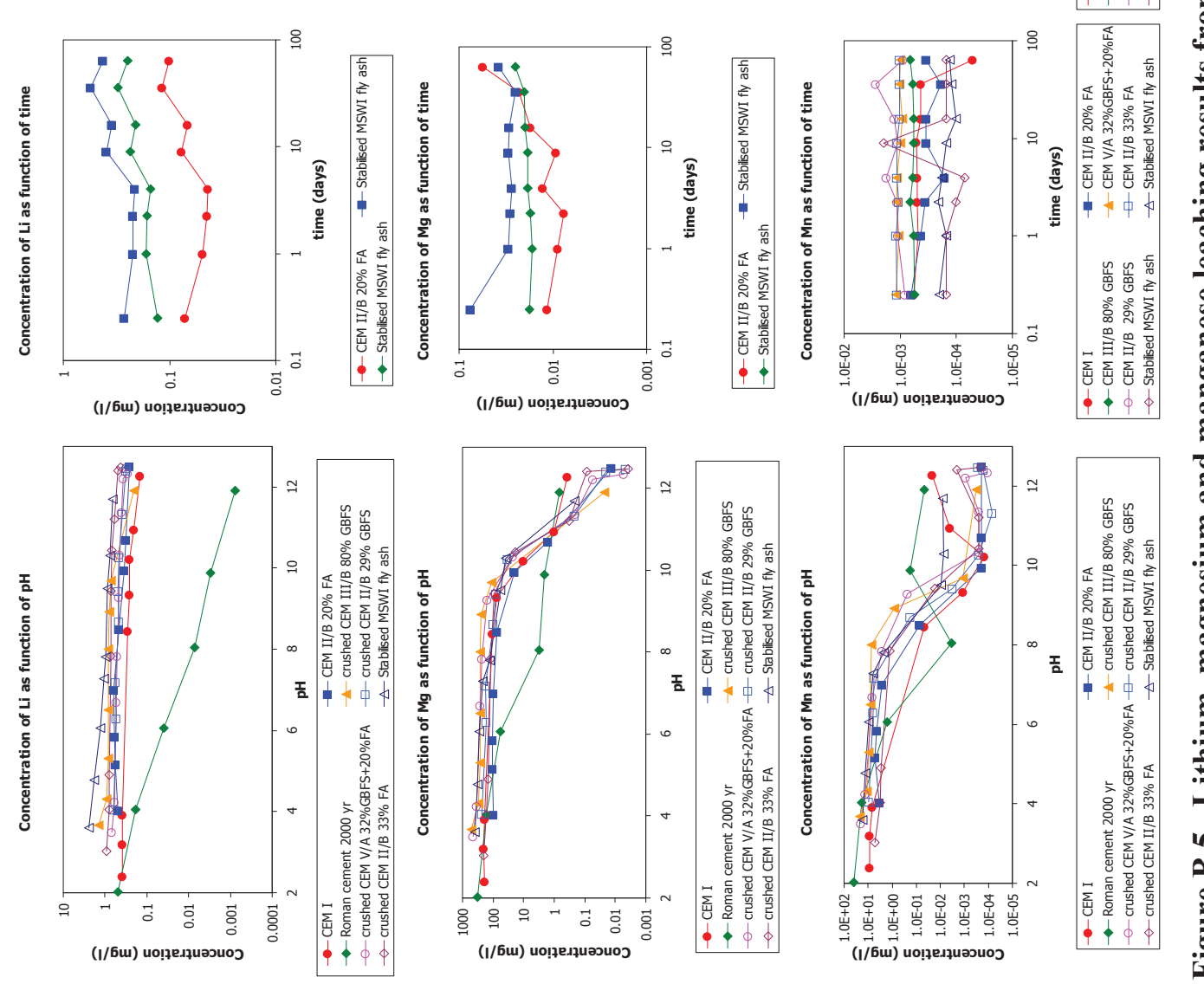

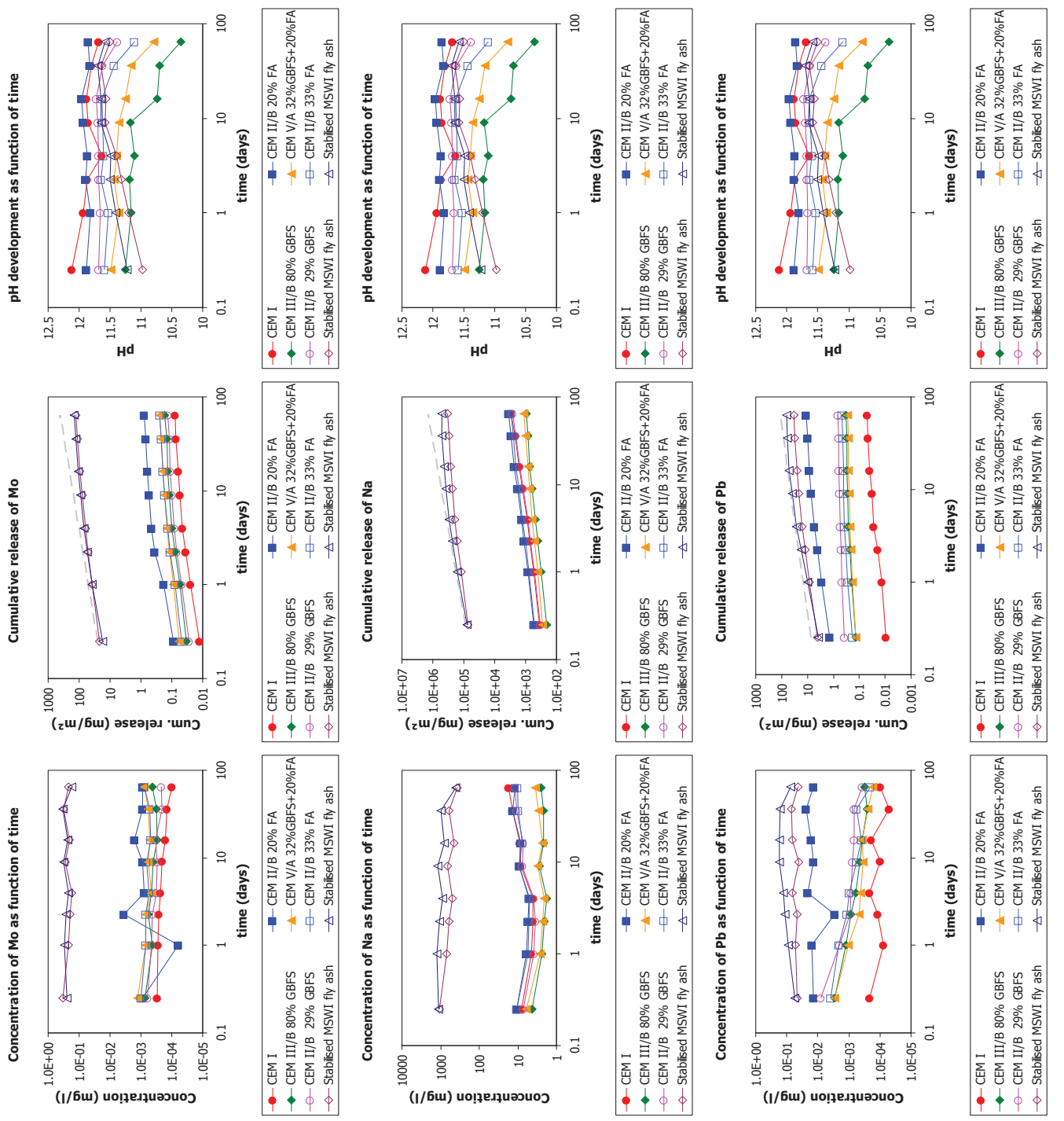

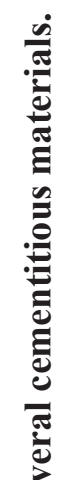
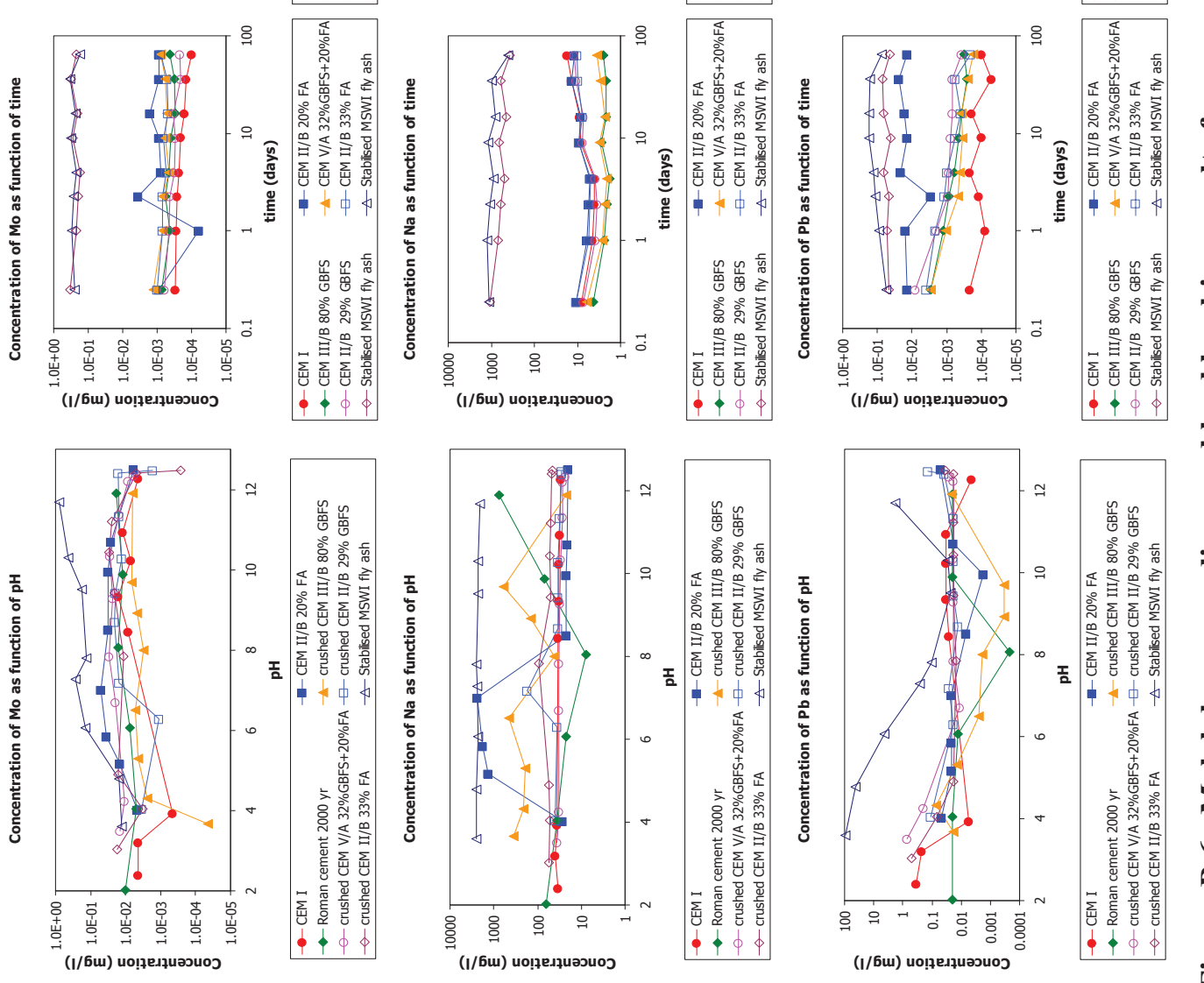

อ 

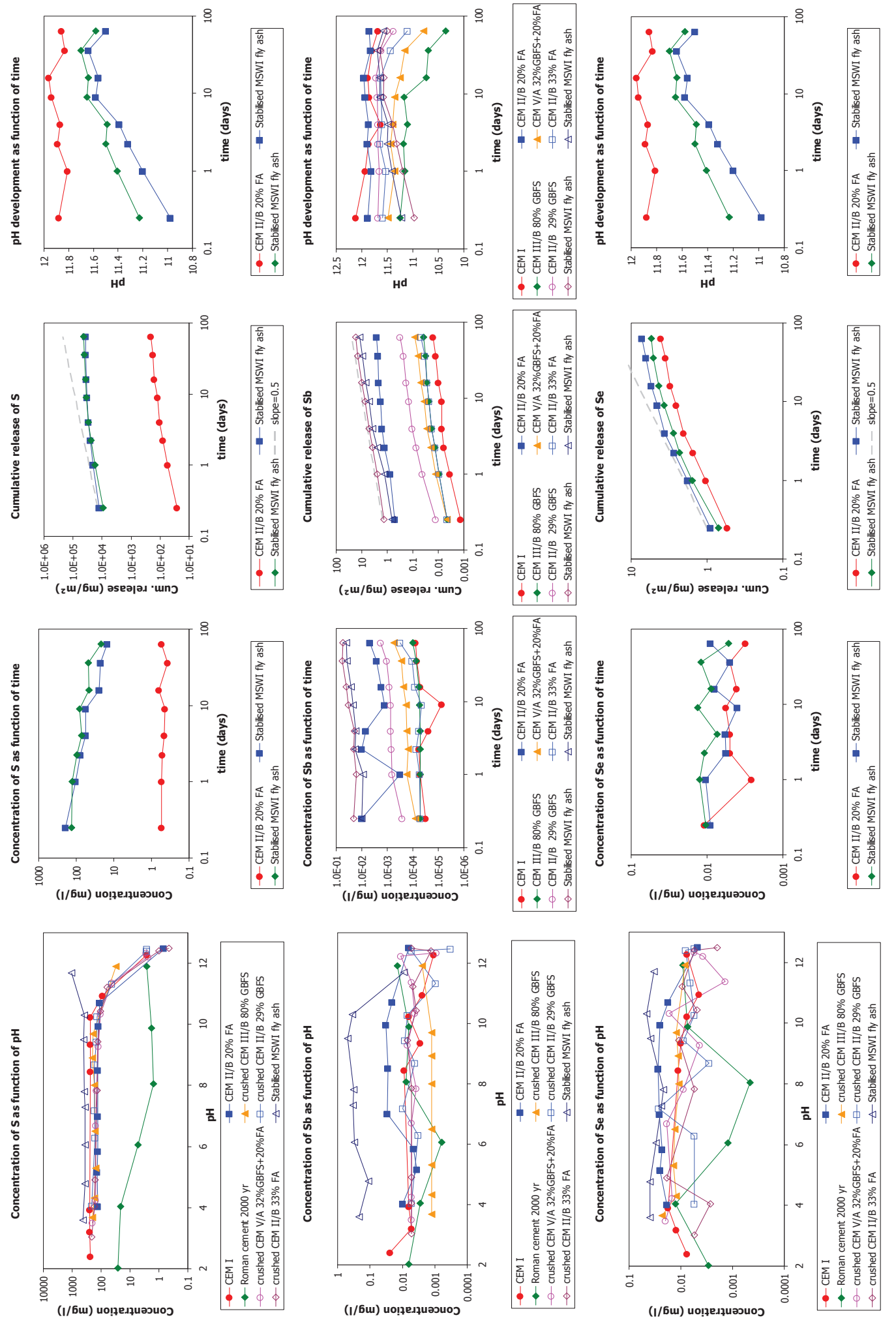

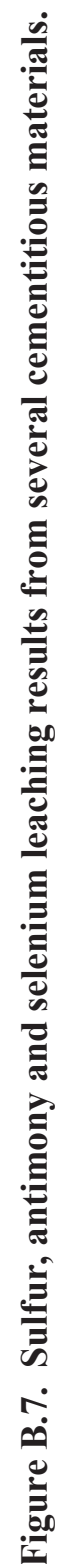



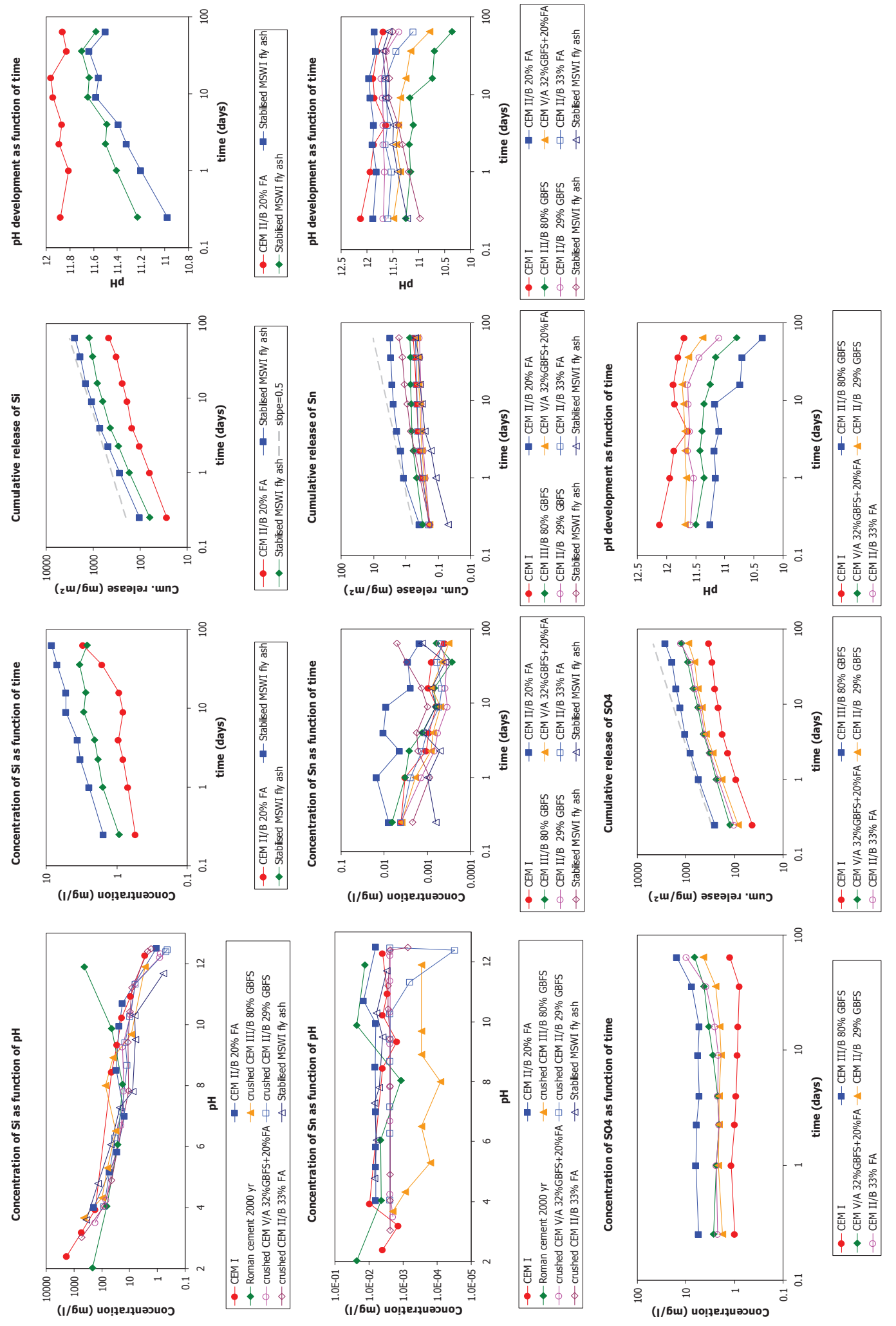

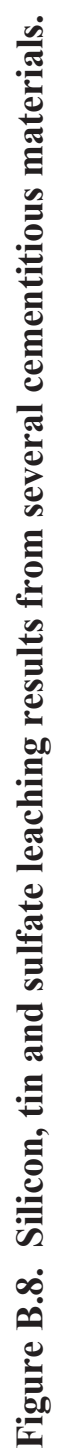



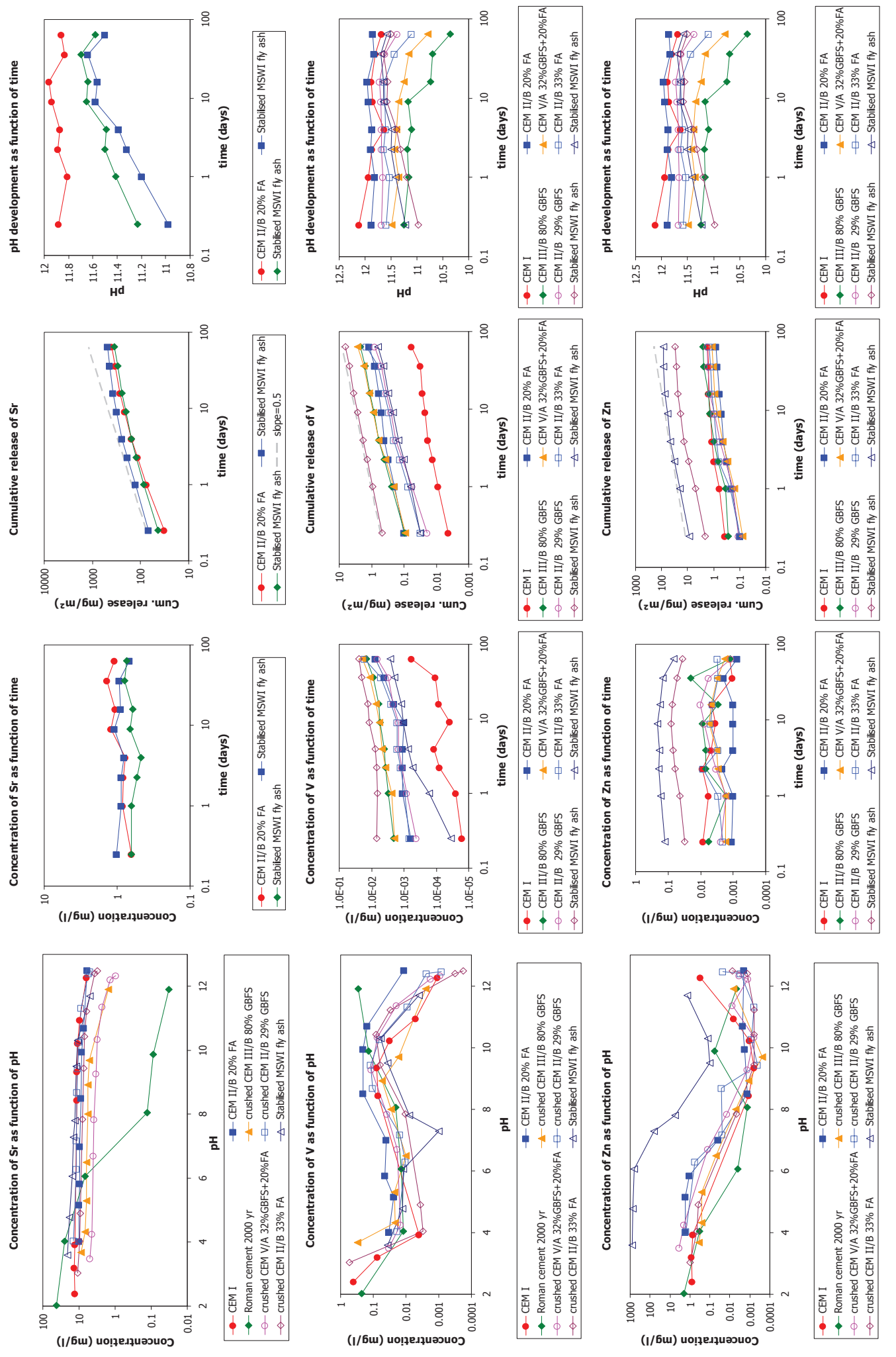

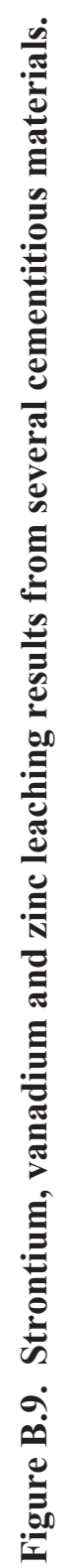


Review of Mechanistic Understanding and Modeling and Uncertainty Analysis Methods for Predicting Cementitious Barrier Performance

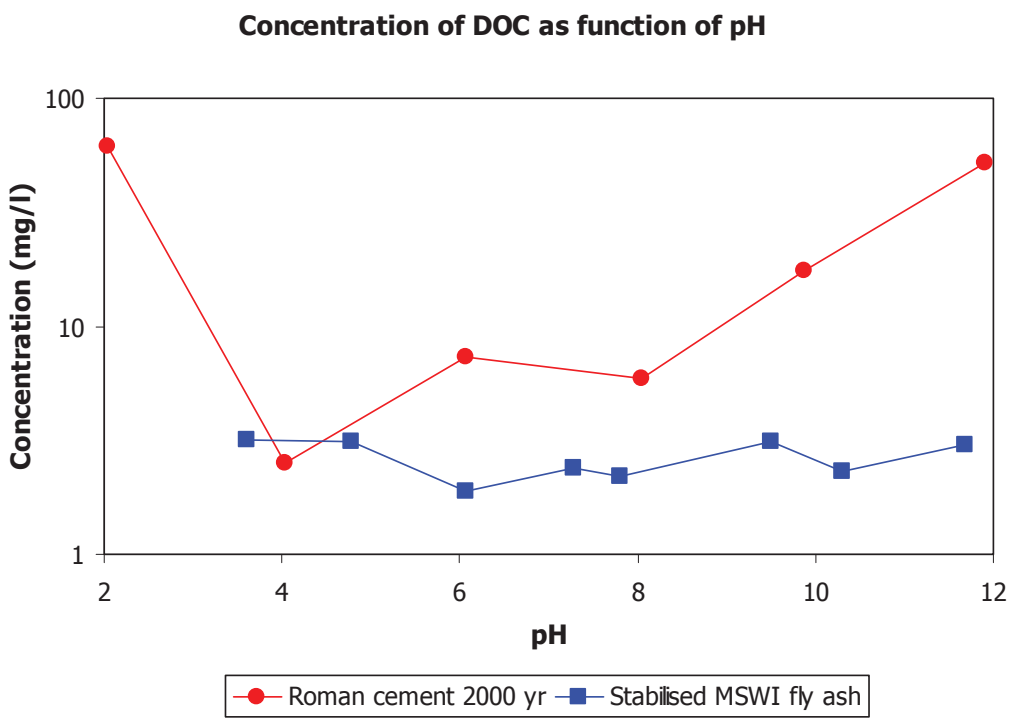

Figure B.10. Acid neutralization capacity of stabilized MSWI fly ash and roman cement. 


\section{APPENDIX C. Acid Neutralization Capacity.}

The acid neutralization capacity (ANC) in combination with field exposure properties like acidification, carbonation and other sources of neutralization dictate how long it takes for the surface of the specimen to be neutralized. This will in turn lead to another leaching characteristic than the fresh product.

The $\mathrm{pH}$ dependence test provides a very valuable means of evaluating environmental behavior of cement mortar than any other test. The $\mathrm{pH}$ dependence test data cover a wide range of potential exposure conditions service life (own $\mathrm{pH}$ and externally imposed $\mathrm{pH}$ ), recycling stage as aggregate and end-of-life conditions after full carbonation.

The results derived from the $\mathrm{pH}$ dependence test for the cements studied in ECRICEM I and II are given to indicate generic behavior in Figure C.1. Blended cements generally show a lower ANC than regular Portland cements.

The ANC of cement-based products is high (Figure C.1). Therefore only the surface of cement-based products can be neutralized and thus shows leaching characteristics corresponding to the neutral $\mathrm{pH}$. Element solubility is controlled by different conditions within the mortar and on the surface of a carbonated specimen. Since the surface is in direct contact with the surrounding environment, this condition is more determining for the release than the highly alkaline interior of the material.

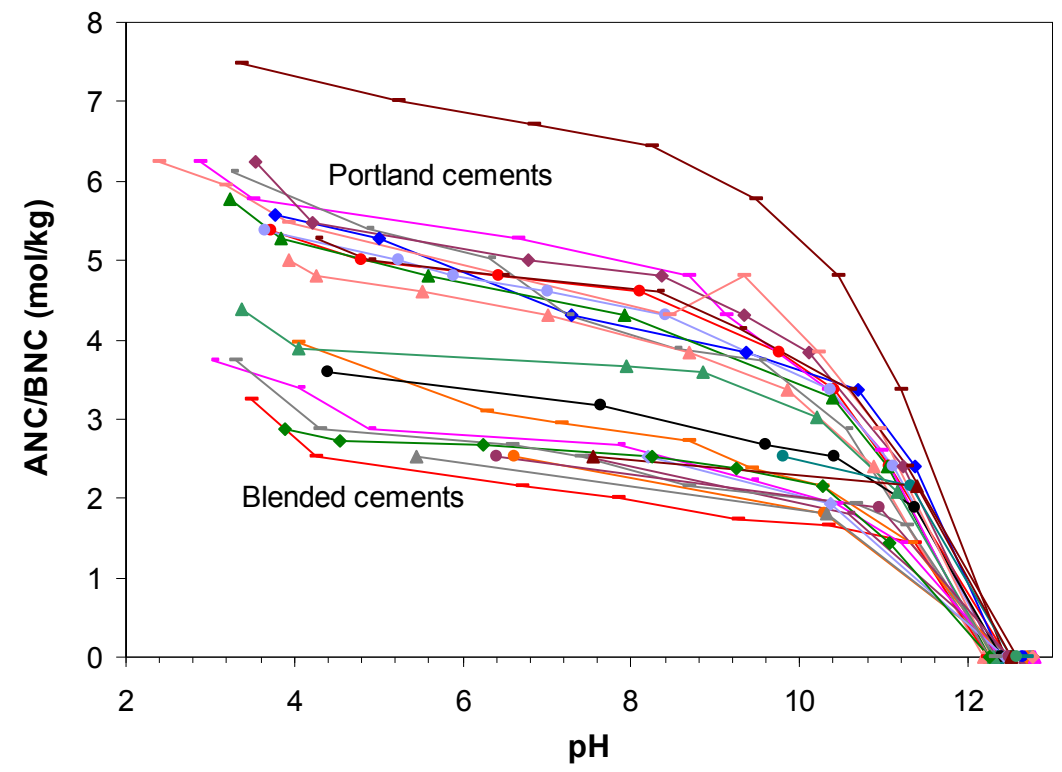

Figure C.1. Acid neutralization capacity of cement mortars from the $\mathrm{pH}$ dependence leaching test. 


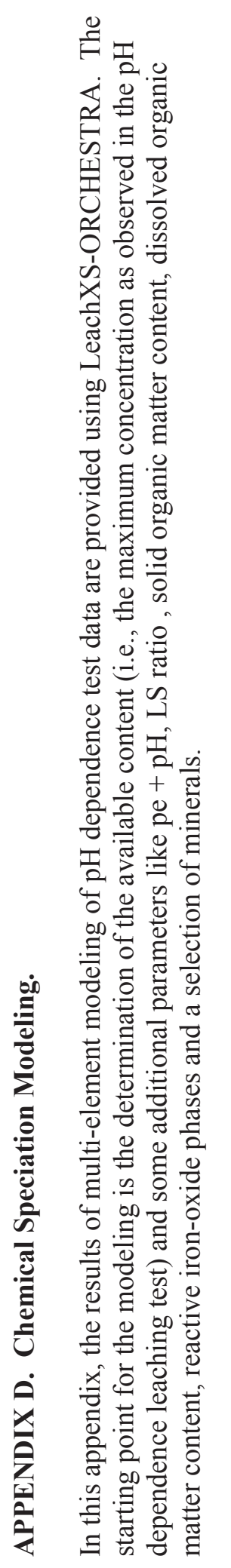

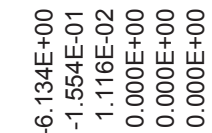
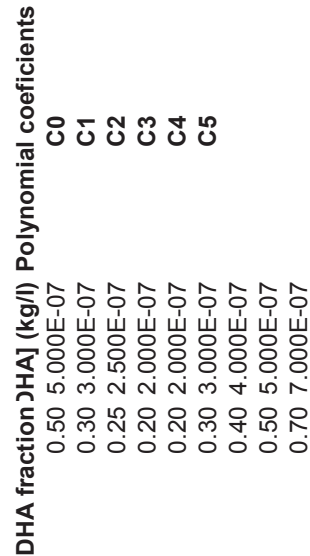

$\widehat{-} 888888888$

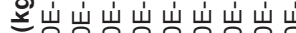

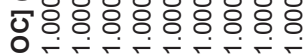

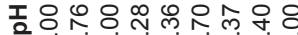

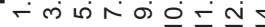

$\frac{\pi}{0}$
$\frac{1}{1}$
0
0

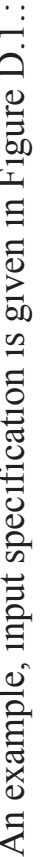

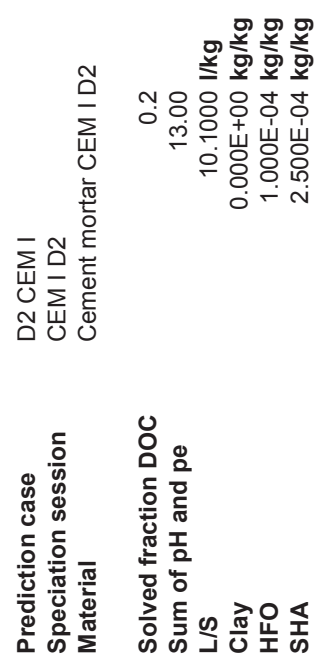

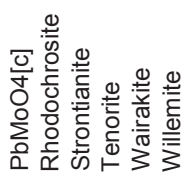
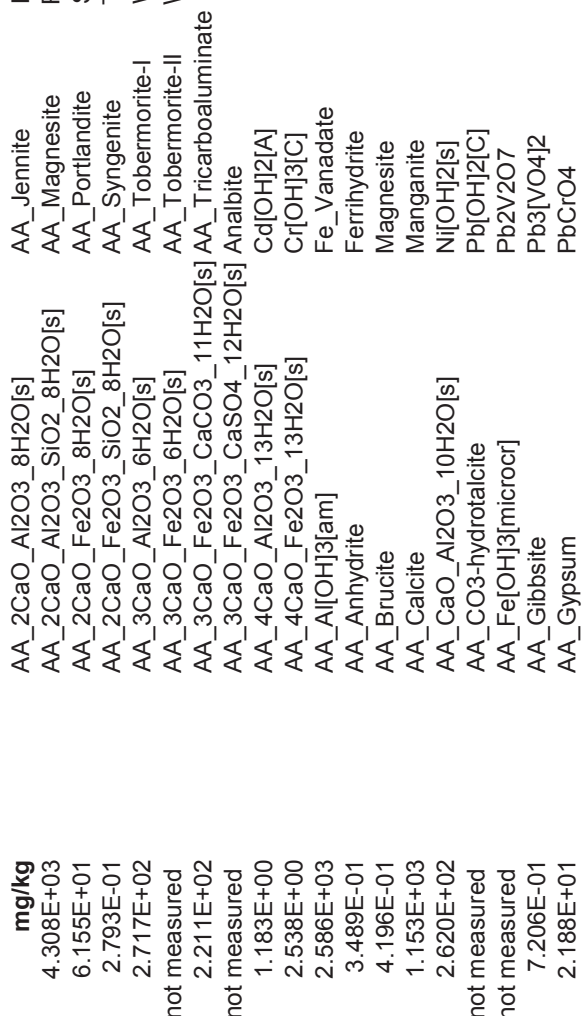

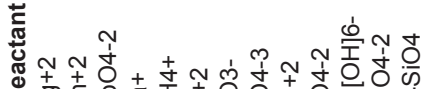
뭉

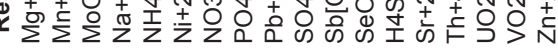

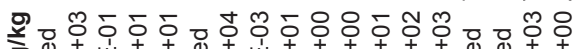

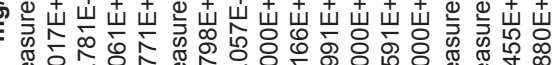
嵅 후

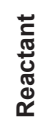
무 모

흐

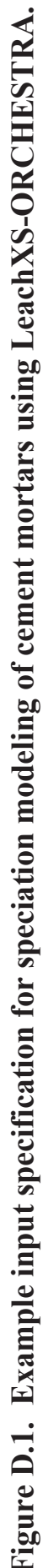



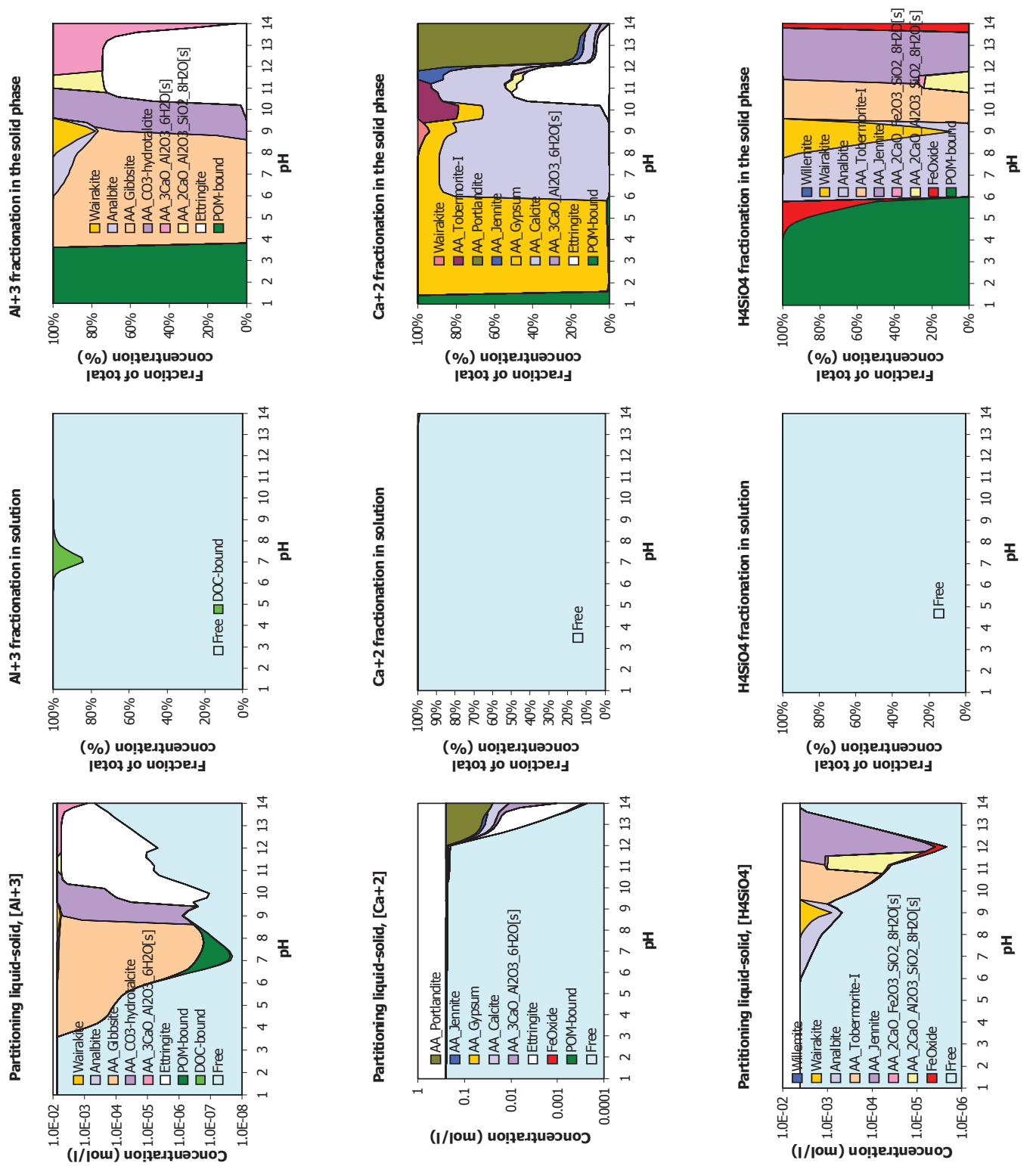

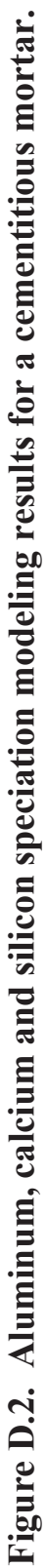
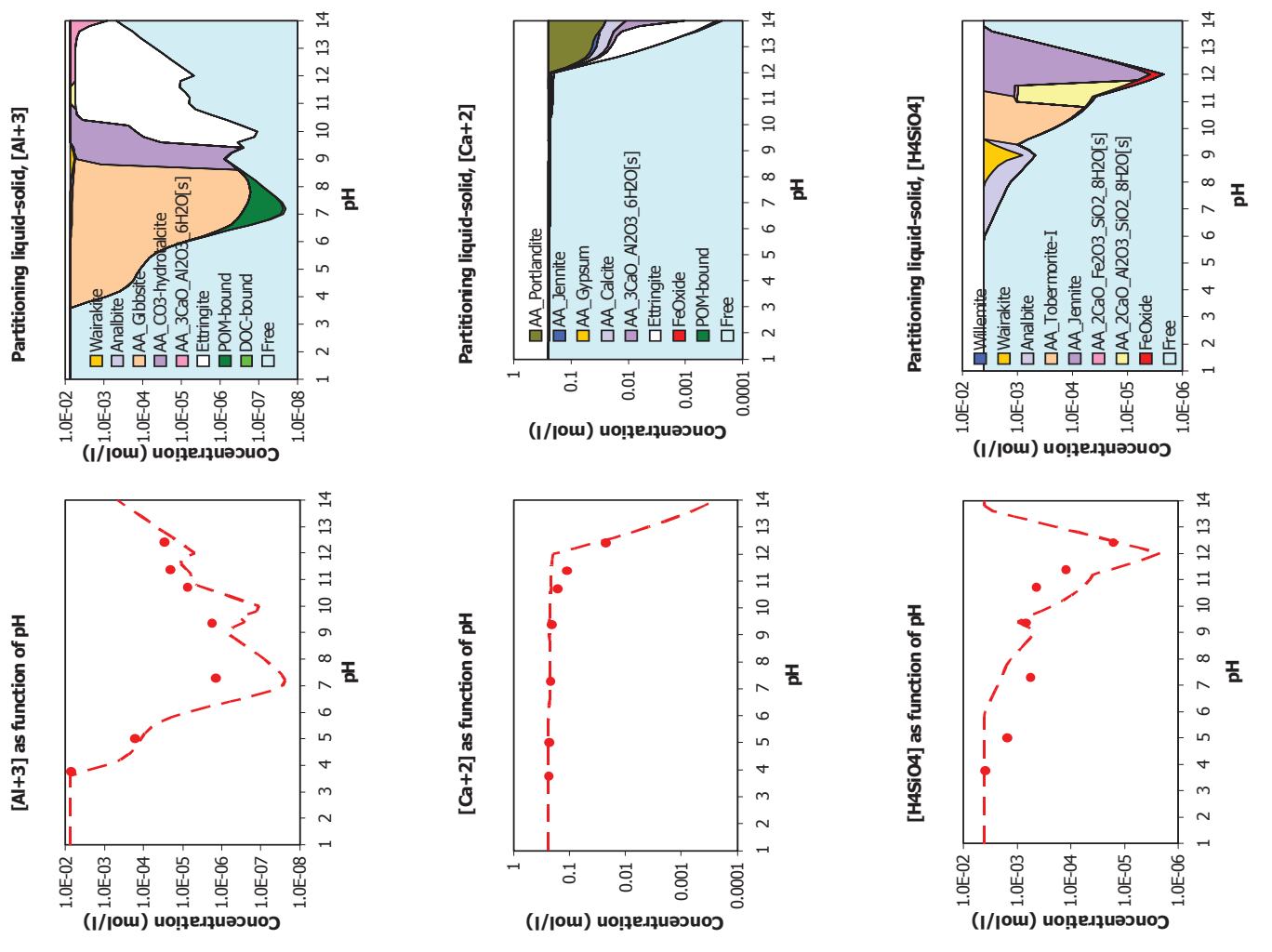

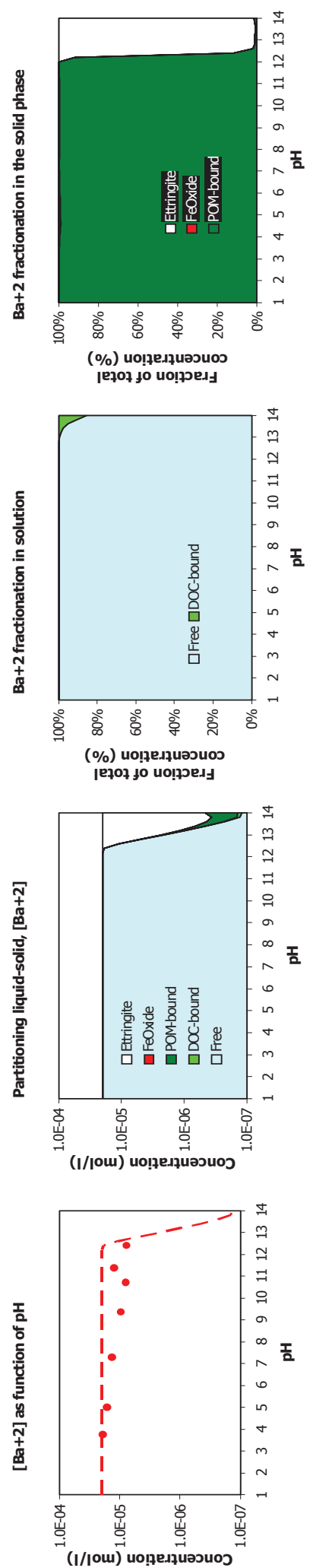
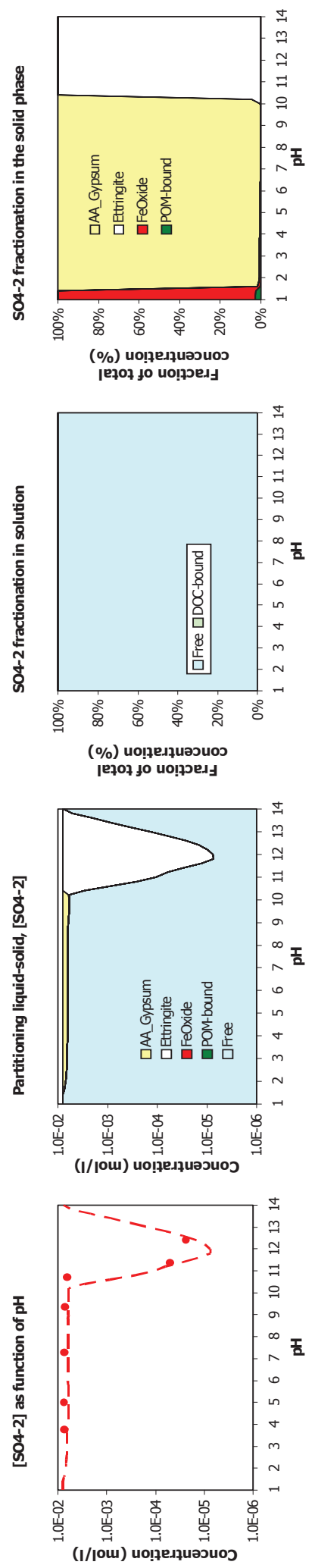

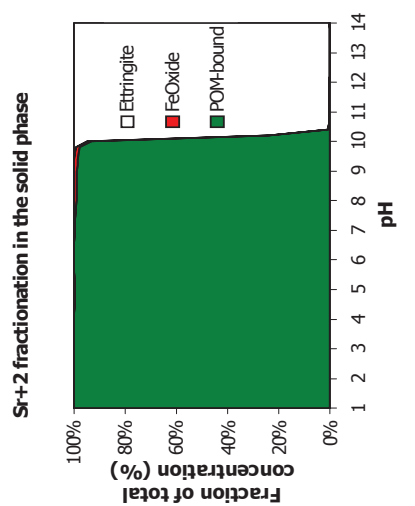

\%) uo!pexpuasuos

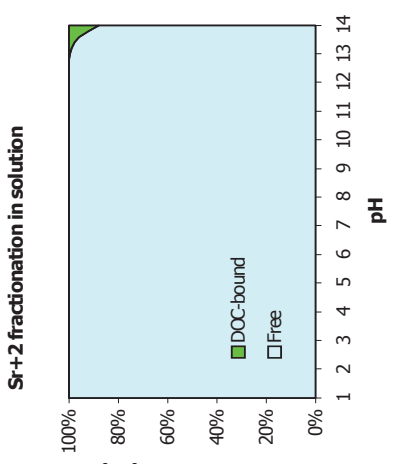

(\%) uo!łenұəวuо

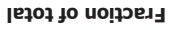
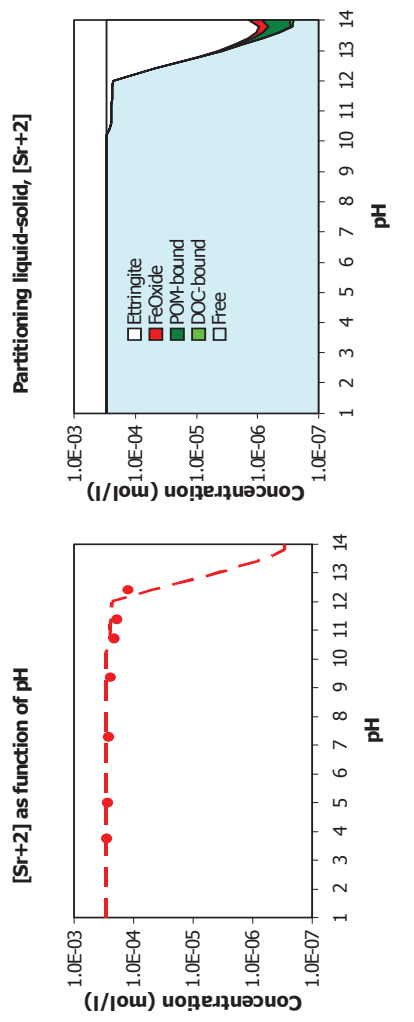

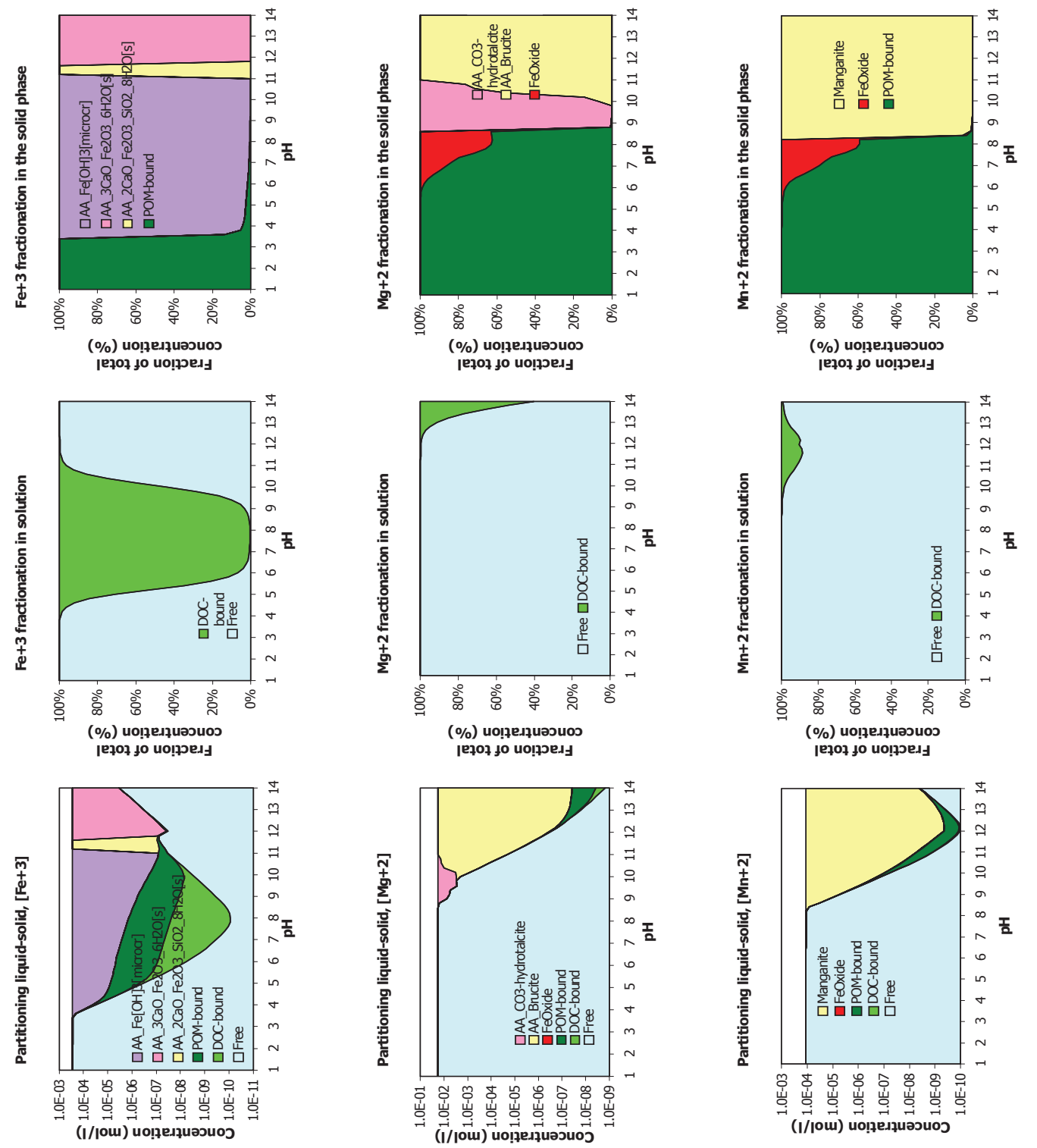

苞
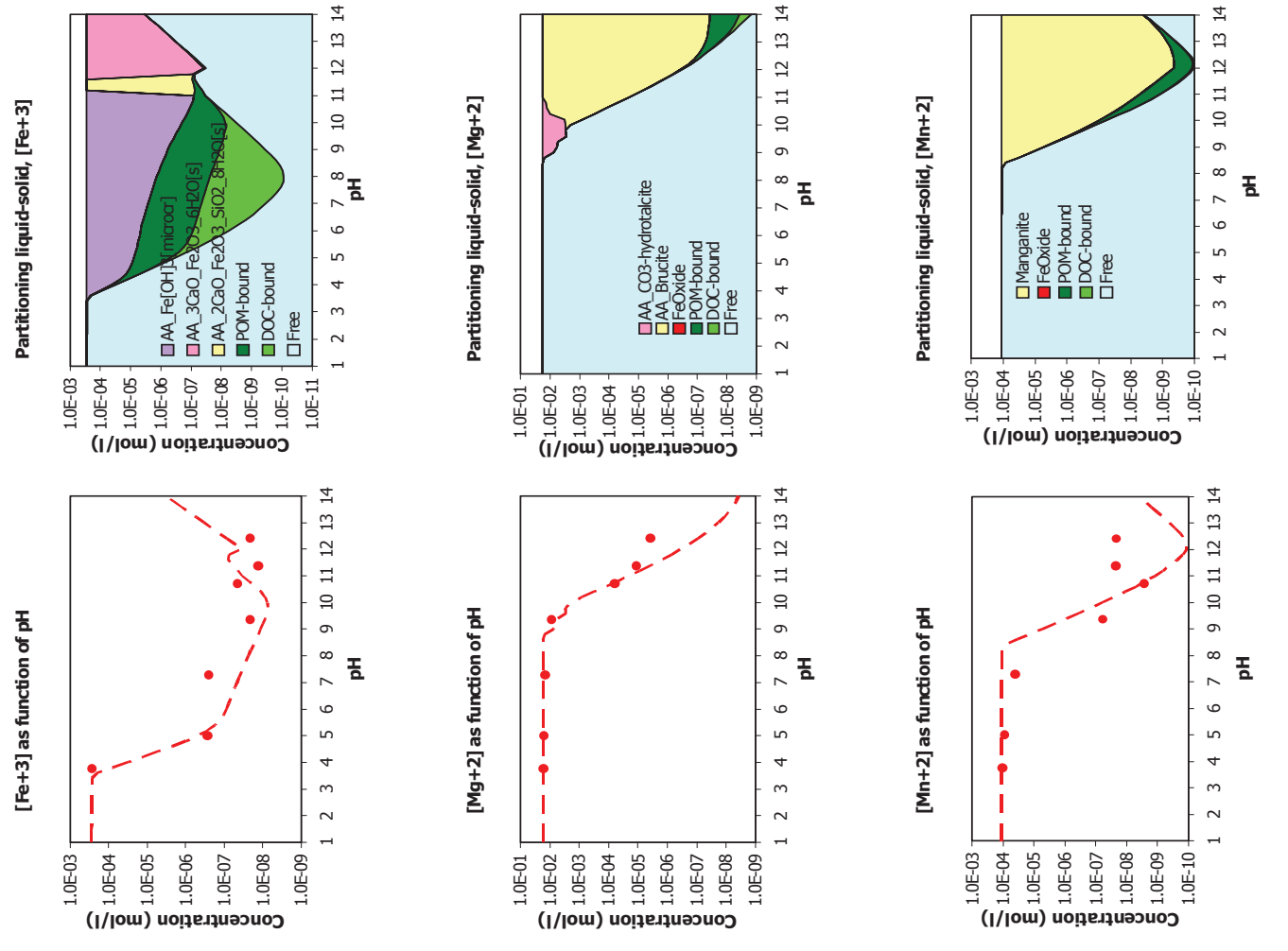

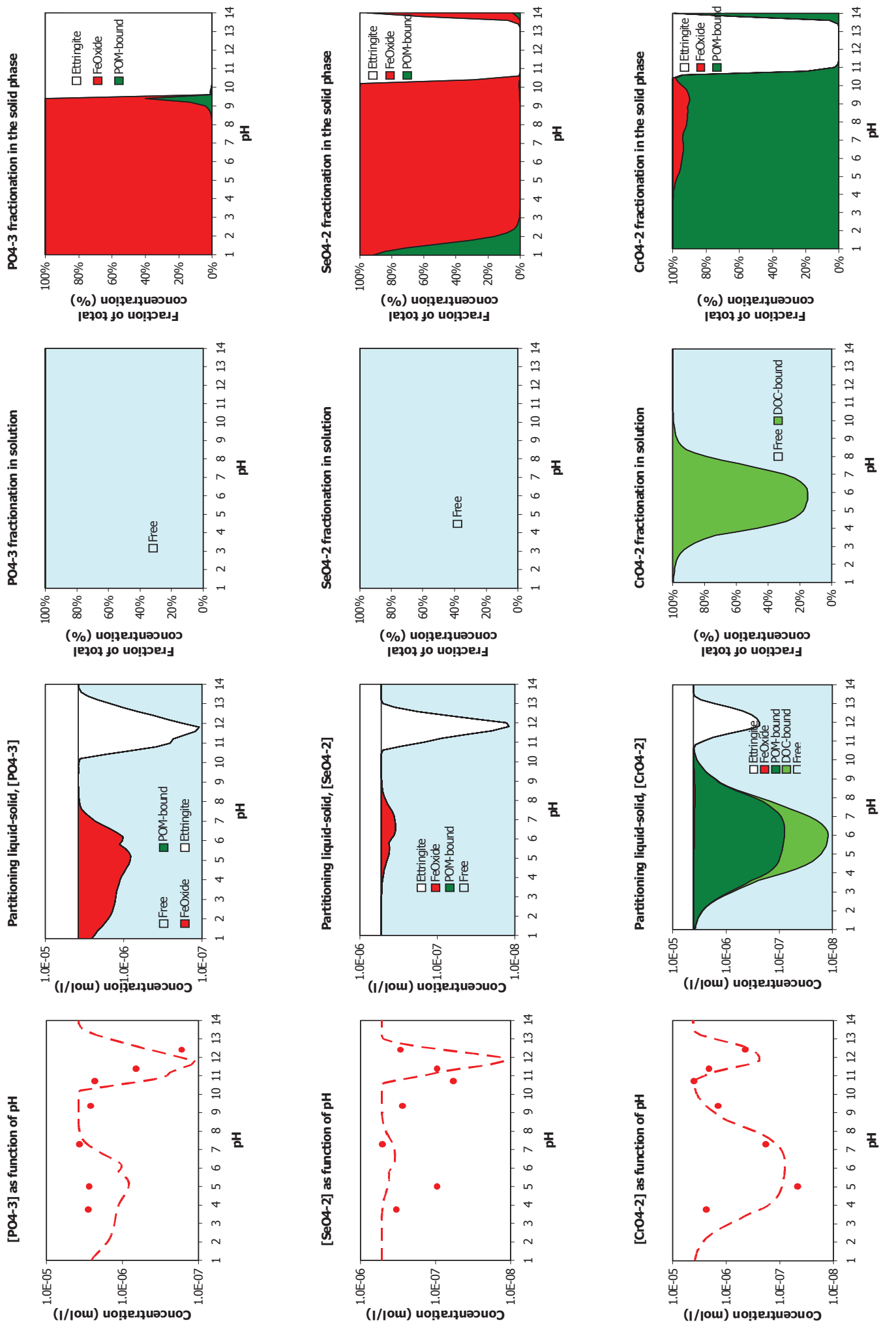

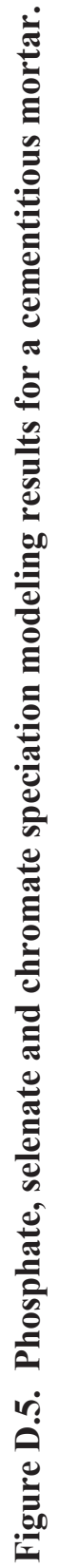



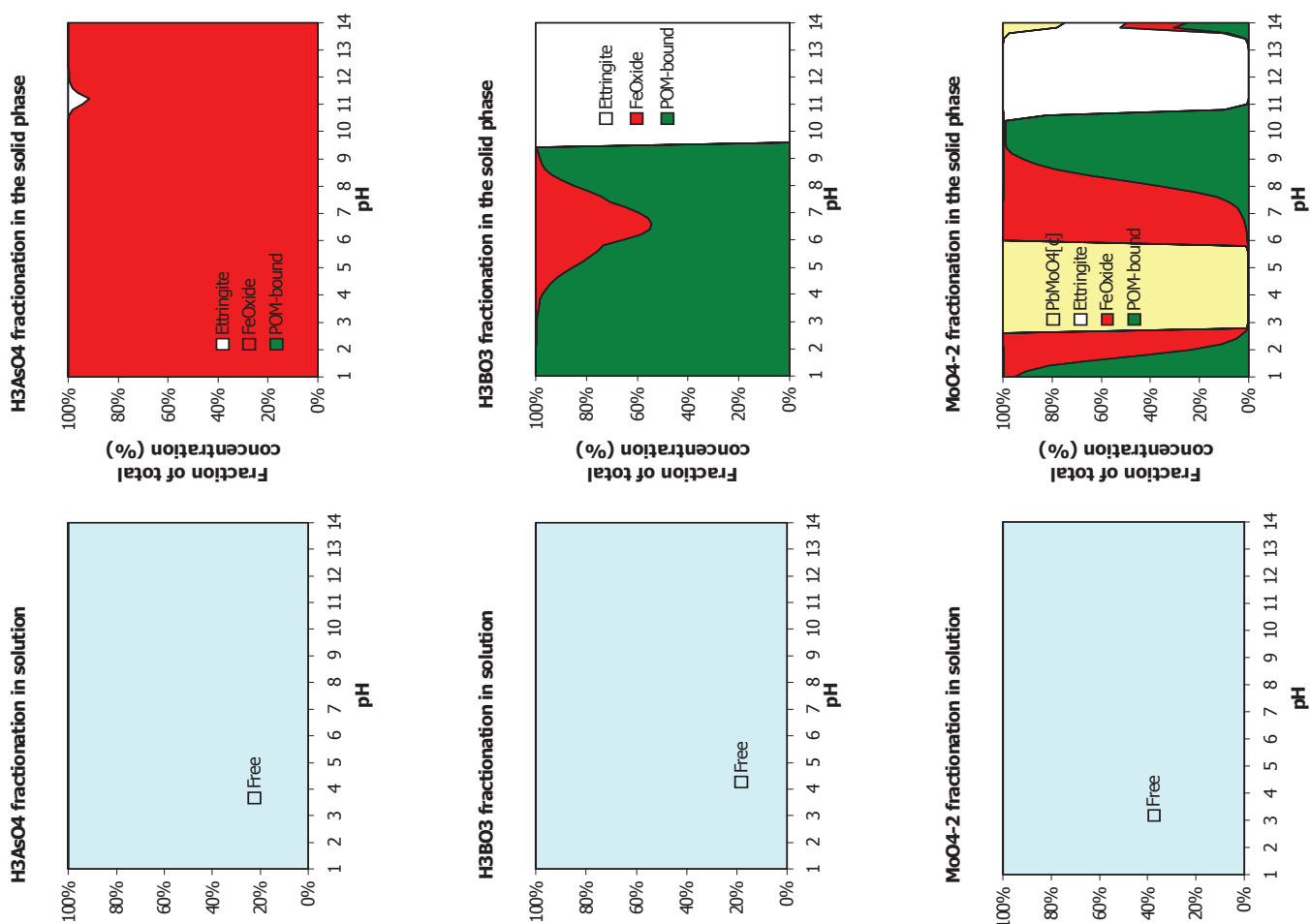

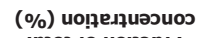
ןе707 jo uo!posed
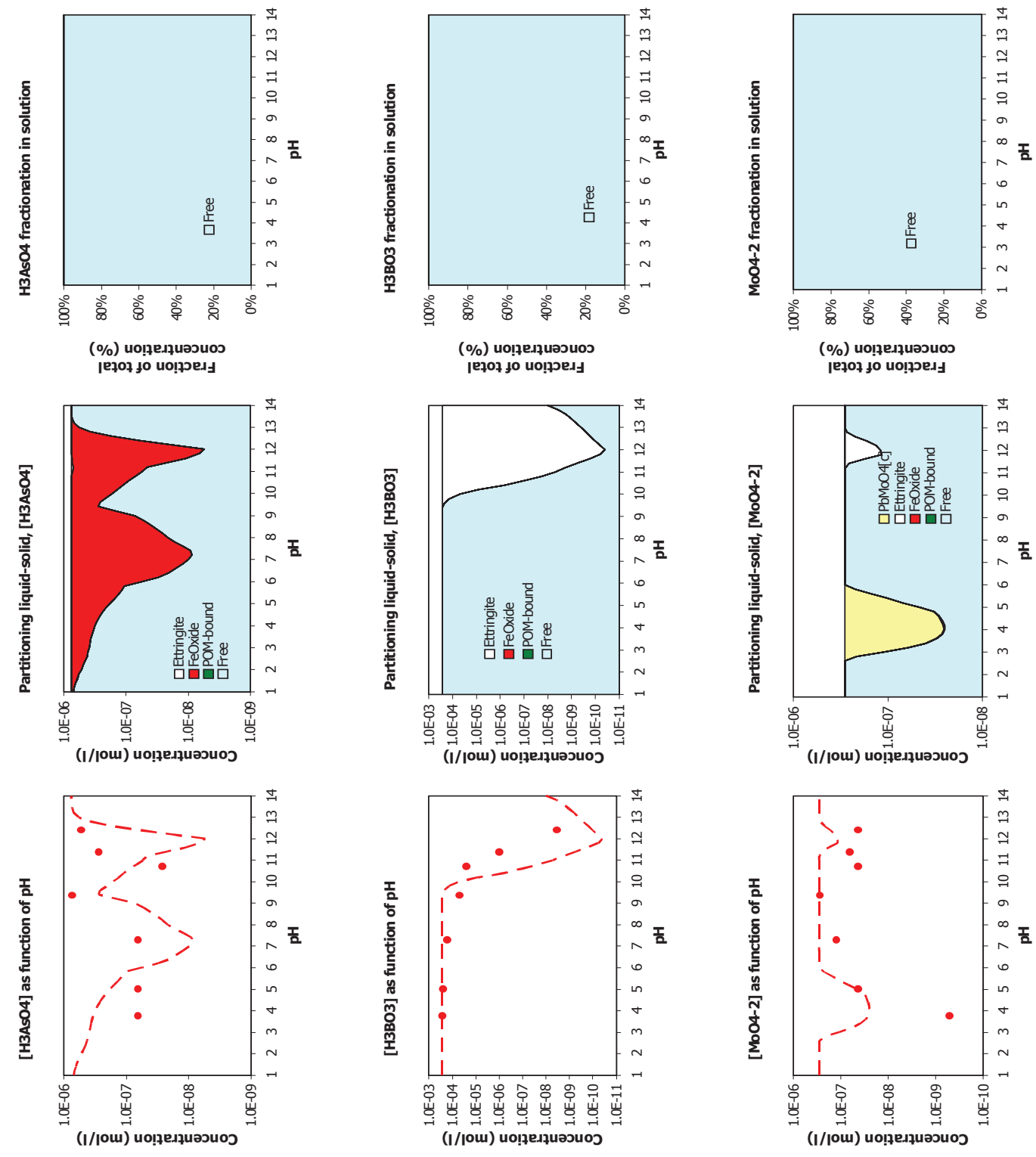

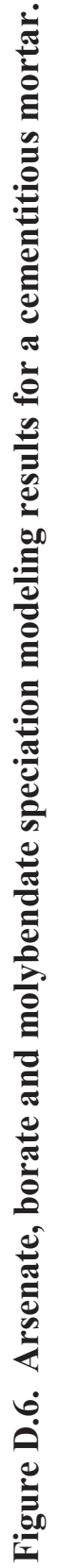



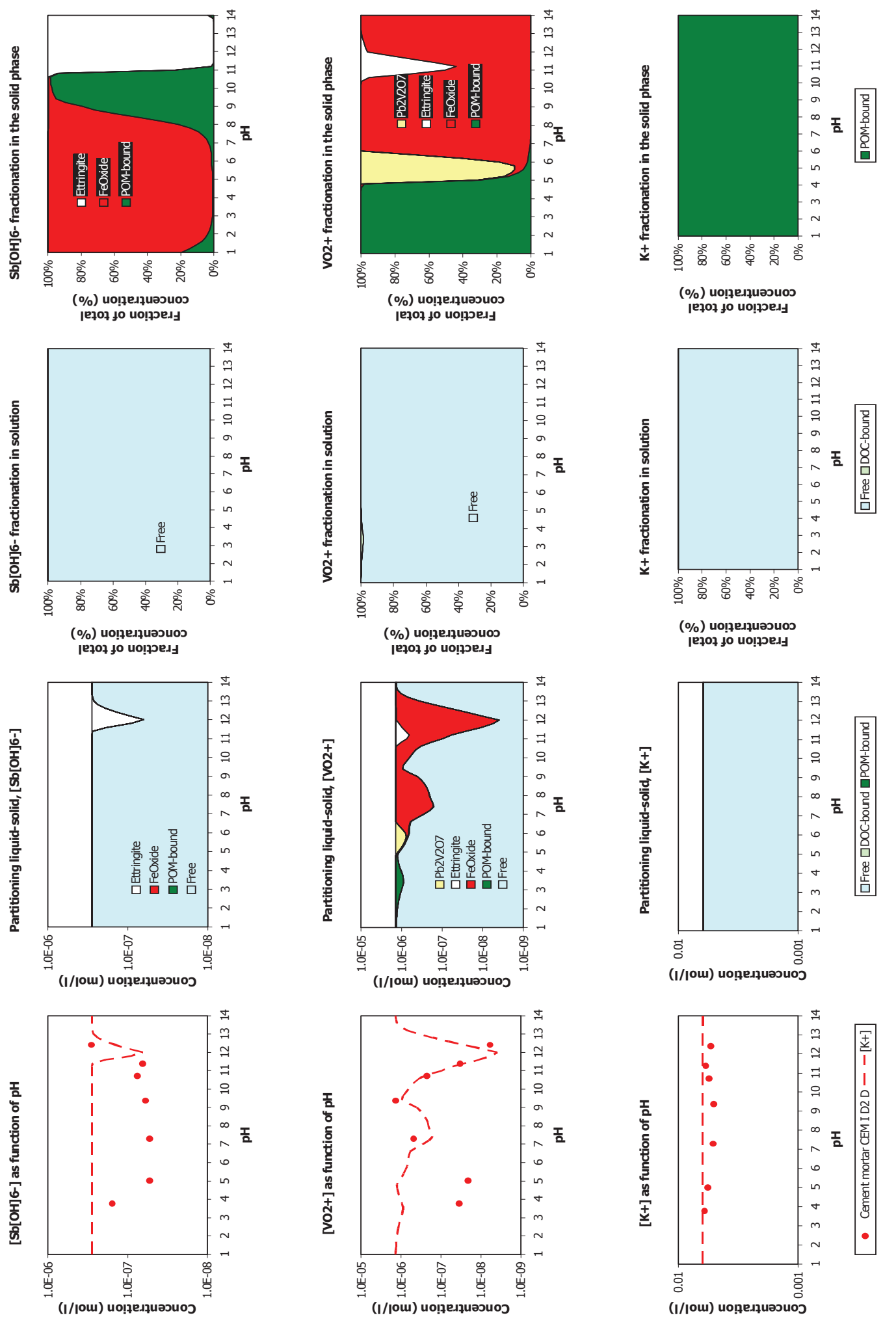

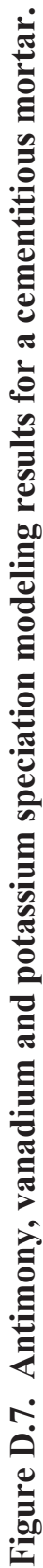



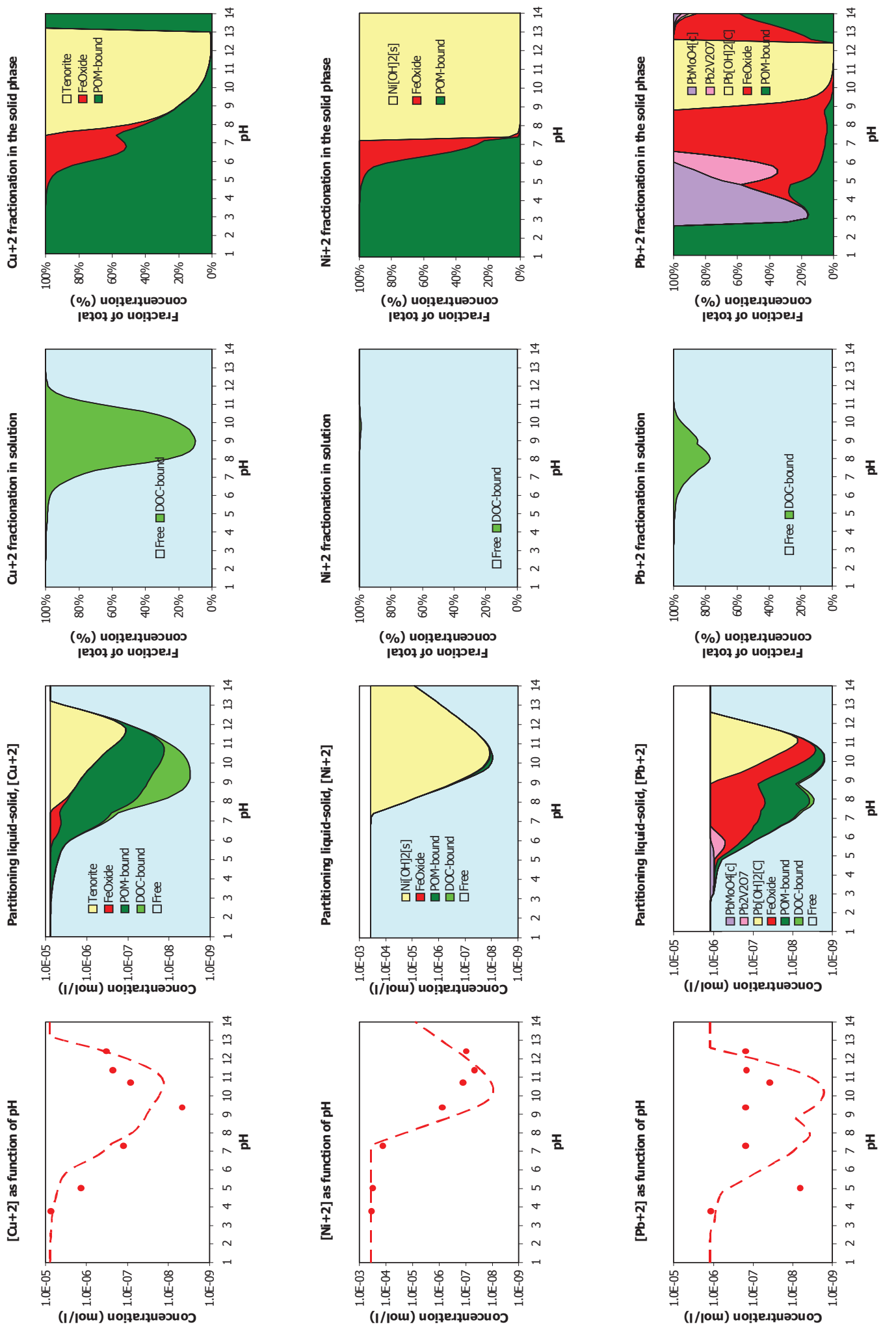

ป⿱艹⿹勹亾 

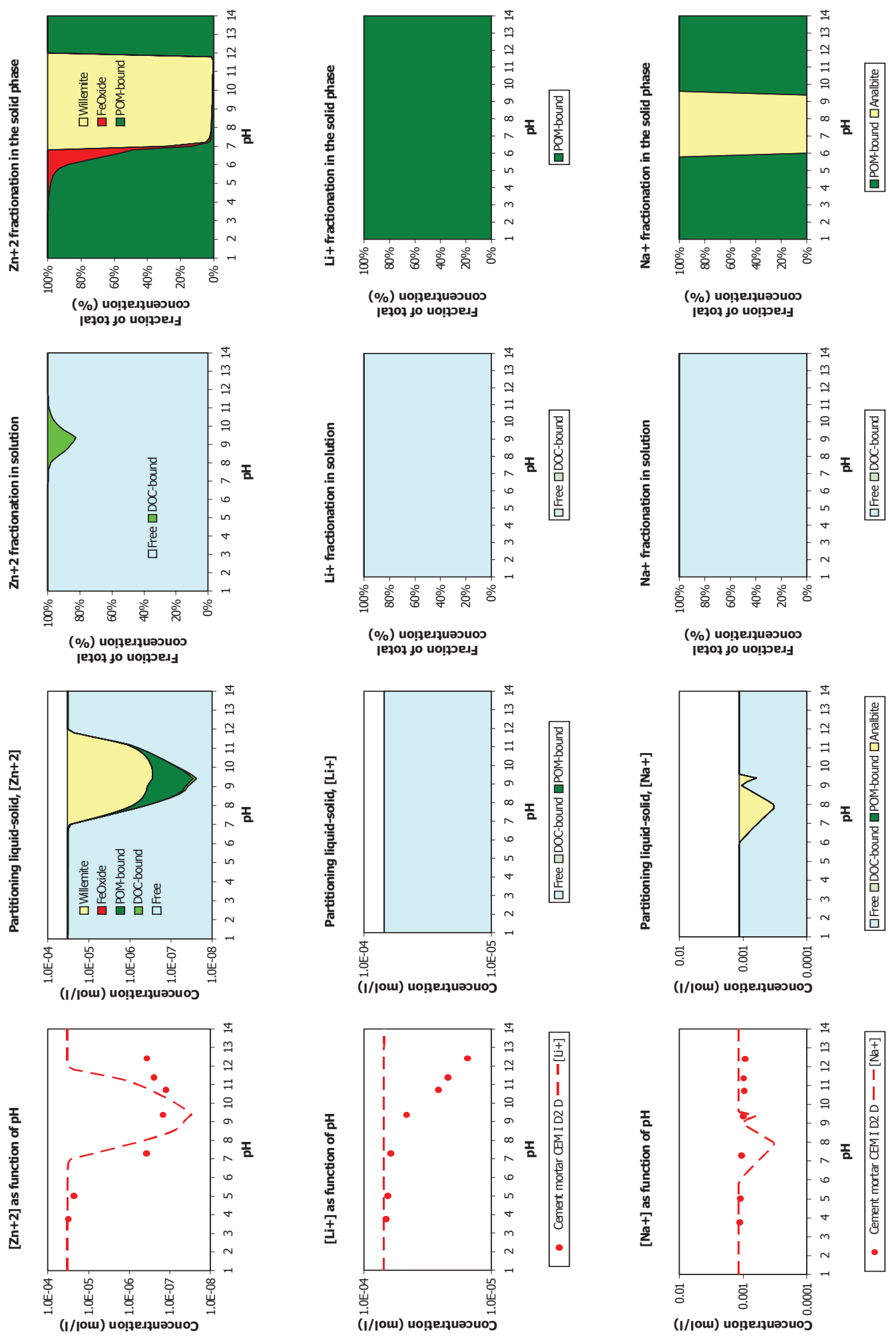

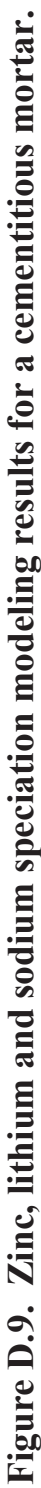




\section{Appendix E. Comparison of Stabilized Hazardous Waste and Simulation Grout.}

In the graphs shown below, the leaching behavior as a function of $\mathrm{pH}$ ( $\mathrm{pH}$ dependence test) and as a function of time (monolith leach test) for the following materials is given:

- Material blank (MBD)

- Stabilized waste mix (SWD)

- Academic mix (AMD)

- Cement stabilized MSWI fly ash NL

- Cement stabilized MSWI fly ash NL

- Cement stabilized MSWI fly ash UK

- Cement stabilized MSWI fly ash UK

Graphs for the following elements are given in the figures indicated:

Fig. E.1. Al, As, B

Fig. E.2. $\quad \mathrm{Ba}, \mathrm{Ca}, \mathrm{Cd}$

Fig. E.3. $\quad \mathrm{CN}$ total, $\mathrm{CN}$ volatile, $\mathrm{Co}$

Fig. E.4. $\mathrm{Cr}, \mathrm{Cs}, \mathrm{Cu}$

Fig. E.5. F, Fe, $\mathrm{Hg}$

Fig. E.6. I, K, Li

Fig. E.7. $\mathrm{Mg}, \mathrm{Mn}, \mathrm{Mo}$

Fig. E.8. Na, Ni, P

Fig. E.9. $\mathrm{Pb}, \mathrm{Rb}, \mathrm{Re}$

Fig. E.10. $\quad \mathrm{SO}_{4}$ as $\mathrm{S}, \mathrm{Sb}, \mathrm{Se}$

Fig. E.11 Si, Sn, Sr

Fig. E.12. U, V, Zn

The first graph gives the release as a function of $\mathrm{pH}$, the second graph shows the concentration in eluates from the monolith leach test as a function of time. The third graph shows the cumulative release expressed in $\mathrm{mg} / \mathrm{m}^{2}$ as a function of time and the fourth graph shows the $\mathrm{pH}$ as a function of time (days). 

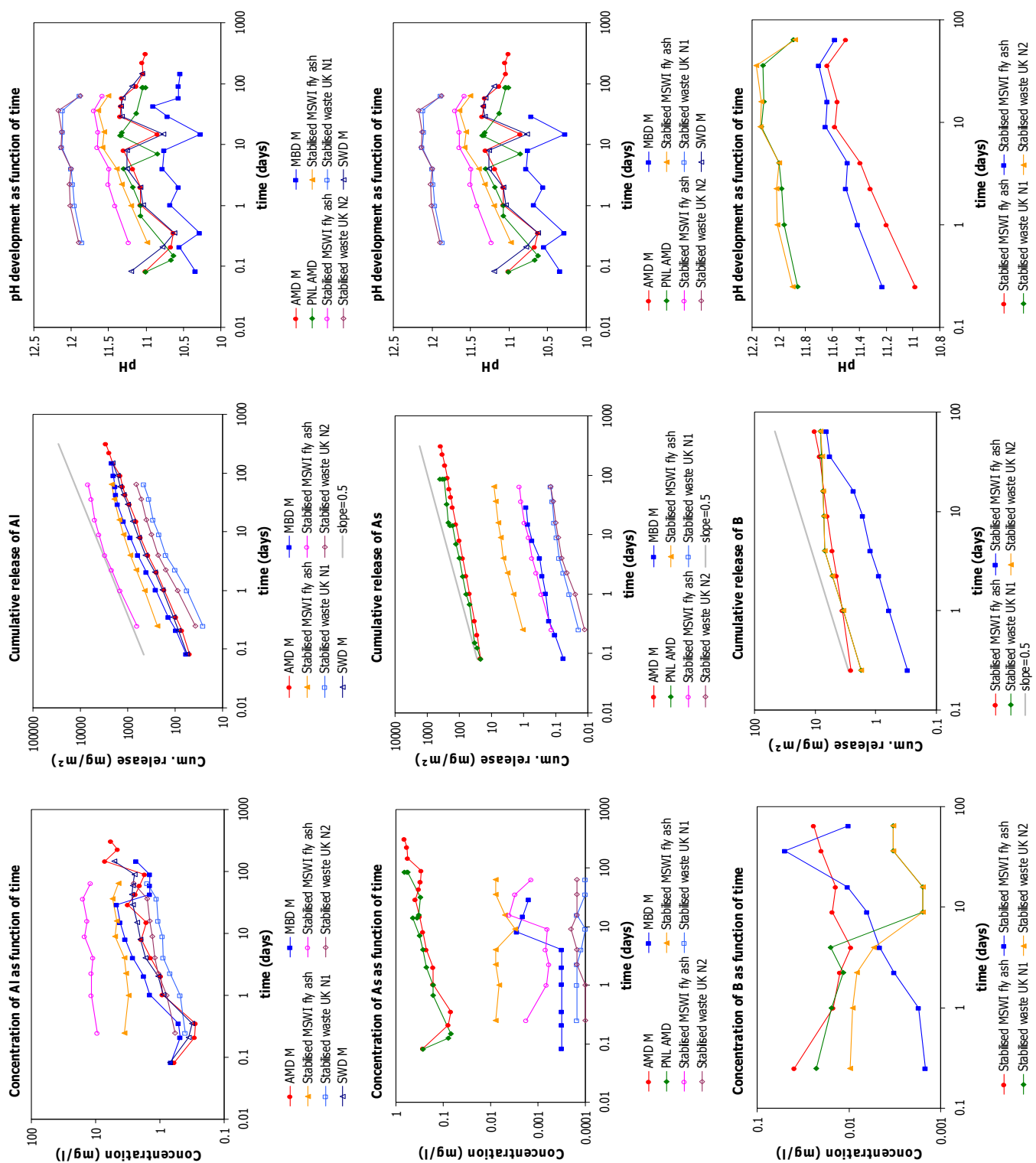

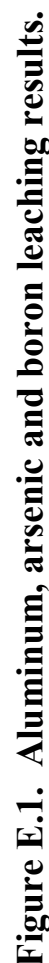



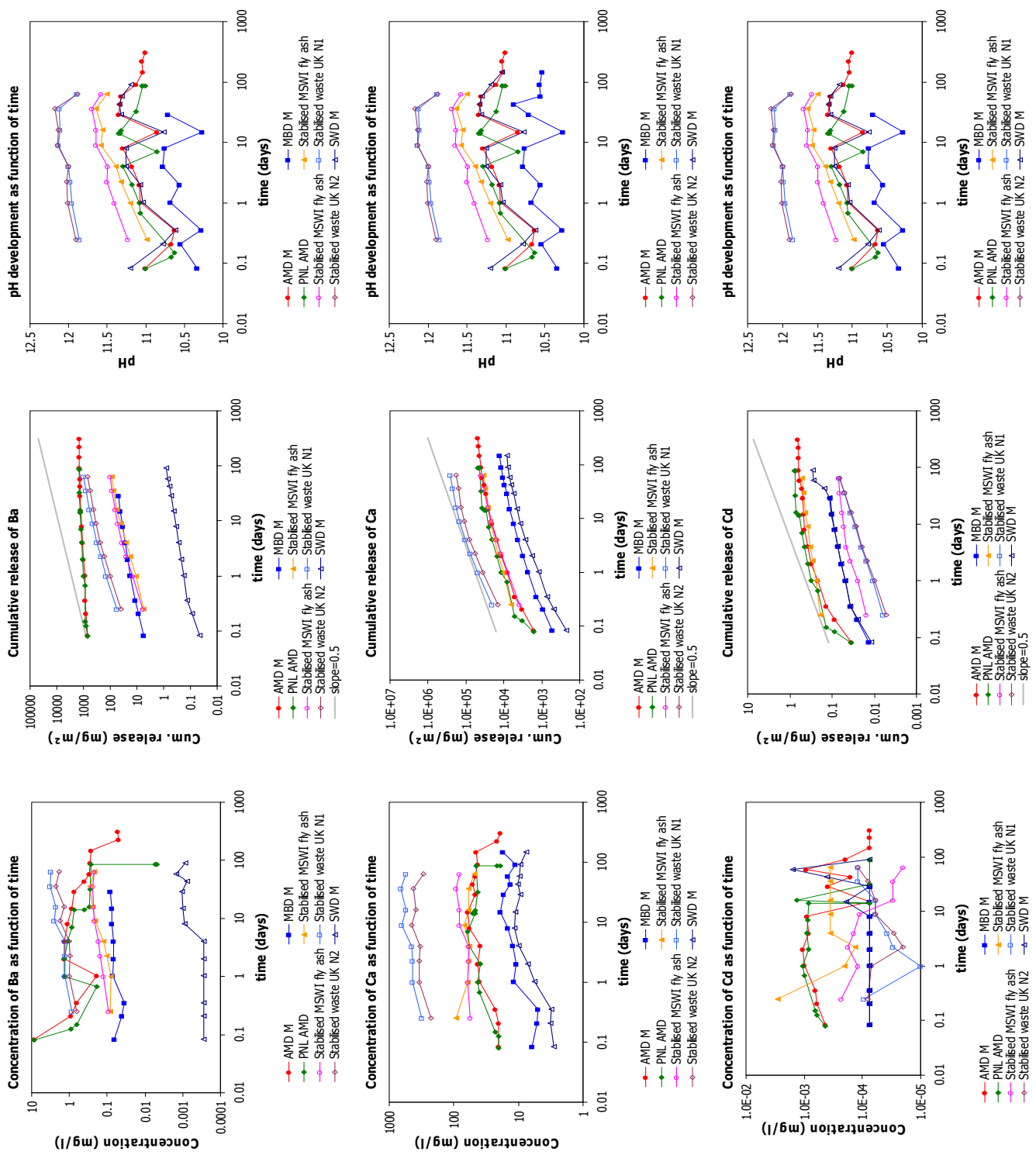

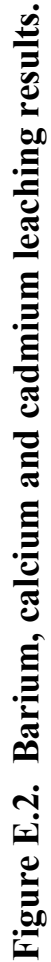



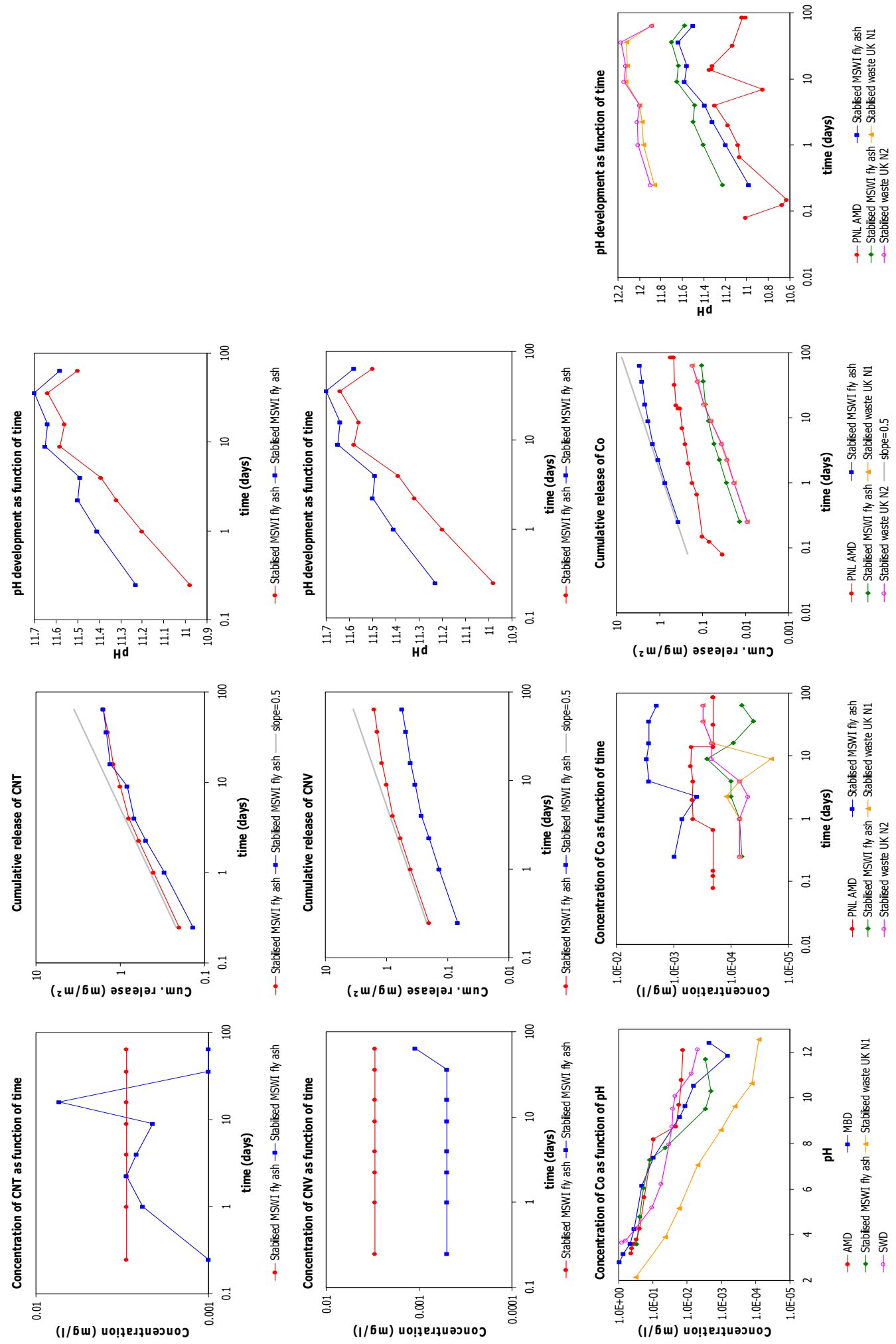

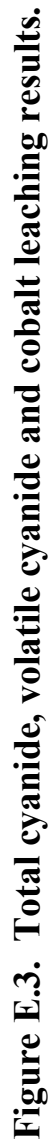



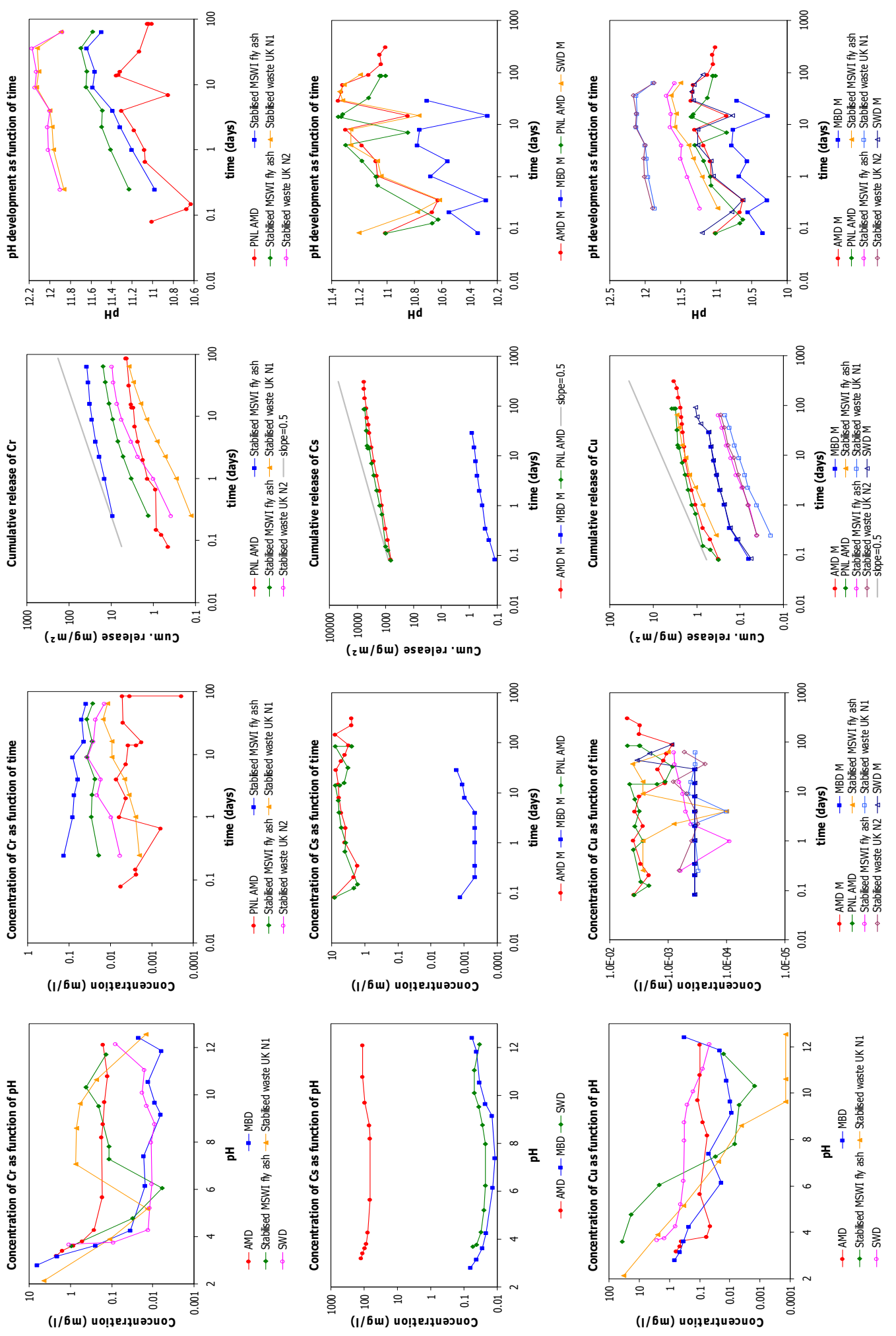

 

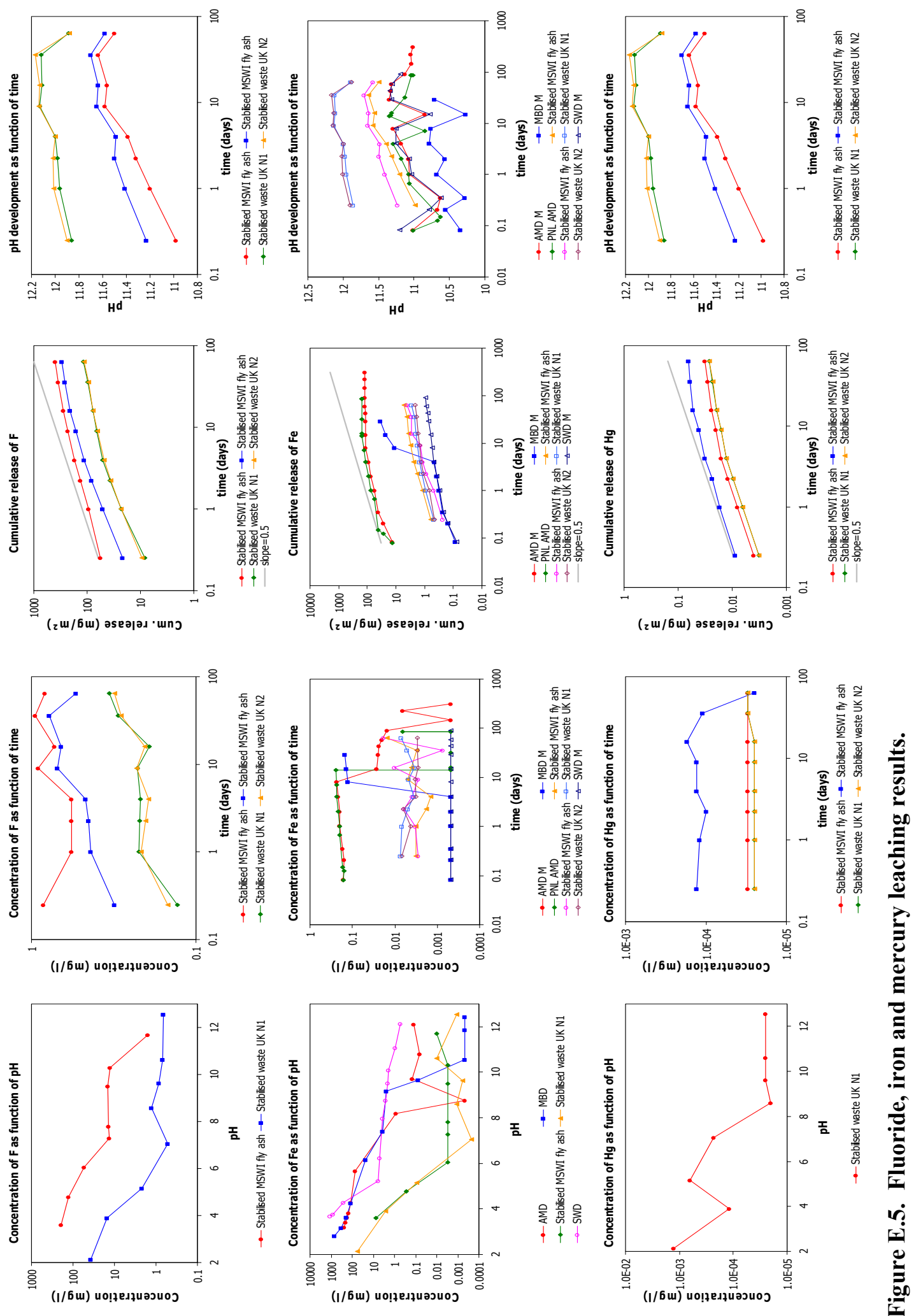

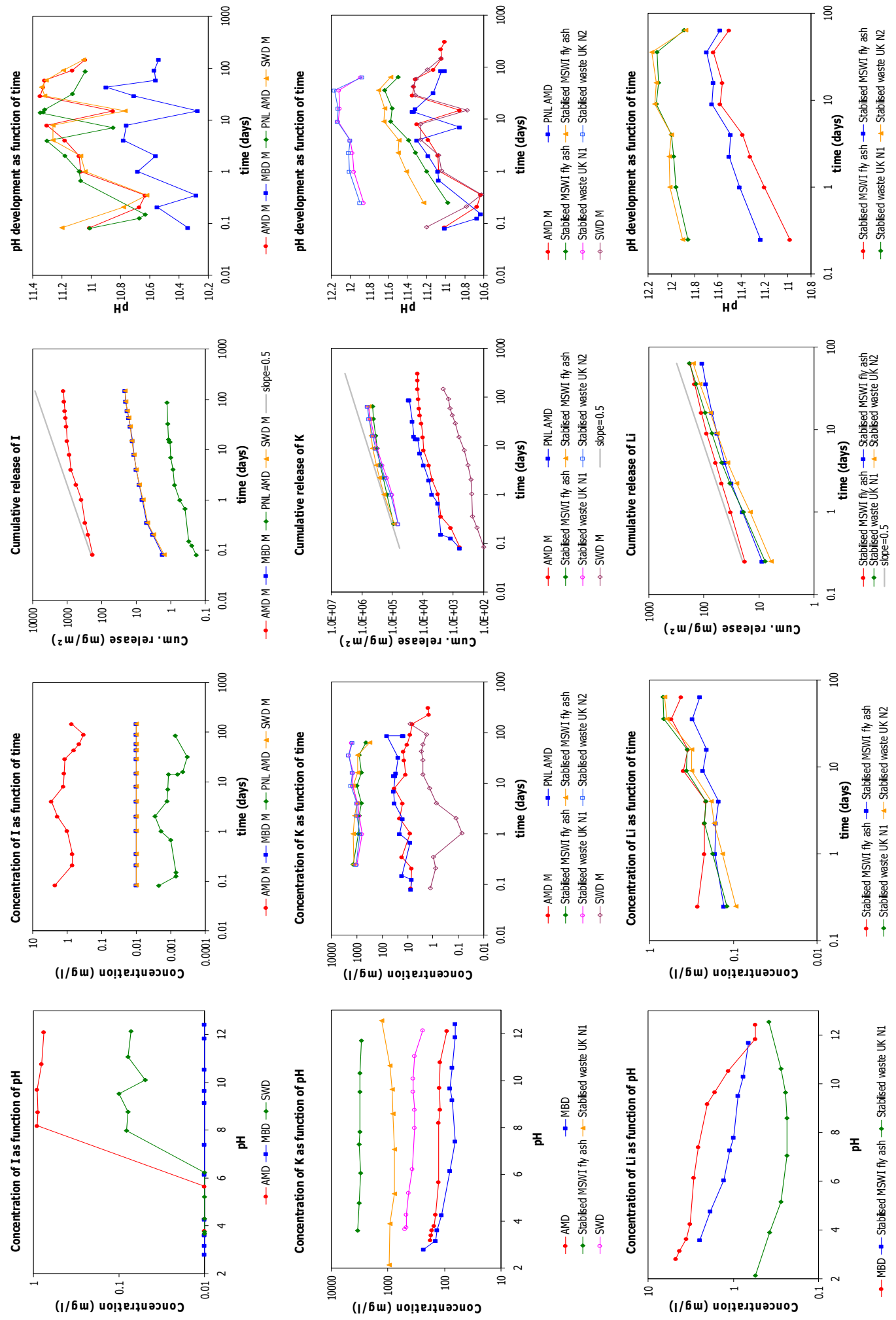

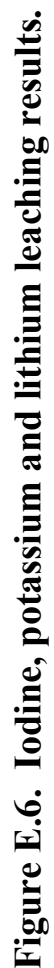

VII-92 

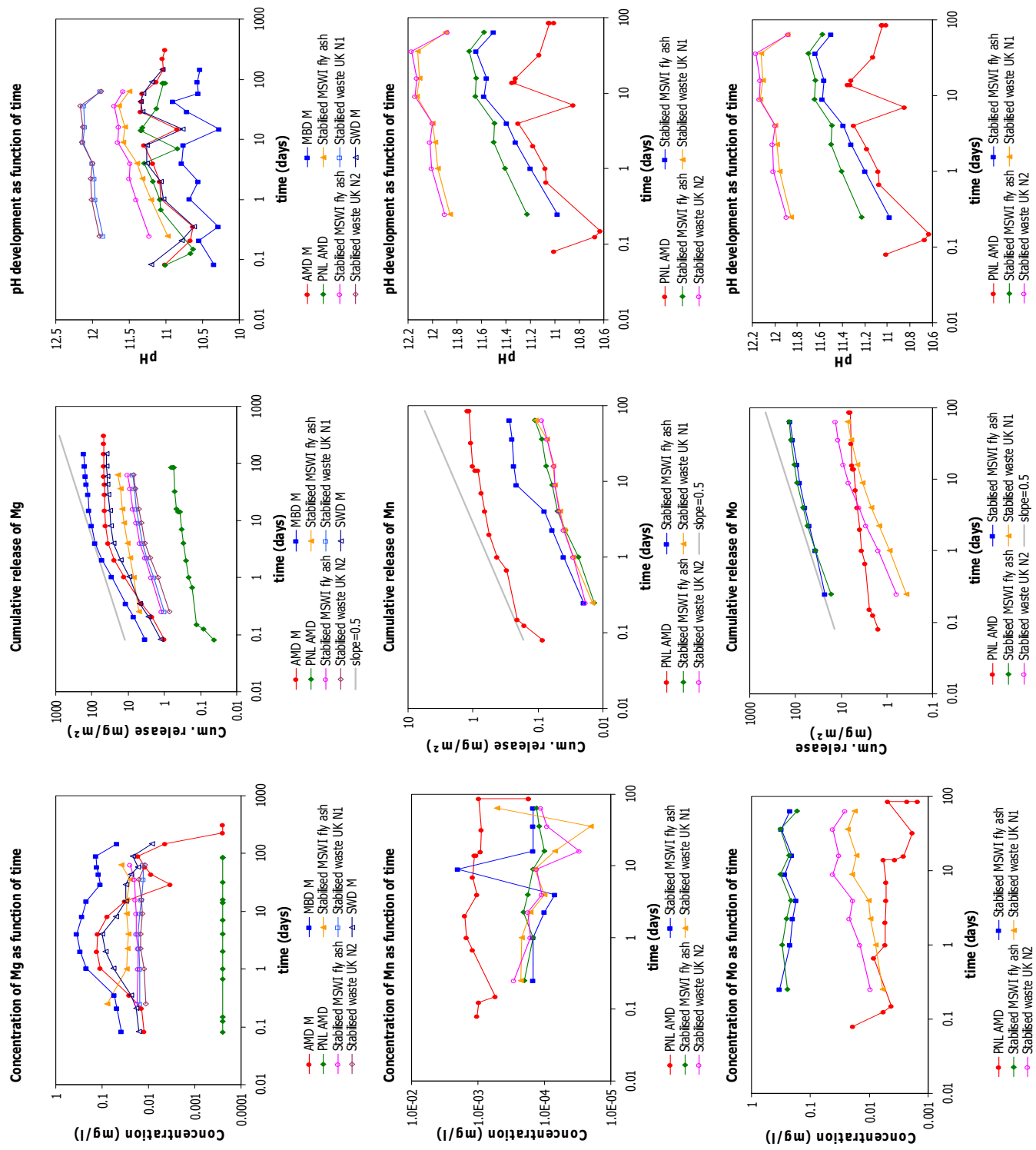

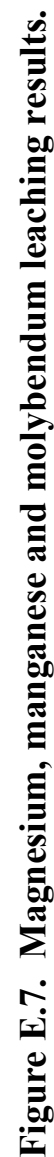



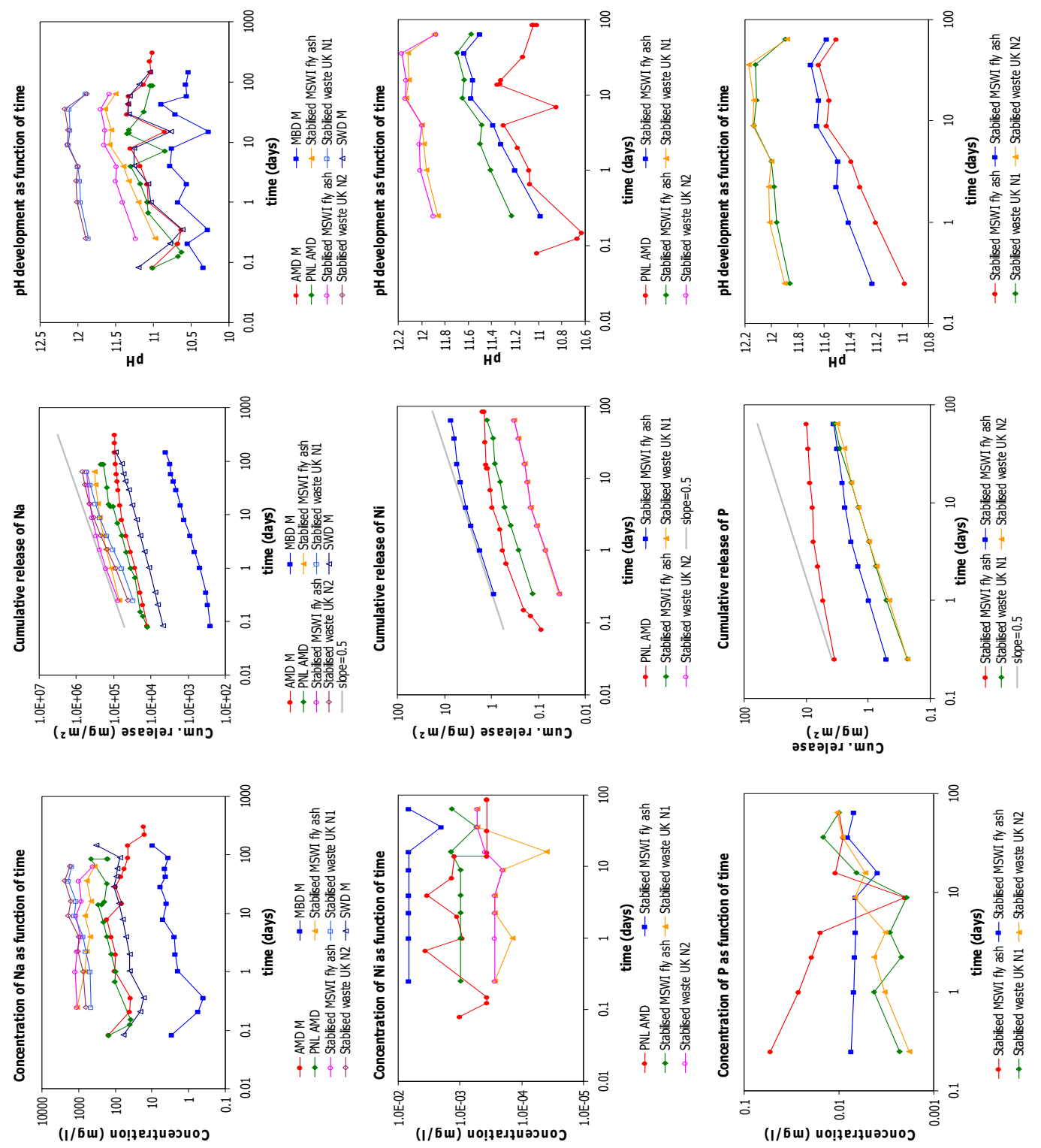

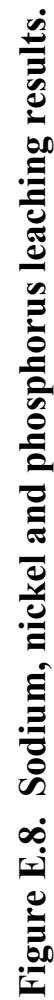



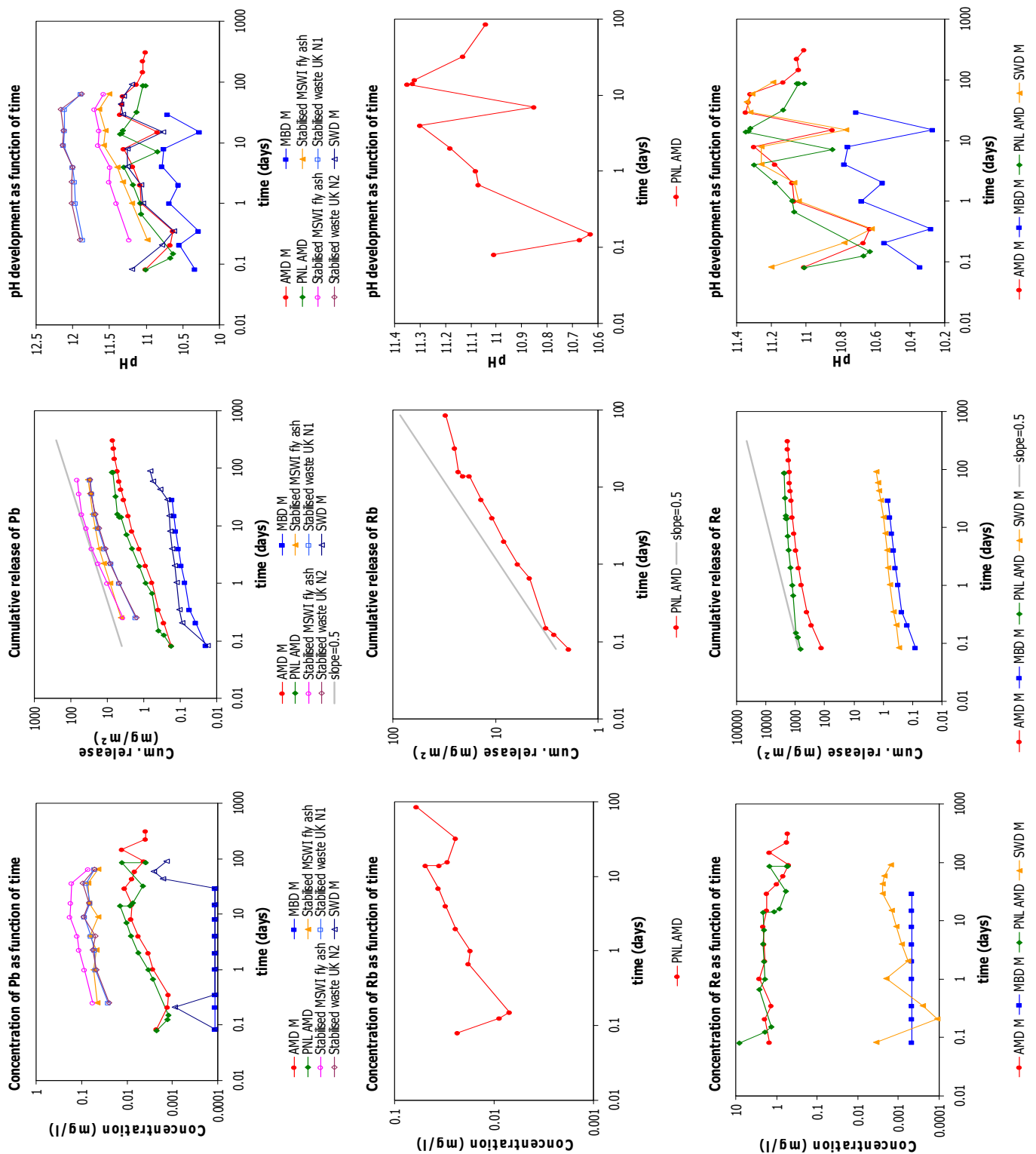

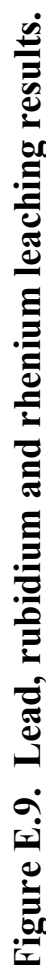



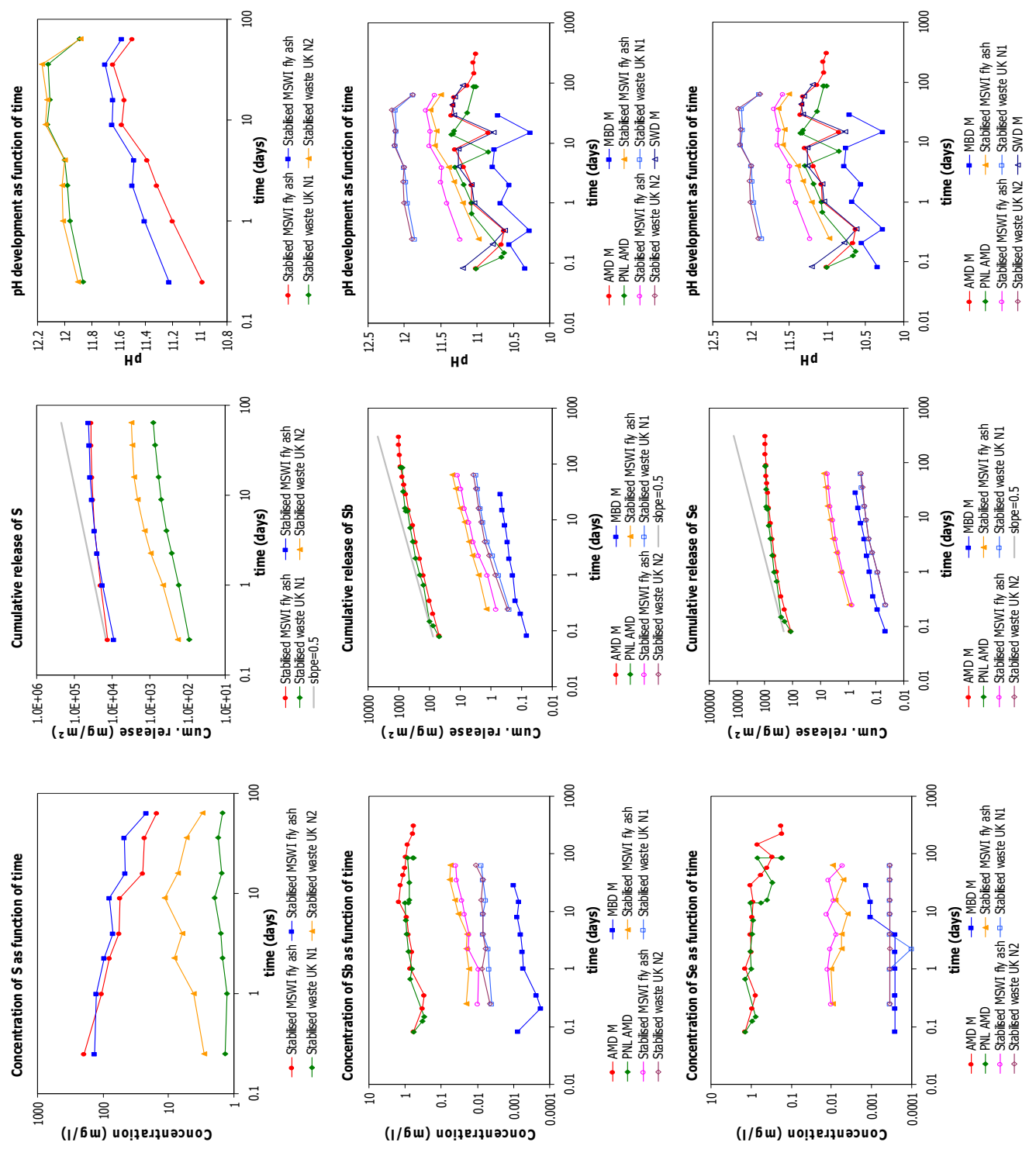

فํ. 

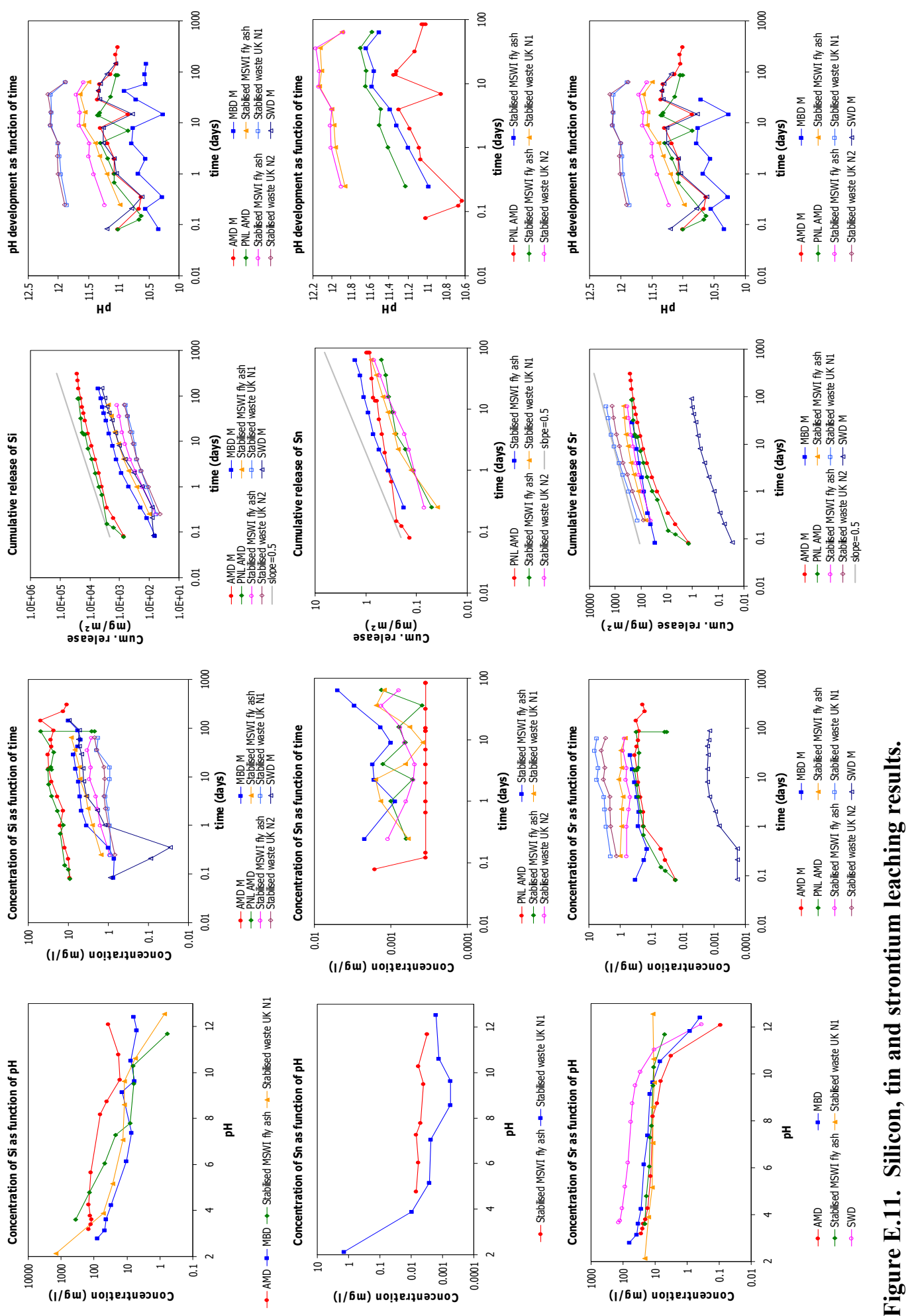

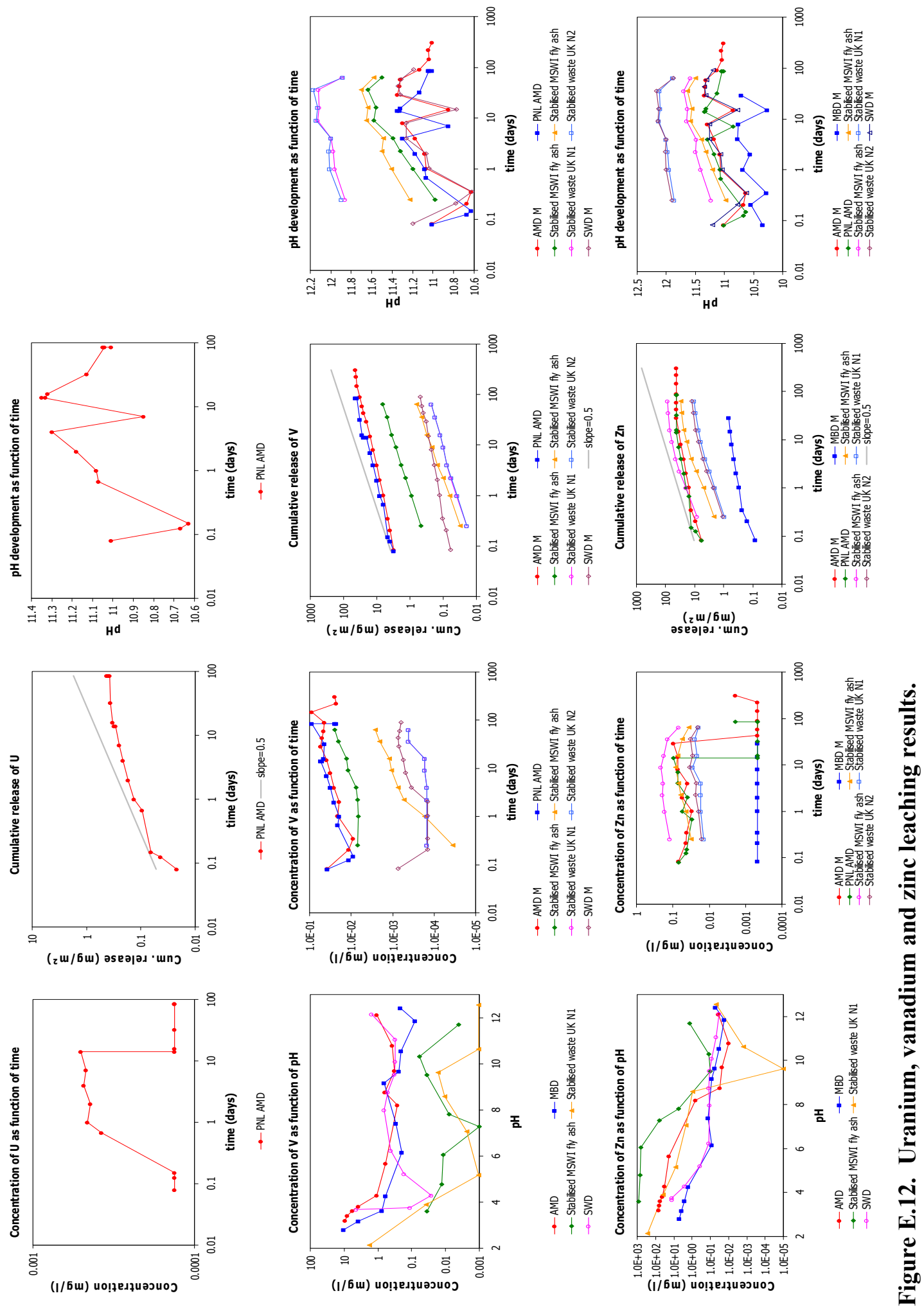


\title{
REVIEW OF THERMODYNAMIC AND ADSORPTION DATABASES
}

\author{
J. C. L. Meeussen \\ Email:meeussen@ecn.nl \\ Energy Research Centre of the Netherlands \\ Petten, The Netherlands \\ H. A. van der Sloot \\ Email: vandersloot@ecn.nl \\ Energy Research Centre of the Netherlands \\ Petten, The Netherlands \\ J. J. Dijkstra \\ Email: info@simcotechnologies.com \\ Energy Research Centre of the Netherlands \\ Petten, The Netherlands \\ D. S. Kosson \\ Email: david.kosson@vanderbilt.edu \\ Vanderbilt University, School of Engineering \\ Consortium for Risk Evaluation with Stakeholder Participation, III \\ Nashville, TN 37235
}

November 2009

CBP-TR-2009-002, Rev. 0 
Review of Mechanistic Understanding and Modeling and Uncertainty Analysis Methods for Predicting Cementitious Barrier Performance

VIII-ii 
LIST OF TABLES.. VIII-iv

LIST OF ABBREVIATIONS AND ACRONYMS VIII-v

ABSTRACT VIII-1

1.0 INTRODUCTION VIII-1

1.1 Mechanistic and Deterministic Models. VIII-2

1.1.1 Internal Consistency of the Mechanistic Modeling Approach. VIII-3

1.2 Database vs. Conceptual Model ............................................................................................ VIII-4

2.0 THERMODYNAMIC DATA SOURCES AND TYPES ...............................................................VIII-4

2.1 Equilibrium Between Solid Phases and Dissolved Species..................................................... VIII-4

2.1.1 MINTEQA2 Database ............................................................................................... VIII-5

2.1.2 Lawrence Livermore National Laboratory Database.................................................... VIII-5

2.1.3 Yucca Mountain Geochemistry Database ……............................................................... VIII-6

2.1.4 Nagra/PSI Thermodynamic Database........................................................................ VIII-6

2.1.5 CEMDATA07 …............................................................................................ VIII-6

2.1.6 Japanese Atomic Energy Agency Database .................................................................. VIII-6

2.1.7 Thermoddem Database ........................................................................................ VIII-6

2.1.8 Additional Database for Selected Solid Solutions ...................................................... VIII-6

2.2 Sorption of Soluble Species on Solid Surfaces........................................................................... VIIII-7

2.2.1 Sorption Parameters for Hydrated Metal Oxides.......................................................... VIII-8

2.2.2 Sorption Parameters for Dissolved and Particulate Organic Matter............................. VIII-9

2.2.3 Clay Interaction Parameters ................................................................................... VIII-9

2.2.4 $K_{d}$ Values for Radionuclides .............................................................................. VIII-9

2.3 Use of Combined Thermodynamic and Sorption Data ...................................................... VIII-10

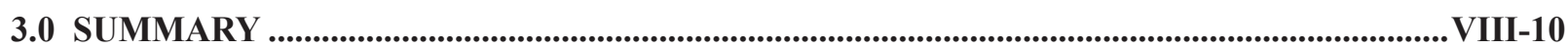

4.0 REFERENCES......................................................................................................................................... VIII-12 


\section{LIST OF TABLES}

Page No.

Table 1. Fundamental Phases and Speciation to be Considered as Part of Multi-Phase Chemical Equilibrium VIII-2

Table 2. Stability Constants for Cement Solid Solutions Containing Specific Anionic Species VIII-7

Table 3. Overview of Main Contents of Different Thermodynamic Databases .VIII-10 


\section{LIST OF ABBREVIATIONS AND ACRONYMS}

$\begin{aligned} \text { BRGM } & \text { Bureau de Recherches Géologiques et Minières } \\ \text { CBP } & \text { Cementitious Barriers Partnership } \\ \text { CEN } & \text { European Committee for Standardization } \\ \text { EN } & \text { European norm } \\ \text { GTLM } & \text { Generalized two layer model } \\ \text { HFO } & \text { Hydrous ferric oxide } \\ \text { JAEA } & \text { Japanese Atomic Energy Agency } \\ K_{d} & \text { Partition coefficient between solid and liquid phase } \\ \text { LFER } & \text { Linear Free Energy relationships } \\ \text { LLNL } & \text { Lawrence Livermore National Laboratory } \\ \text { NICA } & \text { Non-ideal competitive adsorption model (NICA-Donan) } \\ \text { NIST } & \text { National Institute of Standards and Technology } \\ \text { PSI } & \text { Paul Scherrer Institute } \\ \text { PZC } & \text { Point of zero charge } \\ \text { TS } & \text { Technical specification } \\ \text { WHAM } & \text { Windermere humic aqueous model }\end{aligned}$


Review of Mechanistic Understanding and Modeling and Uncertainty Analysis Methods for Predicting Cementitious Barrier Performance 


\title{
REVIEW OF THERMODYNAMIC AND ADSORPTION DATABASES
}

\author{
J. C. L. Meeussen \\ H. A. van der Sloot \\ J. J. Dijkstra \\ Energy Research Centre of the Netherlands \\ Petten, The Netherlands \\ D. S. Kosson \\ Vanderbilt University, School of Engineering \\ Consortium for Risk Evaluation with Stakeholder Participation, III \\ Nashville, TN 37235
}

\section{ABSTRACT}

The objective of this chapter provide a summary of thermodynamic databases that have been used and are available to predict 1) equilibrium phase assemblages in cementitious materials and 2) the impact of sorption processes on the concentrations of ionic species in an aqueous phase in contact with cementitious materials and soils. In addition, a brief summary of approaches to thermodynamic modeling is provided.

\subsection{INTRODUCTION}

The specific chemical form of individual substances defines to a large extent how constituents present in materials are distributed amongst solid phases and susceptible to reactive transport processes. For cementitious materials and barriers, multi-phase thermodynamic equilibrium and reactive transport are the basis for understanding the distribution and release of solid phase constituents, either primary matrix components or trace constituents of concern, and the ingress of chemical species that may cause transformations of the properties of the material (e.g., chemical degradation). Chemical "speciation" refers to the different chemical forms in which an element may be present, such as, free ions, dissolved complexes, mineral phases, other solid phases, ions adsorbed onto hydrated mineral surfaces or dispersed as colloids. In addition to chemical speciation, the mobility of contaminants in the environment is also a function of transport processes (convection, diffusion) and time-dependent processes, such as, chemical reactions (represented as reaction kinetics) and slow changes in the geochemical properties of materials (e.g., weathering/ aging reactions). Table 1 provides a summary of the typical interactions considered for systems comprised of cementitious materials and trace ionic species, such as, radionuclides and metals.

Thermodynamic data form the basis for chemical speciation modeling of equilibrium and reactive transport of constituents within cementitious materials. These data consist of reliable equilibrium constants for the (1) dissolution and precipitation of solid phases of interest between aqueous and solid phases and (2) formation of dissolved species in aqueous solution. Several databases are available which contain information for the matrix phases present in cementitious materials and for phases and elements found in a variety of waste streams including radionuclides.

In practice however, there are many instances, where thermodynamic data are limited, have not been measured, or where it is not possible to provide accurate quantification of the equilibrium 
Table 1. Fundamental Phases and Speciation to be Considered as Part of Multi-Phase Chemical Equilibrium

Solid Phases (dissolution and precipitation phenomena)

Crystalline (mineral) phases

Amorphous (non crystalline) phases

Solid solutions (crystalline and amorphous)

Reactive Solid Surfaces (adsorption, desorption and ion-exchange phenomena)

Iron oxides (i.e., iron (hydr)oxides)

Aluminum oxides (i.e., aluminum (hydr)oxides)

Manganese oxides (i.e., manganese (hydr)oxides)

Clay minerals

Organic matter (e.g., precipitated humic and fulvic acids)

\section{Aqueous Phase}

Free dissolved species

Chelated and complexed species

Species associated with dissolved organic carbon

Colloids

\section{Gas Phase}

Inert gases present as major constituents (i.e., nitrogen)

Reactive gases present as major (i.e., oxygen, water) or trace (i.e., carbon dioxide) constituents

chemistry and individual solid-liquid partitioning processes. In such cases, partition coefficients $\left(K_{d}\right)$ are often used as an approximation to describe and predict the concentrations of ionic species in the aqueous phase relative to the concentrations in the associated solid phases. They are applicable under specific conditions where sorption and desorption processes are the dominant partitioning mechanism (i.e., dilute solutions), rather than when aqueous saturation of a species with respect to a specific mineral phase or congruent dissolution are the controlling partitioning mechanisms. Partition coefficients are linear extrapolations of an empirical value applicable to a specific set of chemical conditions (solid phases, aqueous concentration, ionic strength, $\mathrm{pH}$, temperature, etc.). Partition coefficients are not mechanistic except in the Henry's Law regime (i.e., very dilute solution) and therefore their application to aqueous concentrations and conditions beyond their initial definition should be performed with care. Often in practice, $K_{d}$ values are extrapolated to extend the range of estimating partitioning beyond where measurements are available.

\subsection{Mechanistic and Deterministic Models}

Models used to describe speciation may be either empirical, mechanistic, or a combination thereof. Empirical models typically are case and material specific and are based on specific experiments or observations, which limit their extension to predictions beyond the conditions of their initial definition. Since fundamental processes on a molecular scale are valid across a wide variety of materials, application scenarios, and environmental conditions, models that explicitly reflect individual component chemical processes (hereafter referred to as mechanistic models) have a much wider applicability than empirical models. Examples of empirical models include linear partition coefficients and Freundlich adsorption models. 


\section{Review of Mechanistic Understanding and Modeling and Uncertainty Analysis Methods for Predicting Cementitious Barrier Performance}

During the past decades, mechanistic models have been developed that describe the chemical interactions that various cementitious phases and inorganic contaminants undergo as the result of aging and exposure to environmental conditions (including contact with soils, sediments, and the aquatic environment). In addition, mechanistic models have been developed to describe sorption processes on reactive surfaces (clay minerals, natural organic matter and iron (hydr)oxides) ${ }^{1}$ found in natural and anthropogenic environments. Several models include "generic" thermodynamic and sorption binding parameter data sets which have been derived for a wide range of inorganic species which are frequently of interest, such as, various metals, oxyanions and radionuclides. These models can be applied to a variety of systems and conditions.

Due to the process-based character of the underlying process models and parameter data amongst material systems and scenarios, a mechanistic geochemical modeling approach is well suited for predicting longterm release properties from contaminated materials in the environment.

\subsubsection{Internal Consistency of the Mechanistic Modeling Approach}

The long-term predictive value of a mechanistic model strongly depends on the way the model is parameterized, i.e., the way in which the specific thermodynamic and sorption parameters and estimates of material-specific properties/input parameters are selected for use in the model. The mechanistic modeling approach described in this chapter relies on consistency between the:

- Hypothesized component processes (i.e., system conceptual model),

- Chosen (sorption) sub-models to simulate these processes,
- Necessary model input parameters, and

- Experimental methods or pre-existing data to define these parameters.

For the selection of sub-models (e.g., sorption), models are preferred for which "generic" parameter sets for a wide range of substances (major, minor and trace constituents) have been derived. Although such generic parameter sets may not provide the best description of measurements for a particular system, these parameter sets are internally consistent and are therefore more generally valid. In addition, when the purpose is to model long-term and complex (natural and waste) systems, there is a need for parameter sets that cover a broad range of major, minor and trace elements in order to account for multi-component interactions. Examples of multi-component interactions are competition between different elements for the (limited) sorption "sites" on reactive surfaces, as well as the formation of precipitates and soluble complexes.

In order to achieve a generally valid modeling approach, the models and associated parameter sets selected must have consistent reference states and underlying assumptions. Only peer-reviewed thermodynamic and binding parameter data should be used. In this respect, it is important to note that mechanistic sorption models and associated generic parameter sets may not be available for all of the potentially important sorption processes. In those cases, an attempt can be made to derive the necessary sorption characteristics from those of similar reactive surfaces for which this type of information is available. When sorption models are used in this way the amount of the reactive surface area of this material also must be determined. Important reactive surfaces that are treated in this way include amorphous and crystalline iron and aluminum (hydr) oxides, clays, and reactive fractions of dissolved and particulate organic matter (humic and fulvic acids).

\footnotetext{
${ }^{1}$ The terminology (hydr)oxides refers to the range of hydrated states of metal oxide surfaces (e.g., iron, aluminum, manganese).
} 
A number of widely used (geo)chemical reaction or thermodynamic and binding parameter databases and sorption models are discussed in the sections that follow. In each case, the models and databases are internally consistent in the way that they are initially formulated (e.g., reference state, temperature, units). However, transfer of database information (parameters or sub-models) from one modeling framework to another must be accomplished with care to insure that internal consistency is maintained.

\subsection{Database vs. Conceptual Model}

A clear distinction is needed between a thermodynamic database and a thermodynamic conceptual model. The thermodynamic database contains stability constants derived from experimental work and parameters which are used as input for models describing sorption processes (e.g., iron-oxide and organic matter), dissolution and precipitation, and aqueous speciation (e.g., complexation and chelation reactions).

A conceptual thermodynamic model includes a number of important aspects:

- Definition of the scenario to be evaluated including identification of the control volume, key processes taking place, bulk and trace element chemistry, solid phases present (including amorphous phases and solid solutions such as C-S-H and trace species incorporated in ettringite), and boundary conditions;

- Methods for calculating activity coefficients (e.g., Debye-Hückel, Pitzer);

- Reaction temperature dependence (e.g., Van't Hoff, empirical reaction constant temperature coefficients, temperature-dependent heat capacity); Models and parameters for binding to solid phases (e.g., empirical equations, surface complexation, ion-exchange); and

- Models and parameters for aqueous phase speciation (e.g., aqueous complexation, association with dissolved organic carbon).

Each feature of the model will have its own set of coefficients that must be included in the thermodynamic database. However, for each of the enumerated aspects, there are multiple valid approaches for construction a system model. Because there are no truly ab initio calculations (calculations on a molecular statistical thermodynamics basis without underlying measured coefficients), the only way to test a conceptual model is to compare model predictions to measured data.

In theory, for a given conceptual model, one could optimize the thermodynamic parameters to best agree with a single observation. In practice, however, one tries to achieve a conceptual model that can handle a range of scenarios and conditions with minimal or no change in thermodynamic properties. To achieve this, the researcher seeks a constrained optimization where, for a given conceptual model, the model calculation "best" agrees with the full range of scenarios.

\subsection{THERMODYNAMIC DATA SOURCES AND TYPES}

\subsection{Equilibrium Between Solid Phases and Dissolved Species}

The minimum thermodynamic data required to calculate equilibrium between dissolved species and precipitated solid phases consists of a complete set of solid phase formation reactions ${ }^{2}$ plus solubility

\footnotetext{
${ }^{2}$ Formation reactions are the stoichiometric chemical equations for the precipitation and dissolution equilibrium between the solid and aqueous phases. Solubility constants are the equilibrium constants for the formation reactions assuming that the solid phase has unit activity.
} 
constants. The minimum thermodynamic data required to calculate equilibrium concentrations of soluble species consists of aqueous formation reaction equations, including the complete reaction stoichiometry of the aqueous species plus an accompanying equilibrium constant. To describe the temperature dependence of a reaction, entropy and enthalpy changes are needed to calculate the theoretical temperature dependency of the reaction constants

Formation constants of aqueous species and solid phases are based on (assumed) chemical equilibrium. In practice, chemical equilibrium between solid and liquid phases is rarely met, while equilibrium amongst dissolved aqueous species is achieved rapidly. In short-term laboratory leaching experiments, concentrations have been shown to approach equilibrium even in case of strongly heterogeneous waste materials (Dijkstra et al., 2006a). In case of slow dissolution-precipitation reactions, a kinetic description (formation/solubility as a function of time) is required to reflect the extent of approach to equilibrium, either on an empirical basis or a thermodynamic basis where the difference in Gibbs Free energy between the current system state and the equilibrium state provides the driving force for reaction. Kinetic parameters, however, are rarely available for most chemical reactions.

Compilations of thermodynamic data commonly used in equilibrium computer speciation software are available for public use. These databases consist of reactions, constants and parameters for the formation of solid phases and dissolved species. Publically available databases applicable to the $\mathrm{CBP}$ project are described below.

\subsubsection{MINTEQA2 Database}

The MINTEQA2 V4 chemical reaction database version 4 (U.S.EPA, 1999) is freely available on the Internet (http://www.rockware.com/product/data. php?id=132; see also, http://www.epa.gov/ceampubl/ mmedia/minteq/) in different formats compatible with common geochemical speciation programs (MINTEQ, Geochemist's WorkBench, PHREEQC). It contains a large set of aqueous complexation and precipitation reactions and probably is the most extensively used source of thermodynamic data for chemical speciation purposes in the world. Thermodynamic data in version 4.0 and later versions have been expanded and been strongly improved over earlier versions. The main difference with other commonly used thermodynamic databases is that version 4.0 and later versions rely largely on the Critically Selected Stability Constants of Metal Complexes Database published by the National Institute of Standards and Technology (NIST). This NIST database includes an objective evaluation of the quality of the thermodynamic data. This database contains solubility constants for a number of solid phases that are constituents of cementitious materials. Furthermore, it contains thermodynamic data for a limited set of radioactive elements, and a set of surface complexation reactions for the Generalized Two Layer Model (GTLM) of Dzombak and Morel (1990).

\subsubsection{Lawrence Livermore National Laboratory Database}

The Lawrence Livermore National Laboratory (LLNL) thermodynamic database is the default thermodynamic database used in the popular geochemical speciation program Geochemist's Workbench (Bethke, 1998). Like MINTEQA2, this database (referred to as thermo.com.V8.R6.230, available at $h t t p: / / w w w . r o c k w a r e . c o m / p r o d u c t / d a t a$. php?id=132) contains many aqueous complexation and precipitation reactions with references to the original literature sources. The LLNL database is also available in different formats, such as a format compatible with PHREEQC. In comparison with the MINTEQA2 database the LLNL thermo.com. V8R6230 database contains a much larger data set for 
radioactive elements. However, this database does not contain thermodynamic data for adsorption reactions.

\subsubsection{Yucca Mountain Geochemistry Database}

A database (data0.ymp.R2) that includes thermodynamic data, sorption parameters and radionuclide $K_{d}$ values for cement and geologic materials was developed for the Yucca Mountain Geologic Repository Project and was extensively reviewed.

\subsubsection{Nagra/PSI Thermodynamic Database}

The Swiss Nagra/PSI Chemical Thermodynamic Data Base 01/01 by Hummel, Berner et al (2002) contains thermodynamic data for a range of radioactive elements. The Nagra/PSI database defines a basic set of components and phases (available at http://les.web. psi.ch/TDBbook/index.htm). This database does not contain sorption data.

\subsubsection{CEMDATA07}

The Lothenbach et al. (2007 and 2008) cements database, CEMDATA07, was developed within the context of and supplements the Nagra / PSI database. This database is the most complete set of thermodynamic cement chemistry reactions (available at $h t t p: / / w w w . e m p a . c h / p l u g i n / t e m p l a t e /$ empa/*/74250/---/l=1). CEMDATA07 has detailed information on cement hydration phases and includes descriptions of the behavior of major elements in cement chemistry (e.g., calcium, alumina, silica). CEMDATA07 was developed by combining the equilibrium model GEMS (http://gems.web.psi. $c h /$ ) and the Nagra/PSI database. This database has no sorption data and does not contain radionuclide information.

\subsubsection{Japanese Atomic Energy Agency Database}

The Japanese Atomic Energy Agency (JAEA) developed a thermodynamic database that includes a wide range of radioactive species. This database can be downloaded in different formats, such as the one for PHREEQC (available at http://migrationdb.jaea. go.jp/english.html). The database is quite extensive but English documentation is limited. With respect to speciation of radionuclides, this database may be a valuable addition to MINTEQA2 v4. Data on adsorption reactions for radionuclides and other species are included in this database.

\subsubsection{Thermoddem Database}

In France, the Bureau de Recherches Géologiques et Minieres (BRGM) has taken the initiative to collect thermodynamic data and provide detailed descriptions of the possible relevance of minerals for use in given situations (Piantone et al. 2006). So, in contrast with the other databases described here, the Thermoddem database (available at http://thermoddem.brgm.fr/ presentation.asp) not only contains a large set of chemical reactions, but helps users select a subset of relevant reactions for specific materials (e.g., cement, soil, fly ash) and conditions. Consequently this database is potentially useful for non-specialist users. For example, selecting a solid phase only found under very special exposure conditions for solving an ambient temperature problem is identified as being unlikely.

\subsubsection{Additional Database for Selected Solid Solutions}

In cement paste and mortar, the anion precipitation has been described as a solid solution in ettringite (Klemm 1998). The parameters for $\mathrm{CrO}_{4}{ }^{2-}, \mathrm{AsO}_{3}{ }^{3-}$, $\mathrm{MoO}_{4}^{-}, \mathrm{VO}_{4}{ }^{3-}, \mathrm{PO}_{4}{ }^{3-}, \mathrm{SeO}_{3}{ }^{2-}, \mathrm{SO}_{4}{ }^{2-}, \mathrm{BO}_{3}{ }^{3-}, \mathrm{Ba}^{2+}$ and 
Table 2. Stability Constants for Cement Solid Solutions Containing Specific Anionic Species*

\begin{tabular}{lc}
\multicolumn{1}{c}{ Formula } & $\log \left(\mathbf{K}_{\text {so }}\right)$ \\
\hline $\mathrm{Ca}_{6}\left(\mathrm{Al}(\mathrm{OH})_{4}\right)_{2}\left(\mathrm{SO}_{4}\right)_{3}(\mathrm{OH})_{4} \cdot 12 \mathrm{H}_{2} \mathrm{O}$ & 45 \\
$\mathrm{Ca}_{6}\left(\mathrm{Al}(\mathrm{OH})_{4}\right)_{2}(\mathrm{CrO})_{3} \cdot(\mathrm{OH})_{4} \cdot 12 \mathrm{H}_{2} \mathrm{O}$ & 47.40 \\
$\mathrm{Ca}_{6}\left(\mathrm{Al}(\mathrm{OH})_{4}\right)_{2}\left(\mathrm{AsO}_{4}\right)_{3} \cdot(\mathrm{OH})_{1} \cdot \mathrm{H}_{2} \mathrm{O}$ & 40.79 \\
$\mathrm{Ca}_{6}\left(\mathrm{Al}(\mathrm{OH})_{4}\right)_{2}\left(\mathrm{H}_{3} \mathrm{BO}_{3}\right)_{3}(\mathrm{OH})_{10} \cdot 18 \mathrm{H}_{2} \mathrm{O}$ & 66.38 \\
$\mathrm{Ca}_{6}\left(\mathrm{Al}(\mathrm{OH})_{4}\right)_{2}\left(\mathrm{SeO}_{4}\right)_{3} \cdot(\mathrm{OH})_{4} \cdot 12 \mathrm{H}_{2} \mathrm{O}$ & 44.40 \\
$\mathrm{Ca}_{6}\left(\mathrm{Al}(\mathrm{OH})_{4}\right)_{2}\left(\mathrm{VO}_{4}\right)_{3}(\mathrm{OH})_{\cdot} 9 \mathrm{H}_{2} \mathrm{O}$ & 45.40 \\
$\mathrm{Ca}_{6}\left(\mathrm{Al}(\mathrm{OH})_{4}\right)_{2}\left(\mathrm{Sb}(\mathrm{OH})_{6}\right)_{3} \cdot(\mathrm{OH})_{7} \cdot 24 \mathrm{H}_{2} \mathrm{O}$ & 58.18 \\
$\mathrm{Ca}_{6}\left(\mathrm{Al}(\mathrm{OH})_{4}\right)_{2}\left(\mathrm{MoO}_{4}\right)_{3}(\mathrm{OH})_{4} \cdot 12 \mathrm{H}_{2} \mathrm{O}$ & 46.40 \\
$\mathrm{Ca}_{6}\left(\mathrm{Al}(\mathrm{OH})_{4}\right)_{2}\left(\mathrm{PO}_{4}\right)_{3}(\mathrm{OH}) .9 \mathrm{H}_{2} \mathrm{O}$ & -11.89 \\
$\mathrm{Ba}_{6}\left(\mathrm{Al}(\mathrm{OH})_{4}\right)_{2}\left(\mathrm{SO}_{4}\right)_{3}(\mathrm{OH})_{4} \cdot 12 \mathrm{H}_{2} \mathrm{O}$ & 60 \\
$\mathrm{Sr}_{6}\left(\mathrm{Al}(\mathrm{OH})_{4}\right)_{2}\left(\mathrm{SO}_{4}\right)_{3}(\mathrm{OH})_{4} \cdot 12 \mathrm{H}_{2} \mathrm{O}$ & 60 \\
\hline
\end{tabular}

*Species on which the solubility products are based: $\mathrm{Ca}^{2+}, \mathrm{Al}(\mathrm{OH})^{4-}, \mathrm{SO}_{4}{ }^{2-}, \mathrm{OH}^{-}$, $\mathrm{CrO}_{4}^{2-}, \mathrm{MoO}_{4}^{-}, \mathrm{PO}_{4}^{3-}, \mathrm{Ba}^{2+}, \mathrm{Sr}^{2+}, \mathrm{Sb}(\mathrm{OH})_{6}^{-}, \mathrm{SeO}_{4}^{2-}, \mathrm{AsO}_{4}^{3-}$

$\mathrm{Sr}^{2+}$ have been derived from modeling the dissolved concentration as obtained from two cement mortars (prepared according to EN 197-1) and tested in a $\mathrm{pH}$ dependence leaching test (CEN/TS 14429). One of the two cements is a regular Portland cement and the other a cement with increased trace element levels prepared in a small kiln. Stability constants are provided in Table 2.

Other cement mortars with varying concentrations of oxyanions and cement stabilized wastes modeled with these parameter settings generally indicate good agreement between measured and predicted concentrations. Obviously, independent experimental verification of the constants is desirable, but at present the descriptions provide an adequate quantification, which provides adequate prediction even at low liquid to solid conditions such as occurs for pore water, which is very helpful in subsequent transport modeling runs.

Solid solutions can be modeled as ideal solid solutions described by (Parkhurst and Appelo, 1999).
This means that the activity of each member phase is equal to its mole fraction. By choosing the solubility products of the end members equal to the equivalent pure phases, the solid solution will always be less soluble than the pure phases of any of the member solids. As a result, the pure phases will not form in the calculations. The solid solution will dissolve completely if the product of saturation indices of all member phases is less than 1 .

\subsection{Sorption of Soluble Species on Solid Surfaces}

In addition to the formation of solution complexes and precipitates, sorption processes influence the distribution of ions and chemicals dissolved in an aqueous phase that is in contact with solids. Sorption processes can occur between dissolved ions or molecules and suspended colloids, including large organic molecules of natural origin (e.g., humic substances), organic material, or inorganic solids. 
Sorption processes apply to a wide variety of solid surfaces including the external and internal surface area of the phases making up cementitious materials and soils.

The most dominant colloidal and solid reactive surfaces for metals in soils are believed to be dissolved and natural humic substances (i.e., humic and fulvic acids), surfaces of clay minerals and (hydr)oxides of iron, aluminum and manganese. Sorption onto these surfaces, can occur through electrostatic interaction or by chemical reactions with reactive groups, such as, carboxylic or phenolic groups on organic molecules. Sorption of most inorganic contaminants is generally non-linear, i.e., the sorbed amount depends in a non-linear way on the concentration in solution, and is influenced by many multi-component interactions, e.g., competition between different species in solution for the same adsorption sites. For these reasons empirically-based models that are based on a single species in dilute or ideal aqueous solution are unsuitable to describe reactive transport processes on longer time and distance scales.

During the past decades, models have been developed that describe multi-component sorption interactions on the reactive surfaces identified above. Adsorption models most relevant to the performance of cementitious materials and stabilization of chemical and radioactive species are described below.

\subsubsection{Sorption Parameters for Hydrated Metal Oxides}

Adsorption behavior of (hydr)oxide surfaces can described by a variety of semi-mechanistic models that are consistent with thermodynamic databases, such as, MINTEQA2, that describe solution complexation behavior. The first one discussed here is the generalized two layer model GTLM by Dzombak and Morel (1990), which is the most widely used model. The second one is the CD-MUSIC (charge distribution multi-site competitive adsorption model) developed by Hiemstra et al., (1996; 1989a, 1989b). The CD-MUSIC approach is more recent and more in line with latest mechanistic insights and is better able describe competitive interactions. However, the GTLM model comes with an extended set of databases with "generic" adsorption reactions and constants, while the set of available reactions for the CD-MUSIC is more limited. Both models use a similar format for the description of the adsorption reactions, consisting of an equilibrium reaction plus reaction constant for each adsorbing species. However, reactions and constants determined for one model cannot be used with another model. Although default parameters for both models have been shown to lead to acceptable predictions of contaminant release in soils and cementitious materials over a wide range of conditions (Weng et al., 2001; Dijkstra et al., 2004, and Kaplan, 2008), system specific parameters, such as, specific surface area and point of zero charge (PZC), must be determined.

Most reactions and parameters for dissolved species are available for sorption on iron (hydr)oxides such as hydrous ferric oxides (HFO) and goethite $(\alpha-\mathrm{FeOOH})$, for which these models were originally developed. Recently, GTLM and CD-MUSIC have also been applied to multi-component sorption to aluminum (hydr)oxides (e.g., Meima and Comans, 1998) and manganese oxides (Tonkin et al., 2004).

Surface precipitation is a term for the process where, at very high surface coverages of a species onto a sorbent surface, a surface phase may be formed whose composition varies continuously between that of the original sorbent metal (hydr)oxide and a solid crystalline or amorphous precipitate of the sorbing cation (Dzombak and Morel, 1990). Surface precipitation is an integral part of the GTLM of Dzombak and Morel (1990) and can be described fairly well as the formation of an ideal solid solution. Conditions under which surface precipitation may be expected can be met in waste materials with high 


\section{Review of Mechanistic Understanding and Modeling and Uncertainty Analysis Methods for Predicting Cementitious Barrier Performance}

concentrations of metal contaminants (Dijkstra et al., 2006)

\subsubsection{Sorption Parameters for Dissolved and Particulate Organic Matter}

Interactions between solutes and organic matter are important, especially in determining behavior of cationic trace elements. In contrast with oxides that have well defined surfaces with well defined binding sites, organic matter surfaces are composed of a heterogeneous mixture of binding sites. There are currently two ways in which interaction with these surfaces are modeled. The first is to mimic a heterogeneous collection of sites by defining a large set of discrete surface sites with slightly varying chemical properties (binding constants). An example of this approach is the well known WHAM model of Tipping (1994). The second approach is a numerical approach which assumes a continuous distribution of reactive surface sites with different binding properties, as in the NICA-Donnan model (Kinniburgh et al., 1999). As with the metal (hydr) oxides, adsorption reactions and parameters for the WHAM and NICA-Donnan models are not interchangeable, but for both models adsorption reactions and constants are available for a wide range of solutes.

The advantage of the discrete approach (WHAM model) is that this fits relatively easily within existing numerical equilibrium frameworks, although it is computationally intensive because of the large number of chemical entities (sites and species). The advantage of the continuous approach (NICADonnan model) is its elegance, small set of required parameters, numerical efficiency, and applicability in a wider concentration range in comparison with the discrete model. The NICA model has demonstrated better predictive capabilities that are well tested on multi-component natural and waste systems (Dijkstra et al., 2004; 2008). The disadvantage of this approach is that it is difficult to implement numerically in combination with existing frameworks.

\subsubsection{Clay Interaction Parameters}

Ion exchange reactions for clays are available in databases, such as, MINTEQ, PHREEQC, and Geochemist's Workbench. They are mathematically represented in the form of the so-called GainesThomas convention (Gaines and Thomas, 1953) ${ }^{3}$. The resulting equations require ion-specific and surface-specific parameters. Sorption onto clay minerals is predominantly electrostatic and associated with the permanently charged surfaces of many common clay minerals. In general, the relative importance of this process in concrete and cement stabilized wastes is generally low in contrast to greater significance in soils (Dijkstra et al., 2004). However, specific and strong interactions between radionuclides and clays are known for cadmium and radiocesium (De Koning and Comans, 2004 and references therein). Ion exchange can also be modeled with a fairly simple Donnan-approach, which is based on electrostatic interactions between the sorbing ion and the charge of the surface, and requires no ionspecific exchange parameters.

\subsection{4 $\boldsymbol{K}_{\boldsymbol{d}}$ Values for Radionuclides}

In the performance assessments carried out at nuclear sites, $K_{d}$ 's are frequently used to describe both the source term release as well as the transport in the near and the far field. Examples of $K_{d}$ data used for suites of radionuclides in waste form and concrete

\footnotetext{
${ }^{3}$ Equilibrium among aqueous and exchange species requires that all mass-action equations for the exchange species are satisfied. For example, the association reaction for the exchange species $\mathrm{CaX}_{2}$ is $\mathrm{Ca}^{2+}+2 \mathrm{X}^{-}=\mathrm{CaX}_{2}$, where $\mathrm{X}^{-}$is the exchange master species for the default database. The use of equivalent fractions for activities and this form for the chemical reaction is known as the Gaines-Thomas convention (Gaines and Thomas, 1953) and is the convention used in the PHREEQC and some other databases.
} 
performance assessments are given in Kaplan et al. (2008), Krupta et al. (2004) and by Krupka and Serne (1998). The JAEA thermodynamic database (see Section 2.1.6) includes $K_{d}$ values for a wide range of radionuclides and other constituents on cementitious and other materials.

\subsection{Use of Combined Thermodynamic and Sorption Data}

For modeling interactions of contaminants in the environment and in cementitious materials, often a combination is made between reactions from a common thermodynamic database such as MINTEQA2, and several of the listed sorption models. This approach is often referred to as a "multisurface" modeling approach, which describes the dominant interactions that contaminants undergo in the natural and anthropogenic environment. There are several good overview/review papers in which the approach is discussed more thoroughly (Merdy et al. 2006, van Riemsdijk et al. 2006).

This approach has been used for modeling interactions in natural waters (Lofts et al., 1998; Unsworth, 2004), extensively in soils (Lofts et al., 2001; Weng et al., 2001, Cances et al., 2003, Dijkstra et al., 2004; Fest et al., 2005;), river floodplains (Schroder et al., 2005), and granular and monolithic waste materials (van der Sloot et al., 2006; Carter et al., 2008; Dijkstra et al., 2008; Tiruta-Barna et al., 2005).

\subsection{SUMMARY}

Table 3 provides a summary comparison of the main contents of the thermodynamic databases described above.

Table 3. Overview of Main Contents of Different Thermodynamic Databases

\begin{tabular}{|c|c|c|c|c|c|c|}
\hline \multirow[b]{2}{*}{ Database } & \multirow{2}{*}{$\begin{array}{l}\text { Aqueous } \\
\text { Speciation }\end{array}$} & \multirow{2}{*}{$\begin{array}{c}\text { Mineral } \\
\text { Precipitation }\end{array}$} & \multicolumn{3}{|c|}{ Adsorption } & \multirow{2}{*}{$\begin{array}{c}\text { Radio } \\
\text { nuclides }\end{array}$} \\
\hline & & & Oxides & $\begin{array}{l}\text { Organic } \\
\text { Matter }\end{array}$ & Clay & \\
\hline MINTEQA2 V4 & Yes & Yes $(>400)$ & $\begin{array}{l}\text { Yes, } \\
\text { HFO }\end{array}$ & No & No & Some \\
\hline $\begin{array}{l}\text { LLNL } \\
\text { (thermo.cem.V8.R6.230) }\end{array}$ & Yes & Yes & & No & No & Yes \\
\hline $\begin{array}{l}\text { Nagra/PSI Chemical } \\
\text { Thermodynamic Data Base } \\
01 / 01\end{array}$ & Yes & Yes & No & No & No & Yes \\
\hline BRGM (Thermoddem) & Yes & Yes & Yes & No & No & Yes \\
\hline Cement 07 & $\begin{array}{c}\text { Yes } \\
\text { (Cement } \\
\text { specific) }\end{array}$ & $\begin{array}{c}\text { Yes } \\
\text { (Cement } \\
\text { specific) }\end{array}$ & No & No & No & No \\
\hline JAEA & Yes & Yes & No & No & No & Yes \\
\hline
\end{tabular}

VIII-10 
Thermodynamic data (for aqueous solution speciation and precipitates) is estimated to be rather well covered by the databases listed in Section 2.1.

However, temperature dependence parameters in the currently available thermodynamic databases are incomplete and most data are reported at a standard state of $25^{\circ} \mathrm{C}$.

For sorption processes, the available "generic" parameter data sets contain parameters for a few actinide, transuranic and rare earth elements (Am, $\mathrm{Cm}, \mathrm{Dy}, \mathrm{Eu}, \mathrm{Th}, \mathrm{U}, \mathrm{Be}, \mathrm{Pu}, \mathrm{Np}, \mathrm{Pd})$, but an evaluation has to be made as to which relevant parameters are missing. Sorption parameters that are not readily available can often be derived using published LFER's (Linear Free Energy Relationships) or by assuming "surrogate" behavior of a compound for which information is more complete. Information on the temperature dependence of sorption processes is virtually absent. 


\subsection{REFERENCES}

Bethke, C.M. 1998. The Geochemist's Workbench ${ }^{\mathrm{TM}}$, release 3.0, A User's Guide to Rxn, Act2, Tact, React, and Gtplot. Hydrology Program, University of Illinois

Borjesson, K.S. and Emrn, A.T. 1993. SOLISOLA program using phreeqe to solve solid solution/ aqueous equilibria. Computers and Geosciences, 19( 8):1065-1070.

Brendler,V., Arnold, T., Richter, A. and Bernhard, G. 2004. Capability of surface complexation models and databases for predicting radionuclide sorption. Waste Management 2004 (conference proceedings), Tucson, AZ, WM-4070

Cances, B., Ponthieu, M., Castrec-Rouelle, M., Aubry, E. and Benedetti, M.F. 2003. Metal ions speciation in a soil and its solution: experimental data and model results. Geoderma, 113:341-355.

Carter, C.M., van der Sloot, H.A., Cooling, D., van Zomeren, A. and Matheson, T. 2008. Characterization of untreated and neutralized bauxite residue for improved waste management. Environmental Engineering Science, 25:475-489.

Dijkstra, J.J., van der Sloot, H.A. and Comans, R.N.J. 2006. The leaching of major and trace elements from MSWI bottom ash as a function of $\mathrm{pH}$ and time. Applied Geochemistry, 21: 335-351.

Dijkstra, J.J., Meeussen, J.C.L. and Comans, R.N.J. 2004. Leaching of heavy metals from contaminated soils: an experimental and modeling study. Environmental Science and Technology, 38:43904395 .
Dijkstra, J.J., Meeussen, J.C.L., van der Sloot, H.A. and Comans, R.N.J. 2008. A consistent geochemical modelling approach for the leaching and reactive transport of major and trace elements in MSWI bottom ash. Applied Geochemistry, 23:1544-1562.

Dijkstra, J.J., Meeussen, J.C.L., van der Sloot, H.A. and Comans, R.N.J. 2008. A consistent geochemical modelling approach for the leaching and reactive transport of major and trace elements in MSWI bottom ash. Applied Geochemistry, 23:1544-1562.

Dzombak, D.A. and Morel ,F.M.M. 1990. Surface Complexation Modeling: Hydrous Ferric Oxide. John Wiley and Sons, Inc., New York.

Fest, E.P.M.J., Temminghoff, E.J.M., Griffioen, J. and Van Riemsdijk, W.H. 2005. Proton Buffering and Metal Leaching in Sandy Soils. Environmental Science and Technology, 39:7901-7908.

Gaines, G.L., and Thomas, H.C., 1953. Adsorption studies on clay minerals. II. A formulation of the thermodynamics of exchange adsorption.

J. of Chemical Physics, 21:714-718.

GEMS - http://gems.web.psi.ch.

Gustafsson, J.P., Pechova, P. and Berggren, D.

2003. Modeling metal binding to soils: the role of natural organic matter. Environmental Science and Technology, 37:2767-2774.

Hiemstra, T. and van Riemsdijk, W.H. 1996. A surface structural approach to ion adsorption: the charge distribution (CD) model. J. of Colloid and Interface Science, 179:488-508. 
Hiemstra, T., van Riemsdijk, W.H. and Bolt, G.H. 1989a. Multisite proton adsorption modeling at the solid/solution interface of (hydr)oxides: a new approach. I. Model description and evaluation of intrinsic reaction constants. J. of Colloid and Interface Science, 133:91-104.

Hiemstra,T., de Wit,J.C.M. and van Riemsdijk,W.H. 1989b. Multisite proton adsorption modeling at the solid/solution interface of (hydr)oxides: a new approach, II. application to various important (hydr) oxides. J. of Colloid and Interface Science, 133:105117.

Hummel, W., Berner, U., Curti, E., Pearson, F. J., Thoenen, T. 2002. Nagra/Psi Chemical Thermodynamic Data Base 01/01, UniversalPublishers, 592 pp.

Kaplan, D.I, Roberts, K., Coates, J., Siegfried, M., Serkiz, S. 2008. Saltstone and concrete interactions with radionuclides: sorption $\left(K_{d}\right)$, desorption, and reduction capacity measurements. SRNSSTI-2008-00045.

Kinniburgh, D.G., van Riemsdijk, W.H., Koopal, L.K., Borkovec, M., Benedetti, M.F. and Avena, M.J. 1999. Ion binding to natural organic matter: competition, heterogeneity, stoichiometry and thermodynamic consistency. Colloids and Surfaces A: Physicochemical and Engineering Aspects, 151:147166.

Koning, A. J. de, Comans, R. N. J., 2004. Reversibility of radiocaesium sorption on illite. Geochimica and Cosmochimica Acta, 68:2815-2823.

Klemm, W.A.. 1998. Ettringite and oxyanion substituted ettringites - their characterization and applications in the fixation of heavy metals: A synthesis of the literature. Portland Cement Association.
Krupka, K.M. and Serne, J.R. 1998. Effects on Radionuclide Concentrations by Cement-GroundWater - Interactions in Support of Performance Assessment of Low-Level Radioactive Waste Disposal Facilities. NUREG/CR-6377, 1998. U.S. Nuclear Regulatory Commission, Washington, DC.

Krupka, K.M., Serne, R.J. and Kaplan, D.I. 2004. Geochemical Data Package for the 2005 Hanford Integrated Disposal Facility Performance Assessment. PNNL-13037 Rev. 2.

Lofts, S., Simon, B.M., Tipping, E. and Woof, C. 2001. Modelling the solid-solution partitioning of organic matter in European forest soils. European $J$. of Soil Science, 52:215-226.

Lothenbach, B. and Wieland, E. 2006. A thermodynamic approach to the hydration of sulphate-resisting Portland cement. Waste Management, 26(7):706-719.

Lothenbach, B. and Winnefeld, F. 2006. Thermodynamic modelling of the hydration of Portland cement. Cement and Concrete Research, 36(2): 209-226.

Lothenbach, B., Matschei, T., Moschner, G. and Glasser, F. P. 2008. Thermodynamic modelling of the effect of temperature on the hydration and porosity of Portland cement. Cement and Concrete Research, 2008(38):1-18.

Lothenbach, B., Winnefeld, F., Alder, C., Wieland, E. and Lunk, P. 2007. Effect of temperature on the pore solution, microstructure and hydration products of Portland cement pastes. Cement and Concrete Research, 37:483-491.

Lothenbach, B. and Gruskovnjak, A. 2007. Hydration of alkali-activated slag: Thermodynamic modelling. Advances in Cement Research, 19:81-92. 
Meeussen, J.C.L. 2003. ORCHESTRA: An objectoriented framework for implementing chemical equilibrium models. Environmental Science and Technology, 37:1175-1182.

Meima, J.A.and Comans, R.N.J. 1998. Application of surface complexation/precipitation modelling to contaminant leaching from weathered municipal solid waste incinerator bottom ash. Environmental Science and Technology, 32:688-693.

Milne, C.J., Kinniburgh, D.G., van Riemsdijk, W.H. and Tipping, E. 2003. Generic NICA-Donnan model parameters for metal-ion binding by humic substances. Environmental Science and Technology, 37: 958-971.

MINTEQA2/PRODEFA2, A Geochemical assessment model for environmental systems: user manual supplement for version 4.0. 1999. Athens, GA, US-EPA, National Exposure Research Laboratory, Ecosystems Research Division.

Merdy,P., Huclier,S. and Koopal,L.K. 2006. Modeling metal-particle interactions with an emphasis on natural organic matter. Environmental Science and Technology, 40:7459-7466.

Parkhurst, D.L. and Appelo, C.A.J., 1999. User's guide to PHREEQC (version 2) - a computer program for speciation, reaction-path, 1D-transport, and inverse geochemical calculations. US Geological Survey Water Resources Inv. Rep. 99-4259, 312p. (wwwbrr.cr.usgs.gov/projects/GWC_coupled/ phreeqc/)

Piantone, P. , Nowak, C., Lassin, A., Blanc, P. , Burnol, A. 2006. Thermoddem : THERmodynamique et MOdélisation de la Dégradation. DEchets Minéraux. BRGM/RP-54547-FR, (http://thermoddem. brgm.fr/Fichiers/BRGM-54547-FR.pdf; http:// thermoddem.brgm.fr/ documents.asp)
Reiller, P. 2005. Prognostcating the humic complexation for redox sensitive actinides through analogy, using charge neutralization model.

Radiochimica Acta, 93:43-55.

Reiller, P., Evans, N.D.M. and Szabo, G. 2008. Complexation parameters for the actinides(iv)-humic acid system: a search for consistency and application to laboratory and field observations. Radiochimica Acta, 96:345-358.

Reiller, P., Moulin, V., Casanova, F. and Dautel, C. 2002. Retention behaviour of humic substances onto mineral surfaces and consequences upon thorium (IV) mobility: case of iron oxides. Applied Geochemistry, 17(12):1551-1562.

Saunders, J.A. and Toran, L.E. 1995. Modeling of radionuclide and heavy metal sorption around low- and high $\mathrm{pH}$ waste disposal sites at Oak Ridge, Tennessee. Applied Geochemistry, 10(6):673-684.

Schroder, T.J., Hiemstra, T., Vink, J.P.M. and van der Zee, S.E.A.T.M. 2005. Modeling of the solid solution partitioning of heavy metals and arsenic in embanked flood plain soils of the rivers Rhine and Meuse. Environmental Science and Technology, 39: 7176-7184.

Tipping, E., Rieuwerts, J., Pan, G., Ashmore, M.G., Lofts, S., Hill, M.T.R., Farago, M.E. and Thornton, I. 2003. The solid-solution partitioning of heavy metals $(\mathrm{Cu}, \mathrm{Zn}, \mathrm{Cd}, \mathrm{Pb})$ in upland soils of England and Wales. Environmental Pollution, 125:213-225.

Tipping, E. 1994. WHAM - A chemical equilibrium model and computer code for waters, sediments, and soil incorporating a discrete site/electrostatic model of ion-binding by humic substances. Computers and Geosciences, 20:973-1023. 
Tiuta-Barna, L., Barna, R. and Moszkowicz, P. 2005. Release dynamic process identification for a cement based material in various leaching conditions, Part II: Modelling the release dynamics for different leaching conditions. J. of Environmental Management, 4:171180.

Tonkin, J.W., Balistrieri, L.S. and Murray, J.W. 2004. Modeling sorption of divalent metal cations on hydrous manganese oxide using the diffuse double layer model. Applied Geochemistry, 19: 29-53.

Unsworth, E.R., Warnken, K.W., Zhang, H., Davison, W., Black, F., Buffle, J., Cao, J., Cleven, R., Galceran, J., Gunkel, P., Kalis, E., Kistler, D., vanLeeuwen, H.P., Martin, M., Noel, S., Nur, Y., Odzak, N., Puy, J., van Riemsdijk, W., Sigg, L., Temminghoff, E., Tercier-Waeber,M.L., Toepperwien, S., Town, R.M., Weng, L. and Xue, H. 2006. Model Predictions of Metal Spec iation in Freshwaters Compared to Measurements by In Situ Techniques. Environmental Science and Technology, 40: 1942-1949. van der Sloot, H.A., Meeussen, J.C.L., van Zomeren, A. and Kosson, D.S. 2006. Developments in the characterisation of waste materials for environmental impact assessment purposes. $J$. of Geochemical Exploration, 88:72-76.

van der Sloot, H.A., van Zomeren, A., Meeussen, J.C.L., Seignette, P. and Bleijerveld, R. 2007. Test method selection, validation against field data, and predictive modelling for impact evaluation of stabilised waste disposal. J. of Hazardous Materials, 141:354-369.

van Riemsdijk, W.H., Koopal, L.K., Kinniburgh, D.G., Benedetti, M.F. and Weng, L. 2006. Modeling the Interactions between Humics, Ions, and Mineral Surfaces. Environmental Science and Technology, 40:7473-7480.

Weng, L., Temminghoff, E.J.M. and van Riemsdijk, W.H. 2001. Contribution of individual sorbents to the control of heavy metal activity in sandy soil. Environmental Science and Technology, 35:44364443. 



\title{
REVIEW OF APPROACHES TO COUPLING PHYSICAL, STRUCTURAL AND CHEMICAL MECHANISMS
}

\author{
Eric Samson \\ Email: esamson@simcotechnologies.com \\ SIMCO Technologies, Inc. \\ Quebec City, Canada \\ J. C. L. Meeussen \\ Email:meeussen@ecn.nl \\ H. A. van der Sloot \\ Email: vandersloot@ecn.nl \\ Energy Research Centre of the Netherlands \\ Petten, The Netherlands \\ Andy Garrabrants \\ Email: a.garrabrants@vanderbilt.edu \\ Vanderbilt University, School of Engineering \\ Consortium for Risk Evaluation with Stakeholders Participation, III
}

Nashville, TN 37235

November 2009

CBP-TR-2009-002, Rev. 0 
Review of Mechanistic Understanding and Modeling and Uncertainty Analysis Methods for Predicting Cementitious Barrier Performance 


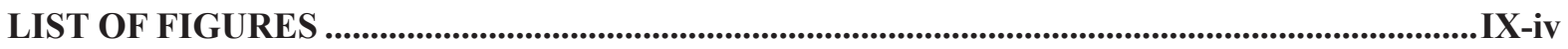

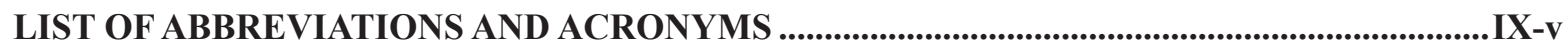

LIST OF NOMENCLATURE ......................................................................................................

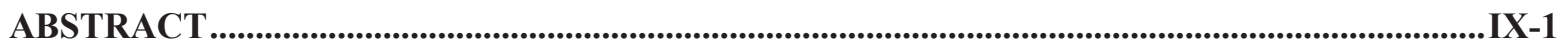

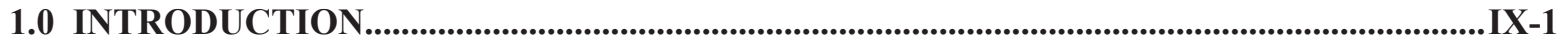

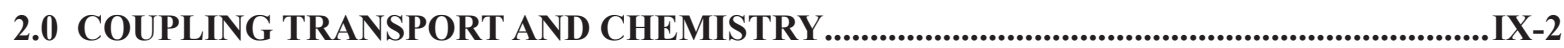

2.1 General Overview of Ionic Transport ........................................................................................IX-3

2.2 General Overview of Chemical Reactions ................................................................................IX-5

2.3 Linear Transport Equations Coupled with Chemistry........................................................IX-7

2.4 Operator Splitting Approaches ..................................................................................................... IX-9

2.5 Nonlinear Transport Equations Coupled with Chemistry …...........................................IX-10

3.0 THERMO-HYDRO-MECHANICAL MODELS .....................................................................

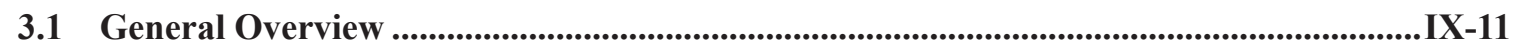

3.2 Simplified THM Models ................................................................................................................IX-15

3.3 Adding Cement Hydration to THM Models..................................................................IX-15

4.0 COUPLED IONIC TRANSPORT AND MECHANICAL MODELS........................................IX-16

4.1 Simplified Transport Coupling .............................................................................................................IX-16

4.2 Multi-ionic Transport Coupling …......................................................................................

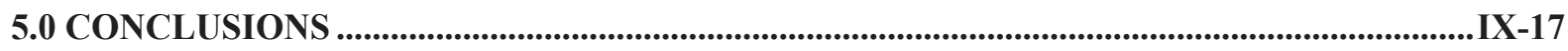

6.0 REFERENCES.............................................................................................................................................IX-19 
Review of Mechanistic Understanding and Modeling and Uncertainty Analysis

Methods for Predicting Cementitious Barrier Performance

\section{LIST OF FIGURES}

Page No.

Figure 1. Factors Affecting the Rate of Leaching from Solid Materials Including Cementitious Waste Forms and Concrete Waste Containment Structures

(adapted from Garrabrants et al. 2005) ............................................................................ IX-3

Figure 2. Relationship Between the Calcium in Solution vs. the $\mathrm{CaO} / \mathrm{S}_{1} \mathrm{O}_{2}$ Ratio and s................... IX-18 


\section{LIST OF ABBREVIATIONS AND ACRONYMS}

$\begin{aligned} \text { ADE } & \text { Advective-Dispersive Equation or Advective-Diffusive Equation } \\ \text { ASR } & \text { Alkali-Silica Reaction } \\ \text { DEF } & \text { Delayed Ettringite Formation } \\ \text { DSA } & \text { Direct Substitution Approach } \\ \text { FHWA } & \text { Federal Highway Administratio } \\ \text { HMW } & \text { Harvies, Moller and Weare implementation of Pitzer's ionic interaction model } \\ \text { IX } & \text { Ionic Exchange } \\ \text { LEA } & \text { Local Equilibrium Assumption } \\ \text { opc } & \text { ordinary Portland cement } \\ \text { OS } & \text { Operator Splitting } \\ \text { REV } & \text { Representative Elementary Volume } \\ \text { SIA } & \text { Sequential Iterative Approach } \\ \text { SNIA } & \text { Sequential Non Iterative Approach } \\ \text { THM } & \text { Thermo-hydro-mechanical }\end{aligned}$




\section{LIST OF NOMENCLATURE}

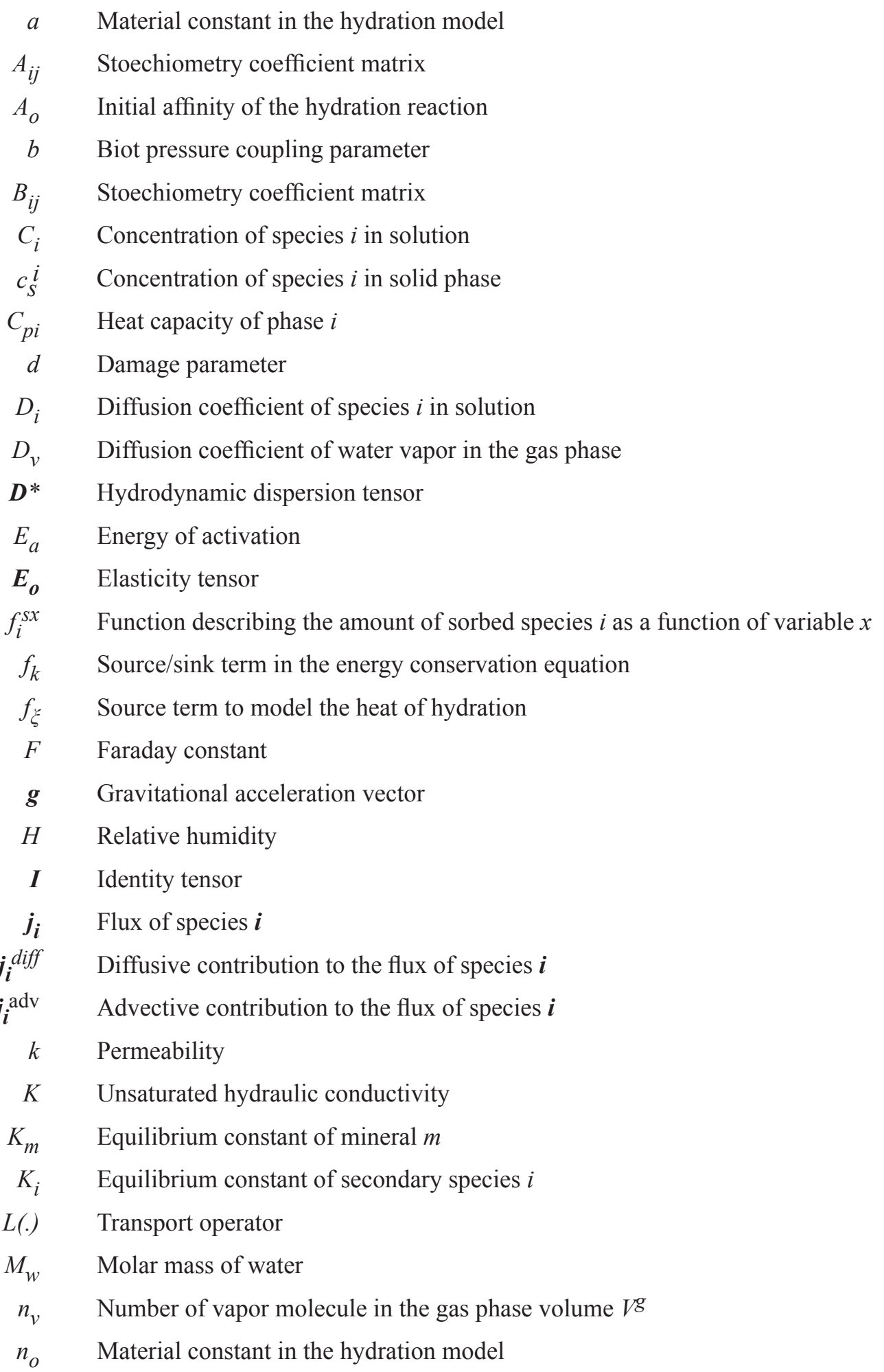




\section{LIST OF NOMENCLATURE (contd)}

$\begin{aligned} \bar{n} & \text { Material constant in the hydration model } \\ N & \text { Number of species in solution } \\ N_{x} & \text { Number of secondary species in solution } \\ N_{p} & \text { Number of immobile species } \\ N_{c} & \text { Number of main species (components) in solution } \\ p & \text { Average pressure } \\ p_{i} & \text { Pressure in phase } i \\ p_{k} & \text { Concentration of species } k \text { in mineral form } \\ Q_{\xi} & \text { Material parameter in the heat of hydration model } \\ r_{i} & \text { Source/sink term for the homogeneous reaction } \\ R & \text { Ideal gas constant } \\ s_{i} & \text { Concentration of species } i \text { sorbed on the solid matrix } \\ S & \text { Saturation } \\ t & \text { time } \\ T & \text { Temperature } \\ T^{r} f & \text { Reference temperature } \\ \mathbf{u} & \text { Displacement vector } \\ u_{i} & \text { Total soluble concentration of species } i \\ v i & \text { Velocity vector of fluid } i \text { ( } i=\text { gas, liquid water, vapor) } \\ V_{g} & \text { Volume of the gas phase } \\ V_{d} & \text { Ageing parameter } \\ w & \text { Water content } \\ w_{i} & \text { Total concentration of species } i \\ z_{i} & \text { Solid phase content } \\ & \text { Position } \\ x_{i} & \text { concentration of secondary species } \\ & \end{aligned}$




\title{
LIST OF NOMENCLATURE (contd)
}

\author{
$\boldsymbol{\alpha} \quad$ Dynamic dispersivity tensor \\ $\alpha^{T} \quad$ Thermal dilatation coefficient \\ $\alpha_{\xi} \quad$ Thermal expansion parameter associated with the heat of hydration \\ $\beta_{i} \quad$ Mole fraction \\ $\varepsilon \quad$ Total strain \\ $\varepsilon^{e} \quad$ Elastic strain \\ $\varepsilon^{c h} \quad$ Strain caused by the heat released during the hydration of cement \\ $\varepsilon^{o} \quad$ Autogeneous strain \\ $\varepsilon^{T} \quad$ Strain caused by thermal expansion \\ $\varphi \quad$ Porosity \\ $\gamma_{i} \quad$ Chemical activity coefficient of species $i$ \\ $\Gamma \quad$ Moisture potential \\ $\lambda \quad$ Capillary potential \\ $\lambda_{\text {eff }} \quad$ Effective thermal conductivity \\ $\mu_{i} \quad$ Dynamic viscosity of phase $i$ \\ $\mu_{l \rightarrow v} \mu_{y \rightarrow l} \quad$ Water vaporization/condensation terms \\ $v^{i j} \quad$ Stoechiometry coefficient \\ $\rho_{i} \quad$ Density of phase $i$ \\ $\sigma \quad$ Total stress tensor \\ $\sigma^{\prime} \quad$ effective stress tensor \\ $\xi \quad$ Degree of hydration \\ $\xi_{\infty} \quad$ Maximum degree of hydration \\ $\psi \quad$ Electrodiffusion potential
}




\title{
REVIEW OF APPROACHES TO COUPLING PHYSICAL, STRUCTURAL AND CHEMICAL MECHANISMS
}

\author{
Eric Samson \\ SIMCO Technologies, Inc. \\ Quebec City, Canada \\ J. C. L. Meeussen \\ H. A. van der Sloot \\ Energy Research Centre of the Netherlands \\ Petten, The Netherlands \\ Andy Garrabrants \\ Vanderbilt University, School of Engineering \\ Consortium for Risk Evaluation with Stakeholders Participation, III \\ Nashville, TN 37235
}

\begin{abstract}
This chapter reviews approaches used to model coupling between different degradation mechanisms affecting concrete structures. Two main categories of models were identified: reactive transport modeling and thermohydro-mechanical models.
\end{abstract}

Reactive transport models are concerned with the transport of chemical species in porous materials and the multiple interactions they can have with the solid matrix. These models couple transport equations with complex chemical models. They ignore the mechanical aspects of deleterious chemical reactions such as crack formation upon sulfate attack.

On the other hand, there are models that couple fluid transport with thermal and mechanical equations, called thermo-hydro-mechanical (THM) models. These models can be used to simulate crack formation caused by drying shrinkage or heat release during the hydration of cement. However, classic THM models do not incorporate the transport of species in the fluid phases and the chemical exchange with the solid minerals.

Reactive transport models incorporating mechanical considerations, or THM models dealing with detailed transport and chemistry relationships, are nearly non-existent. Given the mechanisms and time scales involved in nuclear waste storage problems, models incorporating detailed reactive transport with a THM framework could be used to provide a global durability assessment for those structures.

\subsection{INTRODUCTION}

Modeling the behavior of concrete structures over very long time periods in order to assess the durability of nuclear waste storage structures involves many different phenomena ranging from chemical interactions to crack formation. Concrete durability analyses over short durations (e.g., $<100$ years) usually focus on specific problems that can studied with a limited set of parameters. However, the 
durability of nuclear storage structures is a problem that extends over thousands (up to 10,000) of years. Many problems that are uncoupled over a few years can become coupled together over such a long time interval. For instance, the leaching of calcium and hydroxide ions from materials in contact with low $\mathrm{pH}$ groundwater can be considered harmless over 100 years if the concrete mixture was designed correctly. However, over 10,000 years, it is possible that the decalcification of the solid matrix will have an impact on the overall performance of the structure and a durability analysis for such cases must consider chemical and mechanical aspects.

This chapter reviews approaches used to model coupling between different degradation mechanisms affecting concrete structures. Two main categories of models were identified: reactive transport and thermohydro-mechanical models.

Reactive transport models are concerned with the transport of chemical species in porous materials and the multiple interactions they can have with the solid matrix. These models couple transport equations with complex chemical models. They ignore the mechanical aspects of deleterious chemical reactions such as crack formation upon sulfate attack.

On the other hand, there are models that couple fluid transport with thermal and mechanical equations, called thermo-hydro-mechanical (THM) models.

These models can be used to simulate crack formation caused by drying shrinkage or heat release during the hydration of cement. However, classic THM models do not incorporate the transport of species in fluid phases and chemical exchange with the solid minerals.

A global durability prediction approach would couple reactive transport and THM models. As the review showed, only limited attempts at such a global model have been made so far.

\subsection{COUPLING TRANSPORT AND CHEMISTRY}

The interest in ionic transport modeling dates back to the 1970s. At the time, the new awareness of environmental problems led to the development of models dedicated to predicting the rate of ingress of contaminants in groundwater. Leaching of contaminants from a material of interest and transport of leached species within the subsurface to groundwater sources were the main focus of these early models. Thus, hydrogeology and environmental sciences have been the primary fields interested in this type of modeling. Performance assessment models developed under the US DOE Office of Environmental Management focus on near-field release (i.e., leaching from the source material) and far-field (i.e., subsurface transport) approaches. Later, similar approaches have been used in civil engineering to address the durability of cementitious materials (e.g., reinforcement corrosion via carbonate and chloride ingress).

The early model approaches consisted of singlespecies transport using an advection-diffusion equation $(\mathrm{ADE})$ that incorporated a very simplified term to account for all chemical reactions. This type of model is known today as the " $K_{d}$ " approach (Fetter 1999). The lumped chemistry of the $K_{d}$ approach may be applicable when species concentrations are quite low, the geochemistry of the system is unknown or not considered in detail, and interaction of the diffusing species is relatively unaffected by external influences. These conditions typically are not the case for cementitious materials but are encountered in waste forms which can contain dissolved salts (nitrates, nitrites, sulfates, aluminates, carbonates, phosphates, borates, oxalates, chlorides, fluorides, etc.), numerous radionuclides species, industrial chemicals, etc.

Figure 1 illustrates the complex system of issues to be covered when dealing with coupled chemical reaction 


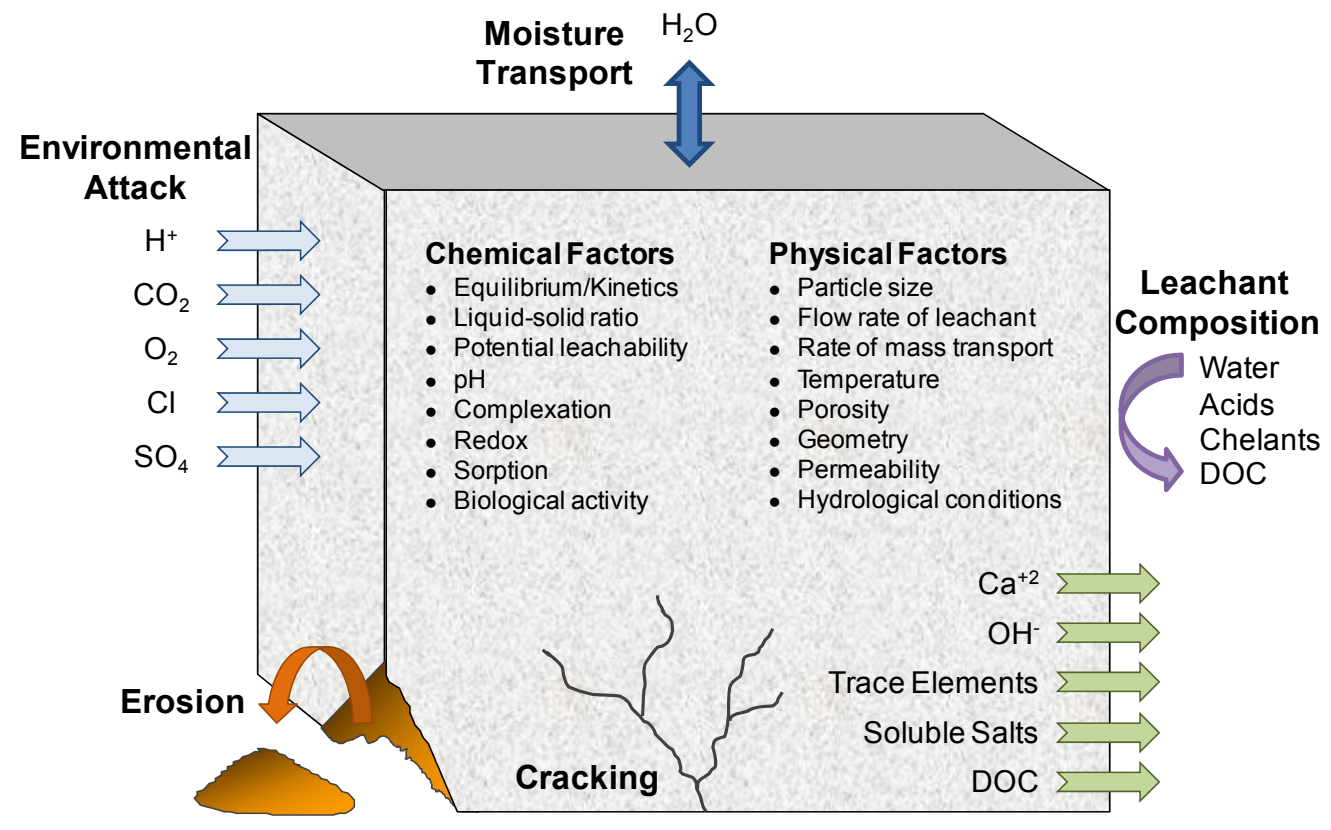

Figure 1. Factors Affecting the Rate of Leaching from Solid Materials Including Cementitious Waste Forms and Concrete Waste Containment Structures (adapted from Garrabrants et al. 2005).

and transport solid wastes such as cementitious materials. All aspects of relevance are covered here ranging from physical properties like temperature variation and mechanical influences to chemical aspects covering a full suite of major, minor and trace elements affecting the release of species of interest. In order to describe these complex physio-chemical phenomena, diffusion/advection equations have been coupled with increasingly complex chemical models describing multiple ionic transport equations with simultaneous reactions.

The relevant transport equations are briefly reviewed in the next section. A more complete description can be found in the chapters concerned with the hydraulic properties and the chemical degradation mechanisms. This is followed by a description of basic chemical reaction modeling. The coupling between linear transport models and chemistry is then reviewed. Finally, the last section is dedicated to the coupling between nonlinear transport equations and chemistry.

\subsection{General Overview of Ionic Transport}

The transport of ionic species in porous materials is the result of two main mechanisms: diffusion and advection ${ }^{1}$. Diffusion results from the random motion of dissolved species in the solution while

\footnotetext{
${ }^{1}$ Cementitious materials are porous and contain pore fluid as the result of residual mixing water and/or contact with moisture from the environment. Moisture and dissolved contaminants and corrodents migrate through this pore solution. If the aqueous pore solution is not continuous in the pores, transport of soluble species is for practical purposes zero. However, in this case transport of gaseous species through the unsaturated pores becomes very important. Solid state diffusion and conductance are not considered here.
} 
advection is the contribution from the solvents's own movement. The complete flux expression is the sum of both terms (Helfferich 1961):

$\mathbf{j}_{i}=\mathbf{j}_{i}{ }^{\text {diff }}+\mathbf{j}_{i}$ adv

where: $\mathbf{j}_{\boldsymbol{i}}$ is the flux of species $\boldsymbol{i}$ and the subscript

"diff" and "adv" stand for the diffusion and advection contribution respectively.

The diffusion part of Equation (1) is related to the gradient of the electrochemical potential (Bockris 1970). The final expression is (Samson 2007):

$$
\begin{aligned}
\mathbf{j}_{i}^{\text {diff }} & =\underbrace{-D_{i} \operatorname{grad}\left(c_{i}\right)}_{\text {diffusion }}-\underbrace{\frac{D_{i} z_{i} F}{R T} c_{i} \operatorname{grad}(\psi)}_{\text {elect. coupling }}- \\
& -\underbrace{D_{i} c_{i} \operatorname{grad}\left(\ln \gamma_{i}\right)}_{\text {chemical act. }}-\underbrace{\frac{D_{i} c_{i} \ln \left(\gamma_{i} c_{i}\right)}{T} \operatorname{grad}(T)}_{\text {temperature coupling }}
\end{aligned}
$$

where: $c_{i}$ is the concentration, $D_{i}$ is the diffusion coefficient, $z_{i}$ is the valence number of the species, $F$ is Faraday constant, $R$ is the ideal gas constant, $T$ is the temperature, $\Psi$ is the diffusion potential, and $\gamma_{i}$ is the chemical activity coefficient. The term involving the diffusion potential is responsible for maintaining electroneutrality in the solute despite the differences in diffusion coefficient of each individual species. The chemical activity term accounts for the non-ideal behavior of diffusion for high concentrations.

Most models found in the literature are based on a simplified version of Equation (2). The vast majority of models dedicated to contaminant transport in groundwater neglect the electrical coupling, chemical activity effects, and temperature coupling terms. In most cases, they only consider the diffusion term. The corresponding equation is called the Fick's diffusion relationship:

$$
\mathbf{j}_{i}^{\text {diff }}=-D_{i} \operatorname{grad}\left(c_{i}\right)
$$

Recent models specifically dedicated to transport in cementitious materials considered the electrical coupling term to account for the highly charged pore solution of those materials (e.g., Samson 2007b, Truc 2000).

The advection term can be written as (Bear 1991):

$$
\mathbf{j}_{\mathbf{i}}^{a d v}=c_{i} \mathbf{v}
$$

where: $\mathbf{v}$ is the fluid velocity vector. The fluid moves in a porous material under the action of external pressure, gravity and capillary forces (Fetter 1999). In saturated materials, the capillary effects are non-existent. The driving forces are limited to gravity and pressure gradients.

In that case, the fluid obeys Darcy's generalized law (Bear 1988):

$\mathbf{v}=-\frac{k}{\mu}\left(\operatorname{grad}\left(p_{l}\right)-\rho_{l} \mathbf{g}\right)$

where: $k$ is the liquid permeability of the material, $\mu$ is the dynamic viscosity of the liquid phase, $p_{l}$ is the liquid pressure, $\rho_{l}$ is the fluid density and $\mathbf{g}$ is the gravity acceleration vector.

In unsaturated materials, the pore water is under a negative pressure caused by surface tension (Fetter 1999), called the capillary potential. The total moisture potential is the sum of the capillary and gravitational potentials (Fetter 1999):

$\Gamma=\lambda+Z$

where: $\Gamma$ is the total moisture potential, $\lambda$ is the capillary potential, and $Z$ is the gravitational potential.

In that case, moisture movement in porous materials can be modeled on the basis of the Buckingham flux law: 
$\mathbf{v}=-K(\lambda) \operatorname{grad}(\Gamma)$

where: $K(\lambda)$ is the unsaturated hydraulic conductivity.

Because of heterogeneities at the pore level, the flow of a fluid in a porous network induces a phenomenon called mechanical dispersion that spreads the dissolved species in the solution. This is discussed at length in (Bear 1991, Fetter 1999). This effect is modeled as a term that is added to the diffusion coefficient to yield the dispersion coefficient:

$\mathbf{D}_{i}^{*}=\mathrm{D}_{i} \mathbf{I}+\boldsymbol{\alpha} \mathbf{v}$

where: $\mathbf{D}_{i}{ }^{*}$ is the dispersion tensor, $\mathbf{I}$ is the identity tensor, and $\boldsymbol{\alpha}$ is the dynamic dispersivity tensor, which has longitudinal and transverse components.

The dynamic dispersivity depends on the fluid velocity and its impact on the dispersion coefficient can be estimated from the Peclet number $\mathrm{P}_{e}=\mathbf{v} L / D_{i}$, where $L$ is the characteristic flow length. For low Peclet values $\left(\mathrm{P}_{e}<1\right)$, the diffusion is dominant and the mechanical dispersion can be neglected. However, for high $\mathrm{P}_{e}$ values $(>10)$, dispersion dominates. The latter case is especially important from a modeling standpoint. When dispersion dominates, the individual diffusion coefficients can be neglected, which results in each species having the same dispersion coefficient. This allows several simplifications to the transport model and has been used extensively in hydrogeology, as will be shown in Sections 2.3 and 2.4.

When the flux relationships are known, they are substituted in the mass conservation equation (Bear 1991):

$\frac{\partial\left(w^{s} c_{i}^{s}\right)}{\partial t}+\frac{\partial\left(w c_{i}\right)}{\partial t}+\operatorname{div}\left(w \mathbf{j}_{\mathbf{i}}\right)+r_{i}=0$

where: $w$ is the water content, $w^{s}$ is the solid phase content, $C_{i}^{S}$ is the content of species $i$ in the solid phase, and $r_{i}$ is a source/sink term. The term $r_{i}$ accounts for the rate of formation or elimination of species $i$ from chemical reactions occurring solely within the pore solution while the term involving $C_{i}^{S}$ accounts for the exchange between the solid and aqueous phases. These different types of chemical reactions are outlined in the next section.

\subsection{General Overview of Chemical Reactions}

In a comprehensive review on the modeling of chemical reactions in porous media, Rubin (Rubin 1983) divided the reactions in two main categories: sufficiently fast and reversible, and insufficiently fast and/or irreversible. If the rate of reaction is large with respect to the ionic and fluid transport processes, then it belongs to the sufficiently fast category. In this particular case, it is assumed that the local chemical equilibrium (LEA) is preserved throughout the porous system. As emphasized by Steefel (Steefel 1994), LEA has long been one of the most fundamental tenets of hydrothermal and metamorphic geochemistry and petrology.

The same can be said about cementitious materials, where LEA is assumed in most, if not all, reactive transport models. A few dimensional analyses support this assumption. Barbarulo et al. (Barbarulo 2000) performed a dimensional analysis that validated LEA in fluid saturated cementitious materials. In (Samson 2007b), a similar analysis was made based on the Damköhler number for diffusion and advection. In both cases, the local equilibrium assumption was validated.

All reactions falling under the sufficiently fast category are modeled through chemical equilibrium equations (Rubin 1983), which are algebraic, as opposed to the partial differential equations used in transport models. Since the equilibrium is expressed, in most cases, through chemical activity, algebraic 
relations giving the chemical activity coefficients must also be considered while modeling the chemical reactions. The resolution of a transport problem involving chemical reactions is thus called a mixed problem, because it involves algebraic and partial differential equations.

The chemical reactions were then divided by Rubin (1983) into two sub-categories: homogeneous and heterogeneous. The homogeneous reactions are those involving a single phase. This sub-category includes all the complexation reactions, i.e., the formation of products occurring in the aqueous phase. For example, the reaction:

$$
\mathrm{Ca}^{2+}{ }_{(\mathrm{aq})}+\mathrm{OH}^{-}{ }_{(\mathrm{aq})} \rightleftharpoons \mathrm{CaOH}^{+}{ }_{(\mathrm{aq})}
$$

is a homogeneous reaction since it only occurs in the aqueous phase. In this reaction, $\mathrm{Ca}^{2+}$ and $\mathrm{OH}^{-}$are called the primary species and $\mathrm{CaOH}^{+}$is called the secondary species (Steefel 1994). The general equilibrium relationship for that type of reaction is written as:

$K_{i}=\frac{1}{\gamma_{i} x_{i}} \prod_{j=1}^{N c}\left(\gamma_{j} c_{j}\right)^{\nu_{i j}}$

where: $K_{i}$ is the equilibrium constant, $x_{i}$ is the concentration of the secondary species, $\gamma$ is the chemical activity coefficient, $N_{c}$ is the number of components forming the secondary species, $c_{j}$ is the concentration of the primary species, and $v_{i j}$ is the number of moles of primary species $j$ in one mole of secondary species $i$.

Contrary to the previous category, the heterogeneous reactions involve at least two phases (Rubin 1983).

Rubin distinguishes two types of heterogeneous reactions: surface and classical ones. Surface reactions are either adsorption, in which ions are attracted to the surface of the pore network under the influence of electrostatic forces (Bockris 1970), or ion exchange, in which two or more ionic species are exchanged between the surface of the solid and the aqueous phase (Appelo 1996). The classical reactions are precipitation, dissolution, oxidation and reduction. The dissolution of portlandite belongs to this category since it involves the aqueous and the solid phase:

$$
\mathrm{Ca}^{2+}{ }_{(\mathrm{aq})}+2 \mathrm{OH}^{-}{ }_{(\mathrm{aq})} \rightleftharpoons \mathrm{Ca}(\mathrm{OH})_{2(\mathrm{~s})}
$$

Similar to the complexation reaction (Equation (11)), the equilibrium of a mineral $m$ can be expressed as a function of a constant $K_{m}$ (Xu 1999):

$K_{m}=\prod_{i=1}^{N} c_{i}^{\nu_{m i}} \gamma_{i}^{\nu_{m i}}$

where: $N$ is the number of species entering the composition of the mineral $m, c_{i}$ is the concentration of species $i$ in solution and $v_{m i}$ is the number of moles of species $i$ in one mole of mineral $m$.

It should be noted that contrary to Equation (11), the reaction product of dissolution/precipitation reactions is not part of the equilibrium relationship (13), because the solid has an activity coefficient equal to one (Stumm 1996). This peculiarity of the dissolution/ precipitation mechanism induces the formation of mineral fronts inside the porous material, as discussed in (Rubin 1983). Such fronts can be observed in calcium leaching (e.g., Mainguy 2000) and sulfate attack cases (e.g., Maltais 2004).

Heterogeneous reactions also include sorption. This class of chemical reaction includes all reactions involving ions in the pore solution and the surface of the solid matrix, such as ion exchange and surface complexation. Ion exchange is mostly associated with the interaction of cations in the pore solution exchanged with cations in the solid:

$\mathrm{Na}^{+}{ }_{(\mathrm{aq})}+\mathrm{K}_{-} \mathrm{X}_{(\mathrm{s})} \rightleftharpoons \mathrm{K}^{+}{ }_{(\mathrm{aq})}+\mathrm{Na}-\mathrm{X}_{(\mathrm{s})}$

where: $\mathrm{X}$ represent the solid matrix.

The equilibrium relationship for two cations $a$ and $b$ can be written as (Appelo 1996): 
$K_{a / b}=\frac{\beta_{a}^{1 / z_{a}}}{\beta_{b}^{1 / z_{b}}} \frac{\gamma_{b}^{1 / z_{b}} c_{b}^{1 / z_{b}}}{\gamma_{a}^{1 / z_{a}} c_{a}^{1 / z_{a}}}$

where: $\beta$ is the equivalent mole fraction of the exchangeable cations, with $\Sigma \beta_{i}=1$.

The modeling of other types of heterogeneous chemical reactions such as oxidation and reduction and surface complexation can be found in textbooks (Bethke 2008, Stumm 1996).

All chemical equilibrium calculations involve chemical activity. Several models exist to calculate chemical activity coefficients. Classical electrochemical models like the Debye-Hückel or extended Debye-Hückel relationship are valid for weak electrolytes for which the ionic strength is on the order of $100 \mathrm{mmol} / \mathrm{L}$, while the Davies correction can be used to describe the behavior of more concentrated solutions, i.e., with ionic strengths up to $300 \mathrm{mmol} / \mathrm{L}$ (Pankow 1994). Pore solutions extracted from hydrated cement systems are in the $300 \mathrm{mmol} / \mathrm{L}$ (Hidalgo 2001) to $900 \mathrm{mmol} / \mathrm{L}$ range (Reardon 1992). As reported in (Zemaitis 1986), many models were developed to estimate the activity coefficients for highly concentrated solutions. One of the most commonly used approaches is the implementation of Pitzer's ionic interaction model proposed by Harvie, Moller and Weare (Harvie 1984). Pitzer's model was used by Reardon (Reardon 1990) to model the hydrated paste/solution chemical equilibrium.

\subsection{Linear Transport Equations Coupled with Chemistry}

The early models dedicated to reactive transport in porous materials basically attempted to substitute the chemical equilibrium relationships such as Equations (11) and (13) in the mass conservation Equation (9). This is called the Direct Substitution Approach (DSA), where the transport equations can be expressed according to different formulations
(Kirkner 1988). The next paragraphs summarize three different formulations of the DSA, as described by Kirkner and Reeves. The different formulations were devised assuming saturated materials and a linear transport operator, i.e., electrical coupling and chemical activity effects were neglected. While the saturated assumption could be extended to unsaturated cases, it will be shown that DSA works only if a linear transport model with a uniform dispersion coefficient is used.

The $N$ reactive species in solution are divided in $N_{c}$ components and $N_{x}$ secondary (or complex) species. The equations governing the transport of the $N_{c}$ components and $N_{x}$ secondary species are:

$$
\begin{gathered}
\frac{\partial \phi c_{j}}{\partial t}+\operatorname{div}\left(c_{j} \mathbf{v}-\phi \mathbf{D}^{*} \operatorname{grad} c_{j}\right)=r_{j}^{c} \\
j=1, \ldots, N_{c} \\
\frac{\partial \phi x_{i}}{\partial t}+\operatorname{div}\left(x_{i} \mathbf{v}-\phi \mathbf{D}^{*} \operatorname{grad} x_{i}\right)=r_{i}^{x} \\
i=1, \ldots, N_{x}
\end{gathered}
$$

where: $\phi$ is the porosity and the reactions terms in Equation (9) have been lumped in the $\mathrm{r}_{j}^{c}$ and $\mathrm{r}_{i}^{x}$ terms.

The subscript $i$ of the dispersion tensor has been omitted since it is assumed that the mechanical dispersion dominates over diffusion, which leads to all species having the same dispersion coefficient. In Equations (16) and (17), the porosity replaces the water content of Equation (9) because of the saturated pores assumption.

The authors then introduced the total soluble concentration $u_{j}$ of each species as:

$u_{j}=c_{j}+\sum_{i=1}^{N_{x}} A_{i j} x_{i}$

where: $A_{i j}$ is a stoechiometry coefficient matrix linking the main species to the complexes. 
Substituting Equation (11) in (18) gives:

$u_{j}=c_{j}+\sum_{i=1}^{N_{x}} A_{i j} K_{i} \prod_{k=1}^{N_{c}} C_{k}^{A_{i k}}$

The reaction rates $\mathrm{r}_{j}^{c}$ are defined as:

$r_{j}^{c}=r_{j}^{c(a q)}+r_{j}^{c(s)}+r_{j}^{c(p)}$

where:

$r_{j}^{c(a q)}=-\sum_{i=1}^{N_{x}} A_{i j} r_{i}^{x}$

reaction rate of $j$ due to complexation

$r_{j}^{c(s)}=-\frac{\partial \phi S_{j}}{\partial t}$

reaction rate of $j$ due to soprtion or $1 \mathrm{X}$

$r_{j}^{c(p)}=-\sum_{i=1}^{N_{p}} B_{i j} \frac{\partial \phi P_{i}}{\partial t}$

reaction rate of $j$ due to diss./prec.

In Equations (21) to (23), $s_{j}$ corresponds to the concentration of the main species $j$ sorbed on the solid phase, $\mathrm{p}_{i}$ is the concentration of mineral $i$, $N_{\mathrm{p}}$ is the number of immobile species, and $B_{i j}$ is a stoechiometry coefficient matrix. Kirkner and Reeves showed that it is possible to write the sorbed concentrations as:

$s_{j}=f_{j}^{s c}\left(c_{1}, c_{2}, \ldots, c_{N_{c}}\right)$

Using Equation (19), it is possible to write Equation (24) as a function of the total concentration $u_{j}$ :

$s_{j}=f_{j}^{s u}\left(u_{1}, u_{2}, \ldots, u_{N_{c}}\right)$

Summing the mass conservation Equations (16) and (17) and using the total concentration $u_{j}$ (Equation (19)) eliminates the reaction rates $r_{j}^{c(a q)}$. This operation is possible because all species have the same dispersion coefficient. Substituting the rate expressions (22) and (23), and the sorption function (25) in the summed conservation equations yield:
Formulation A:

$$
\begin{aligned}
\frac{\partial\left(\phi u_{j}\right)}{\partial t}+\frac{\partial\left(\phi f_{j}^{s u}\right)}{\partial t} & +\sum_{k=1}^{N_{p}} B_{k j} \frac{\partial\left(\phi p_{k}\right)}{\partial t}+ \\
& +L\left(u_{j}\right)=0 \quad j=1, \ldots, N_{c}
\end{aligned}
$$

where: $L($.$) is the linear transport operator:$

$$
L(.)=\operatorname{div}\left[(.) \mathbf{v}-\phi \mathbf{D}^{*} \operatorname{grad}(.)\right]
$$

The complexation reactions are implicitly included in the mass conservation equation as part of the definition of $u_{i}$ (Equation (19)).

It is possible to further simplify the transport equations by introducing the total concentration $w_{j}$ as the main variable:

$$
w_{j}=u_{j}+s_{j}+\sum_{k=1}^{N_{p}} B_{k j} p_{k} \quad j=1, \ldots, N_{c}
$$

From this definition, it is possible to write all the concentration variables as a function of the total concentration variable (Kirkner 1988):

$$
\begin{array}{ll}
c_{j}=f_{j}^{c w}\left(w_{1}, \ldots, w_{N_{c}}\right) & j=1, \ldots, N_{c} \\
p_{j}=f_{j}^{p w}\left(w_{1}, \ldots, w_{N_{c}}\right) & j=1, \ldots, N_{p} \\
u_{j}=f_{j}^{u w}\left(w_{1}, \ldots, w_{N_{c}}\right) & j=1, \ldots, N_{c} \\
s_{j}=f_{j}^{s w}\left(w_{1}, \ldots, w_{N_{c}}\right) & j=1, \ldots, N_{c}
\end{array}
$$

Based on these functions, it is possible to write Equation (26) as:

Formulation B:

$\frac{\partial\left(\phi w_{j}\right)}{\partial t}+L\left[f_{j}^{u w}\left(w_{1}, \ldots, w_{N_{c}}\right)\right]=0$

or alternatively: 
Formulation C:

$$
\begin{aligned}
\frac{\partial\left(\phi w_{j}\right)}{\partial t} & +L\left(w_{j}\right)=L\left[f_{j}^{s w}\left(w_{1}, \ldots, w_{N_{c}}\right)\right] \\
& +\sum_{k=1}^{N_{p}} B_{k j} L\left[f_{k}^{p w}\left(w_{1}, \ldots, w_{N_{c}}\right)\right]
\end{aligned}
$$

These different formulations have been used in the literature to solve reactive transport problems. Valocchi et al. (1981) used formulation A (Equation (26)) in their model, which considered ion-exchange reactions but did not include complexation nor dissolution/precipitation. Miller and Benson (1983) and Jennings et al. (1982) also used a formulation similar to A while considering complexation and ion exchange.

Although the chemical reactions are included in formulations $\mathrm{B}$ and $\mathrm{C}$, the total concentration they provide cannot be used directly and must be converted back to the $c_{i}$ and $x_{i}$ variables. To do so requires solving the algebraic chemical expressions separately. This is discussed for instance in (Cederberg 1985). These formulations hint at the operator splitting approaches presented in the following section. However, they are considered under the DSA category because the transport equations still need to be solved simultaneously (Yeh 1989).

It must be noted that all papers cited previously only consider complexation and sorption reactions. As mentioned in (Kirkner 1988), the discontinuities (fronts) induced by the presence of dissolution/ precipitation reactions require a special treatment. Some aspects are discussed in (Kirkner 1984). Most notably, the discontinuities associated with the precipitate content require the use of Diractype interpolation in a finite element formulation, which differs from the classical $C^{O}$ shape functions (Zienkiewicz 1989). Lichtner (1985) presented a model dealing with dissolution/precipitation reactions like a moving front problem. The approach includes specific mass conservation equations at the front locations, which must be added to the mass conservation equations.

\subsection{Operator Splitting Approaches}

One of the first models that separated transport and chemistry was developed by Grove and Wood (1979). The model was used to predict transport of calcium, magnesium, and sulfate in groundwater. The transport Equations (linear ADE, see Equation (27)) are first solved without considering any reaction terms. Next, the chemical reactions are solved using the concentration estimated by the transport step as initial guess. After this, the algorithm goes to the next time step and solves the next transport/chemistry sequence.

But what really triggered interest for splitting transport and chemistry in reactive transport models was the very influential paper published by Yeh and Tripathi in 1989 (Yeh 1989). Their main argument for splitting transport and chemistry was a reduction of CPU time. It also allows avoiding most of the problems associated with the dissolution/ precipitation reactions. Although their arguments were criticized later (Saaltink 2001) because they were theoretical and did not reflect actual calculation results, the paper was so highly regarded that DSA almost completely disappeared from that point on. Since then, splitting approaches have been adopted as the preferred method to model reactive transport problems despite the implicit numerical error that they introduce in the calculations (Kanney 2003, Jacques 2006). The possibility of coupling existing transport and chemical models together proved too attractive compared to the numerical problems and computational burden associated with the fully coupled Direct Substitution Approach. 
The operator splitting approaches are divided in two main categories:

- Sequential Iterative Approaches (SIA) and

- Sequential Non-Iterative Approaches (SNIA).

In the iterative approach, iterations are performed between the transport and chemistry until convergence is reached. In the SNIA, transport and chemistry are solved sequentially without iterations. The model described at the beginning of this section (Grove 1979) belongs to the SNIA category.

The SIA method consists mainly in expressing the formulations given in Section 2.3 so that the transport equations can be solved individually before chemistry is considered on a node per node basis (Yeah 1989). For instance, Walsh et al. (1984) used transport equations corresponding to formulation $\mathrm{C}$ (Equation (34)) solved using an explicit time stepping scheme. This linearizes the transport equations, which can be solved individually. The total concentrations are then separated into the solute, sorbed, and mineral components upon solving the chemical equilibrium equations. In (Engesgaard 1992), a model dealing with complexation, precipitation/dissolution, and oxidation/reduction was presented. The transport equations are expressed according to formulation A (see Equation (26)), where the reaction terms are considered as explicit source/sink terms. During the first iteration, the transport equations are first solved with the reaction terms set to zero. After chemistry, the source/sink terms are estimated based on the variations in the amount of precipitate and included in the transport equations. The iterations continue until a stable solution is reached. A similar algorithm was used in (Simunek 1994).

At the other end of the operator-splitting spectrum is the SNIA, exemplified by the paper from Grove and Wood (1979) summarized at the beginning of this section. SNIA can be selected over SIA for some reasons. Since it completely decouples transport and chemistry, it can prove easier to implement different transport and chemistry schemes in a single simulation platform. Removing the iterations between transport and chemistry can potentially reduce calculation times. However, as mentioned in (Steefel 1994b), SNIA requires a smaller time step than SIA to achieve the same level of accuracy. Strategies to reduce the operator-splitting error in SNIA, by controlling the grid spacing and time step, are discussed in (Jacques 2006). Comparisons between SNIA and SIA are provided in (Steefel 1994b, Walter 1994, Xu 1999). In most cases, SNIA tends to use less CPU time to get the same results. But the performances of SNIA are dependent on the type of chemical reactions. In (Xu 1999), the results showed numerical dispersion when ionic exchange simulations were performed with this algorithm. The dispersion resulted in less sharp concentration fronts than with the SIA algorithm.

Although all references cited previously were concerned with contaminant transport in groundwater, some papers have been specifically devoted to concrete barriers. In recent papers (De Windt 2004, Trotignon 2007), the authors used a SIA algorithm to simulate the long term durability of a concrete slab in contact with soil. In both papers, the simulations were performed on the layered concrete/soil system. In (Marty 2009), a similar problem was considered using a SNIA algorithm.

\subsection{Nonlinear Transport Equations Coupled With Chemistry}

All the papers cited in Sections 2.3 and 2.4 were based on linear equations based on the transport operator, Equation (27). This allows introducing the total soluble concentration given by Equation (19) into the mass transport equation. Following this, it is possible to eliminate the source/sink terms associated with the complexation reactions, which gives Equation (26), based on the total soluble concentration. This is possible when the fluid phase 
flow in the pore network induces a dispersion factor that is strong enough to overcome the individual selfdiffusion coefficient of the soluble species.

In the case of concrete, the permeability of the material is so low that high velocity flows are never encountered, except in macro cracks. In that case, the coupling terms in the flux expression (2) may have a significant influence on the transport of ions. But the difficulties involved with solving these terms have led to the development of models dedicated to concrete that were still using ADE-type equations similar to Equation (16) for long-term durability predictions. For example, most of the models dedicated to chloride ingress are still based on a single ADE equation, as reviewed in the chapter on chemical degradation (see for instance references Saetta 1993, Nagesh 1998, and Martín-Pérez 2001). As mentioned previously, multi-ionic models based on the splittingoperator approach have been used to assess the long term durability of concrete barriers in contact with groundwater (De Windt 2004, Trotignon 2007, Marty 2009).

Some multi-ionic models dedicated to species ingress in concrete have been developed considering the electrical coupling term in Equation (2). The model presented by Truc et al. (2000) takes the electrical coupling into account to model the ingress of chloride in concrete structures. The binding of chloride on the hydrated cement paste is approximated by a relationship similar to Equation (24). Samson and Marchand presented a multi-ionic model based on Equation (2) that was used to model chloride (Samson 2007) and sulfate ingress (Samson 2007b) cases. Their model uses a SNIA algorithm to couple transport with the chemical equilibrium relationships. In (Samson 2007b), the authors showed that neglecting the electrical coupling may lead to erroneous predictions of sulfate ingress rate. That type of model is able to consider the different selfdiffusion coefficients of the considered species while maintaining the electroneutrality of the solution.
However, the extensive computational time needed to solve the transport equations, coupled with the absence of self-diffusion data for secondary species (Li 1974), forced the authors to neglect homogeneous complexation reactions. No study could be found to assess the impact of this on long-term durability simulations.

\subsection{THERMO-HYDRO-MECHANICAL MODELS}

Many degradation phenomena observed on concrete structures are directly related to water content and temperature gradients in the material. Some of these degradation phenomena occur at early ages, such as drying shrinkage and heat of hydration-induced crack formation. In other cases, the damage may occur later in the life of the structure, even though the material has gained strength from the hydration process. This is the case for instance for structures exposed to freezing and thawing cycles and the long-term deformations induced by creep.

Modeling these phenomena is performed using thermo-hydro-mechanical (THM) approaches. While many different THM models have been proposed, they are in most cases based on solving the conservation equations for the gas and fluid phases, coupled to mechanical and thermal relationships. The global THM framework is reviewed in the following section. THM models based on simplified fluid transport equations were also reviewed. Finally, the last subsection is dedicated to modeling mechanical damage induced by the cement hydration process.

\subsection{General Overview}

The general framework outlined in this section closely follows the description found in (Gawin 1996). Other THM models can be found in (Baggio 1995, Bary 2000, Khalili 2001, Obeid 2001, Gawin 2006, Bary 2008). 
In order to simulate moisture transfer, most THM models found in the literature are based on separate mass conservation equations for the gas, water vapor and liquid vapor phases. This type of model has also been reviewed in the chapter dedicated to hydraulic properties. The mass conservation equations for the fluid phases, under the assumption of a rigid solid matrix, can be expressed as (Mainguy 2001):

Liquid phase:

$\frac{\partial\left(\phi S \rho_{l}\right)}{\partial t}+\operatorname{div}\left(\phi S \rho_{l} \mathbf{v}_{l}\right)+\mu_{l \rightarrow v}=0$

Vapor phase:

$\frac{\partial\left(\phi \rho_{v}(1-S)\right)}{\partial t}+\operatorname{div}\left(\phi(1-S) \rho_{v} \mathbf{v}_{v}\right)-\mu_{l \rightarrow v}=0$

Dry air phase:

$$
\frac{\partial\left(\phi \rho_{a}(1-S)\right)}{\partial t}+\operatorname{div}\left(\phi(1-S) \rho_{a} \mathbf{v}_{a}\right)=0
$$

where: the subscript $l, v$ and $a$ stand for the liquid, vapor and dry air phases respectively, $\phi$ is the porosity, $S$ is the saturation of the liquid phase, $\rho$ is the density, $\mathbf{v}$ is the velocity (flow) vector, and $\mu_{l \rightarrow v}$ is a source term accounting for the condensation/vaporization at the liquid/gas interface.

In most THM models, the coupling with mechanics allows consideration of cases where the solid matrix assumption is not valid. In this case, terms involving the deformation of the matrix are added to the mass transport Equations (35) to (37). In order to keep the model to a reasonable size, it is possible to combine the liquid and vapor phase conservation equations to eliminate the condensation/vaporization term. Also, relationships between vapor pressure, water content, saturation and capillary pressure can be used so that the resulting equation is based on a single state variable. This approach was used in (Baggio 1995, Gawin 1995, Gawin 2002, and Gawin 2006). The following paragraphs give the basic conservation equations considered in most THM models (Gawin 1995).
Water species (liquid + vapor):

The mass conservation equation for the combined liquid and gaseous water is given by:

$$
\begin{aligned}
\phi \frac{\partial\left((1-S) \rho_{v}\right)}{\partial t} & +\phi \rho_{l} \frac{\partial S}{\partial t}+\alpha(1-S) \rho_{v} \frac{\partial(\operatorname{div} \mathbf{u})}{\partial t}+ \\
& +b S \rho_{l} \frac{\partial(\operatorname{div} \mathbf{u})}{\partial t}+\operatorname{div}\left(\rho_{v} \mathbf{v}_{g}\right) \\
& +\operatorname{div}\left(\rho_{l} \mathbf{v}_{l}\right)+\operatorname{div}\left(\rho_{g} \mathbf{v}_{v}^{d}\right)=0
\end{aligned}
$$

where: $\mathbf{u}$ is the displacement vector of the solid matrix, the subscript $g$ refers to the gas phase, $\alpha$ is Biot's constant, $\mathbf{v}_{g}$ is the bulk velocity of the gas phase and $\mathbf{v}_{v}{ }^{d}$ is the flow of vapor due to diffusion.

Constitutive relationships provide the flow equations for the different phases. For the liquid phase, the flow equation corresponds to Darcy's law:

$\mathbf{v}_{l}=-\frac{k_{l}}{\mu_{l}}\left(\operatorname{grad}\left(p_{l}\right)-\rho_{l} \mathbf{g}\right)$

where: $k_{l}$ is the liquid permeability of the material, $\mu l$ is the dynamic viscosity of the liquid phase, $\rho_{l}$ is the liquid pressure, and $\mathbf{g}$ is the gravity acceleration vector.

A similar expression is used for the gas phase flow:

$$
\mathbf{v}_{g}=-\frac{k_{g}}{\mu_{g}}\left(\operatorname{grad}\left(p_{g}\right)-\rho_{g} \mathbf{g}\right)
$$

Finally, the flow of vapor due to diffusion can be expressed as (Whitaker 1977):

$$
\mathbf{v}_{v}^{d}=-D_{v} \operatorname{grad}\left(\frac{\rho_{v}}{\rho_{g}}\right)
$$

where: $D_{v}$ is the diffusion coefficient of vapor.

In order to express Equation (38) as a function of a single state variable for water, most models rely on the definition of capillary pressure $p_{c}$, which relates liquid and gas pressures (Bear 1988): 
$p_{c}=p_{g}-p_{l}$

and Kelvin's relationship (Kaviany 1995):

$p_{c}=-\frac{\rho_{l} R T}{M_{w}} \ln \left(\frac{p_{v}}{p_{v}^{s}}\right)=-\frac{\rho_{l} R T}{M_{w}} \ln (H)$

where: $R$ is the ideal gas constant, $T$ is the temperature,

$M_{w}$ is the molar mass of water, $p_{v}{ }^{s}$ is the saturated vapor pressure, and $H$ is the relative humidity.

Also, the ideal gas law can be used to relate the vapor density of Equation (41) to the vapor pressure:

$\frac{\rho_{v}}{M_{w}}=\frac{n_{v}}{V^{g}}=\frac{p_{v}}{R T}$

where: $n_{v}$ is the number of vapor molecule in the gas phase volume $V^{g}$.

Substituting relationships (42)-(44) in the flow Equations (39)-(41) allows expressing the water species conservation equation as either liquid pressure, vapor pressure, or capillary pressure. If the relationship between saturation or water content and capillary pressure is known, such as Van Genuchten's relationship (Van Genuchten 1980), it is possible to use these state variables instead.

A comprehensive discussion on the choice of the state variable can be found in (Gawin 2006). The authors suggest using the pressure variables instead of saturation or water content because these variables are not continuous at the interface between two materials having different porosities and moisture retention characteristics. It is thus not possible with these variables to solve problems where different material layers (material interfaces) are present.

Dry air:

The mass conservation equation for dry air is given by (Gawin 1995):

$$
\begin{aligned}
\phi \frac{\partial\left((1-S) \rho_{a}\right)}{\partial t} & +\alpha(1-S) \rho_{a} \frac{\partial(\operatorname{div} \mathbf{u}}{\partial t} \\
& +\operatorname{div}\left(\rho_{a} \mathbf{v}_{g}\right)-\operatorname{div}\left(\rho_{g} \mathbf{v}_{v}^{d}\right)=0
\end{aligned}
$$

Similar to the water species relationship, flow Equations (40) and (41) are substituted in (45) to yield the full dry air conservation relationship.

\section{Energy conservation:}

The evolution of temperature in the porous material is calculated from the energy balance relationship. Most authors assume that the different phases (solid matrix, liquid and gas) of the material are in thermal equilibrium. In these conditions, the energy balance equation is given by (Gawin 1995):

$$
\begin{aligned}
\rho C_{p} \frac{\partial T}{\partial t}+\left(C_{p l} \rho_{l} \mathbf{v}_{l}\right. & \left.+C_{p g} \rho_{g} \mathbf{v}_{g}\right) \operatorname{grad}(T) \\
& -\operatorname{div}\left(\lambda_{\text {eff }} \operatorname{grad}(T)\right)+\sum_{k} f_{k}=0
\end{aligned}
$$

where: $\rho$ is the average density of the material, $C_{p}$ is the specific heat, $\lambda_{\text {eff }}$ is the effective thermal conductivity, and $f_{k}$ represents the various sink or source terms that affect temperature.

Many different phenomena may contribute to the term $f_{k}$ in Equation (46). Gawin (2002) reported terms associated with phase change (evaporation) and dehydration of water. In (Ulm 1995, Ulm 1998, Gawin 2006), the modeling of the heat generated during the hydration of concrete and its coupling with mechanics is discussed (see Section 3.3).

In (Khalili 2001), the authors devised a THM model without assuming thermal equilibrium between the solid, liquid, and gas phases. In that case, three separate energy balance equations similar to (46) were considered for each phase, with thermal exchange terms between the phases being added. 


\section{Mechanical coupling:}

In many THM models, the time-dependent mass and energy conservation equations are coupled to the static linear momentum balance equation, assuming that the deformations induced by the fluids and energy transport are slow enough to be considered as a series of static mechanical problems. In that case, the linear momentum balance equation is given by (Gawin 1995):

$\operatorname{div}(\boldsymbol{\sigma})+\rho \mathbf{b}=0$

where: $\boldsymbol{\sigma}$ is the total stress tensor, $\mathbf{b}$ is a body force vector, usually corresponding to gravity, and $\rho$ is the average density of the material, expressed as a weighted average of the separate phase density:

$\rho=(1-\phi) \rho_{s}+\phi S \rho_{l}+\phi(1-S) \rho_{g}$

where: $\rho_{\mathrm{S}}$ is the density of the solid matrix.

The constitutive equation is expressed as a function of the effective stress $\boldsymbol{\sigma}^{\prime}$, which was first introduced in soil mechanics (Gray 2001). The effective stress expression for an isotropic material is given by (Bary 2000):

$\boldsymbol{\sigma}^{\prime}=\boldsymbol{\sigma}+b p \mathbf{I}$

where: $b$ is the Biot scalar parameter, $p$ is the average pressure and $\mathbf{I}$ is the identity tensor.

The average pressure is given by (Gawin 1995):

$p=S p_{l}+(1-S) p_{g}$

The effective stress relationship links the pressure variations in the material resulting from moisture content variations with mechanical deformations. As an alternative to the relative stress expression, Coussy derived an incremental form of Equation (49) (Coussy 1995): $\mathrm{d} \boldsymbol{\sigma}^{\prime}=\mathrm{d} \boldsymbol{\sigma}+\left(\mathrm{d} p^{g}-S \mathrm{~d} p^{c}\right) \mathbf{I}$

which in most cases yield results similar to expression (49) according to (Gray 2001).

The simplest mechanical coupling case corresponds to a linear elastic model (Gawin 1995), where the total stress tensor is related to the elastic strain by:

$\boldsymbol{\sigma}=\mathbf{E}_{\mathbf{o}}: \varepsilon^{e}$

where: $\varepsilon^{e}$ is the elastic strain contribution and $\mathbf{E}_{\mathrm{o}}$ is the elasticity matrix.

The total strain $\varepsilon$ is given by (Gawin 1995):

$\varepsilon=\varepsilon^{e}+\varepsilon^{T}+\varepsilon^{o}$

where: $\varepsilon^{T}$ is the strain caused by thermo-elastic expansion and $\varepsilon^{\mathrm{O}}$ is the autogeneous strain.

The thermal strain is written as (Cervera 1999b):

$\varepsilon^{T}=\alpha_{T}\left(T-T^{\mathrm{ref}}\right) \mathbf{I}$

where: $\alpha_{T}$ is the thermal dilatation coefficient and $T^{r e f}$ is a reference temperature for which the thermal strain is null.

In (Gawin 2002), the elastic linear model was expanded to a nonlinear damage model to simulate concrete exposed to temperature above the critical point of water. In that case, the stress-strain relationship is written as:

$\boldsymbol{\sigma}=(1-d) \mathbf{E}_{\mathbf{o}}: \varepsilon^{\epsilon}$

where: $d$ is the scalar damage parameter (Mazars 1989).

Kahalili and Loret (Khalili 2001) presented a THM model where the mechanical formulation is based on an elasto-plastic constitutive law to simulate moisture induced shrinkage. In (Baggio 1995), the authors devised a THM approach where the mechanical model 
is based on viscoelasticity and damage. Similar to the SNIA algorithm of reactive transport modeling, the calculations are performed in two sequential steps. The hydro-thermal simulations are performed first, and then the mechanical analysis is performed using a separate code.

The THM framework described in the previous paragraphs has been expanded theoretically in (Schrefler and Pesavento 2004). Averaging the microscopic mass balance and constitutive equations over a Representative Elementary Volume (REV), they obtained a set of conservation equations that includes interface terms that can be used to model different exchange phenomena between the various phases. The final system of equations is made of 30 equations with 30 corresponding independent variables. Although the global model could hardly be solved when all equations are considered, it provides a solid framework for devising specific applications.

\subsection{Simplified THM Models}

Given the complexity of the equations involved, solving THM models can prove a daunting task. Not surprisingly, simplifications have been made in some cases in order to keep the numerical problem manageable. In some other cases, the model can be simplified due to the nature of the problem to be solved.

This is the case for instance in (Bary et al. 2000). The authors present a model to simulate the damage caused by high fluid pressure on concrete structures such as dams. In that case, the material can be considered saturated and the temperature uniform, which simplifies the set of equations.

Similar to the moisture transport models reviewed in the chapter on hydraulic properties, many authors assumed that the gas pressure is constant in the porous material. This allows removing dry air from the set of equations and also simplifies the remaining water species conservation equation as shown in (Chijimatsu 2000, Obeid 2001, Bary 2008). In (Meschke 2003), the authors used a nonlinear diffusion approach similar to the approach proposed by Bazant (Bazant 1971) but based on the capillary pressure state variable instead of the relative humidity.

\subsection{Adding Cement Hydration to THM Models}

The THM modeling framework has been used frequently to model the relationship between the heat of hydration and the damage induced to the concrete matrix by the strong temperature gradients during the early ages of the material. Although the intensity of the hydration phenomena decreases rapidly after a few hours in the material's life, the potential microcracks in the hydrated cement paste can increase the transport properties and have detrimental effects in the future.

To consider the heat of hydration in coupled THM equations, Cervera et al. (Cervera 1999, Cervera $1999 \mathrm{~b}$ ) added a source term $f_{\xi}$ to the energy conservation Equation (46) that models the heat generated by the chemical reactions when the cement is mixed with water:

$f_{\xi}=Q_{\xi} \dot{\xi}$

where: $Q_{\xi}$ is a material constant and $\xi$ is the degree of hydration.

The rate of hydration $\dot{\xi}$ is given by:

$\dot{\xi}=\frac{k}{n_{o}}\left(\frac{A_{o}}{k \xi_{\infty}}+\xi\right)\left(\xi_{\infty}-\xi\right) \exp \left(-\frac{\bar{n} \xi}{\xi_{\infty}}\right) \exp \left(-\frac{E_{a}}{R T}\right)$

where: $A_{O}$ is the initial affinity of the hydration reaction, $\xi_{\infty}$ is the maximum degree of hydration, $E_{a}$ is the activation energy of the hydration process, $R$ is the ideal gas constant, and $T$ is the temperature. The other parameters, i.e., $k, n_{\mathrm{o}}, \bar{n}$, are material constants to be determined experimentally. 
The hydration degree and Equation (57) are added to the THM model as a new state variable and equation. They must be solved in addition to the other conservation equations.

The hydration process is coupled to the mechanical model by adding a component to the total strain Equation (53) called the chemical strain $\varepsilon^{\mathrm{ch}}$, which is the contribution from the self-generated heat of hydration of cement. This strain is proportional to the hydration degree:

$$
\varepsilon^{\mathrm{ch}}=\alpha_{\xi} \xi \mathbf{I}
$$

where: $\alpha_{\xi}$ is the thermal expansion parameter associated with the heat of hydration.

Similar models considering the hydration process were described in (Ulm 1995, Ulm 1998, Gawin 2006).

\subsection{Coupled Ionic Transport and Mechanical Models}

The concern over the long-term stability of concrete in contact with groundwater or contaminated water in the context of nuclear waste storage has initiated the development of models that attempt at coupling THM models with reactive transport approaches. A number of phenomena that are important in weathering and behavior of cementitious barriers and grouts are governed by a combination of chemical, physical, and mechanical processes. Important properties are: stability of cementitious phases, permeability for water, ions and gases, chemical composition (pH, redox), crack development. Examples of such interactions are: effect of chemical speciation (form) on mobility and transport rates of substances, effect of locally formed precipitates on porosity and tortuosity, stress and material damage caused by precipitation of expanding minerals, increased porosity of material by leaching of matrix components, and decreased material strength by leaching of matrix components

Understanding these effects and quantitative estimation of long terms effects requires models that can accommodate the different process descriptions.

A "complete" model should contain sub models for:

- Multi-component chemical reactions. It has a lot of advantages to use standard thermodynamic equilibrium model frameworks. In this way it is possible to use existing thermodynamic databases and easier to make use of progress made in this field,

- Mass transport processes (diffusion, convection, electrochemical coupling, heat conduction),

- Local chemical conditions (local concentrations of all physico-chemical species),

- Coupling relationships between chemistry, local pressures, porosities, strength etc.

Integration of these models needs to be tight, because chemical and physical properties change dynamically in time and place. Effectively this means that a lot of information has to be exchanged between the different sub-models during runtime, per time step. This effectively makes it necessary to integrate these models within a single framework in which all submodels run at the same time. But so far, these efforts have been very limited. They are summarized in this section.

\subsection{Simplified Transport Coupling}

Most attempts to link reactive transport in cementitious materials with THM models were concerned with the decalcification of the hydrated cement paste and the impact it has on the mechanical resistance of the material and the possible damage induced to the matrix. In all the papers reviewed for this section (Gérard 1998, Ulm 1998, Kuhl 2004, Kuhl 2004b), the concentration of calcium was 
used as the driving mechanism behind the matrix dissolution. Accordingly, the transport of ions was limited to a single equation modeling the diffusion of calcium:

$$
\frac{\partial s}{\partial t}+\frac{\partial w c}{\partial t}-\operatorname{div}\left(D_{\text {ca }} \operatorname{grad}(c)\right)=0
$$

where: $c$ is the concentration of calcium in the pore solution of the material, $s$ is the amount of calcium in the solid phase (as portlandite and C-S-H), $w$ is the water content, and $D_{\text {ca }}$ is the diffusion coefficient of calcium.

The first term on the left hand side of Equation (59) accounts for the calcium released in the pore solution upon portlandite and C-S-H dissolution. In all models cited previously, it is estimated from the $\mathrm{C} / \mathrm{S}$ ratio vs. $c$ relationship shown on Figure 2 (the experimental data in Figure $2 b$ were taken from (Berner 1992)). Going from Figure $2 a$ to Figure $2 b$ is hypothetical at best since there is no direct relationship between the amount of portlandite and C-S-H and the calcium in pore solution, as emphasized by the equilibrium relationship (13).

To couple transport and matrix dissolution to the mechanical model, Gérard et al. (Gérard 1998) introduced an ageing parameter $V_{d}[0: 1]$ that depends on the amount of calcium dissolved. According to Figure 2, it can also be related to the calcium in solution. The ageing parameter is then incorporated in the damage model (Equation (55)) as:

$\boldsymbol{\sigma}=\left(1-V_{d}\right)(1-d) \mathbf{E}_{\mathbf{o}}: \varepsilon^{e}$

According to this formulation, the ageing parameter contributes to reduce the mechanical properties of the material as the matrix is dissolved.

In (Gérard 1998), the authors also consider a feedback effect that modifies the transport parameters as a function of the damage level.

\subsection{Multi-ionic Transport Coupling}

As shown in the previous section, most models attempting to couple reactive transport and THM models have been limited to simplified ionic diffusion equations. Only one model coupling multi-ionic reactive transport and damage mechanics could be found. The model, developed by Planel (Planel 2002), uses a reactive transport model based on the SIA algorithm based on linear transport equations (see Equation (27)) to simulate the precipitation of ettringite and gypsum upon exposure to groundwater containing sulfate.

The mechanical portion of this model is based on a damage model similar to Equation (55). In this case, the damage parameter is a function of the volume of ettringite that is precipitated compared to the initial porosity of the material. The dissolution of C-S-H and its impact on the pore volume is also considered.

\subsection{CONCLUSIONS}

The review of approaches to couple physical, structural, and physical mechanisms showed two main categories of models: reactive transport and thermo-hydro-mechanical. Reactive transport models couple transport of species in the pore network with chemical reactions within the pores and with the solid matrix. On the other hand, the thermo-hydromechanical models focus on the impact that fluid and thermal flow have on the mechanical resistance of concrete.

The review showed that reactive transport models incorporating mechanical considerations or THM models dealing with detailed transport and chemistry relationships are nearly non-existent. Given the mechanisms and time scales involved in nuclear waste storage problems, models incorporating detailed reactive transport with a THM framework could be developed and used to provide a global durability assessment for those structures. 


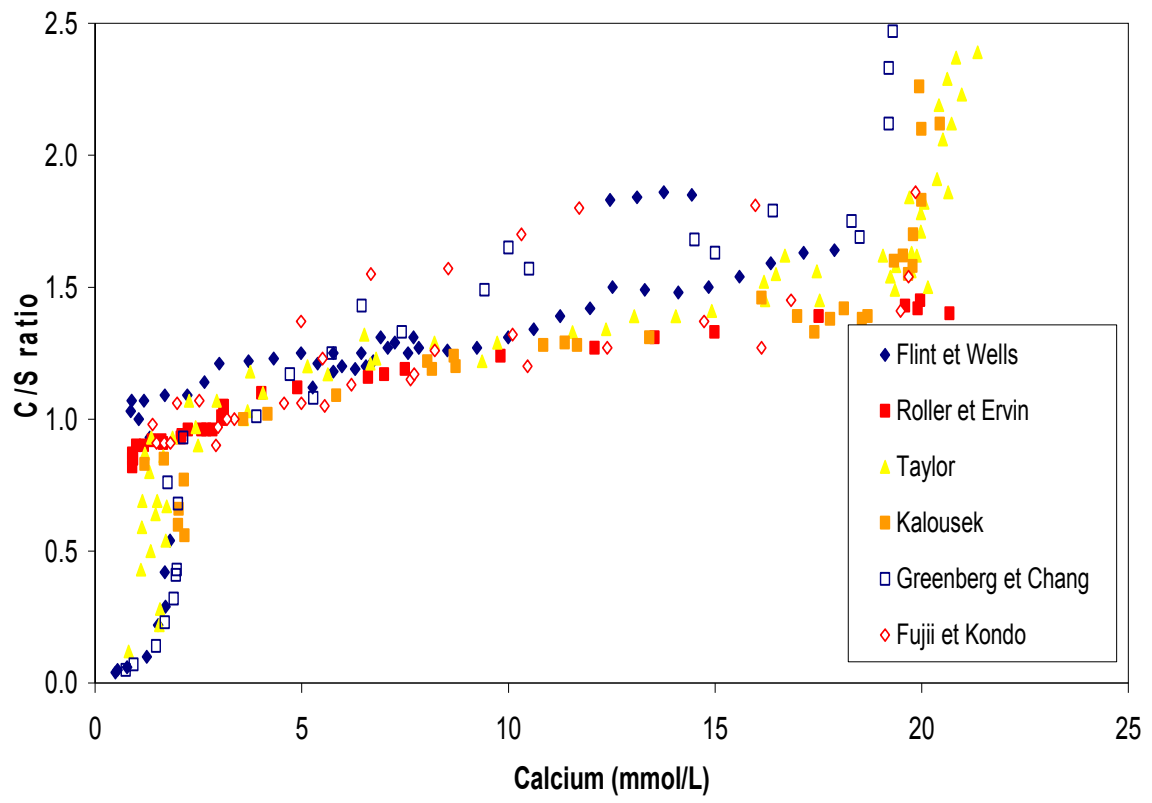

a. $\mathrm{CaO} / \mathrm{SiO}_{2}$ vs. Calcium in Solution (Berner 1992)

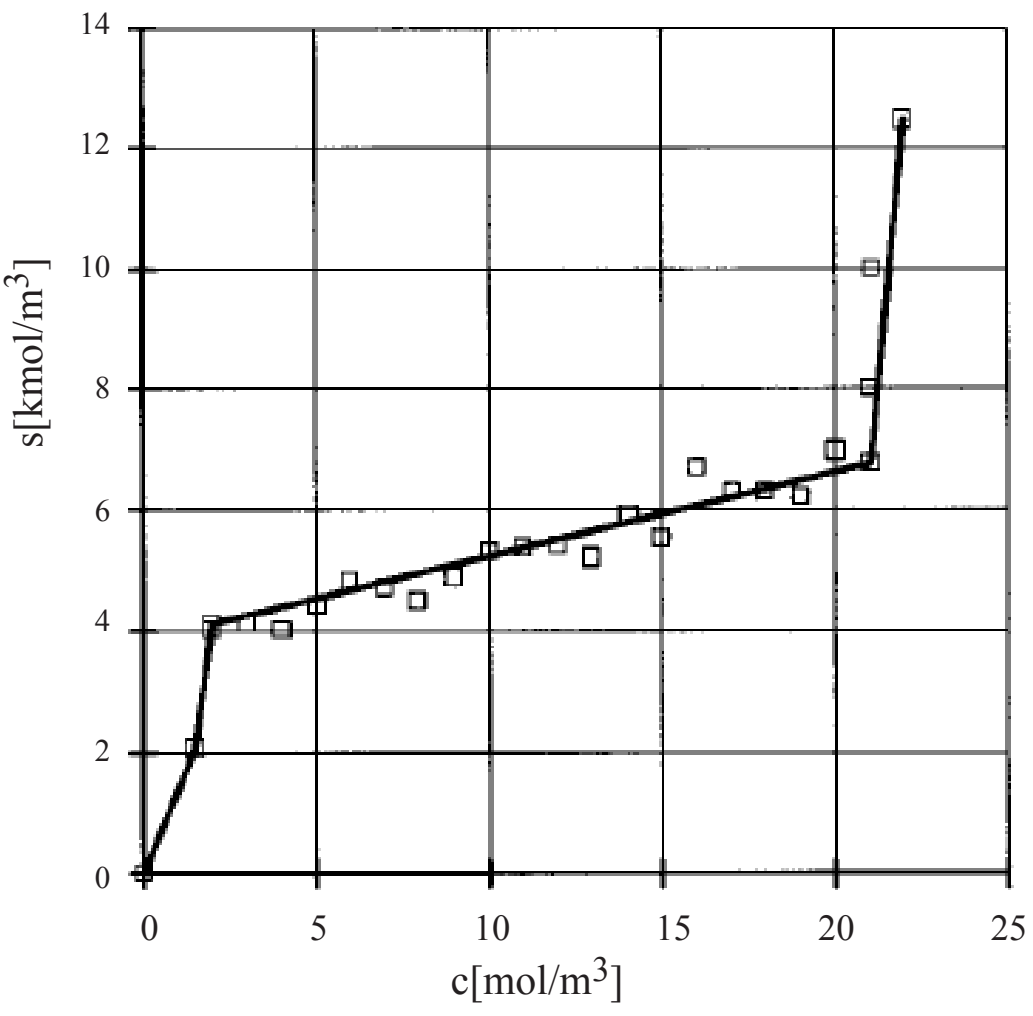

b. Solid Content s vs. Calcium in Solution (UIm 1999)

Figure 2. Relationship Between the Calcium in Solution vs. the $\mathrm{CaO} / \mathrm{S}_{1} \mathrm{O}_{2}$ Ratio and s. 


\subsection{REFERENCES}

Appelo, CAJ 1996, 'Multicomponent ion exchange and chromatography in natural systems' in Reviews in Mineralogy - Reactive Transport in Porous Media, vol. 34, pp. 193-227.

Baggio, P Majorana, CE Schrefler, BA 1995, 'Thermo-hygro-mechanical analysis of concrete', Int. J. Num. Meth. Fluids, vol. 20, pp.573-595.

Barbarulo, R Marchand, J Snyder, KA Prené, S 2000, 'Dimensional analysis of ionic transport problems in hydrated cement systems', Cement and Concrete Research, vol. 30, pp. 1955-1960.

Bary, B Bournazel, JP Bourdarot, E 2000, 'Porodamage approach applied to hydro-fracture analysis of concrete', Journal of Engineering Mechanics, vol. 126, pp. 937-943.

Bary, B Ranc, G Durand, S Carpentier, O 2008, ‘A coupled thermo-hydro-mechanical-damage model for concrete subjected to moderate temperatures', Int. J. Heat Mass Transfer, vol. 51, pp. 2847-2862.

Bazant, ZP Najjar, LJ 1971, 'Drying of concrete as a nonlinear diffusion problem', Cement and Concrete Research, vol. 1, pp. 461-473.

Bear, J 1988, Dynamics of Fluid in Porous Media, Dover (New-York, USA).

Bear, J Bachmat, Y 1991, Introduction to Modeling of Transport Phenomena in Porous Media, Kluwer Academic Publishers (Dordrecht, The Netherlands).

Berner, UR 1992, 'Evolution of pore water chemistry during degradation of cement in a radioactive waste repository environment', Waste Management, vol. 12, pp. 201-219.
Bethke, CM 2008, Geochemical and Biogeochemical Reaction Modeling, $2^{\text {nd }}$ ed., Cambridge University Press (Cambridge, U.K.).

Bockris, JO'M \& Reddy, AKN 1970, Modern

Electrochemistry - An Introduction to an

Interdisciplinary Area, Plenum Press (USA).

Cederberg, GA Street, RL Leckie, JO 1985, 'A

groundwater mass transport and equilibrium chemistry model for multicomponent systems', Water Resources Research, vol. 21, pp. 1095-1104.

Cervera, M Olivier, J Prato, T 1999, 'Thermo-chemomechanical model for concrete. I: Hydration and aging', Journal of Engineering Mechanics, vol. 125, pp. 1018-1027.

Cervera, M Olivier, J Prato, T 1999b, 'Thermochemo-mechanical model for concrete. II: Damage and creep', Journal of Engineering Mechanics, vol. 125, pp. 1018-1027.

Chijimatsu, M Fujita, T Kobayashi, A Nakano, M 2000, 'Experiment and validation of numerical simulation of coupled thermal, hydraulic and mechanical behavior in the engineered buffer materials', Int. J. Num. An. Meth. Geomechanics, vol. 24, pp.403-424.

Coussy, O 1995, Mechanics of Porous Continua, John Wiley \& Sons (U.K.)

De Windt, L Pellegrini, D van der Lee, J 2004, 'Coupled modeling of cement/claystone interactions and radionuclide migration', Journal of Contaminant Hydrology, vol. 68, pp.165-182.

Engesgaard, P Kipp, KL 1992, 'A geochemical transport model for redox-controlled movement of mineral fronts in groundwater flow systems: A case of nitrate removal by oxidation of pyrite', Water Resource Research, vol. 28, pp. 2829-2843. 
Fetter, CW 1999, Contaminant Hydrogeology, Prentice-Hall (New-Jersey, USA).

Gawin, D Schrefler, BA 1996 'Thermo-hydromechanical analysis of partially saturated porous materials' Engineering Computations, vol. 13, pp.113-143.

Gawin, D Pesavento, F Schrefler, BA 2002, 'Modelling of hygro-thermal behaviour and damage of concrete at temperature above the critical point of water', Int. J. Num. An. Meth. Geomechanics, vol. 26, pp.537-562.

Gawin, D Pesavento, F Schrefler, BA 2002b, 'Simulation of damage-permeability coupling in hygro-thermo-mechanical analysis of concrete at high temperature', Comm. Num. Meth. Eng., vol. 18, pp. 113-119.

Gawin, D Pesavento, F Schrefler, BA 2006, 'Hygrochemo-mechanical modeling of concrete at early ages and beyond. Part I: Hydration and hygro-thermal phenomena', Int. J. Num. Meth. Eng., vol. 67, pp.299331.

Gérard, B Pijaudier-Cabot, G Laborderie, C 1998, 'Coupled diffusion-damage modeling and the implications on failure due to strain localidsation', vol. 35, pp. 4107-4120.

Gray, WG Schrefler, BA 2001, 'Thermodynamic approach to effective stress in partially saturated porous media', Eur. J. Mech. A/Solids, vol. 20, pp. 521-538.

Grove, DB Wood, WW 1979, 'Prediction and field verification of subsurface-water quality changes during artificial recharge, Lubbock, Texas', Groundwater, vol. 17, pp.250-257.

Hall, C Hoff, WD 2002, Water Transport in Brick, Stone and Concrete, Spon Press (New-York ,USA).
Harvie, CE Moller, N \& Weare, JH 1984, 'The prediction of mineral solubilities in natural waters: The Na-K-Mg-Ca-H-Cl-OH- $\mathrm{HCO}_{3}-\mathrm{CO}_{3}-\mathrm{CO}_{2}-\mathrm{H}_{2} \mathrm{O}$ system to high ionic strengths at $25^{\circ} \mathrm{C}^{\prime}$, Geochimica et Cosmochimica Acta, vol. 48, pp. 723-751.

Helfferich F 1961, Ion Exchange, McGraw-Hill (USA).

Jacques, D Simunek, J Mallants, D van Genuchten, MT 2006, 'Operator splitting errors in coupled reactive transport codes for transient variably saturated flow and contaminant transport in layered soil profiles', Journal of Contaminant Hydrology, vol. 88, pp.197-218.

Jennings, AA Kirkner DJ Theis TL 1982, 'Multicomponent equilibrium chemistry in groundwater quality models', Water Resources Research, vol. 18, pp. 1089-1096.

Khalili, N Loret, B 2001, 'An elasto-plastic model for non-isothermal analysis of flow and deformation in unsaturated porous media: formulation', Int. J. Solids and Structures, vol. 38, pp. 8305-8330.

Kanney, JF Miller, CT Kelley CT 2003, 'Convergence of iterative split operator approaches for approximating nonlinear reactive transport problems', Advances in Water Resources, vol. 26, pp. 247-261.

Kaviany, M 1995, Principles of heat transfer in porous media, Springer (New-York, USA).

Kirkner, DJ Reeves, HW Jennings, AA 1984, 'Finite element analysis of Multicomponent contaminant transport including precipitation-dissolution reactions' in Finite Elements in Water Resources, Laible, JL et al. eds., pp. 309-318. 
Kirkner, DJ Reeves, HW 1988, 'Multicomponent mass transport with homogeneous and heterogeneous chemical reactions: Effect of the chemistry on the choice of numerical algorithm, 1. Theory', Water Resources Research, vol. 24, pp. 1719-1729.

Garrabrants, AC, and Kosson, DS 2005, 'Leaching processes and evaluation tests for inorganic constituent release from cement-based matrices', in Stabilization/Solidificaiton of Hazardous, Radioactive and Mixed Wastes, Spence, RD and Shi, C (eds), CRC Press, Boca Raton, pp. 229-280.

Kuhl, D Bangert, F Meschke, G 2004, 'Coupled chemo-mechanical deterioration of cementitious materials. Part I: Modeling', Int. J. Solids and Structures, vol. 41, pp. 15-40.

Kuhl, D Bangert, F Meschke, G 2004b, 'Coupled chemo-mechanical deterioration of cementitious materials. Part II: Numerical methods and simulations', Int. J. Solids and Structures, vol. 41, pp. 41-67.

Li, YH Gregory, S 1974, 'Diffusion of ions in sea water and in deep-sea sediments', Geochimica and Cosmochimica Acta, vol. 38, pp. 703-714.

Lichtner, PC 1985, 'Continuum model for simultaneous chemical reactions and mass transport in hydrothermal systems', Geochimica et Cosmochimica Acta, vol. 49, pp. 779-800.

Mainguy, M Tognazzi, C Torrenti, JM \& Adenot, F 2000, 'Modelling of leaching in pure cement paste and mortar', Cement and Concrete Research, vol. 30, pp. 83-90.

Mainguy, M Coussy, O Baroghel-Bouny, V 2001, 'Role of air pressure in drying of weakly permeable materials', Journal of Engineering Mechanics, vol. 127 , pp. 582-592.
Maltais, Y Samson, E \& Marchand, J 2004, 'Predicting the durability of Portland cement systems in aggressive environments - laboratory validation', Cement and Concrete Research, vol. 34, pp. 15791589.

Martín-Pérez, B Pantazopoulou, SJ \& Thomas, MDA 2001, 'Numerical solution of mass transport equations in concrete structures', Computers and Structures, vol. 79, pp. 1251-1264.

Marty, NCM Tournassat, C Burnol, A Giffaut, E Gaucher, E.C 2009, 'Influence of reaction kinetics and mesh refinement on the numerical modelling of concrete clay interactions', Journal of Hydrology, vol. 364, pp.58-72.

Mazars, J Pijaudier-Cabot, JP 1989, 'Continuum damage theory - application to concrete', Journal of Engineering Mechanics, vol. 115, pp.345-365.

Meschke, G Grasberger, S 2003, 'Numerical modeling of coupled hygromechanical degradation of cementitious materials', Journal of Engineering Mechanics, vol. 129, pp.383-392.

Miller, CW Benson, LV 1983, 'Simulation of solute transport in a chemically reactive heterogeneous system: Model development and application', Water Resources Research, vol. 19, pp. 381-391.

Nagesh, M \& Bhattacharjee, B 1998, 'Modeling of chloride diffusion in concrete and determination of diffusion coefficients', ACI Materials Journal, vol. 95, pp. 113-120.

Obeid,W Alliche, A Mounajed, G 2001, 'Identification of the physical parameters used in the thermo-hygro-mechanical model (application to the case of cement mortar)', Transport in Porous Media, vol. 45, pp. 215-239.

Pankow, JF 1994, Aquatic Chemistry Concepts, Lewis Publishers, USA. 
Planel, D 2002, Les effets couples de la precipitation d'espèces secondaires sur le comportement mecanique et la degradation chimique des bétons, Ph.D. thesis (in French) (Marne-La-Vallée, France).

Reardon, EJ 1990, 'An ion interaction model for the determination of chemical equilibria in cement/water systems', Cement and Concrete Research, vol. 20, pp. 175-192.

Reardon, EJ 1992, 'Problems and approaches to the prediction of the prediction of the chemical composition in cement/water systems', Waste Management, vol. 12, pp. 221-239.

Rubin, J 1983, 'Transport of reacting solutes in porous media: relation between mathematical nature of problem formulation and chemical nature of reactions', Water Resources Research, vol. 19, pp. 1231-1252.

Saaltink, MW Carrera, J Ayora, C 2001, 'On the behavior of approaches to simulate reactive transport', Journal of Contaminant Hydrology, vol. 48, pp. 213-235.

Saetta, A Scotta, R \& Vitaliani, R 1993, 'Analysis of chloride diffusion into partially saturated concrete', ACI Materials Journal, vol. 90, pp. 441-451.

Samson, E \& Marchand, J 2007, 'Modeling the effect of temperature on ionic transport in cementitious materials', Cement and Concrete Research, vol. 37, pp. 455-468.

Samson, E \& Marchand, J 2007b, 'Modeling the transport of ions in unsaturated cement-based materials', Computers and Structures, vol. 85, pp. 1740-1756.

Schrefler, BA Pesavento, F 2004, 'Multiphase flow in deforming porous material', Computers and Geotechnics, vol. 31, pp. 237-250.
Simunek, J Suarez, DL 1994, 'Two-dimensional transport model for variably saturated porous media with major ion chemistry', Water Resources Research, vol. 30, pp. 1115-1133.

Steefel, CI \& Lasaga, AC 1994, 'A coupled model for transport of multiple chemical species and kinetic precipitation/dissolution reactions with application to reactive flow in single phase hydrothermal systems', American Journal of Science, vol. 294, pp. 529-592.

Steefel, CI \& MacQuarrie, KTB 1994b, ‘Approaches to modeling of reactive transport in porous media', in Reviews in Mineralogy - Reactive Transport in Porous Media, vol. 34, pp. 83-129.

Stumm, W Morgan, JJ 1996, Aquatic Chemistry Chemical Equilibria and Rates in Natural Waters, $3^{\text {rd }}$ ed., Wiley Interscience (New-York, USA).

Trotignon, L Devallois, V Peycelon, H Tiffreau, C Bourbon, X 2007, 'Predicting the long term durability of concrete engineered barriers in a geological repository for radioactive waste', Physics and Chemistry of the Earth, vol. 32, pp.259-274.

Truc, O Ollivier, JP \& Nilsson, LO 2000, 'Numerical simulation of multi-species diffusion', Materials and Structures, vol. 33, pp. 566-573.

Ulm, JF Coussy, O 1995, 'Modeling of thermochemomechanical couplings of concrete at early ages', Journal of Engineering Mechanics, vol. 121, pp. 785-794.

Ulm, JF Coussy, O 1998, 'Couplings in early-age concrete: from material modeling to structural design', Int. J. Solids and Structures, vol. 35, pp. 4295-4311.

Ulm, JF Torrenti, JM Adenot, F 1999, 'Chemoporoplasticity of calcium leaching in concrete', Journal of Engineering Mechanics, vol. 125, pp. 1200-1211.

IX-22 
Valocchi, AJ Street, RL Roberts, PV 1981, 'Transport of ion-exchanging solutes in groundwater: chromatographic theory and field simulations', Water Resources Research, vol. 17, pp. 1517-1527.

Van Genuchten, MT 1980, 'A closed form equation for predicting the hydraulic conductivity of unsaturated soils', Soil Science Society of America, vol. 44, pp. 892-898.

Walsh, MP Bryant, SL Shechter, RS Lake, LW 1984, 'Precipitation and dissolution of solids attending flow through porous media', AIChE Journal, vol. 30, pp. 317-328.

Walter, AL Frind, EO Blowes, DW Ptacek, CJ Molson, JW, 'Modeling of multicomponent reactive transport in groundwater 1. Model development and evaluation', Water Resources Research, vol. 30, pp. 3137-3148.

Whitaker, S 1977, 'Simultaneous heat, mass and momentum transfer in porous media: a theory of drying', Advances in Heat Transfer, vol. 13, pp. 119203.
Yeh, GT Tripathi, VS 1989, 'A critical evaluation of recent developments in hydro-geochemical transport models of reactive multichemical components', Water Resources Research, vol. 25, pp. 93-108.

Xu, T Samper, J Ayora, C Manzano, M Custodio, E 1999, 'Modeling of non-isothermal multi-component reactive transport in field scale porous media flow systems', Journal of Hydrology, vol.214, pp.144-164.

Zemaitis, JF Clark, DM \& Rafal, M 1986, 'Scrivner N.C., Handbook of aqueous electrolyte thermodynamics', American Institute of Chemical Engineers, New-York, USA.

Zienkiewicz, OC Taylor, RL 1989, The Finite Element Method, $4^{\text {th }}$ ed., McGraw-Hill (London, U.K.). 



\title{
REVIEW OF INTEGRATING PROGRAMS AND CODE STRUCTURES USED FOR DOE ENVIRONMENTAL ASSESSMENTS
}

\author{
Kevin G. Brown \\ Email: kevin.g.brown@vanderbilt.edu \\ Vanderbilt University, School of Engineering \\ Consortium for Risk Evaluation with Stakeholder Participation, III \\ Nashville, TN 37235 \\ Gregory P. Flach \\ Email: gregory.flach@srnl.doe.gov \\ Savannah River National Laboratory \\ Savannah River Nuclear Solutions, LLC \\ Savannah River Site \\ Aiken, SC 29808
}


Review of Mechanistic Understanding and Modeling and Uncertainty Analysis Methods for Predicting Cementitious Barrier Performance 
CONTENTS

Page No.

LIST OF FIGURES X-iv

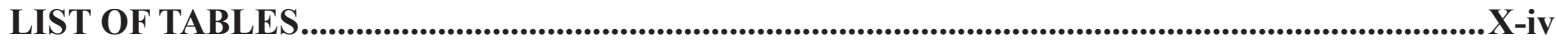

LIST OF ABBREVIATIONS AND ACRONYMS ..............................................................................

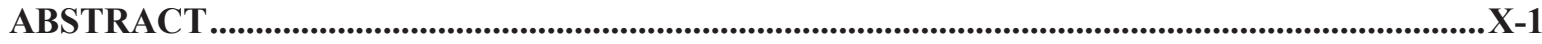

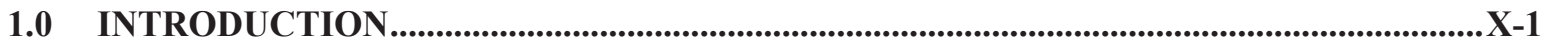

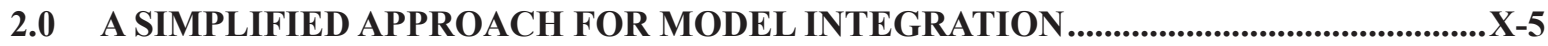

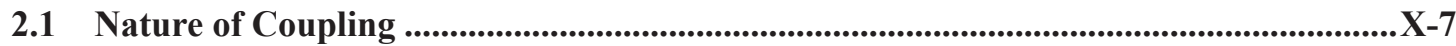

2.2 Computing Environment......................................................................................................... X-7

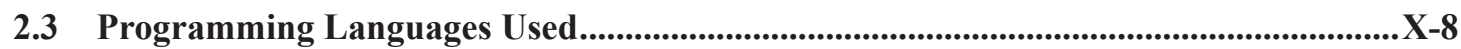

2.4 Additional Considerations ............................................................................................................. X-8

2.5 Selection Criteria for the CBP Model Framework .............................................................X-9

3.0 EXAMPLES OF INTEGRATED MODELING APPROACHES AND PLATFORMS ........X-9

3.1 Monolithic Approach Example: CEMENT Code ...................................................................X-10

3.2 Fidelity Approach Example: Framework for Risk Analysis in Multimedia Environmental Systems (FRAMES) ....................................................................X-10

3.3 Hybrid Approach Example: Design Analysis Kit for Optimization and Terascale Applications (DAKOTA) ...............................................................................................X-12

3.4 Hybrid Approach Example: GoldSim Monte Carlo Simulation Program ......................X-14

3.4.1 Screening Risk Tool for USDOE Buried Wastes ......................................................

3.4.2 SNL Coupled GoldSim-BLT-MS Software Package ................................................

3.4.3 Coupled GoldSim-PHREEQC Geochemical Code ......................................................

3.5 Custom Interface Approach Example: Parallel Virtual Machine......................................X-20

3.6 Other Codes Used for Cementitious Barriers ...................................................................

3.7 Radiological Performance Assessment for the Z-Area Disposal Facility using PORFLOW-3D........................................................................X-23

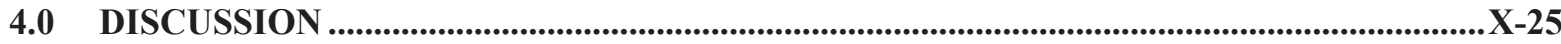

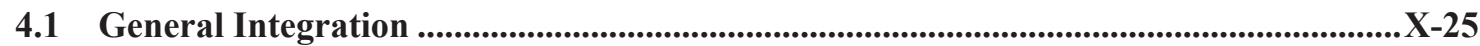

4.2 General Uncertainty Discussion ..............................................................................................X-26

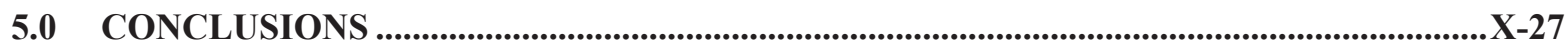

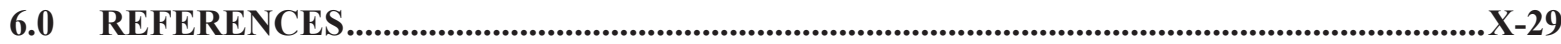




\section{LIST OF FIGURES}

Page No.

Figure 1. Generalized Performance Assessment Conceptualization $\mathrm{X}-3$

Figure 2. Specifications, Properties, and Phenomena for the Evaluation of Performance of Cementitious Barriers $\mathrm{X}-4$

Figure 3. Simplified Approach to Model Integration for the Risk Screening Tool for Department of Energy (DOE) Buried Wastes. X-6

Figure 4. Connecting the RT3D Program to Upstream and Downstream Modules within the FRAMES-2.0 Workspace. $\mathrm{X}-11$

Figure 5. Illustrating the Linkage of Three Models of Differing Scale and Resolution Using Frames as Middleware $\mathrm{X}-12$

Figure 6. The Loosely-coupled or "Black-box" Interface Between DAKOTA and A User-supplied Simulation Code $\mathrm{X}-13$

Figure 7. Implementation of the Screening Risk Tool and Proposed Detailed Risk Tool Using the GoldSim Monte Carlo Simulation Software. ...........X-16

Figure 8. Conceptual Model of A Monte Carlo Risk Analysis..............................................................

Figure 9. Flow Chart for GoldSim/BLT-MS Integration Model ..........................................................

Figure 10. Schematic of Data Flow for the Method of Direct Linkage Between GoldSim and PHREEQC Using a Dynamic Linked Library..... $\mathrm{X}-20$

Figure 11. Parallel Virtual Machine Computational Model $\mathrm{X}-22$

Figure 12. Parallel Virtual Machine Architectural Overview. $\mathrm{X}-22$

Figure 13. Integration of Computational Methods for the Radiological Performance Assessment of Intact SDF Vaults

Figure 14. Integration of Computational Methods for the Radiological Performance Assessment of Degraded SDF Vaults $\mathrm{X}-24$

Figure 15. Interrelationships Among Near-field Performance Assessment Computations $\mathrm{X}-26$

\section{LIST OF TABLES}

Table 1. Examples of Fixed and Uncertain Parameters in the GoldSim BLT-MS Integrated Software Package 


\section{LIST OF ABBREVIATIONS AND ACRONYMS}

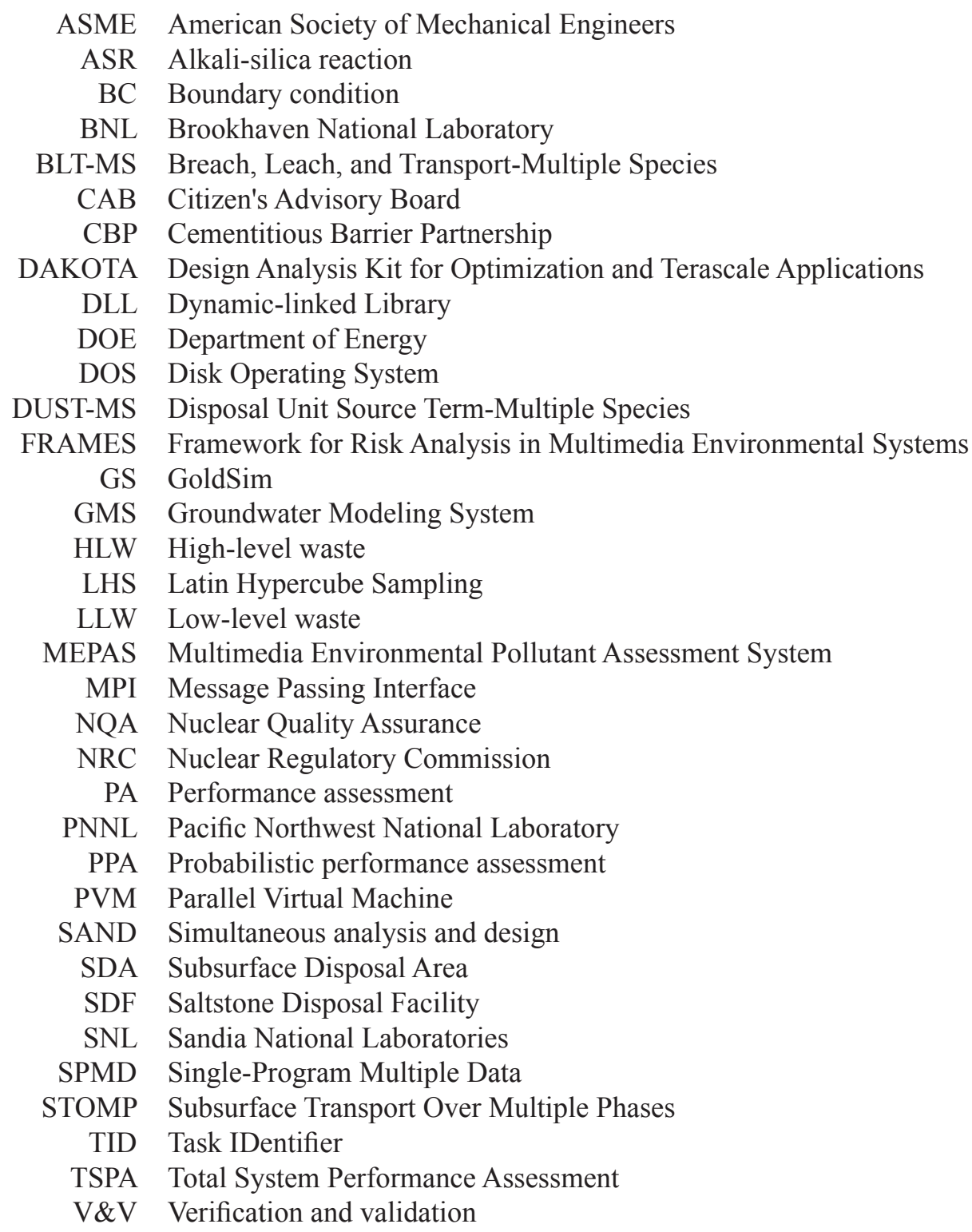


Review of Mechanistic Understanding and Modeling and Uncertainty Analysis Methods for Predicting Cementitious Barrier Performance 


\title{
REVIEW OF INTEGRATING PROGRAMS AND CODE STRUCTURES USED FOR DOE ENVIRONMENTAL ASSESSMENTS
}

\author{
Kevin G. Brown \\ Vanderbilt University, School of Engineering \\ Consortium for Risk Evaluation with Stakeholder Participation, III \\ Nashville, TN 37235 \\ Gregory P. Flach \\ Savannah River National Laboratory \\ Savannah River Nuclear Solutions, LLC \\ Savannah River Site \\ Aiken, SC 29808
}

\begin{abstract}
A fundamental understanding of the behavior of cementitious barriers will be needed to reduce uncertainty in performance evaluations and to improve designs. These barriers are often one of the primary control mechanisms to prevent or limit radionuclide releases from nuclear facilities. Improved tools are needed to allow performance assessments to fully incorporate and consider the effectiveness of cementitious barriers, which in part limits the types and quantities of contaminants that may be disposed of in shallow land disposal. A set of simulation tools are needed to predict 1) the hydraulic properties, 2) the stability of the relevant cement matrix phases and 3) the release fluxes of contaminants in response to variable boundary conditions and system stresses over relevant time periods. The developed tools should include explicit evaluation of uncertainty in the resulting performance estimates. In this chapter, examples of relevant integration frameworks and couplings are described in the context of the CBP modeling needs. Each of the frameworks described has strengths and weaknesses based on the models that will be selected and the extent and nature of the interactions among the models.
\end{abstract}

\subsection{INTRODUCTION}

An important objective of the Cementitious Barrier Partnership (CBP) project is to develop a reasonable and credible set of simulation tools to predict the structural, hydraulic, and chemical performance of cement barriers used in nuclear applications over relevant time frames. These barriers are often one of the primary controls to prevent or limit radionuclide release from nuclear facilities. Without adequate tools to estimate future contaminant releases, performance and risk assessments cannot fully incorporate the likely effectiveness of concrete barriers, which may limit the kinds and quantities of radionuclides that may be disposed of in shallow land disposal. Furthermore, understanding the behavior of cementitious barriers at a more fundamental level is needed to evaluate and improve designs for nuclear waste disposal and other critical applications including nuclear power plants and spent nuclear fuel pool storage. A set of simulation tools are needed to predict: 1) the hydraulic properties, 2) the stability of the relevant 


\section{Review of Mechanistic Understanding and Modeling and Uncertainty Analysis Methods for Predicting Cementitious Barrier Performance}

cement matrix phases and 3) the release fluxes of contaminants in response to variable boundary conditions and system stresses over relevant time periods. The developed tools should include explicit evaluation of uncertainty in the resulting performance estimates.

A simplified approach to model integration is initially provided that can be used to guide the selection and development of both the models and the needed framework for predicting waste-management related properties of cementitious barriers. Examples of relevant integrations or couplings of models are described in the context of the CBP needs. Each of the integration platforms had strengths and weaknesses depending on the models selected and the nature and extent of interactions among the selected models.

The mechanisms that effect both the structural integrity of cementitious barriers and their capacities to isolate contaminants from the environment can be conceptualized as a series of interacting processes describing physical, hydraulic, and chemical performance. In summary, changes in hydraulic properties, structural performance, and contaminant releases are the net consequences of changes in the physicalchemical structure of the cementitious material in response to ingress and egress of chemical constituents, on-going chemical reactions, and internal and external physical stresses. Contaminants released from the barrier can migrate to human receptors through various exposure media (e.g., vadose zone, groundwater, or surface water) through different potential pathways (e.g., inhalation or ingestion). These potential mechanisms and processes can be abstracted as illustrated in Figure $1^{1}$. The area of interest for the CBP (i.e., including hydraulic properties and contaminant fluxes from the cementitious barrier) is indicated by a dashed line in Figure 1.

The fluxes of contaminants exiting the cement barrier in question as a function of time are of primary interest to the CBP. However, for contaminants to be released from the cement matrix or barrier at rates above that of simple diffusion, the concrete must undergo some sort of aging or degradation process and a contaminant transport mechanism must be available (e.g., with percolating water or by diffusion). There are a number of processes known to degrade concrete, which will provide for both the release of contaminants from the cement matrix and their subsequent migration from the barrier to the surrounding environment. Some of the known degradation processes include chemical attack (e.g., by chloride, sulfate, oxygen and/or carbonate), frost attack, corrosion of structural members, gas generation, and gel expansion.

Figure 2 provides a simplified conceptual model for many known causes of concrete degradation and how these causes might interact to impact durability, barrier performance, and structural performance (Long, Henderson \& Montgomery 2001; Pretorius 2001). The degradation processes that affect durability also tend to impact the performance of the cement as a waste matrix because of changes in pore structure and diffusivity of oxygen and contaminants. Cracking plays a major role in the performance of the concrete barrier by increasing the rate of transport of contaminants to the environment under many scenarios. The development of cracks impacts the transport of oxygen, water, and dissolved species (e.g., sulfate or chloride) into the concrete ${ }^{2}$ and contaminants from

\footnotetext{
1 Figure 1 is based on a presentation entitled "Long-Term Performance of Surface and Sub-Surface Engineered Barriers" by Jacob Philip and Thomas Nicholson of the U.S. Nuclear Regulatory Commission (NRC) to the National Academy of Science on May 26, 2006. The presentation is available at http://dels.nas.edu/besr/docs/PhilipNicholson.pdf (accessed October 1, 2008).

2 Transport impacts and cracking are coupled in that the movement of sulfate and other species (originally by diffusion) into the concrete can cause cracking of the concrete, which then may result in increased transport. It has been suggested by Walton (1992) that in "the absence of cracks, high quality concrete will almost always do an outstanding job of isolating waste because of its low permeability and high available surface area for sorption. In the presence of cracks, concrete only sometimes works well for waste isolation."
} 


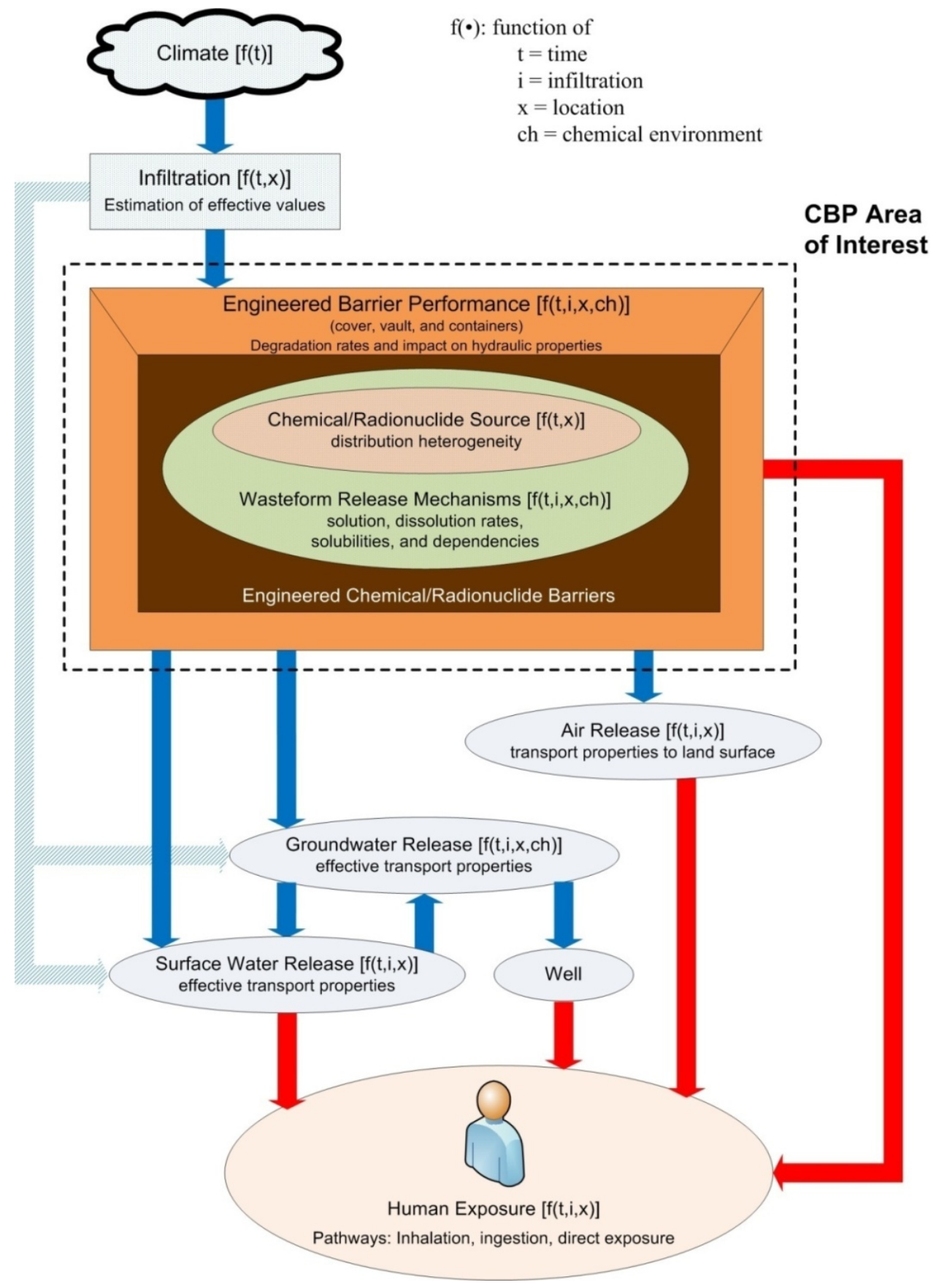

Figure 1. Generalized Performance Assessment Conceptualization (Adapted from A Diagram from Philip and Nicholson (2006)'1) 


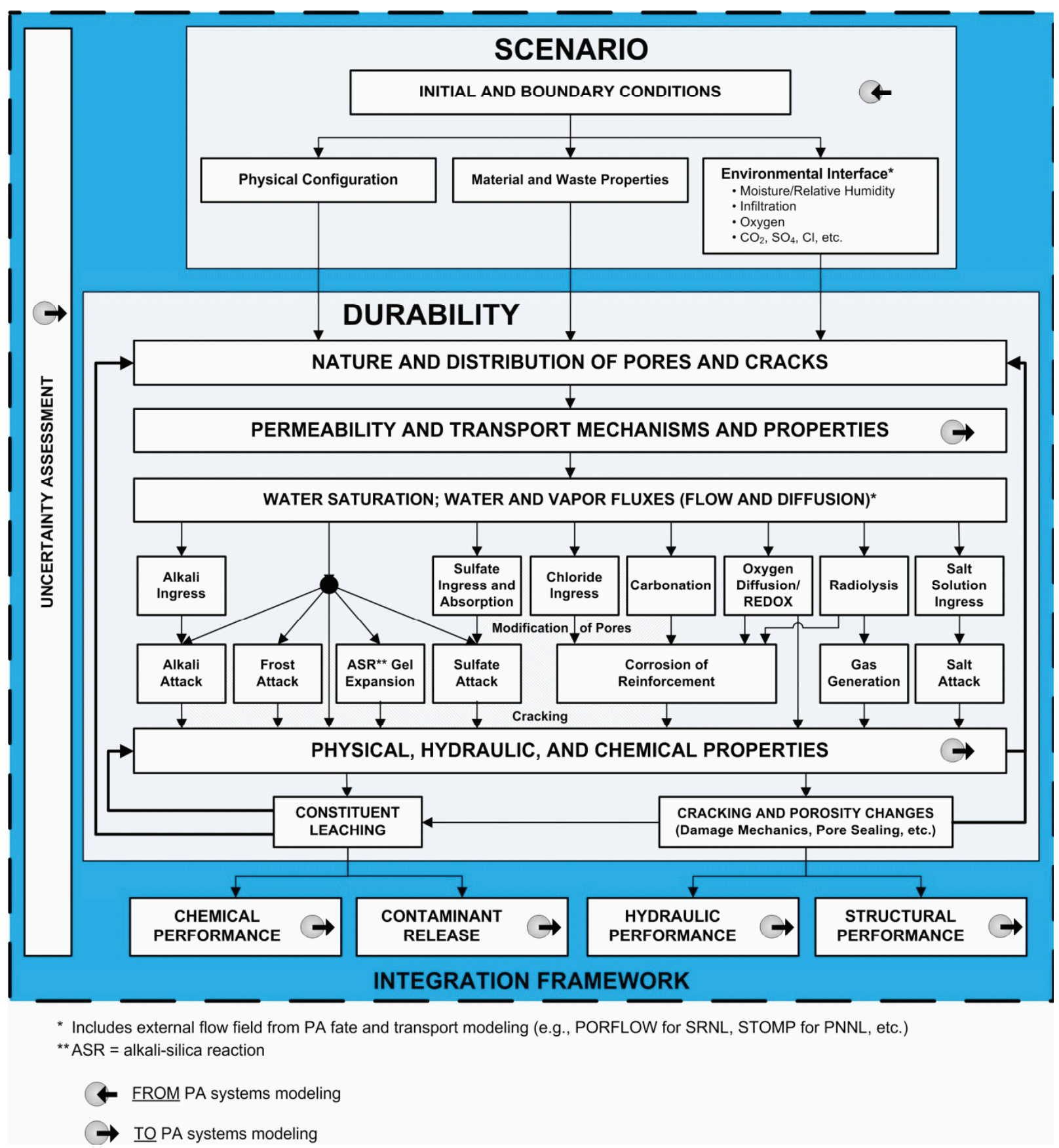

Figure 2. Specifications, Properties, and Phenomena for the Evaluation of Performance of Cementitious Barriers (Adapted from Long et al. (2001) and Pretorius (2001)) 


\section{Review of Mechanistic Understanding and Modeling and Uncertainty Analysis Methods for Predicting Cementitious Barrier Performance}

the cement matrix to the environment (Walton 1992). Degradation also affects the structural properties and performance of the concrete in its ability to withstand loads and limit load-induced cracking.

Another aspect of modeling concrete deterioration and subsequent contaminant transport apparent from the conceptualization in Figure 2 is that it may be possible to represent concrete degradation as a coupled set of modular process that interact with the broader performance assessment computations. Modules can be developed (if not already available) for important degradation processes and then coupled to provide a comprehensive model of concrete deterioration. For example, models are available for many of the important degradation and transport processes represented in Figure 2 (e.g., sulfate and chloride ingress and attack or carbonation). Thus a coupled, modular approach is the expected CBP approach to develop state-of-the-art tools to model concrete behavior for nuclear applications ${ }^{3}$. A modular approach to software design also generally results in easier development and produces better quality results than monolithic design and programming approaches (Lee 1994).

\subsection{A SIMPLIFIED APPROACH FOR MODEL INTEGRATION}

At a fine enough level of detail, any model integration problem could likely be considered unique; each may use a different framework, require different models, or answer different questions than another integrated solution. However, model integration approaches often have many elements in common, and a process to be followed can be generalized. Figure 3 provides a simplified conceptual framework that was used to develop the screening risk tool for U.S. Department of Energy (DOE) shallow land burial wastes (Brown
2008). Although the framework in Figure 3 was followed for a specific purpose, it can be used to develop a more general integrated model development framework to inform any such integration process including that for cementitious barriers.

As illustrated in Figure 3, one of the first steps is to conceptualize the problem in terms of the necessary solution and the characteristics that must be captured in order to solve the problem. The approach adopted should be commensurate with the importance, complexity, and maturity or "stage" (e.g., screening, cleanup level definition) of the problem to be solved. These considerations impact not only model selection and integration efforts but also how input data and model parameters should be managed.

Because of the expense involved with quantitative assessment of uncertainties in a simulation (e.g., design and analysis of data, defining relevant probability distributions, structuring uncertainty analyses, or updating), the ability to perform sensitivity analyses is critical to the efficient use of resources. The parameters that most influence model outputs should be identified so that efforts and resources can be focused appropriately. The most typical sensitivity analysis examines the impacts of parameters or input data oneat-a-time and may omit important interaction effects. More sophisticated sensitivity analysis techniques are available depending on the nature and importance of the problem and whether the additional complexity is warranted. These alternative methods may be called externally much in the same manner as the models used to predict needed cementitious barrier behavior. Furthermore, sensitivity and uncertainty analyses are rarely performed in a vacuum; insights from model developers and users are often available and represent an excellent starting place for these analyses.

\footnotetext{
${ }^{3}$ A monolithic approach to software development is also possible where all needed functionality is programmed in a single, monolithic code and tight coupling can be instituted. However, the gain in coupling and efficiency from a monolithic code structure may occur at a cost of increased development time (especially if modules or callable programs already exist) as well as the typical issues of low re-usability and interoperability when compared to more modular or component-based schemes. It has been assumed that because programs are available with much of the necessary functionality that a modular scheme will be adopted for the CBP.
} 


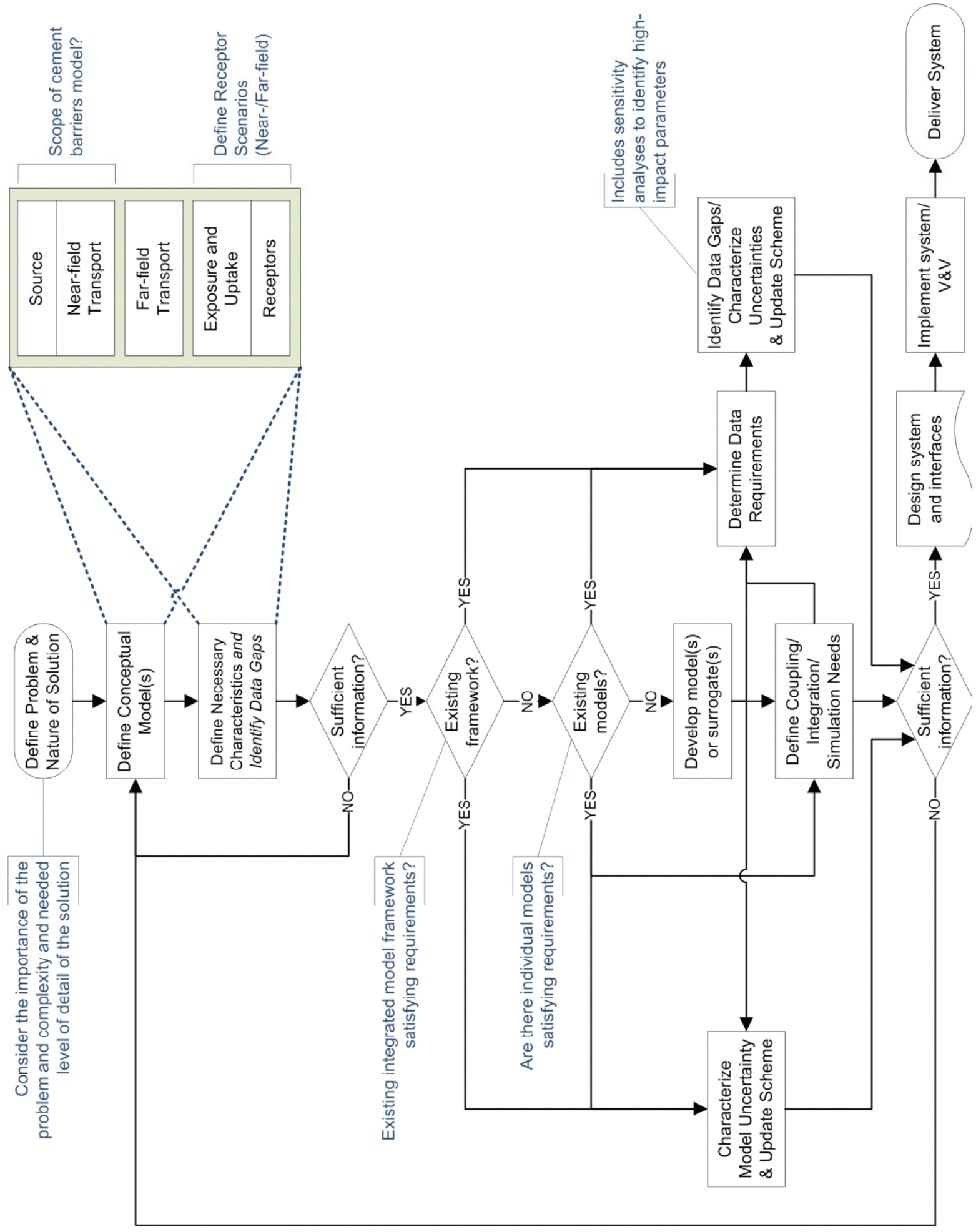

Figure 3. Simplified Approach to Model Integration for the Risk Screening Tool for Department of Energy (DOE) Buried Wastes (Brown 2008) 


\section{Review of Mechanistic Understanding and Modeling and Uncertainty Analysis Methods for Predicting Cementitious Barrier Performance}

\subsection{Nature of Coupling}

How individual models in the CBP framework will be implemented and the nature of the dependencies (i.e., coupling) among the model implementations (denoted subordinate codes) requires examination. The degree and directions of the coupling required among the individual subordinate codes will depend on numerical stability considerations for the physical phenomena modeled. Coupling can be classified along the following lines for the integrated simulation framework ${ }^{4}$ :

- None - The subordinate codes are not related

- Unidirectional - The codes are run once in an appropriate sequence with "downhill" information flow and without internal feedback loops between subordinate models.

- Very weak - There is coupling between simulations; that is, each subordinate can run independently for an entire transient with iteration needed between transients to synchronize results.

- Weak - There is coupling between timesteps; that is, subordinates must be synchronized after each timestep or at defined timestep intervals.

- Strong - There is coupling within timesteps; that is, the subordinate programs must proceed together during each timestep.

The degree of coupling required by the physical processes modeled will have a critical impact on the software integration, and methods have been developed for handling complexities arising from coupling (Matthies, Niekamp \& Steindorf 2006). Because the integrated framework to be developed by the CBP is intended to provide temporally- and spatially-varying constituent fluxes and important hydraulic properties as input to a higher-level performance assessment
(PA) code (e.g., PORFLOW or STOMP), the considerations raised in these sections also apply to interactions between the CBP framework and PA code.

It may be preferable to tightly couple models if the models run sufficiently fast and have interfaces that allow them to be tightly coupled with each other. Under these conditions, the integration framework would be primarily a passer of information amongst individual models and a collector of results (i.e., a blackboard) for resulting evaluation. However, the interactions and interdependencies (i.e., coupling) likely to exist among any set of models (especially complex phenomenological models) needed to solve a sophisticated, real-world problem are such that a tight coupling of models is likely to present logistical and computational difficulties ${ }^{5}$. The temporal nature and spatial complexity of the solution likely needed for a state-of-the-art analysis of concrete barriers will likely exacerbate any model coupling and surrogate model development issues. The coupling of individual subordinate models within the integrated framework (as well as the framework and PA model) will be as loose (or weak) as possible based on the numerical stability of the physical phenomena being represented (Cole 2002; Weaver, Tomlinson \& Aumiller 2000; Weaver, Tomlinson \& Aumiller 2001). This "weak coupling" strategy will allow the CBP tools to leverage off existing programs and maintain as much fidelity as possible to the original codes and solutions.

\subsection{Computing Environment}

The hardware and software platforms that are used to develop and run an integrated framework are also important considerations. One possible classification for computing environments is: ${ }^{6}$

\footnotetext{
${ }^{4}$ The classification is taken from a personal communication from G. Flach of SRNL on March 31, 2009. There are additional classification schemes for coupling considerations (King 2005; Page-Jones 1980; Stevens, Myers \& Constantine 1974).

${ }^{5}$ Individual models may have performances too slow for use in an integrated framework. Under these circumstances, it may be possible to develop surrogate models or to extract the underlying relationships for direct implementation in the simulation framework, which would make their coupling more straightforward. The technique is also influenced by the quality of the supporting information. Ultimately, the sophistication of the integrating model will be commensurate with the nature of the supporting information.

${ }^{6}$ The classification is taken from a personal communication from G. Flach of SRNL on March 31, 2009.
} 
- Heterogeneous environment - Multiple operating systems (e.g., LINUX and Microsoft Windows) and different hardware platforms are needed.

- Homogeneous environment - The same operating system and hardware platform can be used.

- Single machine - The coupled software runs on a single machine (although possibly with parallel or multiple processors).

For example, if necessary models must be run on different operating systems, then a framework is necessary that operates in a heterogeneous environment with communication among subordinate codes over a network. On the other hand, a homogeneous environment or single machine could be used if 1) all needed models can run on a single operating system/ hardware configuration or 2) surrogate models can be developed, when needed, to run under the selected configuration. This consideration also applies to the integrated CBP framework and PA model.

The option that requires the least work from model developers would be to call legacy model codes (running in a single operating system) as external, standalone processes from the framework system. However, the needed models may not run on the necessary operating system or executing a model may be computationally too expensive especially if a large number of runs are needed during a simulation (e.g., for an uncertainty analysis). A common alternative to improve computational efficiency is to develop surrogate models that can be integrated directly into the simulation framework and called instead of the more complex models (Field Jr. 2005; Qian et al. 2006). However, using surrogate models not only tends to increase overall model uncertainty (which must be accounted for), it can also change the fundamental nature of the uncertainties in the models because of the tendency of the surrogate model development process to smooth the results. Properly constructed surrogate models must not lose any important model response information.

\subsection{Programming Languages Used}

Another important aspect that impacts coupling in the system is model implementation (e.g., development environment or native language). Often the native language used to implement a model impacts the manner in which another program can interact with the model code. For example, in the Parallel Virtual Machine (PVM) described in Section 3.5, the C and $\mathrm{C}++$ bindings for the user interface library are implemented as functions; whereas, those for FORTRAN codes are implemented as subroutines (Geist et al. 1994). The CBP framework program, expected to be composed of coupled, subordinate models selected to describe necessary physical phenomena, is intended to supply temporally- and spatially-varying contaminant fluxes and hydraulic properties to a PA model. Thus, linking considerations extend beyond the CBP framework itself.

\subsection{Additional Considerations}

There are aspects of the conceptual framework in Figure 3 that are non-technical but still very important to the successful development of a credible simulation tool. First, the software tools must follow applicable design guidelines not only because this is a requirement for DOE software ${ }^{7}$, but because software design is good programming practice. Because of the desire to maintain fidelity to legacy codes, the nature of the simulation tool should lend itself to modular software design, which will further promote ease of understanding, maintenance, and extensibility. Modularity in a software system will make it easier to stage required development and testing among multiple developers. Finally, the level of required verification and validation $(\mathrm{V} \& \mathrm{~V})$ will also impact

\footnotetext{
${ }^{7}$ Software development for use by the U.S. Department of Energy (DOE) must satisfy the requirements of ASME NQA-1 (ASME 2000).
} 
the development and, ultimately, acceptance of the cementitious barrier simulation tools.

\subsection{Selection Criteria for the CBP Model Framework}

A modular approach to software design, development, and maintenance is expected for the tools to be developed for the CBP. This approach has many potential benefits to both developers and end users. Some of the benefits of a modular design include (Lee 1994; Shorter \& Adair 2008; Tuchschmid et al. 2006): ${ }^{8}$

- Development - Program development can be easily staged or performed in parallel using multiple developers.

- Prototyping - This is the stage between design and coding where complex algorithms can be demonstrated or alternative algorithms tested in modules.

- Testing and Debugging - Since modules will have well-defined interfaces, modules can often be evaluated independently by testing the interfaces. Some modules may be tested alone; others may need to be coupled with stub procedures to simulate related modules.

- Understandability - The modular nature of the system lends itself to being much easier to understand than a monolithic, procedural code.

- Extensibility - New results or components can be integrated into the system quickly and easily.

- Scalability - Additional computational resources can be utilized (when needed) in a scalable fashion.

- Real-time capability - Realistic simulator behavior requires compliance with various real-time constraints including execution in reasonable time on accessible hardware.

- Maintainability - The system can be sustained in a research environment often subject to changing information and innovations.
- Flexibility - Modules and components should be exchangeable to supporting different application domains and situations.

Various frameworks - modular and otherwise - have been developed to model complex systems. Examples of the various types of approaches available to simulate complex systems, especially those related to the CBP, follow.

\subsection{EXAMPLES OF INTEGRATED MODELING APPROACHES AND PLATFORMS}

Examples of approaches and platforms that have been used to develop integrated simulation tools for environmental assessments are described to illustrate alternatives to the problem posed by the CBP. These examples of approaches and platforms include

- Monolithic Approach - Implement all functionality in a single, monolithic code

» CEMENT code (Seitz \& Walton 1993)

- Fidelity Approach - Maintain fidelity to original programs

» Framework for Risk Analysis in Multimedia Environmental Systems (FRAMES) (Whelan et al. 1997)

- Hybrid Approach - Adopt principles of both Monolithic and Fidelity Approaches to strike the needed balance between coupling and fidelity

» Design Analysis Kit for Optimization and Terascale Applications (DAKOTA) (Eldred et al. 2006a; Eldred et al. 2006b; Eldred et al. 2006c)

» GoldSim Monte Carlo simulation program (GTG 2005b; GTG 2005c)

- Custom Interface Approach - Develop custom interface for information passing

» Parallel Virtual Machine (PVM) (Cole 2002; Geist et al. 1994).

\footnotetext{
${ }^{8}$ Although presented as benefits, many elements in the list can also be considered requirements for a successful modular system.
} 
Other tools are briefly described (i.e., BARRIER and 4Sight) to illustrate the breadth of available tools. Finally, the modeling effort to couple flow and transport, infiltration, geochemistry, etc. to support the SRS Saltstone performance assessment (PA) is described. The tools that will be developed by the CBP will provide the source term information for a PA like that described for Saltstone.

\subsection{Monolithic Approach Example: CEMENT Code}

The CEMENT computer code was developed by the Idaho National Engineering Laboratory to implement simplified models describing the processes critical to concrete service life and performance as a barrier to flow and transport for use in performance assessments for concrete vaults and waste forms (Seitz \& Walton 1993). Multiple concrete degradation processes are modeled (i.e., reinforcement corrosion, sulfate attack, freeze/thaw, and alkali-aggregate reactions) with an emphasis on rebar corrosion and cracking. The CEMENT code was developed as a monolithic FORTRAN 77 program with subroutines representing the various degradation and transport processes. The subroutines and thus the various processes were not meant to be run in a coupled fashion.

\subsection{Fidelity Approach Example: Framework for Risk Analysis in Multimedia Environmental Systems (FRAMES)}

The Framework for Risk Analysis in Multimedia Environmental Systems (FRAMES) was developed by the Pacific Northwest National Laboratory (PNNL) in conjunction with the US NRC ${ }^{9}$ (Whelan \& Castleton 2006a; Whelan et al. 1997). FRAMES is a platform that allows users to integrate selected legacy environmental software models for risk assessment and management problems (Whelan \& Castleton 2006a; Whelan \& Castleton 2006b; Whelan et al. 1997). The program is a flexible and holistic approach to understanding how industrial activities may affect humans and the environment. With specific changes, legacy models can be integrated across scientific disciplines allowing for tailored solutions to specific activities and providing meaningful information to stakeholders and decision makers. FRAMES can be used to develop environmental scenarios and provide options for selecting appropriate models to conduct human and environmental risk management analyses.

The FRAMES program is a visual, object-oriented platform for linking potentially disparate legacy models and databases for conducting assessments. The design facilitates addition of new objects and modules to provide a highly adaptive modeling environment for evaluating a wide variety of exposure and risk scenarios. FRAMES couples user-defined models, databases, and legacy models and systems to transfer data and perform assessments. The FRAMES program (Whelan \& Castleton 2006a)

- allows the problem to be conceptualized visually;

- allows the user to choose from different models and databases to address the problem;

- provides sensitivity and uncertainty analysis capabilities; and

- provides tools to visualize, tabulate, and document the results.

The FRAMES program is a Windows-based/ Plug\&Play system that allows users to import models into the system without the aid of a developer (Whelan \& Castleton 2006a). Virtual constructs of real-world objects can be "dragged and dropped" into the system allowing analysts to visually analyze the problem as illustrated in Figure 4. Minimum data are required and models only transfer pertinent

\footnotetext{
${ }^{9}$ Additional information for the version 2.0 of FRAMES can be found on the PNNL Earth: Environmental Assessment and Risk Tools site at http://mepas.pnl.gov/earth/ and http://mepas.pnl.gov/Frames, V2/index.stm (accessed October 1, 2008).
} 


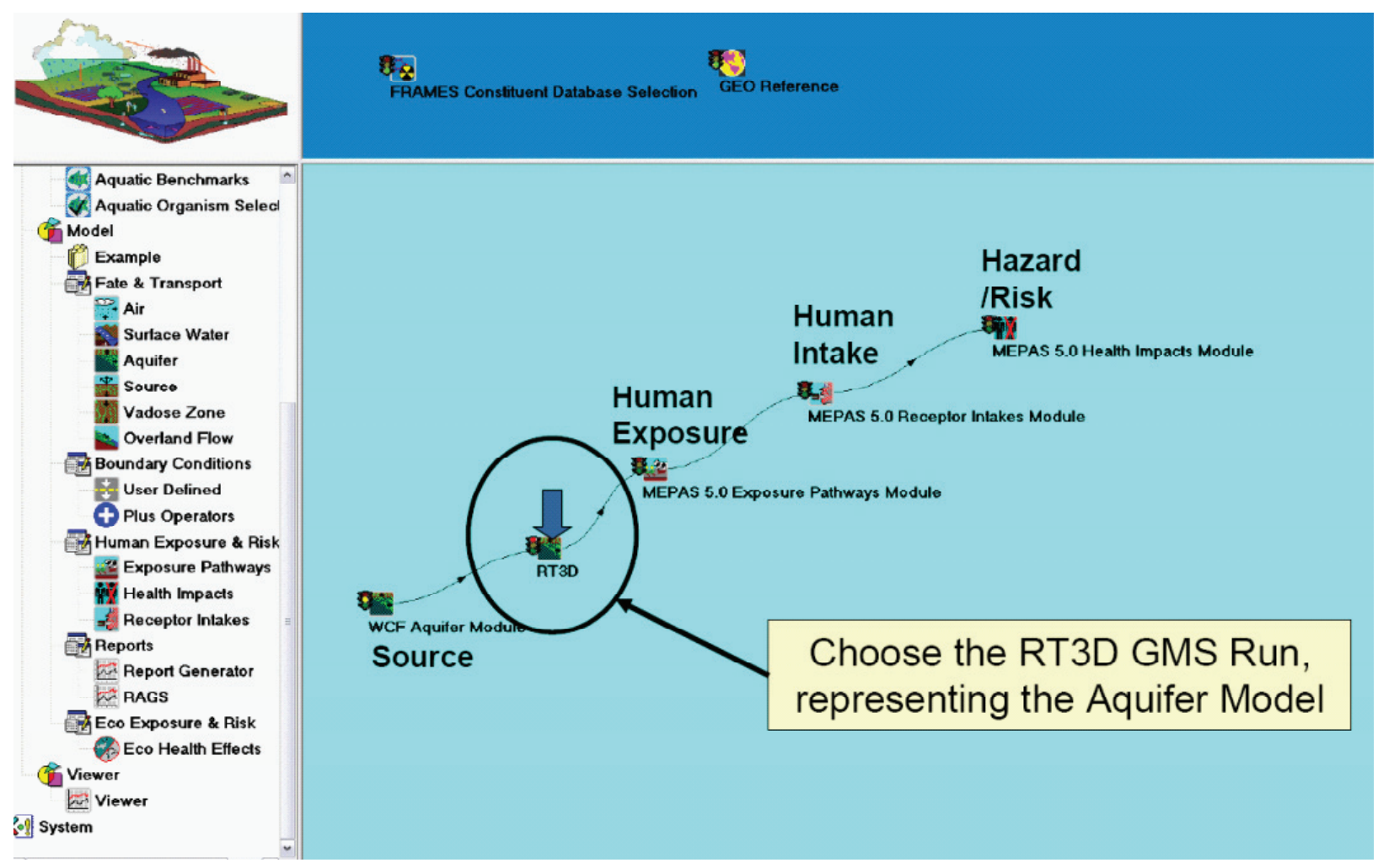

\section{Figure 4. Connecting the RT3D Program to Upstream and Downstream Modules within the FRAMES-2.0 Workspace (Reproduced from Whelan and Castleton (2006a))}

information. Monte Carlo sensitivity and uncertainty wrappers provide integrated models with a means to perform probabilistic analyses. The user can also link to external models and/or databases remotely via web access (although this can significantly compromise computational efficiency). Available databases include those for properties of chemicals and radionuclides, human exposure parameters and risk factors, aquatic and terrestrial toxicity reference values, biological species life-history profiles, food bioaccumulation factors, and biota sediment accumulation factors.
Conceptually, FRAMES acts as middleware ${ }^{10}$ to assure the seamless communication among modeling components (Whelan \& Castleton 2006b) ${ }^{11}$. No model or framework actually exists inside FRAMES - the FRAMES program acts as a portal to the model. Figure 5 provides an example of how middleware functions. The user chooses and runs a source-term model to produce the information (e.g., mass flux rates) needed by FRAMES. FRAMES then transfers this information to the user-selected aquifer model (e.g., RT3D in $\mathrm{GMS}^{12}$ ) assuring appropriate

\footnotetext{
${ }^{10}$ Typically, "middleware" is software connecting components or applications.

${ }^{11}$ The OpenMI interface is another standard for linking environmental models (OpenMI 2007). The standard defines an interface that allows existing time-dependent models to exchange data at run-time.

${ }^{12}$ The Groundwater Modeling System (GMS) is a graphical interface created by the Brigham Young University for various groundwater models - one of these models is the PNNL RT3D. The RT3D code solves coupled partial differential equations to describe reactive-flow and transport of multiple mobile and/or immobile species in a three-dimensional saturated porous media (Clement \& Jones 1998).
} 


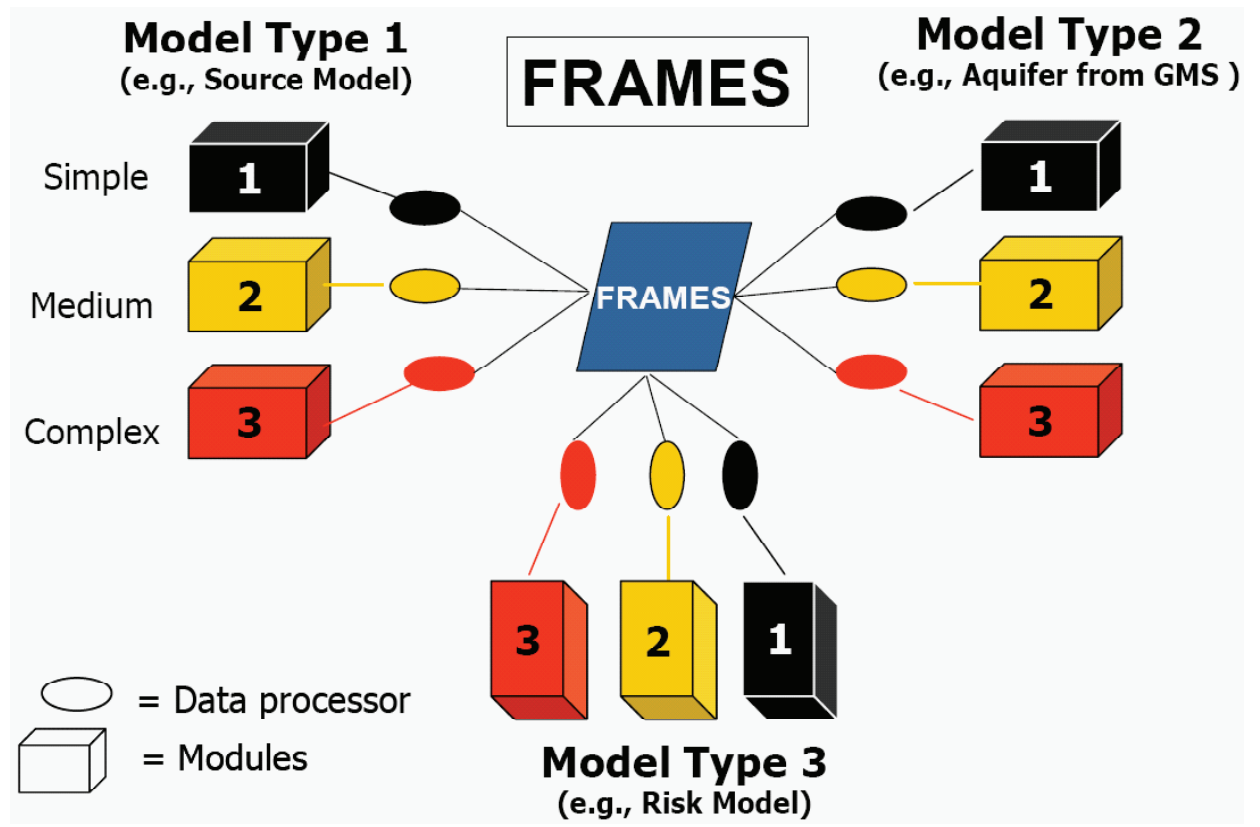

\section{Figure 5. Illustrating the Linkage of Three Models of Differing Scale and Resolution Using Frames as Middleware (Reproduced from Whelan and Castleton (2006b))}

conversions are made. The aquifer model is then run and produces data (e.g., concentrations) also for use by FRAMES, which makes the necessary conversions, and transfers the data to the selected exposure, intake, and risk models of choice.

\subsection{Hybrid Approach Example: Design Analysis Kit for Optimization and Terascale Applications (DAKOTA)}

The Design Analysis Kit for Optimization and Terascale Applications (DAKOTA) toolkit provides a flexible and extensible interface among simulation codes and allows new optimization and uncertainty quantification algorithms to be developed (Eldred et al. 2006a; Eldred et al. 2006b; Eldred et al. 2006c). DAKOTA provides algorithms for optimization, uncertainty quantification, parameter estimation, and sensitivity/variance analysis with design of experiments and parameter study methods. These components may be used independently or within advanced strategies including surrogate-based optimization, mixed integer programming, or optimization under uncertainty (Eldred et al. 2006c). By using objectoriented design principles to implement the key components for iterative systems analyses, DAKOTA provides a flexible and extensible environment for design and analysis of computational models on high performance computers.

One advantage that DAKOTA offers is access to a broad range of iterative capabilities that can be obtained through a relatively simple interface between DAKOTA and the simulator (Eldred et al. 2006c). Figure 6 illustrates the typical loosely-coupled relationship between DAKOTA and a simulation code ${ }^{13}$.

\footnotetext{
${ }^{13}$ The solid lines in Figure 6 indicate file input/output operations. Dotted lines indicate passing data that must be handled by the user. DAKOTA writes a parameters file that contains the current variables and then starts the simulation code. When the simulation completes, DAKOTA reads the response data from a results file. This process is repeated until all runs have been completed.
} 


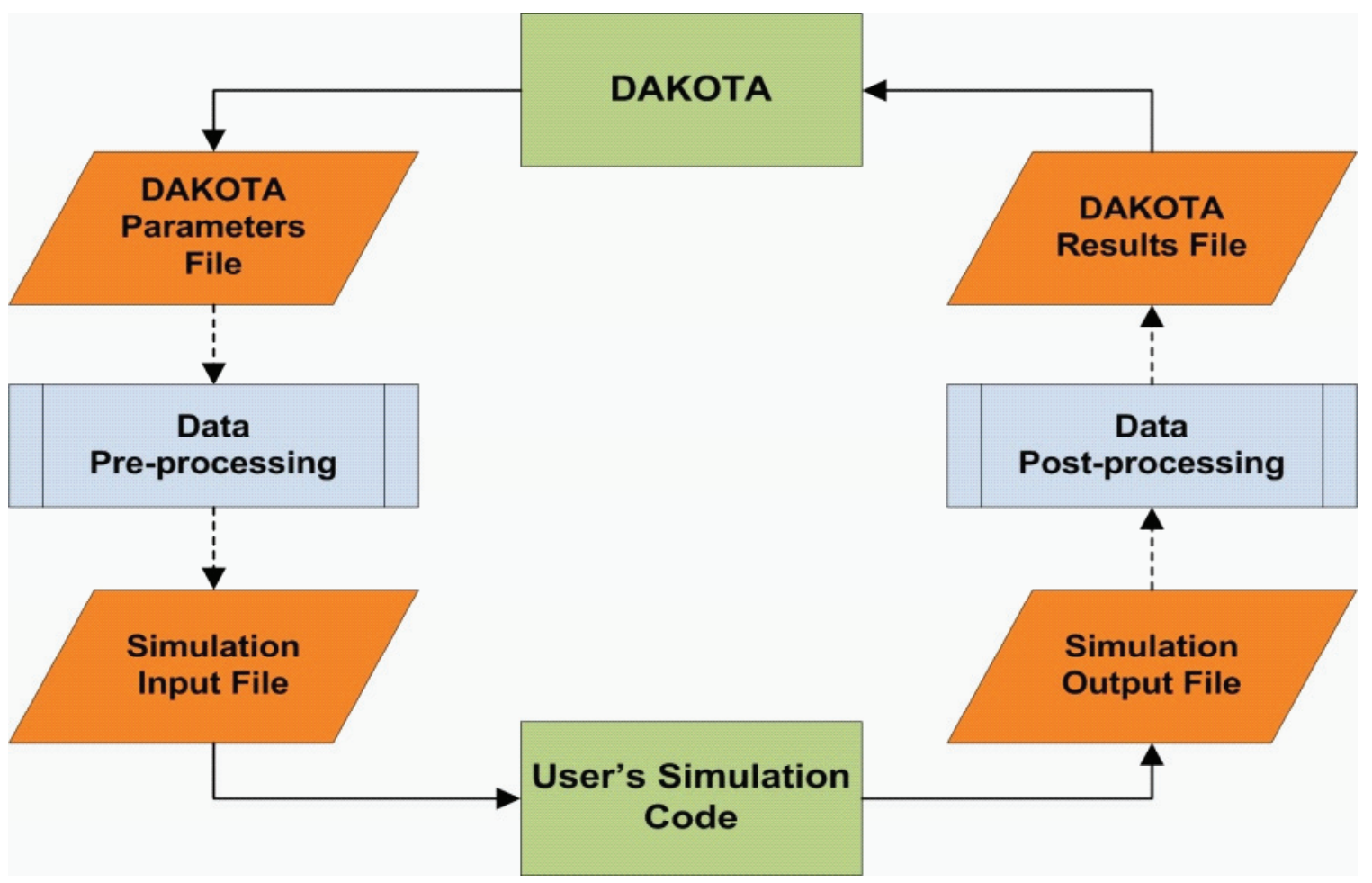

Figure 6. The Loosely-coupled or "Black-box" Interface Between DAKOTA and A User-supplied Simulation Code (Adapted from Eldred et al. (2006c))

Data is exchanged between DAKOTA and the simulation code using data files; DAKOTA does not require access to simulation program source code. During operation, DAKOTA executes the simulation code in a separate external process.

In some cases, it is necessary to have a closer coupling between DAKOTA and a simulation code than that represented in Figure 6. This close coupling is accomplished through either a direct interface or a simultaneous analysis and design (SAND) interface (Eldred et al. 2006c). For the direct interface, the simulation code is modified to act as a subroutine in DAKOTA $^{14}$. The major advantage of a direct interface is the elimination of the overhead resulting from file $\mathrm{I} / \mathrm{O}$ and process creation. A SAND interface requires extensive modifications to the simulation code so that the optimizer has access to the internal matrices in the simulation code. Both the optimization routine and simulation code converge simultaneously. While this approach can greatly reduce the computational expense, considerable software development must be expended to achieve this intrusive coupling.

DAKOTA is both a production tool for engineering design and analysis and a research tool for developing new optimization and uncertainty quantification algorithms (Eldred et al. 2006c). Because of the objectoriented design of DAKOTA, new algorithms, strategies, methods, etc. can be added easily. DAKOTA can

\footnotetext{
${ }^{14}$ The direct interface can be considered "semi-intrusive" because it requires relatively minor modifications to the simulation code (Eldred et al. 2006c).
} 
also serve as a rapid prototyping tool for new algorithm development. By making a broad range of components available, new capabilities can be constructed rapidly to leverage off previous software investment. DAKOTA has been used to solve engineering design and optimization problems and has provided motivation for research into new areas of optimization.

\subsection{Hybrid Approach Example: GoldSim Monte Carlo Simulation Program}

GoldSim is commercial Monte Carlo simulation software for dynamically modeling complex systems (GTG 2005a; GTG 2005b; GTG 2005c). The GoldSim simulation software:

- Includes modules for finance, reliability, and contaminant transport,

- Supports risk and decision analysis by simulating future performance,

- Quantitatively represents uncertainties and risks inherent in complex systems,

- Performs deterministic (often point-value) simulations, and

- Simulates simultaneously both continuous and discrete processes (i.e., it is a hybrid simulator ${ }^{15}$ ).

The GoldSim software has been used in many applications including modeling environmental, business, and engineered systems ${ }^{16}$. A typical use is to support the development of performance assessments for proposed and existing engineered waste management sites. GoldSim can be used to either develop simplified models or couple to existing models; examples for both are provided.

\subsubsection{Screening Risk Tool for USDOE Buried Wastes}

To provide a foundation for risk-informed decision making, a framework and methodology were developed for the consistent and transparent evaluation of the life-cycle risks and risk trade-offs associated with the disposition of wastes in shallow land burial and corresponding site remedial activities (Brown 2008). According to the U.S. Nuclear Regulatory Commission (NRC), risk is one of the inputs needed (along with costs, technical feasibility, cultural and societal impacts, etc.) to make a risk-informed decision.

To demonstrate the usefulness of the risk analysis framework, a general conceptual burial model was developed to describe the wide variety of possible waste, contaminant release, and environmental conditions at DOE shallow land burial sites (Brown 2008). Because no available tool incorporated all necessary features, the necessary elements (e.g., contaminants, transport processes, environmental media, and receptors) of the conceptual model were incorporated into a screening risk tool developed in the GoldSim Monte Carlo simulation software. Because a screening level analysis was the purpose of the tool, it was considered reasonable to use only built-in GoldSim functionality to maximize the efficiency of the simulation (i.e., no external programs or databases were called) ${ }^{17}$. The screening risk tool was used to evaluate exposure and accident risks for buried waste disposition over relevant spatial and temporal scales (Brown 2008).

\footnotetext{
${ }^{15}$ The term "hybrid" to describe the simulator type (i.e., simulates both continuous and discrete processes) is used in a different sense than when this term when applied to the code development approach. For the code development approach, "hybrid" indicates that concepts from the monolithic style and that maintaining the fidelity of the existing codes are adopted. GoldSim can be considered both a hybrid simulator and a hybrid approach to implementation because algorithms can be directly implemented in GoldSim or existing codes can be called externally.

${ }^{16}$ Examples of the types of problems to which GoldSim has been applied are listed at http://www.goldsim.com/ (accessed October 1, 2008).

${ }^{17}$ A similar approach was taken by Esh et al. to develop an independent performance assessment model to facilitate review of DOE' s non-HLW determination for the Saltstone Disposal Facility (SDF) at the Savannah River Site (Esh, Ridge \& Thaggard 2006).
} 


\section{Review of Mechanistic Understanding and Modeling and Uncertainty Analysis Methods for Predicting Cementitious Barrier Performance}

The GoldSim screening risk tool incorporates simple models, simplifying assumptions, and minimal system site information to estimate life-cycle risks for shallow land burial site disposition (Brown 2008). The manners in which contaminant transport and environmental media are implemented in the screening risk tool are illustrated in Figure 7. As indicated in this figure, a more detailed and accurate risk tool can also be developed by using GoldSim as an integrating platform from which more detailed codes that can be called as external programs. The screening risk tool provides an integrated platform for quantitatively evaluating the life-cycle risks and risk trade-offs needed as input to decision-making for shallow land burial site disposition (Brown 2008). The framework and methodology as implemented in the screening risk tool has promoted transparency and consistency in DOE risk analysis ${ }^{18}$.

\subsubsection{SNL Coupled GoldSim-BLT-MS Software Package}

GoldSim can be used as an integrating framework from which extant, external programs can be called and their results dynamically coupled into the simulation. One example is the software package developed by the Sandia National Laboratories (SNL) in which GoldSim was coupled with the deterministic Breach, Leach, and Transport-Multiple Species (BLT-MS) external code to provide probabilistic analysis capability. The resulting software package has been used for the preliminary assessment of candidate low-level waste repository sites (Mattie, Knowlton \& Arnold 2007).
SNL developed a paradigm for the probabilistic performance assessment (PPA) of candidate low-level radioactive waste (LLW) disposal sites using legacy U.S. Nuclear Regulatory Commission (NRC) sponsored software within a Monte Carlo framework. The Breach, Leach, and Transport-Multiple Species (BLTMS) code (Sullivan et al. 1996) has been used to evaluate potential releases from a candidate disposal facility ${ }^{19}$. The BLT-MS code (which provides pointvalue estimates) was coupled with GoldSim to create a framework for evaluating uncertainties in a potential LLW repository system.

The BLT-MS code includes the following functionality (Mattie, Knowlton \& Arnold 2007):

- The code is able to simulate the degradation of waste containers (i.e., source term) for both localized and generalized corrosion;

- The code includes four types of waste-form release or leaching mechanisms including rinse release, diffusion release, dissolution, and solubility-limited release; and,

- The code incorporates a finite element-based transport solver for the far-field transport of radionuclides including advection, sorption, ingrowth and decay, sources and sinks for Neumann, Cauchy, and Dirichlet-type boundary conditions.

The BLT-MS code was originally developed in FORTRAN and compiled to run under DOS. The functionality of the code was not altered; however, modifications to the input/output constructs of the model were made to couple the code with GoldSim (Mattie, Knowlton \& Arnold 2007).

\footnotetext{
${ }^{18}$ The information described was developed for the Idaho Site high-level waste (HLW) calcined bin sets and Subsurface Disposal Area (SDA) (Brown et al. 2005; Switzer et al. 2005) and was presented to the Idaho Site Citizen's Advisory Board (CAB) in July 2005. The Idaho Site CAB endorsed the reports and strongly recommended to the DOE that the provisions of the reports be followed. The CAB recommendations (i.e., \#123 and \#124) are available at http://www.cresp.org/ (accessed October 1, 2008).

${ }^{19}$ The BLT-MS code was developed by Brookhaven National Laboratory (BNL) for the NRC for LLW compliance analyses (Mattie, Knowlton \& Arnold 2007). Two codes have the needed capability to simulate source-term releases and transport of radionuclides. These are the two-dimensional BLT-MS and the one-dimensional Disposal Unit Source Term-Multiple Species (DUST-MS) code (Sullivan 2001). BLT-MS was selected for the performance assessment model because of its multidimensional capabilities (Mattie, Knowlton \& Arnold 2007).
} 


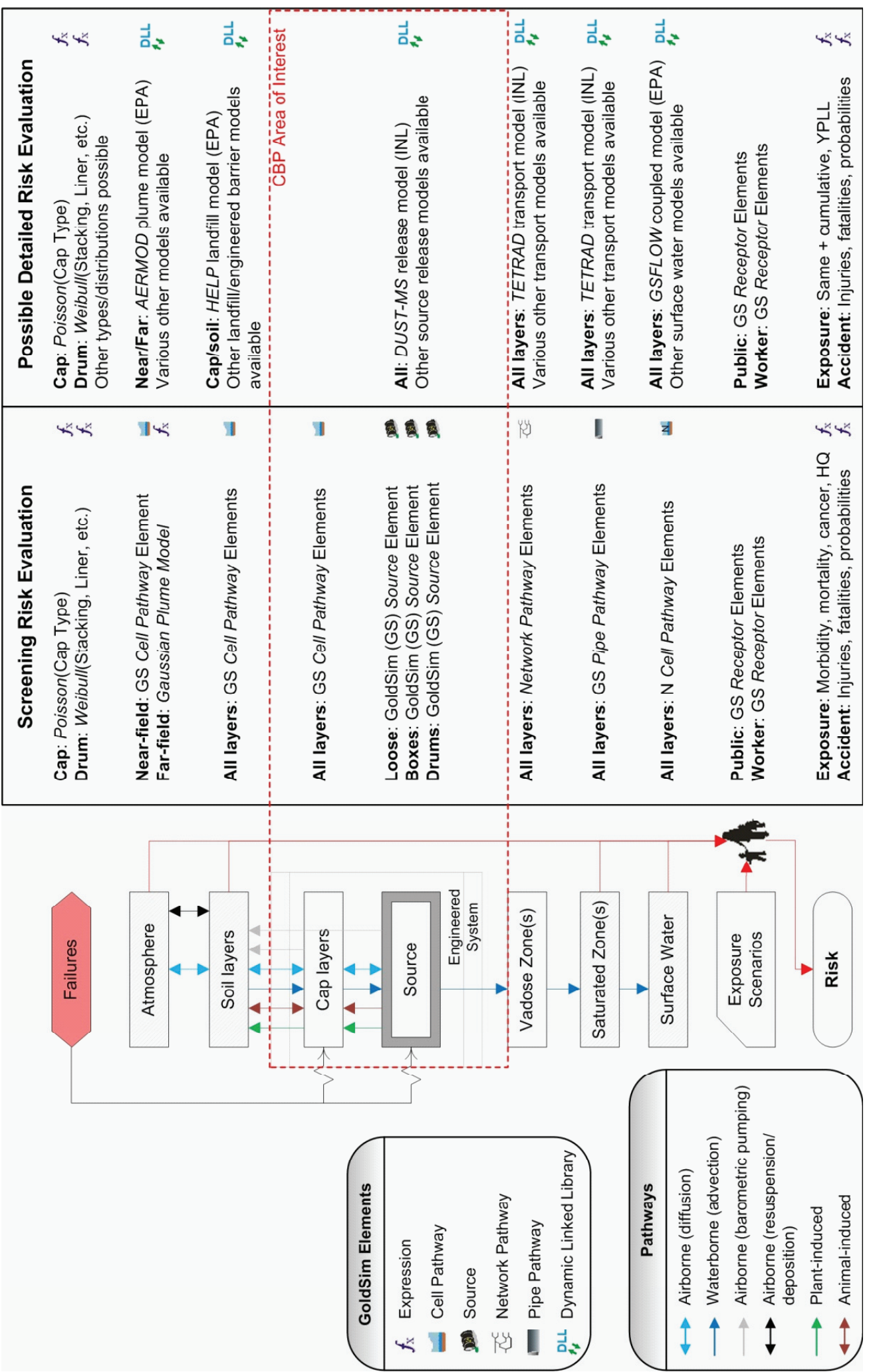

Figure 7. Implementation of the Screening Risk Tool and Proposed Detailed Risk Tool Using the GoldSim Monte Carlo Simulation Software 


\section{Review of Mechanistic Understanding and Modeling and Uncertainty Analysis Methods for Predicting Cementitious Barrier Performance}

Figure 8 illustrates a highly simplified conceptual model describing how a point-value relationship (or, in this case, the BLT-MS model) can used to estimate uncertainties in predicted risks. A set of input values are generated representing the random variables and provided to the model from which a corresponding risk is predicted - this describes a single realization. A sufficient number of realizations provide the uncertainty distribution for risk. ${ }^{20}$

The conceptual model illustrated in Figure 8 typically oversimplifies the analysis of uncertainties in predicted human health risks because (Brown 2008):

- Probabilistic exposure analysis is performed (i.e., toxicity is fixed and often overly conservative ${ }^{21}$ ) not probabilistic risk analysis.

- To be more accurate, uncertain parameters should be separated into those that are stochastic and those that are variable and a two-dimensional Monte Carlo simulation performed (Burmaster 1997; Cullen \& Frey 1999; Frey 1998; Frey \& Bharvirkar 2002; Frey \& Rhodes 1998; Hattis \& Burmaster 1994; Hoffman \& Hammonds 1994).

- Uncertain parameters are often assumed to be independent or uncorrelated, which may or may not be the case and will change the resulting uncertainty distribution estimates.

The parameters that are considered fixed versus those that are considered uncertain in the GoldSim-BLT software package are listed in Table 1.

A conceptual model of how to apply Monte Carlo to risk analysis was illustrated in Figure 8. The manner in which the BLT-MS program is coupled with GoldSim to provide risk analysis for candidate low-level waste (LLW) disposal sites is summarized in Figure 9 (Mattie, Knowlton \& Arnold 2007). The user initially (1) constructs a BLT-MS Model using the BLT-MS preprocessor to generate a master input file (where numbers correspond to those in Figure 9). Then in GoldSim, the user (2) specifies the uncertain parameters and distributions and (3) the duration of the simulation and number of realizations desired. The user (4) saves the GoldSim/BLT-MS Integration Model and (5) runs the integrated model.

Upon execution, GoldSim (6) samples uncertain distributions using Latin Hypercube Sampling (LHS). The first realization is (7) started and GoldSim passes the uncertain values to the input dynamic linked library (DLL) using predefined arrays. Another DLL (8) reads the BLT-MS input file and writes a new input file containing point-values for uncertain parameters replaced with sampled values. Upon completion of the read DLL, GoldSim then (9) runs the launch DLL, which executes the BLT-MS model for the input file (constructed in Step 8). Upon completion of the BLT-MS run, the launch DLL (10) extracts selected data from the BLT-MS output files and passes the output to the integrated GoldSim model for storage and use. To save copies of the BLT-MS output files during local or networked runs using GoldSim's Distributed Processing Module (GTG 2007), the file capture DLL is used to (11) copy selected output files to a central location. Steps 7-11 are (12) repeated until all realizations have been executed. Upon completion of the simulation, the integrated model (13) is saved and the user can review the results in GoldSim.

\footnotetext{
${ }^{20}$ Haldar and Mahadevan (2000) discuss how to determine sufficiency in sampling as well as techniques for more efficient sampling than Monte Carlo. GoldSim includes Latin Hypercube and Importance Sampling methods to supplement Monte Carlo (GTG 2005b; GTG 2005c).

${ }^{21}$ Attempts have been made to quantify exposure likelihoods for ecological risk assessments (Hope 2000; Hope 2001; USEPA 2001); however, few attempts appear to have been made for human receptors. It has also been indicated that the ecological dose-response relationship may be treated probabilistically for regulatory purposes (USEPA 2001). Thus it appears that ecological probabilistic risk assessments may often be more faithful to traditional probabilistic risk assessment methods than their human health counterparts.
} 


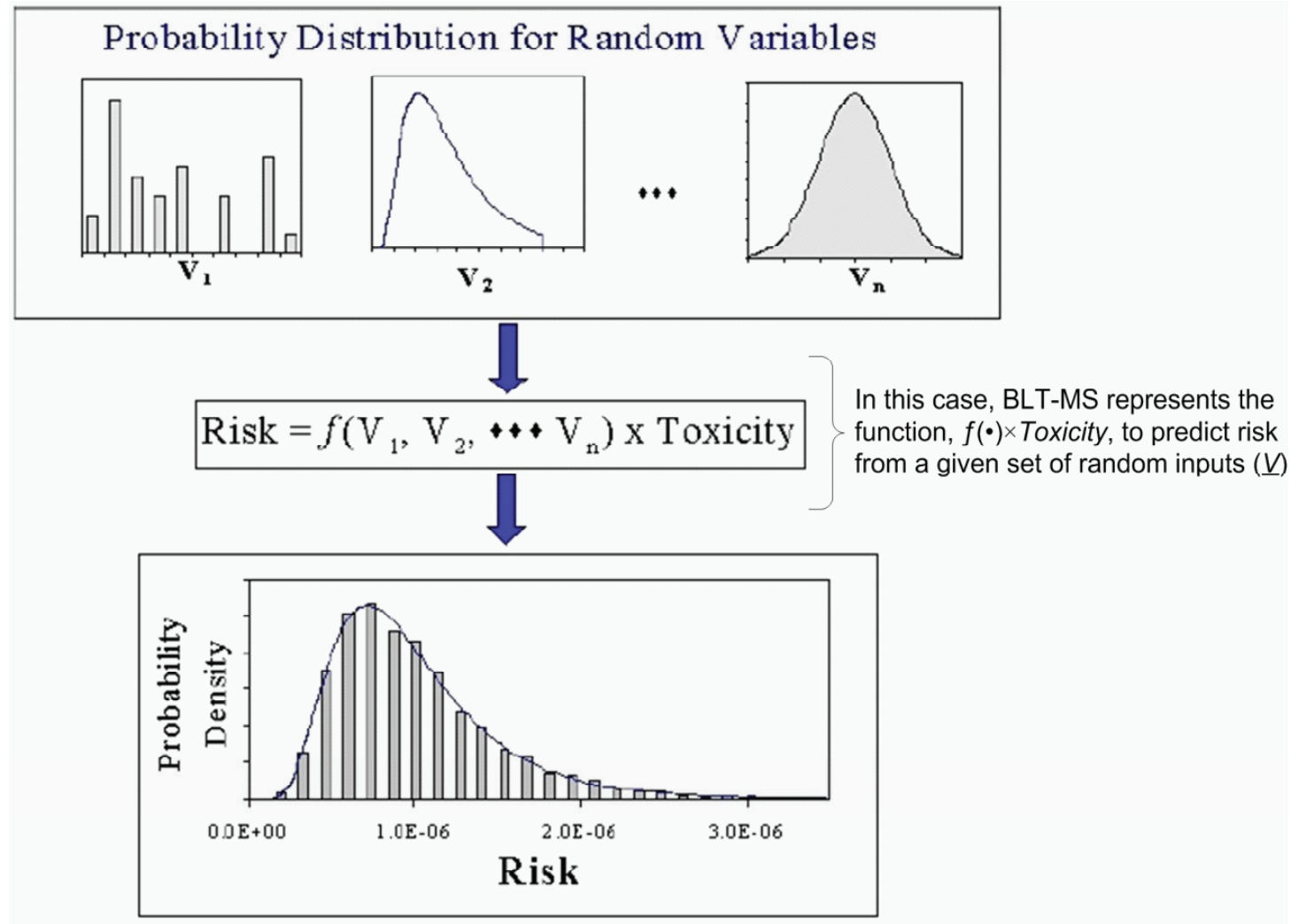

Figure 8. Conceptual Model of A Monte Carlo Risk Analysis (Reproduced from USEPA (2001)) Random Variables $\left(\mathrm{V}_{1}, \mathrm{~V}_{2}, \ldots, \mathrm{V}_{\mathrm{n}}\right)$ Refer to Variables That can be Characterized by Probability Distributions. A Point-value Risk is Predicted for Each Set of Random Values-in this Case, the BLT-MS Code would Be Used. Repeated Sampling Results in A Frequency Distribution of Risk.

Table 1. Examples of Fixed and Uncertain Parameters in the GoldSim BLT-MS Integrated Software Package (Mattie, Knowlton \& Arnold 2007)

Fixed Parameter or Parameter Set

Finite-element mesh design parameters/specifications

Material properties within the finite element mesh

Finite element nodes for boundary conditions (BC's), including fixing the $\mathrm{BC}$ type for a given node

Number of isotopic species

Number of decay chains and branching fractions

Number of container types

Number of waste types
Uncertain Parameter or Parameter Set

Initial concentrations within the source term

Boundary flux/concentration quantities

Breaching characteristics for a given container type

Leaching characteristics for a given waste type

Transport characteristics of host rock/soil

Darcy flux and moisture content within host rock/soil 


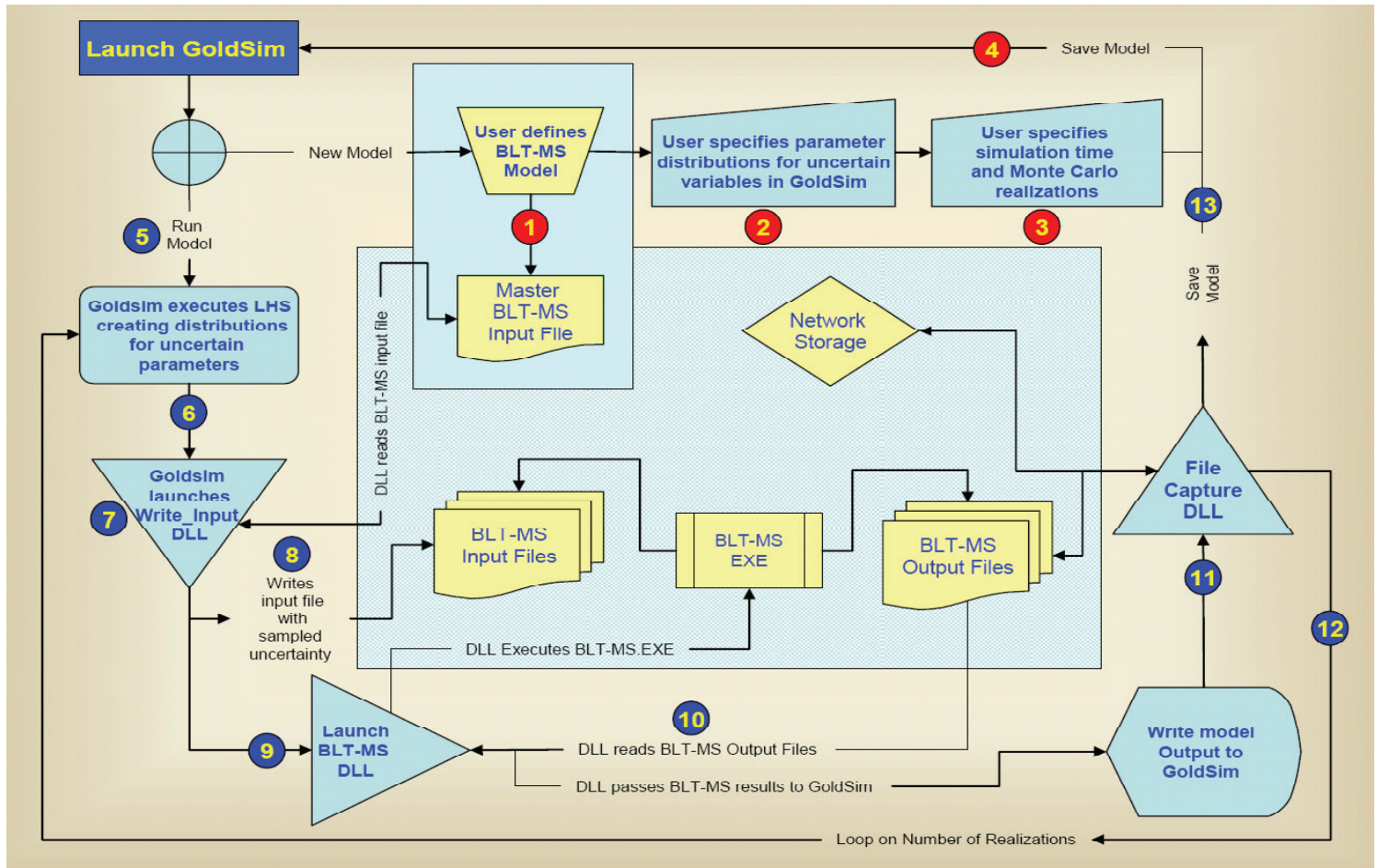

Figure 9. Flow Chart for GoldSim/BLT-MS Integration Model (Reproduced from Mattie et al. (2007))

\subsubsection{Coupled GoldSim-PHREEQC Geochemical Code}

Another example involves coupling a complex geochemical code to GoldSim using the external linkage capability in GoldSim via a dynamic linked library $(\mathrm{DLL})^{22}$. Situations where linking GoldSim to a geochemical model may be useful include (Eary 2007):

- Mixing problems - In systems where the effects of variable inputs to a mixture must be modeled, linkage to a geochemical model may be needed.

- Chemical equilibration - Hydrochemical systems where equilibria from changes in conditions or reactants must be modeled may benefit from linking to a geochemical model.
- Aqueous speciation - Systems where the speciation of dissolved species must be considered will likely require a geochemical model.

Figure 10 provides a schematic of how the PHREEQC (Parkhurst \& Appelo 1999) geochemical code can be coupled with GoldSim to perform geochemical calculations.

There are several considerations when determining whether or not a DLL should be used to couple a geochemical model to GoldSim for a particular modeling problem (Eary 2007). Advantages of this approach include:

\footnotetext{
${ }^{22}$ Other examples are provided at www.goldsim.com coupling the PHREEQC geochemical code to GoldSim using either a Lookup table or spreadsheet.
} 


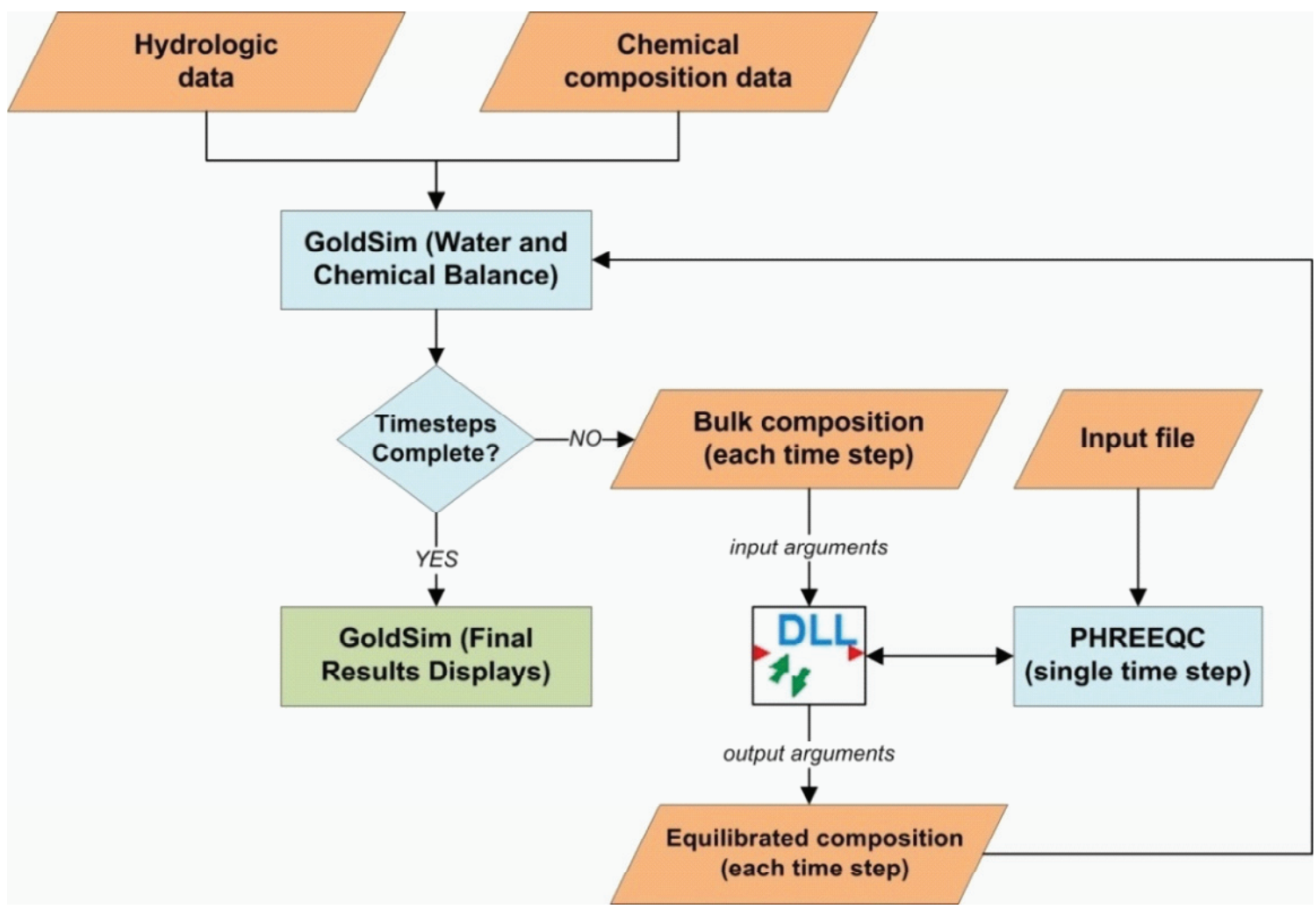

Figure 10. Schematic of Data Flow for the Method of Direct Linkage Between GoldSim and PHREEQC Using a Dynamic-linked Library (Adapted from Eary (2007))

- Applicability to multiple chemical systems with careful development of the conceptual model,

- Ability to integrate the effects of a large number of different chemical processes on solution compositions for each time step, and

- Relatively fast execution when compared to a spreadsheet linkage approach because the need for a spreadsheet as an intermediary is eliminated.

Disadvantages of using a DLL to couple a geochemical code to GoldSim include:

- Requires a large amount of time to define chargebalanced solution compositions if there are more than a few inflows,
- Questions concerning the robustness of the approach to real-world problems, and

- Requires a working knowledge of $\mathrm{C}++$ to modify and rebuild the DLL code for different modeling scenarios and species lists.

\subsection{Custom Interface Approach Example: Parallel Virtual Machine}

The Parallel Virtual Machine (PVM) is a set of integrated software tools and libraries that emulates a general-purpose computing framework on interconnected computers of varied architectures (Geist et al. 1994). The overall objective of the PVM is to enable a collection of heterogeneous computing 


\section{Review of Mechanistic Understanding and Modeling and Uncertainty Analysis Methods for Predicting Cementitious Barrier Performance}

environments to be used cooperatively for concurrent or parallel computation. The principles on which PVM is based include (Geist et al. 1994): ${ }^{23}$

- User-configured host pool. Computational tasks execute on a set of machines (either single- or multiprocessor) selected by the user for the run. The host pool may be changed at run-time, which is an important feature for fault tolerance.

- Transparent hardware access. Applications may view hardware as an "attributeless" collection of virtual processing elements or may exploit the capabilities of specific machines by positioning selected tasks on appropriate computers.

- Process-based computation. The basic unit of parallelism is a task, which is an independent sequential thread of control alternating between communication and computation.

- Explicit message-passing model. Computational tasks cooperate by explicitly sending messages to and receiving messages from each other.

- Heterogeneity support. PVM permits messages containing multiple datatypes to be exchanged between machines having different data representations.

- Multiprocessor support. PVM uses native message-passing facilities on multiprocessors to take advantage of the underlying hardware.

The PVM system is comprised of two parts: the daemon ${ }^{24}$ and a library of interface routines. The daemon resides on all the computers comprising the virtual machine and performs the basic computational tasks ${ }^{25}$. The library of interface routines contains a functionally complete set of primitives ${ }^{26}$ needed for cooperation among application tasks including those for message passing, creating processes, coordinating tasks, and modifying the virtual machine.

The PVM computing model is based on conceptualizing an application as a series of cooperating tasks (Geist et al. 1994). Each task is responsible for one piece of the application. An application may be parallelized along its functions (i.e., "functional parallelism") where each task performs a different function. More commonly, an application is divided into a set of identical tasks (i.e., "data parallelism" or singleprogram multiple data (SPMD) model) in which each only solves a small part of the data as illustrated in Figure 11. PVM supports any mixture of functional or data parallelism methods. The potential heterogeneity of the computing systems supported by PVM is illustrated in Figure 12.

PVM currently supports the $\mathrm{C}, \mathrm{C}++$, and FORTRAN programming languages to include interfaces for many target applications in the 1990s. The $\mathrm{C}$ and $\mathrm{C}++$ bindings for the PVM user interface library are implemented as functions and those for FORTRAN are implemented as subroutines. All tasks are identified by a unique integer task identifier (TID) from which messages are sent and received. The user writes programs containing embedded calls to the PVM library where each program corresponds to a task making up the application (Geist et al. 1994). To execute an application, the user typically starts one copy of a task from a machine within the host pool, which subsequently initiates other PVM tasks that compute locally and exchange messages with each other using TIDs. Because of the ubiquitous nature of the virtual

\footnotetext{
${ }^{23}$ According to http://www.mcs.anl.gov/research/projects/mpi/ (accessed May 15, 2009), PVM has been displaced by the Message Passing Interface (MPI) for technical computing; however, both are specifications for libraries that can be used for parallel computing. PVM will be used as an example of the approach.

${ }^{24}$ A computer daemon is a program that continuously runs (typically in the background) that triggers actions when it receives specific input.

${ }^{25}$ An example of a daemon is a mail program that runs in the background and handles all the incoming and outgoing electronic mail on a computer (Geist et al. 1994).

${ }^{26}$ Primitives are the most elementary form available in a programming language (e.g., machine instructions, microcode instructions, interpreted statements, etc.).
} 


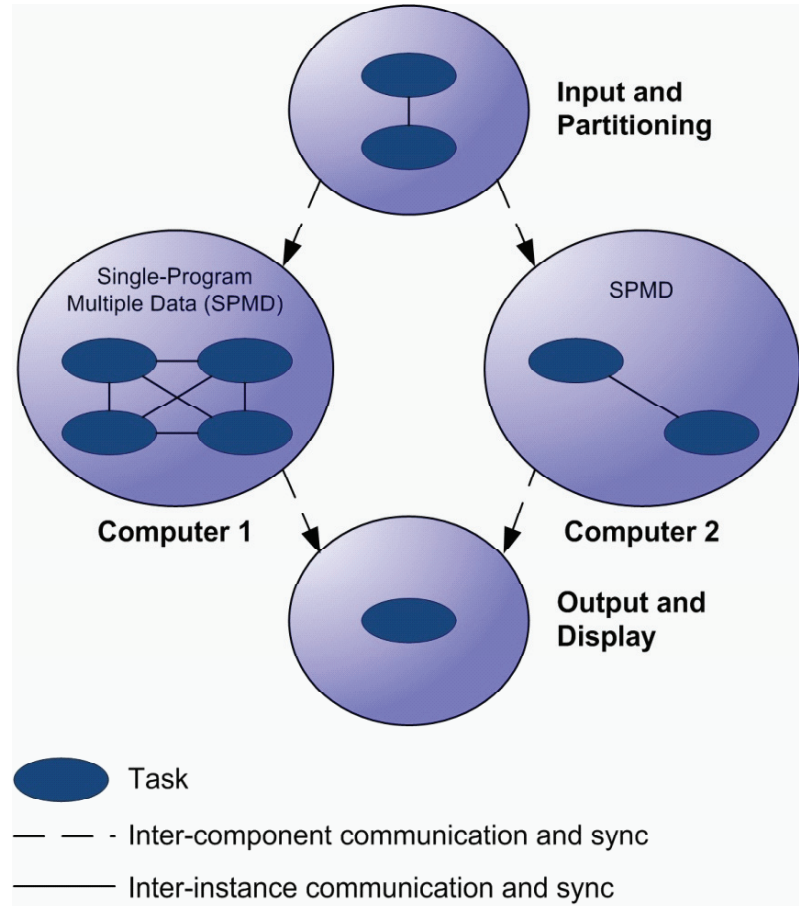

Figure 11. Parallel Virtual Machine Computational Model (Adapted from Geist et al. (1994))

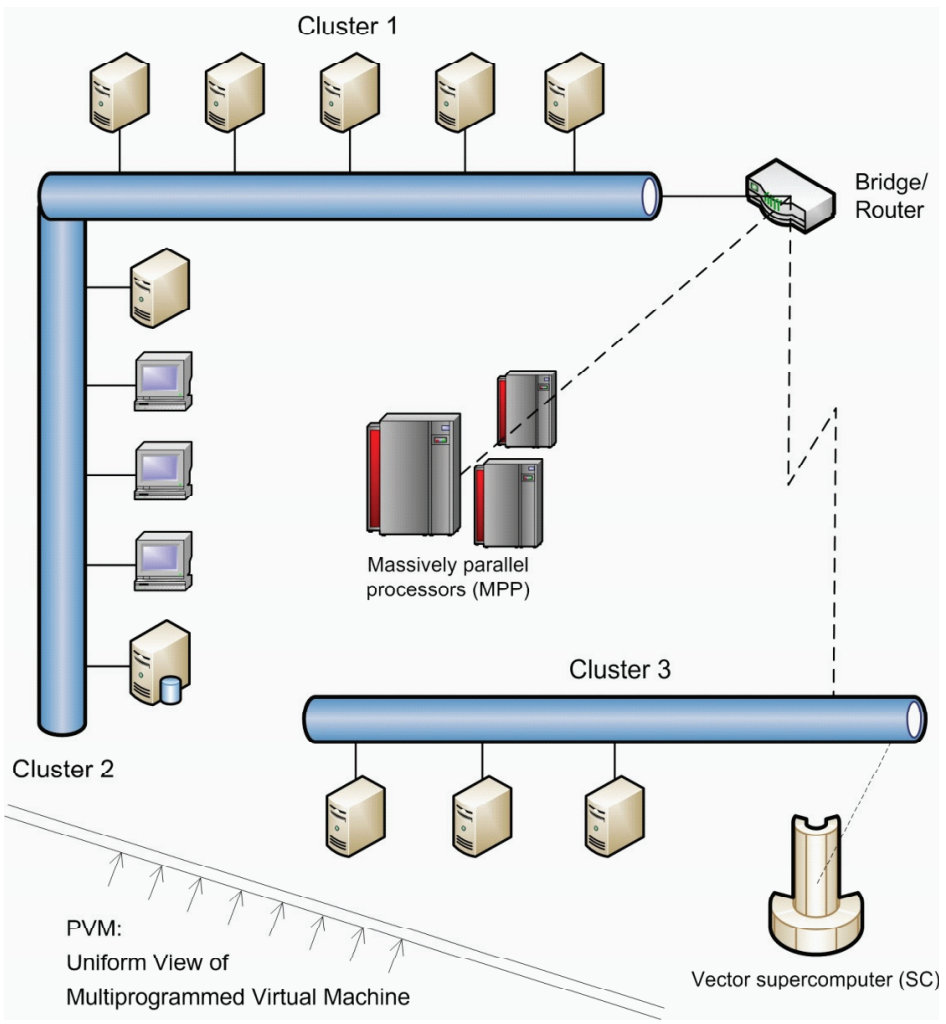

Figure 12. Parallel Virtual Machine Architectural Overview (Adapted from Geist et al. (1994)) 
machine concept and its simple but complete interface, PVM has gained widespread acceptance in highperformance scientific computing (Geist et al. 1994).

\subsection{Other Codes Used for Cementitious Barriers}

Additional examples of modeling cementitous barriers are provided to give a better indication of extent to which these barriers have been historically modeled. These modeling efforts are:

\section{- BARRIER code (Rogers and Associates}

Engineering) - This code represents one of the first attempts at modeling the long-term performance of barriers used in low-level waste (LLW) disposal (Icenhour 1995; Shuman et al. 1988). The code provides radionuclide source term, environmental transport, and dose calculation capabilities. Release mechanisms include constant leach rate, nuclide-specific leaching, advection with partitioning between liquid and solid phases, and diffusion. The concrete degradation mechanisms include sulfate attack, calcium hydroxide leaching, freezethaw cycling, and corrosion of reinforcing metal.

- 4Sight computer code (NIST) - This computer program (developed by the National Institute of Standards and Technology for the NRC) (http:// concrete.nist.gov/4sight/) was designed as a resource for estimating the service life of new underground concrete structures (Snyder \& Clifton 1995). The program uses combined numerical models for ion transport, chemical reaction, and subsequent changes to transport coefficients to model the response of a concrete structure to its environment. 4Sight uses a continuum scale transport/reaction model to predict the dissolution and/ or precipitation of minerals and salts.
- Saltstone Disposal Facility Performance Assessment Model (Nuclear Regulatory Commission) - This model was developed in the GoldSim Monte Carlo software to support NRC review of the Saltstone Disposal Facility (SDF) at the Savannah River Site (Esh, Ridge \& Thaggard 2006). The model is comprised of abstracted models representing those processes likely to drive system performance including degradation of the engineered barrier and oxidation and physical degradation (e.g., sulfate attack or cracking) of the saltstone waste form. The model includes source term and near-field release, saturated zone and surface water transport, and dose assessment.

\subsection{Radiological Performance Assessment for the Z-Area Disposal Facility Using PORFLOW-3D}

The final modeling effort described here is the 1992 performance assessment (PA) model developed for the Z-Area Saltstone Disposal Facility (SDF) at the Savannah River Site (SRS) (Cook \& Fowler 1992). The SDF is a near-surface disposal facility that receives DOE low-activity wastes immobilized in a cementitious waste form denoted saltstone that are contained in a reinforced concrete vault (Cook \& Fowler 1992). The SDF PA requires understanding of the wastes that will be disposed and the environment into which they will be placed over long periods of time. Thus multiple models have been used to predict the performance of the disposal system.

The manner in which models are integrated for the SDF radiological performance assessment is illustrated in Figure 13 and Figure 14 for intact and degraded vaults, respectively. As can be seen in these figures, the PORFLOW-3D code is used as the primary 


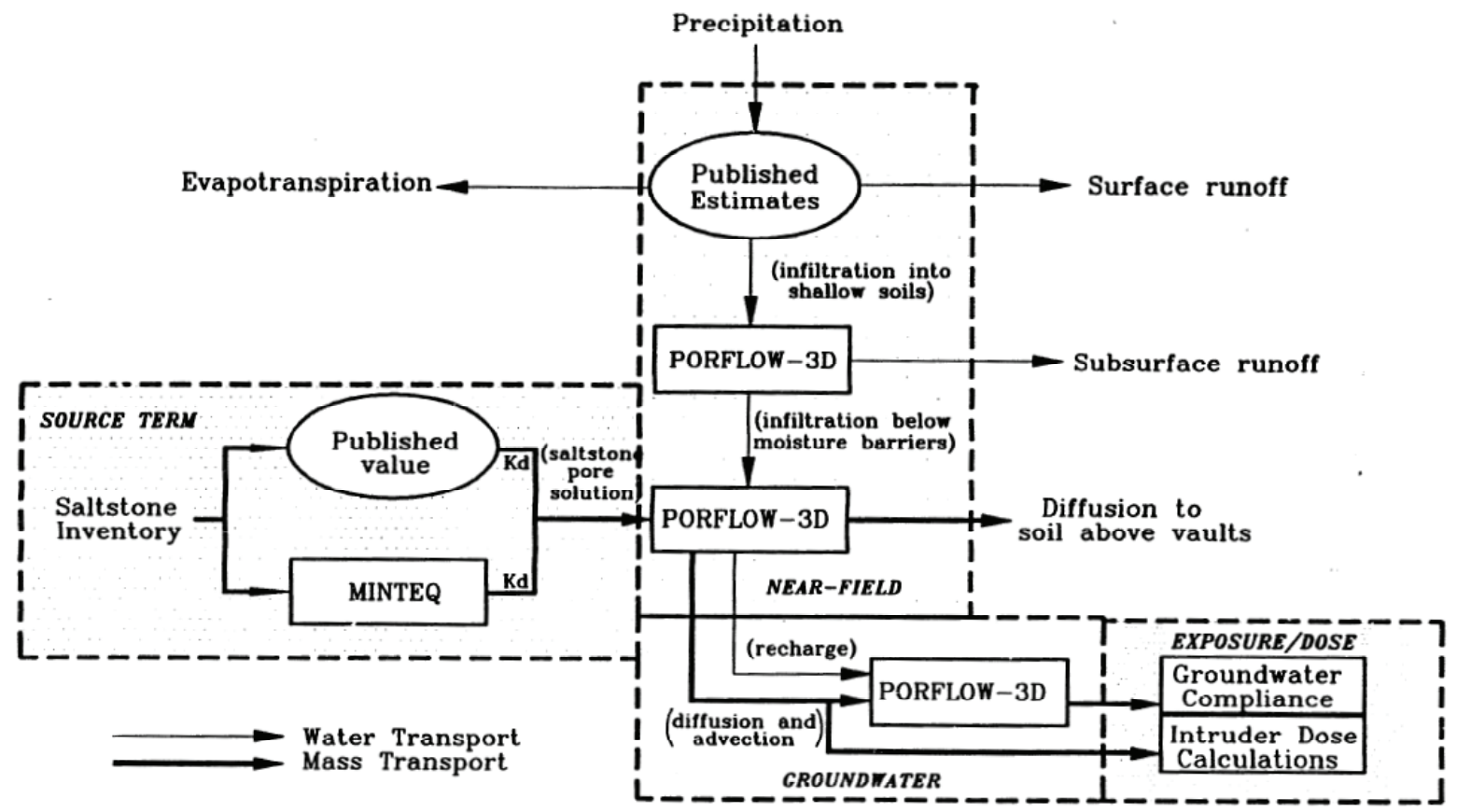

Figure 13. Integration of Computational Methods for the Radiological Performance Assessment of Intact SDF Vaults (Reproduced from Cook and Fowler (1992))

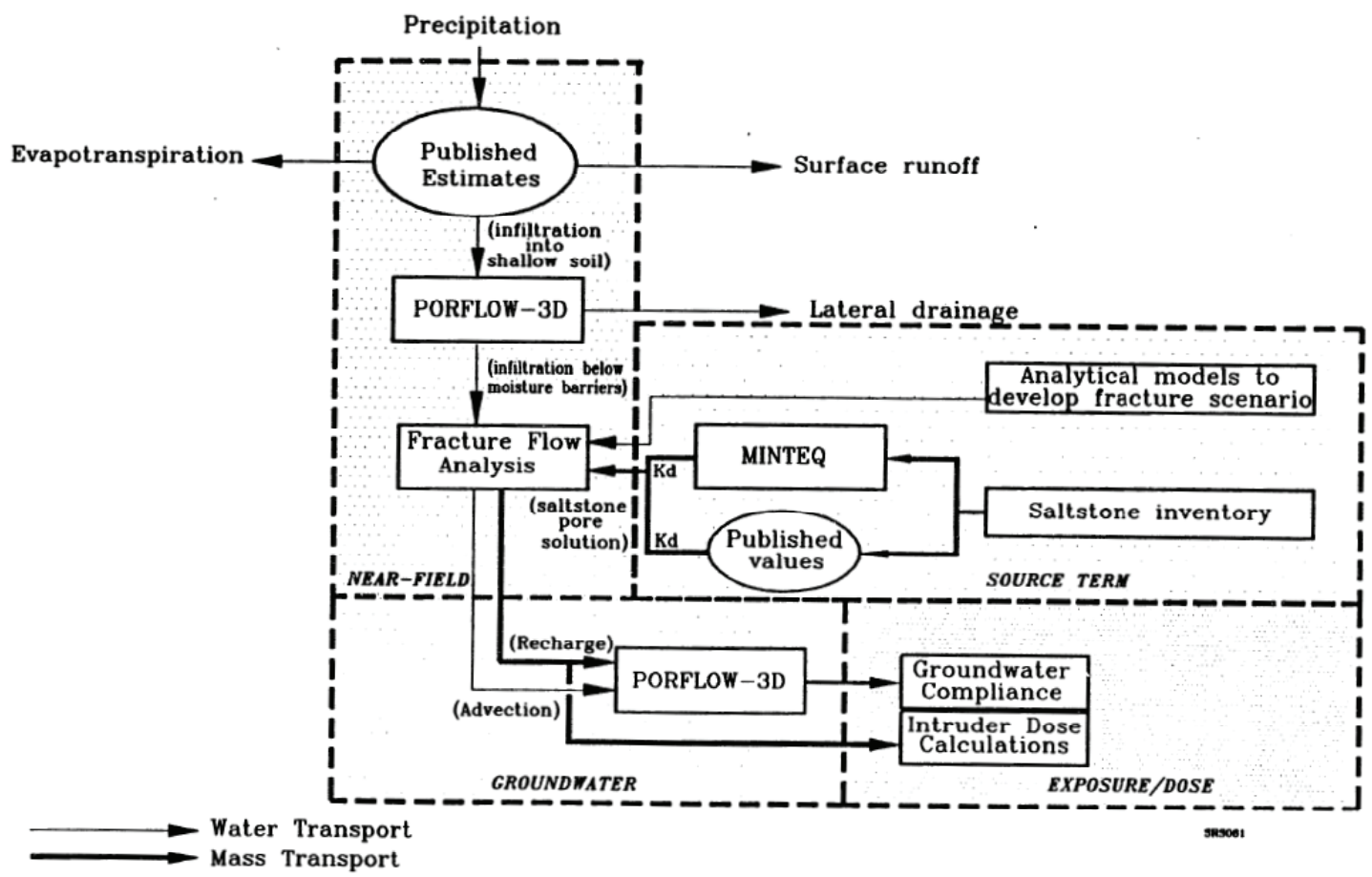

Figure 14. Integration of Computational Methods for the Radiological Performance Assessment of Degraded SDF Vaults (Reproduced from Cook and Fowler (1992)) 


\section{Review of Mechanistic Understanding and Modeling and Uncertainty Analysis Methods for Predicting Cementitious Barrier Performance}

model to estimate the performance of the SDF vault ${ }^{27}$. PORFLOW-3D is a three-dimensional code capable of simulating multi-phase fluid flow in variably saturated porous or fractured media ${ }^{28}$.

The PORFLOW-3D code is used in the near-field region, which is also of primary interest to the $\mathrm{CBP}$. Figure 15 illustrates the interrelationships among the various computations needed to predict the performance of SDF vaults. One use of CBP product tools is to generate the source term results for input to the existing radiological PA model.

\subsection{DISCUSSION}

\subsection{General Integration}

A set of simulation tools to predict the performance of cement barriers can be developed using various approaches and software tools. Four approaches (i.e., monolithic, fidelity, hybrid, and custom interface) with relevant examples were described that potentially could be used to develop the integrated framework for the CBP model although other tools are available. The tools described all have strengths and weaknesses.

DAKOTA is a powerful, object-oriented tool for solving complex iterative problems (e.g., optimization and uncertainty quantification) on high-performance computing platforms. However, when compared to a tool such as FRAMES or the GoldSim Monte Carlo simulator, the DAKOTA software will likely require additional work to develop the solution needed for the CBP problem. For example, the CBP framework solution will require a user-friendly interface because of its intended user base; the needed interface would either have to be developed or an existing one integrated into the framework. There are additional essential components (e.g., source release or environmental media and transport) that are already parts of or available in other models considered (i.e., GoldSim and FRAMES) that would need to be developed or selected and integrated into the framework.

FRAMES is another powerful, object-oriented platform for linking potentially disparate legacy models and databases for conducting assessments to understand how industrial activities might affect humans and the environment. Unlike the DAKOTA program, however, FRAMES does have source release and environmental transport and media component models readily accessible. The source term module included in FRAMES, Multimedia Environmental Pollutant Assessment System (MEPAS), describes contaminated aquifers, ponds, or vadose zones (Streile et al. 1996; Strenge 2001). However, it is conceivable that the models created by the CBP could be integrated into a framework like FRAMES to estimate far-field effects.

Because of the ubiquitous nature of the virtual machine concept and its simple but complete interface, the Parallel Virtual Machine (PVM) has gained widespread acceptance in high-performance scientific computing applications. Currently, only models developed in $\mathrm{C}, \mathrm{C}++$, and FORTRAN can be coupled using the PVM interfaces. It is unlikely that all models selected for use in the CBP framework will be available in these three languages ${ }^{29}$.

\footnotetext{
${ }^{27}$ It may be inferred from the representations in Figure 13 and Figure 14 that these systems are coupled; however, any information exchange or coupling is performed by the users and is not programmed into the systems.

${ }^{28}$ Another example of such a code is the Subsurface Transport Over Multiple Phases (STOMP) code developed by PNNL that calculates the time-dependent thermal flow, moisture flow, and contaminant transport (including aqueous and vapor phases) in variably saturated media (White \& Oostrom 1996; White, Oostrom \& Lenhard 1995). The code can be run in one, two, or three dimensional modes and has been used by the Hanford Groundwater Remediation Project and by the team preparing the Hanford Tank Closure and Waste Management Environmental Impact Statement.

${ }^{29}$ The investigation of models for potential CBP use resulted in the selection of various models including Leach ${ }^{\mathrm{XS}}(\mathrm{C \#})$ and ORCHESTRA (Java) that will not be available in $\mathrm{C}, \mathrm{C}++$, or FORTRAN.
} 


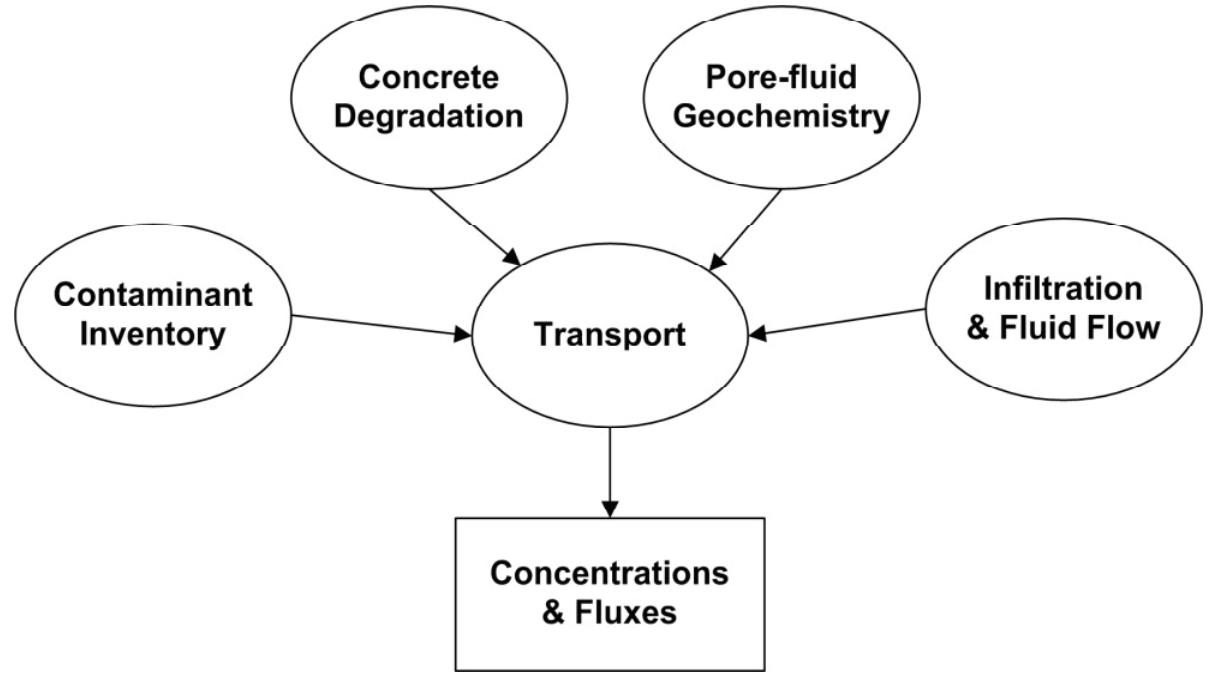

Figure 15. Interrelationships Among Near-field Performance Assessment Computations (Reproduced from Cook and Fowler (1992))

GoldSim possesses a graphical interface as well as built-in source release, environmental transport and media, and sensitivity/uncertainty capabilities. The built-in GoldSim functionality will likely not be sufficient to implement all needed features for the CBP models; however, the external linking capabilities could allow the use of GoldSim as a framework platform.

\subsection{General Uncertainty Discussion}

The results obtained from the CBP integrated model will be used to develop performance assessments for cementitious barriers in nuclear and other pertinent application. These results will include both the fluxes of contaminants from and the critical hydraulic properties of the concrete barrier. However, in performance assessment space, it is not sufficient to only provide predictions of required properties; the uncertainties or sensitivities in the required results are needed to support the performance assessment (PA) process.
There are times when a "deterministic" or pointvalue analysis may be sufficient to answer questions posed by decision-makers during a PA. The pointvalue analysis is typically supplemented by a series of bounding or sensitivity analyses to demonstrate that the actions to be taken will be protective of human health and the environment. However, it is often preferable for complex sites to base decisions on probabilistic performance analyses, and uncertainty quantification analysis becomes critical for these $\operatorname{sites}^{30}$. It appears that the DOE is beginning the process of using probabilistic or hybrid deterministic/ probabilistic approaches more in the performance assessment process.

Of the example integration frameworks described in this chapter, the GoldSim and FRAMES applications provide built-in capabilities for sensitivity and uncertainty analyses. For example, GoldSim provides basic uncertainty analysis capabilities including Monte Carlo, Latin Hypercube, and Importance Sampling methods (GTG 2005c). Correlations between parameters can be introduced into the GoldSim simulation.

\footnotetext{
${ }^{30}$ Uncertainty quantification should be important for either analysis; however, the uncertainties tend to be much more evident in the probabilistic analysis.
} 


\section{Review of Mechanistic Understanding and Modeling and Uncertainty Analysis Methods for Predicting Cementitious Barrier Performance}

If Bayesian methods are required for updating parameter or data uncertainties or if more sophisticated techniques are needed to analyze modeling or other types of uncertainties, then these would be implemented and called as external routines just as with the other integration frameworks examined in this chapter. In contrast, the Parallel Virtual Machine (PVM) provides a basic platform which can support user-defined uncertainty and sensitivity functionality in the same manner as other routines. Extension of the concepts underlying the optimization features in DAKOTA to uncertainty quantification is currently being investigated.

Sensitivity analyses are also needed in the PA process especially during the initial stages of the assessment when the purpose is to identify influential model parameters (that may require detailed or site-specific characterization) and hazardous and radioactive contaminants of potential concern. For example, GoldSim provides two basic sensitivity analysis platforms: tornado charts and X-Y function charts (GTG 2005b) ${ }^{31}$. Both platforms provide graphical representations of the degree to which the selected (dependent) result is sensitive to independent variables. However, both of these methods provide only simple one-parameter-at-a-time-type sensitivity analysis capabilities. DAKOTA also provides sensitivity algorithms. It is likely that more sophisticated and efficient sensitivity methods will be needed for the CBP framework and would be required for any of the frameworks presented in this chapter.

\subsection{CONCLUSIONS}

Understanding the behavior of cementitious barriers is necessary to evaluate and improve designs. These barriers are often the primary control mechanism to prevent or limit radionuclide releases from nuclear facilities. Without an adequate set of tools to estimate future contaminant releases, assessments cannot fully incorporate and consider the effectiveness of cementitious barriers, which, in turn, limits the nature of those radionuclides that may be disposed of in shallow land disposal. Simulation tools will be needed to predict 1) the hydraulic properties, 2) the stabilities of the relevant cement matrix phases, and 3) the release fluxes of contaminants in response to variable boundary conditions and system stresses over relevant time periods.

The framework conceptualized to provide the set of simulation tools to estimate future performance of cement barriers can be provided by a number of different software tools. Different approaches were described with examples to illustrate the various types of systems that could potentially be used for the CBP application. These approaches ranged from a monolithic structure to hybrid systems to a custom message passing interface. The integration approaches had strengths and weaknesses depending on the models selected and the nature and extent of interactions among the selected models. To leverage off legacy systems to the extent possible, the expected approach for the CBP will be a hybrid, modular approach with weak coupling among the subsystem based on the stability of the overall integrated system.

The outputs from the CBP tools will be used to develop performance assessments for cementitious barriers in nuclear and other pertinent applications. These results will most likely include both the fluxes of contaminants from and the important hydraulic properties of the concrete barrier. However, for performance assessments, it is not sufficient to only provide predictions of these properties; the uncertainties or sensitivities in these parameters will be needed to support the performance assessment process. It is

\footnotetext{
${ }^{31}$ To develop the tornado chart, independent variables other than that selected are held at their "deterministic" values and three simulations are executed at the central value and lower and upper bounds (GTG 2005b). To define the X-Y chart, GoldSim performs a series of simulations varying one independent variable at a time through its range of values; it is often thus more computationally intensive than the tornado chart.
} 
Review of Mechanistic Understanding and Modeling and Uncertainty Analysis

Methods for Predicting Cementitious Barrier Performance

likely that more sophisticated and efficient sensitivity and uncertainty methods than available in the plat-

forms examined in this chapter will be needed for the CBP simulation tools. 


\subsection{REFERENCES}

ASME 2000, Quality Assurance Requirements for Nuclear Facility Applications, Standard No. NQA1-2000, American Society of Mechanical Engineers, New York.

Brown, KG 2008, Life-Cycle Risk Analysis for Department of Energy (DOE) Buried Wastes, Ph.D. Dissertation, Vanderbilt University, Nashville, TN.

Brown, KG, Switzer, C, Kosson, DS, Clarke, JH, Parker, FL, Powers, CW, Mayer, HJ \& Greenberg, M 2005, 'Preliminary Risk Evaluation of Options for Buried Waste Disposition at the Idaho Site', available at www.cresp.org. [October 1, 2008].

Burmaster, DE 1997, 'Computations Illustrating Variability and Uncertainty', available at www.alceon. com. [October 1, 2008].

Clement, TP \& Jones, NL 1998, RT3D Tutorials for GMS Users, PNNL-11805, Pacific Northwest National Laboratory, Richland, Washington.

Cole, RK 2002, 'Coupling of MELCOR to Other Codes under an Executive Program using PVM Message Exchange (Report Number SAND20022440C)', 2002 RELAP5 Users Seminar. Available from: MELCOR Technical Library: <http://melcor. sandia.gov/techlibrary.html $>$ [October 1, 2008].

Cook, JR \& Fowler, JR 1992, Radiological performance assessment for the Z-Area Saltstone Disposal Facility, Report No. WSRC-RP-92-1360, Westinghouse Savannah River Company, Aiken, SC.

Cullen, AC \& Frey, HC 1999, Probabilistic

Techniques in Exposure Assessment: A Handbook for Dealing With Variability and Uncertainty in Models and Inputs, Plenum Publishing Corporation, New York.
Eary, T 2007, 'Example 3: Direct Linkage between GoldSim and PHREEQC through a 'DLL" Element', available at www.goldsim.com. [July 2007].

Eldred, MS, Giunta, AA, Brown, SL, Adams, BM, Dunlavy, DM, Eddy, JP, Gay, DM, Griffin, JD, Hart, WE, Hough, PD, Kolda, TG, Martinez-Canales, ML, Swiler, LP, Watson, J-P \& Williams, PJ 2006a, DAKOTA, A Multilevel Parallel Object-Oriented Framework for Design Optimization, Parameter Estimation, Uncertainty Quantification, and Sensitivity Analysis: Version 4.0 Developers Manual, Report No. SAND2006-4056, Sandia National Laboratories, Albuquerque, New Mexico.

Eldred, MS, Giunta, AA, Brown, SL, Adams, BM, Dunlavy, DM, Eddy, JP, Gay, DM, Griffin, JD, Hart, WE, Hough, PD, Kolda, TG, Martinez-Canales, ML, Swiler, LP, Watson, J-P \& Williams, PJ 2006b, DAKOTA, A Multilevel Parallel Object-Oriented Framework for Design Optimization, Parameter Estimation, Uncertainty Quantification, and Sensitivity Analysis: Version 4.0 Reference Manual, Report No. SAND2006-4055, Sandia National Laboratories, Albuquerque, New Mexico.

Eldred, MS, Giunta, AA, Brown, SL, Adams, BM, Dunlavy, DM, Eddy, JP, Gay, DM, Griffin, JD, Hart, WE, Hough, PD, Kolda, TG, MartinezCanales, ML, Swiler, LP, Watson, J-P \& Williams, PJ 2006c, DAKOTA, A Multilevel Parallel ObjectOriented Framework for Design Optimization, Parameter Estimation, Uncertainty Quantification, and Sensitivity Analysis: Version 4.0 User's Manual, Report No. SAND2006-6337, Sandia National Laboratories, Albuquerque, New Mexico.

Esh, DW, Ridge, AC \& Thaggard, M 2006, 'Development of Risk Insights for Regulatory Review of a Near-surface Disposal Facility for Radioactive Waste', in Proceedings of 2006 Waste Management Symposium (WM'06), WMSymposia, Tucson, Arizona, p. 16 pp. Available from: http://www. wmsym.org/abstracts/2006/prof6199.html. 
Field Jr., RV 2005, A decision-theoretic method for surrogate model selection, Report No. SAND20053223, Sandia National Laboratories, Albuquerque, NM.

Frey, HC 1998, 'Quantitative Analysis of Uncertainty and Variability in Environmental Policy Making', in Uncertainty Modeling and Analysis in Civil Engineering, ed. BM Ayyub, CRC Press, Boca Raton, FL, pp. 381-423.

Frey, HC \& Bharvirkar, R 2002, 'Quantification of Variability and Uncertainty: Case Study of Power Plant Hazardous Air Pollutant Emissions', in Human and Ecological Risk Assessment: Theory and Practice, 1st edn, vol. 1, Wiley Interscience, New York, pp. 587-618.

Frey, HC \& Rhodes, DS 1998, 'Characterization and Simulation of Uncertain Frequency Distributions: Effects of Distribution Choice, Variability, Uncertainty, and Parameter Dependence', Human and Ecological Risk Assessment, vol. 4, no. 2, pp. 423469.

Geist, A, Beguelin, A, Dongarra, J, Jiang, W, Manchek, R \& Sunderam, V 1994, PVM: Parallel Virtual Machine; A Users' Guide and Tutorial for Networked Parallel Computing, The Massachusetts Institute of Technology Press, Cambridge, MA.

GTG 2005a, GoldSim Contaminant Transport Module User's Guide [includes Radionuclide Transport Module Description], Version 3.0 (May 2005), GoldSim Technology Group, Issaquah, WA USA.

GTG 2005b, GoldSim User's Guide: Probabilistic Simulation Environment (Volume 1 of 2), Version 9.0 (May 2005), GoldSim Technology Group, Issaquah, WA.
GTG 2005c, GoldSim User's Guide: Probabilistic Simulation Environment (Volume 2 of 2), Version 9.0 (May 2005), GoldSim Technology Group, Issaquah, WA.

GTG 2007, GoldSim Distributed Processing Module, Version 9.60 (March 2007), GoldSim Technology Group, Issaquah, WA.

Haldar, A \& Mahadevan, S 2000, Probability, Reliability, and Statistical Methods in Engineering Design, John Wiley \& Sons, Inc., New York.

Hattis, D \& Burmaster, DE 1994, 'Assessment of Variability and Uncertainty Distributions for Practical Risk Analyses', Risk Analysis, vol. 14, no. 5, pp. 713730 .

Hoffman, FO \& Hammonds, JS 1994, 'Propagation of Uncertainty in Risk Assessments: The Need to Distinguish Between Uncertainty Due to Lack of Knowledge and Uncertainty Due to Variability', Risk Analysis, vol. 14, no. 5, pp. 707-712.

Hope, BK 2000, 'Generating Probabilistic SpatiallyExplicit Individual and Population Exposure Estimates for Ecological Risk Assessments', Risk Analysis: An International Journal, vol. 20, no. 5, pp. 573-590.

Hope, BK 2001, 'A Case Study Comparing Static and Spatially Explicit Ecological Exposure Analysis Methods', Risk Analysis: An International Journal, vol. 21, no. 6, pp. 1001-1010.

Icenhour, AS 1995, Analysis of Source Term Modeling for Low-Level Radioactive Waste Performance Assessments, Report No. ORNL/TM12908, Oak Ridge National Laboratory, Oak Ridge, Tennessee. 
King, D 2005, Parting Software and Program Design, Ph.D. Dissertation, University of York, Helsington, York, UK.

Lee, K 1994, 'X Application Software Engineering: The Benefits of Modular X Software', The X Journal, September 1994.

Long, AE, Henderson, GD \& Montgomery, FR 2001, 'Why assess the properties of near-surface concrete?', Construction and Building Materials, vol. 15, no. 1, pp. 65-79.

Matthies, HG, Niekamp, R \& Steindorf, J 2006, 'Algorithms for strong coupling procedures', Computer Methods in Applied Mechanics and Engineering, vol. 195, no. 17-18, pp. 2028-2049.

Mattie, PD, Knowlton, RG \& Arnold, BW 2007, A User's Guide to the GoldSim/BLT-MS Integrated Software Package: A Low-Level Radioactive Waste Disposal Performance Assessment Model, Report No. SAND2007-1354, Sandia National Laboratories, Albuquerque, New Mexico.

OpenMI 2007, Scope for the OpenMI. Part A of the OpenMI Document Series, The OpenMI Association.

Page-Jones, M 1980, The practical guide to structured systems design, Yourdon Press, New York.

Parkhurst, DL \& Appelo, CAJ 1999, User's Guide to PHREEQC (Version 2)--A Computer Program for Speciation, Batch-Reaction, One-Dimensional Transport, and Inverse Geochemical Calculations, USGS Water-Resources Investigations Report 994259, U.S. Geological Survey, Reston, Virginia.

Pretorius, J 2001, Volume Prediction for Concrete Repair, Dissertation for Doctor Ingeneriae, Rand Afrikaans University.
Qian, Z, Seepersad, CC, Joseph, VR, Allen, JK \& Wu, CFJ 2006, 'Building Surrogate Models Based on Detailed and Approximate Simulations', Journal of Mechanical Design, vol. 128, no. 4, pp. 668-677.

Seitz, R \& Walton, JC 1993, Modeling Approaches for Concrete Barriers Used in Low-Level Waste Disposal Report No. NUREG/CR-6070 (EGG-2701), Idaho National Engineering Laboratory, Idaho Falls, Idaho.

Shorter, C \& Adair, M 2008, 'mapbuilder-lib Software Design Description', October 1, 2008. [October 1, 2008].

Shuman, R, Rogers, VC, Chau, N, Merrell, GB \& Rogers, V 1988, Performance assessment for low-level waste disposal facilities: Interim report, Report No. EPRI-NP-5745M, Electric Power Research Institute, Palo Alto, CA.

Snyder, KA \& Clifton, JR 1995, 4sight Manual: A computer program for modeling degradation of underground low level waste concrete vaults, Report No. NISTIR 5612, National Institute of Standards and Technology, Gaithersburg, Maryland.

Stevens, WP, Myers, GJ \& Constantine, LL 1974, 'Structured design', IBM Systems Journal, vol. 13, no. 2, pp. 115-139.

Streile, GP, Shields, KD, Stroh, JL, Bagaasen, LM, Whelan, G, McDonald, JP, Droppo, JG \& Buck, JW 1996, The Multimedia Environmental Pollutant Assessment System (MEPAS)®: Source-term release formulations, Report No. PNNL-11248, Pacific Northwest Laboratory, Richland, Washington.

Strenge, D 2001, Requirements for the MEPAS ${ }^{\circledR}$ Chronic Exposure Module Report No. PNNLSA-32274, Pacific Northwest National Laboratory, Richland, Washington. 
Sullivan, TM 2001, DUST-MS (Disposal Unit Source Term - Multiple Species): Data Input Guide, Brookhaven National Laboratory, Upton, NY.

Sullivan, TM, MacKinnon, RJ, Kinsey, RR, Aronson, A \& Divadeenam, M 1996, BLT-MS (Breach, Leach, and Transport -- Multiple Species) data input guide. A computer model for simulating release of contaminants from a subsurface low-level waste disposal facility, Report No. NUREG/CR-6492 (BNLNUREG-52509), Brookhaven National Laboratory, Upton, NY.

Switzer, C, Brown, KG, Kosson, DS, Clarke, JH, Parker, FL, Powers, CW, Mayer, HJ \& Greenberg, M 2005, 'Preliminary Risk Evaluation of Calcined HighLevel Waste Disposition at the Idaho Site', October 1, 2008, p. 256 [October 1, 2008].

Tuchschmid, S, Grassi, M, Bachofen, D, Fruh, P, Thaler, M, Szekely, G \& Harders, M 2006, 'A Flexible Framework for Highly-Modular Surgical Simulation Systems', in Biomedical Simulation, vol. 4072/2006, Springer Berlin, Heidelberg, Germany, pp. 84-92.

USEPA 2001, Risk Assessment Guidance for Superfund: Volume III - Part A, Process for Conducting Probabilistic Risk Assessment, EPA Report No. 540-R-02-002, U.S. Environmental Protection Agency, Washington, DC.

Walton, JC 1992, Performance of Intact and Partially Barriers Degraded Concrete in Limiting Mass Transport, Report No. NUREG/CR-5445, Idaho National Engineering Laboratory, Idaho Falls, Idaho.

Weaver, WL, Tomlinson, ET \& Aumiller, DL 2000, 'A generic semi-implicit coupling methodology for use in RELAP5-3D(C), Report Number B-T-3321', in 2000 RELAP5 Users Seminar, September 12-14, 2000, Jackson Hole, Wyoming. Available from: / servlets/purl/774250-MqhK2O/webviewable/.
Weaver, WL, Tomlinson, ET \& Aumiller, DL 2001, 'An Executive Program For Use With RELAP53D(C), Report Number B-T-3394', in Proceedings of 2001 RELAP5 Users Seminar, Sun Valley, Idaho. Available from: http://www.osti.gov/servlets/ purl/835065-eGlusF/webviewable/.

Whelan, G \& Castleton, KJ 2006a, Examining the Linkage Between FRAMES and GMS, Report No. PNNL-15653, Pacific Northwest National Laboratory, Richland, Washington.

Whelan, G \& Castleton, KJ 2006b, Groundwater Modeling System Linkage with the Framework for Risk Analysis in Multimedia Environmental Systems, Report No. PNNL-15654, Pacific Northwest National Laboratory, Richland, Washington.

Whelan, G, Pelton, MA, Castleton, KJ, Strenge, DL, Buck, JW, Gelston, GM, Hoopes, BL \& Kickert, RN 1997, Concepts of a Framework for Risk Analysis In Multimedia Environmental Systems, Report No. PNNL-11748, Pacific Northwest National Laboratory, Richland, Washington.

White, MD \& Oostrom, M 1996, STOMP, Subsurface Transport Over Multiple Phases, theory guide, Report No. PNNL-11217, Pacific Northwest National Laboratory, Richland, WA.

White, MD, Oostrom, M \& Lenhard, RJ 1995, 'Modeling fluid flow and transport in variably saturated porous media with the STOMP simulator. 1. Nonvolatile three-phase model description', Advances in Water Resources, vol. 18, no. 6, pp. 353-364. 


\title{
UNCERTAINTY ANALYSIS METHODS
}

\author{
Sankaran Mahadevan \\ Email: sankaran.mahadevan@vanderbilt.edu \\ Vanderbilt University, School of Engineering \\ Consortium for Risk Evaluation with Stakeholders Participation, III \\ Nashville, TN 37235 \\ and \\ Sohini Sarkar \\ Email: sohini.sarkar@vanderbilt.edu \\ Vanderbilt University, School of Engineering \\ Consortium for Risk Evaluation with Stakeholders Participation, III \\ Nashville, TN 37235
}


Review of Mechanistic Understanding and Modeling and Uncertainty Analysis Methods for Predicting Cementitious Barrier Performance 


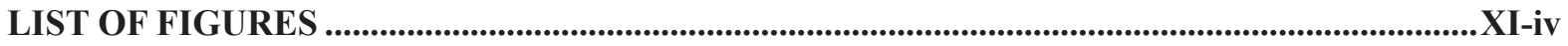

LIST OF ABBREVIATIONS AND ACRONYMS .......................................................................

LIST OF NOMENCLATURE ..................................................................................................................

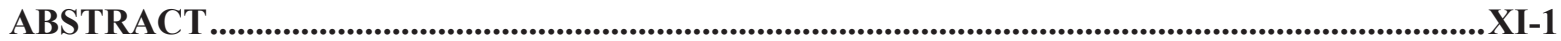

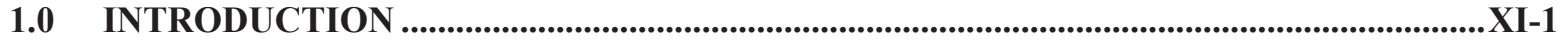

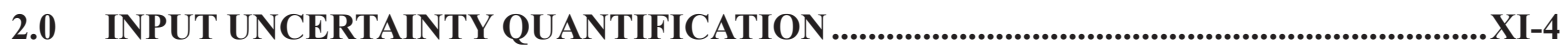

2.1 Physical Variability ............................................................................................................................ XI-4

2.1.1 Modeling Variability in System Properties...................................................................... XI-5

2.1.2 Modeling Variability in External Conditions.................................................................

2.1.3 Stationary External Processes............................................................................... XI-6

2.1.4 Non-Stationary External Processes ................................................................................

2.2 Data Uncertainty............................................................................................................................... XI-7

2.2.1 Sparse Statistical Data ...........................................................................................

2.2.2 Measurement Error .................................................................................................. XI

2.2.3 Data Available in Interval Format …….................................................................... XI-8

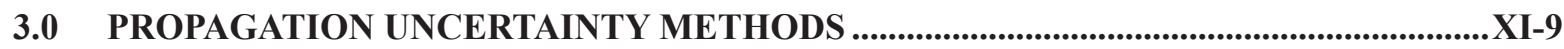

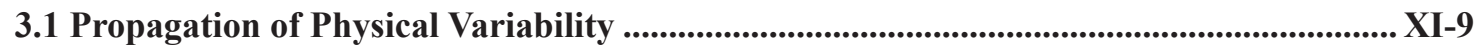

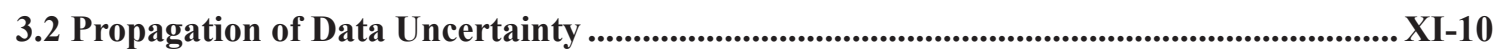

3.3 Surrogate Models....................................................................................................................................... XI-11

3.3.1 Stochastic Response Surface Method.......................................................................... XI-11

3.3.2 Kriging or Gaussian Process Models ......................................................................... XI-12

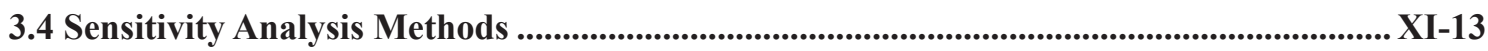

3.5 Multi-Physics Models ............................................................................................................................. XI-13

3.6 Model Error Quantification ................................................................................................................... XI-14

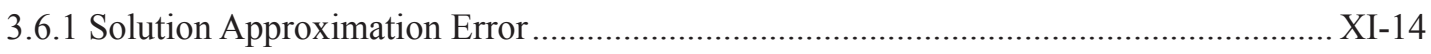

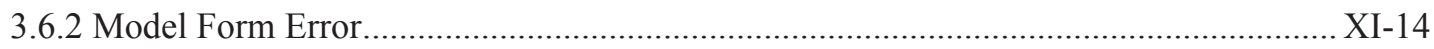

4.0 MODEL CALIBRATION, VALIDATION AND EXTRAPOLATION ....................................XI-15

4.1 Model Calibration....................................................................................................................... XI-15

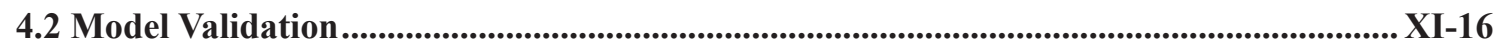

4.3 Confidence Assessment in Extrapolation....................................................................................... XI-17

5.0 PROBABILISTIC PERFORMANCE ASSESSMENT ........................................................

5.1 Individual Criteria ................................................................................................................................... XI-18

5.2 Multiple Criteria........................................................................................................................................... XI-19 
CONTENTS (contd)

Page No.

6.0 CONCLUSION XI-20

7.0 REFERENCES $. \mathrm{XI}-22$

\section{LIST OF FIGURES}

Figure 1. Uncertainty Quantification, Propagation and Management Framework .................................. XI-4

Figure 2. Precipitation Data for Aiken, SC (National Oceanic and Atmospheric Administration)......... XI-6

Figure 3. Example of Physical Variability Propagation.............................................................................. XI-10

Figure 4. Gaussian Process Model With Uncertainty Bounds............................................................... XI-12

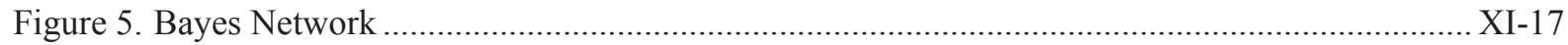

Figure 6. First-order Reliability Method …………............................................................................. 


\section{LIST OF ABBREVIATIONS AND ACRONYMS}

$\begin{array}{ll}\text { ARIMA } & \text { Autoregressive Integrated Moving Average } \\ \text { CDF } & \text { Cumulative Distribution Function } \\ \text { FORM } & \text { First-order Reliability Method } \\ \text { GP } & \text { Gaussian Process } \\ \text { IID } & \text { Independent and Identically Distributed } \\ \text { KLE } & \text { Karhunen-Loeve Expansion } \\ \text { LHS } & \text { Latin Hypercube Sampling } \\ \text { MCMC } & \text { Markov Chain Monte Carlo } \\ \text { MPP } & \text { Most Probable Point } \\ \text { PA } & \text { Performance Assessment } \\ \text { PCE } & \text { Polynomial Chaos Expansion } \\ \text { PDF } & \text { Probability Density Function } \\ \text { RE } & \text { Richardson Extrapolation } \\ \text { SRSM } & \text { Stochastic Response Surface Method } \\ \text { SRV } & \text { Standard Random Variable } \\ \text { S-N } & \text { Stress vs. Number of Cycles } \\ \text { SORM } & \text { Second-order Reliability Method } \\ \text { V\&V } & \text { Verification and Validation }\end{array}$




\section{LIST OF NOMENCLATURE}

\begin{tabular}{|c|c|}
\hline B & Vector of Reliability Indices \\
\hline$B$ & Bayes Factor \\
\hline$B^{i}$ & Backward Operator of Order $i$ \\
\hline $\mathrm{C}\left(\chi_{1}, \chi_{2}\right)$ & Covariance Function of a Random Process \\
\hline $\mathrm{N}\left(\mu \sigma^{2}\right)$ & Gaussian Distribution With Mean $\mu$ and Variance $\sigma^{2}$ \\
\hline$P\left(H_{o}\right), P\left(H_{o}\right)$ & Prior Probabilities of Null and Alternative Hypotheses \\
\hline$P\left(H_{o} \mid D\right), P\left(H_{l} \mid D\right)$ & Probabilities of $H_{0}$ and $H_{a}$ Given Observed Data $D$ \\
\hline$P\left(D \mid H_{o}\right), P\left(D \mid H_{p}\right)$ & Probabilities of Observing Data $D$ Given $H_{0}$ and $H_{a}$ \\
\hline$P_{f} \quad r-r$ & Probability of Failure \\
\hline R & Correlation Matrix \\
\hline $\mathbf{X}$ & Vector of Input Random Variables \\
\hline$c, c_{1}$ & Constants \\
\hline$f_{i}(x)$ & Eigenfunctions of $\mathrm{C}\left(x_{1}, x_{2}\right)$ \\
\hline$f_{x}(x)$ & Joint Probability Density Function of $\boldsymbol{X}$ \\
\hline $\mathbf{g}(\mathbf{X})$ & Model Output \\
\hline$k$ & Regulatory Requirement \\
\hline$y_{\exp }$ & Experimental Observation \\
\hline$y_{\text {true }}$ & True Value of the Parameter \\
\hline$z_{t} z_{t-i}$ & Observations at $t^{\text {th }}$ and $(t-i)^{\text {th }}$ Time Steps \\
\hline$\nabla^{p^{\mathrm{d}},-i}, \nabla^{\mathrm{D}}$ & Backward Difference Operators of Degree $d$ and $D$ \\
\hline$\Phi(\mathbf{B}, \mathbf{R})$ & Standard Normal Multivariate CDF \\
\hline$\Phi_{\mathrm{p}}()$ & Polynomial of Order $P$ \\
\hline$\Theta_{0}^{p}()$ & Polynomial of Order $Q$ \\
\hline$\alpha^{Q}$ & Unit Gradient Vector of the Limit State in Standard Normal Space \\
\hline$\beta$ & Reliability Index \\
\hline$\varepsilon_{\mathrm{d}}$ & Discretization Error \\
\hline$\varepsilon_{\text {exp }}$ & Measurement Error \\
\hline$\varepsilon_{\mathrm{h}}$ & Input Parameter Error \\
\hline$\varepsilon_{\text {model }}^{\mathrm{n}}$ & Model Form Error \\
\hline$\varepsilon_{\text {num }}^{\text {model }}$ & Numerical Solution Error \\
\hline$\varepsilon_{\text {obs }}$ & Overall Prediction Error \\
\hline$\varepsilon_{\mathrm{s}}$ & Stochastic Analysis Error \\
\hline$\varepsilon_{\mathrm{t}}^{\mathrm{s}}$ & Error at $t^{\text {th }}$ Time Step \\
\hline$\varepsilon_{t-\mathrm{i}}$ & Error at $(t-i)^{t h}$ Time Step \\
\hline$\eta$ & Vector of Random Variables in Uncorrelated Standard Normal Space \\
\hline$\lambda_{\mathrm{i}}$ & Eigenvalues of $\mathrm{C}\left(x_{1}, x_{2}\right)$ \\
\hline$\varnothing_{1}$ & Coefficients of ARIMA Model \\
\hline$\emptyset_{p}^{1}()$ & Polynomial of Order $p$ \\
\hline$\theta_{i}$ & Coefficients of ARIMA Error Model \\
\hline$\theta_{q}^{1}()$ & Polynomial of Order $p$ \\
\hline$\varpi(x, \chi)$ & Random Process Dependent on Spatial Coordinate $x$ and an Event $\chi$ \\
\hline$\varpi(x)$ & Mean of the Random Process $\varpi(x, \chi)$ \\
\hline$\xi_{1}$ & Sets of Uncorrelated Standard Normal Random Variables \\
\hline
\end{tabular}




\title{
UNCERTAINTY ANALYSIS METHODS
}

\author{
Sankaran Mahadevan \\ Sohini Sarkar \\ Vanderbilt University, School of Engineering \\ Consortium for Risk Evaluation with Stakeholders Participation, III \\ Nashville, TN 37235
}

\section{ABSTRACT}

This report surveys available analysis techniques to quantify the uncertainty in performance assessment (PA) arising from various sources. Three sources of uncertainty - physical variability, data uncertainty, and model error - are considered. The uncertainty quantification methods are described in the context of four types of analyses needed, namely, (1) quantification of uncertainty in the inputs to the PA models, (2) propagation of input uncertainty through the PA models, (3) model error quantified through verification and validation activities, and (4) probabilistic PA. Random variable and random process descriptions of physical variability are outlined. Methods for handling data uncertainty through flexible families of probability distributions, confidence bounds, interval analysis and Bayesian analysis are described. Useful surrogate modeling and sensitivity analysis techniques for efficient uncertainty propagation analysis are discussed, as well as methods to quantify the various sources of model error. Statistical hypothesis testing techniques (both classical and Bayesian) are discussed for the validation of PA models, and a Bayesian approach to quantify the confidence in model prediction with respect to field conditions is developed. First-order approximations as well as efficient Monte Carlo sampling techniques for probabilistic PA are described.

\subsection{INTRODUCTION}

Uncertainty quantification is important in assessing and predicting performance of complex engineering systems, especially in the absence of adequate experimental or real-world data. Simulation of complex physical systems involves multiple levels of modeling ranging from the material to component to subsystem to system. Interacting models and simulation codes from multiple disciplines (multiple physics) may be required, with iterative analyses between some of the codes. As the models are integrated across multiple disciplines and levels, the problem becomes more complex and assessing the predictive capability of the overall system model becomes more difficult. Many factors contribute to the uncertainty in the prediction of the system model including: variability in model input variables, modeling errors, assumptions and approximations, measurement errors, and sparse and imprecise data.

The overall goal of this report is to discuss possible methods and tools for quantifying uncertainty. Sources of uncertainty are listed below:

- Physical variability

- Data uncertainty

- Model error

Physical variability: This type of uncertainty, also referred to as aleatory or irreducible uncertainty, arises from natural or inherent random variability of physical processes and variables, due to many factors such as environmental and operational variations, 
construction processes, and quality control. This type of uncertainty is present both in system properties (e.g., material strength, porosity, diffusivity, geometry variations, reaction rates) and external influences and demands on the system (e.g., concentration of chemicals, temperature, humidity, mechanical loads). As a result, in model-based prediction of system behavior, there is uncertainty regarding the precise values for model parameters and model inputs, leading to uncertainty about the precise values of the model output. Such quantities are represented in engineering analysis as random variables, with statistical parameters such as mean values, standard deviations, and distribution types estimated from observed data or in some cases assumed. Variations over space or time are modeled as random processes.

Data uncertainty: This type of uncertainty falls under the category of epistemic uncertainty (i.e., knowledge or information uncertainty) or reducible uncertainty (i.e., the uncertainty is reduced as more information is obtained). Data uncertainty occurs in different forms. In the case of a quantity treated as a random variable, the accuracy of the statistical distribution parameters depends on the amount of data available. If the data is sparse, the distribution parameters themselves are uncertain and may need to be treated as random variables. On the other hand, information may be imprecise or qualitative, and it is not easy to treat this type of uncertainty through random variables. In some cases, data regarding some variables may only be available as a range of values, based on expert opinion. Non-probabilistic representations such as fuzzy sets and evidence theory are available for describing such uncertainties. Measurement error (either in the laboratory or in the field) is another important source of data uncertainty.

Model error: This results from approximate mathematical models of the system behavior and from numerical approximations during the computational process, resulting in two types of error in general solution approximation error, and model form error.
The performance assessment (PA) of a complex system involves the use of numerous analysis models, each with its own assumptions and approximations. The errors from the various analysis components combine in a complicated manner to produce the overall model error. This is also referred to as model bias.

The roles of several types of uncertainty in the use of model-based simulation for performance assessment can be easily illustrated with the following example. Consider the probability of an undesirable event denoted by $g(\mathbf{X})<k$, which can be computed from

$$
P(g(\mathbf{X})<k)=\int_{g(\mathbf{X})<k} f_{\mathbf{X}}(\mathbf{x}) d \mathbf{x}
$$

where:

$\mathbf{X}$ is the vector of input random variables, $f_{\mathbf{x}}(\mathbf{x})$ is the joint probability density function of $\mathbf{X}, \mathrm{g}(\mathbf{X})$ is the model output, and $k$ is the regulatory requirement in performance assessment.

Every term on the right hand side of Equation (1) has uncertainty. There is inherent variability represented by the vector of random variables $\mathbf{X}$, data uncertainty (due to inadequate data) regarding the distribution type and distribution parameters of $f_{\mathbf{x}}(\mathbf{x})$, and model errors in the computation of $\mathrm{g}(\mathbf{X})$. Thus it is necessary to systematically identify the various sources of uncertainty and develop the framework for including them in the overall PA uncertainty quantification.

The uncertainty analysis methods covered in this report are grouped along four major steps of analysis that are needed for probabilistic PA:

- Input uncertainty quantification

- Uncertainty propagation analysis

- Model uncertainty quantification (calibration, verification, validation, and extrapolation)

- Probabilistic performance assessment 


\section{Review of Mechanistic Understanding and Modeling and Uncertainty Analysis}

Methods for Predicting Cementitious Barrier Performance

A brief summary of the analysis methods covered in the four steps is provided below:

Input uncertainty quantification: Physical variability of parameters can be quantified through random variables by statistical analysis. Parameters that vary in time or space are modeled as random processes or random fields with appropriate correlation structure. Data uncertainty that leads to uncertainty in the distribution parameters and distribution types can be addressed using confidence intervals and Bayesian statistics. Methods to include several sources of data uncertainty, namely, sparse data, interval data and measurement error, are discussed.

Uncertainty propagation analysis: Both classical and Bayesian probabilistic approaches can be investigated to propagate uncertainty between individual sub-models and through the overall system model. To reduce the computational expense, surrogate models can be constructed using several different techniques. Methods for sensitivity analysis in the presence of uncertainty are discussed.

Model uncertainty quantification (calibration, verification, validation, and extrapolation): Model calibration is the process of adjusting model parameters to obtain good agreement between model predictions and experimental observations (McFarland, 2008). Both classical and Bayesian statistical methods are discussed for model calibration with available data. One particular concern is how to properly integrate different types of data, available at different levels of the model hierarchy. Assessment of the "correct" implementation of the model is called verification, and assessment of the degree of agreement of the model response with the available physical observation is called validation (McFarland, 2008). Model verification and validation activities help to quantify model error (both model form error and solution approximation error). A possible Bayesian approach is discussed for quantifying the confidence in model extrapolation from laboratory conditions to field conditions.
Probabilistic performance assessment: Limit-statebased reliability analysis methods are discussed to help quantify the PA results in a probabilistic manner. Methods are also discussed to compute the confidence bounds in probabilistic PA results. Monte Carlo simulation with high-fidelity analyses modules is computationally expensive; hence surrogate (or abstracted) models are frequently used with Monte Carlo simulation. In that case, the uncertainty or error introduced by the surrogate model also needs to be quantified.

Figure 1 shows the four stages, within a conceptual framework for systematic quantification, propagation and management of various types of uncertainty. The methods discussed in this report address all the four steps shown in Figure 1. While uncertainty has been dealt with using probabilistic as well as non probabilistic (e.g., fuzzy sets, possibility theory, evidence theory) formats in the literature, this report will focus only on probabilistic analysis, mainly because the mathematics of probabilistic computation are very well established, whereas the non-probabilistic methods are still under development and generally result in interval computations that are expensive when applied to large problems with many variables.

The different stages of analysis in Figure 1 are not strictly sequential. For example, stage 3 (verification and validation - commonly denoted as V\&V) appears after system analysis and uncertainty propagation. However, it is almost impossible to perform $\mathrm{V} \& \mathrm{~V}$ on the system scale, because of extrapolation in time and space; therefore $\mathrm{V} \& \mathrm{~V}$ is usually done for the sub-models. Also, several of the inputs to the overall system model may be calibrated based on the results of sub-model analysis, sensitivity analysis, and $V \& V$ activities. Thus the four stages in Figure 1 simply group together the different types of analysis, and might occur in different sequences for different problems and different sub-models. 


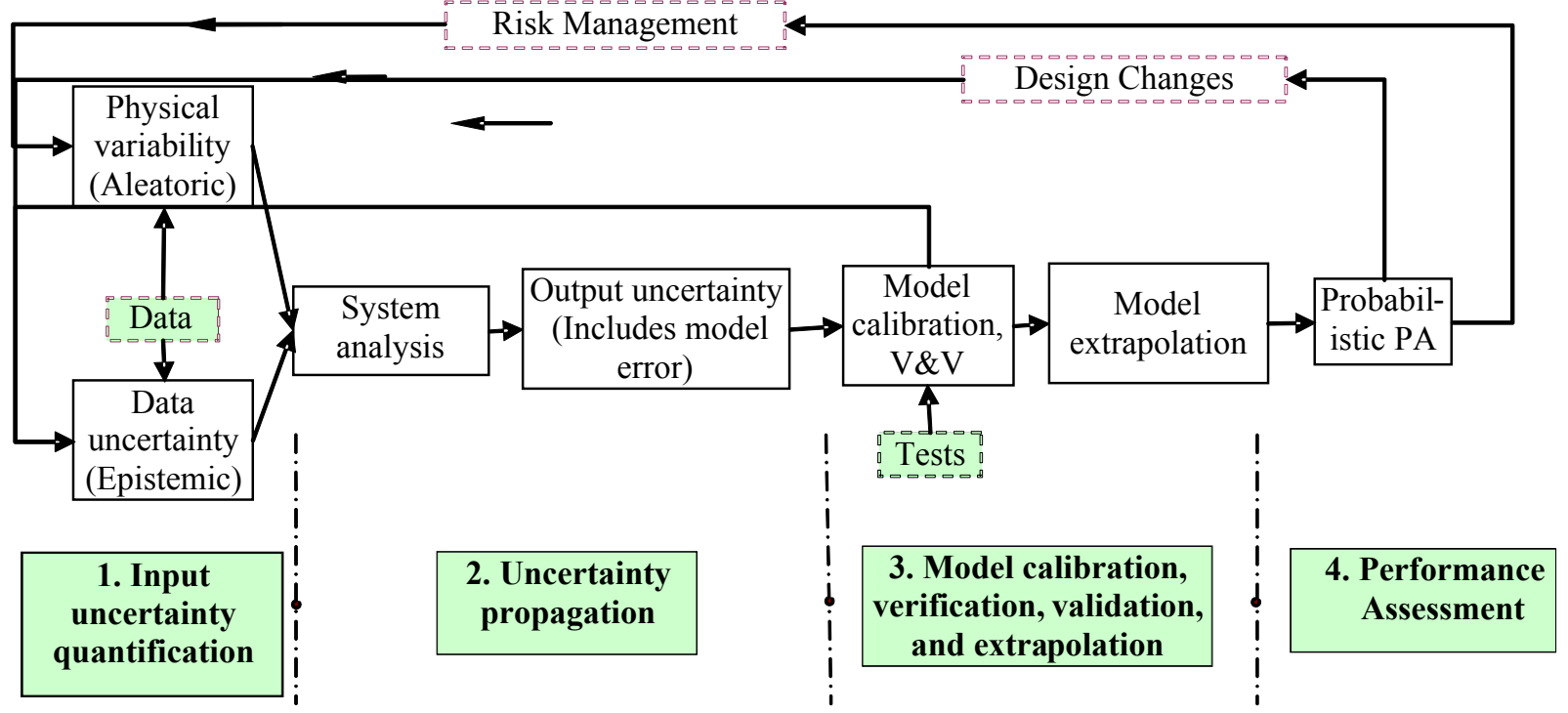

Figure 1. Uncertainty Quantification, Propagation and Management Framework

\footnotetext{
${ }^{1}$ The box Data in the input uncertainty quantification stage includes laboratory data, historical field data, literature sources, and expert opinion.

${ }^{2}$ The box Design Changes may refer to conceptual, preliminary, or detailed design, depending on the development stage.

${ }^{3}$ The boxes Design Changes and Risk Management are outside the scope of this report, although they are part of the overall uncertainty framework.
}

Uncertainty analysis methods currently used in PA activities are discussed in another Cementitious Barriers Partnership report. The quantification of uncertainty in current PAs is limited to quantifying the probability distributions of key parameters. A more comprehensive implementation of uncertainty quantification for environmental PAs has been hampered by the numerous sources of uncertainty and the long time durations considered in the PAs. The methods presented in this report provide a basis for advancing the current state of the art in uncertainty quantification of environmental PAs.

The remainder of this report is organized as follows: Section 2 discusses methods to quantify the uncertainty in the inputs to the system analysis model, addressing both physical variability and data uncertainty. Model error is addressed in Sections 3 and 4.

\subsection{INPUT UNCERTAINTY QUANTIFICATION}

\subsection{Physical Variability}

Examples of cementitious barrier model input variables with physical variability (i.e., inherent, natural variability) include:

- Material properties (e.g., mechanical, thermal, porosity, permeability, diffusivity)

- Geometrical properties (e.g., structural dimensions, concrete cover depth)

- External conditions (e.g., mechanical loading, boundary conditions, physical processes such as freeze-thaw, chemical processes such as carbonation, chloride or sulfate attack) 


\section{Review of Mechanistic Understanding and Modeling and Uncertainty Analysis Methods for Predicting Cementitious Barrier Performance}

Many uncertainty quantification studies have only focused on quantifying and propagating the inherent variability in the input parameters. Well-established statistical (both classical and Bayesian) methods are available for this purpose.

\subsubsection{Modeling Variability in System Properties}

In probabilistic analysis, the sample-to-sample variations (random variables) in the parameters are addressed by defining them as random variables with probability density functions (PDFs). This assumes that the system/material is homogeneous on a macroscale. For example, chloride ion diffusivity has been modeled using a lognormal distribution (Hong, 2000; Gulikers, 2006; Rafiq et al., 2004; Chen, 2006) and water-cement ratio has been modeled using a normal distribution (Chen, 2006) and uniform and triangular distributions (Kong et al., 2002).

Some parameters may vary not only from sample to sample (as is the case for random variables), but also in spatial or time domain. Parameter variation over time and space can be modeled as random processes or random fields. For example, concrete cover depth and compressive strength have been modeled as random fields using squared exponential correlation functions (Stewart and Mullard, 2007).

Some well known methods for simulating random processes are spectral representation (SR) (Gurley, 1997), Karhunen-Loeve expansion (KLE) (Ghanem and Spanos, 2003, Huang et al., 2007; Mathelin et al., 2005), and polynomial chaos expansion (PCE) (Huang et al., 2007; Mathelin et al., 2005; Red-Horse and Benjamin, 2004). The PCE method has been used to represent the stochastic model output as a function of stochastic inputs.
Consider an example of representing a random process using KLE, expressed as

$$
\varpi(x, \chi)=\varpi(x)+\sum_{i=1}^{\infty} \sqrt{\lambda_{i}} \xi_{i}(\chi) f_{i}(x)
$$

where:

$\varpi(x)$ is the mean of the random process $\varpi(x, \chi), \lambda_{\mathrm{i}}$ and $f_{i}(x)$ are eigenvalues and eigenfunctions of $\mathrm{C}\left(x_{1}, x_{2}\right)$, and $\xi_{\mathrm{i}}(\chi)$ is a set of uncorrelated standard normal random variables ( $x$ is a space or time coordinate, and $\chi$ is an index representing different realizations of the random process).

Using Equation (2), realizations of the random process $\varpi(x, \chi)$ can be easily simulated by generating samples of the random variables $\xi(\chi)$, and these realizations of $\varpi(x, \chi)$ can be used as inputs to PA.

\subsubsection{Modeling Variability in External Conditions}

Some boundary conditions (e.g., temperature and moisture content) might exhibit a recurring pattern over shorter periods and also a trend over longer periods. An example of variability in an external condition, i.e., rainfall, is illustrated in Figure 2. It is evident from the figure that the rainfall data has a pattern over a period of 1 year and a downward trend over a number of years. These can be numerically represented by a seasonal model using an autoregressive integrated moving average (ARIMA) method generally used for linear ${ }^{1}$ nonstationary ${ }^{2}$ processes (Box et al., 1994). This method can be used to predict the temperature or the rainfall magnitudes in the future so that it can be used in the durability analysis of the structures under future environmental conditions.

\footnotetext{
${ }^{1}$ The current observation can be expressed as a linear function of past observations.

${ }^{2} \mathrm{~A}$ process is said to be non-stationary if its probability structure varies with the time or space coordinate.
} 


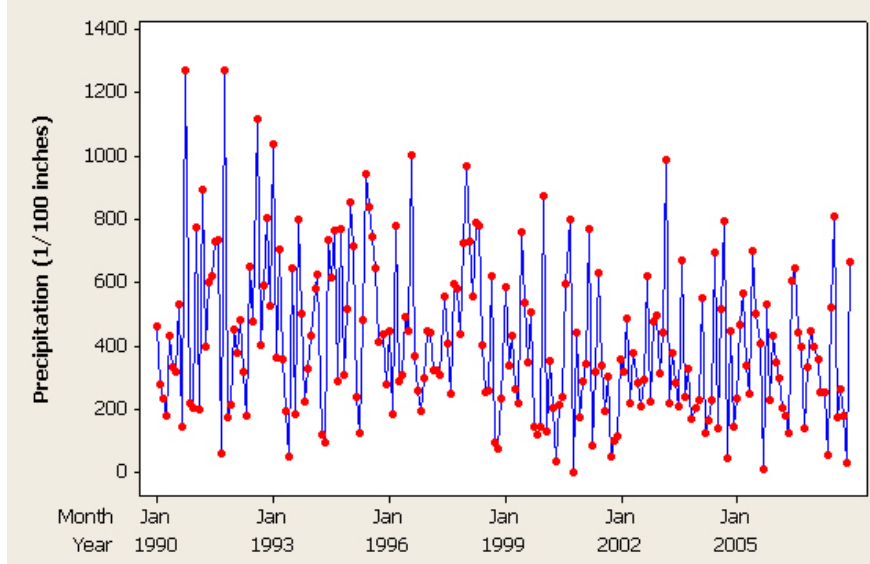

Figure 2. Precipitation Data for Aiken, SC (National Oceanic and Atmospheric Administration)

\subsubsection{Stationary External Processes}

For a stationary process ${ }^{3}$, the ARIMA method expresses the observation at the $t^{\text {th }}$ time step in terms of the observations at previous time steps as

$z_{t}=c+\sum_{i=1}^{p} \phi_{i} z_{t-i}+\varepsilon_{t}$

where:

$z_{t}$ and $z_{t-i}$ are observations at the $t^{t h}$ and $(t-i)^{\text {th }}$ time steps, $c$ is a constant, $\phi_{\mathrm{i}}$ s are coefficients and $\varepsilon_{t}$ is the error between the observed and the predicted values at $t^{\text {th }}$ time step.

Assuming that the error at $t^{\text {th }}$ time step is also dependent on the errors at previous time steps, $\varepsilon_{\mathrm{t}}$ can also be expressed as

$\varepsilon_{t}=c_{1}+\sum_{i=1}^{q} \theta_{i} \varepsilon_{t-i}$

where:

$c_{1}$ is a constant and $\theta_{\mathrm{i}}$ 's are coefficients.
Using a backward operator $B$ such that $B^{i} z_{t}=z_{t-i}$ and combining Eqs. (3) and (4), results in Equation 5.

$\phi_{p}(B) z_{t}=\theta_{q}(B) \varepsilon_{t}$

where:

$\phi_{p}(\mathrm{~B})$ and $\theta_{q}(\mathrm{~B})$ are polynomials of $\mathrm{p}^{\text {th }}$ and $\mathrm{q}^{\text {th }}$ order. The coefficients of the polynomials can be determined using the least-squares method.

\subsubsection{Non-Stationary External Processes}

A random non-stationary process fluctuates about a mean value that exhibits a specific pattern. If the differences in levels of fluctuation are considered, the process can be simulated using the same method as for stationary processes. For example, differentiating a second order polynomial twice will result in a constant. Thus, a non-stationary process of $d^{\text {th }}$ degree can be expressed as

$\phi_{p}(B) \nabla^{d} z_{t}=\theta_{q}(B) \varepsilon_{t}$

\footnotetext{
${ }^{3}$ A process is said to be stationary if its probability structure does not vary with the time or space coordinate.
} 
where:

$\nabla$ is called the backward difference operator of the $d^{\text {th }}$ degree.

If the process exhibits patterns over a shorter period $(s)$ and a trend over a longer period, the process can be expressed as

$$
\begin{aligned}
& \Phi_{P}\left(B^{s}\right) \nabla_{s}^{D} z_{t}=\Theta_{Q}\left(B^{s}\right) \varepsilon_{t} \\
& \text { where: } \\
& \Phi_{P}\left(B^{s}\right) \text { and } \Phi_{Q}\left(B^{s}\right) \text { are polynomials of order } P \text { and } Q, B^{s} z_{t} \\
& =z_{t-s,} \text { and } D \text { is the order of differentiation. }
\end{aligned}
$$

A similar model may be used to relate the current error (error between observation and model prediction at $t^{\text {th }}$ time step) to the previous errors (errors between observations and model predictions at previous time steps) as

$$
\varphi_{p}(B) \nabla^{d} \varepsilon_{t}=\theta_{q}(B) a_{t}
$$

where:

$$
\varphi_{p}(B) \text { and } \theta_{q}(B) \text { and are polynomials of order } p \text { and } q, d \text { is }
$$
the order of differentiation and $a_{t}$ is a white noise process.

The final model is obtained by combining Eqs. (7) and (8) as

$\varphi_{p}(B) \Phi_{P}\left(B^{s}\right) \nabla^{d} \nabla_{s}^{D} z_{t}=\theta_{q}(B) \Theta_{Q}\left(B^{s}\right) a_{t}$

Eq. (9) is referred to as a general multiplicative model of order $(p \times d \times q) \times(P \times D \times Q)_{s}$. This method can be used to simulate a seasonal process.

It may also be important to quantify the statistical correlations between some of the input random variables. Many previous studies on uncertainty quantification simply assume either zero or full correlation, in the absence of adequate data. A Bayesian approach may be pursued for this purpose, as described in subsection 2.2 .

\subsection{Data Uncertainty}

A Bayesian updating approach is described below to quantify uncertainty due to inadequate statistical data and measurement errors $\left(\varepsilon_{\text {exp }}\right)$. This is consistent with the framework proposed in Figure 1, and is used to update the statistics of different physical variables and their distribution parameters. The prior distributions are based on available data and expert judgment, and these are updated as more data becomes available through experiments, analysis, or real-world experience.

\subsubsection{Sparse Statistical Data}

For any random variable that is quantitatively described by a probability density function, there is always uncertainty in the corresponding distribution parameters due to small sample size. As testing and data collection activities are performed, the state of knowledge regarding the uncertainty changes, and a Bayesian updating approach can be implemented. For example, suppose we decide that an input variable $X$ follows a Gaussian distribution $N\left(\mu, \sigma^{2}\right)$ with $\mu$ and $\sigma$ estimated from the data.

There is uncertainty in the normal distribution assumption, as well as in the estimates of the distribution parameters $\mu$ and $\sigma$, depending on the sample size. In the Bayesian approach, $\mu$ and $\sigma$ are also treated as random variables, and their statistics are updated based on new data. However, we do not know the distribution of $\mu$ and $\sigma$ a priori, so we may assume Gaussian for $\mu$ and Gamma distribution for $\phi=\sigma^{-2}$ as an initial guess for example, and then do a Bayesian update after more data is collected.

The Bayesian approach also applies to joint distributions of multiple random variables, which also helps to include the uncertainty in correlations between the 


\section{Review of Mechanistic Understanding and Modeling and Uncertainty Analysis} Methods for Predicting Cementitious Barrier Performance

variables. A prior joint distribution is assumed (or individual distributions and correlations are assumed), and then updated as data becomes available.

Instead of assuming a well known prior distribution form (e.g., uniform, normal) for sparse data sets, either empirical distribution functions, or flexible families of distributions based on the data can be constructed. A bootstrapping ${ }^{4}$ technique can then be used to quantify the uncertainty in the distribution parameters. The empirical distribution function is constructed by ranking the observations from lowest to highest value, and assigning a probability value to each observation.

Examples of flexible distribution families include the: Johnson family, Pearson family, gamma distribution, and stretched exponential distribution. The use of the Johnson family distribution has been explored by Marhadi et al., 2008, and extended to quantify the uncertainty in distribution parameters by McDonald et al., 2009. In constructing the Johnson family distribution, the available data is used to calculate the first four moments, and then the distribution form is chosen based on the values of the four moments. A jack-knife procedure is used to estimate the uncertainty in the distribution parameters, based on repeated estimation by leaving out one or more data points in each estimation.

\subsubsection{Measurement Error}

The measured quantity $y_{\text {exp }}$ usually deviates from the unknown true value $y_{\text {true }}$ due to the uncertainties in the test setup, equipment, environment, and operator. For example, large errors in the measurement of expansion due to sulfate attack can be seen in the experiments performed by Ferraris et al., 1997. The measurement error $\varepsilon_{\text {exp }}$ can be expressed as $y_{\text {exp }}=y_{\text {true }}$ $+\varepsilon_{\text {exp }}$. The measurement error in each input variable in many studies (e.g., Barford, 1985) is assumed to be independent and identically distributed (IID) with zero mean and an assumed variance, i.e., $\varepsilon_{\exp }($ $N\left(0, \sigma_{\text {exp }}^{2}\right)$. Due to the measurement uncertainty, the distribution parameter $\sigma_{\text {exp }}$ cannot be obtained as a deterministic value. Instead, it is a random variable with a prior density $\tau\left(\sigma_{\text {exp }}\right)$. Thus, when new data is available after testing, the distribution of $\sigma_{\exp }$ can be easily updated using the Bayes theorem.

Another way to represent measurement error $\varepsilon_{\exp }$ is through an interval only, and not as a random variable. In that case, one can only say the true value $\mathrm{y}_{\text {true }}$ lies in the interval $\left[y_{\exp }-\varepsilon_{\exp }, y_{\exp }+\varepsilon_{\exp }\right]$ without any probability distribution assigned to $\varepsilon_{\text {exp }}$. Methods to include data in interval format are discussed next.

\subsubsection{Data Available in Interval Format}

Some quantities in the system model may not have probabilistic representation, since data may be sparse or may be based on expert opinion. Some experts might only provide information about a range of possible values for some model input variable.

Representations such as fuzzy sets, possibility theory, and evidence theory have been used. This report is focused on probabilistic methods to include interval data.

Transformations have been proposed from a nonprobabilistic to probabilistic format, through the maximum likelihood approach (Langley, 2000; Ross et al., 2002). Such transformations have attracted the criticism that information is either added or lost in the process. Two ways to address the criticism are: (1) construct empirical distribution functions based on interval data collected from multiple experts or experiments (Ferson et al., 2007); or (2) construct flexible families of distributions with bounds on distribution

\footnotetext{
${ }^{4}$ Bootstrapping is a data-based simulation method for statistical inference by re-sampling from an existing data set (Efron et al., 1994).
} 
parameters based on the interval data, without forcing a distribution assumption (McDonald et al., 2008).

These can then be treated as random variables with probability distribution functions and combined with other random variables in a Bayesian framework to quantify the overall system model uncertainty. The use of families of distributions will result in multiple probability distributions for the output, representing the contributions of both physical variability and data uncertainty.

\subsection{PROPAGATION UNCERTAINTY METHODS}

In this section, methods to quantify the contributions of different sources of uncertainty and error as they propagate through the system analysis model, including the contribution of model error, are discussed, in order to quantify the overall uncertainty in the system model output.

This section will cover two issues: (1) quantification of model output uncertainty, given input uncertainty (both physical variability and data uncertainty), and (2) quantification of model error (due to both model form selection and solution approximations).

Several uncertainty analysis studies, including a study with respect to the Yucca Mountain high-level waste repository, have recognized the distinction between physical variability and data uncertainty (Helton and Sallaberry, 2009a \& 2009b). As a result, these methods evaluate the variability in an inner loop calculation and data uncertainty in an outer loop calculation. Another example is provided by Holdren et al., 2006 in a baseline risk assessment study with respect to the Idaho Cleanup Project, where contributions of different sources of uncertainty are separately analyzed, such as from inventory, infiltration, sorption characteristics, model calibration, and simulation periods.

\subsection{Propagation of Physical Variability}

Various probabilistic methods (e.g., Monte Carlo simulation and first-order or second-order analytical approximations) have been studied for the propagation of physical variability in model inputs and model parameters, expressed through random variables and random process or fields. Stochastic finite element methods (e.g., Ghanem and Spanos, 2003; Haldar and Mahadevan, 2000) have been developed for single discipline problems in structural, thermal, and fluid mechanics. An example of such propagation is shown in Figure 3. Several types of combinations of system analysis model and statistical analysis techniques are available:

- Monte Carlo simulation with the deterministic system analysis as a black-box (e.g., Robert and Cesalla, 2004) to estimate model output statistics or probability of regulatory compliance;

- Monte Carlo simulation with a surrogate model to replace the deterministic system analysis model (e.g., Ghanem and Spanos, 2003; Isukapalli et al., 1998; Xiu and Karniadakis, 2003; Huang et al., 2007), to estimate model output statistics or probability of regulatory compliance;

- Local sensitivity analysis using finite difference, perturbation or adjoint analyses, leading to estimates of the first-order or second-order moments of the output (e.g., Blischke and Murthy, 2000); and

- Global sensitivity and effects analysis, and analysis of variance in the output (e.g., Box et al., 1978).

These techniques are generic, and can be applied to multi-physics analysis with multiple component modules as in the PA of cementitious barriers. However, most applications of these techniques have only considered physical variability. The techniques need to include the contribution of data uncertainty and model error to the overall model prediction uncertainty. 


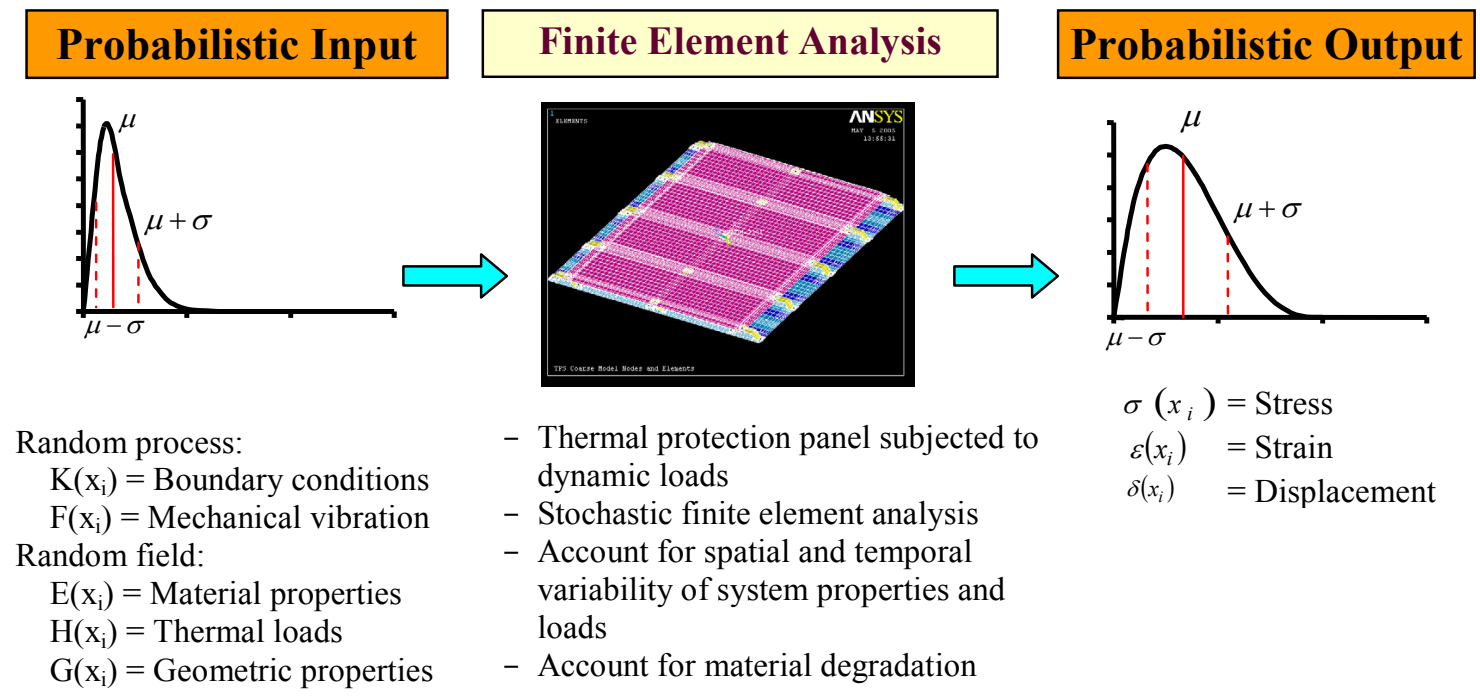

Figure 3. Example of Physical Variability Propagation

Computational effort is a significant issue in practical applications, since these techniques involve a number of repeated runs of the system analysis model. The system analysis may be replaced with an inexpensive surrogate model in order to achieve computational efficiency; this is discussed in Section 3.2. Efficient Monte Carlo techniques have also been pursued to reduce the number of system model runs, including Latin hypercube sampling (LHS) (Mckay et al., 1979; Farrar et al., 2003) and importance sampling (Mahadevan and Raghothamachar, 2000; Zou et al. 2003).

\subsection{Propagation of Data Uncertainty}

Three types of data uncertainty were discussed in Section 2. Sparse point data results in uncertainty about the parameters of the probability distributions describing quantities with physical variability. In that case, uncertainty propagation analysis takes a nested implementation. In the outer loop, samples of the distribution parameters are randomly generated, and for each set of sampled distribution parameter values, probabilistic propagation analysis is carried out as in Section 3.1. This results in the computation of multiple probability distributions of the output, or confidence intervals for the estimates of probability of non-compliance in PA.

In the case of measurement error, choice of the uncertainty propagation technique depends on how the measurement error is represented. If the measurement error is represented as a random variable, it is simply added to the measured quantity, which is also a random variable due to physical variability. Thus a sum of two random variables may be used to include both physical variability and measurement error in a quantity of interest. If the measurement error is represented as an interval, one way to implement probabilistic analysis is to represent the interval through families of distributions or upper and lower bounds on probability distributions, as discussed in Section 2.2.3. In that case, multiple probabilistic analyses, using the same nested approach as in the case of sparse data, can be employed to generate multiple output distributions or confidence intervals for the model output. The same approach is possible for interval variables that are only available as a range of values, as in the case of expert opinion. 


\section{Review of Mechanistic Understanding and Modeling and Uncertainty Analysis}

Methods for Predicting Cementitious Barrier Performance

Propagation of uncertainty is conceptually very simple, but computationally quite expensive to implement, especially when both physical variability and data uncertainty are to be considered. The presence of both types of uncertainty requires a nested implementation of uncertainty propagation analysis (simulation of data uncertainty in the outer loop and simulation of physical variability in the inner loop). If the system model runs are time-consuming, then uncertainty propagation analysis could be prohibitively expensive. One way to overcome the computational hurdle is to use an inexpensive surrogate model to replace the detailed system model, as discussed next.

\subsection{Surrogate Models}

Surrogate models (also known as response surface models) are frequently used to replace the expensive system model, and used for multiple simulations to quantify the uncertainty in the output. Many types of surrogate modeling methods are available, such as linear and nonlinear regression, polynomial chaos expansion, Gaussian process modeling (e.g., Kriging model), splines, moving least squares, support vector regression, relevance vector regression, neural nets, or even simple look-up tables. For example, Goktepe et al., 2006 used neural network and polynomial regression models to simulate expansion of concrete specimens under sulfate attack. All surrogate models require training or fitting data, collected by running the full-scale system model repeatedly for different sets of input variable values. Selecting the sets of input values is referred to as statistical design of experiments, and there is extensive literature on this subject. Two types of surrogate modeling methods are discussed below that might achieve computational efficiency while maintaining high accuracy in output-uncertainty quantification. The first method expresses the model output in terms of a series expansion of special polynomials such as Hermite polynomials, and is referred to as a stochastic response surface method (SRSM). The second method expresses the model output through a Gaussian process, and is referred to as Gaussian process modeling.

\subsubsection{Stochastic Response Surface Method}

The common approach for building a surrogate or response surface model is to use least squares fitting based on polynomials or other mathematical forms based on physical considerations. In SRSM, the response surface is constructed by approximating both the input and output random variables and fields through series expansions of standard random variables (e.g. Isukapalli et al., 1998; Xiu and Karniadakis, 2003; Huang et al., 2007). This approach has been shown to be efficient, stable, and convergent in several structural, thermal, and fluid flow problems. A general procedure for SRSM is as follows:

- Representation of random inputs (either random variables or random processes) in terms of Standard Random Variables (SRVs) by K-L expansion, as in Equation (2).

- Expression of model outputs in chaos series expansion. Once the inputs are expressed as functions of the selected SRVs, the output quantities can also be represented as functions of the same set of SRVs. If the SRVs are Gaussian, the output can be expressed a Hermite polynomial chaos series expansion in terms of Gaussian variables. If the SRVs are non-Gaussian, the output can be expressed by a general Askey chaos expansion in terms of non-Gaussian variables (Ghanem and Spanos, 2003).

- Estimation of the unknown coefficients in the series expansion. The improved probabilistic collocation method (Isukapalli et al., 1998) is used to minimize the residual in the random dimension by requiring the residual at the collocation points equal to zero. The model outputs are computed at a set of collocation points and used to estimate the coefficients. These collocation points are the 
roots of the Hermite polynomial of a higher order. This way of selecting collocation points would capture points from regions of high probability (Tatang et al., 1997).

- Calculation of the statistics of the output that has been cast as a response surface in terms of a chaos expansion. The statistics of the response can be estimated with the response surface using either Monte Carlo simulation or analytical approximation.

\subsubsection{Kriging or Gaussian Process Models}

Gaussian process (GP) models have several features that make them attractive for use as surrogate models. The primary feature of interest is the ability of the model to "account for its own uncertainty." That is, each prediction obtained from a Gaussian process model also has an associated variance, or uncertainty. This prediction variance primarily depends on the closeness of the prediction location to the training data, but it is also related to the functional form of the response. For example, see Fig. 4, which depicts a one-dimensional Gaussian process model. Note how the uncertainty bounds are related to both the closeness to the training points, as well as the shape of the curve.

The basic idea of the GP model is that the output quantities are modeled as a group of multivariate normal random variables. A parametric covariance function is then constructed as a function of the inputs. The covariance function is based on the idea that when the inputs are close together, the correlation between the outputs will be high. As a result, the uncertainty associated with the model prediction is small for input values that are close to the training points, and large for input values that are not close to the training points. In addition, the GP model may incorporate a systematic trend function, such as a linear or quadratic regression of the inputs (in the notation of Gaussian process models, this is called the mean function, while in Kriging it is often called a trend function). The effect of the mean function on predictions that interpolate the training data is small, but when the model is used for extrapolation, the predictions will follow the mean function very closely.

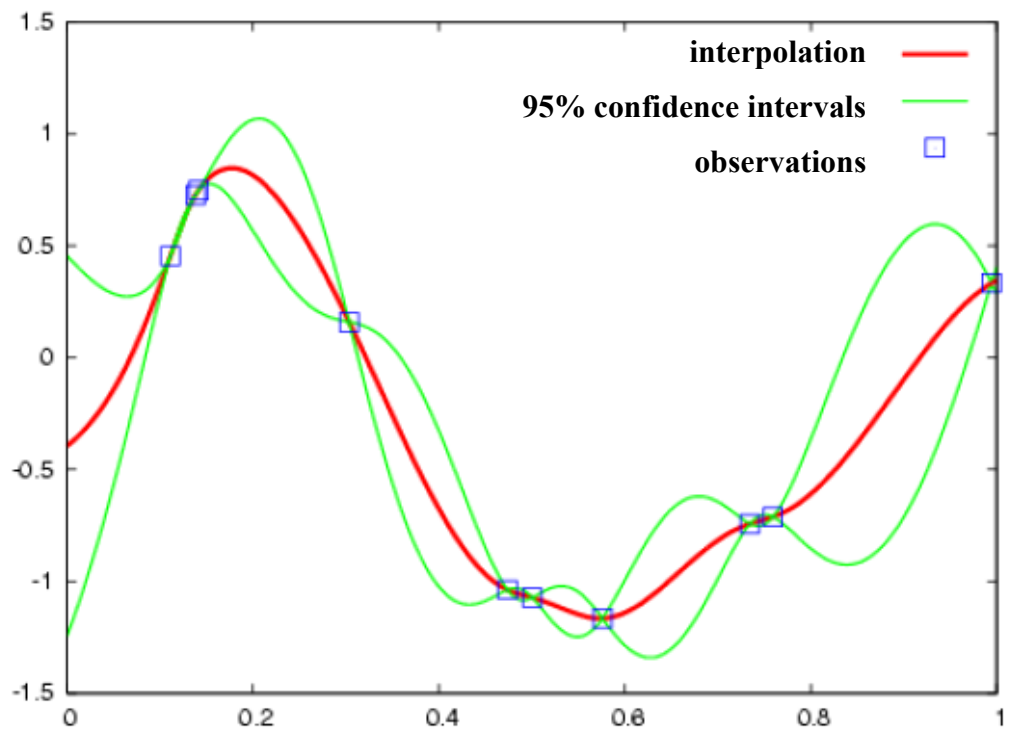

Figure 4. Gaussian Process Model With Uncertainty Bounds 


\section{Review of Mechanistic Understanding and Modeling and Uncertainty Analysis}

Methods for Predicting Cementitious Barrier Performance

Within the GP modeling technique, it is also possible to adaptively select the design of experiments to achieve very high accuracy. The method begins with an initial GP model built from a very small number of samples, and then one intelligently chooses where to generate subsequent samples to ensure the model is accurate in the vicinity of the region of interest. Since the GP model provides the expected value and variance of the output quantity, the next sample may be chosen in the region of highest variance, if the objective is to minimize the prediction variance. The method has been shown to be both accurate and computationally efficient for arbitrarily shaped functions (Bichon et al., 2007).

\subsection{Sensitivity Analysis Methods}

Sensitivity analysis serves several important functions: (1) identification of dominant variables or sub-models, thus helping to focus data collection resources efficiently; (2) identification of insignificant variables or sub-models of limited significance, helping to reduce the size of the problem and computational effort; and (3) quantification of the contribution of solution approximation error. Both local and global sensitivity analysis techniques are available to investigate the quantitative effect of different sources of variation (physical parameters, models, and measured data) on the variation of the model output. The primary benefit of sensitivity analysis to uncertainty analysis is to enable the identification of which physical parameters have the greatest influence on the output (Campolongo et al., 2000; Saltelli et al., 2000). An analysis of the impact of the parametric uncertainty is conducted to weed out those that have an insignificant effect upon the system output. For example, Chen (2006) performed sensitivity analysis to identify the important parameters affecting the service life of the concrete structures.

Three sensitivity analysis methods are factor screening, local-, and global-sensitivity analysis approaches. Factor screening determines which parameters have the greatest impact on the system output variability, by evaluating the output at the extreme values within the ranges of the parameters. Local sensitivity analysis utilizes first-order derivatives of system output quantities with respect to the parameters. It is usually performed for a nominal set of parameter values. Global sensitivity analysis typically uses statistical sampling methods, such as Latin Hypercube Sampling, to determine the total uncertainty in the system output and to apportion that uncertainty among the various parameters. Classical and Bayesian statistical analysis techniques, including the analysis of variance and differential sensitivity analysis, can be pursued to assess the global influence of an input parameter on an output variable by sampling from each input parameter's probability density function or from intervals of possible values.

\subsection{Multi-Physics Models}

In the past decade, different approaches have been proposed to quantify the uncertainty for individual physical models or simulation codes (e.g. see, Glimm and Sharp, 1999; Hanson, 1999; Devolder et al., 2002; Bae et al., 2003; Hanson and Hemez, 2003; Oberkampf et al., 2003; Millman et al., 2006; Witteveen and Bijl, 2006). For example, Hanson (1999) proposed a Bayesian probabilistic method for quantifying uncertainties in simulation predictions. Bae et al. (2003) used evidence theory to handle epistemic uncertainty about a structural system. Mathelin et al. (2004) and Witteveen and Bijl (2006) applied a polynomial chaos-based stochastic method for uncertainty propagation in numerical simulations. However, these existing approaches have not accounted for the uncertainty quantification in multiple modules of the system model, where the challenge is to combine data (available from different sources, in different formats) and model predictions regarding different physical phenomena (e.g., diffusion, chemical reaction, and mechanical damage), thus using all available information to quantify the overall prediction uncertainty. Urbina and Mahadevan (2009) have recently proposed a Bayes network approach to uncertainty quantification in multi-physics models. 


\subsection{Model Error Quantification}

Model errors may relate to governing equations, boundary and initial condition assumptions, loading description, and approximations or errors in solution algorithms (e.g., truncation of higher order terms, finite element discretization, curve-fitting models for material damage such as S-N curve). Overall model error may be quantified by comparing model prediction and experimental observation, properly accounting for uncertainties in both. This overall error measure combines both model form and solution approximation errors, and so it needs to be considered in two parts. Numerical errors in the model prediction can be quantified first, using sensitivity analysis, uncertainty propagation analysis, discretization error quantification, and truncation (residual) error quantification. The measurement error in the input variables can be propagated to the prediction of the output. The error in the prediction of the output due to the measurement error in the input variables is approximated by using a first-order sensitivity analysis (Rebba et al., 2006). Then the model form error can be quantified based on all the above errors, following the approach illustrated for a heat transfer problem by Rebba et al. (2006).

\subsubsection{Solution Approximation Error}

Several components of prediction error, such as discretization error (denoted by $\varepsilon_{\mathrm{d}}$ ) and uncertainty propagation analysis error $\left(\varepsilon_{\mathrm{s}}\right)$ can be considered. Several methods to quantify the discretization error in finite element analysis are available in the literature. However, most of these methods do not quantify the actual error; instead, they only quantify some indicator measures to facilitate adaptive mesh refinement. The Richardson extrapolation (RE) method comes closest to quantifying the actual discretization error (Richards, 1997). (In some applications, the model is run with different levels of resolution, until an acceptable level of accuracy is achieved; formal error quantification may not be required.)
Errors in uncertainty propagation analysis $\left(\varepsilon_{\mathrm{s}}\right)$ are method-dependent, i.e. sampling error occurs in Monte Carlo methods, and truncation error occurs in response surface methods (either conventional or polynomial chaos-based). For example, sampling error could be assumed to be a Gaussian random variable with zero mean and variance given by $\sigma^{2} / \mathrm{N}$ where $\mathrm{N}$, is the number of Monte Carlo runs, and $\sigma^{2}$ is the original variance of the model output (Rubinstein, 1981). The truncation error is simply the residual error in the response surface.

Rebba et al. (2006) used the above concept to construct a surrogate model for finite element discretization error in structural analysis, using the stochastic response surface method. Gaussian process models may also be employed for this purpose. Both options are helpful in quantifying the solution approximation error.

\subsubsection{Model Form Error}

The overall prediction error is a combination of errors resulting from numerical solution approximations and model form selection. A simple way is to express the total observed error (difference between prediction and observation) as the sum of the following error sources:

$$
\begin{aligned}
& \varepsilon_{\text {obs }}=\varepsilon_{\text {num }}+\varepsilon_{\text {model }}-\varepsilon_{\text {exp }} \\
& \text { where: } \\
& \varepsilon_{\text {num }}, \varepsilon_{\text {model }}, \text { and } \varepsilon_{\text {exp }} \text { represent numerical solution error, model } \\
& \text { form error, and output measurement error, respectively. }
\end{aligned}
$$

However solution approximation error results from multiple sources and is probably a nonlinear combination of various errors such as discretization error, round-off and truncation errors, and stochastic analysis errors. One option is to construct a regression model consisting of the individual error components (Rebba et al., 2006). 
The residual of such a regression analysis will include the model form error (after subtracting the experimental error effects). By denoting $\varepsilon_{\mathrm{obs}}$ as the difference between the data and prediction, i.e., $\varepsilon_{o b s}=$ $y_{\text {exp }}-y_{\text {pred }}$, we can construct the following relation by considering a few sources of numerical solution error (Rebba et al., 2006):

$\varepsilon_{\text {obs }}=\mathrm{f}\left(\varepsilon_{\mathrm{h}}, \varepsilon_{\mathrm{d}}, \varepsilon_{\mathrm{s}}\right)+\varepsilon_{\text {model }}-\varepsilon_{\text {exp }}$

where:

$\varepsilon_{\mathrm{h}}, \varepsilon_{\mathrm{d}}$, and $\varepsilon_{\mathrm{s}}$ represent output error due to input parameter measurement error, finite element discretization error, and uncertainty propagation analysis error, respectively, all of which contribute to numerical solution error.

Rebba et al. (2006) illustrated the estimation of model form error using the above concept for a onedimensional heat conduction problem, assuming a linear form of Eq. (11). However, the function $\mathrm{f}\left(\varepsilon_{\mathrm{h}}\right.$, $\left.\varepsilon_{\mathrm{d}}, \varepsilon_{\mathrm{s}}\right)$ is nonlinear, and may be approximated through a response surface with respect to the three error variables, using a polynomial chaos expansion. The quantity $\varepsilon_{\text {model }}-\varepsilon_{\text {exp }}$ is simply the residual error of such a response surface. Thus the distribution of model error $\varepsilon_{\text {model }}$ is quantified by knowing the distributions of residual error and measurement error.

Note that the above approach to quantifying model form error is only within the context of model validation - where actual data is available from targeted validation experiments - and compared with corresponding model predictions. In the context of $\mathrm{PA}$, however, the concern is with extrapolation in time and space, and no direct comparison is possible between prediction and observation (at the time when the PA is done). Quantifying the model errors during extrapolation is difficult, and a Bayesian methodology might need to be pursued within restrictive assumptions (e.g., no change in physics). The Bayesian approach is discussed in Section 4.

\subsection{MODEL CALIBRATION, VALIDATION AND EXTRAPOLATION}

After quantifying and propagating the physical variability, data uncertainty, and model error for individual components of the overall system model, the probability of meeting performance requirements (and our confidence in the model prediction) needs to be assessed based on extrapolating the model to field conditions (which are uncertain as well), where sometimes very limited or no experimental data is available. Rigorous verification, validation, and calibration methods are needed to establish credibility in the modeling and simulation. Both classical and Bayesian statistical methodologies have been successfully developed during recent years for single physics problems, and have the potential to be extended to multi-physics models of cementitious barrier systems. The methods should have the capability to consider multiple output quantities or a single model output at different spatial and temporal points.

This section discusses methods for (1) calibration of model parameters, based on observation data; (2) validation assessment of the model, based on observation data; and (3) estimation of confidence in the extrapolation of model prediction from laboratory conditions to field conditions.

\subsection{Model Calibration}

Two types of statistical techniques may be pursued for model calibration uncertainty, the least squares approach, and the Bayesian approach. The least squares approach estimates the values of the calibration parameters that minimize the discrepancy between model prediction and experimental observation. This approach can also be used to calibrate surrogate models or low-fidelity models, based on high-fidelity runs, by treating the high-fidelity results similar to experimental data. 
The second approach is Bayesian calibration (Kennedy and O'Hagan, 2001). This approach is flexible and allows different forms for the calibration factor, and it has been illustrated for a heat transfer example problem (McFarland and Mahadevan, 2007, McFarland, 2008).

In the literature, several researchers have calibrated their models using experimental results, especially if the phenomenon being modeled is complicated and the model is based on simplifying assumptions. For example, Tixier and Mobasher (2003) calibrated two parameters (reaction rate constant and fraction of porosity available for solid product deposition), and Krajcinovic et al. (1992) calibrated one parameter (reaction rate constant), while modeling the degradation of concrete structures under sulfate attack.

\subsection{Model Validation}

Model validation involves comparing prediction with observation data (either historical or experimental) when both have uncertainty. Since there is uncertainty in both model prediction and experimental observation, it is necessary to pursue rigorous statistical techniques to perform model validation assessment rather than simple graphical comparisons, provided data is even available for such comparisons. Statistical hypothesis testing is one approach to quantitative model validation under uncertainty, and both classic and Bayesian statistics have been explored. Classical hypothesis testing is a well-developed statistical method for accepting or rejecting a model based on an error statistic (see e.g., Trucano et al., 2001; Hills and Trucano, 2002; Paez and Urbina, 2002; Hills and Leslie, 2003; Rutherford and Dowding, 2003; Dowding et al., 2004; Chen et al., 2004; Oberkampf and Barone, 2006). Validation metrics have been investigated in recent years based on Bayesian hypothesis testing (Zhang and Mahadevan, 2003; Mahadevan and Rebba, 2005; Rebba and Mahadevan, 2006), reliability-based methods (Rebba and Mahadevan, 2008), and risk-based decision analysis (Jiang and Mahadevan, 2007 \& 2008).
In Bayesian hypothesis testing, prior probabilities were assigned for the null and alternative hypotheses; $P\left(H_{0}\right)$ and $P\left(H_{a}\right)$ respectively, such that $P\left(H_{0}\right)$ $+P\left(H_{d}\right)=1$. Here $H_{0}$ : model error $<$ allowable limit, and $H_{a}$ : model error $>$ allowable limit. When data $D$ is obtained, the probabilities are updated as $P\left(H_{0} \mid D\right)$ and $P\left(H_{a} \mid D\right)$ using the Bayes theorem. Then a Bayes factor (Jeffreys, 1961) $B$ is defined as the ratio of likelihoods of observing $D$ under $H_{0}$ and $H_{a}$; i.e., the first term in the square brackets on the right hand side of

$$
\frac{P\left(H_{0} \mid D\right)}{P\left(H_{a} \mid D\right)}=\left[\frac{P\left(D \mid H_{0}\right)}{P\left(D \mid H_{a}\right)}\right] \frac{P\left(H_{0}\right)}{P\left(H_{a}\right)}
$$

If $B>1$, the data gives more support to $H_{0}$ than $H_{a}$. Also the confidence in $H_{0}$, based on the data, comes from the posterior null probability $P\left(H_{0} \mid D\right)$, which can be rearranged from Eq. (12a) as

$$
\frac{P\left(H_{0}\right) B}{P\left(H_{0}\right) B+1-P\left(H_{0}\right)}
$$

Typically, in the absence of prior knowledge, equal probabilities may be assigned to each hypothesis and thus $P\left(H_{0}\right)=P\left(H_{a}\right)=0.5$. The posterior null probability can then be further simplified to $B /(B+1)$. Thus a $B$ value of 1.0 represents $50 \%$ confidence in the null hypothesis being true.

The Bayesian hypothesis testing is also able to account for uncertainty in the distribution parameters, as mentioned in Section 2.2. For such problems, the validation metric (Bayes factor) itself becomes a random variable. In that case, the probability of the Bayes factor exceeding a specified value can be used as the decision criterion for model acceptance/rejection.

Notice that model validation only refers to the situation when controlled, target experiments are performed to evaluate model prediction, and both the model runs and experiments are done under the same set of input and boundary conditions. The validation is done only by comparing the outputs of the model and the experiment. Once the model is calibrated, 
verified and validated, it may be investigated for confidence in extrapolating to field conditions different from laboratory conditions. This is discussed in the next section.

\subsection{Confidence Assessment in Extrapolation}

The Bayesian approach can also be used for assessing the confidence in extrapolating model prediction from laboratory conditions to field conditions, from lower resolution to higher resolution analysis, and from the lower level to the higher level in system analysis, through the construction of the Bayes network (Jensen and Jensen, 2001). Bayes networks are directed acyclic graphical representations with nodes to represent the random variables and arcs to show the conditional dependencies among the nodes. Data in any one node can be used to update the statistics of all other nodes. This property makes the Bayes network a powerful tool to extrapolate model confidence from laboratory conditions to field conditions (Mahadevan and Rebba, 2005). After computing the posterior distribution of the output under field conditions, through the Bayes network, the confidence in the prediction can be calculated similar to Section 4.2, using the Bayes factor.

Markov Chain Monte Carlo (MCMC) simulation is used for numerical implementation of the Bayesian updating analysis. Several efficient sampling techniques are available for MCMC, such as Gibbs sampling, the Metropolis algorithm, and the MetropolisHastings algorithm (Gilks et al., 1996).

Figure 5 shows an illustrative Bayes network for confidence extrapolation. An ellipse represents a random variable and a rectangle represents observed data. A solid line arrow represents a conditional probability link, and a dashed line arrow represents the link of a variable to its observed data if available. The probability densities of the variables $\Omega, z$, and $y$ are updated using the validated data $\mathbf{Y}$. The updated statistics of $\Omega, z$, and $y$ are then used to estimate the updated statistics of the decision variable $d$ (i.e., assessment metric). In addition, both model prediction and predictive experiments are related to input variables $\mathbf{X}$ via physical parameters $\Phi$. Note that there is no observed data available for d; yet the confidence in the prediction of $d$, can be calculated by making use of observed data in several other nodes and propagation of posterior statistics through the Bayes network.

The Bayes network thus links the various simulation codes and corresponding experimental observations to facilitate two objectives: (1) uncertainty quantification and propagation and (2) extrapolation of confidence assessment from validation domain to application domain.

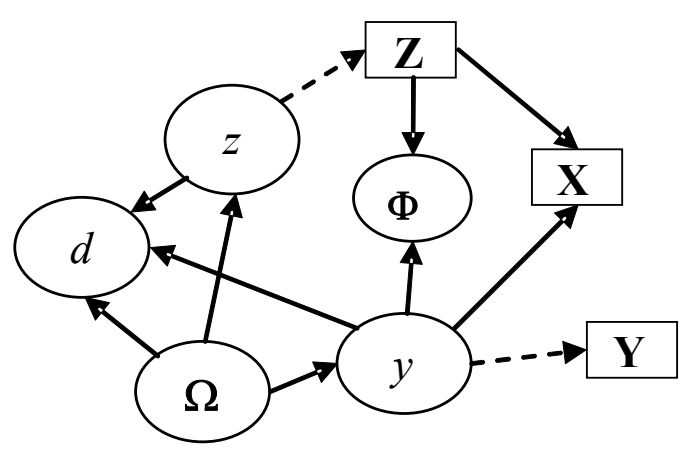

Figure 5. Bayes Network 


\subsection{PROBABILISTIC PERFORMANCE ASSESSMENT}

Several methods are available in the reliability methods literature to efficiently perform probabilistic performance assessment, as fast alternatives to expensive Monte Carlo simulation. Performance assessment can be conducted with respect to single or multiple requirements. Efficient reliability analysis techniques that are based on first-order or second-order approximations or adaptive importance sampling can be used for this purpose. When multiple requirements are defined, computation of the overall probability of satisfying multiple performance criteria requires integration over a multidimensional space defined by unions and intersections of individual events (of satisfaction or violation of individual criteria).

An important observation here is that the same methods that are described here for reliability analysis can also be used to compute the cumulative distribution function (CDF) of the output, which may be of more general interest with respect to uncertainty quantification of model output. The term reliability analysis here refers only to computing the probability of exceeding or not meeting a single threshold value, which is a special case of constructing the entire CDF.

This section will discuss methods for probabilistic performance assessment with respect to individual criteria (5.1) and multiple criteria (5.2).

\subsection{Individual Criteria}

Probabilistic performance assessment can be based on the concept of a limit state that defines the boundary between success and failure for a system (Haldar and Mahadevan, 2000). The limit state function, $g$, is derived from a system performance criterion and formulated such that $g<0$ indicates failure. If the input parameters in the system analysis are uncertain, so will be the predicted value of $g$. The probability of system failure, i.e. $P(g<0)$ may be obtained from the volume integral under the joint probability density function of the input random variables over the failure domain as

$$
P_{f}=\int \ldots \int_{g \leq 0} f_{X}\left(x_{1}, x_{2}, \ldots, x_{n}\right) d x_{1} d x_{2} \ldots d x_{n}
$$

where:

$P_{f}$ is the probability of failure, $f_{\mathrm{X}}$ is the joint probability density of a random variable vector $\boldsymbol{X}$ with $n$ elements; vector $\boldsymbol{x}$ represents a single realization of $\boldsymbol{X}$. Note that the integral is taken over the failure domain, or where $g \leq 0$, so $P_{f}=P(\mathrm{~g} \leq 0)$.

The basic Monte Carlo simulation method evaluates the above integral by drawing random samples from the distributions of the variables $\boldsymbol{X}$, and by evaluating whether $g \leq 0$ in each run. Then the failure probability is simply the number of samples with $g \leq 0$ divided by the total number of samples. While this technique is very simple to implement, it is also very expensive for problems with low failure probability.

The First Order Reliability Method (FORM) approximately estimates the failure probability as $P_{f}=\Phi(-\beta$, where $\beta$ is the minimum distance from the origin to the limit state in the space of uncorrelated standard normal variables ${ }^{5}$, as shown in Figure 6 (Hasofer and Lind, 1974). The minimum distance point on the limit state is referred to as the most probable point (MPP), and $\beta$ is referred to as the reliability index. Finding the MPP is an optimization problem:

$$
\text { Minimize } \beta=\|\eta\| \text {, subject to } \mathrm{g}_{\eta}(\eta)=0
$$

\footnotetext{
${ }^{5}$ In general, a set of random variables x may be non-normal and correlated, but these may be transformed to an uncorrelated standard normal space (i.e. the space of random normal variables with 0 mean and unit standard deviation) via a transformation T, i.e $\eta=T(x)$.
} 


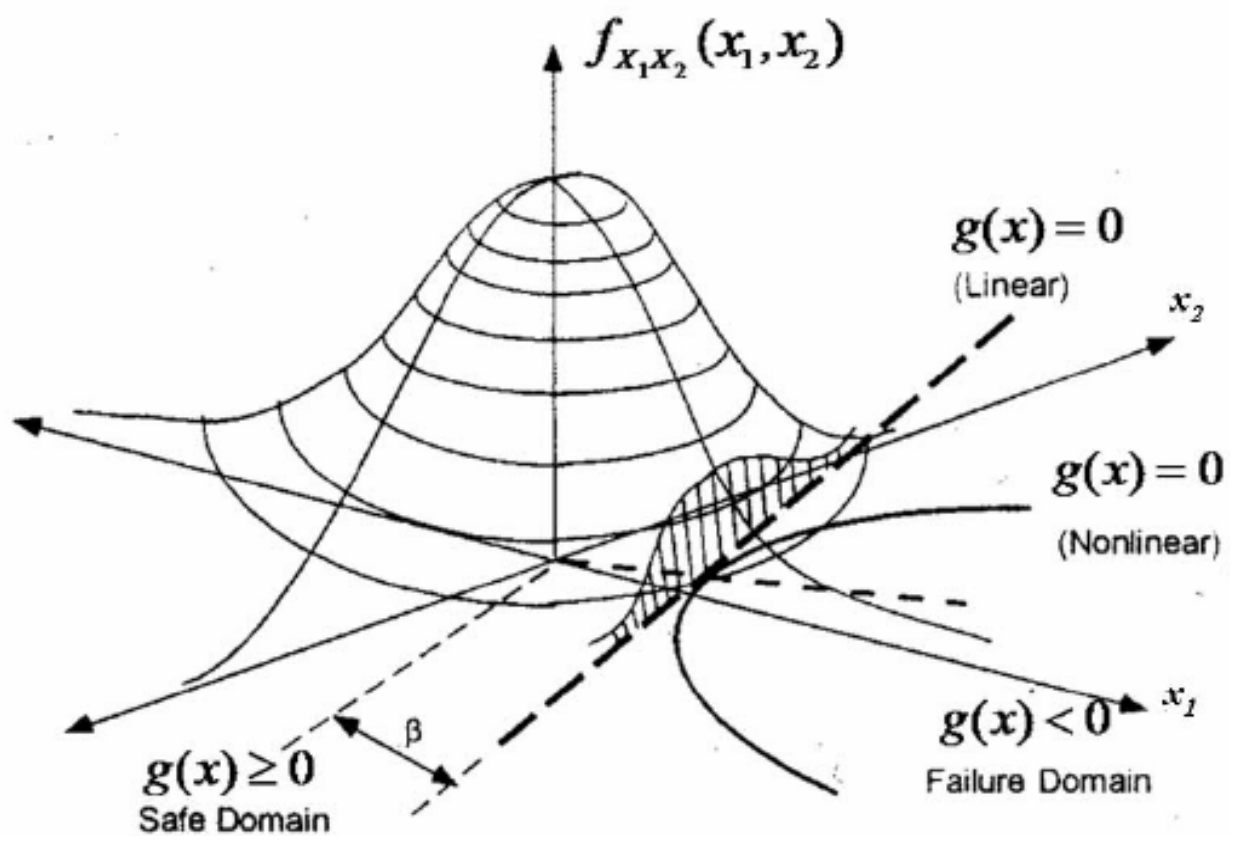

Figure 6. First-order Reliability Method

where:

$\boldsymbol{\eta}$ is the vector of random variables in the space of uncorrelated standard normal variables, and $\|\eta\|$ denotes the norm of that vector.

Several optimization techniques, such as Newton search (Rackwitz and Fiessler, 1978), and sequential quadratic programming (Schittkowski, 1983) can be used to find the MPP. Second-order reliability methods (SORM) are also available for higher accuracy; these take into account the curvature of the limit state in the failure probability calculation (e.g., Breitung, 1984; Tvedt, 1990). Compared to basic Monte Carlo simulation, FORM and SORM require many fewer iterations to converge to the MPP, and thus drastically reduce the computational expense.

\subsection{Multiple Criteria}

When a PA is conducted with respect to multiple requirements, the overall system-level probability of meeting the requirements is calculated through unions or intersections of individual failure probabilities.

In the case of unions (i.e., system fails if any one of the individual criteria is not met), the failure probability is

$P_{F, \text { Series }}=P\left\{\bigcup_{k} g_{k}(\mathbf{x}) \leq 0\right\}$

This system failure probability may be computed using either Monte Carlo simulation, or by extending the results of the first-order approximation in Section 5.1. Let $\mathbf{B}$ be the vector of reliability indices for each of the limit states, and the elements of the matrix $\mathbf{R}$ be the dot products of the corresponding $\boldsymbol{\alpha}$ vectors (unit gradient vector of the limit state at the MPP in standard normal space) obtained from the FORM analysis for each limit state. Then the system failure probability in the above equation can be approximated as $1-\Phi(\mathbf{B}, \mathbf{R})$, where $\Phi(\mathbf{B}, \mathbf{R})$ is the standard normal multivariate CDF with correlation matrix $\mathbf{R}$. Closed-form representations of $\Phi(\mathbf{B}, \mathbf{R})$ exist for the 
bivariate case (Dunnett and Sobel, 1954). If more than two limit states are considered, then one may elect to use bounding formulae (Ditlevsen, 1979), importance sampling methods (e.g., Mahadevan and Dey, 1998; Ambartzumian et al., 1998), multiple linearizations (Hohenbichler and Rackwitz, 1987), or a moment-based approximation (Pandey, 1998). For nonlinear limit states, the joint failure domain may be identified through an iterative linearization procedure (Mahadevan and Shi, 2001).

Similar concepts can be applied when the system failure is defined through intersections of individual failures (i.e., system fails only if all the individual criteria are not met). In that case, the failure probability is

$$
P_{F, \text { Parallel }}=P\left\{\bigcap_{k} g_{k}(\mathbf{x}) \leq 0\right\}
$$

Again, the failure probability of the parallel system can be calculated either by Monte Carlo simulation, or from the results of the FORM analysis of its components as $\Phi(-\mathbf{B}, \mathbf{R})$. In case FORM-based estimation is too approximate, Monte Carlo simulation can be used for higher accuracy, but with a large number of simulations. Efficient sampling techniques such as importance sampling (Mahadevan and Dey, 1998) may be used to reduce the computational expense.

In some cases, overall system failure definition may not be a simple union or intersection of individual failures, but may need to be represented as combinations of unions and intersections. In most cases, the system will not necessarily be in one of the two states (failed or safe), but in one of several levels of performance or degradation. Accounting for evolution of system states through time considerably increases the computational effort. The effort increases further when iterative multi-physics analysis is necessary, as in the case of several simultaneously active degradation processes. One option is to use first-order, second moment approximations to $\mathbf{B}$ and $\mathbf{R}$ (Mahadevan and Smith, 2006), to reduce the computational expense, but at the cost of accuracy. A trade-off between accuracy and computational expense may be necessary.

An important observation to note is that the probability calculations described in Sections 5.1 and 5.2 are only with respect to physical variability, represented by the random variables $\boldsymbol{X}$. The presence of data uncertainty and model errors makes the probability estimates themselves uncertain. Thus one can construct confidence bounds on the CDF of the output, based on a nested two-loop analysis. In the outer loop, realizations of the variables representing information uncertainty (such as distribution parameters of the probability distributions) and model errors are generated, and for each such realization, the output CDF is constructed in the inner loop. The collection of the resulting multiple CDFs is then used to construct the confidence bounds on the CDF. This nested implementation can become computationally demanding; in that case, a single loop implementation that simultaneously performs both outer loop and inner loop analyses may be pursued (McDonald et al., 2009).

\subsection{CONCLUSION}

Uncertainty quantification in performance assessment involves consideration of three sources of uncertainty - inherent variability, information uncertainty, and model errors. This report described available methods to quantify the uncertainty in model-based prediction due to each of these sources, and addressed them in four stages - input characterization based on data; propagation of uncertainties and errors through the system model; model calibration, validation and extrapolation; and performance assessment. Flexible distribution families were discussed to handle sparse data and interval data. Autoregressive models were discussed to handle time dependence. Methods to quantify model errors resulting from both model form selection and solution approximation were discussed. Bayesian methods were discussed for model calibration, validation and extrapolation. An important issue is computational expense, when iterative analysis 
between multiple codes is necessary. Uncertainty quantification multiplies the computational effort of deterministic analysis by an order of magnitude. Therefore the use of surrogate models, and first-order approximations of overall output uncertainty, were described to reduce the computational expense.

Many of the methods described in the report have been applied to mechanical systems that are small in size, or time-independent, and the uncertainties considered were not very large. None of these simplifications is available in the case of long-term performance assessment of engineered barriers for radioactive waste containment, and real-world data to validate long-term model predictions is not available. Thus the extrapolations are based on laboratory data or limited term observations, and come with large uncertainty. Therefore the benefit of uncertainty quantification is not so much in predicting failure probability or similar measures, but in facilitating engineering decision making, such as comparing different design and analysis options, and allocating resources for uncertainty reduction through further data collection and/or model refinement. 


\subsection{REFERENCES}

Ambartzumian, R, Der Kiureghian, A, Ohanian, V \& Sukiasian, H 1997, 'Multinormal probability by sequential conditioned importance sampling.' In Advances in Safety and Reliability, Proceedings of ESREL '97, Vol. 2, 17-20 June, Lisbon, pp. $1261-1268$.

Bae, H-R, Grandhi, RV \& Canfield, RA 2003, 'Uncertainty quantification of structural response using evidence theory.' AIAA Journal, 41(10), 2062-2068.

Bichon, BJ, Eldred, MS, Swiler, LP, Mahadevan, S \& McFarland, JM 2007. 'Multimodal Reliability Assessment for Complex Engineering Applications using Efficient Global Optimization,' Proceedings, 9th AIAA Non-Deterministic Approaches Conference, Waikiki, HI.

Barford, NC 1985, Experimental measurements: precision, error, and truth. Wiley, NewYork, 1985.

Blischke, WR \& Murthy, DNP 2000, Reliability: Modeling, Prediction, and Optimization. Wiley, New York.

Breitung, K 1984, 'Asymptotic approximations for multinormal integrals.' Journal of Engineering Mechanics, 110(3), 357-366.

Box, GEP, Hunter, WG \& Hunter JS 1978, Statistics for Experimenters, An Introduction to Design, Data Analysis, and Model Building. Wiley Interscience.

Box, GEP, Jenkins, GM \& Reinsel GC 1994, Time series analysis forecasting and control (3rd edition). Prentice Hall, Englewood Cliffs, New Jersey,.
Campolongo, F, Saltelli, A, Sorensen, T \& Tarantola, S 2000, 'Hitchhiker's guide to sensitivity analysis.' Sensitivity Analysis, A Saltelli, K Chan, and EM Scott. eds., John Wiley \& Sons, pp. 15-47.

Chen, D 2006, Computational framework for durability assessment of reinforced concrete structures under coupled deterioration processes. Ph.D. Dissertation, Department of Civil and Environmental Engineering, Vanderbilt University.

Chen, W, Baghdasaryan, L, Buranathiti, T \& Cao, J 2004, 'Model validation via uncertainty propagation and data transformation.' AIAA Journal, 42(7), $1406-1415$.

Devolder, B, Glimm, J, Grove, JW, Kang, Y, Lee, Y, Pao, K, Sharp, DH \& Ye, K 2002, 'Uncertainty quantification for multiscale simulations.' ASME Journal of Fluids Engineering, 124(1), 129 - 141.

Ditlevsen, O 1979, 'Narrow reliability bounds for structural systems.' Journal of Structural Mechanics, 7(4), 453-472.

Dowding, KJ, Hills, RG, Leslie, I, Pilch, M, Rutherford, BM \& Hobbs, ML 2004, Case study for model validation: Assessing a model for thermal decomposition of polyurethane foam, Sandia National Laboratories Tec. Rep. Sand. No 20043632, Albuquerque, New Mexico, 2004.

Dunnett CW \& Sobel, M 1954, 'A Bivariate generalization of student's t-distribution, with tables for certain special cases.' Biometrika, 41(1/2), 153-169.

Efron, B \& Tibshirani, RJ 1994, An Introduction to the Bootstrap, Chapman \& Hall/CRC. 
Farrar, CR, Sohn, H, Hemez, FM, Anderson, MC, Bement, MT, Cornwell, PJ, Doebling, SW, Schultze, JF, Lieven, N \& Robertson, AN 2003, Damage prognosis: Current status and future needs. Tec. Rep. LA-14051-MS, Los Alamos National Laboratory, Los Alamos, New Mexico.

Ferraris, CF, Clifton, JR, Stutzman, PE \& Garboczi, EJ 1997, 'Mechanisms of degradation of Portland cement-based systems by sulfate attack.' Mechanisms of Chemical Degradation of CementBased Systems, London, 185-192, 1997.

Ferson, S, Kreinovich, V, Hajagos, J, Oberkampf W \& Ginzburg, L 2007, Experimental Uncertainty Estimation and Statistics for Data Having Interval Uncertainty. Sandia National Laboratories Tec. Rep. Sand. No 2003-0939, Albuquerque, New Mexico.

Ghanem, R \& Spanos, P 2003, Stochastic Finite Elements: A Spectral Approach, Springer-Verlag, New York.

Gilks, WR, Richardson, S \& Spiegelhalter, DJ 1996, Markov Chain Monte Carlo in Practice, Interdisciplinary Statistics Series, Chapman and Hall, Boca Raton, Florida.

Glimm, J \& Sharp, DH 1999, 'Prediction and the quantification of uncertainty.' Physica D, 133(1-4), 152-170.

Goktepe, AB, Inan, G, Ramyar, K \& Sezer, A 2006. 'Estimation of sulfate expansion level of pc mortar using statistical and neural approaches', Construction and Building Materials, 20, 441-449.

Gulikers, J 2006, 'Considerations on the reliability of service life predictions using probabilistic approach. Journal de Physique IV, 136, 233-241, 2006.
Gurley, KR 1997, 'Modeling and simulation of non-Gaussian processes', PhD thesis, University of Notre Dame, April 1997.

Haldar, A \& Mahadevan, S 2000, Probability, Reliability and Statistical Methods in Engineering Design, J. Wiley \& Sons, New York.

Hanson, KM 1999, 'A framework for assessing uncertainties in simulation predictions.' Physica D, 133(1-4), 179-188.

Hanson, KM \& Hemez, FM 2003, 'Uncertainty quantification of simulation codes based on experimental data.' Proceedings of 41st AIAA Aerospace Sciences, Jan. 6-9, 2003, Reno, Nevada.

Hasofer, AM \& Lind, NC 1974, 'Exact and invariant second moment code format.' Journal of the Engineering Mechanics Division, ASCE, 100(EM1), 111-121.

Helton, JC \& Sallabery, CJ 2009a, 'Conceptual basis for the definition and calculation of expected dose in performance assessments for the proposed high-level radioactive waste repository at Yucca Mountain, Nevada', Reliability Engineering and System Safety 94, 677- 698.

Helton, JC \& Sallabery, CJ 2009b, 'Computational implementation of sampling-based approaches to the calculation of expected dose in performance assessments for the proposed high-level radioactive waste repository at Yucca Mountain, Nevada', Reliability Engineering and System Safety 94, 699721.

Hills, RG \& Leslie, I 2003, Statistical validation of engineering and scientific models: Validation experiments to application. Sandia National Laboratories Tec. Rep. Sand. No 2003-0706, Albuquerque, New Mexico. 
Hills, RG \& Trucano, TG 2002, Statistical validation of engineering and scientific models: A maximum likelihood based metric, Sandia National Laboratories Tec. Rep. Sand. No 2001-1783, Albuquerque, New Mexico.

Hohenbichler M \& Rackwitz, R 1987, 'First-order concepts in systems reliability.' Structural Safety; 1(3), 177-188.

Holdren, KJ, Anderson, DL, Becker, BH, Hampton, NL, Koeppen, LD, Magnussen, SO \& Sondrup, AJ 2006, Remedial investigation and baseline risk assessment of operable unit 7 13/14, U. S. Department of Energy, Idaho Operations Office.

Hong, HP 2000, Assessment of reliability of ageing reinforced concrete structures. Journal of Structural Engineering, 1260(12), 1458-1465.

Huang, S, Mahadevan, S \& Rebba, R 2007, 'Collocation-based stochastic finite element analysis for random field problems', Probabilistic Engineering Mechanics, 22, 194-205, 2007.

Isukapalli, SS, Roy, A \& Georgopoulos, PG 1998, 'Stochastic response surface methods (SRSMs) for uncertainty propagation: Application to environmental and biological systems.' Risk analysis, 18(3), 351-363.

Jeffreys, H 1961, Theory of Probability, 3rd. ed., Oxford University Press, London.

Jensen, FV \& Jensen, FB 2001, Bayesian Networks and Decision Graphs, Springer-Verlag, New York.

Jiang, X \& Mahadevan, S 2007, 'Bayesian riskbased decision method for model validation under uncertainty.' Reliability Engineering and System Safety, 92(6), 707-718.
Jiang, X and Mahadevan, S 2008, 'Bayesian validation assessment of multivariate computational models', Journal of Applied Statistics, 35(1), 4965.

Kennedy, MC \& O'Hagan, A 2001, Bayesian calibration of computer models (with discussion). Journal of the Royal Statistical Society, Series B, 63(3), 425-464.

Kong, JS, Ababneh, AN, Frangopol, DM \& Xi, Y 2002, Reliability analysis of chloride penetration in saturated concrete. Probabilistic Engineering Mechanics, 17, 305-315.

Krajcinovic, D, Basista, M, Mallick, K \& Sumarac, D 1992, Chemo-micromechanics of brittle solids. Journal of the Mechanics and Physics of solids, 40(5), 965-990.

Langley, RS 2000, 'A unified approach to the probabilistic and possibilistic analysis of uncertain systems', ASCE Journal of Engineering Mechanics, $126,1163-1172$.

Mahadevan, S \& Dey, A 1998, 'Ductile system reliability analysis using adaptive importance sampling.' Structural Safety, 20(2), 137-154.

Mahadevan, S \& Rebba, R 2005, 'Validation of reliability computational models using Bayes networks.' Reliability Engineering and System Safety, 87(2), 223-232.

Mahadevan, S \& Raghothamachar, P 2000, 'Adaptive simulation for system reliability analysis of large structures.' Computers and Structures, 77(6), 725-734.

Mahadevan, S \& Shi, P 2001, 'Multiple linearization method for nonlinear reliability analysis.' ASCE Journal of Engineering Mechanics, 127(11), 1165-1173. 
Mahadevan, S \& Smith, N 2006, 'Efficient firstorder reliability analysis of multidisciplinary systems.' International Journal of Reliability and Safety, 1(1/2), 137-154.

Marhadi, KS, Venkataraman, S and Pai, S 2008, 'Quantifying uncertainty in statistical distribution of small sample data using Bayesian inference of unbounded Johnson distribution', Proceedings, 49th AIAA/ASME/ASCE/AHS/ASC Structures, Structural Dynamics and Materials Conference, Schaumburg, Illinois.

Mathelin, L, Hussaini, MY, Zhang, TA \& Bataille, F 2004, 'Uncertainty propagation for a turbulent, compressible nozzle flow using stochastic methods.' AIAA Journal, 42(8), 1169-1176.

Mathelin, L, Hussaini, MY \& Zang, TA 2005, 'Stochastic approaches to uncertainty quantification in CFD simulations', Numerical Algorithms, 38, 209-236.

McDonald, M, Zaman, K \& Mahadevan, S 2008, Uncertainty quantification and propagation for multidisciplinary system analysis, 12th AIAA/ISSMO Multidisciplinary Analysis and Optimization Conference, Paper No. 134794, Victoria, British Columbia, Canada.

McDonald, M, Zaman, K \& Mahadevan, S 2009, 'Representation and first-order approximations for propagation of aleatory and distribution parameter uncertainty.' AIAA-2009-2250, 50th AIAA/ASME/ ASCE/AHS/ASC Structures, Structural dynamics, and Materials Conference, 4-7 May 2009, Palm Springs, California.

McFarland, JM 2008, Uncertainty analysis for computer simulations through validation and calibration. PhD dissertation, Vanderbilt University, Nashville, TN.
McFarland, J, Mahadevan, S, Swiler, L \& Giunta, A 2007, 'Bayesian calibration of the QASPR simulation.' In Proceedings of the 9th AIAA NonDeterministic Approaches Conference, Honolulu, Hawaii.

Mckay, MD, Conover, WJ \& Beckman, RJ 1979. 'A comparison of three methods for selecting values of input variables in the analysis of output from a computer code.' Technometrics, 21, 239-245.

Millman, DR, King, PI, Maple, RC, Beranx, PS \& Chiltonk, LK 2006, 'Uncertainty quantification with a B-spline stochastic projection.' AIAA journal, 44(8), 1845-1853.

Nigam, NC 1983, Introduction to random vibrations. MIT Press.

Oberkampf, WL \& Barone, MF 2006, 'Measures of agreement between computation and experiment: Validation metrics.' Journal of Computational Physics 217(1), 5-36.

Oberkampf, WL, Trucano, TG \& Hirsch, Ch 2003, Verification, Validation, and Predictive Capabilities in Computational Engineering and Physics, Sandia National Laboratories Tec. Rep. Sand. No 20033769, Albuquerque, New Mexico.

Paez, TL \& Urbina, A 2002, Validation of mathematical models of complex structural dynamic systems, Proceedings of the Ninth International Congress on Sound and Vibration, Orlando, Florida.

Pandey, MD 1998, 'An effective approximation to evaluate multinormal integrals.' Structural Safety, 20(1), 51-67. 
Rackwitz, R \& Fiessler B 1978, 'Structural reliability under combined load sequences.' Computers and Structures, 9(5), 489-494.

Rafiq, MI, Chryssanthopoulos, MK \& Onoufriou, T 2004, 'Performance updating of concrete bridges using proactive health monitoring methods', Reliability Engineering and System Safety, 86(3), 247-256.

Rebba, R 2005, Model Validation and Design under Uncertainty. PhD dissertation, Vanderbilt University, Nashville, TN, USA.

Rebba, R \& Mahadevan, S 2006, 'Model predictive capability assessment under uncertainty', AIAA Journal, 44(10), 2376-2384.

Rebba, R \& Mahadevan, S 2008, 'Computational methods for model reliability assessment', Reliability Engineering and System Safety, 93, 1197-1207.

Rebba, R, Mahadevan, S \& Huang, S 2006, 'Validation and error estimation of computational models.' Reliability Engineering and Safety System, 91(10-11), 1390-1397.

Red-Horse, JR \& Benjamin, AS 2004, 'A probabilistic approach to uncertainty quantification with limited information', Reliability Engineering and System Safety, 85, 183-190, 2004.

Robert, CP \& Casella, G 2004, Monte Carlo Statistical Methods. 2nd ed. Springer-Verlag, New York.

Ross, TJ, Booker, JM \& Parkinson, WJ 2002, Fuzzy Logic and Probability Applications: Bridging the Gap. Society for Industrial and Applied Mathematics, Philadelphia, PA.
Richards, SA 1997, 'Completed Richardson extrapolation in space and time.' Communications in Numerical Methods in Engineering, 13(7), 558-573.

Rubinstein, RY 1981, Simulation and the Monte Carlo method. New York, Wiley.

Rutherford, BM, Dowding, K 2003, An approach to model validation and model-based predictionpolyurethane foam case study, Sandia National Laboratories, Tec. Rep. Sand. No 2003-2336, Albuquerque, New Mexico.

Saltelli, A, Chan, K \& Scott, EM 2000, Sensitivity Analysis. John Wiley \& Sons.

Schittkowski, K 1983, 'On the convergence of a sequential quadratic programming method with an augmented Lagrangian search direction.' Mathematische Operationsforschung und Statistik, Series Optimization, 14, 197-216.

Stewart, MG \& Mullard, JA 2007, Spatial timedependent reliability analysis of corrosion damage and the timing of first repair for RC structures. Engineering Structures, 29, 1457-1464.

Tatang, MA, Pan, W, Prinn, RG \& McRae, GJ 1997, 'An efficient method for parametric uncertainty analysis of numerical geophysical models.' Journal of Geophysical Research, 102(D18), 21925-21932.

Tixier, R \& Mobasher, B 2003, Modeling of damage in cement-based materials subjected to external sulfate attack. II: comparison with experiments. Journal of Materials in Civil Engineering, 15(4), 314-322. 
Trucano, TG, Easterling, RG, Dowding, KJ, Paez, TL, Urbina, A, Romero, VJ, Rutherford, BM \& Hills, RG 2001, Description of the Sandia validation metrics project, Sandia National Laboratories Tec. Rep. Sand. No 2001-1339, Albuquerque, New Mexico.

Tvedt, L 1990, 'Distribution of quadratic forms in normal space - application to structural reliability.' Journal of Engineering Mechanics, ASCE, 116(6), 1183-1197.

Urbina, A \& Mahadevan, S 2009, Uncertainty quantification in hierarchical computational model development, Proceedings, 12th AIAA NonDeterministic Approaches Conferences, Palm Springs, California.
Witteveen, J \& Bijl, H 2006, 'Using polynomial chaos for uncertainty quantification in problems with Nonlinearities.' Paper No. AIAA-2006-2066, Proceedings, 47th AIAA/ASME/ASCE/AHS/ASC Structures, Structural Dynamics, and Materials Conference, 14th AIAA/ASME/AHS Adaptive Structures Conference, Newport, Rhode Island.

Xiu, D \& Karniadakis, GE 2003, 'Modeling uncertainty in flow simulations via generalized polynomial chaos.' Journal of Computational Physics, 187(1), 137-167.

Zhang, R \& Mahadevan, S 2003, 'Bayesian methodology for reliability model acceptance.' Reliability Engineering and System Safety, 80(1), 95-103.

Zou, T, Mahadevan, S \& Mourelatos, Z 2003, 'Reliability-based evaluation of automotive wind noise quality.' Reliability Engineering and System Safety, 82(2), 217-224. 



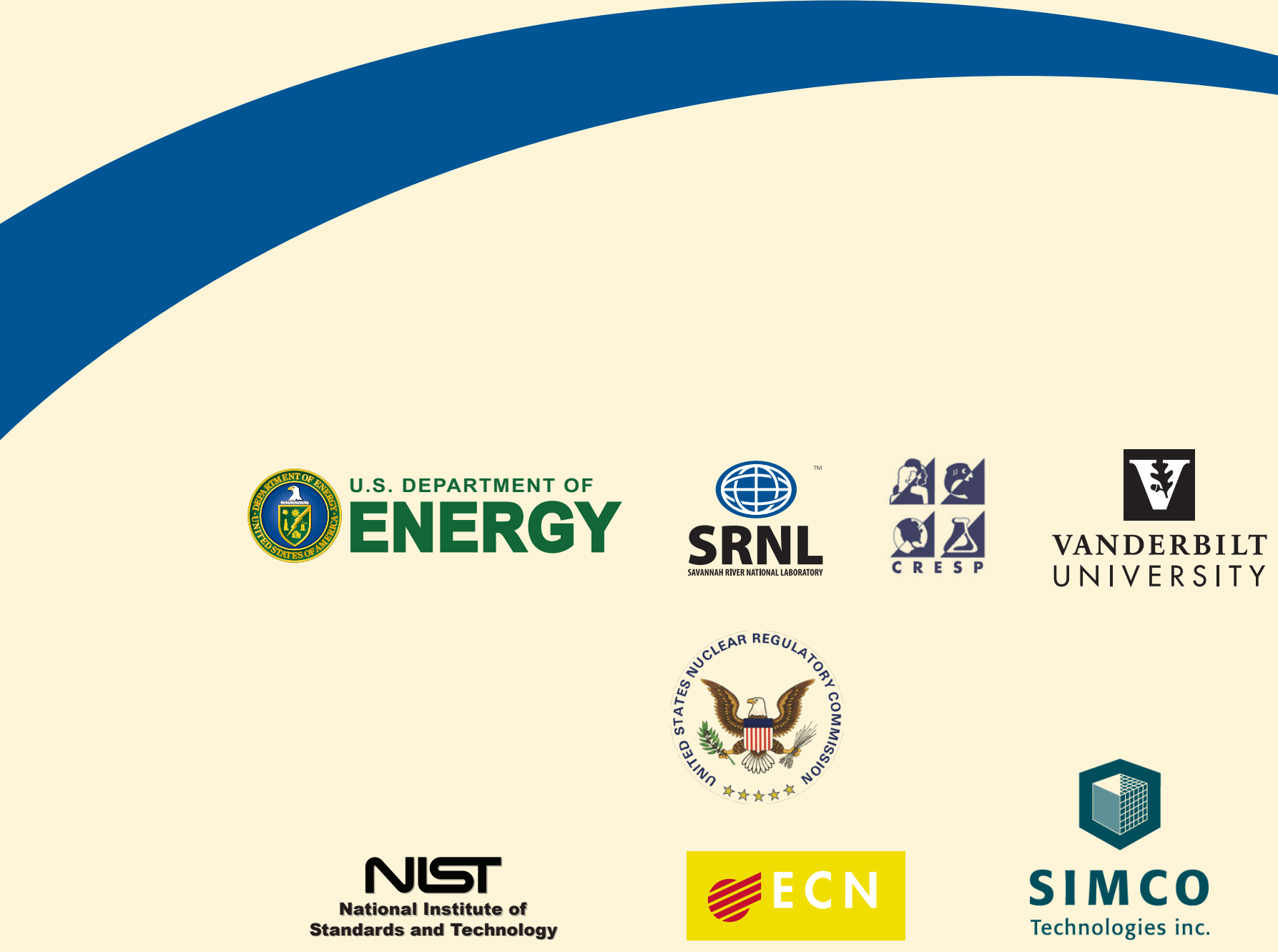

